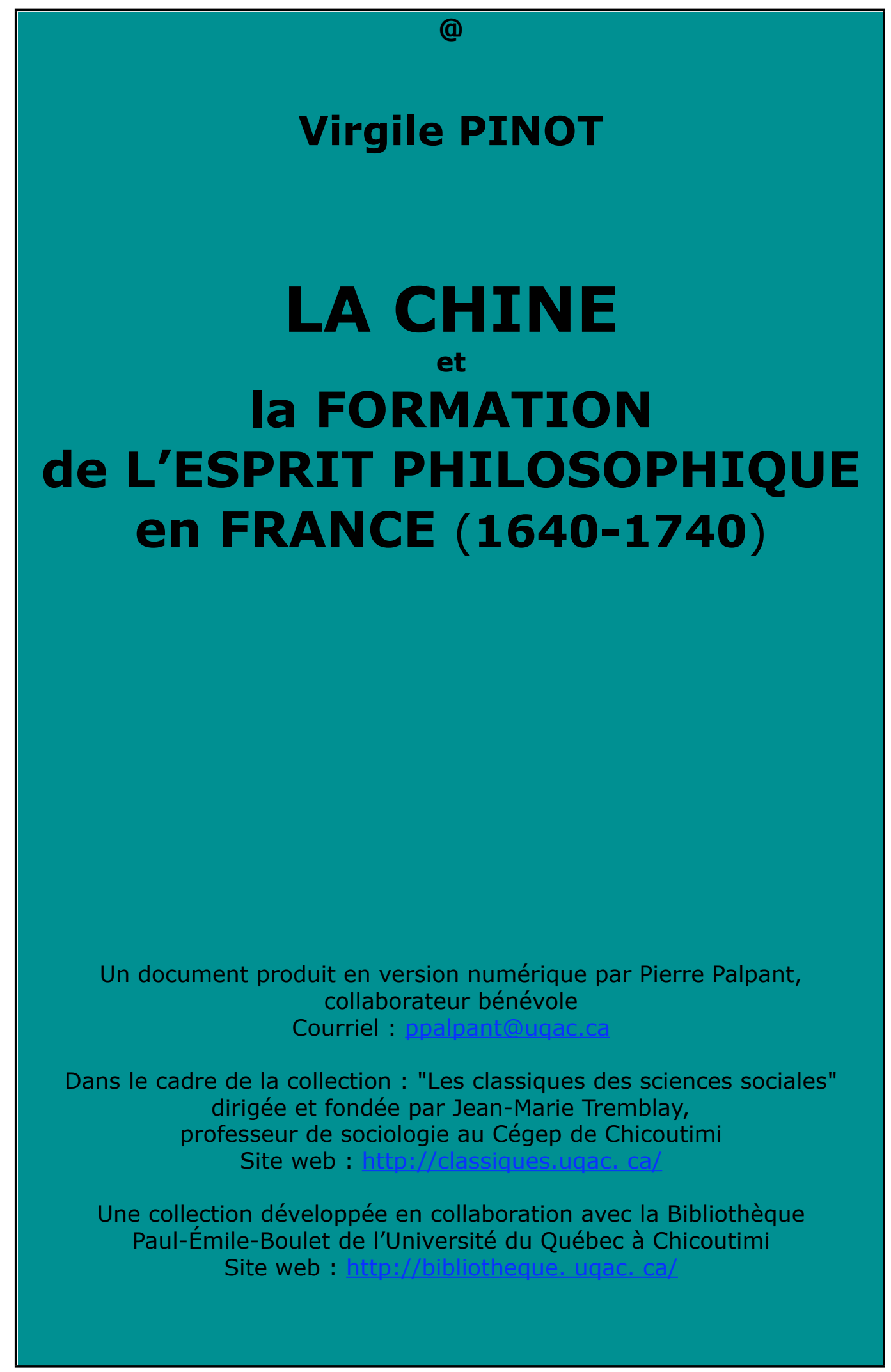




\section{La Chine et la formation de l'esprit philosophique en France}

Un document produit en version numérique par Pierre Palpant, collaborateur bénévole,

Courriel : ppalpant@uqac.ca

à partir de :

\section{LA CHINE et LA FORMATION de L'ESPRIT PHILOSOPHIQUE en FRANCE (1640-1740)}

\section{par Virgile PINOT}

Thèse présentée à la Faculté des Lettres pour le Doctorat ès-Lettres ${ }^{1}$.

Librairie orientaliste Paul Geuthner, Paris, 1932, 480 pages.

Police de caractères utilisée : Verdana, 12, 11 et 10 points.

Mise en page sur papier format Lettre (US letter), 8.5'x11".

[note : un clic sur @ en tête de volume, des chapitres et en fin d'ouvrage, permet de rejoindre la table des matières.]

Nous n'avons pu trouver les dates de naissance et de décès de Virgile Pinot. Par l'avant-propos de l'ouvrage que nous éditons, nous savons simplement que V. Pinot a publié un travail sur les «Physiocrates et la Chine » en 1906, ce qui laisse supposer une naissance au plus tard dans les années 1880-85. D'autre part V. Pinot écrit, toujours dans le même avant-propos : « Avant de parler de Voltaire et la Chine, ce qui, nous l'espérons, ne tardera guère ». Mais à notre connaissance, aucun texte n'a été publié par V. Pinot après 1932.

Édition complétée le 15 décembre 2006 à Chicoutimi, Québec.

1 La faculté n'entend donner aucun approbation ni improbation aux opinions émises dans les thèses ; ces opinions doivent être considérées comme propres à leurs auteurs. 


\section{La Chine \\ et la formation de l'esprit philosophique en France}

TABLE DES MATIÈRES

$\underline{\text { Index }}-$ Bibliographie

Avant-propos

LIVRE PREMIER

Les sources de la connaissance de la Chine

CHAPITRE I : JÉSUITES ET MISSIONNAIRES

I. - Les Missions catholiques en Extrême-Orient au XVIIe siècle

Les missions en Chine avant l'arrivée des Jésuites. - Les origines de la mission des Jésuites. - Les Jésuites mathématiciens et astronomes en Chine au XVIIe siècle. - Les Jésuites en Chine et les arts manuels. La formation de la légende de la Chine savante.

Les origines de la Société des Missions Étrangères. - Désir de la Papauté de constituer en Extrême-Orient une hiérarchie indépendante des Églises nationales. - Difficultés : le droit de patronage des Portugais aux Indes et le gallicanisme.

L'affaire du serment imposé par le Pape aux religieux missionnaires. Résistance du Roi de France en vertu des principes gallicans. - D'où l'idée de Colbert d'envoyer en Chine des Jésuites, Mathématiciens du Roi. - Méfiances de Rome contre ce projet. - Départ précipité des Jésuites Mathématiciens pour le Siam et pour la Chine.

II. - Les Ambassades des Français au Siam (1685-1687).

Ambassade du Chevalier de Chaumont (1685). - Ses instructions. Les questions religieuses priment les questions commerciales. Constance Phaulkon. - Sa duplicité. - Ses véritables intentions. - Le rôle du P. Tachard. - La mission de La Loubère et de Cébéret. - Leurs instructions. - Les questions commerciales tiennent désormais la première place. - Le P. Tachard revient en Europe comme envoyé du Roi de Siam près du Roi de France et du Pape. - Ses instructions : demander au Pape la suppression des Vicaires apostoliques et des Missionnaires au profit des Jésuites. - Il obtient seulement la suppression du serment. - Tentatives de conciliation. - Révolution du Siam de 1688 qui anéantit ces projets.

\section{CHAPITRE II : LA QUERELLE DES CÉRÉMONIES CHINOISES}

La Querelle des Rites du Malabare. - Différences radicales entre les procédés d'évangélisation des Jésuites et ceux des autres ordres religieux. - En Chine les Jésuites croient nécessaire de composer avec le culte de Confucius et le culte des ancêtres. - Préliminaires de la lutte. - Pascal révèle cette querelle au public français. - Le $\mathrm{II}^{\mathrm{e}}$ tome 


\section{La Chine et la formation de l'esprit philosophique en France}

de La Morale pratique des Jésuites. - Jurieu prête main-forte aux Jansénistes : L'Esprit de M. Arnauld. - Riposte des Jésuites : Deffense des nouveaux Chrétiens de la Chine, du P. Le Tellier.

Mandement de Maigrot condamnant les idées des Jésuites sur les cultes chinois (26 mars 1693). - Réponse des Jésuites : les Nouveaux Mémoires sur l'Etat présent de la Chine, du P. Le Comte.

Les rapports de la Querelle des Cérémonies chinoises avec les autres querelles théologiques et religieuses : I'affaire du Péché philosophique. - L'affaire du Quiétisme. - L'année 1700. - Condamnation des Jésuites en Sorbonne sur leur interprétation des cultes chinois. Condamnation de la morale relâchée des Jésuites par l'assemblée du Clergé. - Rôle de Bossuet et de l'archevêque de Paris dans ces affaires. - Le problème du salut des Infidèles.

L'affaire des Cérémonies chinoises à Rome. - Rôle de l'orientaliste Renaudot, agent du Cardinal de Noailles. - Le Pape envoie en Chine un Légat a latere. - La Légation du Patriarche de Tournon. - Elle ne termine la controverse ni en Chine ni en Europe. - Activité à Rome du P. Roslet, agent du Cardinal de Noailles. - Le P. Le Tellier devient confesseur du roi. - Il demande à Rome la condamnation de 33 propositions du livre du P. Quesnel. - Riposte des Jésuites : demande de condamnation du livre du P. Jouvanc. - Le P. Le Tellier dénonce $\underline{70}$ propositions nouvelles du livre du P. Quesnel. - Bulle Unigenitus.

Constitution Ex illa die (1715). - Légation de Mezzabarba (1720-1721). - Les huit « permissions » ne terminent pas la Querelle. - La constitution Ex quo singulari (1742) met fin à la lutte par la condamnation des Jésuites. - C'est dans une atmosphère de combat que sont publiés les principaux écrits des Jésuites sur la Chine.

\section{CHAPITRE III : LES ÉCRITS DES JÉSUITES SUR LA CHINE}

Nombreux écrits des Jésuites sur la Chine, dont une petite partie seule a été publiée. - Les raisons de ces suppressions de textes : les Jésuites de Paris pensent à la Querelle des Cérémonies chinoises toujours pendante.

Le Confucius Sinarum Philosophus et la préface du P. Couplet sur la religion des anciens chinois. - Corrections du reviseur de Paris, tendant à faire croire que les anciens Chinois ont cru à un Dieu créateur et à l'immortalité de l'âme. - Les Lettres édifiantes et curieuses: leur air de fausse candeur. Les rédacteurs de Paris suppriment les textes qui traitent des superstitions des Chinois, notamment de leur croyance aux esprits. - La Description de la Chine du P. du Halde : abondance des documents originaux mis à sa disposition. - Omissions, suppressions, corrections. - La raison de ces altérations ; essayer de prouver par les faits les théories des Jésuites sur les cultes chinois.

Les Jésuites, par leurs théories sur les cultes chinois et par la démonstration qu'ils ont essayé d'en donner, ont travaillé pour le rationalisme du XVIII ${ }^{\mathrm{e}}$ siècle et pour le déisme voltairien. 


\title{
La Chine et la formation de l'esprit philosophique en France
}

\author{
LIVRE DEUXIEME \\ La découverte de la Chine et la formation de l'esprit \\ philosophique
}

\section{CHAPITRE I : L'ANTIQUITÉ DE L'HISTOIRE CHINOISE ET LA CHRONOLOGIE}

Les premières relations sur la Chine signalent l'antiquité de la Chine. La Peyrère avec sa thèse des Préadamites nie I'universalité du Déluge et insinue l'idée de l'éternité du monde. - De quelques préadamites : Gui Patin, Knutzen, en Allemagne, un peu plus tard Bayle. - Le P. Martini croit que la Chine a été habitée avant le Déluge. - Isaac Vossius recule les origines du monde. - Polémique avec Horn. - Le P. Riccioli accepte la chronologie chinoise, mais avec la version des Septante. - La Chronologie du P. Couplet : audaces apparentes, prudence au fond. - Allix. - Le P. Pezron, à cause de la chronologie chinoise renonce à la Vulgate pour la Version des Septante. - La Loubère et Cassini : leur doutes sur l'authenticité de la chronologie chinoise. - Vallemont refuse d'admettre la chronologie chinoise. Maigrot la croit ancienne, mais la réduit pour la faire concorder avec la Bible. - Hypothèse du P. Tournemine pour concilier la Vulgate et la Version des Septante, ce qui permet d'accepter la chronologie chinoise. - Le protestant Duhamel admet cette hypothèse. Réaction : Dom Calmet, Renaudot nient I'antiquité de I'histoire chinoise. Les Libertins préadamites qui croient à l'antiquité du monde : Tyssot de Patot et le continuateur de L'Espion Turc. - Attaques contre l'idée du Déluge universel : Lenglet-Dufresnoy, Levesque de Burigny.

Les études des Jésuites sur l'ancienne histoire chinoise. - Les trois théories: les symbolistes ; les PP. historiens de Pékin ; les PP. de Paris.

Fréret : sa méthode, prouver l'authenticité de l'histoire chinoise par elle-même, indépendamment de toute idée religieuse. Ses précautions : montrer que I'histoire chinoise peut être réduite et ne doit inquiéter en rien les théologiens.

Conséquence de ce mouvement avant 1740 : on est plus porté à douter du Déluge universel que de l'antiquité de la chronologie chinoise.

\section{CHAPITRE II : LA PHILOSOPHIE ET LA RELIGION DES CHINOIS}

\section{I. - Les Missionnaires et les théologiens}

Le P. Trigault: superstitions dans le peuple, matérialisme et athéisme chez les Lettrés. - La Mothe le Vayer trouve dans les doctrines de Confucius la religion et la morale naturelles. - Le P. Martini apporte des faits en faveur de l'athéisme des Chinois et des opinions en faveur de leur spiritualisme. - Deux partisans du consentement universel : le P. Beurrier, Huet. - Le P. Couplet, corrigé par les Jésuites de Paris : la 


\section{La Chine et la formation de l'esprit philosophique en France}

religion chinoise a les mêmes sources que le judaïsme et le christianisme. - Le problème du salut des Infidèles et le livre du Cardinal Sfondrati. - La lettre des cinq évêques. - L'année 1700. Condamnation par la Sorbonne des idées des Jésuites sur la religion des Chinois. - Le Jugement du Dr Coulau et le livre de Hyde. Critiques de Bossuet et d'Ellies du Pin. - Le Séminaire des Missions étrangères par sa publication des traités des PP. Longobardi et de Sainte-Marie cherche à prouver l'athéisme des Chinois.

\section{II. - Les Philosophes}

Bayle avant 1700 : ses préoccupations, la tolérance et les rapports de la religion et de la morale : il invoque l'athéisme des lettrés siamois et chinois; en 1702, il affirme l'athéisme de la secte des Lettrés de la Chine ; en 1705, pour ruiner l'argument du consentement universel, il prouve l'athéisme de toute la nation chinoise. - Elie Benoist, critique de Bayle. - Malebranche, inspiré par de Lyonne, ennemi des Jésuites, admet l'athéisme des Chinois. - Leibniz défend le spiritualisme des Chinois : les anciens textes chinois reproduisent les principes de la religion naturelle. - Critique de l'opuscule du P. Longobardi. Levesque de Burigny par l'exemple chinois cherche à montrer que l'athéisme a été la doctrine des anciens philosophes : c'est l'argument du consentement universel retourné. - Fréret : Confucius a une doctrine secrète, réservée à ses disciples ; la doctrine officielle est purement morale et ne traite ni de métaphysique ni de religion. La doctrine secrète révèle des traces évidentes de spinozisme. Donc les Lettrés chinois sont panthéistes et athées.

Ainsi les philosophes, à part Leibniz, sont d'accord avec les adversaires des Jésuites pour soutenir que les Chinois sont athées. Par là se trouve ruiné l'argument du consentement universel, même sous la forme nouvelle qu'Elie Benoist avait essayé de lui donner.

\section{III. - Le Figurisme}

Les figuristes ont essayé de prouver par l'interprétation allégorique des caractères et des livres chinois, non la vérité d'une religion spiritualiste quelconque mais la vérité du christianisme annoncé prophétiquement dès les origines du monde.

Pascal et la théorie des figuratifs. - Les PP. Bouvet et de Prémare. L'influence des Jésuites figuristes de Chine sur le P. Lafitau, auteur des Mœurs des sauvages amériquains. - Les mythes des religions américaines, qui sont encore des religions primitives, peuvent conserver des traces de la première révélation. - Ramsay: Son Discours sur la Mythologie, à la suite des Voyages de Cyrus. - Inspiré par le P. de Prémare : La loi des trois états, idée des Jésuites figuristes. - Mais il n'échappe pas au reproche de déisme. Pas plus que les figuristes il n'arrive à sauver, en faveur du christianisme l'argument du consentement universel. 


\section{La Chine et la formation de l'esprit philosophique en France}

\section{CHAPITRE III : LA MORALE ET LA POLITIQUE DES CHINOIS}

Les Missionnaires constatent que la morale chinoise n'est pas une morale dogmatique, mais une codification des règles de bien vivre ; la morale se confond avec la politique.

Importance de la publication du livre du P. Couplet : le chanoine Simon Foucher et I'auteur de La Morale de Confucius vantent la morale chinoise parce qu'elle est exempte de subtilités métaphysiques. Régis met en valeur la définition de la charité selon Confucius, définition qui peut être le principe d'une morale sociale, indépendamment de toute religion. - Bernier, dans ses Etrenes à Madame de la Sablière insiste à son tour sur le caractère d'universalité de cette définition. Sa traduction inédite des trois premiers livres de Confucius. Les raisons de ce travail : déterminer d'après l'exemple chinois les rapports de la morale et de la politique. La morale d'après les principes de Confucius est la Science des Princes. - Des Coutures, un moraliste honnête homme qui n'a pas connu la morale chinoise aurait souscrit aux principes de Confucius traduits par Bernier. L'idéal du roi, tel que le conçoit La Bruyère se trouve réalisé en Chine.

Les réformateurs : Fénelon repousse l'exemple chinois parce que la morale chinoise n'est qu'une morale d'expérience, mais les principes de la politique idéale du Télémaque ressemblent parfois à la politique chinoise vantée par les Jésuites. - Vauban invoque l'exemple de la Chine pour justifier son projet de dîme royale, ses projets de politique physiocratique, et ses projets en faveur de l'augmentation de la population. - Le problème de la mendicité et du vagabondage. - Le Pseudo-Leguat: sa solution du problème du paupérisme d'après l'exemple des Chinois de Batavia.

Discussions sur la morale et la politique chinoises : Renaudot, ennemi des Jésuites les critique; Silhouette, ami du P. Tournemine les vante avec exagération. Un indépendant, d'Argens, célèbre la morale chinoise parce qu'elle est indépendante de la religion.

Le parallèle entre les Chinois et les Européens

\section{Conclusion}




\begin{abstract}
La Chine
et la formation de l'esprit philosophique en France
\end{abstract}

A Monsieur Gustave LANSON 


\section{La Chine \\ et la formation de l'esprit philosophique en France}

\section{AVANT - PROPOS}

p.9 Lorsqu'on lit les ouvrages du XVIII ${ }^{e}$ siècle, récits de voyages ou articles de journaux, écrits des philosophes ou des économistes, on est étonné de voir revenir si souvent le nom de la Chine et de trouver tant de preuves de l'admiration qu'elle a provoquée : la Chine, à en juger seulement par le nombre des témoignages, semble plus en faveur que I'Angleterre elle-même, dont l'influence sur les idées a cependant été si grande à la même époque. La Chine sans aucun doute est à la mode au XVIII ${ }^{e}$ siècle.

Les différentes manifestations de la mode orientale et chinoise ont été décrites par M. Martino, et son travail n'est plus à faire. Mais qui dit mode ne dit pas nécessairement influence. On peut se faire habiller à Londres sans rien connaître de l'esprit anglais, sans rien emprunter aux idées anglaises. On a pu costumer à la chinoise en France au XVIII ${ }^{\mathrm{e}}$ siècle des personnages de romans ou de tragédies, sans que ces personnages aient rien de chinois. On a peut-être bu du thé dans de la porcelaine des Ming, voire en devisant de Confucius, sans éprouver le besoin de rectifier ses idées morales ou politiques d'après les idées des Chinois. Et même l'admiration pour une nation étrangère n'est pas une preuve d'une influence exercée par cette nation sur ceux qui l'admirent. Il y eut peut-être beaucoup de gens qui ont été dans le même état d'esprit que Saint-Evremond, qui était prêt à célébrer la vertu des Chinois, mais qui n'eût pas voulu vivre à Pékin, parce qu'on n'y trouvait 


\section{La Chine \\ et la formation de l'esprit philosophique en France}

pas de beurre et qu'on n'y mangeait pas d'huîtres. Le docte et grave Mathieu Marais, bien qu'en termes moins choisis, a exprimé exactement la même idée.

Leur admiration pour la Chine ne leur a pas donné le désir de «s'inoculer l'esprit chinois ».

Pour avoir le désir de « s'inoculer » l'âme d'une nation étrangère il faut semble-t-il éprouver d'abord une inquiétude d'esprit, ou de sentiment qui empêche de se satisfaire entièrement de tout ce ${ }_{\text {p.10 }}$ qui constituait, jusqu'à ce jour, la vie intellectuelle et morale. Mais il faut, en outre, que cette nation étrangère vienne, au moment précis où se manifeste cette inquiétude, apporter de quoi satisfaire des besoins et des désirs qui, pour être informulés ou inconscients, n'en sont pas moins déterminés. Et le mot de Pascal s'applique ici aussi «Tu ne me chercherais pas si tu ne m'avais déjà trouvé ». Si Bernier, la dernière année de sa vie, s'appliqua à traduire la morale de Confucius, c'est que, après avoir philosophé cinquante ans, il doutait des choses qu'il avait cru les plus assurées; et Confucius lui apportait, avec sa politique fondée sur la morale, de quoi satisfaire non seulement le philosophe qu'il avait toujours été, mais le philosophe vieilli qui ne voulait plus construire uniquement des systèmes dans les nuages, mais cherchait à les appuyer solidement sur les fondements de l'expérience.

Nous risquons donc de trouver une influence étrangère à des époques névralgiques, à des moments de crises, crises individuelles ou crises sociales, et c'est le cas pour la Chine dont l'action s'est exercée surtout à deux périodes : après 1685, 


\section{La Chine et la formation de l'esprit philosophique en France}

lorsqu'on commence à passer au crible les idées religieuses, politiques et morales traditionnelles, et après 1760 lorsque les philosophes et les économistes cherchent à constituer une science sociale, qui doit servir de base à la politique et à la morale. Or, remarquons-le, au moment où l'influence de la Chine est le plus considérable, c'est-à-dire après 1760, I'admiration pour la Chine, qui avait été pour ainsi dire un dogme jusque vers 1750 , n'est plus entière. On doute même alors de la vertu des Chinois. On range le gouvernement chinois dans les gouvernements despotiques, et les physiocrates, pour faire admettre le gouvernement chinois comme modèle de tout bon gouvernement, sont obligés de constituer leur théorie du despotisme légal ${ }^{1}$. D'autre part, la plus belle époque de la mode chinoise ne coïncide pas avec ces périodes d'influence. Elle se place entre 1745 et 1755 lorsque Mme de Pompadour, qui donne le ton, se plaît à s'entourer de chinoiseries : c'est le moment où la Compagnie des Indes fait ses plus beaux bénéfices (qui diminueront ensuite), c'est le moment où Boucher dessine ses femmes chinoises, où tout le monde veut avoir dans ses appartements des trumeaux à sujets chinois. Sans doute il serait faux de prétendre que cette mode a été sans action ${ }_{\text {p.11 }}$ sur la période qui l'a suivie - Quesnay, I'inventeur de la théorie du despotisme légal, qui était le médecin de Mme de Pompadour, a vécu dans sa familiarité - mais les deux courbes, celle de la mode et celle de l'influence pendant une période déterminée de l'art et de la littérature, restent indépendantes l'une de l'autre ;

\footnotetext{
1 Virgile Pinot : Les Physiocrates et la Chine au XVIII ${ }^{\mathrm{e}}$ siècle, Revue d'histoire moderne et contemporaine, t. VIII, 1906-1907, p. 200-214.
} 


\section{La Chine \\ et la formation de l'esprit philosophique en France}

bien qu'elles se rapprochent ou se confondent même quelquefois pendant un certain temps, elles conservent chacune leur individualité.

C'est l'influence exercée par la Chine au XVIII ${ }^{e}$ siècle sur les idées et les mœurs françaises, et rien d'autre, que nous avons I'intention d'étudier, sans pour cela négliger à l'occasion l'action que la mode des chinoiseries a pu avoir à certaines époques. Nous avions songé tout d'abord à traiter ce sujet en un seul ouvrage en prenant Voltaire pour centre, puisqu'aussi bien il est souvent considéré comme le grand propagateur du «virus » chinois. Mais nous avons dû nous rendre compte que bien longtemps avant que Voltaire parlât de la Chine, ce pays avait préoccupé et passionné érudits, savants et philosophes. Entre 1640 et 1740 , il se fait un lent travail d'information et I'on déploie beaucoup d'érudition pour arriver à connaître la chronologie, l'ancienne histoire, la philosophie, la morale des Chinois. Il faut donc connaître tout cette période d'élaboration pour savoir quelle est la grandeur de la dette de Voltaire à l'égard de ses devanciers, pour savoir par suite quel est son apport personnel. Avant de parler de Voltaire et la Chine, ce qui, nous l'espérons, ne tardera guère, il faut étudier le rôle de la Chine dans la formation de l'esprit philosophique du XVII ${ }^{\mathrm{e}}$ siècle.

Et d'autre part, en examinant les ouvrages d'information sur la Chine dans la première moitié du XVIII ${ }^{\mathrm{e}}$ siècle, on ne peut pas ne pas être frappé de ce fait que ce sont uniquement - à par quelques relations de voyages sans grande importance - des écrits de Jésuites. Contre l'impartialité de ces ouvrages, quelque 


\section{La Chine et la formation de l'esprit philosophique en France}

voix se sont élevées : St-Simon, Fréret, d'autres encore, sans parler des Missionnaires de la Société des Missions étrangères, ou des Dominicains, ennemis des Jésuites. Il était donc nécessaire de faire une étude critique de ces ouvrages, pour savoir si les Jésuites nous ont donné au début du XVIII ${ }^{\mathrm{e}}$ siècle une idée - nous ne dirons pas exacte - mais tout au moins impartiale de la Chine. Étude critique qui devait aussi être historique, à cause de cette Querelle des Cérémonies chinoise que quelques-uns de ces écrits ont déchaînée et qui a duré pendant tout le temps que se sont élaborés les principaux

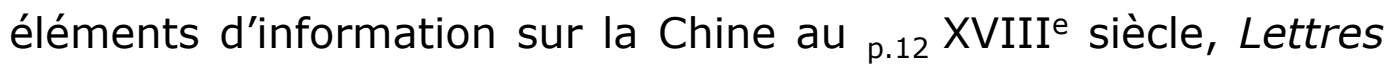
édifiantes et curieuses et Description de la Chine du P. du Halde.

Au moment de publier les premiers volumes de cette étude générale sur la Chine et l'esprit philosophique en France au XVIII ${ }^{e}$ siècle, je manquerais au plus grave des devoirs et en même temps à celui qui coûte le moins, j'entends au devoir de la reconnaissance, si je ne disais tout ce que je dois à M. Gustave Lanson. Il a bien voulu me signaler en 1905, alors que j'étais étudiant à la Sorbonne, l'importance de la Chine pour le développement des idées au XVIII ${ }^{\mathrm{e}}$ siècle ; depuis cette époque, il a sans cesse encouragé les travaux que j'ai entrepris sur cette question, et il m'a fourni avec une bonne grâce dont je ne saurais trop le remercier, non seulement des renseignements utiles mais les directions nécessaires. Puisse ce travail n'être pas trop inférieur à ce qu'il pourrait en attendre !

J'ai dû examiner de nombreux manuscrits non seulement dans les dépôts ordinaires, Archives Nationales, Bibliothèque 


\section{La Chine \\ et la formation de l'esprit philosophique en France}

Nationale, Bibliothèque de l'Arsenal, mais encore dans des dépôts plus particuliers, tels que la Bibliothèque de I'Observatoire astronomique de Paris et les Archives du Service hydrographique de la Marine (Dépôt des Cartes et Plans de la Marine) où j'ai toujours trouvé un accueil empressé dont je garde une fidèle reconnaissance. Je dois aussi des remerciements particuliers aux fonctionnaires de la Bibliothèque Royale de I'Université de Lund, qui, non contents de mettre à ma disposition leur bibliothèque, ont bien voulu en outre me procurer livres et manuscrits des autres bibliothèques de Suède ou de l'étranger. Qu'ils soient donc ici remerciés. 


\author{
La Chine \\ et la formation de l'esprit philosophique en France
}

\author{
LIVRE PREMIER
}

LES SOURCES DE LA

CONNAISSANCE DE LA CHINE 


\section{La Chine \\ et la formation de l'esprit philosophique en France}

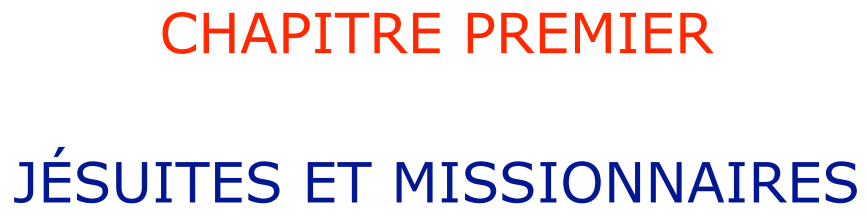

@

p.15 Le 3 mars 1685, appareillaient à Brest, sous les ordres de M. de Vaudricourt, le vaisseau de ligne Oiseau et la frégate Maligne qui partaient pour le Siam.

Ces deux navires emmenaient, outre les ambassadeurs siamois qui rentraient chez eux après avoir obtenu à Paris un grand succès de curiosité ${ }^{1}$, la première ambassade que Louis XIV eût jamais envoyée à un souverain d'Extrême-Orient. Le Chevalier de Chaumont en était le chef, et il avait à ses côtés pour l'assister, et au besoin pour le remplacer, le petit abbé de Choisy qui, voulant rompre avec sa vie de débauche, ne se sentait pas le courage de le faire autrement qu'en mettant des milliers de lieues entre lui et « les occasions».

Il y avait aussi à bord M. Vachet, de la Société des Missions étrangères de Paris, qui retournait à sa mission de Siam après avoir accompagné les ambassadeurs siamois à Paris, et qui emmenait trois prêtres de sa Société. Il y avait en outre sur ces navires plusieurs Jésuites qui, pour n'être pas encore connus à cette époque, ne laisseront pas de se faire par la suite une renommée assez tapageuse, les PP. Tachard, Visdelou, Bouvet,

\footnotetext{
1 Si cette première ambassade siamoise n'eut pas le succès éclatant de la seconde, en 1686, nous savons du moins d'après les mémoires de Bénigne Vachet, récemment publiés par A. Launay : Histoire de la mission de Siam, Documents historiques, t. I, p. 143-144, que les Parisiens firent preuve d'une curiosité à laquelle les Siamois essayèrent de se soustraire.
} 


\section{La Chine et la formation de l'esprit philosophique en France}

de Fontaney, Gerbillon et Le Comte, qui avaient des lettres de Mathématiciens du Roi, les recommandant à la bienveillance particulière de tous les souverains d'Extrême-Orient ${ }^{1}$. Ils partaient pour essayer ${ }_{\text {p.16 }}$ d'amener au christianisme plusieurs nations englobant plus de cent millions d'habitants : la Chine, la Tartarie et la Corée. Ils emportaient quelques présents pour Sa Majesté Chinoise, des sphères armillaires et deux machines de Romer, car S. M. Chinoise aimait I'astronomie. Et avec cela il leur fallait conquérir un monde au christianisme ! Mais leur ardeur et leur confiance n'étaient pas inférieures à l'immensité de la tâche.

Sans doute les passagers de l'Oiseau et de la Maligne n'avaient pas toujours le temps, par les coups de vent ou sous la chaleur des tropiques de songer au grand rêve de la christianisation des Indes qu'ils avaient fait au départ, car il leur fallait soigner et encourager les malades, lorsque le mal de mer leur laissait à eux-mêmes quelque répit ; il leur fallait aussi, avant de catéchiser les infidèles, catéchiser les équipages dont la foi n'était pas toujours bien vive, et parmi lesquels il y avait même quelques protestants « mal convertis ». Aussi les exercices de piété ne chômaient guère : c'était tantôt une exhortation du P. Le Comte et tantôt un catéchisme du P. Tachard. Certains jours cependant, notamment un jour de Pâques, où, après la morue du carême, on avait tâté d'une poule dodue et d'un mouton gras à point, le frivole abbé de Choisy, l'estomac bien garni, ne se sentait pas d'aise à l'idée de la

${ }^{1}$ Crétineau-Joly : Histoire de la Compagnie de Jésus, t. V, p. 33.34, a publié par la lettre accordée au P. de Fontaney. Les lettres accordées aux autres jésuites étaient identiques. 


\section{La Chine et la formation de l'esprit philosophique en France}

mission qu'il allait remplir au Siam. « Le Terme approche, ces grands événements se vont démêler, nous saurons bientôt ce qui en arrivera. Un Roi se faire Chrétien, un million d'âmes suivre son exemple, voilà peut-être ce que nous allons voir, voilà au moins ce que nous allons tenter. $Y$ eut-il jamais un plus beau dessein ? Et peut-il entrer dans l'esprit de I'homme une idée plus noble, une pensée plus magnifique ? »1. Car le petit abbé de Choisy, bien qu'il ne fût pas encore prêtre, comptait bien être I'aumônier du roi de Siam, lorsque celui-ci se serait converti.

Le P. Tachard, dans le récit qu'il nous a laissé de son voyage au Siam, n'a pas les mêmes accents pathétiques ; il parle seulement en bon religieux qui semble uniquement préoccupé de sa besogne quotidienne. Il est modeste et ne se vante pas, il semble prendre à tâche au contraire de s'effacer devant les mérites de ses compagnons de voyage : il célèbre la piété de ses confrères les Jésuites, mais il paraît ignorer complètement l'existence des autres ecclésiastiques, les Missionnaires. Il n'a pas l'impartialité de l'abbé de Choisy qui note dans son journal que «les Jésuites et les Missionnaires sont tous les jours en querelle, à qui aura le plus de soin des malades, à qui aura la dernière place à table »2. Le $P$. Tachard ne peut avoir cette sereine impartialité, ou cette indifférence, de l'abbé de Choisy. Le P. Tachard peut feindre I'oubli, M. Vachet et ses confrères ne lui sont pas pour cela indifférents. Comme Jésuite, il n'ignore pas en effet que dans les pays lointains d'Extrême-Orient, il n'aura

\footnotetext{
${ }^{1}$ Choisy : Journal ou suite du Voyage de Siam en forme de Lettres familières, p. 38.

2 Choisy, op. cit., p. 8.
} 


\section{La Chine et la formation de l'esprit philosophique en France}

pas seulement à lutter contre I'hostilité des indigènes, mais aussi à combattre l'influence de ces MM. des Missions étrangères. Peu à peu, grâce aux Vicaires apostoliques, les missionnaires de la Société des Missions ont réussi à supplanter les Jésuites au Tonkin, en Cochinchine, au Laos; ils ont acquis déjà pour ainsi dire le monopole des missions du Siam, et ils commencent à s'insinuer en Chine, où seuls jusqu'alors les Jésuites avaient réussi à pénétrer sur les traces de St-François Xavier.... La lutte est engagée depuis quelques années déjà entre les Jésuites et la Société des Missions étrangères pour le monopole des missions en Extrême-Orient. L'affaire de I'ambassade de Siam où Jésuites et Missionnaires vont s'affronter, est le prélude et l'une des causes de l'affaire des Cérémonies chinoises.

\section{I. - Les Missions Catholiques en Extrême-Orient au XVII Siècle}

Il ne serait pas tout à fait juste de dire que les Jésuites furent les premiers à pénétrer en Chine. Bien avant la fondation de I'ordre des Jésuites, aux XIII ${ }^{\mathrm{e}}$ et XIVe siècles, des Franciscains, envoyés en mission à différentes reprises par des souverains d'Europe, avaient réussi à pénétrer jusqu'en Tartarie ; telle I'ambassade de Jean de Plan Carpin, envoyée par le pape Innocent IV vers le Grand-Khan de Tartarie, et telle I'ambassade de frère Guillaume Ruysbroeck (Rubruquis) envoyé par SaintLouis vers les princes mongols avec une double mission, religieuse et politique, pour tâcher de les convertir au 


\section{La Chine et la formation de l'esprit philosophique en France}

christianisme et pour les attirer dans son parti contre les Sarrasins ${ }^{1}$. Un peu plus tard, un autre ${ }_{\text {p.18 }}$ franciscain, Jean de Montecorvin, légat et nonce du Saint-Siège, parvint jusqu'à Kambalick - le Cambalu de Marco Polo -, c'est-à-dire le Pékin actuel, où il réussit à se fixer et à construire une église. Le pape érigea Kambalick en archevêché, mais cette église et cet archevêché disparurent en même temps que la domination mongole, à l'avènement de la dynastie des Ming (1369) ${ }^{2}$.

Il faut donc accorder aux Franciscains le mérite qui leur est dû, et que les Jésuites ont essayé de faire oublier ${ }^{3}$. Mais cela dit, on ne peut s'empêcher de remarquer que les résultats de ces ambassades des Franciscains, au point de vue de l'évangélisation, furent absolument nuls. Quant à l'archevêché de Pékin du XIVe siècle, il était tellement oublié au XVII ${ }^{\mathrm{e}}$ que le pape, en 1690, érigea Pékin en évêché comme s'il instituait un siège nouveau.

Si les Jésuites ne furent pas les premiers à pénétrer en Chine, ils furent tout au moins les premiers à mener une action patiente, concertée et suivie pour s'y introduire, pour s'y maintenir et pour y prêcher le christianisme. C'est le P. Mathieu

\footnotetext{
1 A. Thomas, Histoire de la mission de Pekin, p. 50-55. Jean de Plan Carpin et Rubruquis ont écrit des relations de leurs ambassades. Si le frère de Plan Carpin ne réussit pas à convertir le grand Khan, il réussit du moins à saisir les secrets de sa tactique militaire, ce qui lui permit de donner d'utiles conseils aux armées qui pouvaient avoir à combattre les Mongols.

2 Id., op. cit., p. 56-62.

3 Le P. Le Comte, jésuite, dans son chapitre : De l'établissement et du progrès de la Religion Chrétienne à la Chine (Nouveaux Mémoires sur l'Etat présent de la Chine) ne dit rien de ces ambassades.
} 


\section{La Chine et la formation de l'esprit philosophique en France}

Ricci ${ }^{1}$ qui fonda la mission de Chine. Il attendit dix-huit ans dans les provinces de la Chine méridionale une occasion favorable pour se glisser jusqu'à la cour et gagner la faveur de l'empereur. Il y parvint en 1601 et il offrit à l'empereur une montre à répétition et une horloge. Ces curiosités furent du goût du souverain qui fit construire une tour pour placer cette horloge 2 . Mais avant d'accorder au Jésuite l'autorisation de rester à la cour, il fut obligé de consulter le tribunal des rites qui ne se montra pas favorable. Les reliques que le P. Ricci apportait notamment parurent suspectes : « Il présente [dit le tribunal] une bourse dans laquelle il dit qu'il y a des os d'immortels, comme si les immortels en montant en haut n'emportaient pas leurs os $\gg 3$. Aussi le tribunal des rites exprima l'avis qu'il fallait renvoyer le P. Ricci dans son pays. Malgré cela, l'empereur permit au jésuite de demeurer à la cour.

p.19 Quelques années plus tard, en 1613, les Jésuites qui essaimaient peu à peu de l'établissement portugais de Macao, s'étaient fait déjà une assez grande réputation de mathématiciens et d'astronomes pour que le tribunal des rites de la cour de Nankin demandât a l'empereur qu'on chargeât les Jésuites de la réforme du calendrier ${ }^{4}$. Ils se poussaient en même temps dans la confiance des mandarins, ils arrivaient même parfois à les convertir, si bien qu'en 1629 le célèbre lettré

\footnotetext{
1 J. Brucker : Le P. Mathieu Ricci, fondateur des missions en Chine. Etudes (20 juillet, 20 septembre 1910).

2 Mailla, Histoire de la Chine, t. X, p. 343, note 1.

${ }^{3}$ Id., op. cit., t. X, p. 390.

4 Mailla, Histoire de la Chine, t. X, p. 398-8.
} 


\section{La Chine et la formation de l'esprit philosophique en France}

Sin-Kouan-Ki, qui était chrétien, s'adjoignit au tribunal des mathématiques les PP. Longobardi et Sebreck, auxquels succédèrent les PP. Adam Schall et Jacques Rho ${ }^{1}$. Le P. Adam Schall entretenait les meilleures relations avec les ministres et I'empereur lui témoignait sa faveur ; en 1636, ce Père établit près du Palais une fonderie de canons ${ }^{2}$ pour aider les Chinois à lutter avantageusement contre les Tartares avec lesquels ils étaient en guerre depuis de nombreuses années. Ces canons du $P$. Schall ne sauvèrent d'ailleurs pas la dynastie, mais le P. Schall fut aussi bien traité par les Tartares victorieux qu'il l'avait été par les empereurs de la dynastie chinoise ; en 1645, il fut nommé président de tout ce qui regarde la littérature céleste, et, le 2 avril 1653, il reçut le titre de Docteur Très Profond 3 . Comme le dira Voltaire, le conquérant tartare adoptait les usages des Chinois conquis.

L'année suivante, l'empereur décida qu'on ne se servirait plus dorénavant de l'astronomie des Mahométans et qu'on emploierait celle des Européens. Dès ce moment, fut introduit l'usage d'avoir des astronomes européens au tribunal des mathématiques. Mais le nombre en était très limité : un des présidents et deux assesseurs. Il en était encore ainsi à la fin du XVIII ${ }^{\mathrm{e}}$ siècle. « Les missionnaires astronomes ne composent ni les uns ni les autres les éphémérides, écrit le P. Amiot à Bertin. Ils ne sont point chargés de calculer pour les Chinois. Leur

\footnotetext{
${ }^{1}$ Cordier, Histoire de la Chine, t. III, p. 250-251.

2 Id., ibid., t. III, p. 251.

3 Id., ibid., p. 250-251.
} 


\section{La Chine \\ et la formation de l'esprit philosophique en France}

emploi consiste à revoir les erreurs s'il s'en trouve. Les appointements ou les gages que l'empereur leur donne sont attachés au degré de mandarinat dont ils sont décorés. Comme les premiers européens qui ont été admis dans le Tribunal d'astronomie qui est à Pékin étaient de la nation portugaise, qui était alors la seule, c'est la mission qui a fourni jusqu'à présent des astronomes à ce même tribunal » 1 .

p.20 Malgré cette faveur dont ils jouissaient à cause de leurs connaissances scientifiques, les Jésuites devaient sans cesse se défendre contre toute sorte d'ennemis, dont les uns faisaient surtout preuve d'hostilité contre le christianisme et dont les autres haïssaient l'esprit de nouveauté qu'apportaient les Européens. Le P. Schall lui-même éprouva ces inimitiés sous la minorité de l'empereur Kang hi. Les Jésuites furent alors accusés par un musulman d'être venus apporter en Chine l'esprit de révolte et de faction en se servant, pour séduire les Chinois, du prétexte de les instruire dans leur religion. On enleva au P. Schall sa place de président du tribunal des mathématiques et on le fit mettre aux fers avec ses trois compagnons, les PP. Verbiest, Buglio et Magalhaens. La religion chrétienne fut proscrite et tous les missionnaires, sauf quatre, furent exilés à Canton. Le P. Schall fut condamné d'abord à être étranglé, mais la sentence ayant paru trop douce, il fut condamné ensuite à être écartelé. Cependant sur les instances de l'impératrice, il fut remis en

${ }^{1}$ Id., ibid., p. 251. 


\section{La Chine \\ et la formation de l'esprit philosophique en France}

liberté ; il ne survécut d'ailleurs que peu de temps à son emprisonnement 1 .

Le délateur Yang-Kouang-Sien qui avait succédé au P. Schall dans la charge de président du tribunal des mathématiques, voulant poursuivre ses avantages, dénonça le P. Verbiest, flamand de nation, arrivé en Chine en 1659, coupable suivant lui de vouloir détruire les instruments astronomiques de Yao et de Chouen, pour leur substituer ceux d'Europe. A ce moment, le P. Verbiest venait d'achever l'examen en deux volumes du calendrier que le vice-président du tribunal des mathématiques avait composé pour l'année 1669 et, dans son rapport, il en signalait les erreurs. A la suite de ce rapport, les membres du bureau des observations astronomiques furent chargés d'examiner l'affaire et la commission spéciale désignée à cet effet, déclara exacts les chiffres du P. Verbiest. En conséquence, le tribunal des rites demanda et obtint la destitution de YangKouang-Sien ; I'empereur Kang hi fit suspendre l'interdit qui pesait sur vingt-quatre missionnaires depuis la persécution suscitée par Yang, et il autorisa les Jésuites à pratiquer leur religion, en leur interdisant toutefois, de faire de la propagande ${ }^{2}$.

La mission des PP. Jésuites à Pékin semble donc ne s'être établie et maintenue que grâce à un heureux concours de circonstances, malgré toutes sortes de difficultés et même de persécutions. Il faut l'avouer, I'audace était grande de chercher à

\footnotetext{
1 Mailla, op. cit., t. XI, p. 57-59. Cordier, op. cit., p. 265.

2 Cordier, op. cit. p. 166-167.
} 


\section{La Chine et la formation de l'esprit philosophique en France}

s'implanter p.21 dans un pays si attaché à ses traditions et de vouloir y introduire une religion nouvelle, même avec le secours des mathématiques et de l'astronomie. Car même en astronomie les Chinois n'aimaient pas rompre avec des traditions immémoriales. Les Jésuites eurent l'avantage de trouver une aide précieuse dans la faveur que leur marqua le jeune empereur Kang hi, prince intelligent, ami du progrès, qu'ils finiront par nous rendre suspect par la suite à cause des éloges exagérés qu'ils lui prodigueront, mais qui fut certainement pour eux un appui sur lequel ils purent toujours compter et que même leurs dissentiments entre eux, si graves qu'ils fussent, ne réussirent pas à leur aliéner.

Mais ici une remarque s'impose. Les Jésuites ont à l'envi célébré l'esprit chinois, à cause de l'amour et du respect que les Chinois portent aux mathématiques et à I'astronomie, à un tel point même que pour l'amour de ces sciences, disent-ils, les Chinois se laissent instruire des mystères du christianisme. Et en vantant les Chinois, les Jésuites se vantaient du même coup, car ils voulaient voir dans ce respect des Chinois pour les sciences une action providentielle qui désignait tout spécialement pour la prédication en Chine l'ordre des Jésuites, ordre savant, plutôt que les moines mendiants et les petits frères. La réalité n'est pas aussi belle que voudraient le laisser supposer les Jésuites. Au cours du rapide exposé que nous avons fait de l'entrée des Jésuites en Chine, nous avons vu qu'ils ont eu au début autant de peine à faire accepter l'astronomie européenne que la doctrine chrétienne. Il leur a fallu biaiser longtemps avant de s'introduire au tribunal des mathématiques, il leur a fallu se 


\section{La Chine et la formation de l'esprit philosophique en France}

ménager l'appui de mandarins influents. Et lorsqu'ils eurent forcé I'entrée de ce tribunal, ils n'y furent pas tous employés ; du temps de Kang hi, nous l'avons vu, il y avait vingt-quatre Jésuites à Pékin et trois d'entre eux étaient des mathématiciens officiels. Que faisaient donc les autres pour être tolérés à Pékin ?

Kircher nous a raconté 1 I'arrivée de P. Ricci en Chine qui ressemble, toutes proportions gardées, à l'arrivée de n'importe quel voyageur dans une région encore inexplorée. Comme tout explorateur, il commence par déballer sa bimbeloterie pour exciter l'intérêt des indigènes ; mais, comme la Chine est un pays civilisé, au lieu d'étoffes voyantes et de petits miroirs, il exhibe son horloge : «Parmi tant de belles curiosités qu'avaient ces Pères, il y avait un horologe qui estoit très beau, en ce que les roues estoient admirablement bien travaillées et qui, outre qu'il marquoit tous les jours p.22 le cours de la lune et du soleil, il faisoit encore reconnoistre toute la différence des heures qu'il y a d'un pays à l'autre. Il estoit couvert d'un cristal fait à triangles qu'ils [les Chinois] se persuadoient estre une pierre précieuse d'une valeur inestimable ou bien quelque petite partie du Ciel ». Le bruit de I'arrivée du P. Ricci et de ses compagnons se répandit dans la province de Canton et dans les provinces environnantes, et tout le monde voulut les voir. « Ceux qui ne pouvoient pas les voir ni entendre ce qu'ils disoient demandoient qu'on les exposast en public et que I'on envoyeroit pour cet effet des lettres par tout l'empire pour en avertir tous ceux qui les voudroient voir avec leurs raretés ». Pour satisfaire à cette

\footnotetext{
${ }^{1}$ Kircher, La Chine illustrée, p. 132.
} 


\section{La Chine et la formation de l'esprit philosophique en France}

curiosité, Ricci montra aux Chinois des cartes géographiques où toute la terre était marquée, mais ils furent déconfits en remarquant que la Chine n'était pas le centre du monde. Aussi s'empressa-t-il de faire une nouvelle carte générale, et il la divisa en deux hémisphères, faisant en sorte que la Chine se trouvât au milieu du monde.

Le P. Ricci, qui était un homme habile, composa pendant son séjour en Chine, un certain nombre d'ouvrages d'enseignement pour les Chinois sur les sujets les plus variés. On trouve naturellement, dans ce singulier catalogue d'auteur, des traités de morale et des ouvrages de mathématiques, mais aussi une « méthode de faire des horloges solaires appelées «Gnomica », « un abrégé de la façon de se servir et de faire des Astrolabes », enfin un livre « de la musique et de la fabrique du Clavesymbale européen $\gg 1$.

Ce n'est donc pas seulement grâce aux nobles sciences de la mathématique et de l'astronomie que les Jésuites réussirent à s'introduire en Chine, mais aussi grâce à ce que I'on appelait alors «les arts », c'est-à-dire pour parler franc, grâce à toute sorte de métiers dont la nouveauté était capable de séduire la curiosité des Chinois. Ainsi le P. Pantoya s'assurait les faveurs des mandarins en leur donnant des « cadrans d'yvoire que ce Père faisoit à la perfection »2. Le P. Schall, comme nous l'avons $\mathrm{vu}$, fondait des canons. Au XVIII ${ }^{\mathrm{e}}$ siècle, les Jésuites qui partaient en Chine, même s'ils étaient mathématiciens ou

\footnotetext{
${ }^{1}$ Kircher, op. cit., p. 159.

2 Semedo, Histoire universelle du grand royaume de la Chine, p. 294.
} 


\section{La Chine et la formation de l'esprit philosophique en France}

astronomes - ce qui pourtant, suivant les Jésuites eux-mêmes, aurait dû suffire - ne manquaient pas d'apprendre avant de quitter l'Europe, un métier manuel qui leur donnait une chance de plus de se pousser dans la faveur de l'empereur. Nous voyons par exemple, en 1739 , le P. de p.23 la Roche et le P. d'Incarville, avant leur départ, travaillant plusieurs mois dans une verrerie pour apprendre à faire du verre plat, tandis que le P. de la Roche apprenait à graver sur cuivre ${ }^{1}$.

Nous avons une description vivante de l'existence des PP. Jésuites de Pékin au commencement du XVIII ${ }^{e}$ siècle. Cette description nous vient d'un officier de la Compagnie de la Chine, qui n'aime pas particulièrement les Jésuites, mais ses affirmations, qui pourraient nous paraître suspectes à cause de cette antipathie, sont confirmées par quelques confidences des jésuites eux-mêmes ${ }^{2}$. Or, d'après cette description, les métiers manuels - disons si l'on veut les arts mécaniques - tiennent dans la vie des PP. une place plus grande que les mathématiques.

« Le P. Gerbillon est supérieur des PP. françois, il va présentement rarement au palais, s'il n'est appelé pour servir

\footnotetext{
1 Lettre du P. du Halde au P. Foureau, 13 octobre 1789, B. N.-N. A. F., 6556 f. $26 v^{\circ}-27 r^{\circ}$.

2 Le P. Gaubil notamment se plaint au P. Souciet de ne pouvoir faire comme il le voudrait des observations astronomiques parce que ses fonctions de musicien dans l'orchestre de l'empereur sont trop absorbantes : « Nous n'avons pas ici d'observatoire et toutes les fois qu'il faut observer, c'est un opéra, on est obligé de manquer bien des observations ». (Le P. Gaubil au P. Souciet, 23 octobre 1731. Obs. Astr., A. $B^{1} 10\left(150-1,48^{2}\right.$ f. $\left.1 v^{\circ}\right)$.
} 


\section{La Chine et la formation de l'esprit philosophique en France}

d'interprète au sieur Ghirardini, peintre italien, quy travaille souvent en présence de l'empereur.

«Le P. Bouvet est comme le curé des chrétiens de l'église des PP. françois, c'est luy quy leur administre les sacremens, il a esté aussi bien que le P. Visdelou, maistre des mathématiques du Prince héritier.

« Le P. Pernon fait les instrumens quy servent à l'empereur comme clavecins, épinettes et les accorde lorsqu'ils ne le sont plus, il joue de ces instrumens aussy bien que de la flute devant l'empereur et c'est luy quy, après le P. Pereyra, a montré à S. M. à se servir de ces instrumens ; il joue aussy un peu de violon.

« Le P. Parennin connaît la flute et le flageolet et un peu la trompette marine, c'est luy quy a présenté le premier ce dernier instrument à l'empereur...

« Lorque l'empereur veut prendre le divertissement de la symphonie, il fait appeler ces deux PP. avec le sieur Ghirardini quy joue de la basse, de la viole et de la trompette marine...

« Le P. Pereyra a esté le premier maistre de musique de l'empereur. C'est de tous les PP. celuy quy a I'honneur de le p.24 voir et quy luy parle le plus souvent. Il est machiniste et comme armurier de l'empereur, il raccommode et met en état les armes de S. M. et les tient propres il travaille aussy aux montres, aux horloges et aux cadrans... »1.

\footnotetext{
1 Journal du voyage de la Chine fait dans les années 1701, 1702, 1703, in Madrolle, Les premiers voyages français à la Chine, p. 145-8.
} 


\section{La Chine et la formation de l'esprit philosophique en France}

Comme on le voit, ce ne sont pas les plus grands mathématiciens qui sont le plus en faveur. Le P. Pereyra, le mieux en cour, est surtout un maître de musique. Quant au savant P. Parrenin, son grand mérite est d'avoir introduit la trompette marine à la cour de Pékin.

Cependant au XVII ${ }^{e}$ siècle s'établit la légende que c'était par les mathématiques et l'astronomie qu'on pouvait parvenir à la cour de l'empereur de Chine. La chose est vraie sans aucun doute et assez curieuse pour qu'elle suscitât un intérêt passionné. Les Jésuites insistèrent sur ce fait, car ils y voyaient une sorte de miracle en faveur de leur compagnie ${ }^{1}$, et la gravure, plus encore que toutes les déclarations enthousiastes, rendit familière cette idée que les Jésuites étaient en Chine présidents du tribunal des mathématiques et mandarins. N'avaiton pas vu dans le beau livre du P. Kircher, les PP. Ricci, Schall et Grimaldi habillés en mandarins ou portant le bonnet de docteur chinois ?

La preuve que cette légende existait dès le moment où on songea à envoyer des Jésuites français en Chine, c'est que le $P$. de la Chaize et les Jésuites français s'y laissèrent prendre euxmêmes. Les Jésuites qui partirent en Chine en 1685 étaient des

\footnotetext{
1 « Il semble que c'estoit I'héritage, destiné par la providence divine en la distribution du monde, aux Religieux de la Compagnie de Jésus, qui pour estre venus des derniers à la culture des terres de l'Eglise ne laissent pas néantmoins d'estre des premiers, après l'Apostre Sainct Thomas, qui ont cultivé ces vastes Royaume séparez du vieux monde par un monde nouveau » (Semedo, op. cit., Avant-Discours, s. p.). Il est possible que chez Semedo, médiocrement cultivé, ceci ne soit qu'une simple formule, mais le $P$. Gaubil, avec de meilleures raisons, croit aussi à ce miracle. (cf. la lettre du P. Gaubil au P. Souciet, du 31 août 1734, ap. Jos. Brucker : Correspondance scientifique d'un missionnaire, Revue du Monde catholique, t. LXXVI, 1883, p. 218).
} 


\section{La Chine et la formation de l'esprit philosophique en France}

savants et rien autre chose. Ils s'aperçurent vite de leur erreur. Pour supplanter les Portugais à Pékin, il fallait non seulement des savants, mais des hommes habiles en toute sorte de métiers et capables d'exciter la curiosité de l'empereur. Ce sont des hommes de ce genre que le P. Bouvet revint chercher en 1697. Revenant en Europe, le P. Bouvet avait pour mission « d'amener un plus grand nombre de Jésuites françois en la p.25 Chine sous le nom de mathématiciens, de musiciens, de joueurs d'instrumens, d'horlogeurs, etc., qu'ils sçavoient estre agréables à l'empereur et capables de le divertir et de détruire ou du moins d'affaiblir le crédit que les PP. Jésuites portugais s'étoint acquis par ces sortes de talens $\gg 1$. Heureusement le P. Parrenin, que le P. Bouvet ramena cette fois-là, savait jouer de la trompette marine. Sans cela nous aurions été privés des savantes lettres de ce Père à $M$. de Mairan.

Une légende était donc formée dès avant le départ de la première mission française, légende qui reposait sans doute sur un fait exact, mais légende malgré tout, parce qu'on avait singulièrement grossi le fait initial qui lui avait donné naissance ; légende importante pour la suite de cette histoire, parce qu'elle eut une influence sur le choix des Jésuites que I'on envoya en Chine la première fois ; légende heureuse au total parce que nous n'aurions sans doute pas les belles collections des Jésuites sur la Chine, si I'on s'était contenté d'y envoyer des horlogers ou de simples joueurs de trombone.

1 Journal du voyage de la Chine fait dans les années 1701, 1702, 1703. - B. N. N. A. Fr. 2086, f. 3. Ce passage n'a pas été publié par Madrolle. 


\title{
La Chine et la formation de l'esprit philosophique en France
}

\begin{abstract}
$*$
Les premières relations sur la Chine, sur la grandeur de ses villes et sur l'excellence de son gouvernement, les récits des missionnaires sur la protection particulière que les savants mathématiciens et astronomes trouvent à la cour de Chine habituent peu à peu, au cours du XVII e siècle, à cette idée que des relations intellectuelles sont possibles avec un peuple si éloigné et jusqu'alors presque inconnu. La légende, bien qu'habilement propagée, de la Chine savante et protectrice des savants européens eût peut-être malgré tout été insuffisante à décider Louis XIV à envoyer en Chine une mission de Jésuites mathématiciens si des causes plus immédiates n'étaient venues le décider : les intérêts politiques et religieux.
\end{abstract}

Les missionnaires européens étaient en réalité peu nombreux en Extrême-Orient au XVII ${ }^{e}$ siècle ${ }^{1}$. La vigne du Seigneur p.26 manquait d'ouvriers. Encore s'ils avaient pu exercer librement leur ministère, sans être inquiétés par les particuliers ou par les autorités! Mais il leur fallait le plus souvent se cacher, vivre parfois, comme le fit le P. Fuciti au Tonkin, dans une mauvaise barque pendant douze ans pour aller le soir chez quelques fidèles, dont la maison servait de rendez-vous et d'église, confesser, prêcher et baptiser ${ }^{2}$. Ajoutons à cela la difficulté des

\footnotetext{
1 Suivant le Catalogue Patrum Societatis Jesu du P. Couplet, il y avait eu, depuis le commencement de la mission en Chine jusqu'en 1681, 105 jésuites missionnaires. Ceux qui existaient encore à l'époque du P. Couplet ne se trouvaient pas seulement à Pékin ou à Macao, mais ils étaient répartis dans toutes les provinces. (Voir la carte de leur répartition dans le Confucius Sinarum Philosophus). Cependant ils avaient déjà deux églises à Pékin.

2 Tachard, Voyage de Siam, p. 117.
} 


\section{La Chine et la formation de l'esprit philosophique en France}

voyages, la cupidité ou l'hostilité des bateliers, les mandarins désireux de faire payer leur silence par quelque « rareté d'occident », et nous n'aurons qu'une faible idée des difficultés auxquelles se heurtaient les missionnaires.

Dans les derniers jours de 1652, arriva à Paris le P. de Rhodes, missionnaire jésuite au Tonkin et en Cochinchine, qui venait en Europe, sur l'ordre de ses supérieurs, « pour trouver moyen de secourir ces belles églises en leur procurant des évêques et en leur amenant de nouveaux missionnaires »1. Le Pape, qu'il avait vu à Rome, l'avait chargé de trouver quelques hommes dignes d'êtres nommés évêques dans ces régions lointaines. Le missionnaire avait alors parcouru, mais vainement, I'Italie, le Piémont, la Suisse catholique. Il venait d'arriver à Paris et continuait ses recherches. Il découvrit alors cette société de jeunes gens qu'avait fondée le P. Bagot, Jésuite, en 1646, sous le vocable de la Sainte-Vierge. Il leur représenta la riche moisson qu'on pouvait faire en Extrême-Orient, et quelques-uns de ces jeunes gens se déclarèrent prêts à partir. Le 14 février 1653, le Jésuite annonçait à son Général cette découverte inattendue. Le Comité du Saint-Sacrement, qui s'intéressait à I'entreprise du P. Bagot, fut informé tout de suite du concours que le P. de Rhodes avait trouvé dans cette société, puisqu'il note dans ses annales à la date du 26 février 1653 : « Il y eut alors de grands projets et de grandes entreprises de missions étrangères auxquelles la Compagnie s'intéresse puissamment $\gg 2$.

\footnotetext{
${ }^{1}$ A. Launay, Histoire de la Société des missions étrangères, t. I, p. 13.

2 R. Allier, La Cabale des Dévots, p. 151.
} 


\section{La Chine et la formation de l'esprit philosophique en France}

Aussitôt la Congrégation de la Propagande ordonnait au nonce à Paris de choisir parmi ces jeunes gens les ecclésiastiques les plus propres à l'épiscopat. Le choix du nonce tomba sur les abbés Pallu, François de Laval et Pique. En même temps on chercha des ressources pour les trois évêchés nouveaux : ce furent les membres de la Compagnie du Saint-Sacrement qui les fournirent. p.27 La duchesse d'Aiguillon se montra généreuse et les Confrères de la Compagnie du Saint-Sacrement, au commencement de mai firent « des contributions bien considérables pour soutenir les missions des Jésuites au Levant »1. Il n'y avait alors aucune rivalité entre les Jésuites et la Compagnie du St-Sacrement, bien au contraire, et lorsque, un peu plus tard, le P. de Rhodes quitte la France, la Compagnie, dit d'Argenson, «prit part aux desseins du P. de Rhodes qui partait pour le Tonkin avec des missionnaires de son ordre $\gg 2$.

Les premières difficultés allaient venir d'ailleurs, des Portugais et de leur droit historique sur les églises des Indes, droit qui ne leur conférait en principe que des privilèges religieux, mais qu'ils étaient prêts à défendre avec d'autant plus d'énergie qu'il leur procurait de grands avantages commerciaux. A cette époque, le commerce suivait déjà le pavillon, il suivait surtout les missions.

Le droit de patronage sur les Indes, qui avait été accordé aux Portugais par les papes Nicolas V, Calixte III et Sixte IV, leur attribuait généralement et sans limite tout ce qu'ils pourraient acquérir depuis le cap Bojador jusqu'aux extrémités du midi.

\footnotetext{
${ }^{1}$ R. Allier, La Cabale des Dévots, p. 152.

2 ibid., p. 152.
} 


\section{La Chine et la formation de l'esprit philosophique en France}

C'était le moment où les explorateurs portugais commençaient à découvrir les terres situées au delà du cap Bojador. Un peu plus tard, la découverte du cap de Bonne-Espérance et de la route maritime des Indes obligea le pape Alexandre VI à modifier cette concession. Ce pape, traçant alors une ligne imaginaire depuis les Açores jusqu'au pôle sud, décida que tout ce qui sera au-delà de cette ligne vers I'occident serait aux Espagnols, quand ils I'auraient conquis, les Portugais conservant tout ce qui trouvait à l'est de cette ligne.

Ce droit de patronage conférait une juridiction pleine et entière et sans aucune restriction à l'archevêque de Goa, en qualité de primat, et à ses suffrageants, dans toutes les Indes ; et, en même temps, défense était faite à toutes les nations catholiques et à tous les particuliers d'aller dans les Indes sans la permission du roi de Portugal ${ }^{1}$. Cette dernière clause qui obligeait les missionnaires des nations autres que le Portugal à passer par Lisbonne pour aller y retirer leurs passeports donnait aux Portugais un droit de contrôle sur tous les missionnaires et leur permettait p.28 d'écarter des Indes orientales les missionnaires des nations dont ils suspectaient les ambitions commerciales en Extrême-Orient. Or, la seule nation catholique qui pouvait inquiéter le commerce portugais dans les Indes était la France, les Espagnols ayant assez à faire dans I'Amérique du Sud.

1 [Seriey], Analyse du mémorial de I'archevêque de Brague, ambassadeur roi du Portugal pour revendiquer son droit de patronage en 1680, Histoire de l'établissement du christianisme dans les Indes orientales, t. I, p. 67 sq. 


\section{La Chine et la formation de l'esprit philosophique en France}

Aussi, le projet de la Compagnie du St-Sacrement ne réussit pas tout d'abord. Vainement l'archevêque de Reims, Vincent de Paul et quelques autres envoyèrent une supplique au pape pour qu'il créât au Tonkin et en Cochinchine des évêques in partibus et qu'il les députât dans cette région au nom du Saint-Siège. Les Portugais agirent sur la congrégation de la Propagande et I'affaire traîna en longueur, si bien que les candidats aux sièges de vicaires apostoliques en Extrême-Orient perdirent patience ; Pique accepta la cure de St-Josse, François de Laval se retira à Caen ${ }^{1}$.

Cependant, en 1658, la Propagande se décida à donner un avis favorable, et le pape désigna (9 septembre 1659), deux évêques pour les missions d'Extrême-Orient : Pallu fut nommé évêque d'Héliopolis, et de Lamotte-Lambert évêque de Béryte, avec les fonctions de vicaires apostoliques dans la Chine et les pays voisins ${ }^{2}$.

Cette décision ne pouvait que satisfaire le gouvernement du roi de France, non seulement pour des raisons spirituelles ou des raisons de prestige, mais aussi pour les espérances de développement commercial que cette nomination d'évêques français en Extrême-Orient pouvait faire naître. Aussi le duc de Chaumes, ambassadeur de France près de Clément IX fut-il chargé d'assurer le pape que le roi accorderait son appui aux vicaires apostoliques ; et en même temps il reçut l'ordre d'exprimer au pape «la satisfaction particulière éprouvée par le

\footnotetext{
${ }^{1}$ Launay, Histoire de la Société des missions étrangères, t. I, p. 19-22.

2 ibid., t. I, p. 34.
} 


\section{La Chine et la formation de l'esprit philosophique en France}

Roi en apprenant que le Saint-Siège veut bien employer des ecclésiastiques françois à la conversion des Infidèles dans les royaumes de I'Orient et que, y ayant envoyé des évêques, c'est parmi les sujets de Sa Majesté qu'il lui a plu de les choisir $\gg 1$. Suivant sa promesse, le roi accorda à chacun des vicaires apostoliques une rente viagère de 1.000 livres, qu'il portera par la suite à 3.000 livres. Les membres de la Compagnie du p.29 SaintSacrement de leur côté offrirent soit des subventions en argent comptant, soit des rentes viagères et la Compagnie ellemême fournit en une seule fois la somme énorme de 120.000 livres ${ }^{2}$.

Restait à assurer le transport des nouveaux vicaires apostoliques en Extrême-Orient, ce qui n'était pas une petite difficulté. Il ne fallait pas compter évidemment sur les navires des Portugais qui ne prêteraient pas la main à ces tentatives que faisait le Saint-Siège pour diminuer leur droit de patronage. Les Anglais étaient toujours méfiants à l'égard de futurs concurrents pour le commerce. Quant aux Hollandais, ils se refusaient à transporter des papistes. On songea donc d'abord à acheter un navire en Hollande, mais les Hollandais commencèrent par refuser de le laisser partir, et quand ils se furent décidés à lever l'embargo, le navire alla se perdre dans les bouches de l'Escaut, avant d'avoir atteint la pleine mer. Alors la Compagnie du Saint-

1 Id., Documents, t. I., p. 523, Jean de Boislisle dans les Mémoriaux du conseil de 1661, t. II, p. 12-13 publie d'après les archives des Affaires Etrangères la lettre que le Roi lui-même adressa en 1661 à chacun des rois de la Cochinchine, du Tonkin et de la Chine pour recommander Pallu et ses compagnons.

2 Launay, Histoire de la Société des Missions Etrangères, t. I, p. 53. 


\section{La Chine et la formation de l'esprit philosophique en France}

Sacrement se décida à fonder une « Compagnie de la Chine pour la propagation de la foi et l'établissement du commerce dans l'empire de la Chine, les royaume du Tonkin et de Cochinchine et isles adjacentes $\gg$. Ce fut une entreprise mort-née ${ }^{1}$.

Il ne restait donc plus que la voie de terre, et c'est la route pleine d'embûches que les missionnaires se décidèrent à suivre, se conformant d'ailleurs aux instructions de la Propagande qui cherchait à se libérer des entraves que les Portugais s'efforçaient de mettre au transport de nouveaux missionnaires. Les vicaires apostoliques essayèrent de se frayer un chemin à travers la Perse, le Thibet et la Tartarie, et, dans le recueil des lettres de Pallu, nous trouvons une singulière instruction à l'usage des nouveaux missionnaires en Chine, en Cochinchine et au Tonkin, avec des conseils pour organiser ce chemin de terre qui permettrait désormais d'échapper aux fantaisies ou au mauvais vouloir des rouliers des mers, Portugais, Anglais et Hollandais.

« Nous devons, écrivait Pallu, premièrement faire toutes les diligences possibles pour connoistre et fraier des chemins assurés pour aller dans la Chine, la Cochinchine et le Tonkin, indépendamment des Portugois, des Anglois et des Hollandois qui tiennent pour ainsi dire la clef de ces vastes mers qui conduisent dans toutes les parties des Indes et dans l'extrémité de I'Asie. Nous devons en second lieu travailler avec une diligence égale à établir dans ces routes des correspondances fidelles et assurées pour p.30 envoyer et recevoir des lettres, pour toucher les deniers nécessaires à la subsistance de nostre

${ }^{1}$ R. Allier, La cabale des Dévots, p. 164. 


\section{La Chine \\ et la formation de l'esprit philosophique en France}

mission et pour avoir des lieux de retraite dans les temps fascheux où on est obligé de céder à la violence $\gg 1$.

Ces instructions sont datées d'Ispahan, du 10 septembre 1662, et Pallu avait déjà pu s'apercevoir que les adversaires qu'il fallait dépister, Portugais, Anglais et Hollandais, étaient sur leurs gardes et qu'ils ne se laisseraient pas déposséder sans lutte des avantages qu'ils possédaient. Dans une lettre, qui est postérieure de deux mois à celle qui contient les instructions que nous venons de rapporter, Pallu signale à ses amis de Paris, le soin avec lequel les Hollandais tiennent compte du passage des différents voyageurs, et l'on voit qu'il n'est pas loin d'admirer I'organisation de ce service de renseignements. « Le commandant d'icy a écrit à celuy de Surate que Monsieur François Pallu, évesque d'Héliopolis, alloit à la Chine avec deux ecclésiastiques, que deux autres estoient déjà passés, qu'on ne sçavoit pas leur dessein, que le succès le manifesteroit bientôt »2.

En même temps, Pallu donnait certains conseils pour désarmer ces susceptibilités des Hollandais, et suivant lui, le meilleur moyen était de leur témoigner une absolue confiance, et surtout de s'abstenir de faire du commerce.

Ici, il faut s'entendre. Pallu ne veut évidemment pas dire que le missionnaire doit se désintéresser des questions commerciales : il sait trop bien que dans ces pays lointains où une protection efficace de la mère-patrie fait défaut,

\footnotetext{
${ }^{1}$ Lettres de Mgr. Pallu, t. I, p. 10.

2 ibid., t. I, p. 20.
} 


\section{La Chine et la formation de l'esprit philosophique en France}

commerçants et missionnaires peuvent se rendre de mutuels services. Mais il veut dire par là que le missionnaire ne doit pas faire de commerce pour son propre compte, comme on le reprochait aux Jésuites à cette époque. D'ailleurs les intérêts du commerce ne lui étaient pas à lui-même indifférents, puisqu'il restait en communication avec Colbert. Le 2 janvier 1672, par exemple, il lui soumet un plan d'établissement de comptoir au Tonkin :

«Monsieur de Bérythe a trouvé occasion d'y aller sur un vaisseau en guise d'aumosnier. Il y a si bien disposé les choses qu'il a obtenu du roi pour deux de nos ecclésiastiques, qui étoient déguisés en habit de marchand, le pouvoir d'y demeurer et de faire bastir une maison en un beau lieu qui leur fut assigné, dans l'espérance qu'il donna que la compagnie françoise y pourroit bien p.31 venir prendre un établissement. Il en a écrit à MM. les Directeurs généraux et leur a envoyé des mémoires très instructifs du négoce qu'on y peut faire.

« Je vous supplie, Monsieur, pour l'intérêt de la foi d'où dépend celui de la Compagnie, de porter MM. les Directeurs généraux à disposer incessamment tout ce qui est nécessaire pour l'établissement d'un comptoir en ce royaume, ou au moins pour $y$ faire un voyage. Cette affaire ne peut estre que très avantageuse à la Compagnie $\gg 1$.

En passant à Surate, il faisait écrire par Blot et Baron une lettre au roi de Siam pour lui demander sa protection et une autre au roi d'Annam pour lui témoigner le désir d'installer une

1 Lettres de Mgr. Pallu, t. I, p. 216 ; t. II, p. 223. 


\section{La Chine et la formation de l'esprit philosophique en France}

factorerie au Tonkin, et le prier d'agréer quelques présents. En même temps, il s'occupait du sort spirituel des Français des Indes qui étaient soumis aux ecclésiastiques relevant de la couronne du Portugal, et avec lesquels ils n'entretenaient que de mauvaises relations, provoquées par les rivalités commerciales. Aussi, il demandait qu'on établit dans chaque factorerie un chapelain qui, au temporel, ne relèverait que de la compagnie, et au spirituel, des évêques français ${ }^{1}$.

Pallu était donc loin de se désintéresser des intérêts commerciaux. Il les subordonnait sans doute aux intérêts religieux, ce qu'on ne saurait sans injustice lui reprocher, tandis que les directeurs des compagnies commerciales auraient préféré que le commerce passât d'abord. Quelquefois, ils se plaignirent de cette ingérence des missionnaires dans leurs affaires. Kæppelin cite 2 une lettre du marchand Roques, adressée aux directeurs de la compagnie des Indes orientales, datée du 10 janvier 1682, pour les mettre en garde contre l'ambition et l'esprit envahissant des missionnaires. Roques accusait ces derniers de vouloir s'ingérer dans la direction des affaires et de profiter de la piété de Baron pour le presser de fonder partout des établissements servant aux nécessités de la propagande plutôt qu'aux intérêts du commerce. Il avait précisément en vue I'insistance de Mgr Pallu au sujet de cette fondation d'un comptoir au Tonkin dont I'utilité pour la compagnie était douteuse. En outre, la propagande religieuse

\footnotetext{
1 ibid., t. II, p. 214-5.

2 Kæppelin, La compagnie des Indes Orientales et François Martin, p. 176.
} 


\section{La Chine et la formation de l'esprit philosophique en France}

des missionnaires, qui excitaient par là le fanatisme des Orientaux, lui paraissait funeste aux intérêts de la Compagnie. Dissentiments p.32 passagers, inévitables dans cette association d'intérêts aussi différents dans leur principe que les intérêts religieux et les intérêts commerciaux, mais qui par le fait des circonstances pouvaient profitablement s'entr'aider.

Les principales difficultés des missionnaires apostoliques vinrent, comme il fallait s'y attendre, de la mauvaise humeur des Portugais et de I'hostilité de l'archevêque de Goa, d'autant plus qu'ils étaient partis sans passeports du Portugal et sans avoir fait enregistrer leurs bulles à la chancellerie de Lisbonne. En effet, à peine eurent-ils commencé à exercer leurs fonctions sacerdotales qu'ils se virent excommuniés par l'archevêque de Goa, voire même attaqués à main armée par les Portugais qui voulaient se saisir de leur personne et les transporter de vive force à Goa. En faisant le récit de ces événements à Colbert, Pallu demandait que le roi de France fit une protestation énergique près du gouvernement portugais :

« Il est absolument nécessaire écrivait-il, que (S. M.) fasse déclarer au roy de Portugal par la bouche de son ambassadeur, qu'elle ne veut et n'entend pas que ses sujets en quelque estat et condition qu'ils soient ayent aucune dépendance non pas même pour le spirituel d'aucun évêque portugois ou de sa nomination n'y d'aucun autre estranger sous quelque titre que ce soit dans toute l'estendue des Indes hors les lieux qui sont de son domicile actuel dont il est le maistre et le seigneur ; 


\section{La Chine et la formation de l'esprit philosophique en France}

«Que les Indes sont des terres libres et franches où toutes sortes de nations de l'Europe peuvent venir y vivre en liberté et agir indépendamment les unes des autres, comme il se pratique dans le Levant, dans les lieux de la domination du Grand Seigneur où chaque nation observe et suit ses coutumes particulières et nommément les Chrétiens qui $y$ ont leurs évêques et les pasteurs de leurs propres nations $\gg 1$.

Pallu pouvait compter sur le gouvernement du roi. En effet, depuis quelques années, le roi et Colbert suivaient les événements d'Extrême-Orient. On sait combien Colbert s'intéressait au développement du commerce dans les Indes. Non seulement, il favorisait les compagnies, mais il essayait aussi d'intéresser le public à leurs progrès ${ }^{2}$. Comme il n'ignorait pas la faiblesse réelle des p.33 Portugais en Extrême-Orient, non plus que la puissance des Hollandais, il eut l'idée d'une association avec le Portugal, où la France apporterait ses forces militaires et navales et le Portugal ses établissements et son prestige dans les Indes. Il fit donc proposer au gouvernement portugais en 1669 de constituer en commun une compagnie pour le commerce des Indes, ou même de partager les pays qui étaient encore soumis à la domination des Portugais, et les

\footnotetext{
${ }^{1}$ Lettres de Mgr. Pallu, t. II, p. 212-4.

2 Kæppelin, op. cit., p. 36. Colbert se servant des procédés modernes de la réclame faisait vanter par des écrivains à gages les pays lointains où il avait I'intention de porter le commerce de la France. (Cf. Charpentier : Discours d'un fidèle sujet du Roy touchant l'establissement d'une compagnie Françoise pour le commerce des Indes orientales. Paris, 1664). Mais à en croire une lettre de Gui Patin à Falconet du 13 février 1665, si I'on parlait beaucoup de ce commerce des Indes, bien des gens « s'excusaient » d'y placer de l'argent. (Ed. Réveillé-Parise, t. III, p. 511-2).
} 


\section{La Chine et la formation de l'esprit philosophique en France}

places qu'ils y possédaient. Les instructions données à ce sujet à I'ambassadeur du roi à Lisbonne, énuméraient toutes les forces dont les Hollandais pouvaient disposer dans les Indes ${ }^{1}$, et elles constataient, par contre, que les Portugais « n'y avoient plus ni vaisseaux, ni troupes $\gg 2$. La négociation n'aboutit pas, et il ne fut plus question par la suite de ce projet de partage des établissements portugais. Les Portugais, loin de consentir à composer, étaient décidés à défendre et leur commerce et leur droit de patronage, mais Colbert, averti un peu plus tard que I'ambassadeur du Portugal devait demander au pape la suppression des missions étrangères, ordonna au duc de Chaulnes de s'opposer résolument à cette prétention ${ }^{3}$.

La cour de Rome, de son côté, n'était guère disposée à admettre les prétentions des Portugais. Sans doute, le droit de patronage avait rendu de grands services aux missions catholiques au $X V I^{e}$ siècle, lorsque le Portugal était une nation puissante et riche, car ce patronage ne créait pas seulement des droits au Portugal, mais il lui imposait aussi des devoirs, notamment celui d'entretenir à ses frais toutes les missions des Indes. Mais dans la seconde moitié du XVII ${ }^{e}$ siècle, le Portugal manquait d'hommes et d'argent. Il ne pouvait plus entretenir les missions. Le Saint-Siège et la congrégation de la Propagande étaient donc portés à limiter le droit de patronage qui n'était plus qu'un obstacle, bien loin d'être une aide. Aussi le 10 novembre

\footnotetext{
${ }^{1}$ Recueil des instructions données aux ambassadeurs. Portugal (p. 116-18).

2 ibid., p. 118.

3 P. Clément, Lettres, instructions, mémoires de Colbert, t. VI, p. 93-4.
} 


\section{La Chine et la formation de l'esprit philosophique en France}

1673, Clément $X$ signa un bref qui exemptait les vicaires apostoliques de la juridiction de l'archevêque et de l'inquisition de Goa. Et le 23 décembre de la même année, fut expédiée aux vicaires apostoliques la constitution p.34 Decet Romanum, qui précisait de nouveau leur juridiction et leur permettait de se rendre en Extrême-Orient sans passer par Lisbonne ${ }^{1}$.

Mais les Portugais, ne se tenant pas pour battus, revinrent à la charge en 1677 . Ils proposèrent alors à Rome de reconnaître les vicaires apostoliques dans la Chine et autres lieux et de s'y soumettre absolument au spirituel, à condition que les vicaires apostoliques ne fussent pas français, parce que « il est à craindre, disaient-ils, que comme ces derniers ont plus converti de monde que les autres missionnaires, ceux qui sont déjà chrétiens ou qui le deviendront dans la suite par leur moyen, ne s'attachent trop à eux et n'éloignent enfin peu à peu de leurs ports et de leur trafic les marchands des autres pays d'Europe pour rendre les François maîtres du négoce, par la liaison étroite qui se forme nécessairement entre ceux qui embrassent la foi catholique et ceux qui la leur annoncent $\gg^{2}$.

Non seulement le Portugal ne réussit pas cette fois encore dans ses tentatives, mais le Saint-Siège, aggravant en outre ses dispositions antérieures, riposta en créant six grands vicariats pour l'Extrême-Orient, dont deux pour la Chine, et il institua en même temps deux administrateurs généraux, dont l'un, Mgr

\footnotetext{
${ }^{1}$ Launay, Histoire de la Société des missions étrangères, t. I, p. 195.

${ }^{2}$ Id., op. cit., t. I, p. 237-8.
} 


\section{La Chine et la formation de l'esprit philosophique en France}

Pallu, fut placé à la tête de toutes les missions de Chine ${ }^{1}$. C'est contre ces dispositions nouvelles que protesta le Portugal en 1680, par l'intermédiaire de son ambassadeur, l'archevêque de Brague, qui était chargé de rappeler les documents historiques sur lesquels était fondé le droit de patronage portugais. Le SaintSiège répondit qu'il était facile de voir d'après la Bulle de Léon $X$ de 1514 , que le droit de patronage s'étendait seulement sur les églises «qui sont ou qui seront bâties ou érigées dans les provinces conquises ou recouvrées par les Portugais et nullement sur les pays soumis à la domination des Princes infidèles ». En conséquence, le pape faisait valoir son droit souverain, absolu, d'envoyer des évêques in partibus Infidelium ${ }^{2}$.

Il semble donc que Louis XIV et Colbert n'aient eu qu'à se féliciter de la tournure que prenaient les événements en Extrême-Orient. Une communauté d'intérêts semblait lier le roi de France et le Saint-Siège pour lutter contre le droit de tutelle des églises des Indes que les Portugais s'arrogeaient en vertu de p.35 traditions périmées. A cet égard, la création d'une hiérarchie ecclésiastique indépendante des églises nationales, comme celle que le pape semblait vouloir constituer en nommant des vicaires apostoliques, avait cet avantage au point de vue français de soustraire les missions au contrôle du Portugal et de I'archevêque de Goa. Au surplus, les dignitaires de cette hiérarchie nouvelle étaient tous des Français. Mais il y avait malgré tout une difficulté : tous ces administrateurs généraux et

\footnotetext{
${ }^{1}$ Id., op. cit., t. I, p. 242.

2 [Seriey], op. cit., t. I, p. 69-71.
} 


\section{La Chine et la formation de l'esprit philosophique en France}

vicaires apostoliques relevaient uniquement du Saint-Siège au temporel non moins qu'au spirituel, si bien qu'ils cessaient d'obéir au roi de France. Le roi de France, en travaillant à libérer les missionnaires français du patronage portugais, risquait de ne travailler que pour le pape. Ce n'était certainement pas ce que cherchait Louis XIV.

\section{$*$}

Tous les missionnaires qui partaient pour l'un des pays d'Extrême-Orient, soumis à la juridiction des Vicaires apostoliques, quel que fût leur ordre, devaient prêter devant les Vicaires apostoliques un serment dont la forme était imposée. Ce serment, suivant l'analyse qu'en donne I'historien de la Société des missions étrangères, exprimait la reconnaissance du pouvoir absolu et universel du Souverain Pontife, la promesse de ne faire aucun office ecclésiastique dans les lieux soumis aux vicaires apostoliques sans leur permission, de ne pas se retrancher derrière les privilèges, de ne pas discuter les Constitutions apostoliques et les décrets de la Propagande, et particulièrement la Bulle Decet Romanum du 23 décembre 1673 qui confirmait les brefs et décrets antérieurs en faveur des vicaires apostoliques ${ }^{1}$.

Sans doute, ce serment pouvait se justifier par le désir qu'avait le Saint-Siège de se libérer des entraves du patronage portugais et d'en libérer en même temps les religieux des autres

\footnotetext{
1 Launay, Histoire de la société des missions étrangères, t. I, p. 248. Cet historien officiel de la société des missions, qui a eu à sa disposition toutes les archives de la société est très discret et très bref sur cette question du serment. Quant à l'abbé A. Thomas qui, s'inspirant aussi de l'esprit de cette société, a voulu faire dans son Histoire de la Mission de Pékin une histoire complète de la querelle des rites chinois, il n'en souffle mot.
} 


\section{La Chine et la formation de l'esprit philosophique en France}

nations ; mais en y regardant de plus près, nous voyons que cette formule de serment contenait la déclaration suivante : «Le Souverain Pontife ayant une puissance suprême et absolument indépendante pour la conduite spirituelle des âmes dans toute la terre et la permission ${ }_{\text {p.36 }}$ ny le consentement d'aucun fidèle ou infidèle de quelque estat et dignité qu'il soit sans excepter même les rois, ne luy estant nullement nécessaire pour envoyer des ouvriers qui preschent, annoncent, établissent et avancent la religion chrestienne et la foy catholique parmi les Infidèles et notamment dans la Chine, le Tonquin, la Cochin-Chine, Cambodge, Siam et dans les autres provinces voisines... »1.

Tous les religieux s'insurgèrent contre ce serment, jugeant contraire à leurs règles de prêter serment d'obéissance entre les mains d'un évêque étranger à leur ordre 2 ; mais les Jésuites, qui ne voulaient pas se contenter d'une protestation platonique, et qui se cherchaient un appui près du roi de France contre les prétentions des vicaires apostoliques et du Saint-Siège, firent des extraits de cette formule de serment pour en faire ressortir certaines propositions contraires aux théories de l'église gallicane, et ils demandèrent une consultation aux «Docteurs » sur ces propositions. Sur la première proposition qui leur fut soumise : «Le Souverain-Pontife a une puissance souveraine et entièrement indépendante pour le gouvernement spirituel dans toute la terre... », les Docteurs répondirent que de cette proposition, on devait tirer nécessairement les conséquences

\footnotetext{
1 B. N. Fr. 9773 , f. 67.

2 Launay, Histoire de la société des missions étrangères, t. I, p. 249.
} 


\section{La Chine et la formation de l'esprit philosophique en France}

suivantes $: 1^{\circ}$ que le jugement du Souverain-Pontife pour le spirituel est infaillible et que son autorité est irréfragable ; $2^{\circ}$ que le pape est au-dessus du concile et de toute l'église répandue dans tout l'univers ; $3^{\circ}$ qu'il faut dispenser les sujets des Roys et des autres souverains du serment de fidélité, etc. ${ }^{1}$.

Nous ne savons comment et jusqu'à quel point les Jésuites français firent usage de cette consultation près du roi de France, mais nous savons fort bien - et d'après les confidences de Pallu lui-même - qu'en 1680, cette affaire du serment avait détruit la confiance que le roi avait mise au début dans les Missionnaires de la Société des Missions et dans les vicaires apostoliques. Pallu s'en aperçut lorsqu'il revint en France en 1680. Il chercha vainement à se faire recevoir par le roi, et il vit clairement que les artisans de cette défaveur, c'étaient les Jésuites. «J'ai sceu depuis d'une personne de qualité de mes amis, écrivait-il, que $M$. de Paris lui a dit que le Roy ne vouloit rien nous donner, ne pouvant pas, dit ce prélat, se confier à une personne qui n'a pas p.37 esté fidèle à ses bienfaiteurs (il entend les Jésuites) $\gg 2$. Quant à la cause de cette défaveur, pas de doute, c'était le serment ; aussi Pallu demandait-il à un ami d'insister auprès du pape pour qu'on ne l'imposât plus dorénavant aux Jésuites afin d'éviter leur inimitié, et par eux l'inimitié du roi : «Cette demande paraît bien raisonnable car si ce serment n'a esté ordonné que pour faire obéir les PP. Jésuites, il semble qu'il ne sera pas nécessaire de les inquiéter sur ce sujet quand on les

\footnotetext{
1 B. N. Fr. 9773 , f. 70.

2 Lettres de Mgr. Pallu, t. I, p. 331.
} 


\section{La Chine \\ et la formation de l'esprit philosophique en France}

trouvera soumis, surtout si on voit que ce serment doive causer de grands troubles, désunir les cœurs et couper la bonne correspondance $\gg 1$.

Le Portugal d'ailleurs, encore moins que la France, ne pouvait accepter ce serment, car ce serment était la reconnaissance par les missionnaires dépendant de la couronne du Portugal des droits que s'arrogeait le Saint-Siège d'envoyer des vicaires apostoliques en Extrême-Orient, et par suite du droit que réclamait la Propagande de modifier à son gré - et à son avantage - le patronage portugais. Aussi le vice-roi de Goa défendit-il au supérieur général des PP. de Saint Dominique au royaume de Siam, ainsi qu'à tous les provinciaux de la Compagnie de Jésus, des ordres de Saint-François, de Saint Augustin et des Capucins, de se soumettre à cette formalité du serment, « étant donné que la contestation au sujet du patronage portugais étoit toujours pendante en cour de Rome », et il leur défendit en même temps « de rendre aucune obéissance aux évêques étrangers envoyés par ladite congrégation de la Propagande ni aux autres missionnaires qu'elle y pourroit envoier et de ne les point reconnoitre pour prélats ordinaires, parce qu'il n'y pouvoit pas avoir d'autres ordinaires que les évêques nommés par $\mathrm{S}$. A. et sur tous les autres l'archevêque primat de cet Orient lequel on devoit partout reconnoitre pour le prélat ordinaire $\gg 2$.

1 ibid., t. I, p. 332.

2 B. N. Fr. 9773 , f. $45-7$. 


\section{La Chine et la formation de l'esprit philosophique en France}

L'abbé Launay affirme que la formule de serment fut rectifiée un peu plus tard, et que le texte rectifié fut composé par Mgr Pallu lui-même. Cette nouvelle formule, dit-il, comprenait ces mots : « Nous reconnoissons par ce présent acte que Sa Majesté, nous donnant la permission et le congé d'aller aux Missions, a aussi trouvé bon et consenti que nous prêtions ledit serment ainsi que nous sommes résolus et disposés de le faire entre les mains de l'évêque d'Héliopolis » 1.

p.38 Cependant, une lettre du P. Tysanier, Jésuite, datée de Macao, du 28 novembre 1684 , nous apprend que c'est l'ancienne formule de serment qu'on lui a imposée. Il avait entendu dire, en effet, par le P. Pomereau, de Lisbonne, que « les sujets de Sa Majesté Très Chrétienne expliqueroient dans leur formule qu'ils faisoient ce jurement avec la permission et consentement de leur Roy ». Mais le vicaire apostolique lui déclara «qu'il n'y avoit qu'une seule formule pour tous les missionnaires et pour tous les supérieurs des missions ». Il prêta donc ce serment au nom des Jésuites dont il était le supérieur. Mais les religieux espagnols, à la réserve de trois Pères Dominicains, aimèrent mieux abandonner leur mission 2.

D'autre part, les quatorze Jésuites qui partirent avec le P. Tachard en 1687 pour le Siam, furent obligés, avant leur départ, à Brest, de prêter serment devant Artus de Lionne, évêque

\footnotetext{
${ }^{1}$ Launay, Histoire de la société des missions étrangères, t. I, p. 250.

2 B. N. Fr. 9773 , f. $43-4$.
} 


\section{La Chine et la formation de l'esprit philosophique en France}

désigné de Rosalie ${ }^{1}$. Et il est à croire que cette formule de serment était l'ancienne formule incriminée, puisqu'avant de prêter ce serment, les Jésuites dressèrent une protestation par devant notaire contre cette obligation qui leur était imposée. Ils déclaraient dans cette protestation, qu'ils ne faisaient ce serment que pour éviter les peines et censures ecclésiastiques auxquelles ils se trouveraient exposés en cas de refus. Et ils ajoutaient : «Nous avons en outre, par les présentes, déclaré et déclarons que notre intention et volonté, en prêtant ledit serment et tous les autres actes qui nous pourroient estre présentés à signer par lesdits vicaires et commissaires apostoliques, n'est pas et ne sera jamais de croire, dire ny faire aucune chose contre la puissance et les droits de Sa Majesté, contre les devoirs et I'obéissance des Sujets à l'égard de leur souverain, desquels nous ne nous départirons jamais... ». Cette protestation était déposée « par ordre exprès de Sa Majesté entre les mains de M. le marquis de Seignelay $\gg 2$.

Il est difficile d'admettre que cette solennelle protestation eût été imposée par le roi et signée par les Jésuites, si la formule du p.39 serment avait contenu d'une manière explicite l'autorisation du roi, et par suite si cette formule avait ménagé les droits du roi.

\footnotetext{
${ }^{1}$ Le reçu de la prestation de ce serment se trouve B. N. Fr. 9773, f. 73 . Il est signé $A$. de Lionne Epus Rosal. Electus.

2 B. N. Fr. 9773, f. 75. On trouve la note suivante au $v^{\circ}$ du fo 76 : « Protestation faite par le P. Tachard et par les 14 autres Pères partis avec luy pour Siam suivant les ordres du Roy, de laquelle ils ont mis un exemplaire par ordre de Sa Majesté entre les mains de Mr. le marquis de Seignelay, Sa Mté ayant déclaré qu'autrement elle n'auroit souffert en nulle manière qu'ils eussent presté ce serment. »
} 


\section{La Chine \\ et la formation de l'esprit philosophique en France}

$*$

Nous avons maintenant quelques éléments qui nous permettent de comprendre comment Louis XIV en vint à l'idée d'envoyer en Chine des Jésuites mathématiciens.

En 1684, le Portugal était déchu de son ancienne puissance aux Indes. Son héritage était à prendre. Mais cet héritage tomberait-il entre les mains des Hollandais ou des Anglais ? Colbert se mit sur les rangs pour essayer d'en recueillir au moins une partie, et il encouragea la Compagnie des Indes. De son côté, le Portugal, qui ne voulait pas se laisser dépouiller, avait une arme de défense excellente, son ancien droit de patronage sur toutes les églises et toutes les missions d'Extrême-Orient, qui, grâce à l'obligation des passeports portugais et de l'enregistrement des Bulles à la chancellerie de Lisbonne pour les sujets des nations catholiques lui permettait d'écarter les missionnaires français des Indes.

D'autre part, le Saint-Siège et la Congrégation de la Propagande se voyaient entravés dans leurs efforts de propagation de la foi au Siam, au Tonkin, en Chine, par ce droit de patronage : les Portugais n'avaient pas assez de missionnaires pour évangéliser des immenses contrées, ils n'avaient plus assez d'argent pour entretenir des missions. Et en outre, comme le faisait remarquer la Propagande à I'archevêque de Brague, si le pape Léon $X$ avait accordé ce droit de patronage sur les terres conquises par les Portugais ou sur les terres qu'ils pourraient conquérir, il avait réservé les royaumes des Princes 


\section{La Chine et la formation de l'esprit philosophique en France}

infidèles où le Portugal n'avait pas de droits de souveraineté : tel était le cas du Siam, du Tonkin, du Cambodge, de la Chine ${ }^{1 .}$

En envoyant des missionnaires et des vicaires apostoliques au Siam et en Chine, le Saint-Siège avait sans doute choisi des Français. Mais il l'avait fait plus par nécessité que par choix, le $P$. de Rhodes n'ayant trouvé qu'en France des missionnaires disposés à partir. Et il avait pris ses précautions pour ne pas reconstituer en faveur de la France un autre droit de patronage. Il voulait créer une hiérarchie ecclésiastique indépendante des églises nationales. Pour cela, il avait décidé que les vicaires p.40 apostoliques ne dépendraient que de lui au temporel comme au spirituel, et il les avait armés de cette formule du serment qui leur permettrait de soumettre à leur autorité, et par suite à l'autorité de Rome, les religieux des différentes nations. L'envoi des Jésuites mathématiciens en Chine, ne dépendant que du roi au temporel et de leurs supérieurs au spirituel ne fut qu'un expédient du gouvernement du roi pour avoir en Chine des missionnaires qui ne fussent pas seulement les délégués du pape. Mais la résistance de Rome à ce projet qui n'était pourtant qu'un compromis entre les droits du roi et ceux du pape dut être vive, si I'on en juge par le temps qu'il fallut pour le réaliser.

Le P. de Fontaney nous apprend que c'est du temps de Colbert qu'on eut l'idée pour la première fois d'envoyer des Jésuites mathématiciens en Chine. Colbert fit appeler ce Père avec Cassini pour lui communiquer ses vues à ce sujet : « Les

1 [Seriey], Histoire de l'établissement du christianisme dans des Indes orientales, t. I, p. 69-71, 


\section{La Chine et la formation de l'esprit philosophique en France}

sciences, mon Père, dit le ministre, ne méritent pas que vous preniez la peine de passer les mers et de vous réduire à vivre dans un autre monde, éloignés de votre patrie et de vos amis. Mais comme le désir de gagner des âmes à Jésus-Christ porte souvent vos pères à entreprendre de pareils voyages, je souhaiterois qu'ils se servissent de l'occasion et que dans le temps où ils ne sont pas si occupés à la prédication de l'Évangile, ils fissent sur les lieux quantité d'observations qui nous manquent pour la perfection des sciences et des arts $\gg 1$. Il semble donc, d'après ce récit, que ce soit Colbert qui ait eu le premier l'idée de cet envoi de missionnaires en Chine.

Le P. de Fontaney ne nous dit pas à quelle époque se place cette entrevue avec Colbert. Mais nous savons, grâce à l'Histoire de I'Académie des sciences, qu'en 1681, le P. de Fontaney était prêt à partir pour la Chine : «Dans le même temps [alors que Varin et Deshayes se préparaient à partir pour les îles du CapVert] ${ }^{2}$, le P. de Fontaney, Jésuite, Professeur de mathématiques au collège de Louis-le-Grand, qui venoit de publier ses Observations sur la dernière comète ${ }^{3}$, se disposait à aller à la Chine avec quelques autres Pères de la même compagnie en qualité de ${ }_{\text {p.41 }}$ missionnaires. Il conféra avec $M$. Cassini de son

\footnotetext{
1 Lettre du P. de Fontaney au P. de la Chaize, 15 février 1703. Lettres édifiantes et curieuses, t. IV, p. 82.

2 Ils partirent de Paris au commencement d'octobre 1681 (Histoire de I'Académie des Sciences depuis son établissement en 1666 jusqu'en 1699, t. I, p. 337).

3 Observations sur la comète de 1680 et 1681 faites au Collège de Clermont par le P. J. de Fontaney, de la Compagnie de Jésus, Professeur de mathématiques, Paris, in-12, 1681. - Cf. Lalande, Bibliographie astronomique, p. 300-1.
} 


\section{La Chine et la formation de l'esprit philosophique en France}

voyage et des observations qu'il devoit faire. On ne pouvoit pas trouver une plus belle occasion d'entreprendre une géographie nouvelle $\gg 1$.

La décision de Colbert doit dater de 1681 ou, au plus tôt, de la fin de l'année 1680 ; c'était précisément le moment où Pallu essayait vainement de se faire recevoir par Louis XIV et où I'affaire du serment commençait à envenimer les relations entre les Jésuites et les Missionnaires. Mais c'était aussi l'année où le roi du Portugal chargeait I'archevêque de Brague, à Rome, de revendiquer son droit de patronage.

Un document important émanant des Jésuites nous permet de connaître les sentiments des Jésuites à l'égard des vicaires apostoliques et des Missionnaires, au moment où Colbert formait le projet d'envoyer en Chine des Jésuites mathématiciens, et avant que sa décision ne fût prise. Ce document est un rapport où les Jésuites déclarent accepter la proposition que leur a faite Colbert d'aller en Orient et en Chine. Ils y énumèrent ensuite les différentes routes qu'ils comptent prendre, et enfin ils examinent les difficultés qu'ils peuvent rencontrer et le moyen de les résoudre.

${ }^{1}$ Histoire de l'Académie des sciences, t. I p. 338. 


\section{La Chine et la formation de l'esprit philosophique en France}

« Monseigneur Colbert agréant le projet dressé par $M$. Cassini 1 pour envoyer des Jésuites mathématiciens et bons observateurs pour prendre les longitudes et les latitudes et les déclinaisons de I'ayman en différents endroits de l'Orient et jusque dans la Chine d'où ils enverront leurs observations aussi bien que de tous lieux où ils passeront, et Sa Majesté qui a encore plus de zèle pour la religion que pour la gloire et la grandeur de son règne, jugeant en même temps cette occasion favorable pour profiter des dispositions merveilleuses qui sont dans la Chine pour convertir un nombre infini d'infidèles dans ce vaste empire où les mathématiciens missionnaires trouveront toujours une entrée p.42 facile et de grands avantages pour prescher librement I'Évangile, ces Pères auront une extrême joye d'avoir I'honneur d'estre employés à une si grande et si sainte entreprise à laquelle ils s'estimeront très heureux de sacrifier leurs travaux et leur vie $\gg 2$.

Ils indiquent ensuite les itinéraires qu'ils pourraient suivre.

\footnotetext{
${ }^{1}$ Il peut sembler à première vue, d'après ce texte, que c'est Cassini qui eut le premier l'idée d'envoyer en Chine des Jésuites mathématiciens. Mais il semble pourtant qu'il faille entendre par l'expression « agréant le projet dressé par M. Cassini », l'agrément donné à un rapport dressé par Cassini sur les observations qu'on pouvait faire en Orient et en Chine. Rien d'étonnant que ce rapport lui eût été demandé par Colbert, qui s'intéressait activement à cette époque aux travaux astronomiques et géographiques de I'Académie des sciences, pour faire une carte de France et pour établir un méridien. Il accordait de généreuses subventions à La Hire, Cassini, etc., pour leurs voyages et leurs travaux. (Colbert, Lettres, instructions, mémoires, t. V, p. 403 et note 6). Il aurait désiré également avoir de bonnes cartes marines des côtes d'Afrique et des Indes pour que les navigateurs français ne fussent plus à la merci des pilotes hollandais. Ce texte n'est donc pas en contradiction avec l'affirmation du P. de Fontaney.
}

2 B. N. Fr. 17240 , f. 246 r ${ }^{\circ}$ 


\section{La Chine et la formation de l'esprit philosophique en France}

Une «troupe de six ou sept Jésuites » se rendrait par Ormus à Ispahan, porter des présents au roi de Perse ; d'autres iraient directement à Macao pour « passer de là jusqu'à la cour de l'empereur de Chine, auquel ils feront aussy des présens de deux machines de Romer et de plusieurs autres curiosités de Mathématiques pour en obtenir toutes les facilités nécessaires pour faire leurs observations dans les plus grandes villes et pour faire passer, s'il se peut, quelqu'un d'entre eux dans la Grande Tartarie »1. D'autres enfin, iront par Alep jusqu'aux Indes et de là, en Chine ; I'année suivante, on pourra en envoyer en Chine par les vaisseaux des Hollandois, ce qui est la voie la plus courte. Enfin, pour l'avenir, « on pourra de temps en temps envoyer à la Chine de pareils secours de Missionnaires françois et Mathématiciens qui ne contribueront pas peu à establir le commerce et la réputation de la nation française dans ce grand Empire »2.

Mais il y a des difficultés : d'abord, le patronage portugais. Les Jésuites cependant ne pensent pas que ce patronage soit un obstacle à leur mission, parce qu'ils sont Jésuites. En effet, « les supérieurs des Jésuites portugois dans les Indes ne sont nullement opposés aux Jésuites françois et s'estant bien trouvez de ceux qui furent envoyez à la Chine, il y a trente ans, au nombre de vingt-cinq, ont souvent témoigné qu'on leur envoyast de pareils secours, dont ces missions ont un si grand et si

\footnotetext{
1 ibid., f. $246 v^{\circ}$.

2 ibid., f. 247 r ${ }^{\circ}$.
} 


\section{La Chine \\ et la formation de l'esprit philosophique en France}

pressant besoin qu'on peut dire que c'est le seul moyen de les conserver $\gg 1$.

Il y a cependant des difficultés plus graves, c'est la présence en Extrême-Orient des Missionnaires et des vicaires apostoliques et c'est le serment qu'ils veulent imposer. Ici encore, l'obstacle n'est pas insurmontable, à condition qu'on n'hésite pas à faire preuve d'énergie.

«Le second obstacle que l'on pourroit craindre dans l'exécution de ce dessein ne pourroit venir que des vicaires apostoliques et missionnaires françois envoyez par la Congrégation de la propagande de Rome, qui dans ce temps estant toute composée de ${ }_{\text {p.43 }}$ sujecz dévoués à l'Espagne et peu équitables à l'égard des Jésuites, troubleroit ces Pères dans leurs fonctions, exigeant d'eux un serment que Sa Majesté ne pourroit pas agréer. Mais outre que ces Messieurs n'ont nulle veuë, nul dessein ny nul moyen d'entrer dans la Chine que sous la protection des Espagnols des Philippines, qu'ils ne peuvent y avoir de commerce que par l'isle Formose et par les Chinois Chevelus qui n'occupent qu'une petite partie de la Chine où il est probable que les Tartares, qui est la nation dominante, achèveront bientost de les subjuguer, il est manifeste que les Jésuites, les François non plus que les Portuguois, ne pensant point à demeurer dans ce costé de la Chine et ayant dans tout le reste de ce vaste empire infiniment plus d'occupation que mille Missionnaires n'en pourroient soutenir, ils ne pourront rien avoir à démesler en ce pays-là avec ces Messieurs à qui ils

1 B. N. Fr. 17240 , f. 247. 


\section{La Chine et la formation de l'esprit philosophique en France}

abandonnent les Missions des Royaumes de Tonkin, de la Cochinchine et de Siam, etc., où un beaucoup plus grand nombre de missionnaires ne pourroit suffire à la moindre partie du bien qui s'y peut faire, et où il y a bien de l'apparence que ces Missionnaires de la Propagande seront obligés de borner leur zèle, surtout s'ils refusent de mener avec eux les Italiens ou Siciliens sujects du Roy d'Espagne, que cette mesme Congrégation tasche de mesler parmi eux pour se rendre plus maistresse de leurs missions afin de pouvoir les en exclure euxmesmes quelque jour.

« D'ailleurs, le serment que la congrégation de la Propagande exige des missionnaires Jésuites du Tonkin et de la Cochinchine, ne regarde en aucune façon les Jésuites missionnaires de la Chine, de qui on ne l'exige point, et de qui il seroit aussi fort inutile de l'exiger puisqu'ils ne peuvent rien avoir à démesler avec ces Messieurs qui n'ont et ne peuvent avoir aucun establissement à la Chine.

Enfin et les Jésuites Mathématiciens qui iront à la Chine et ceux qui gouvernent jusqu'à maintenant ces Missionnaires de la Propagande ayant tous I'honneur d'estre françois et sujects du Roy, et tirant leur subsistance de France, I'authorité de Sa Majesté sera plus que suffisante pour les maintenir dans une union étroite. Les vicaires apostoliques ne demanderont pas plus d'eux que font les Evesques de France, à quoy ils les trouveront toujours très disposés et la Congrégation de la propagande se gardera bien d'exiger ce serment, ny de rien ordonner de violent contre ces Pères, d'abord qu'elle aura suject d'appréhender 


\section{La Chine et la formation de l'esprit philosophique en France}

qu'on ne fasse faire à ces Messieurs françois un serment contraire par lequel ils s'obligeroient de vivre en ces pays-là en bon françois et en bons sujects du Roy et de p.44 n'y recevoir aucuns ordres de cette congrégation suivant les lois du Royaume et les privilèges de I'Église Gallicane » 1.

Comme on le voit, les Jésuites acceptent de gaîté de cœur les conséquences qui peuvent résulter de cet envoi de missionnaires mathématiciens en Chine. Ils ne font pas figure de gens timides qui n'accepteraient cette mission que par obéissance. Loin de se faire prier, en invoquant les difficultés qu'ils pourraient rencontrer, ils indiquent eux-mêmes les moyens de lever ces difficultés et ils n'hésitent même pas devant les moyens les plus violents. Après avoir lu ce texte on peut se demander vraiment si c'est Colbert qui a eu l'idée d'envoyer les Jésuites en Chine, ou si ce ne sont pas plutôt les Jésuites qui ont profité du crédit qu'ils avaient pris du ministre, et aussi de leurs connaissances scientifiques, pour établir une mission de Jésuites français en Chine. A tout le moins nous les voyons résolus à lutter contre les Missionnaires.

L'affaire n'eut pas de suite, tout au moins immédiatement, peut-être à cause de la mort de Colbert, qui survint sur les entrefaites. Un peu plus tard arriva à Paris, le P. Couplet, Jésuite flamand missionnaire en Chine, qui fut présenté à Louis XIV, par

${ }^{1}$ B. N. Fr. 17240 , f. $247 v^{\circ}-248 v^{\circ}$. 


\section{La Chine et la formation de l'esprit philosophique en France}

le P. de la Chaize ${ }^{1}$. Il lui exposa la nécessité d'envoyer des missionnaires en Chine, lui faisant valoir l'importance d'une semblable mission non seulement pour l'accroissement de la religion, mais aussi pour les connaissances scientifiques qu'on en pourrait retirer, et Louvois, qui avait succédé à Colbert pria l'Académie des sciences de dresser un mémoire des choses les plus remarquables qu'on désirait p.45 avoir de la Chine, afin d'en charger le P. Couplet ${ }^{2}$. Suivant le P. Tachard et le P. de la Chaize ${ }^{3}$, le départ des Jésuites fut décidé à cette époque. Mais on n'en parla pas avant que l'occasion de les faire partir se fût présentée. L'occasion ne semblait pas facile à trouver. Sans doute, les mandarins siamois arrivèrent à Paris, conduits par $\mathrm{M}$. Vachet, missionnaire, qui avait l'ordre de M. de Metellopolis,

\footnotetext{
1 « Comme le P. Couplet que je présentai à S. M. luy a fait comprendre les grands fruits que I'on pouvoit faire dans la Chine si I'on pouvoit y faire passer des gens d'esprit et de vertu... (Lettre du P. de la Chaize au P. de Noyellez, 29 décembre 1684, in Chantelauze. Le $P$. de La Chaize, p. 53). D'après une lettre du 25 septembre 1684 et insérée dans le Mercure Galant de septembre 1684, le $P$. Couplet et le jeune Chinois qu'il amenait en Europe allèrent le 15 de ce mois saluer le Roi à Versailles, et le lendemain assistèrent au dîner du Roi. « Le jeune Indien estoit en ses habits Indiens, ayant une riche veste de Brocard d'or fond bleu, avec des figures de Dragons, et un visage affreux sur le haut de chaque manche. Il avait par-dessus une espèce de tunique de soye verte. Sa Majesté après avoir entendu ses prières en langue Chinoise lui fit servir une Assiette sur la Table, pour voir la propreté et l'adresse des Chinois à manger avec deux petites baguettes d'yvoire à quatre pans, et d'un pied de long, qu'ils tiennent dans la main droite entre deux doigts (p. 213-d). Ils allèrent ensuite chez $M$. Hubin, Emailleur du Roy voir des expériences par le vide. Il s'y trouvait une société illustre. Peu de jours après le P. Couplet et son Chinois reçurent des visiteurs à la maison de St Louis et ils leur montrèrent quantité de portraits sur du tafetas de la Chine et notamment le Docteur Confucius, avec ses grandes moustaches noires » (p. 216-7).

2 Nous publions ce mémoire de I'Académie des sciences destiné au P. Couplet dans notre thèse complémentaire : Documents inédits relatifs à la connaissance de la Chine en France (1685-1740), p. 7-9.

3 Tachard, Voyage de Siam, p. 2. Lettre au P. de Noyelles, général de la Compagnie de Jésus à Rome, in Chantelauze, Le Père de La Chaize, p. 53.
} 


\section{La Chine et la formation de l'esprit philosophique en France}

vicaire apostolique au Siam, de demander au roi d'envoyer au Siam une ambassade, ce qui aurait les meilleurs effets pour la religion et pour le commerce. Cependant, au cours de la première entrevue que le missionnaire eut avec Seignelay, celuici lui déclara tout net qu'il n'enverrait pas d'ambassade. « Il me dit, écrit Vachet, qu'il avoit vu nos mémoires, mais qu'ils n'étoient pas véritables, et que je me gardasse bien sur toutes choses de parler d'un ambassadeur parce que le roi étoit résolu de n'en pas envoyer $\gg 1$. Cependant quelques semaines après, à la suite de l'audience de congé, le roi déclara qu'il avait fait choix d'un ambassadeur, le chevalier de Chaumont 2, résultat tellement inespéré pour le vicaire apostolique lui-même, qu'il n'était pas loin de faire des reproches à Vachet, pour avoir trop bien réussi dans sa négociation ${ }^{3}$.

Sans doute, les espérances exagérées de la conversion du roi de Siam que Vachet avait données avaient pu contribuer pour une part à déterminer finalement le roi à l'envoi d'une

${ }^{1}$ Launay, Histoire de la mission de Siam, t. I, p. 138.

${ }^{2}$ Id., op. cit., t. I, p. 149.

3 « Je n'eusse pas cru que $M$. Vachet eût si bien réussi comme il l'a fait... Il a si bien fait auprès d'elle [S. M.] et de ses ministres qu'il a obtenu cette ambassade, car il a cela, comme vous le connaissez, qu'il persuade assez facilement. Il est vrai qu'en certaines choses, il s'est un peu trop avancé. » Mgr Laneau à Maigrot, in Launay, op. cit., t. I, p. 159. Cf. aussi Mémoires de Forbin, p. 469, n. 1. Fénelon dans son sermon pour la fête de l'Epiphanie Sur la Vocation des Gentils, prêché en présence des ambassadeurs de Siam, le 6 janvier 1685, semble admettre comme une vérité reconnue que les Siamois ne sont venus en France que pour demander d'être instruits des vérités chrétiennes, « Sache par nos histoires la postérité la plus reculée que I'Indien est venu mettre aux pieds de Louis les richesses de l'aurore en reconnoissance de l'Évangile reçu par ses soins ! »Fénelon, Fuvres, t. XVII, p. $180-1$. 


\section{La Chine et la formation de l'esprit philosophique en France}

ambassade, mais d'autre part, cette ambassade, c'était le moyen cherché depuis longtemps de transporter les Jésuites en Extrême-Orient. Le passage du P. Couplet à Paris était de date récente, les espoirs qu'il avait p.46 donnés d'un mission fructueuse en Chine n'étaient pas oubliés. Et s'ils avaient risqué de l'être, les Jésuites avaient des amis influents à la Cour pour les rappeler à l'esprit du roi, notamment le duc du Maine, sans parler de leur défenseur attitré, le P. de la Chaize.

Le 29 décembre 1684, le P. de la Chaize prévient le Général des Jésuites à Rome, que le roi s'est décidé à envoyer une mission de Jésuites en Chine. C'est un véritable chant de triomphe qu'il entonne : «Je croy que le temps est venu auquel Dieu veut se servir de nostre compagnie pour sa gloire et pour I'augmentation de son Eglise plus que nous mesmes n'aurions osé l'espérer... ». Il expose ensuite les raisons scientifiques qui ont pu décider le roi à l'envoi de cette mission ; mais il ne dissimule pas le moins du monde que les Jésuites subordonneront leurs préoccupations scientifiques à une mission plus importante, car ils devront «.... sous prétexte d'estre ainsi les observateurs et les mathématiciens du Roy, instruire les peuples des véritez de la foy ». Mais comment le Saint-Siège vat-il accepter ce prétexte ? Le trouvera-t-il suffisant pour compenser ce que comporte en réalité la décision du roi, à savoir une diminution du pouvoir spirituel de Rome, si les souverains temporels se mettent à envoyer des missionnaires ? Le P. de la Chaize prévoit bien qu'il y aura des obstacles, et il cherche à y répondre par avance : « La grâce que j'ay à luy demander (à Votre Paternité) est qu'elle veuille bien que toutes choses se 


\section{La Chine et la formation de l'esprit philosophique en France}

fassent au nom du Roy sans appréhender que les Vicaires Apostoliques François nous donnent de l'inquiétude ny que nous fassions aucune affaire qui puisse raisonnablement choquer MM. de la Congrégation de la Propagande »1.

La chose ne dut pas aller toute seule à Rome, car au reçu d'une lettre du P. de Noyelles, le P. de la Chaize se crut obligé de se disculper. S'il n'avait pas prévenu plus tôt le général, c'est que «le peu de temps dont il avait disposé » l'en avait empêché 2 . D'ailleurs, il avait fait un rapport au nonce sur cette question. Et il ajoutait : « [Je lui ai fait connaître] qu'au surplus ces Pères allant sur les vaisseaux de S. M. et par ses ordres n'auroient mille difficultés de se soumettre aux vicaires apostoliques qui estoient ${ }_{\text {p.47 }}$ François en cas qu'ils fussent obligez de demeurer quelque temps à Siam. Ce prélat m'a demandé un mémoire instructif de toute cette affaire, et des desseins du Roy que je luy ai donné bien volontiers et qu'il m'a promis d'envoyer à Mgr le cardinal Cibo pour empescher qu'on inquiète Votre Paternité sur ce point en cas qu'on vinst à s'en formaliser dans la Congrégation de la Propagande »3 . Le tour était joué, les Jésuites mathématiciens, à cette date, étaient en mer depuis près de deux semaines.

\footnotetext{
${ }^{1}$ Chantelauze, op. cit., p. 54.

2 Les occupations du P. de la Chaize à ce moment avaient dû être bien absorbantes, car sa lettre au P. de Noyelles n'est que du 29 décembre, et dès le 21 décembre les Jésuites désignés pour partir en Chine étaient allés à I'Observatoire astronomique observer l'éclipse de lune, et le Mercure galant avait signalé cet évènement sensationnel. (Cf. Histoire de l'Académie des sciences de 1666 à 1669, t. I, p. 445).

3 Lettre du P. de la Chaize au P. de Noyelles, 14 mars 1685, in Chantelauze, op. cit., p. 556.
} 


\section{La Chine et la formation de l'esprit philosophique en France}

Les Jésuites emportaient à Pékin, outre les présents destinés à l'empereur, une lettre du P. de la Chaize au P. Verbiest, président du tribunal des mathématiques. Le ton pompeux de cette lettre semble indiquer que le $\mathrm{P}$. de la Chaize supposait qu'elle pourrait être montrée à l'empereur de Chine, car il y vantait «les deux plus puissants souverains du monde et les deux plus grands protecteurs des sciences ». Il y avouait cependant que le but essentiel des PP. Jésuites n'était pas de faire des observations astronomiques, mais de convertir les infidèles. C'était une croisade contre l'infidèle entreprise par Louis XIV en même temps que la croisade à l'intérieur contre les hérétiques, et le $P$. de la Chaize ne trouvait pas d'expressions assez grandiloquentes pour louer comme il le fallait son pénitent, ce «Grand Roy que Dieu a donné à l'Europe pour le Défenseur et le restaurateur de la vraie foy, et qu'il destine suivant toutes les prophéties à la destruction du Mahométisme ? »1. Car le P. de la Chaize, comme les contemporains d'ailleurs ${ }^{2}$, croyait que les Chinois et les Siamois, étaient mahométans.

Tous les Jésuites qui partirent en Chine sont d'accord pour déclarer que dans l'esprit du roi, le but essentiel de leur mission

1 Lettre du P. de la Chaize au P. Verbiest, apud Tachard, Voyage de Siam, p. 18-23.

2 Dans une chanson qui fut composée à cette époque au sujet de l'abbé de Choisy, nous trouvons la même erreur :

Choisy converti par Dangeau

S'en va prescher jusqu'à la Chine.

Il part chrétien et fort dévot.

Mais je jurerais à sa mine

S'il trouve Dangeau à Siam

Qu'il en revien mahométan.

(Mémoires de l'abbé de Choisy, éd. Michaud et Poujoulat, p. 549, col. 1). 


\section{La Chine et la formation de l'esprit philosophique en France}

était la conversion des infidèles, les sciences n'étant que le prétexte. Ils ne l'auraient pas affirmé solennellement dans l'épître dédicatoire ${ }_{\text {p.48 }}$ de leur premier ouvrage scientifique ${ }^{1}$, si le fait avait été contraire aux instructions qu'ils avaient reçues. D'ailleurs le P. Le Comte, qui écrivait quelques années plus tard, nous déclare sans ambages, que le roi sachant bien qu'il ne pouvait envoyer de missionnaires - ce qui était réservé à la puissance spirituelle - avait accepté cet expédient des Jésuites à la fois mathématiciens et missionnaires. Mais il ajoute : «On luy avoit mesme fait comprendre que parmi les moyens, dont la prudence humaine peut utilement se servir dans les actions les plus saintes, il n'y en avoit point qui eussent plus avancé les affaires de la Religion à la Chine que les Mathématiques »2. Cet «On » dans la bouche d'un Jésuite est plein de modestie.

\section{$*$}

Il peut nous sembler, à distance des siècles, tout à fait vain de savoir si les Jésuites qui partirent en Chine en 1685, y étaient envoyés comme mathématiciens ou comme missionnaires. A notre point de vue sans doute cela importe peu, puisqu'ils devaient être à la fois l'un et l'autre. De telles subtilités n'auraient pas de quoi nous arrêter si l'état d'esprit de ces Jésuites au moment de leur départ ne nous importait pas avant

1 Observations physiques et mathématiques pour servir à la perfection de L'Astronomie et de la Géographie envoyées de Siam à l'Académie royale des sciences à Paris par les PP. jésuites françois qui vont à la Chine en qualité de mathématiciens du Roy. (Cf. Histoire de l'Académie des sciences, t. VII, p. 607-9).

2 Le Comte, Nouveaux Mémoires sur l'état présent de la Chine, t. II, p. 258-9. 


\section{La Chine et la formation de l'esprit philosophique en France}

tout pour déterminer les causes de la lutte qu'ils vont mener un peu plus tard contre les vicaires apostoliques. Or, ces Jésuites se considéraient surtout comme missionnaires (les mathématiques n'étant qu'un accessoire favorable à leur mission) et comme missionnaires soutenus et patentés pour ainsi dire par le roi de France. Contre le pape, qui étend peu à peu les privilèges des vicaires apostoliques, ils cherchent à dresser le roi de France, au nom des libertés de l'église gallicane. Pour sauver leurs missions d'Extrême-Orient, dont ils risquent d'être dépossédés peu à peu par les missionnaires de la Propagande, ils se tournent vers le roi. Sans doute, il est impossible d'affirmer d'après les documents que nous possédons, que ce sont les Jésuites qui ont suggéré à Colbert l'idée d'envoyer en Chine une mission de Jésuites, bien que Colbert eût avec les Jésuites les relations que I'on sait, mais il nous est possible d'affirmer, d'après le document p.49 que nous avons cité, que les Jésuites, loin de repousser les offres de Colbert, les ont acceptées d'enthousiasme et que dans leur rapport, ils ont même indiqué en faveur du projet de Colbert, un argument capable d'entraîner la décision du roi. Les Jésuites se posent donc en champions de la France contre les Missionnaires, porte-parole du Saint-Siège.

Est-il besoin d'ajouter que telle n'était certainement pas l'idée de Louis XIV ou de ses ministres ? Le roi avait soutenu de tout son pouvoir au début les vicaires apostoliques parce qu'ils étaient français, et malgré les rivalités ultérieures, tout en soutenant les Jésuites, il subventionnera aussi la Société des missions étrangères, parce que Jésuites et Missionnaires peuvent tous contribuer à sa gloire, c'est-à-dire à l'intérêt de la France. 


\section{La Chine et la formation de l'esprit philosophique en France}

Mais en 1685, au moment où il inaugure une politique active en Extrême-Orient, politique religieuse et politique commerciale, les vicaires apostoliques lui sont devenus suspects depuis l'affaire du serment. Il ne les combat sans doute pas, bien au contraire, il les aide dans leur mission, mais il préfère malgré tout se fier aux Jésuites, qui ont su se poser en défenseurs de l'église gallicane. De cette préférence momentanée que le roi leur accorde, les Jésuites veulent se faire une arme. S'ils partent en ExtrêmeOrient avec des idées de lutte, I'hostilité contre les vicaires apostoliques est plus dans leur esprit que dans celui du roi. Cependant ils vanteront tellement cette protection, que le pape, pour défendre les droits du pouvoir spirituel créera en 1690, trois évêchés en Chine, dont un à Pékin, et les confiera aux vicaires apostoliques.

Lorsque le petit abbé de Choisy, dans ses notes de voyage, cherche à tenir la balance égale entre les Jésuites et les Missionnaires qui sont à bord de l'Oiseau, il se montre homme prudent sous sa légèreté apparente, et cette prudence était nécessaire. Il va être témoin pendant son séjour au Siam de la lutte ardente - première passe d'armes avant la Querelle des Cérémonies chinoises - que vont se livrer Jésuites et Missionnaires.

II. - Les Ambassades des Français au Siam 


\section{La Chine \\ et la formation de l'esprit philosophique en France}

(1685-1687)

Les vicaires apostoliques et les Missionnaires semblaient avoir réussi dans leur mission de Siam. Non que le nombre de leurs $\mathrm{p}$. 50 conversions fût bien grand ; mais tout au moins ils n'y souffraient pas de persécutions, et le roi de Siam semblait les favoriser : il leur faisait bâtir des églises, et il ne paraissait pas trop attaché à ses idoles. D'où les missionnaires inféraient que le roi n'était pas loin de se faire chrétien, et que, si on le pressait un peu sur ce point, il se résoudrait à se convertir, avantage immense pour la propagation de la foi au Siam et dans tout I’Extrême-Orient.

Les vicaires apostoliques ne s'étaient pas contentés de « faire mission » mais persuadés, comme nous l'avons vu, qu'une collaboration étroite des missionnaires et des commerçants pouvait être également profitable aux uns et aux autres, ils s'étaient efforcés d'introduire au Siam la Compagnie des Indes Orientales. Mgr Pattu, évêque d'Héliopolis, insista à différentes reprises pour que la compagnie fondât un comptoir au Siam. Celle-ci se décida en 1680 à envoyer un navire avec le marchand Deslandes. Ce n'est pas que le Siam fût un pays de grandes richesses naturelles, mais il produisait tout au moins du poivre et c'était en outre l'entrepôt des marchandises de Chine et du Japon, pays fermés aux Européens.

Deslandes fut bien reçu du roi de Siam. Il obtint la liberté du commerce français, décida le roi à envoyer une ambassade en 


\section{La Chine et la formation de l'esprit philosophique en France}

France et il convainquit le Barcalon, ou premier ministre, de la nécessité de développer la culture du poivrier ${ }^{1}$.

Une première ambassade se perdit en mer, et l'on n'en eut plus jamais de nouvelles. La seconde qui arriva à Paris en 1684 et qui était conduite par M. Vachet, missionnaire, fut bien reçue par Seignelay, Colbert de Croissy et Louis XIV, qui décidèrent, mais après bien des hésitations à envoyer au Siam le chevalier de Chaumont. Les instructions qui lui furent remises lui recommandaient d'aider la compagnie à créer un comptoir dans ce pays, de protéger l'agent de la compagnie au Siam, de suivre ses avis pour les questions de commerce ${ }^{2}$. Mais $M$. Vachet avait dépeint sous de si belles couleurs les dispositions que le roi de Siam avait de se faire chrétien, que dans les instructions remises au Chevalier de Chaumont, les questions religieuses primaient les questions commerciales, et dans la lettre au Barcalon, Seignelay spécifiait les deux résultats qu'il attendait de cette ambassade : l'avancement de la religion et l'établissement du commerce français au Siam ${ }^{3}$.

p.51 L'escadre de M. de Vaudricourt arriva devant la barre de Siam le 24 septembre 1685. Aussitôt, M. Vachet descendit à terre pour rendre visite à « $M$. Constance » et pour lui exposer les résultats de sa négociation en France.

Ce «M. Constance », de son nom Constantin Phaulkon, était un astucieux aventurier. Grec d'origine, mais cherchant à se

\footnotetext{
${ }^{1}$ Kæppelin, op. cit. p. 187-188.

${ }^{2}$ Id., ibid., p. 189.

${ }^{3}$ Id., ibid., p. 197.
} 


\section{La Chine et la formation de l'esprit philosophique en France}

donner pour le descendant d'un noble vénitien, gouverneur de Céphallonie ${ }^{1}$, il avait couru les mers depuis sa jeunesse, tantôt riche, tantôt réduit aux expédients suivant le hasard des bonnes affaires ou des naufrages, et il avait fini par s'établir au Siam, où il avait amassé une belle fortune. Souple et insinuant, il s'était poussé dans la faveur du roi de Siam, à tel point que le roi lui avait proposé la place de Barcalon ou de premier ministre. Mais Phaulkon, qui préférait une puissance durable aux vains honneurs qui excitent l'envie, s'était contenté d'être le conseiller écouté et tout-puissant du roi, sans titre officiel qui eût pu provoquer la jalousie des indigènes. Malgré cette prudence dont il avait fait preuve, Phaulkon n'était pas rassuré sur les dispositions des Siamois à son égard. Sans doute, il pouvait compter sur I'appui du roi, tant que celui-ci vivrait, mais le roi était mal portant et Phaulkon avait tout à redouter, et à bref délai, d'un changement de règne. Pour se prémunir contre ce danger, il se cherchait en Europe une nation qui pût lui procurer un appui effectif. S'il choisit la France, c'est assurément par intérêt personnel. Pensait-il que la France, connaissant moins bien I'Extrême-Orient que les Anglais et les Hollandais, se laisserait guider plus facilement par lui et qu'il jouerait mieux d'elle pour ses intérêts particuliers ? Croyait-il seulement que les Siamois accepteraient plus volontiers les Francais, au lieu des Anglais et des Hollandais qui étaient craints et détestés dans tout I'Extrême-Orient ? Quels que soient les mobiles qui aient poussé Constance, il est de fait que depuis quelques années, il

1 Tachard, Voyage de Siam, p. 187. 


\section{La Chine et la formation de l'esprit philosophique en France}

favorisait les Missionnaires, encourageait la compagnie des Indes, avait envoyé des ambassadeurs à Louis XIV avec M. Vachet. Il en attendait en retour une ambassade de France qui devait lui apporter des avantages matériels et un appui contre les Hollandais. En effet, les Hollandais, mécontents de voir la Compagnie des Indes Orientales s'établir au Siam et par là accaparer le commerce de Chine, mécontents aussi de l'influence grandissante des missionnaires, étaient sur le point, au moment de l'arrivée du Chevalier de Chaumont, de « se saisir p.52 de l'embouchure de la rivière pour se rendre maistres du commerce »1. Si la crainte « d'offenser le Roi [de France] en offensant son ami le Roi de Siam » pouvait contenir quelque temps les Hollandais et les faire marcher « bride en main », comme dit Choisy 2, mieux valait encore cependant s'appuyer sur de bonnes troupes.

On comprend donc l'étonnement et la fureur de Phaulkon Iorsqu'il apprit que le Chevalier de Chaumont venait au Siam tout simplement pour proposer au roi de se convertir au christianisme. Les missionnaires eux-mêmes en furent surpris, et l'abbé de Lionne dit « tout net » à l'abbé de Choisy dès l'arrivée « que ce ne seroit peut-être pas une petite affaire de lui en faire la proposition » 3 . Quant à Phaulkon, il ne put maîtriser sa colère et il interpella vivement l'évêque de Metellopolis : «Eh qui est donc celui qui a ainsy trompé le Roy de France ? Mgr l'evesque

\footnotetext{
${ }^{1}$ Choisy, Journal du Voyage de Siam, p. 158.

${ }^{2}$ Id., op. cit., p. 158.

3 Choisy, Fragments de mémoires, p. p. Launay, Histoire de la mission de Siam, Documents, p. 162.
} 


\section{La Chine et la formation de l'esprit philosophique en France}

luy répartit en levant les épaules qu'il n'en savoit rien et qu'il en étoit fort marry. Le Seigneur Constance luy repartit qu'il prist garde avec beaucoup d'attention de ne se point charger d'une maison qui menaçoit de ruine et qui l'accableroit en tombant, que cette affaire estoit de la dernière conséquence et qu'il répondroit à Dieu du malheureux succez qu'elle auroit, car, adjouta-t-il, depuis que vostre Seigneurie est icy, avez-vous veu la moindre apparence de la part du Roy mon maistre, si vous en exceptez ses bonnes œuvres, d'où l'on puisse inférer la moindre possibilité de sa conversion ? Je n'en sache nulle, répondit Mgr I'Evesque et je suis fort estonné qu'il se soit trouvé des gens qui ayent osé en donner quelque assurance à Sa Majesté Très Chrestienne $\gg 1$.

Constance, s'il faut l'en croire lui-même, démontra longuement à l'évêque que cette demande intempestive n'était avantageuse ni pour la conversion du roi de Siam, ni pour les intérêts du roi de France, car «I'héritier présomptif du Roy du Siam, déjà si mal intentionné contre le Roy son frère et contre ceux qui sont dans son intérest ne manqueroit pas, après sa mort, de les maltraiter et ${ } .53$ de détruire tout ce que son prédécesseur auroit commencé » et d'autre part les Hollandais « ne s'oublieroient pas en cette occasion et employroient leur crédit, leurs forces et leur argent pour oster de leur chemin un

\footnotetext{
1 Mémoire de Monsr. Constance ministre du roy de Siam sur l'ambassade que le Roy lui a envoyé pour l'inviter à se faire chrestien. B. N. Fr. 15.476, f. 1-25. Dans le même volume se trouvent de nombreuses lettres du P. Tachard et d'autres Jésuites, qui aident à préciser le rôle du P. Tachard au cours des deux ambassades de Siam. - une copie de ce mémoire se trouve B. N. Fr. 9773, f. 48-58.
} 


\section{La Chine et la formation de l'esprit philosophique en France}

aussi grand obstacle que le seroit pour eux la nation françoise et la religion romaine $\gg 1$.

Au lieu de se démasquer ainsi, il y avait, suivant Phaulkon, un moyen beaucoup plus simple et plus sûr d'assurer à la fois les intérêts de la religion et ceux de la France. Mais ce plan merveilleux, ou bien Phaulkon n'osa pas le communiquer à l'évêque de Métellopolis ; ou bien l'évêque ne voulut pas se charger de le proposer à l'ambassadeur, et Phaulkon se mit à louvoyer en attendant d'avoir trouvé I'homme qu'il lui fallait.

Sous prétexte de régler le cérémonial de la réception, il s'en vint trouver l'ambassadeur et lui demanda « familièrement »ce qu'il comptait dire dans son compliment au roi de Siam. L'ambassadeur lui montra le texte de son discours, et Phaulkon feignit l'étonnement en voyant qu'il ne s'agissait guère que de religion dans ce discours. En effet, $s^{\prime}$ il y est vaguement question de commerce, la religion chrétienne du moins y est vantée en longues phrases pompeuses : «Le roi mon maistre vous conjure par l'intérest qu'il prend à votre véritable gloire de considérer que cette suprême Majesté dont vous êtes revêtu sur la terre, ne peut venir que du vray Dieu, c'est-à-dire, d'un Dieu tout puissent, éternel, infini, tel que les Chrestiens le reconnoissent qui seul fait régner les Rois et règle la fortune de tous les peuples $\gg 2$. Constance voulut faire des objections, mais $-\mathrm{du}$ moins d'après le mémoire justificatif qu'il a fait rédiger l'évêque de Métellopolis l'entraîna en lui disant qu'ils prendraient

\footnotetext{
1 B. N. Fr. 15.476 , f. 6.

2 Tachard, Voyage de Siam, p. 235.
} 


\section{La Chine et la formation de l'esprit philosophique en France}

ensemble les mesures pour obvier à tous les inconvénients qui pourroient suivre si ce compliment « estoit expliqué publiquement $\gg 1$. Le même jour Artus de Lionne vint trouver Constance, lui demanda une audience secrète et lui proposa I'ordre du Saint-Esprit, s'il obtenait la conversion du roi de Siam. Constance ne refusa pas ce qu'on lui offrait, bien que ce grand cordon fût loin de valoir les avantages matériels qu'il attendait, mais, attendant son heure, il fit contre fortune bon cœur, et il répondit modestement que « même sans récompense, la reconnaissance qu'il devoit à Dieu, devoit l'engager à faire tout ce qui seroit nécessaire à l'heureux succès de cette négociation $\gg 2$.

p.54 Le jour de l'audience arrivé, l'ambassadeur fit son discours tel qu'il avait projeté de le faire. L'évêque de Métellopolis le traduisit en portugais, et Constance l'expliqua au roi de Siam « comme il en estait convenu avec M. de Métellopolis ${ }^{3}$ (à ce qu'il prétend du moins), c'est-à-dire qu'il le falsifia. Il se contenta de phrases vagues sur l'amitié des deux rois ; quant à l'objet même de la négociation, l'ambassadeur en parlerait au roi en séance secrète. Quelques heures après la cérémonie, Constance alla rendre visite à I'ambassadeur. Le Chevalier de Chaumont lui fit part « des grandes résolutions que le Roy de France avoit prises pour le bien de ce Royaume en cas que le Roy de Siam se

\footnotetext{
1 B. N. Fr. 15.476 , f. 9.

2 B. N. Fr. 15.476 , f. 10.

3 B. N. Fr. 15.476 , f. 11.
} 


\section{La Chine et la formation de l'esprit philosophique en France}

convertist »1. Constance essaya de détourner l'ambassadeur de suivre ses instructions à la lettre. Il lui montra le danger qui en résulteroit pour les missionnaires «qui avoient mal informé sa Majesté Très Chrestienne et que peut-estre il les chasseroit tous de ses estats comme faussaires », que « sans faire tant d'éclat on pouvoit si l'on savoit s'y prendre comme il faut gagner toute la nation à J. C. sans que le Diable y pust mettre aucun obstacle, ce qu'il ne manqueroit pas de faire, si on ne prenait d'autres mesures $\gg 2$. L'ambassadeur lui objecta que ses instructions étaient formelles et qu'il ne pouvait se dispenser de les exécuter. En bon casuiste, Constance lui démontra que vouloir parler d'abord de religion, c'était gâter toute l'affaire, c'était par conséquent suivre les instructions à la lettre, mais non dans leur esprit ; tandis qu'en prenant « d'autres voies secrettes et seures pour exécuter un si grand dessein $\gg 3$ on se conformerait en réalité aux désirs du Roi de France.

Le Chevalier de Chaumont ne se laissa pas persuader par toute cette dialectique. A I'audience secrète que le roi de Siam lui accorda quelques jours après, il répondit au roi qui lui demandait quelles étaient ces affaires secrètes dont il avait à l'entretenir « qu'il n'avoit rien à lui proposer que la Religion Chrestienne ». Encore une fois Constance « expliqua le compliment de la manière qu'il jugea la plus avantageuse au service de Dieu et à la gloire du Roy de France », c'est-à-dire

\footnotetext{
${ }^{1}$ B. N. Fr. 15.476 , f. 13.

2 B. N. Fr. 15.476 , f. $15-16$.

3 B. N. Fr. 15.476, f. 19.
} 


\section{La Chine et la formation de l'esprit philosophique en France}

qu'il le falsifia encore une fois, et cette audience se passa en compliments de part et d'autre, « estant traité des Hollandois, des missionnaires et de la compagnie du commerce de France, jusqu'à ce qu'une petite pluie qui survint interrompît la conversation $\gg 1$.

L'entrevue entre Constance et l'ambassadeur à la suite de cette audience fut assez orageuse. On s'accusa mutuellement de mauvaise foi, le Chevalier de Chaumont reprochant à Phaulkon d'avoir altéré ses paroles en les traduisant, celui-ci reprochant à l'ambassadeur de lui avoir promis de réfléchir sur les raisons qu'il lui avait données et de ne l'avoir pas fait. Les jours suivants, Constance revint à la charge essayant d'amener le Chevalier de Chaumont à résipiscence. Peine perdue. Le Chevalier de Chaumont lui donna sa réponse définitive : il devait exécuter à la lettre les ordres du roi. Alors Constance de s'emporter en paroles menaçantes : « J'avoue que Votre Excellence aura peut-estre raison dans son procédé parce que je ne sai pas les desseins secretz qu'on peut couvrir de ce prétexte. Je luy diray pourtant que le Roy de Siam, mon maistre, ne manquera pas à la première ouverture de cette proposition de demander, comme je fis à Mgr l'Evesque, qui est celuy quy a ainsy trompé le Roy de France. Et quelle réponse lui feroi-je, moi ? Que ce sont les missionnaires. Voilà un fort bel endroit pour donner au Roy mon maistre, la haute estime qu'il devroit avoir des apostres et des pasteurs de sa conversion lorsqu'il

1 B. N. Fr. 15.476 , f. $20-21$. 


\section{La Chine \\ et la formation de l'esprit philosophique en France}

reconnoistra qu'ils ont esté capables d'une si grande fourberie $\gg 1$.

Ce mémoire, qui ne fut sans doute pas écrit par Phaulkon (car Phaulkon était bien incapable d'écrire en français), mais inspiré par lui pour se justifier près du roi de France d'avoir fait échouer la négociation du Chevalier de Chaumont, s'efforce avec grand soin de faire retomber la responsabilité des mauvaises informations qui ont été données au roi sur les vicaires apostoliques et les Missionnaires. Que M. Vachet, pendant son séjour en France, ait exagéré les tendances du roi de Siam à se faire chrétien, cela est évident : l'évêque de Métellopolis et l'abbé de Lionne le reconnaissent non moins que Forbin ou l'abbé de Choisy. Mais ce qu'il y a de particulier dans ce mémoire, c'est l'âpre rancune dont il témoigne à l'égard des Missionnaires, c'est le désir ardent de bien les désigner comme les coupables. Ce n'est donc pas un hasard si ce mémoire se trouve à côté de tant de lettres du P. Tachard relatives à ces ambassades de Siam, où le P. Tachard défend le rôle qu'il y a joué. Ce mémoire n'est pas seulement une défense de Phaulkon, c'est aussi un essai de justification du P. Tachard. En accablant les Missionnaires, pour se justifier, le Jésuite faisait coup double.

Constance en effet, n'avait pas réussi dans ses négociations avec l'ambassadeur. Sur l'article de la religion, comme nous l'avons vu, il s'était heurté à la fermeté inébranlable du Chevalier de Chaumont. Il n'eut pas plus de succès lorsqu'il vint offrir à l'ambassadeur, dans un mémoire confidentiel « où son

1 B. N. Fr. 15.476 , f. 25. 


\section{La Chine et la formation de l'esprit philosophique en France}

dévouement passionné pour le roi de France empiétait un peu sur sa fidélité au roi de Siam », une ligue offensive et défensive contre les Hollandois ${ }^{1}$. Il proposait de donner au roi de France, la ville de Banco, « à condition qu'on y envoyât des troupes, des ingénieurs, de l'argent et des vaisseaux »2. Le Chevalier de Chaumont et Choisy se récusèrent sur une semblable négociation, étant donné que le roi ne voudrait pas s'engager à une dépense de quatre ou cinq millions qui peut-être seraient perdus. Sur ce refus de l'ambassadeur, Constance qui tenait à ce projet, gage de sa sécurité future, chercha un homme assez audacieux pour se charger de présenter ce projet au roi, un homme ayant assez de crédit pour avoir des chances de le faire réussir. Il trouva le $\mathrm{P}$. Tachard.

Le P. Tachard, nous dit Choisy, était « un esprit doux, souple, rampant, et pourtant hardi, pour ne pas dire téméraire $\gg 3$. Il accepta le projet de Constance, l'assura que l'ambassadeur et l'abbé de Choisy n'avaient aucun crédit à la cour, mais que « s'il vouloit en écrire au P. de la Chaize, Sa Révérence en viendroit bien à bout $\gg 4$.

Il fut donc décidé que le P. Tachard repasserait en Europe sous le prétexte d'aller chercher douze Jésuites mathématiciens pour l'observatoire que le roi de Siam faisait construire à Louvo.

\footnotetext{
1 Lanier, Etude historique sur les relations de la France et du Royaume de Siam, p. 68.

2 Choisy, Mémoires, p. 612.

${ }^{3}$ Id., ibid., p. 612.

${ }^{4}$ Id., ibid., p. 612.
} 


\section{La Chine et la formation de l'esprit philosophique en France}

Il emporterait une lettre de Phaulkon pour le P. de la Chaize, et il exposerait lui-même au roi et au P. de la Chaize les seuls moyens pratiques d'introduire la religion et le commerce au Siam.

Voici en quoi consistait ce plan merveilleux, suivant Phaulkon. Il fallait d'abord introduire dans le royaume, et avec le plus grand secret, un certain nombre de personnes « sages et habiles pour le gouvernement militaire et civil qui ne demanderoient rien tout d'abord au roi de Siam » pour s'attirer la bienveillance du roi et du peuple. Peu à peu, Phaulkon, par son influence personnelle, p.57 les ferait mettre dans les postes importants « conseils du Roy, charges de guerre et de finances, dans les gouvernements, dans les intendances des provinces, des places et des vaisseaux ». Il serait même souhaitable qu'il y eût parmi ces soixante ou soixante-dix personnes, quelques «Pères Jésuites en habit déguisé qui ne fussent point connus de ces séculiers ».

Le roi de France pourrait en outre envoyer des colons « pour peupler les plus fortes places et les endroits les plus importants du païs ». Phaulkon se chargerait de leur faire bâtir des maisons, de leur procurer des champs et des jardins, des bœufs et des vaches. En cas de révolution, ils pourraient servir comme officiers ou comme soldats, suivant leurs capacités. Enfin, et c'était la chose essentielle pour Phaulkon, le roi de France occuperait et fortifierait la place de Cingor : «Afin que cela s'exécute plus aisément et se maintienne plus seurement en cas de révolution, Sa Majesté Très Chrestienne envoyera 


\section{La Chine et la formation de l'esprit philosophique en France}

incessamment fortifier la place de Cingor, la garnira de soldats et d'artillerie avec les vaisseaux et les autres choses nécessaires pour un grand établissement. Tout cela dans la suite sera ainsy que je vous l'ay fait voir, pour prendre un tel accroissement, que le Roy se procurera un advantage considérable aussi bien qu'aux Estats de Siam, surtout si sa Majesté veut establir deux colonies sur ces mers $\gg 1$.

Cette lettre de Phaulkon au P. de la Chaize était toute de sa façon, nous dit le P. de Fontaney dans une lettre chiffrée au P. Verjus ; les Jésuites y avaient seulement prêté la main. Et le P. de Fontaney, en s'excusant d'avoir été obligé de le faire, mettait en garde contre Phaulkon : «Monsieur Constance écrit une grande lettre au P. de la Chaize, toute de sa façon. La conclusion est que pour convertir il faut envoyer ici des troupes qu'il paye par sa main, dont il soit le général. Il parle de faire des forteresses françoises dans les endroits où il ne peut rien. Il ne ${ }_{p}$. ${ }_{58}$ parle point d'avoir de bons missionnaires parce que peut-estre cela ne luy donne ny pouvoir ny profit. Je vous prie de croire et de le dire au P. d. I. C. [P. de la Chaize] que je n'ay point de part à ces expédients que je les aurois empeschez si j'avois pû pour

\footnotetext{
1 A. N. K. 1.334, Mémoire pour establir le Religion et le commerce à Siam [du P. Tachard] suivi de la copie du Mémoire escrit et signé de la main du Sgr. Constance et donné au P. Tachard, pour le communiquer au $R$. $P$. de la Chèze et en rendre compte au Roy. C'est ce mémoire de Phaulkon que nous venons d'analyser. Il existe dans les archives des Missions étrangères une copie de ce mémoire, un peu différente de celle-ci dans sa rédaction. En outre I'article important sur la place forte à occuper et à fortifier y est entièrement supprimé. Le préambule recommande au $P$. Tachard de faire toutes ses diligences auprès du Pape, du P. Général et du P. de la Chaise pour obtenir du roi les avantages désirés. (Launay, Histoire de la Mission de Siam, t. I, p. 179-180). La présence de cette copie dans les archives des Missions étrangères prouve que les Missionnaires étaient au courant, du moins en ce qui concernait la religion et le commerce, des démarches du P. Tachard.
} 


\section{La Chine et la formation de l'esprit philosophique en France}

demeurer dans la simple proposition d'envoyer d'habiles missionnaires. Les François mesmes ne souffriront jamais son humeur qui est trop impérieuse et violente pour nostre nation. Je vous mande cela afin que vous preniez vos mesures au juste louant promettant mais donnant toujours dans des mesures fausses, car la Graeca fides des latins est en luy dans toute sa perfection $\gg 1$.

Phaulkon n'avait donc pas séduit tous les Jésuites au même degré que le P. Tachard. Et même nous pouvons nous demander jusqu'à quel point le Jésuite s'était laissé entortiller par la faconde du Levantin et si dans cette négociation qu'ils semblaient mener d'un commun accord, il n'y avait pas une dupe qui était précisément Phaulkon.

En effet, le Mémoire pour establir la religion et le commerce à Siam du P. Tachard, s'écarte sensiblement des intentions de Phaulkon ; sur certains points même, et non des moindres, il les combat. Phaulkon voudrait par exemple que les Français occupent une place forte au Siam et Seignelay le demande «pour assurer le commerce ». Le P. Tachard voit dans ce projet toute sorte de dangers et il cherche à en détourner Seignelay : «Premièrement, les peuples qui ne sont pas accoutumez aux François en seront troublez et peut-estre fort mécontents, mais surtout les hollandois et anglois qui prendront leurs mesures pour ruiner le commerce de Siam, ce qui leur sera peut-estre asses facile parce que les françois n'y peuvent avoir de longtemps des forces capables de les en empescher ». Le P.

1 Lettre du P. de Fontaney au P. Verjus. A Siam, le 18 de novembre 1686, B. N. Fr. 15.476, f. 56. 


\section{La Chine et la formation de l'esprit philosophique en France}

Tachard pour sa part, ne veut pas tant d'éclat. Il voudrait que tout se fit peu à peu et dans le plus grand secret. Il a un plan merveilleux pour rendre en peu de temps le Siam entièrement français et chrétien. Pour cela, il suffit de s'entourer de beaucoup d'ombre. et de silence. Des suggestions de Phaulkon, le P. Tachard en retient quelques-unes : on pourrait mettre par exemple des gouverneurs français dans toutes les places importantes ; les capitaines de navires qui font le commerce au Siam pourraient également être des Français ; Constance propose aussi d'introduire au Siam sous un déguisement quelques Jésuites. Excellente idée. Mais ici I'imagination du P. Tachard s'excite, et p.59 ces quelques Jésuites qui, suivant Phaulkon, devaient être perdus au milieu de beaucoup d'autres Français, deviennent le conseil de gouvernement du roi de Siam, tenant en mains toutes les ficelles qui font mouvoir tous les Français dispersés dans les provinces. En somme, un véritable protectorat, mais dissimulé, et dont la direction sera entièrement entre les mains des Jésuites ${ }^{1}$.

Le P. Tachard était un homme à l'imagination vive, mais il gardait cependant le sens des réalités. Il se rendait compte de l'écart qu'il y avait entre le projet de Phaulkon, déjà favorable aux Français et aux Jésuites, et celui qu'il proposait à Seignelay. Aussi il reconnaissait qu'il fallait gagner Constance à ces idées nouvelles et il indiquait un certain nombre d'avantages qu'il croyait bon de lui accorder. Il demandait pour lui « des lettres de naturalité, un titre de comte et la promesse d'une terre « érigée

\footnotetext{
1 A. N. K. 1.334.
} 


\section{La Chine et la formation de l'esprit philosophique en France}

avec ce titre et mille escus de revenus à ladite terre $\gg 1$. Par contre, Seignelay désirait que Phaulkon entrât dans la compagnie des Indes et y mît vingt mille écus. Le P. Tachard en prenait l'engagement pour lui 2, mais il demandait que Phaulkon fût nommé directeur général de la compagnie « avec quelques prérogatives $\gg 3$.

Seignelay ne se laissa pas séduire par le P. Tachard. De bonnes troupes et de solides forteresses lui semblèrent un appui plus certain pour le développement du commerce français au Siam que des Jésuites déguisés dans le conseil du roi. Cependant, le nouvel ambassadeur La Loubère, emporta pour Phaulkon le brevet de l'ordre de Saint-Michel, des lettres de naturalité, le droit de porter trois fleurs de lys d'or dans ses armes, et, pour son fils, le don d'une terre de 3.000 livres de rente avec le titre de comte ${ }^{4}$.

En somme, le P. Tachard avait réussi dans cette négociation que lui avait confiée Phaulkon ; il avait même mieux réussi pour la satisfaction de Constance que pour la sienne puisqu'il n'avait pu détourner Seignelay d'envoyer une expédition militaire pour occuper Bankok et Merguy. A cet égard, les plans fantastiques et les desseins tortueux du P. Tachard n'avaient pu prévaloir sur les désirs exprimés nettement par les directeurs de la compagnie des Indes.

1 B. N. Fr. 15.476 , f. 92.

2 A. N. K. 1.334 .

3 B. N. Fr. 15.476 , f. 92.

4 Lancer, op. cit., p. 96. 


\section{La Chine et la formation de l'esprit philosophique en France}

Si le chevalier de Chaumont avait échoué dans sa négociation p.60 principale qui était de convertir le roi de Siam, il avait du moins obtenu un certain nombre d'avantages commerciaux, notamment la reconnaissance de la liberté du commerce français, ce qui était de grande importance à cause des marchandises de Chine et du Japon qu'on ne pouvait acheter qu'au Siam. En outre, les Français obtenaient le monopole de la culture du poivrier ${ }^{1}$.

Ces avantages cependant ne pouvaient suffire à la compagnie des Indes, car un arrêt du 26 octobre qui interdisait d'introduire en France les toiles peintes et les étoffes à fleur d'or et d'argent des Indes et de la Chine, risquait de la ruiner si elle ne réussissait pas à faire en grand le commerce des objets de la Chine et du Japon. Aussi, les directeurs de la compagnie adressèrent-ils à Seignelay un long mémoire pour le documenter au sujet des instructions à donner aux envoyés du roi, de La Loubère et Cébéret, qui devaient partir pour le Siam en 1687. C'était un historique de l'œuvre de Deslandes au Siam, une critique du traité obtenu par le chevalier de Chaumont, et un exposé des points où il était nécessaire de le modifier ou de le compléter pour assurer l'entière et effective liberté du commerce, et l'acquisition de Bangkok et de Merguy. En effet, l'objet essentiel des instructions royales remises à La Loubère et à Cébéret, et même à Desfarges, le commandant des troupes, était l'établissement du commerce « fondement de cette

\footnotetext{
${ }^{1}$ Kæppelin, op. cit., p. 189.
} 


\section{La Chine \\ et la formation de l'esprit philosophique en France}

entreprise », et le second - mais le second seulement - la propagande religieuse ${ }^{1}$.

Les intérêts du commerce l'emportaient donc sur la propagation de la foi. Le P. Tachard lui-même se rallia à cette politique, et à son second retour du Siam, en 1688, il se vantait de l'avoir défendue dans l'intérêt même de la religion. «...Je m'estimeray trop heureux si par des travaux et des peines.... je puis contribuer à l'établissement solide des françois dans les Indes, et aux avantages du commerce de la Compagnie des Indes, d'où dépend absolument l'établissement de la Religion Chrétienne. J'en suis si persuadé que je me fais un grand mérite de travailler en quelque chose aux deux premiers, ne doutant pas que les Indes ne soient bientost en état de se faire presque toutes chrétiennes quand elles seront devenues françoises. Ainsi mon employ qui paroitra peut-estre éloigné de ma profession si on n'en considère que les premières p.61 apparences, sera très apostolique, au moins il me paroist tel, quand j'en pénètre les heureuses suites $\gg 2$.

Après l'échec de la négociation du Chevalier de Chaumont, il n'était personne qui gardât l'espoir de convertir le roi de Siam, et par lui le Siam tout entier. S'il avait pu avoir des illusions à cet égard pendant un certain temps, l'abbé de Choisy lui-même en avait été détrompé au cours d'une conversation confidentielle qu'il avait eue avec Constance Phaulkon. C'était au moment où

${ }^{1}$ Id., op. cit, p. 207.

2 Lettre du P. Tachard, écrite de Brest le 26 juillet [1688], sans indication de destinataire, mais adressée sans doute au P. Verjus. B. N. Fr. 15.476, f. 74. 


\section{La Chine et la formation de l'esprit philosophique en France}

notre petit abbé qui rêvait à la merveilleuse fortune qu'il pourrait faire en devenant aumônier du roi de Siam, commençait malgré tout à se demander s'il n'avait pas été dupe des imaginations de M. Vachet. Il alla donc trouver Phaulkon, décidé à savoir la vérité, quoiqu'il dût en coûter à son amour-propre. Phaulkon tout d'abord I'amusa de bonnes paroles, l'assurant qu'il resterait au Siam comme aumônier du roi. Mais après une longue conversation en tête à tête, ou l'abbé de Choisy usa de toute sa finesse d'esprit et de sa séduction d'homme du monde pour mettre en confiance le favori, Choisy finit par déclarer qu'il ne croyait aucunement à la possibilité de la conversion du roi : «Vous avez raison, lui répondit Phaulkon, aussi ne se fera-t-il point chrétien, et même pour le bien de la religion, il ne seroit à propos qu'il le fist si tôt. Il faut commencer par convertir une partie du royaume. A-t-on jamais vu un roi changer de religion sans avoir un gros parti dans son état ? De plus le roi est vieux et mal sain, tout rechangerait à sa mort, et peut-être qu'on persécuterait la religion chrétienne comme la cause des désordres. Je le remerciai extrêmement de sa bonne foi. Il continua et me dit qu'à la première audience il n'avait osé dire au roi tout ce que M. I'ambassadeur lui avait dit sur la religion, à cause des mandarins présents et que jusqu'à la lecture de la lettre du roi de France, Sa Majesté n'avait point su que toute cette grande ambassade n'avait pour but que sa conversion : que Sa Majesté lui avait ouvert son cœur là-dessus, qu'elle était persuadée que toutes les religions sont bonnes, que même elle avait dit : Tu es chrétien, si tu te fais de ma religion, je te croirai un coquin. Que d'ailleurs le roi ne laissait pas d'être fort obligé 


\section{La Chine et la formation de l'esprit philosophique en France}

au roi de France, que cela ne partait que de bonne amitié... Je lui laissai dire tout ce qu'il voulut ; c'était un torrent de vérités... »1.

Le P. Tachard dans son Voyage de Siam est encore plus

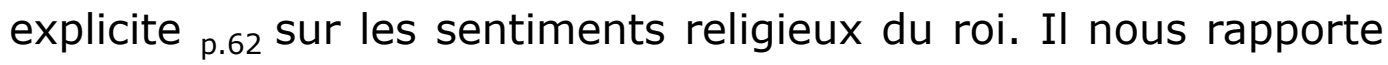
la réponse que fit le roi à Phaulkon, lorsque celui-ci lui proposa de la part de l'ambassadeur de France de se faire chrétien : c'est une véritable profession de déisme. Il commence par déclarer que Dieu, s'il I'avait voulu, aurait créé I'unité de religion. Or, il ne l'a pas fait. Par conséquent « ne doit-on pas croire que le vray Dieu prend autant de plaisir à estre honoré par des cultes et des cérémonies différentes, qu'à estre glorifié par une prodigieuse quantité de créatures qui le louent chacune à sa manière ? Cette beauté et cette variété que nous admirons dans I'ordre naturel seroient-elles moins admirables dans l'ordre surnaturel, ou moins dignes de la sagesse de Dieu ? »2.

Le P. Tachard ne partageait donc pas les illusions de $M$. Vachet. Non qu'il désespérât de christianiser un jour le Siam ; mais il ne comptait pas pour cela sur la conversion du roi. Il attendait seulement ce résultat de l'action patiente des quatorze Jésuites mathématiciens qu'il emmenait pour l'observatoire de

\footnotetext{
1 Fragment de mémoires de l'abbé de Choisy, p. p. Launay, Histoire de la Mission de Siam, t. I, p. 165.

2 Tachard, Voyage de Siam, p. 309-11. Bayle qui, en 1686, écrivait son Commentaire philosophique et cherchait des arguments en faveur de la tolérance, semble avoir eu vent dès le retour de l'ambassade du Chevalier de Chaumont des Idées des Siamois sur la religion. Il se déclare pressé de connaître la relation du P. Tachard, et il nous apprend que la relation du Chevalier de Chaumont, avant d'être livrée au public avait été remaniée en ce qui concerne la religion. (Cf. Nouvelles de la république des Lettres, octobre 1686 , p. $1160 \cdot 1)$.
} 


\section{La Chine et la formation de l'esprit philosophique en France}

Louvo. La méthode brusque et hardie de M. Vachet n'est pas la sienne.

Le P. Tachard accompagnait I'ambassade extraordinaire de La Loubère et Cébéret, à titre de conseiller officieux, à titre surtout d'ami de Constance Phaulkon. Aussi lorsque I'ambassade fut arrivée devant la barre de Siam, on le dépêcha en avant pour obtenir de Phaulkon la signature du traité que I'on avait préparé, avant qu'on laissât débarquer les troupes, et on lui donna des «instructions ». Ces instructions sont curieuses. Sur le chapitre de la religion - celui qui nous intéresse surtout ici - elles reprennent les idées exprimées par le roi de Siam dans son entretien avec Phaulkon, du moins telles que le P. Tachard nous les rapporte dans le récit de son premier voyage au Siam. Elles examinent, pour les critiquer sans doute, mais elles examinent malgré tout les idées de la diversité des cultes, que Dieu luimême tolère, et de l'indifférence de Dieu au culte qu'on lui rend si le cœur est sincère, et elles expriment l'espoir que le roi un jour se convertira. Cependant, elles indiquent nettement que le désir d'obtenir cette conversion n'est plus l'objet essentiel de l'ambassade, comme du temps du p.63 Chevalier de Chaumont, mais seulement une espérance d'avenir, et elles concluent : «...A cela prez, Sa Majesté croit avec raison qu'un Roy est véritablement son amy et son allié quand il excelle en dignité, en mérite et en grandeur, et que pour unir les cœurs des grands Princes les vertus semblables suffisent où les Religions sont différentes.... ${ }^{1}$. Singulière profession de tolérance, moins de

1 B. N. Fr. 15.476 , f. 53. 


\section{La Chine et la formation de l'esprit philosophique en France}

deux ans après la Révocation de l'Édit de Nantes ! Les intérêts de la Compagnie des Indes avaient prévalu sur l'intolérance.

Nous ne ferons pas le récit de cette seconde ambassade au Siam que Lanier a déjà fait ${ }^{1}$. Qu'il nous suffise de remarquer que les querelles entre les Jésuites et les Missionnaires semblent avoir atteint, pendant cette ambassade, leur plus haut degré de violence. Nous avons un écho de ces luttes dans les lettres adressées en France par le P. Tachard. Il s'y plaint - en des termes qui sont parfois dépourvus d'onction - de La Loubère, de I'évêque de Métellopolis, d'Artus de Lionne, évêque de Rosalie, celui-là même qui avait reçu son serment avant le départ de Brest. Il en veut à La Loubère parce qu'il a écouté l'évêque de Métellopolis, plus que les Jésuites. Il essaie donc d'insinuer, une fois I'ambassade terminée, que La Loubère a échoué dans sa mission, qu'il « est parti de Siam fort mal content et... a laissé le Roy de cet Etat et son ministre encore plus mal satisfaits $\gg 2$. Il en veut surtout à Artus de Lionne, qu'un autre Jésuite, le P. d'Espagnac appelle un boute-feu 3 , parce qu'on le soupçonne d'avoir empêché l'évêque de Métellopolis d'envoyer des Jésuites missionnaires au Tonkin ${ }^{4}$. Et alors la haine du P. Tachard ne garde plus de mesure, et il ne recule pas devant les accusations les plus graves. Il affirme qu'Artus de Lionne « furieusement piqué » du peu d'égards que le roi de Siam et son ministre ont

1 Lanier, op. cit., p. 87-98.

2 Lettre du P. Tachard, sans date et sans indication de destinataire (le P. de la Chaize ou le P. Verjus ?) B. N. Fr. 15.476, f. 36.

3 Lettre du P. d'Espagnac, 2 janvier 1688. B. N. Fr. 15.476, f. 48.

4 ibid., f. 48. 


\section{La Chine et la formation de l'esprit philosophique en France}

eu pour sa personne, froideur qu'il attribue au P. Tachard, s'en est vengé en écrivant à Rome. «Votre Révèrence peut présumer de quelles couleurs ils [Artus de Lionne et l'évoque de Métellopolis] m'ont dépeint dans les lettres qui vont à Rome, puisque M. I'abbé de Lionne a dit à quelques-uns de nos Pères qu'il avoit eu déjà soin dez le premier voyage de faire mon caractère à Messieurs de la Propagande, les instruisant du dessein qui m'amenoit en France et qu'il p.64 jugeoit si indigne d'un religieux »1. Et il va même jusqu'à accuser Artus de Lionne d'avoir forcé, au cours du premier voyage, avec l'aide de l'abbé de Choisy et de M. Vachet, le coffre où se trouvaient tous ses papiers, pour en envoyer des copies à Rome 2 .

Ce ton d'aigreur, ces accusations qu'il ne faut accepter qu'avec réserves, nous donnent la mesure des rivalités entre les Jésuites et les Missionnaires. Cependant peut-être faut-il en rabattre un peu, car le P. Tachard a joué un tel rôle dans ces ambassades de Siam (rôle que les autres Jésuites n'approuvaient pas toujours) que ses accusations ne sont souvent qu'un procédé d'apologétique personnelle. Il accuse pour se défendre ; pour se défendre d'avoir été I'homme de Constance.

C'est en effet un singulier personnage que ce P. Tachard qui, non content d'avoir été le conseiller officieux de l'ambassade française au Siam, consent à passer encore une fois en Europe pour être le porte-parole de Phaulkon, près du roi de France et près du pape. Quand il arrive à Brest en juillet 1688, il fait savoir

\footnotetext{
${ }^{1}$ Lettre du P. Tachard. B. N. Fr. 15.476, f. 39.

2 ibid., f. 39.
} 


\section{La Chine et la formation de l'esprit philosophique en France}

à la Cour qu'il est ambassadeur du roi de Siam ; mais lorsque l'intendant de la marine de Brest lui demande de la part du roi de quelle manière il veut être reçu, il déclare modestement que son caractère l'empêche de prendre le titre et de réclamer les prérogatives d'ambassadeur du roi de Siam ${ }^{1}$. La modestie est fille de la prudence. Il fallait en effet, pour le succès même de la négociation qu'il venait mener en France, enlever de l'esprit du roi tout soupçon de duplicité ; il lui fallait aussi se justifier près du P. de la Chaize contre les accusations possibles de ses confrères les Jésuites, qui ne voyaient pas sans inquiétude ce rôle politique qu'il avait assumé, et contre les accusations certaines des vicaires apostoliques et des Missionnaires que le P. Tachard essayait de combattre au Siam en se servant de son crédit près de Phaulkon.

Aussi, dès son arrivée à Brest, il s'empresse d'écrire au P. de la Chaize pour lui exposer les raisons qui I'ont décidé à revenir en France. La principale raison est qu'il doit présenter lui-même à Louis XIV la lettre du roi de Siam. Mais à côté de cette raison officielle qu'on peut hautement avouer, il y en a d'autres dont le roi et le P. de la Chaize ont besoin d'être informés en particulier. Ce sont d'abord les mésintelligences qui commencent à se p.65 manifester entre les officiers des troupes françaises envoyées au Siam et qui seront telles en effet que ces troupes ne pourront empêcher la révolution de 1688 ; et c'est ensuite « la conduite de MM. les vicaires apostoliques, le peu d'espérance qu'il y a de les gaigner par des soumissions... comme Votre Révérence l'aura

1 Tachard, Second Voyage de Siam, p. 385. 


\section{La Chine et la formation de l'esprit philosophique en France}

déjà reconnu par les lettres qu'elle a reçeues du P. Fontaney... et la manière dont les prélats en ont usé à notre égard et à l'égard des autres Jésuites qui ont fait le serment soit à Siam ou ailleurs ». Enfin, le P. Tachard ajoutait encore ce motif tout personnel, c'est qu'il craignait que les deux envoyés, de La Loubère et Cébéret, peu contents de leurs négociations, ne lui en attribuassent l'échec ${ }^{1}$.

Le plus important est sans doute ce que le P. Tachard ne dit pas. C'est la négociation dont il est chargé en France et à Rome, plus encore par Phaulkon que par le roi de Siam. Nous ne connaissons pas les avantages nouveaux qu'il demandait en France pour Constance. Mais ces avantages devaient être grands, si l'on en juge par ce que le P. Tachard avait obtenu d'aller demander au pape au nom du roi de Siam. Il s'agissait tout simplement d'obtenir l'assentiment du pape pour l'expulsion des Missionnaires du Siam au profit des Jésuites.

Constance Phaulkon en effet, dans une lettre adressée aux cardinaux de la Propagande, et qui fut remise au P. Tachard, commençait par déplorer l'état de la religion chrétienne au Siam et les dissentiments entre les différents ordres de missionnaires, qui empêchaient la religion de faire tous les progrès qu'elle aurait dû faire. Il exprimait le regret que ceux qui « par leur caractère et leur dignité » [c'est-à-dire les vicaires apostoliques] étaient chargés des intérêts de la religion chrétienne n'eussent pas répondu à son propre zèle et à ses propres efforts. Et il réclamait des mesures exemplaires contre les fauteurs de

1 Lettre du P. Tachard, s. d., sans indication de destinataire. B. N. Fr. 15.476, r. 36. 


\section{La Chine et la formation de l'esprit philosophique en France}

désordres : « J'ai communiqué beaucoup de choses d'importance à cet envoyé [le P. Tachard] qu'il prendra la liberté de représenter à Vos Eminences et dont j'espère un si bon effet que j'en auray une consolation particulière, me regardant comme le Général de tous les Chrestiens de I'Orient. En vérité si Vos Eminences pouvoient voir sans ombre et sans déguisement l'état de la foi catholique dans les Indes et la confusion de l'Église de Dieu non seulement elles luy porteroient compassion et tascheroient d'y remédier, mais encore elles feroient p.66 sentir les effets de leur saint zèle par des réprimandes exemplaires et en éloignant même les auteurs de ces désordres » 1 .

Le P. Tachard, dans son discours au pape, précisant les intentions de Phaulkon, indiquait au Saint-Père le seul moyen de rétablir la paix dans les églises d'Extrême-Orient, qui était de replacer les Jésuites dans les anciennes missions qu'ils avaient fondées.

«Cette nombreuse Chrétienté, Très Saint-Père, a souffert les bannissements, les ignominies, la pauvreté, les prisons et les tourmens avec une patience héroïque et un courage digne des premiers martirs de Jésus-Christ, soutenue par la présence de ses premiers pasteurs et animée par les exhortations et les exemples de ses Pères qui I'ont fondée avec tant de fruit et qui I'ont cultivée seuls pendant presque tout un siècle, avec tant de peine et de bénédictions. Mais ces pauvres Chrétiens se voyant privez de ces secours si nécessaires, ont commencé à sentir leur

\footnotetext{
1 Lettre aux cardinaux de la Propagande, remise au P. Tachard. B. N. Fr. 11.773 , f. 87-8.
} 


\section{La Chine et la formation de l'esprit philosophique en France}

faiblesse, et il s'en est même trouvé qui ont commis des fautes que les autres ne peuvent assez déplorer. Cependant ils ne se plaignent pas, parce qu'on leur fait entendre que ce sont les ordres de Votre Sainteté qui ont rappelé les Pères de la Compagnie leurs premiers fondateurs. Ils prennent seulement la liberté de luy remontrer, avec toute I'humilité et la soumission qu'ils doivent, les horribles scandales qui sont arrivez dans leur pays après la sortie de ces Pères. Je n'en diray que trop pour affliger le cœur charitable et paternel de Votre Sainteté en celant les autres désordres et luy disant seulement que depuis que les Jésuites ont été chassés du Tunquin, plus de trois cent mille chrétiens ont refusé de se confesser et de recevoir aucun sacrement $\gg 1$.

Le seul avantage que le P. Tachard obtint au cours de cette ambassade fut la suppression du serment pour les Jésuites 2, mais le pape refusa d'accorder, comme le lui demandaient le $P$. Tachard et le «Général des Chrétiens de I'Orient »la suppression des Missionnaires et des vicaires apostoliques. Bien au contraire, deux ans après, il étendra jusqu'en Chine la juridiction des vicaires apostoliques.... Et ce fut l'affaire des Cérémonies chinoises.

Telles étaient les luttes que se livraient loin de France les plus brouillons des Jésuites et des Missionnaires, le P. Tachard et l'abbé ${ }_{\text {p.67 }}$ de Lionne, sans se rendre compte que c'était en

\footnotetext{
1 Discours du P. Tachard à N. S. P. le Pape. B. N. Fr. 9.773, f. 93.

2 Le Comte, Nouveaux Mémoires sur l'état présent de la Chine, t. II, p. 261. Launay, Documents historiques relatifs à la Société des Missions Etrangères donne le texte de ce décret, t. I, p. 135-6.
} 


\section{La Chine et la formation de l'esprit philosophique en France}

somme la religion qui souffrait de leurs dissentiments. Mais cette lutte n'était pas encouragée en France par les supérieurs des Jésuites ou des Missionnaires. Le P. de la Chaize et l'abbé Brisacier, supérieur des Missions étrangères, cherchèrent au contraire entre eux un accommodement pour mettre fin à ces luttes qui désolaient les églises chrétiennes en Extrême-Orient. En 1687, nous apprend le P. de la Chaize 1 les directeurs du Séminaire des Missions étrangères consentirent à sacrifier quelques-unes des personnes les plus turbulentes de leur société, et en même temps l'abbé Brisacier donna son approbation au livre que le P. Le Tellier, Jésuite, venait d'écrire pour défendre les missions des Jésuites en Chine contre les attaques des jansénistes et des protestants ${ }^{2}$. C'était un acte de courage de la part de Brisacier, et il fut accusé, bien à tort du reste, par des jansénistes comme Quesnel 3, ou par des

\footnotetext{
${ }^{1}$ Chantelauze, op. cit., p. 66.

2 Deffense des nouveaux chrestiens de la Chine. L'approbation de l'abbé Brisacier, dont la révocation en 1700 sera le signal de la Querelle des Cérémonies chinoises, était rédigée ainsi : « J'embrasse avec joye cette occasion qui se présente à moy, de déclarer hautement que dans l'Empire de la Chine les Missionnaires de cette illustre société [les Jésuites] si vénérable par le nombre et par le mérite de ses sujets ont esté les premiers à donner l'exemple d'une entière soumission aux ordres du St. Siège; qu'ils y pratiquent de très éminentes vertus, qu'ils y consacrent tout ce qu'ils ont de crédit à la Cour et dans les provinces à soutenir les autres ouvriers de I'Évangile et qu'ils y ont une parfaite union avec les nôtres auxquels ils ont donné des marques certaines de leur amitié, de leur désintéressement et de leur zèle. C'est ce que je puis attester avec sincérité à la teste de cet ouvrage, où je n'ay rien remarqué que de très conforme à la saine doctrine et aux bonnes mœurs, et où j'estime que les personnes qui seroient préoccupées contre ces Pères trouveront des réflexions capables de les ramener de leurs fascheuses préventions, et de leur faire changer de sentiment »s. p.
}

3 Quesnel, Lettres, t. II, p. 37. 


\section{La Chine et la formation de l'esprit philosophique en France}

indépendants comme le P. Léonard ${ }^{1}$ d'avoir cédé en le faisant à des vues d'intérêt personnel.

Si les directeurs du séminaire des Missions étrangères commencèrent par donner des gages de leurs bonnes intentions, les p.68 négociations pour amener les Jésuites missionnaires à composition durèrent longtemps puisque le «traité de paix » ne fut signé que le 13 mars 1689. C'est une longue déclaration en 16 articles, signée d'une part par les directeurs du séminaire des Missions Etrangères, Tiberge et Brisacier, et d'autre part, par le provincial des Jésuites, par le P. de la Chaize et par le P. Tachard. En outre, ce traité était approuvé par l'archevêque de Paris et autorisé par le roi. La puissance temporelle et la puissance spirituelle s'étaient donc trouvées d'accord pour mettre fin à cette lutte entre les Jésuites et les Missionnaires. Par ce traité on s'engageait réciproquement à régler entre soi les différends qui pourraient naître entre les religieux au Siam, sans y mêler en quoi que ce soit le roi de Siam et ses ministres, sans y mêler non plus le pape ou le roi de France. Ceci semble bien un désaveu de la politique du P. Tachard. Pour les différends qui pourraient naître par la suite entre Jésuites et Missionnaires, les supérieurs des Jésuites et les vicaires apostoliques devaient régler la

\footnotetext{
1 « 1694. Monsieur Brisacier qui est supérieur des missions étrangères à I'alternative avec $M$. Tiberge est un grand politique; beaucoup d'esprit, qui sçait et qui presche aussi bien. L'on le croit de famille de Paris : fort patelin, tout puissant chez Me de Maintenon... on prétend qu'il a eu une abaye pour avoir aprouvé le livre du P. Tellier, jésuite, intitulé : Deffense des nouveaux Chrétiens 1687 contre les 2 voll. de la Morale pratique des Jésuites. » (A. N. - K. 1374, f. $\left.11, r^{\circ}\right)$ ). Le P. Léonard se trompe en attribuant un désir de lucre à l'abbé Brisacier qui fut toujours considéré, même par ses adversaires, comme un homme de bonne foi. La seule abbaye qu'il obtînt jamais avait appartenu à son oncle, le fameux Brisacier ; elle rapportait seulement 1000 livres par an. Cf. Dangeau, Journal, t. III, p. 83.
} 


\section{La Chine et la formation de l'esprit philosophique en France}

question entre eux. «Que si on ne peut sur les lieux assoupir les différends, on en dressera conjointement ou séparément un petit procès-verbal où I'on exposera le fait simplement avec les raisons pour ou contre, et ce procez-verbal sera envoié en France, signé de part et d'autre, et par provision on obéira aux vicaires apostoliques ». Cette question de l'obéissance aux vicaires apostoliques a dû être la cause principale des discordes. Mais quels que soient les motifs qui les ont fait naître nous pouvons tout au moins savoir à quel degré de violence ces discordes purent atteindre, puisque ce texte n'hésite pas à les qualifier de schisme. C'est à ce schisme que le P. Tachard faisait allusion dans son discours au pape en demandant la suppression des Missionnaires. Le tribunal de conciliation entre les Jésuites et les Missionnaires décide au contraire :

« $13^{\circ}$ Qu'on étouffera autant qu'il sera possible entre tous les catéchistes jusqu'au souvenir du schisme; qu'on ne se le reprochera plus et qu'on ne voudra plus aussi le justifier les uns aux autres et que les Vicaires apostoliques, les jésuites et autres missionnaires agiront entre eux avec tant de concert et parleront si souvent et si efficacement de la parfaite union, qu'ils la persuaderont à leurs inférieurs encore plus par leurs exemples que par leurs paroles ; que pour inspirer plus fortement l'esprit de paix aux différents ouvriers, le $P$. Tachard et $M$. Charmot ou quelques autres en leur place iront ensemble au Tonkin ou ailleurs intimer unanimement les ordres du St Siège et les volontés du Roy ${ }^{1}{ }^{»}$.

\footnotetext{
${ }^{1}$ A. N. M. $203 n^{\circ} 7$.
} 


\section{La Chine et la formation de l'esprit philosophique en France}

p.69 Ce traité fut signé au moment où le P. Tachard s'apprêtait à partir une troisième fois pour le Siam. Dès cette époque, il est vrai, circulaient déjà des rumeurs alarmantes à Paris sur l'état politique du Siam, et I'on parlait même d'une révolution, mais, suivant Dangeau ${ }^{1}$, on supposait que ces bruits étaient répandus à dessein par les Hollandais qu'inquiétaient nos progrès au Siam. Malgré tout M. Charmot partit avec le P. Tachard, mais ils n'arrivèrent pas au Siam. A la suite de la révolution de 1688, les étrangers en avaient été chassés. Le P. Tachard resta aux Indes. M. Charmot alla en Chine, où il rejoignit M. Maigrot, prêtre des missions étrangères et docteur de Sorbonne, vicaire apostolique du Foukien 2. Tous les deux, ils vont engager la lutte contre les Jésuites en Chine, et ils seront parmi leurs adversaires les plus acharnés pendant la Querelle des Cérémonies chinoises. Les «ordres du Roy » et les « volontés du Saint-Siège » ne prévalurent pas sur les rivalités qui dressaient les uns contre les autres, Jésuites et Missionnaires.

Il nous est difficile aujourd'hui d'imaginer exactement I'ardeur des luttes qui divisaient les différents ordres religieux en Extrême-Orient au XVII ${ }^{\text {e }}$ siècle : Jésuites contre Dominicains et Franciscains aux Indes et en Chine, Jésuites contre Missionnaires au Siam et au Tonkin. Le Saint-Siège était sollicité à tout instant de prendre parti, mais il évitait autant que possible de le faire pour ne décourager personne. En France, les supérieurs des Missions étrangères essayaient de calmer l'ardeur combative de

\footnotetext{
1 Dangeau, Journal, 21 octobre 1689, t. III, p. 11-2.

2 B. N. Fr, 25.060, f. 239.
} 


\section{La Chine et la formation de l'esprit philosophique en France}

leurs religieux, car ceux qui profitaient de ces discordes, c'étaient les jansénistes et les protestants, c'était Arnaud, c'était Jurieu. A défaut de l'apaisement, qui eût été plus souhaitable, on s'efforçait tout au moins de faire le silence.

A la fin du XVII e siècle tout change. Les querelles des missionnaires qui jusque-là étaient restées confinées en Extrême-Orient vont être transportées en Europe. L'affaire des rites du Malabare durait depuis plus d'un siècle ; mais c'était une simple querelle entre Jésuites et capucins dont on n'avait aucune raison de s'occuper en France. L'affaire des rites chinois était soumise périodiquement depuis près de cinquante ans au jugement du pape. Or peu de gens en France soupçonnaient même, que cette querelle existât. Subitement cette affaire prend une violence inconnue : ce n'est plus seulement à Rome, mais aussi en France qu'on la juge. L'Europe p.70 entière est inondée de libelles pour ou contre les Jésuites. Cette querelle s'insinue en France au milieu de toutes les autres querelles théologiques, et elle n'est peut être pas sans lien avec elles ; elle passionne I'opinion après l'affaire du quiétisme, avant l'affaire de la Bulle Unigenitus. En outre, ce n'est plus une rivalité qui dresse un ordre religieux en face d'une autre ordre religieux, c'est une lutte entre les Jésuites français et la Société des Missions étrangères de Paris, où chacun se sert, pour emporter l'avantage, non seulement d'arguments de fait ou de doctrine, mais aussi de son crédit à la Cour. La politique se mêle désormais à la religion. 


\section{La Chine \\ et la formation de l'esprit philosophique en France}

Qui donc soutenait le Séminaire des Missions étrangères et qui les Jésuites ? Quelle fureur les poussait à vouloir se détruire ?

(@) 


\section{La Chine \\ et la formation de l'esprit philosophique en France}

\section{CHAPITRE II}

\section{La Querelle des Cérémonies Chinoises}

p.71 On ne parle plus guère aujourd'hui de cette Querelle des Cérémonies chinoises qui suscita tant de violentes polémiques dans les premières années du XVIII ${ }^{\mathrm{e}}$ siècle. Les historiens euXmêmes qui à notre époque, se sont occupés des questions religieuses sous le règne de Louis XIV, n'y font que de brèves allusions : ils ne lui attribuent certainement pas une très grande importance. Cependant Voltaire lui a consacré tout un chapitre de son Siècle de Louis XIV, et un chapitre qui prend d'autant plus de valeur qu'il est le dernier de I'ouvrage. Évidemment, comme l'a montré M. Lanson, il y a chez Voltaire une intention, lorsqu'il place à la fin du règne du Grand Roi, le récit des affaires ecclésiastiques; il veut montrer «l'envers du beau règne », et le dernier chapitre sur les Cérémonies chinoises devient « un symbole de la raison chassant le fanatisme »1. Intention philosophique qui n'est pas douteuse, bien que Voltaire soit resté encore historien en écrivant ce chapitre, bien qui n'ait rien inventé pour l'écrire, pas même les plaisanteries qu'il a empruntées aux libelles de l'époque, mais intention qui semble avoir jeté par avance un certain discrédit sur les historiens futurs qui voudraient se mêler de raconter cette affaire. Malgré les dangers auxquels on s'expose en essayant de renouveler la

${ }^{1}$ Lanson, Voltaire, p. 116. 


\section{La Chine \\ et la formation de l'esprit philosophique en France}

tentative de Voltaire - sans aucune des arrière-pensées qu'il pouvait avoir - il n'en faut pas moins nous demander si cette affaire où les Jésuites ont joué leur réputation et leur crédit à Rome et, en France, a été sans influence sur les ouvrages qu'ils ont consacrés à la Chine.

\section{$*$}

A la fin du XVII ${ }^{e}$ siècle, I'affaire des Cérémonies chinoises était déjà une vieille querelle. Elle s'était allumée dès le jour où p.72 différents ordres religieux - Jésuites d'une part, Franciscains et Dominicains de l'autre - s'étaient trouvés en présence en Chine, mais elle avait été précédée par une querelle analogue, entre les mêmes ordres, au Malabare. La querelle des rites du Malabare et la querelle des rites chinois procèdent en principe de la même cause : d'une divergence absolue dans la manière de pratiquer l'évangélisation.

Il y eut en effet, animosité déclarée entre les différents ordres religieux et les Jésuites, le jour où le P. de Nobili, Jésuite, missionnaire aux Indes, décida d'abandonner sa soutane pour prendre la tunique blanche des rajahs et pour vivre à leur manière. Cette décision, qui devait être si lourde de conséquences, montre que le P. de Nobili, avec la souplesse de son ordre et de sa nation, avait compris la psychologie des peuples de l'Orient. Le mémoire qu'il écrivit pour se défendre auprès de l'archevêque de Goa, devant lequel il fut traduit, et qui d'ailleurs le condamna, est un chef-d'œuvre d'habilité politique.

Il remarque d'abord dans son mémoire que l'état social actuel dans les Indes est fondé sur l'idée de caste et sur la hiérarchie 


\section{La Chine et la formation de l'esprit philosophique en France}

des différentes castes. Or, lorsqu'il est arrivé aux Indes, appliquant les principes de I'humilité chrétienne, il a voulu vivre comme les pranguis, la caste inférieure. Il portait la soutane noire et le crucifix sur la poitrine, d'où I'on a conclu aux Indes que sa soutane et le crucifix étaient la marque des pranguis et que le christianisme était la religion des parias. « Se consolera-ton d'un si grand malheur, ajoute le P. de Nobili, en déclamant contre l'orgueil et la sottise des Indiens ? Oui, mais en attendant, des millions d'âmes se perdent, et ces âmes sont rachetées au prix du sang de Jésus-Christ. N'est-il pas plus sage et plus chrétien de chercher à dissiper ce préjugé, de présenter le christianisme pour ce qu'il est en réalité, la religion universelle de tous les peuples et de toutes les conditions ? $\gg 1$. Or, le seul moyen d'y parvenir est de porter le costume des brames et de vivre comme eux ; il sera plus facile ensuite de s'abaisser vers les castes inférieures qu'il ne le serait de s'élever vers les castes supérieures, si l'on portait le costume des parias. «Moi-même, dit le P. de Nobili, avec ma couleur blanche et mon crucifix sur la poitrine, j'ai fini par me faire accepter comme un homme de bonne condition avec qui l'on peut traiter sans déshonneur, et si j'ai subi de pénibles et fréquentes discussions sur ce point, c'est que j'avais eu le malheur ${ }_{\text {p.73 }}$ d'arriver avec ma soutane noire et de loger dans la maison des pranguis $\gg 2$.

En Chine, les Jésuites firent la même expérience et ils adoptèrent une ligne de conduite analogue à celle du P. de Nobili

\footnotetext{
1 J. Bertrand, Mémoires historiques, p. 272.

2 Id., ibid., p. 272.
} 


\section{La Chine et la formation de l'esprit philosophique en France}

aux Indes. Le P. Ricci, fondateur de la mission, avant d'être habitué aux usages chinois, vivait ascétiquement avec les bonzes. Il été honoré par eux mais il ne convertissait personne. «Puisque vous êtes sçavans, lui dit un mandarin, vivez comme les sçavans. Alors vous pourrez parler à tout le monde. Les mandarins accoutumés à considérer les gens de lettres, vous considéreront aussi, ils recevront vos visites : le peuple, vous voyant honorés d'eux, vous respectera et écoutera vos instructions avec joye $\gg 1$. Le Père comprit et suivit les conseils du mandarin ${ }^{2}$.

Les Jésuites s'aperçurent donc qu'en Chine, point n'était besoin de faire profession d'humilité et d'ascétisme, puisque I'humilité et une vie austère n'étaient pas la marque d'une vertu supérieure. Ils comprirent bien vite que pour les Chinois, la hiérarchie morale se confond avec la hiérarchie sociale, puisque l'État, non content de punir les crimes, récompense la vertu. Les honneurs, les dignités ne sont donc pas pour eux une vaine gloriole, mais la preuve évidente d'un mérite distingué. Une robe

${ }^{1}$ Lettres édifiantes et curieuses, t. VIII, p. 224-5.

2 Voici, d'après un missionnaire, la description du curieux costume que portaient les Jésuites : « Une longue robe de toile blanche, une autre pardessus aussi longue, d'une étoffe de soye ordinairement bleue avec une ceinture : sur le tout un petit habit noir ou violet qui descend aux genoux fort ample et à manches larges et courtes; un petit bonnet fait en forme de cone raccourci, chargé tout autour de soyes pendantes ou de crin rouge; des bottes d'été aux pieds, un éventail à la main ; c'est ainsi qu'on doit être ajusté toutes les fois qu'on sort de la maison ou que l'on rend une visite de conséquence. Dans le domestique on quitte une partie de cet attirail. Mais il faut bien se garder de dire la messe sans avoir la tête couverte d'un bonnet particulier et sans avoir pris ses bottes. » (Lettre du P. Jacques, Canton, $1^{\mathrm{er}}$ novembre 1722, Lettres édifiantes et curieuses. t. XVI, p. 54-6). 


\section{La Chine et la formation de l'esprit philosophique en France}

de mandarin est comme un brevet de vertu. Aussi les Jésuites voulurent prendre la robe de mandarin.

Toute différente fut la conduite des autres ordres religieux. Non seulement ils refusèrent d'abandonner leur costume en Extrême-Orient, mais ils voulurent s'en tenir fermement à leurs principe d'humilité. En 1669, lorsque la Société des Missions étrangères codifia les règles qu'elle avait l'intention d'imposer à ses missionnaires en pays étrangers, il semble qu'elle ait choisi des principes qui vont tout à l'encontre des usages suivis par les Jésuites dans p.74 leurs missions d'Extrême-Orient. Les Monita ad Missionarios ne semblent en effet tenir aucun compte des coutumes particulières des différentes nations qu'il faut évangéliser : aucune souplesse, aucune concession aux habitudes nationales, mais au contraire des règles rigides qui peuvent s'appliquer en Amérique aussi bien qu'en Chine. Ces Monita semblent craindre en effet que les missionnaires, pris du vertige des conversions faciles, nombreuses mais peu sincères, comme on le reprochait aux Jésuites, n'arrivent à sacrifier peu à peu quelque chose de leur doctrine et de leurs règles de conduite, pour se plier aux usages des païens. « Le démon met devant les yeux du Missionnaire la gloire de Dieu et de JésusChrist, le grand nombre d'âmes abandonnées, la religion chrétienne qu'il faudrait répandre sur toute la terre; il lui représente les différentes qualités de nature et de grâce dont il est doué ; trompé par cet éclatant mirage, l'apôtre se jette dans une foule d'imprudences, peu à peu il omet ses exercices accoutumés, I'oraison, l'examen particulier ; il oublie le recueillement ; toujours distrait par les choses extérieures, plus 


\section{La Chine et la formation de l'esprit philosophique en France}

attentif aux autres qu'à lui-même, il en arrive à s'abandonner entièrement de telle sorte que privé des secours abondants de la grâce et du Saint-Esprit, il se laisse percer par les traits de la vaine gloire ; il se livre à ce qu'il croit de grandes choses, méprise les petites, secoue le joug de l'obéissance et affecte de ne se consacrer qu'à des entreprises héroïques ». Ces Monita vont même jusqu'à défendre aux missionnaires «l'étude des arts et des sciences quand ils font oublier à I'ouvrier évangélique que son premier devoir est de prescher $\gg 1$.

Les Jésuites, au contraire, estimaient qu'il ne suffisait pas de « prescher » et que le missionnaire devait avoir, outre les marques extérieures de la science, bonnet de docteur ou robe de mandarin, une science véritable, une connaissance précise des doctrines chères aux lettrés chinois et leur habituel sujet de conversation et de discussions, pour mieux combattre ces doctrines et renverser cet obstacle qui s'opposait à la propagation de la foi. La connaissance de la doctrine de Confucius est pour le Jésuite la première des qualités d'un bon missionnaire en Chine.

Seuls de tous les missionnaires, les Jésuites comprirent, peutêtre parce qu'ils étaient plus savants, qu'il était impossible de heurter de front le culte séculaire de Confucius « qui avait donné sa forme au système social et partant au système administratif $\mathrm{p}$. ${ }_{75}$ du Céleste Empire »2. Avec ce culte, ininterrompu depuis l'antiquité, malgré les révolutions et les changements de

\footnotetext{
${ }^{1}$ Launay, Histoire de la Société des Missions étrangères, t. I, p. 98-109.

2 Cordier, Histoire de la Chine, t. III p. 319.
} 


\section{La Chine et la formation de l'esprit philosophique en France}

dynasties, il fallait biaiser, sans trop le louer, mais sans l'attaquer ouvertement. « L'exemple de nos premiers Pères Jésuites qui nous ont laissé cette mission établie par leur vertu et par leur prudence, nous apprend que nous devons être fort retenus lorsque nous louons Confucius auprès des Chinois, de peur que son autorité et l'estime qu'ils en font, qui n'est déjà que trop grande, ne s'augmente trop par notre témoignage, car cette nation présume beaucoup et n'estime rien que ce qui est né chez elle. L'extrémité contraire est encore bien plus à craindre, car si nous attaquons par nos écrits cet homme que toute la nation révère, non seulement ils ne nous pourront souffrir, mais leur haine s'étendra jusques à la doctrine de notre religion et jusques à Jésus-Christ même, et en condamnant de la sorte sans discrétion les écrits de ce philosophe qui s'accordent fort bien avec la raison, et qui a toujours tasché de conformer sa vie et ses mœurs avec sa doctrine, les Chinois considéreront ceux de I'Europe comme des gens qui ont plutost pris à tasche de combattre la raison mesme que la doctrine de leur maistre et qui vont davantage à en étouffer la lumière qu'à obscurcir le nom de Confucius $\gg 1$.

Pour tenir le juste milieu entre l'éloge nécessaire pour désarmer les méfiances des Chinois, et le blâme non moins nécessaire à la propagation de la foi, il faut connaître avec précision cette doctrine de Confucius. Et c'est à la faire connaître à leurs futurs missionnaires que les Jésuites se sont tout d'abord employés. En 1673, le P. Intercetta publie un résumé de la

\footnotetext{
${ }^{1}$ Intorcetta, La science des Chinois, p. 23.
} 


\section{La Chine et la formation de l'esprit philosophique en France}

doctrine de Confucius, et en 1682, il donne dans le recueil de Thévenot, la traduction en latin du II livre de ce philosophe ${ }^{1}$, travaux préparatoires qui aboutiront en 1687 à la publication des PP. Jésuites, contenant, outre une longue préface du P. Couplet sur la religion des Chinois, la traduction des trois premiers livres de Confucius.

Avec cette doctrine de Confucius, les Jésuites pensaient qu'il était possible de composer, parce que c'était une doctrine morale plutôt qu'un code religieux : «Cette religion, disait le P. Ricci, n'admet pas d'idoles mais honore seulement le Ciel et la Terre ou le Roi du Ciel.... ; à cet être suprême qu'ils reconnaissent, les Lettrés n'érigent aucun temple ; ils ne lui ont consacré aucun lieu p.76 pour l'adorer. Conséquemment, ils n'ont ni prestres ni ministres de la religion, ni rites solennels à garder par tous, ni préceptes, ou commandements imposés, ni chef spirituel chargé de déclarer ou promulguer la doctrine et de châtier ceux qui la transgressent. De même, ils ne récitent jamais de prières, ni en commun ni en particulier. Bien plus, ils prétendent que I'Empereur seul doit offrir ces hommages et sacrifier au roi du Ciel... Le vrai temple des Lettrés est celui de Confucius $\gg 2$.

Plus difficile était la conciliation de la religion chrétienne avec le culte des ancêtres, qui a ce caractère particulier d'être pratiqué également par les adeptes des trois religions différentes de la Chine, confucianistes, boudhistes et taoïstes. Il y avait

\footnotetext{
1 Thévenot, Recueil de divers voyages curieux qui n'ont point été publiés, t. II. (Chaque article a une pagination spéciale).

2 Cordier, Histoire de la Chine, t. III p. 319.
} 


\section{La Chine et la formation de l'esprit philosophique en France}

évidemment un grand danger pour les missionnaires à vouloir supprimer ce culte, car ils auraient passé non seulement pour des briseurs d'idoles, mais pour des révolutionnaires venus en Chine pour bouleverser l'état social, fondé sur le respect de la famille. Ne pouvant donc le supprimer, les Jésuites résolurent de I'interpréter. Ils affirmèrent que les honneurs rendus aux morts et aux ancêtres ne constituaient que des cérémonies civiles sans aucun mélange d'idolâtrie. Or, voici en quoi consistait ce culte, suivant un bon connaisseur des choses chinoises :

« Dans I'humble demeure du paysan, comme dans la maison somptueuse du banquier, dans le misérable logis du coolie comme dans l'imposant yamen du mandarin, l'ancêtre est présent au foyer domestique, dans un cadre qui varie suivant la fortune, mais entouré partout de la même vénération. Les ancêtres sont représentés, soit par une simple tablette... d'environ quinze centimètres de haut sur quatre de large, soit, chez les gens aisés, par une salle où sont réunies et rangées, par ordre chronologique, les tablettes de tous les parents défunts. Ces salles sont plus ou moins richement ornées, suivant l'état de fortune du propriétaire : les tablettes se trouvent toujours chez le fils aîné, souvent aussi chez la plupart des membres de la famille. Parfois, derrière la tablette, une cavité permet de recueillir des morceaux de papier portant les noms d'ancêtres éloignés. Tous les jours, on brûle de l'encens et du papier devant les tablettes en accompagnant la cérémonie de génuflexions $\gg 1$.

1 Cordier, op. cit., t. III p. 319. 


\section{La Chine et la formation de l'esprit philosophique en France}

Ces tablettes et ces génuflexions feront couler des flots d'encre pendant la Querelle des Cérémonies chinoises.

p.77 Enfin, il y avait une troisième difficulté qui tenait à I'interprétation de certains mots chinois que l'on pouvait employer pour désigner Dieu. Emploierait-on le mot Tien, le Ciel ? Mais les Chinois ne voulaient-ils pas désigner par là le ciel matériel ? Fallait-il donc se servir de Chang-ti, l'Etre suprême, ou bien de Tien Tchou, le Seigneur du Ciel ? La question était d'autant plus délicate que pour la résoudre il fallait des connaissances philologiques, et en outre une connaissance précise des théories métaphysiques des Chinois, surtout de la secte des Lettrés, toutes connaissances qui manquaient à la fin du XVII siècle.

C'est autour de ces trois questions, culte de Confucius, culte des morts, termes servant à désigner Dieu, que va se livrer toute la bataille des Cérémonies chinoises. D'un côté, nous trouvons les Jésuites qui veulent interpréter les doctrines chinoises pour les adapter autant qu'il est possible aux doctrines chrétiennes et qui veulent aussi s'accommoder aux mœurs chinoises, pour mieux s'insinuer dans la confiance des indigènes ; en face d'eux, se dressent tous les autres ordres religieux et la Société des Missions étrangères qui se posent en champions de la pure doctrine chrétienne et refusent de faire aucune concession aux doctrines chinoises par des interprétations habiles. 


\section{La Chine et la formation de l'esprit philosophique en France}

Si les Jésuites missionnaires en Chine furent toujours tous d'accord pour adapter leurs procédés d'évangélisation aux mœurs chinoises, ils varièrent quelquefois d'opinion sur I'interprétation à donner aux rites chinois. Le P. Ricci, comme nous l'avons vu, avait pensé que la morale de Confucius, interprétée d'une certaine manière, pouvait être utile à la propagation de la foi. Le P. Longobardi, qui le remplaça à Pékin, comme supérieur des Jésuites, fut d'un avis contraire. Il crut voir dans les livres classiques des Chinois que le terme Chang ti (ou Xam-ti) ne désignait pas le Souverain Seigneur du ciel, mais seulement la vertu matérielle du ciel, et que les esprits dont il était parlé dans les livres chinois étaient des êtres corporels. II demanda à ses missionnaires leur opinion à ce sujet et les raisons sur lesquelles ils s'appuyaient. Le P. Sabathino de Ursis lui envoya un traité dans lequel il montrait que les Chinois n'avaient jamais reconnu de substance spirituelle distinguée de la matière, et qu'ainsi ils n'avaient jamais eu de vraie notion ni de Dieu ni des anges, ni de l'âme. Le P. Longobardi, fort de cet avis, composa lui-même un Traité sur quelques points de la religion des ${ }_{\text {p.78 }}$ Chinois qui ne fut d'ailleurs pas imprimé à cette époque, mais qui fut seulement traduit en espagnol par le $P$. Navarrete, et imprimé en français en 1701 par le Séminaire des Missions Étrangères pour faire pièce aux Jésuites. Le sentiment du P. Ricci prévalut cependant dans la Compagnie de Jésus et le 


\section{La Chine et la formation de l'esprit philosophique en France}

vice-provincial des Jésuites, le P. Hurtado fit jeter au feu le livre du P. Longobardi ${ }^{1}$.

Sur ces entrefaites, des Dominicains, notamment le P. Moralez et des Franciscains, dont le P. Antoine de Sainte-Marie, entrèrent en Chine. Immédiatement ils prirent position contre les Jésuites dans la question des rites et le P. de Sainte-Marie écrivit un Traité sur quelques points importants de la mission de la Chine qui ne fut publié qu'en 1701 en même temps que I'opuscule du P. Longobardi par les soins du Séminaire des Missions Etrangères. Le $P$. de Sainte-Marie considérait le culte de Confucius et le culte des ancêtres comme entachés de superstition, et il jugeait que les chrétiens ne les pouvaient tolérer. Il avouait cependant qu'il fallait agir avec circonspection et mesure « sachant bien que les choses morales ont leur étendue et leurs degrés ». L'ardeur combative de ces nouveaux venus, Dominicains et Franciscains, ne tarda pas à exciter contre eux les autorités chinoises, et ils furent expulsés de Chine (1637). Moralez adressa au P. Diaz, visiteur des Jésuites, un mémoire en douze articles sur les rites chinois. Le P. Diaz ayant différé sa réponse, Moralez partit pour Rome où il arriva en 1643 , et il obtint du pape Innocent $X$ un décret prohibant les rites, qu'il fit notifier en 1649 au provincial des Jésuites en Chine.

Mais le décret que les Dominicains avaient obtenu du pape contre des Jésuites n'était que provisoire, puisqu'il fixait un

\footnotetext{
${ }^{1}$ Sur cette première phase de la querelle des rites chinois, cf. I'Histoire de la Chine, du P. de Mailla, t. X, ou l'Histoire de la Chine, de Cordier, t. III.
} 


\section{La Chine et la formation de l'esprit philosophique en France}

certain nombre de points auxquels les religieux devaient se soumettre « jusqu'à ce que Sa Sainteté en ait autrement ordonné ». Aussi les Jésuites, profitant de ce biais, s'empressèrent-ils de députer à Rome le P. Martini qui exposa I'affaire d'une tout autre manière à la Congrégation du SaintOffice et obtint le décret du 23 mars 1656 approuvant les Jésuites. Ce décret autorisait les Chinois convertis à célébrer le culte des ancêtres et de Confucius, mais en en retranchant les choses superstitieuses, et il leur permettait aussi d'assister aux cérémonies pratiquées par les non convertis, à condition d'y être d'une présence purement passive, surtout après avoir fait une protestation de foi, et « lorsqu'il n'y a nul péril de subversion et qu'on ne peut autrement éviter les inimitiés et les haines ».

p.79 Les Dominicains cependant ne désarmaient pas. En 1661, ils envoyèrent un nouveau mémoire à la Propagande et ils obtinrent le 13 novembre 1669 un décret de cette Congrégation, confirmé par le pape Clément IX, qui déclarait que « les deux résolutions antérieures subsistaient et étaient véritables suivant les demandes et les circonstances différemment exposées... « C'était donc une justification des décisions antérieures et contradictoires du Saint-Siège, et c'était un refus en somme fort sage de trancher la question de fait, mais ce n'était pas le moyen de terminer la lutte, puisque cette décision permettait de la recommencer sans cesse en fournissant des faits nouveaux. Aussi dès ce moment la tactique des Jésuites est fixée : toutes les fois qu'ils seront condamnés, ils en appelleront du pape mal informé au pape mieux informé et la querelle recommencera interminablement. 


\section{La Chine et la formation de l'esprit philosophique en France}

C'était une querelle de théologiens qui pouvait durer longtemps, mais qui aurait pu cependant être ignorée en France, tout au moins du public, si la méthode d'évangélisation des Jésuites n'avait été une excellente occasion pour les jansénistes d'attaquer la morale relâchée des Jésuites. Pascal ne laissa pas échapper l'occasion et c'est lui qui révéla au public qu'il y avait une contestation en Extrême-Orient, entre les différents ordres religieux sur la manière d'évangéliser les Chinois.

Pascal, à partir de la cinquième Provinciale, laissant de côté les discussions théoriques sur la grâce, s'attaque à la morale relâchée des Jésuites. Comme l'ont montré $M$. Lanson ${ }^{1}$ et les éditeurs de Pascal 2, c'est Arnauld qui, avec son petit livre de la Théologie morale des Jésuites, a muni Pascal de faits et de citations. Mais dans le livret d'Arnauld, il n'est pas question des procédés d'évangélisation des Jésuites en Chine, et c'est un livre tout différent, le Martyre de la Foi 3 , de Thomas Hurtado qui va lui fournir quelques traits acérés contre les Jésuites missionnaires en Chine, comme il en fournira plus tard à l'auteur du second volume de la Morale pratique des Jésuites. Est-ce Arnauld qui a signalé ce livre à Pascal ? Est-ce Pascal lui-même

1 G. Lanson, Les Provinciales et le livre de la théologie morale des jésuites. R. H. L., 1900, p. 169-195.

2 Pascal, Fuvres, t. IV, p. 275-96.

3 Pascal, Fuvres, t. IV, P. 293. Ce livre contient des digressions sur les restrictions mentales et c'est dans cette partie de l'ouvrage que Pascal a trouvé les faits qu'il cite dans cette provinciale. 


\section{La Chine et la formation de l'esprit philosophique en France}

qui l'a rencontré, par hasard ? p.80 Question qu'il est difficile de décider et qui, d'ailleurs, importe peu ici ${ }^{1}$.

Ce livre de Hurtado exposait sommairement les différents griefs que l'on pouvait faire aux Jésuites missionnaires et rapportait en même temps les condamnations portées par le pape en 1645 contre les pratiques des Jésuites en Chine et aux Indes. « Ils dissimulent la croix, disait Hurtado, et ils ne prêchent que Jésus ressuscité et glorieux ». Ils permettent à leurs néophytes d'adorer l'idole Chacimhoan, mais en rapportant en pensée leur culte et leurs génuflexions à une croix qu'ils portent à la main ou qui est dissimulée sous les fleurs de l'autel. Ils permettent également aux nouveaux chrétiens d'assister aux sacrifices offerts dans les temples consacrés à «Keumfucu, le maître de la philosophie morale des Chinois qui n'est pas seulement respecté comme un philosophe mais vénéré comme un saint $\gg 2$.

Des faits allégués par Hurtado, Pascal extrait d'abord une formule générale : « [Les Jésuites dans les Indes et en Chine] ont permis aux Chrestiens l'idolâtrie », ce qui n'est pas une constatation de fait, mais une interprétation des faits allégués et

\footnotetext{
1 Pascal a lu ce livre rapidement. Pour preuve, il commet une erreur de date. Il prend la date de l'extrait notarié du décret pontifical pour la date du décret lui-même. (Cf. Pascal, Fuvres, t. IV,. p. 296).

2 Voici le texte de Hurtado au sujet de Confucius : «In paedicto Regno habent Chinenses quemdam Magistrum in Philosophia morali literatum, qui olim discessit a vita, vocatum Keum-Fucu, qui ob doctrinam, regelas et documenta adeo in toto Regno acceptus est, ut tam Reges, quam omnes alii cujuscumque conditionis et gradus sint, sibi proponant imitandum et sequendum, saltem quoad speculativum, et tanquam sanctum venerantur et laudant, in omnique civitate et villa praefato Magistro templa sunt erecta... ». (Pascal, Fuvres, t. IV, p. 295.
} 


\section{La Chine et la formation de l'esprit philosophique en France}

un jugement sur ces faits ${ }^{1}$. Or, remarquons-le, c'est précisément contre cette interprétation et contre ce jugement que les Jésuites s'inscriront en faux pendant toute la Querelle des Cérémonies chinoises. Pascal appuie ce jugement sur des autorités, comme le faisait Hurtado, et pour preuve il cite les adorations publiques que les Chinois font à l'idole Chacim-choan, et à leur Keum-fucum, sans nous dire ce qu'était ce Keum-fucum que peu de Français connaissaient alors, et qu'en tout cas les lecteurs des petites lettres ignoraient absolument. Et le manque d'indications sur ce Keum-fucum était d'autant plus grave que le voisinage dans le texte, de l'idole Chacim-choan risquait de faire prendre ce personnage énigmatique pour une idole vénérée des Chinois.

p.81 D'ailleurs Pascal passe rapidement sur cette affaire des Cérémonies chinoises. Il se contente de résumer en quelques phrases, mais pleines de sens et dépassant un peu les faits, les arguments d'un adversaire des Jésuites. Cependant, ce court passage de la cinquième Provinciale n'aurait pas de quoi nous arrêter davantage si l'on n'y trouvait le premier texte qui montre I'intérêt que porte Pascal aux choses de la Chine, et qu'il étudiera d'une manière plus approfondie pour son Apologie, comme en témoignent quelques Pensées ${ }^{2}$. Ce texte est important aussi parce que pour la première fois la Querelle des Cérémonies chinoises cesse d'être une querelle entre ordres religieux et qu'elle perd un peu de son caractère théologique en

\footnotetext{
1 Nicole aggrave encore le sens de ce texte en traduisant dans son édition latine par idolatriam ipsam. (Pascal, Fuvres, t. IV, p. 302).

2 Pascal, Pensées, t. III, p. 334.
} 


\section{La Chine et la formation de l'esprit philosophique en France}

se trouvant exposée au public. Elle devient ainsi un des moyens de combat que les jansénistes vont mettre en œuvre pour abattre les Jésuites : elle sera désormais mêlée à toutes les luttes que vont se livrer ces ennemis irréconciliables.

Cependant, chez Pascal, ce n'était encore guère autre chose qu'une allusion perdue au milieu d'autres attaques contre les Jésuites. Mais dès ce moment, les procédés d'évangélisation des Jésuites en Chine deviennent une des pièces du réquisitoire des jansénistes contre les Jésuites : les missions de Chine serviront de preuve de la morale relâchée des Jésuites et d'argument contre elle.

Le livre qui étala avec force détails les procédés des Jésuites en Chine fut le second tome de la Morale pratique des Jésuites qui fut attribué à Arnauld, mais qui est en réalité de l'abbé du Cambout de Pontchâteau. Cette fois, c'est une attaque à fond, où tous les procédés des Jésuites sont exposés avec complaisance et flétris avec virulence.

L'auteur reproche aux Jésuites d'accommoder la doctrine de l'Évangile « à I'humeur et aux coutumes des Chinois ». Ce principe général posé, il en montre les applications particulières en seize chapitres dont chacun expose un crime particulier des Jésuites contre l'Évangile : «Ils dispensent les Chinois de tous les commandemens de l'Église. Ils ne donnent aux femmes ni les onctions du baptême, ni le sacrement de l'Extrême-onction : ils justifient les plus exorbitantes usures comme de trente pour cent, ce que ne font pas les religieux de St-François et de StDominique. Ils font passer les idolâtries des Chinois, comme les 


\section{La Chine et la formation de l'esprit philosophique en France}

sacrifices à Kun-fu-zu et ceux qu'ils offrent à leurs ancêtres pour des cérémonies politiques, et ils permettent aux mandarins de faire des offrandes à l'idole Chin-hoan, en dirigeant leurs intentions à une croix cachée p.82 sous les fleurs de l'autel de l'idole. Ils n'ont point annoncé à la Chine Jésus-Christ pauvre et crucifié. Ils trouvent mauvais que les Dominicains mettent dans leur église, sur l'autel, I'image de Jésus-Christ crucifié, parce que, disent-ils, les Chinois l'ont en horreur $\gg 1$.

Un chapitre particulier est consacré au P. Martini, Jésuite : «Martinius, Jésuite, mandarin de premier ordre. De son faste. Du conseil qu'il donna à un vice-roy de chasser les autres religieux de la Chine ». Et ce chapitre est illustré par une planche hors-texte représentant la «marche » du P. Martini. Dans un paysage qui a la prétention d'être chinois, puisqu'on aperçoit dans le lointain quelques clochetons chinois, le P. Martini, escorté d'une nombreuse troupe de cavaliers, est porté sur une litière ressemblant à un trône. Il porte le chapeau tartare et il est vêtu de soie brochée, un dragon sur la poitrine. Sur son passage s'incline humblement un capucin, vêtu de bure, une corde autour des reins. Le P. Martini regarde le capucin avec dédain, et les porteurs de la litière se moquent franchement de son costume et de son attitude.

Sans qu'il soit besoin d'entrer dans le détail des différents chapitres dans lesquels l'auteur a rangé les divers reproches qu'il fait aux Jésuites de Chine, on voit que c'est une attaque sans merci contre les Jésuites. Il veut montrer, comme il le dit dans sa

\footnotetext{
${ }^{1}$ La morale pratique des Jésuites, t. II. Table des matières.
} 


\section{La Chine et la formation de l'esprit philosophique en France}

préface, «qu'ils sont partout, en Chine aussi bien qu'en France, des docteurs de relâchement », et il ajoute : «Si on examine de près leur conduite en Europe et aux Indes, on les verra toujours les mêmes et on ne sera pas surpris s'ils ont des maximes si relâchées dans la Chine et au Japon où il sont les maistres, puisqu'on a vu l'un d'eux dans la ville de Viane, en Hollande, prescher publiquement dans son Oratoire qu'on avoit beau aller où on voudroit, chez des Prestres ou des Religieux, on n'en trouveroit jamais aucun qui donnast le paradis à si bon marché que les Jésuites $\gg 1$.

Chemin faisant, dans ce livre qui distribue l'injure non seulement à tous les Jésuites du monde mais encore à tous les adversaires des jansénistes, l'auteur fait remarquer que les protestants se montrent peu enthousiastes en faveur des missions étrangères et, généralisant la question, il observe que les protestants en Extrême-Orient, non seulement n'ont pas été les défenseurs du ${ }_{\text {p.83 }}$ christianisme, mais qu'ils se peuvent même ranger parmi leurs pires adversaires : témoin les Hollandais qui, au Japon, ne craignent pas de renier leur religion pour assurer leur prépondérance commerciale.

Contre ces attaques, les Hollandais et les protestants trouvèrent un défenseur âpre, acharné, dans la personne de Jurieu. La partie était belle pour lui, puisque non seulement il pouvait tomber sur les jansénistes, mais parce qu'il pouvait aussi, avec les armes que le pseudo-Arnauld lui fournissait, dauber sur les Jésuites.

\footnotetext{
1 ibid., t. II. Préface, s. p.
} 


\section{La Chine et la formation de l'esprit philosophique en France}

Aussi, ce n'est rien de moins que la danse du scalp qu'il mène autour des Jésuites dans ce livre : L'Esprit de M. Arnauld. Si les protestants, écrit-il, ne font pas mission et ne convertissent pas, cela vaut encore mieux que de faire de mauvais chrétiens comme ceux que font les Jésuites en Chine, des chrétiens de nom qui ne connaissent même pas Jésus crucifié, des chrétiens à qui on tolère d'adorer leur idole Chin-hoan et leur faux dieu, Kun-fù-zù «qui est le Mercure des Chinois et le dieu des sciences $\gg 1$. Mais sur la question de principe, sur le devoir pour les chrétiens de faire mission, Jurieu est très affirmatif : c'est faire injure aux protestants que de les accuser, comme le fait La Morale pratique, de ne pas vouloir prêcher dans les états des princes infidèles et païens. Et Jurieu repousse de toutes ses forces « l'atroce calomnie » des catholiques et des jansénistes qui voudraient faire croire que la doctrine protestante s'oppose à ce qu'on aille « troubler une fausse religion soutenue par I'autorité du Magistrat et s'élever contre elle »2. Ce n'est donc pas au nom de la tolérance que Jurieu défend les protestants. En réalité, les Jésuites, les jansénistes et Jurieu sont d'accord sur le principe : il faut faire mission. Mais les divergences portent sur les procédés d'évangélisation. Les Jésuites sont seuls de leur opinion, tandis que les protestants et les jansénistes s'accordent à les condamner. Nous sommes loin de Bayle qui, au nom de la tolérance, adjurera l'empereur de Chine d'expulser les Jésuites de ses États.

\footnotetext{
1 Jurieu, L'esprit de Mr. Arnauld, t. II, p. 193.

${ }^{2}$ Id., ibid., t. II, p. 226.
} 


\section{La Chine et la formation de l'esprit philosophique en France}

Pour répondre tant à Jurieu qu'à I'auteur de La Morale Pratique, les Jésuites ne se mirent pas en peine de trouver un théologien éminent, puisque le principe même des missions n'était pas en jeu et qu'il fallait seulement défendre les procédés employés par les Jésuites dans leurs missions, mais ils choisirent un homme habile, et d'ailleurs peu connu, le P. Le Tellier.

p.84 Le P. Le Tellier, à cette époque, n'avait pas encore fait parler de lui. Ce n'était tout au plus qu'un bon humaniste, qu'un bon régent de rhétorique ${ }^{1}$. Plus tard sans doute, il fera grande figure dans le monde, malgré l'ombre discrète dont il aimera toujours à s'envelopper, et il se taillera une grande, mais un peu lourde popularité, même pour ses épaules robustes. On sait du reste de quelle manière Saint-Simon I'habillera 2 . Pour répondre aux jansénistes et à Jurieu, point n'était besoin d'un homme célèbre. Il suffisait d'un homme sachant allier I'habilité à

\footnotetext{
${ }^{1}$ Il a collaboré aux éditions d'auteurs latins ad usum Delphini, collection dans laquelle il a publié un Quinte-Curce. (Cf. Floquet, Bossuet précepteur du Dauphin, p. 240, n. 1 et Sommervogel, Bibliothèque..., t. VII, col. 1912). Un mémoire de d'Aguesseau sur la constitution Unigenitus (collection Adrien Le Paige, cité par A. Le Roy, La France et Rome, p. 269) porte ce jugement sur le P. Le Tellier : «Il avait passé sa vie à régenter des écoliers ou à écrire contre les jansénistes ou contre le séminaire des missions étrangères, croyant pouvoir gouverner l'Église de France comme une classe du collège de Clermont, et par malheur pour cette église, assez hardi et assez heureux pour y réussir. » A la suite de sa Défense des nouveaux chrétiens de la Chine, il semble devenir le défenseur attitré de son ordre et il le défendra aussi dans l'affaire du péché philosophique.

2 Non seulement dans ses Mémoires, mais aussi dans l'opuscule Les Confesseurs du Roy : le P. Tellier. Écrits inédits, t. II. D'ailleurs ce portrait, si virulent qu'il soit, n'atteint pas à la violence du portrait tracé par l'abbé Legendre, Mémoires, p. 274-5, et des histoires scandaleuses que colportaient au XVIII ${ }^{e}$ siècle des manuscrits d'inspiration janséniste. Nous en possédons un, daté de 1765 (Vie du P. Tellier) que la plus élémentaire décence nous empêcherait de citer.
} 


\section{La Chine et la formation de l'esprit philosophique en France}

I'audace, et ces deux qualités, le P. Le Tellier les avait déjà au suprême degré.

Il avait de l'audace et, pour preuve, en tête de son livre, audessus de la gravure liminaire, il inscrit cette devise : «Nous prêchons Jésus crucifié ». Non qu'il eût tort peut-être et en tout cas, il ne nous appartient pas d'en décider ; mais à l'affirmation de Hurtado et de La Morale Pratique, il n'hésitait pas à opposer de la manière la plus visible et la plus frappante, une affirmation contraire, ce qui était une preuve de courage puisqu'il croyait avoir affaire au docteur Arnauld lui-même. Dans sa préface, il indiquait en effet que s'il n'y avait eu que les injures de Jurieu, il aurait pu les mépriser, tandis qu'il ne pouvait laisser passer les affirmations d'Arnauld ${ }^{1}$.

Il combat une à une dans son livre toutes les assertions des jansénistes, et nous ne le suivrons pas dans le détail de cette polémique, mais chemin faisant, il indique ce que sera la tactique des Jésuites dans cette affaire des Cérémonies chinoises qui ne fait que de commencer et à laquelle il prendra une part éminente : «La Chine, dit-il, est un pays fermé aux étrangers ; les nations ${ }_{\text {p. } 85}$ catholiques et protestantes n'y vivent pas à côté les unes des autres comme partout ailleurs, et les documents fournis par l'une des parties ne peuvent se contrôler par les documents fournis par l'autre. Au contraire, la Chine est le pays de prédilection et pour ainsi dire la chose des Jésuites : « Et voilà ce qui a rendu les Jésuites de ce pays-là prévaricateurs et idolâtres, plutôt que ceux du Japon, du Tonkin, de la

${ }^{1}$ Le Tellier, Défense des nouveaux chrétiens de la Chine, t. I, p. 25-6. 


\section{La Chine et la formation de l'esprit philosophique en France}

Cochinchine, des Indes, de l'Afrique et de I'Amérique. Ce n'est pas qu'ils soient plus coupables à la Chine ou plus innocens qu'ailleurs, puisque partout ils sont Jésuites. Mais on a cru que ces relations venant ou paraissant venir de la Chine où ils estoient presque seuls de l'Europe, il ne seroit pas aisé d'en faire venir des témoignages non suspects, et qu'au moins il se passeroit assez de temps pour donner lieu à la calomnie de se répandre et de trouver créance auprès de beaucoup de gens $\gg 1$. Retournant alors l'argument supposé de leurs adversaires, les Jésuites demanderont beaucoup de temps et de délais pour faire venir de Chine les documents capables de prouver la vérité de leurs affirmations, et le privilège qu'ils semblent avoir sur les missions de Chine leur sera un prétexte pour jeter la suspicion sur les documents fournis par leurs adversaires.

Le livre du P. Le Tellier, s'il ne fit pas grand bruit dans le public au moment où il parut - car l'affaire des Cérémonies chinoises n'était pas encore arrivée à son point critique - jeta du moins le désarroi dans le camp janséniste et Arnauld se sentit touché. S'il était vrai, comme essayait de le prouver le P. Le Tellier, que les jansénistes s'étaient prévalu faussement dans La Morale pratique d'un document, le Theatro jesuitico qu'ils attribuaient à l'évêque de Malaga, alors que ce document, manifestement, n'était pas de lui, une ombre de suspicion se trouvait jetée sur tous les documents publiés par les adversaires des Jésuites. Aussi Antoine Arnauld vit la nécessité de répondre au livre du P. Le Tellier. Il songea d'abord à le faire sous un titre (La Balance ou

1 Le Tellier, op. cit., t. I, p. 155-7. 


\section{La Chine et la formation de l'esprit philosophique en France}

La juste Balance) qui aurait manifesté son intention défensive ; mais il ne tarda pas à se résoudre à reprendre le titre général de Morale pratique des Jésuites pour bien marquer sa volonté d'attaquer, et non seulement certains Jésuites en particulier, mais l'ordre lui-même et tout entier : « Ce titre [Morale Pratique], dites-vous, a quelque chose de choquant en ce qu'il attaque tout le corps de la Société. Et c'est au contraire ce qu'il a d'avantageux : car on ne feroit rien si on n'attaquait que quelques désordres des particuliers ${ }_{\text {p.86 }}$ de la compagnie. C'est le corps de la Société qui cause présentement une infinité de maux dans I'Église en décriant par ses médisances ce qu'il y a de plus gens de bien, en employant le crédit qu'elle a auprès des puissances séculières, pour $y$ exercer une tyrannie insupportable, en y entretenant un très grand relâchement dans les mœurs, en opprimant le Clergé autant qu'elle peut, en se rendant formidable aux Evêques mêmes et en s'opposant à toute véritable réformation. On ne peut rendre un plus grand service à l'Église que de les faire connaître pour ce qu'ils sont »1. En même temps, il s'efforçait de faire condamner à Rome le livre du P. Le Tellier.

Malgré cela, l'affaire des rites chinois semble s'assoupir en France. Les Jésuites et les Missionnaires se sont accordés. Le P. Tachard et M. Charmot sont partis, ou se disposent à partir, pour signifier aux Jésuites et aux Missionnaires la paix conclue entre le P. de la Chaize et Brisacier. Il va falloir plusieurs années à Antoine Arnauld pour qu'il en arrive, dans son exposé des

${ }^{1}$ A. Arnauld Correspondance. Fuvres complètes, éd. 1775, t. III, p. 229-230. 


\section{La Chine et la formation de l'esprit philosophique en France}

méfaits des Jésuites chez les nations Infidèles, aux affaires de Chine ${ }^{1}$, et il faudra cinq ans avant que la cour de Rome se décide à condamner, avec bien des adoucissements, le livre du P. Le Tellier ${ }^{2}$. Tout semblait pouvoir s'arranger, lorsque la révolution de Siam et l'échec de la France vinrent rallumer la guerre des religieux en Extrême-Orient.

$*$

Aussitôt après la révolution de Siam, les Portugais s'empressèrent de demander avec plus d'insistance le rappel des vicaires apostoliques et l'érection de nouveaux évêchés en Chine relevant de p.87 l'archevêché de Goa et du protectorat portugais. Les Jésuites portugais de leur côté, jaloux de voir les Jésuites français s'introduire à la cour de Pékin et chercher à les supplanter, prétendaient être les seuls de leur société qui eussent le droit d'aller en Chine et ils voulaient tout au moins que les Jésuites français n'y fussent admis que par eux et à condition de leur obéir ${ }^{3}$. Le pape céda aux instances du Portugal

1 C'est seulement au tome VI de la Morale pratique (1692) et dans les suivants (t. VII, 1693 et $t$. VIII, 1695) qu'il s'attaque aux Jésuites missionnaires en Chine.

2 Une note de l'éditeur des Fuvres d'A. Arnauld (Ed. 1775, t. III, p. 459) rapporte un fragment de lettre de du Vaucel à $M$. Codde, du 8 mars 1692, où nous trouvons quelques indications sur la condamnation de ce livre : « Il y eut un grand conflit dans la Congrégation de l'Index qui se tint lundi ( 3 mars) touchant le livre du P. Tellier. Il n'y eut que huit Cardinaux, les autres s'étoient absentés pour n'avoir point à contester et à soutenir thèse contre le Cardinal d'Estrées... Il n'est pas croyable avec quelle chaleur pour ne pas dire avec quel emportement le Cardinal d'Estrées soutint le livre. Il passa à la pluralité qu'on donneroit cinq mois au P. Tellier pour venir à Rome y faire une nouvelle édition avec les corrections qui lui seront prescrites, qui est ce que les Jésuites avoient eux-mêmes offert voyant bien qu'il n'y avoit pas d'autres moyens d'empêcher la prohibition du livre. »

3 A. N., Papiers du P. Léonard, K. 1374 n 16. 


\section{La Chine et la formation de l'esprit philosophique en France}

et le 10 avril 1690, Alexandre VIII, par les bulles Romani Pontificis et Romanus Pontifex, créa les diocèses de Macao, de Nankin et de Pékin qui devaient dépendre de l'archevêché de Goa ${ }^{1}$. La société des Missions étrangères délégua aussitôt à Rome l'abbé Quéméner pour défendre ses intérêts, car la création d'évêchés à la nomination du Portugal risquait de porter atteinte aux privilèges des vicaires apostoliques. Les missionnaires n'obtinrent pas sans doute du nouveau pape Innocent XII, bien qu'il leur fût tout dévoué, la révocation des bulles Romani Pontificis et Romanus Pontifex, mais le pape chargea Maigrot, vicaire apostolique du Fou-Kien de faire une enquête sur les dissentiments qui partageaient les missionnaires des différents ordres en Chine 2, et, fort de cette autorité, Maigrot s'empressa de se servir de cette arme nouvelle contre les Jésuites et contre les Portugais.

Dès que l'archevêque de Goa apprit la création des évêchés nouveaux à la nomination du Portugal « il fit signifier à $M$. Maigrot, docteur de Sorbonne et vicaire apostolique, qui n'estoit pas ami des Jésuites, par le P. Joseph de Montigno, jésuite portugais, qu'il le révoquoit et avoit chargé ledit P. Joseph de faire l'employ de grand vicaire dans sa province. Ce qui chagrina M. Maigrot qui publia 12 jours après un mandement [26 mars 1693] par lequel il condamne les cérémonies chinoises que les

\footnotetext{
${ }^{1}$ Launay, Histoire de la Société des Missions étrangères, t. I, p. 361-2.

${ }^{2}$ Id., ibid., t. I, p. 386-391.
} 


\section{La Chine et la formation de l'esprit philosophique en France}

jésuites permettoient aux nouveaux chrestiens de ce pais là à l'égard de Confucius $\gg 1$.

Ce mandement provoqua immédiatement des troubles dans les communautés du Fou-Kien. Les religieux portugais refusèrent de s'y soumettre parce qu'il venait d'un vicaire apostolique dont ils ne reconnaissaient pas l'autorité. Maigrot renouvela son ordonnance et interdit tous les prêtres qui n'accepteraient pas le mandement. (Deux missionnaires en résidence à Fou-Tchéou ayant refusé d'obéir, se trouvèrent interdits la semaine de Pâques. Les néophytes de ces missionnaires vinrent trouver le vicaire apostolique en le priant de p.88 lever la peine; celui-ci refusa. Irrités de ce refus, les néophytes l'injurièrent, le jetèrent à terre en le rouant de coups ; un dominicain qui voulut venir à son secours partagea son mauvais sort. Maigrot adressa une plainte à Rome en envoyant son mandement au Pape, et il députa M. Charmot, à Rome pour le défendre 2.

Avec le mandement de M. Maigrot, la Querelle des Cérémonies chinoises change de caractère.

En 1687 en effet les Jésuites, non contents de répondre par le livre du P. Le Tellier aux critiques d'Arnauld ou de Jurieu contre leurs procédés d'évangélisation en Chine, ont passé résolument à I'attaque en publiant leur Confucius Sinarum Philosophus, avec une ample préface du P. Couplet sur la religion des Chinois. Désormais, il ne s'agit plus pour les adversaires des Jésuites de discuter si les Jésuites en Chine permettent I'usure à leurs

\footnotetext{
${ }^{1}$ A. N., Papiers du P. Léonard, K. 1374 n 16.

2 Launay, ibid., , t. I, p. 391-392.
} 


\section{La Chine et la formation de l'esprit philosophique en France}

néophytes, ou s'ils sont trop tolérants à l'égard de leurs nouveaux convertis en leur permettant d'assister à des cultes que I'on prétend être superstitieux, il faut maintenant démontrer que ces cultes sont vraiment superstitieux, que les Chinois, depuis la plus haute antiquité n'ont pas cru en un Dieu unique, créateur du monde et providence des hommes. Depuis le Confucius Sinarum Philosophus, l'affaire des Cérémonies chinoises ne peut plus être une simple affaire de discipline ecclésiastique - ce que restera toujours I'affaire des rites du Malabare - , c'est une question historique : les Chinois ont-ils conservé pure depuis la plus haute antiquité la notion d'un Dieu, créateur de toutes choses, auquel il continuent à rapporter leurs adorations ? C'est aussi une question philologique : que signifient les termes chinois Tien et Chang ti, le ciel matériel ou l'Etre suprême ? Questions d'autant plus graves qu'à la même époque Bayle soutenait, au grand scandale des théologiens, qu'il pouvait y avoir des nations athées. Si les adversaires des Jésuites avaient raison dans l'affaire des Cérémonies chinoises n'étayaient-ils pas les théories de Bayle ? Et, d'autre part, si les Chinois, dont I'histoire authentique remonte aux premiers hommes, ont institué peu à peu des cultes superstitieux bien qu'ayant reçu des descendants d'Adam la révélation de l'Etre suprême, comment est-il possible de soutenir désormais avec la majorité des théologiens que c'est la corruption des mœurs qui fait oublier l'idée du créateur pour adorer la créature, puisque le peuple chinois est le peuple le plus moral de l'univers ?

p.89 Il est possible, comme le prétend le P. Léonard que les rivalités entre Missionnaires et Jésuites en Chine, entre vicaires 


\section{La Chine et la formation de l'esprit philosophique en France}

apostoliques et évêques portugais aient été la cause seconde du mandement de M. Maigrot, qu'elles l'aient précipité tout au moins et qu'elles aient contribué à lui donner un caractère de rigueur inflexible, mais la cause première en doit être cherchée dans la publication du P. Couplet qui avait transformé la Querelle des Cérémonies chinoises, en en faisant une question dogmatique et historique. D'ailleurs Arnauld lui-même à la même époque, réformait la méthode de son prédécesseur de la Morale pratique 1 et dans deux nouveaux volumes essayait de démontrer que les cultes chinois étaient superstitieux, alors que ni l'abbé de Pontchâteau, ni lui-même, n'avaient tenté de faire cette démonstration dans les volumes précédents.

Le mandement de Maigrot était une condamnation absolue des Jésuites et de leurs théories. D'une part, il déclarait que les cérémonies du culte des ancêtres et que les honneurs rendus à Confucius étaient des cultes superstitieux, et d'autre part, il concluait à l'athéisme des Chinois. Aussi il ordonnait qu'on se servît à l'avenir pour désigner Dieu du mot chinois, Tien-chu qui, suivant l'usage, signifie le Seigneur $d u$ Ciel, et qu'on n'emploierait plus ceux de Tien, le Ciel, et de Xamti [Chang ti], le Souverain Empereur, parce que « ce que les Chinois entendent par ces deux mots n'est point le Dieu que les Chrestiens adorent ». Il défendait d'exposer dans aucune église un tableau où soient écrits ces mots chinois King-tien, Adorez le Ciel ; il déclarait que l'exposé fait à Alexandre III n'était point conforme à la vérité en plusieurs choses ; il interdisait aux

${ }^{1}$ Arnauld, La morale pratique des Jésuites, t. VI et VII. 


\section{La Chine et la formation de l'esprit philosophique en France}

chrétiens toute fonction et même l'assistance aux sacrifices ou oblations solennelles qu'on a coutume d'offrir deux fois par an à Confucius et aux ancêtres morts ; il louait les Missionnaires qui avaient aboli l'usage des tableaux exposés dans les maisons particulières en l'honneur des morts où l'on écrit « c'est ici le siège d'un tel défunt »; il condamnait comme fausses, téméraires et scandaleuses les propositions avancées par quelques Missionnaires, que la philosophie, dont les Chinois font profession, si on l'entend bien, n'a rien de contraire à la foi chrétienne, que le culte que Confucius a rendu aux esprits est plutôt un culte politique que religieux, que les livres des Chinois renferment une excellente doctrine sur la physique et la morale. Enfin, il recommandait aux Missionnaires de prendre bien garde qu'aucun des p.90 maîtres chrétiens qui lisent et expliquent les livres des Chinois n'inspirent à ceux qui vont les écouter l'athéisme et les diverses superstitions dont ces livres sont remplis $\gg 1$.

Le mandement de Maigrot est du mois de mars 1693 ; il dut arriver en Europe dans le courant de 1694I. Or c'est seulement en 1696 que l'abbé Quéméner le présenta à Innocent XII, accompagné d'une requête pour que le Saint-Siège réglât ce qu'il lui plairait sur cette question ${ }^{2}$. Il semble donc que les supérieurs des Missions étrangères aient hésité à engager la lutte en Europe. Maigrot, en Chine, pouvait ne pas se soucier des contingences et de la politique, mais Tiberge et Brisacier

\footnotetext{
1 Ce mandement de Maigrot a été reproduit in extenso par A. Thomas, Histoire de la Mission de Pékin, p. 166-170.

${ }^{2}$ Launay, op. cit., t. I, p. 390.
} 


\section{La Chine et la formation de l'esprit philosophique en France}

devaient en tenir compte. Or, en 1696, les circonstances leur étaient devenues favorables et ils pouvaient se sentir forts depuis que sur leur conseil, Madame de Maintenon avait fait nommer Mathieu de Noailles à l'archevêché de Paris, à I'insu du P. de la Chaize ${ }^{1}$. Mathieu de Noailles, on le savait, n'aimait pas les Jésuites. D'autre part, il était difficile aux Jésuites de reculer : aussi le P. Le Comte, de la Compagnie de Jésus, venu en Europe au nom de son ordre pour renseigner le pape sur les affaires de Chine, engagea-t-il la lutte immédiatement en publiant son livre Nouveaux Mémoires sur l'état présent de la Chine 2, qui est la réponse des Jésuites au mandement de Maigrot, et qui valut à son auteur la place enviée de confesseur de la duchesse de Bourgogne.

L'épître dédicatoire des Nouveaux Mémoires au roi, sous sa modestie apparente, célèbre en réalité les merveilleux résultats obtenus en Chine par les Jésuites, résultats politiques, puisque les envoyés du roi n'ont pas été reçus suivant la coutume chinoise comme les envoyés d'un prince tributaire mais comme les p.91 représentants d'un égal de l'empereur de Chine, et

\footnotetext{
$1 \mathrm{M}^{\text {me }}$ de Maintenon, dit St Simon « montra au roi des lettres pressantes de MM. Tiberge et Brisacier, supérieurs des Missions étrangères que pour contrecarrer les Jésuites dont le crédit la gênoit elle avoit mis à la mode auprès du roi... Il lui importoit que l'archevêché de Paris ne fût point à eux [aux Jésuites] pour qu'il fût à elle. M. de Noailles lui étoit un bon garant. En un mot elle l'emporta, et $M$. de Châlons fut nommé à son insu et à l'insu du P. de la Chaize. Le camouflet était violent, aussi les Jésuites ne I'ont-ils jamais pardonné ». (Mémoires, t. II, p. 359-360).

2 Le permis d'imprimer de notre exemplaire, signé du P. Provincial, est du 30 mars 1696 (t. II, p. 536), l'achevé d'imprimer est du 7 juillet 1696 (t. II, s. p.). Il y a plusieurs tirages qui portent la date de 1696 et le livre a paru avant le mois de juillet puisque l'abbé du Bos en parle dans une lettre du 25 mai à l'abbé de St Hilaire, tout en avouant ne l'avoir pas vu. (R. H. L., 1907, p. $151)$.
} 


\section{La Chine et la formation de l'esprit philosophique en France}

résultats religieux puisque l'empereur Kang hi a donné à ses peuples l'autorisation d'embrasser le christianisme, ce qu'il aurait fait lui-même aussi « n'étoient les intérêts de la politique et de la sagesse mondaine ». Ce grand résultat «qu'on avoit depuis cent ans inutilement désiré », le P. Le Comte I'attribue évidemment à Louis XIV pour son zèle pour la religion, mais le Jésuite rappelle discrètement aussi ce qu'ont pu faire pour ce succès les prières et les travaux de son ordre ${ }^{1}$. Cet édit de tolérance de l'empereur Kang hi, qui n'est pas un miracle ordinaire, devient la justification des Jésuites en Chine, de ces missionnaires «que I'hérésie, toujours opposée au véritable zèle, accuse si souvent d'ambition, d'avarice, d'impiété et d'idolâtrie »2. Et en même temps, c'est l'indice et la promesse d'un miracle encore plus grand, la conversion prochaine de l'empereur de Chine « dont le changement seroit infailliblement suivi de la conversion entière de l'Empire ». Or seuls les Jésuites pourront obtenir ce résultat car seuls ils vivent dans la familiarité de l'empereur. N'est-ce donc pas pour cela que « I'hérésie » cherche à détruire la mission de Chine?

Mais ce livre n'est pas seulement un essai de justification des Jésuites, justification fournie par les grands progrès de la religion en Chine, c'est aussi un essai d'explication de cette miraculeuse propagation de la foi. Cette explication, le P. Le Comte la trouve dans la nature particulière de la religion chinoise. Cette religion semble en effet avoir conservé intactes et pures au cours des

\footnotetext{
1 Le Comte, Nouveaux Mémoires sur l'état présent de la Chine. Lettre liminaire, s. p.

${ }^{2}$ Id., ibid., t. II, p. 369.
} 


\section{La Chine et la formation de l'esprit philosophique en France}

âges les premières vérités révélées par Dieu aux premiers hommes. «La Chine, plus heureuse dans ses commencements que nul autre peuple du monde a puisé presque dans la source les saintes et les premières vérités de son ancienne religion ${ }^{1}$. Les premiers empereurs bâtirent des temples à Dieu, et « ce n'est pas une petite gloire à la Chine d'avoir sacrifié au Créateur dans le plus ancien temple de l'Univers »2. La piété primitive se conserva dans le peuple grâce aux empereurs qui prirent soin de I'entretenir, si bien que l'idolâtrie n'arriva pas à se glisser en Chine. «Avant les superstitions dont l'impiété du dieu Fo infecta la Chine, on n'avoit jamais vu d'idoles ou de statues parmi le peuple $\gg 3$, « de sorte ${ }_{\text {p.92 }}$ que ce peuple a conservé près de deux mille ans la connaissance du véritable Dieu, et l'a honoré d'une manière qui peut servir d'exemple et d'instructions mesme aux Chrétiens $\gg 4$. La religion chinoise a ce privilège unique de nous montrer ce que pouvait être la vie humaine à ces âges fortunés où régnaient à la Chine « la paix, la bonne foy et la justice »5, et, en même temps elle nous explique la facilité que les Jésuites éprouvent à convertir en Chine. Les Chinois ne font en somme que retrouver dans le christianisme, mais avec plus de clarté et d'évidence, cette religion primitive dont le souvenir n'est pas entièrement oublié chez eux malgré les progrès qu'ont faits par

\footnotetext{
${ }^{1}$ Le Comte, Nouveaux Mémoires sur l'état présent de la Chine, t. II, p. 133.

2 Id., ibid., t. II, p. 135.

3 Id., ibid., t. II, p. 136.

${ }^{4}$ Id., ibid., t. II, p. 141.

${ }^{5}$ Id., ibid., t. II, p. 141.
} 


\section{La Chine et la formation de l'esprit philosophique en France}

la suite l'idolâtrie et l'athéisme. Le vrai moyen de convertir les Chinois - si cela peut s'appeler une conversion - est donc de leur dessiller les yeux en leur montrant les concordances de principes entre l'ancienne religion chinoise et le christianisme. Les Chinois seront d'autant plus disposés à embrasser la religion chrétienne qu'ils verront qu'elle ne s'oppose pas à leurs traditions et à leur histoire, mais qu'elle n'est au contraire que l'expression de leur histoire et de leurs traditions. En somme cette apologie de la religion chinoise du P. Le Comte est surtout l'apologie des Jésuites et de leurs méthodes en Chine.

\section{$*$}

En 1696, les deux partis opposés, Jésuites et Missionnaires, ont donc fixé, sans atténuation ni faux-fuyants, et par suite sans qu'un compromis semble être possible entre eux désormais, leur attitude et leur doctrine dans la question de la religion et, des rites chinois. Il reste à expliquer pourquoi chacun des deux partis va essayer de faire prévaloir sa doctrine, en s'efforçant de détruire le camp adverse.

Depuis quelque temps, MM. Tiberge et Brisacier avaient une influence à la Cour et cette influence ne faisait que grandir à mesure que s'étendait le pouvoir occulte de Mme de Maintenon. S'ils n'étaient ni l'un ni l'autre confesseurs de la marquise, ni même ses directeurs de conscience, elle les considérait cependant comme des conseillers officieux qu'elle avait chargés de rédiger une partie des règlements de Saint-Cyr ${ }^{1}$, parfois même comme ${ }_{\text {p.93 }}$ des conseillers spirituels, puisqu'elle s'adressa

\footnotetext{
${ }^{1}$ Haussonville ( $d^{\prime}$ ) et Hanotaux, Souvenirs sur Mme de Maintenon, t. I, p. 244.
} 


\section{La Chine et la formation de l'esprit philosophique en France}

à eux en juin 1697, en même temps qu'à Bossuet, à Gaston de Noailles, à Tronson et à Bourdaloue pour avoir une consultation sur le quiétisme. Elle les appelle « ses chers amis »; et elle déclare en parlant d'eux : «Si j'avais eu quelque chose de meilleur, je $m^{\prime} y$ serois adressée »1. Tiberge lui servait d'intermédiaire pour sa correspondance avec l'archevêque de Paris, « voie bonne, dit-elle à l'archevêque, afin de cacher la moitié de notre commerce $\gg 2$.

Tiberge et Brisacier, nous l'avons vu, lui avaient suggéré de faire nommer à l'archevêché de Paris Mathieu de Noailles qui n'était pas ami des Jésuites, non seulement parce qu'on le croyait teinté de jansénisme, mais parce que, dans son diocèse de Châlons, il n'avait pas craint de heurter les Jésuites en fondant un petit séminaire pour faire concurrence au collège des Jésuites ${ }^{3}$. Une fois nommé à Paris, Mathieu de Noailles, toujours avec l'appui de $M^{\text {me }}$ de Maintenon, fit nommer son frère à Châlons pour lui succéder, et nous le voyons en train, la même année, encore avec le concours de $\mathrm{M}^{\mathrm{me}}$ de Maintenon de « faire de bons évêques », comme elle le dit elle-même, c'est-à-dire des évêques opposés aux Jésuites, ce qui devait faire plaisir à Mgr l'évêque de Chartres, confesseur de la marquise, et « faire passer tout le reste $\gg{ }^{4}$. Il semble donc que cette fois le $P$. Léonard ne s'est pas trompé en écrivant à la date de 1695 :

1 Geffroy, Madame de Maintenon d'après sa correspondance authentique, t. I, p. 289.

2 Id., ibid., t. I, p. 278.

3 Le Roy, La France et Rome de 1700 à 1715, p. 19.

4 Lettre du 27 décembre 1695, in Geffroy, op. cit., t. I, p. 261-2. 


\section{La Chine et la formation de l'esprit philosophique en France}

« Les Jésuites ont de la jalousie de ce que MM. des Missions étrangères ont pris du crédit à la cour. Ils se sont rendus maistres de l'esprit de $M^{\text {me }}$ la Marquise de Maintenon. Par ce moyen, le Roy nomme beaucoup de ces Messieurs ou de ceux qui s'y sont retirez [au Séminaire des Missions étrangères] aux eveschez et autres bénéfices, ce qui donne lieu de dire que MM. Brisacier et Tiberge sont maistres de plusieurs evesques de France. Ce qui ne plaist pas aux Jésuites $\gg 1$.

Sur ces entrefaites on cherche (août 1696) un confesseur pour la jeune duchesse de Bourgogne. Il est d'usage de prendre ce confesseur dans la Compagnie de Jésus. $M^{\text {me }}$ de Maintenon n'ignore pas cette règle et elle n'essaye pas de la faire fléchir. Mais elle demande au roi de consulter à ce sujet l'archevêque de Paris « qui p.94 estime fort certains sujets de la compagnie ». «Informez-vous de quelque chose de bon et je le demanderai », répondit le roi ${ }^{2}$. C'est le P. Le Comte qui fut nommé, celui-là même que les Jésuites avaient envoyé de Chine en France et à Rome pour les défendre contre les vicaires apostoliques, l'auteur des Nouveaux Mémoires sur l'état présent de la Chine. Il est permis de penser que le $\mathrm{P}$. Le Comte ne fut pas I'homme de $\mathrm{M}^{\text {me }}$ de Maintenon ni des directeurs du Séminaire des Missions étrangères. Ce fut un succès incontestable pour les Jésuites, mais ils allaient bientôt le payer cher.

A partir de 1697, le cercle d'ennemis se resserre autour des Jésuites et les attaques contre eux redoublent de violence. Cette

\footnotetext{
${ }^{1}$ A. N., Papiers du P. Léonard. K. 1374, n. 11, v.

2 Geffroy, op. cit., t. I, p. 274.
} 


\section{La Chine et la formation de l'esprit philosophique en France}

lutte est menée par ces trois hommes qui forment, suivant l'expression de d'Aguesseau, le triumvirat, c'est-à-dire Bossuet, Mathieu de Noailles et Le Tellier, archevêque de Reims, celui-ci étant remplacé dans certains cas par Godet Desmarais, évêque de Chartres. Bossuet, qui était l'âme de ce triumvirat ne se faisait pas trop d'illusions sur la fermeté de ses alliés et il savait qu'il était nécessaire parfois de les pousser ${ }^{1}$. Il les poussa assez énergiquement pour obtenir avec eux et, est partie grâce à eux, la condamnation des Jésuites à I'Assemblée du clergé de 1700.

Une première affaire qui donna lieu à Bossuet de marquer son hostilité aux Jésuites fut la théorie du péché philosophique du Jésuite Musnier, condamnée sans doute par le pape Alexandre VII le 24 août 1690, mais reprise ensuite par le Cardinal Sfondrati dans son livre Nodus prædestinationis dissolutus, et qu'une lettre de cinq évêques, à la tête desquels se trouvaient l'archevêque de Reims et Bossuet, dénonça au pape le 23 février 1697.

D'après la théorie du Jésuite Musnier, un péché philosophique commis sans aucune connaissance de Dieu, ou sans aucune attention à lui n'est point une offense à Dieu ni un péché mortel. Dans leur lettre au pape du 23 février 1697, les cinq évêques signalaient les conclusions dangereuses que l'on pouvait tirer de ces principes et que le cardinal Sfondrati semblait avoir adoptées dans I'ouvrage que I'on incriminait. Les enfants non baptisés qui n'ont pas connu Dieu ne peuvent pécher et par suite ne peuvent être condamnés. Les nations infidèles, à qui Dieu n'a pas été

1 Bossuet, Correspondance, t. VIII, p. 267. 


\section{La Chine et la formation de l'esprit philosophique en France}

prêché ne peuvent être condamnées aux peines éternelles pour avoir transgressé les p.95 préceptes de la droite raison. Et cette lettre s'efforce de préciser que c'est en faveur des Chinois que cette théorie peu orthodoxe a été édifiée : « Hæc nempe ad Sinenses solatia deferebant, quibus excæcatæ gentis ac de parentum suorum sapientia immensum gloriantis superbiam demulcerent. Horum ergo gratia quaerebatur : An infideles præcepta naturalia transgredientes pœnas æternas mereantur ; et negabant aliqui, quia ignorantia Dei et legislatoris a tam gravi pœna excusantur. Sic enim blandiedatur Sinensibus $\gg 1$.

Ainsi la Querelle des Cérémonies chinoises se complique : ce ne sont plus les méthodes d'évangélisation des Jésuites, ce n'est pas non plus leur morale relâchée que Bossuet attaque ici, c'est une question de théologie, toujours débattue et toujours résolue diversement dans l'école, qu'il demande au pape de résoudre : la question du salut des infidèles 2. Les Japonais, dit-on, demandaient à Saint François-Xavier pourquoi ils recevaient l'Évangile les derniers de toutes les nations, et quel devait être le sort de leurs ancêtres morts sans avoir connu le christianisme. En Chine, où le respect des ancêtres et le culte des morts sont à la base de toutes les préoccupations morales, de semblables questions étaient faites aux missionnaires. Les Païens qui se conduisent avec une certaine honnêteté seront-ils punis d'une peine éternelle ? Et les Jésuites répondaient : non, car ils ne voulaient ni ne pouvaient damner Confucius, ce qui eût suffi à

\footnotetext{
${ }^{1}$ Id., ibid., t. VIII, p. 165.

2 Capéran, Le problème du salut des Infidèles.
} 


\section{La Chine et la formation de l'esprit philosophique en France}

les faire chasser de Chine. Les Infidèles qui ignorent l'existence de Dieu méritent-ils l'enfer en violant la loi naturelle? demandait-on encore. Et les Jésuites de répondre encore : non. C'est contre ces concessions doctrinales que le P. Navarrete avait déjà protesté à Rome en 1674. Mais le Saint-Siège, tout en affirmant sa désapprobation de ces concessions faites par les Jésuites ne les avait pas condamnées par un décret solennel et public. La lettre des cinq évêques n'eut pas un meilleur sort : le pape répondit d'une manière évasive. Bossuet, que ses démêlés avec Fénelon au sujet du quiétisme occupent à partir de ce moment, n'insiste pas et c'est par la Sorbonne qu'il fera juger ensuite, la question du quiétisme une fois réglée, ce point de doctrine. Mais pendant l'affaire du quiétisme il ne laisse pas de se faire tenir au courant de ce qui se fait à Rome sur l'affaire des Cérémonies chinoises, par son neveu l'abbé Bossuet, ou par le P. de Lantenay, par le P. Roslet, I'agent de I'archevêque de Paris ou encore par ${ }_{\text {p.96 }} \mathrm{M}$. Charmot, procureur des Missions étrangères ${ }^{1}$. Les partis d'ailleurs étaient liés de telle manière que Charmot travaillait en même temps pour Bossuet contre Fénelon ; et, après la condamnation de Fénelon, l'abbé Bossuet décernait à $M$. Charmot un satisfecit 2 .

Entre le 19 mars 1697, date à laquelle M. Charmot remet son premier mémoire à la Sacrée Congrégation du Saint-Office et le 16 avril 1699, jour où se réunit pour la première fois la congrégation chargée d'examiner les affaires de la Chine,

\footnotetext{
${ }^{1}$ Bossuet, Correspondance, t. VIII, p. 383 ; t. XII, p. 395-7.

${ }^{2}$ Id., ibid., t. XI, p. 240.
} 


\section{La Chine et la formation de l'esprit philosophique en France}

I'affaire se poursuit à Rome par de nombreux mémoires que I'on s'assène de part et d'autre, mais l'intérêt n'est pas là : il se porte uniquement sur le différend entre Bossuet et Fénelon. Cependant les Jésuites ne sont pas quitte pour cela de toute critique ; on note au contraire avec grand soin les sympathies qu'ils peuvent avoir pour l'archevêque de Cambrai ${ }^{1}$ et $M^{\text {me }}$ de Maintenon dénonce au roi I'admiration du P. Le Comte pour Fénelon et l'indifférence des Jésuites à l'égard du quiétisme 2. Quant à Brisacier, il prend nettement parti contre Fénelon. Il lui fait part à lui-même de ses scrupules et de ses doutes sur les Maximes des Saints ${ }^{3}$ et il le morigène d'un ton acerbe pour avoir écrit les Lettres contre MM. de Paris et de Meaux ${ }^{4}$.

Aussitôt l'affaire du quiétisme terminée, la question des rites chinois réapparaît au premier plan 5 . Charmot, au nom des missions étrangères, presse le pape d'examiner l'affaire sans délai. Il sait qu'Innocent XII est favorable à sa cause, et la santé chancelante du pape lui fait craindre que la succession au trône pontifical ne soit ouverte à bref délai. Et en sous-main, son parti

1 Id., ibid., t. VIII, p. 207.

2 Lettre de Madame de Maintenon à l'archevêque de Paris (17 août 1697) : « J'ai parlé au roi de I'admiration du P. Le Comte pour M. de Cambrai, et du scandale que me donnent les jésuites sur la froideur qu'ils ont pour le quiétisme. On m'a écoutée avec attention, et I'on n'a rien répondu. » Correspondance générale, t. IV, p. 177.

3 Lettre de Brisacier à Fénelon (28 février 1697). Fénelon, Correspondance, t. VII, p. 379-383.

${ }^{4}$ Lettre de Brisacier à Fénelon. Fénelon, Correspondance, t. IX, p. 22.

5 Le bref de condamnation de Fénelon est du 12 mars 1699. La première réunion de la Congrégation du Saint-Office pour les affaires de la Chine est du 16 avril 1699. 


\section{La Chine et la formation de l'esprit philosophique en France}

fait valoir la faveur dont jouissent en France les supérieurs des Missions étrangères ${ }^{1}$. Mais, grand sujet de crainte, Charmot apprend que le p.97 roi semble décidé à soutenir les Jésuites. L'ambassadeur l'avertit en effet, le 17 juillet 1699 que le P. de la Chaize lui a écrit de la part du roi pour lui ordonner de donner sa protection aux Jésuites, et qu'il en devait parler au pape. Charmot le devance et va trouver le pape « qui promit de ne répondre qu'en termes généraux, ce qu'il fit $\gg 2$. A quelques jours de là, nouvelle alerte. Le cardinal de Bouillon, I'ami des Jésuites, a reçu l'ordre du roi de parler en faveur des Jésuites, tant auprès du pape que des cardinaux, et il s'empresse de plaider la cause des Jésuites à la Congrégation du Saint-Office. Mais le même jour Charmot apprend avec plaisir que I'ambassadeur a reçu un ordre direct du roi, lui enjoignant de défendre la religion et la mission de la Chine. Mais, ajoutait la lettre du roi « comme j'ai appris que leur affaire [celle des Jésuites] ne regarde que le dogme de la Chine, je ne veux pas que mon nom paraisse en ces sortes d'affaires qui regardent purement le Saint-Siège $\gg 3$.

Tandis que la tactique des Missionnaires est de presser le Saint-Siège, les Jésuites, soit qu'ils cherchent à retarder le plus

\footnotetext{
${ }^{1}$ Charmot, Mémoires. B. N. Fr. 25060, f. 237, et Lettre au cardinal de Noailles du 20 juillet 1699, avec P. S. du 21 juillet, B. N. Latin 16981, f. 153-4.

2 Lettre de l'abbé de Chantérac à Fénelon (25 avril 1699) : «L'on fait sonner fort haut la faveur et la protection de MM. les supérieurs des missions étrangères et l'on assure qu'elle est fortement déclarée contre les jésuites. » Fénelon, Correspondance, t. X, p. 539.

3 Charmot, Mémoires, B. N. Fr. 25060, t. 2372. Cf. Recueil des Instructions données aux ambassadeurs de France à Rome, t. II, p. 215, qui confirme ces indications.
} 


\section{La Chine et la formation de l'esprit philosophique en France}

possible une condamnation qu'ils sentent inévitable, soit qu'ils spéculent sur la mauvaise santé d'Innocent XII qui ne leur est pas favorable, demandent des délais. Ils font remarquer au pape qu'ils ont écrit en Chine pour avoir des éclaircissements : ils ont, en effet, adressé en 1697 un placet à l'empereur Kang hi luimême pour lui demander son avis sur les termes qui peuvent servir en chinois à désigner Dieu. Leurs amis et le cardinal de Bouillon font courir le bruit que l'affaire ne peut se décider à Rome et qu'il faudrait convoquer un concile en Chine. Ils mettent en branle toute sorte d'influences, le cardinal d'Estrées, le roi de Portugal et le nonce à Paris, pour obtenir ce délai que demande en leur nom le cardinal de Bouillon, chef de la Congrégation du Saint-Office ${ }^{1}$.

L'état de santé du pape s'aggrave à la fin de 1699. Au mois de janvier 1700 , le roi hâte le départ pour Rome des cardinaux d'Estrées, de Janson, de Coislin. La situation devient critique pour Tiberge et Brisacier. MM. des Missions étrangères sentent que leur p.98 « coup de la Chine », comme dit le P. Léonard 2 va être manqué s'ils ne pressent un peu les lenteurs du Saint-Office en lui forçant la main par un coup d'éclat ${ }^{3}$. Aussi ils jettent le gant aux Jésuites en publiant la Lettre de Messieurs des missions

\footnotetext{
1 Charmot, Mémoires, B. N. Fr. 25060, f. 2472.

2 Note du P. Léonard. « MM. des Missions étrangères à Paris furent bien surpris quand ils apprirent l'élection du cardinal Albani à la papauté sous le nom de Clément onze, croyant qu'il ne favoriseroit pas leur coup de la Chine contre les jésuites, ainsy que sembloit le promettre Innocent 12 , ils en sont consternez. » Papiers du P. Léonard. A. N. K. 1374, nº 17.

3 Ils y étaient poussés par Charmot qui de Rome écrivait au cardinal de Noailles pour lui demander d'obtenir de la Sorbonne un jugement doctrinal, sans quoi I'affaire courait grand risque à Rome. B. N. Latin 16981, f. 146-7.
} 


\section{La Chine \\ et la formation de l'esprit philosophique en France}

étrangères au Pape sur les idolâtries et les superstitions chinoises, et ils défèrent à la Faculté de Paris les Nouveaux Mémoires sur l'état présent de la Chine du P. Le Comte, I'Histoire de l'Edit de l'Empereur de la Chine du P. Le Gobien et la Lettre au duc du Maine sur les cérémonies de la Chine du P. Le Comte. De ces ouvrages, ils tirent six propositions qui leur paraissent particulièrement dangereuses et qu'ils demandent à la Sorbonne de condamner :

$1^{\circ}$ La Chine a conservé pendant plus de deux mille ans avant la naissance de J. C. la connaissance du vrai Dieu ; $2^{\circ}$ Elle a eu I'honneur de lui sacrifier dans le plus ancien temple de l'univers ; $3^{\circ}$ Elle l'a honoré d'une manière qui peut servir d'exemple même aux chrétiens ; 4 Elle a pratiqué une morale aussi pure que la religion ; $5^{\circ}$ Elle a eu la foi, I'humilité, le culte intérieur et extérieur, le Sacerdoce, les Sacrifices, la Sainteté, les miracles, I'esprit de Dieu et la plus pure charité, qui est le caractère et la perfection de la véritable religion; $6^{\circ}$ De toutes les nations du monde, la Chine a été la plus constamment favorisée des grâces de Dieu.

En même temps, les supérieurs des Missions étrangères adressaient à tous les députés de l'assemblée du clergé un exemplaire de tous les écrits qu'ils avaient rédigés pour la 


\section{La Chine et la formation de l'esprit philosophique en France}

Sorbonne ou pour le Saint-Office, sur la question des Cérémonies chinoises ${ }^{1}$.

Les supérieurs des Missions étrangères faisaient donc flèche de tout bois pour essayer d'abattre les Jésuites. A Rome aussi bien qu'à Paris devant le pape non moins que devant la Sorbonne ou devant le clergé de France, ils essayaient de convaincre les Jésuites ${ }_{\text {p.99 }}$ d'avoir toléré en Chine l'idolâtrie. Et les Jésuites n'ignoraient pas que leurs véritables adversaires ceux qui tenaient toutes les ficelles - étaient plus haut placés que Tiberge et Brisacier et partant plus difficiles à atteindre. Le P. du Halde écrivait, en effet, quelques années plus tard dans sa Description de la Chine : "Ce fut alors comme une ligue générale d'un parti puissant et animé qui mit tout en œuvre pour jeter leur compagnie [les Jésuites] dans un décri universel. On sçait l'orage qui s'éleva contre elle en France en l'année mil sept cens, tandis qu'on agissoit fortement à Rome. On a sçu par les lettres des chefs de ce Parti que leurs conseils régloient la conduite de M. Charmot ; qu'ils I'aidoient à dresser les écrits soit italiens ou latins qu'il présentoit au Saint-Office ; qu'ils prirent même l'alarme, sur ce que les Supérieurs du Séminaire de Paris ne le soutenoient pas et songeoient à le rappeler ; qu'ils employèrent leur crédit et celui de leurs amis auprès de Madame la Marquise de $* * *$ et de trois autres personnes de confiance et

1 « Les supérieurs des missions étrangères entreprennent la mission jésuitique devant ce tribunal (I'Assemblée du clergé) : ils font à St Germain les mêmes plaintes qu'ils ont faites à Rome : ils demandent justice aux juges naturels de la foi gallicane contre l'impureté et l'abomination du nouveau culte chinois et ils ont donné à chaque député un exemplaire des écrits qu'ils ont faits et présentés à la Congrégation du St Office pour soutenir et justifier leurs accusations. (L'Esprit des cours de l'Europe, juillet 1700, p. 11-2). 


\section{La Chine et la formation de l'esprit philosophique en France}

d'autorité bien capables de mettre le cour au ventre de ces supérieurs, car c'est ainsi qu'ils s'exprimaient, et de les porter à intervenir dans cette cause $\gg 1$. Comme on le voit, plus encore qu'à Tiberge et à Brisacier, qui n'étaient que des instruments, c'est à Madame de Maintenon et au «triumvirat » que les Jésuites en voulurent de toutes les tribulations qu'ils éprouvèrent dans I'affaire des Cérémonies chinoises. D'ailleurs le témoignage de l'abbé Le Dieu confirme les insinuations du P. du Halde. Suivant ce témoin qui a toutes les raisons d'être bien informé, le plan de campagne était fait avant la réunion de l'assemblée du clergé entre I'archevêque de Paris, I'archevêque de Reims et Bossuet, mais « dans un grand secret ». A l'assemblée du clergé qui devait examiner et condamner la morale relâchée des Jésuites, les trois prélats déclaraient hautement « pour ne pas l'effaroucher » qu'ils ne toucheraient ni à Sfondrati ni à la Chine, mais ils insinuaient dans les propositions qu'ils voulaient faire censurer par cette assemblée, quelques propositions extraites d'un livre du Cardinal Gabrielli avec approbatur de Sfondrati 2. Et pour la doctrine de la Chine, ils en destinaient le p.100 jugement à

${ }^{1}$ Du Halde, Description de la Chine, t. III, p. 119.

2 Ces propositions insidieuses furent cependant écartées par l'assemblée mise en éveil ou par les propos inconsidérés de l'archevêque de Reims qui ne pouvait plus se maîtriser depuis que la condamnation des Jésuites paraissait certaine, ou par les Jésuites qui veillaient attentivement à l'affaire de la Chine : « D'autres propositions, 139, 140, sur le culte des anciens philosophes que I'on assure avoir connu Dieu et ne l'avoir pas offensé en immolant un coq à Esculape ont été aussi retranchées parce qu'elles sont du cardinal Gabrielli dans son livre anonyme intitulé : Dispunctio notarum quadringinta. M. de Reims s'étant vanté du plaisir qu'il aurait de condamner un cardinal, ce qui fut rapporté au roi même, a fait insister les évêques pour ôter ces deux propositions dont les évêques disoient que la condamnation retomberoit sur Confucius et sur le culte de la Chine ». (Le Dieu, Journal, t. II, p. 92). 


\section{La Chine et la formation de l'esprit philosophique en France}

la Faculté ${ }^{1}$. A cet égard, les dernières résolutions furent prises dans une réunion qui se tint chez Bossuet à Versailles, le 17 mai - bien que Bossuet eût en main les écrits de Tiberge et de Brisacier depuis le 16 avril - et à laquelle assistaient, outre le triumvirat, les deux supérieurs des Missions étrangères. Ceux-ci communiquèrent à ces prélats leur écrit, et l'on discuta pour savoir « s'ils devoient aussi en faire part au roi pour lui en faire agréer l'impression, ou l'imprimer secrètement sans lui en parler. L'avis des prélats fut qu'il le falloit imprimer sans en parler au roi, qui pourroit arrêter l'écrit ou ordonner qu'on le communiquât au P. de la Chaize, ce qui feroit perdre cette affaire et la cause de l'Église. Par l'événement on a très bien fait : l'écrit se répand dans le public et y est très bien reçu. Chacun y est convaincu et des idolâtries de la Chine et de la fripponnerie des Jésuites » 2 .

L'affaire des Cérémonies chinoises vint devant la Sorbonne pour la première fois le $1^{\text {er }}$ juillet 1700 . Pour juger des discussions qui eurent lieu devant la faculté de théologie nous ne manquons pas de documents, puisque les Jésuites et leurs adversaires en ont tenu journal, mais ces documents, est-il besoin de le dire ? nous sont également suspects, et c'est un grand service que nous a rendu M. Gazier en publiant le Journal d'un docteur de Sorbonne [Noël Varet] (1697-1700) 3, qui a d'autant plus de valeur que ce docteur n'écrit pas pour la postérité, mais qu'il note ses impressions personnelles au jour le

\footnotetext{
${ }^{1}$ Le Dieu, Journal, note du 4 juin 1700, t. II, p. 68.

2 Le Dieu, Journal, t. II, p. 48.

3 Journal d'un Docteur de Sorbonne, p. p. Gazier, Bulletin philologique et historique jusqu'à 1715, 1916.
} 


\section{La Chine et la formation de l'esprit philosophique en France}

jour, en essayant de tenir la balance égale entre les deux partis, et qu'il ne se dissimule pas la difficulté de sa tâche : il n'ignore pas, en effet, que des motifs secrets, le plus souvent des motifs d'intérêt personnel, peuvent faire agir les hommes en apparence les plus sincères.

Le $1^{\text {er }}$ juillet, M. Priou « homme qui demeure aux missions étrangères et qui est un diminutif des abbés Tiberge et Brisacier »1, dépose sur le bureau de la faculté quelques livres qui lui paraissent dignes d'être examinés. C'étaient les livres du P. Le Comte et du P. Le Gobien. Quelques docteurs objectèrent que l'affaire était déjà p.101 devant le pape. Néanmoins à la pluralité des voix, la Faculté décida de nommer des députés pour examiner les propositions incriminées. Et notre docteur observe : «On peut remarquer ici ce que peut la cabale. Il y a six ans que si quelqu'un avoit voulu proposer quelque chose de semblable, il auroit eu une lettre de cachet.

«Les temps sont changés, il faut que la foi change. Ce n'est plus la foi des Jésuites qui règne, c'est la foi des missions étrangères.

« Il en est de même de toute chose et en tout temps ; car il ne faut pas s'imaginer que c'est l'amour de la vérité qui fait agir, c'est la passion dominante de ceux qui sont en faveur.

«Quand un prince est de la religion de son pays, ce sont toujours les articles qui plaisent au prince qui sont les meilleurs et les plus saints. Cela n'empêche pas que parmi ces articles il

\footnotetext{
1 Journal d'un Docteur de Sorbonne, p. 45. Il agissait d'ailleurs en vertu des ordres du cardinal de Noailles. (Le Dieu, Journal, t. II, p. 68).
} 


\section{La Chine et la formation de l'esprit philosophique en France}

n'y en ait véritablement de saints, mais ce n'est pas cela qui les fait recevoir, c'est l'agrément du prince. Si le roi n'avoit pas été choqué contre Monsieur de Fénelon, jamais sa mystiquerie n'auroit été mauvaise $\gg 1$.

Voilà un docteur qui n'a plus guère d'illusions et ne se paie pas de mots. Il ne croit plus au pouvoir de persuasion de la vérité par elle-même et pour elle-même : c'est le prince qui détermine la vérité et l'impose. Ce témoignage est grave. Il nous aide à mieux comprendre les réflexions de La Bruyère sur la dévotion des courtisans 2 et il marque en même temps I'influence qu'ont pu exercer au début du XVII siècle les querelles théologiques sur l'affaiblissement de la foi, en ruinant la notion d'autorité spirituelle et par là le dogme lui-même.

Ce témoignage est important aussi parce qu'il constate ce pouvoir des Missions étrangères qui ont réussi à supplanter les Jésuites grâce à la faveur de Madame de Maintenon et qui entendent en profiter. Pour un temps la lutte n'est plus tant entre les jansénistes et les Jésuites, elle est entre les Missions étrangères et les Jésuites. La Querelle des Cérémonies chinoises est la grande affaire où les deux partis vont jeter toutes leurs forces pour essayer de se détruire l'un l'autre.

La commission qui avait été nommée par la faculté pour examiner les livres incriminés se réunit et décida qu'il y avait lieu d'en discuter. Les partisans des Jésuites protestèrent, faisant remarquer que la question était déjà déférée au pape et qu'il

\footnotetext{
1 Journal d'un Docteur de Sorbonne, p. 46.

${ }^{2}$ La Bruyère, Les Caractères. De la mode, éd. Servais, t. II, p. 152.
} 


\section{La Chine et la formation de l'esprit philosophique en France}

fallait attendre son jugement. La faculté passa outre et l'abbé Boileau lut son rapport. Cet abbé Boileau était le frère de Despréaux. «On a de lui, p.102 dit l'abbé Legendre, quantité de petits traités sur des matières singulières, en latin extraordinaire, affectant de ne se servir que des termes les moins usités et que de mots grecs latinisés. Son Historia Flagellantium où il déclame contre l'usage des disciplines volontaires fit beaucoup crier contre lui ceux même qui auraient voulu qu'on eût aboli cet usage. C'était un petit homme tout de feu »1. Le récit de notre docteur donne des preuves de l'ardeur de I'abbé Boileau : « il dit... que les députés et lui s'étaient assemblés plusieurs fois, qu'ils avaient lu, examiné avec une très grande application les propositions et les livres ; qu'ils avaient eu de I'horreur de voir jusque où l'esprit de I'homme pouvait porter I'irréligion. Il dit tout cela avec des termes de poète, c'est-à-dire très emportés et faisant de temps en temps des goguenarderies indignes de la Faculté; on pourrait dire des turlupinades et bouffonneries. Il lut les propositions des Jésuites et faisait en les lisant des contorsions qui marquaient très bouffonnement et d'une manière intéressée l'indignation où il était $\gg 2$. Voltaire n'en a pas dit autant dans le récit qu'il a fait de ces assemblées de la faculté. Le libelle des Jésuites dont il s'inspire, Journal des assemblées tenues en Sorbonne, malgré I'intention évidente de ridiculiser Boileau et ses partisans, était tenu, à cause du public

\footnotetext{
1 Legendre. Mémoires, p. 278.

2 Journal d'un Docteur de Sorbonne, p. 48.
} 


\section{La Chine et la formation de l'esprit philosophique en France}

à une certaine réserve. Notre docteur qui n'écrit que pour luimême ne se croit pas obligé aux mêmes ménagements.

Les Jésuites firent opposition à la décision prise par la Faculté de continuer les débats, et ils envoyèrent des notaires pour le signifier. Alors il se passa une scène digne du Lutrin : « Aussitôt, comme si la discorde fût tombée tout d'un coup dans la salle de Sorbonne, tout le monde se leva de sa place, et les plus forts comme d'Arnaudin, Lemoine, le curé de Saint-Merri coururent à la porte pour se battre contre les notaires. Le curé de Saint-Merri donna, dit-on, un bon coup de poing à un des notaires, et Lemoine pensa en faire autant à l'autre. Ce fut une confusion la plus grande du monde ; vous auriez dit qu'on allait assiéger la Faculté »1. Tout se calma cependant. et les docteurs purent opiner. D'autres incidents violents s'élevèrent encore au cours des débats, notamment lorsque le docteur Feuvrier soutint qu'il y avait des peuples entiers qui n'étaient point juifs, qui adoraient le vrai Dieu, auxquels Dieu donnait la grâce de la pénitence. Alors on vit encore l'abbé Boileau gesticuler ${ }_{\text {p.103 }}$ et se démener. « Vous auriez dit d'un furieux ; c'étoit comme un cheval qui rue de tous côtés » 2 .

L'affaire fut menée rondement car Bossuet, non seulement en son nom, mais encore au nom du Cardinal de Noailles et de l'archevêque de Reims, écrivit au doyen de la faculté de tenir trois assemblées par semaine au lieu de deux. Les Jésuites essayèrent bien au début de septembre, par l'intermédiaire du P.

\footnotetext{
1 ibid., p. 50.

2 ibid., p. 61.
} 


\section{La Chine et la formation de l'esprit philosophique en France}

de la Chaize, d'obtenir du roi la suppression des assemblées de Sorbonne parce qu'elles «se faisaient avec beaucoup de tumulte et de division »1. Le cardinal de Noailles s'y opposa et le roi lui donna raison. Son crédit était alors plus grand que celui du confesseur.

Le 18 octobre 1700, la Faculté condamna les cinq propositions qui lui était déférées. Si l'une de ces propositions (la seconde) était seulement qualifiée de fausse et téméraire, d'autres, telle la troisième, étaient flétries plus vigoureusement. : [Cette proposition] est fausse, téméraire, scandaleuse, impie, contraire à la parole de Dieu et hérétique, elle renverse la Foi et la Religion chrétienne et rend inutiles la Passion et la Mort de Jésus-Christ. Ces qualifications avaient été portées au préalable au cardinal de Noailles qui les avait approuvées « avec éloge, surtout à cause de l'Hæretica et de l'Impia donnée à la troisième proposition des Jésuites »2. En outre la Faculté déclarait qu'elle ne prétendait en aucune manière approuver les autres choses contenues dans ces livres » 3 .

La Querelle des Cérémonies chinoises, telle qu'elle se pose en 1700 devant la Sorbonne dépasse de beaucoup les rivalités entre les deux partis hostiles, Jésuites et Missionnaires ; elle tourne autour d'une question théologique, débattue depuis longtemps et résolue diversement, la question du salut des Infidèles.

\footnotetext{
${ }^{1}$ Le Dieu, Journal, t. II, p. 132.

${ }^{2}$ Id., ibid., t. II, p. 194-5.

${ }^{3}$ Ellies du Pin, Défense de la censure, Préface, p. XXXVI.
} 


\section{La Chine et la formation de l'esprit philosophique en France}

Dans ce débat Théologique, où les laïcs ne se gênaient pas pour dire leur mot tel La Mothe Le Vayer qui dans son livre De la Vertu des Payens ouvrait généreusement le ciel à un certain nombre de philosophes de l'antiquité et notamment à Confucius, dans ce débat théologique, les Jésuites avaient de bonnes raisons pour se défendre et d'imposantes autorités à invoquer. Ce fut, en effet, une doctrine généralement admise dans I'Église depuis Saint-Paul que «les païens ont connu et connaissent Dieu »1. Le pseudo-Justin admettait, qu'« Orphée, les Sibylles, Homère, p.104 Sophocle, Platon connaissaient le vrai Dieu et son Verbe »2. Et Saint-Thomas déclarait que «bien des Gentils ont reçu des révélations au sujet du Christ »3. Aussi le P. Le Comte ne se faisait pas faute de s'abriter derrière l'autorité de ce docteur : «Si Saint-Thomas enseigne que Dieu a donné quelque connaissance du Messie même aux Gentils, quand on supposeroit que les premiers Chinois en ont eu par le canal de la même tradition [celle qui s'était conservée dans la famille de Noé] une connaissance implicite, diroit-on rien de contraire à la foi et aux bonnes mœurs ? »4. Au contraire, Luther avait flagellé dans son De servo arbitrio (1525) les «Sages du paganisme ». Jansenius l'avait suivi dans cette voie en traitant de « vices » les vertus des philosophes païens ${ }^{5}$.

\footnotetext{
1 Capéran, op. cit., p. 23.

${ }^{2}$ Id., ibid., p. 54.

${ }^{3}$ Id., ibid., p. 193 sq.

4 Le Comte, Éclaircissement sain la dénonciation faite à N. S. P. le Pape des Nouveaux Mémoires de la Chine, cité par Capéran, op. cit., p. 3.

5 Chérel, Fénelon au XVIII en France, p. 129.
} 


\section{La Chine et la formation de l'esprit philosophique en France}

Mais en 1700 ce débat théologique prend une nouvelle ampleur. Il ne s'agit plus, en effet, de décider si quelques philosophes de l'antiquité ou des nations infidèles ont mérité le ciel par leur vertu extraordinaire ; il ne s'agit plus de discuter sur le pouvoir prophétique de certains poètes tels qu'Orphée, ou sur l'inspiration divine des Sibylles - il était désormais difficile de soutenir que les oracles sibyllins étaient inspirés, depuis que Blondel ${ }^{1}$ avait montré, par une pénétrante étude historique et critique l'inauthenticité des livres sibyllins, et depuis les ouvrages de Van Dale et de Fontenelle - il s'agissait désormais de savoir si toute une nation aussi nombreuse et aussi ancienne que la nation chinoise, qui pratiquait depuis des millénaires une religion exempte de superstition, même sans avoir eu part à la révélation mosaïque, et dont la morale semblait reproduire les principes essentiels de la morale chrétienne, sans que le christianisme lui eût été prêché, pouvait être considérée comme étant sauvée. A sauver ou à condamner les Chinois le danger était également grand : en les sauvant on affaiblissait la nécessité de la révélation et par conséquent on supprimait le p.105 $_{\text {privilège du }}$ peuple juif ; en les condamnant on donnait prise aux libertins qui pouvaient alors soutenir la théorie de l'indépendance de la

\footnotetext{
1 Blondel, Les Sibylles (1648). Cependant les Sibylles conservent encore pendant longtemps des défenseurs attardés. C'est ainsi que les Nouvelles littéraires du 20 juillet 1715, t. II, p. 44-5, nous donnent. I'indication du livre suivant, dont les intentions sont claires à en juger par le titre 3 : « Les Oracles des Sibylles traduits sur les meilleurs exemplaires et comparés avec les Prophéties sacrées, particulièrement avec celles de Daniel et de I'Apocalypse, avec des remarques historiques qui montrent qu'une grande partie des prédications des Sibylles sont accomplies à la lettre, et où l'on répond à toutes les objections que l'on fait ordinairement contre ces oracles ». Ce livre est du chevalier Floyer.
} 


\section{La Chine et la formation de l'esprit philosophique en France}

morale et de la religion : l'athéisme (ou l'idolâtrie) et la plus pure morale pouvaient donc coexister.

Question d'autant plus épineuse que la même année, au moment où s'assemblait la Sorbonne pour juger du spiritualisme des Chinois, Hyde venait de publier son livre sur la religion des anciens Perses chez lesquels il retrouve dès la plus haute antiquité des idées religieuses et morales analogues à celles du judaïsme et du christianisme. Et un docteur de Sorbonne, Coulau, au cours même des discussions de la Faculté sur les cultes chinois, reprenant les idées de Hyde et les généralisant, s'efforçait de montrer que les anciens peuples, Gaulois, Égyptiens, Américains et Perses avaient pratiqué le monothéisme. - A quoi se réduisait donc la révélation faite aux Juifs ? - Il reconnaissait encore que Zoroastre avait prophétisé la venue du Messie. Les prophètes des Juifs n'étaient donc pas les seuls prophètes.

Bossuet sentit le venin de cet opuscule qu'il croyait, aux dires de l'abbé Le Dieu « très pernicieux pour la foi et tendre à I'indifférence des religions $\gg 1$. Aussi s'empressa-t-il de rédiger trois mémoires adressés à Brisacier, car fidèle à sa tactique dans cette affaire des Cérémonies chinoises, il voulait bien « aider 》 Tiberge et Brisacier mais il ne voulait pas paraître en personne. En même temps il donnait l'ordre exprès à Brisacier de remettre ses mémoires au cardinal de Noailles « avec prière à cette Eminence de censurer le livre de Coulau ». Le cardinal de Noailles se contenta d'exiger de l'auteur de l'opuscule une

\footnotetext{
${ }^{1}$ Le Dieu, Journal, t. II, p. 204.
} 


\section{La Chine et la formation de l'esprit philosophique en France}

déclaration où celui-ci désavouait ses idées, pensant « qu'il ne lui convenoit pas de faire une censure contre Coulau, à cause de Rome où la matière de la Chine se traite »1. Bossuet trouva la déclaration trop faible, estimant « qu'il y avoit.... un beau fondement d'une censure dans ce que Coulau soutient le salut des Perses par la Sainte-Ecriture, ce que M. de Meaux fait voir dans son premier mémoire être entièrement contraire à la parole de Dieu révélée dans les prophètes et au grand principe de Saint-Paul, dans l'Epître aux Romains et dans celle aux Ephésiens, sur la distinction des deux peuples si fortement établie $\gg 2$. Le cardinal de Noailles ne donna pas satisfaction à Bossuet sur la question de la censure et il se borna à faire saisir p.106 les exemplaires du livre de Coulau par le lieutenant de police ${ }^{3}$. Bossuet trouva un défenseur de ses idées dans un docteur de Sorbonne, et I'un des plus savants, Ellies du Pin, qui, dans sa Défense de la Censure reprit des arguments de Bossuet tirés de son Histoire Universelle « pour faire voir que les gentils n'ont pas connu le vrai Dieu et ne lui ont rendu aucun culte certain que depuis Jésus-Christ ; qu'avant lui Dieu n'étoit connu que de son peuple, et qu'il étoit ignoré des nations livrées à l'Idolâtrie » 4 .

\footnotetext{
${ }^{1}$ Id., ibid., p. 208-209.

2 Id., ibid., p. 209.

3 Le lieutenant de police d'Argenson proposa de faire arrêter l'auteur mais le contrôleur général Pontchartrain mit en marge de son rapport « A l'ordinaire ». Notes de René d'Argenson, lieutenant général de police, p. p. Larchey et E. Mabile (Paris, 1866), p. 60. Cf. Rapports inédits du lieutenant de police René d'Argenson (1697-1715), p. p. Paul Cottin, Paris, 1891.

4 Le Dieu, Journal, t. II, p. 194-195.
} 


\section{La Chine et la formation de l'esprit philosophique en France}

Ce n'est pas ici le lieu de rechercher quelles étaient au vrai les idées de Bossuet sur le problème du salut des infidèles, non plus que l'importance de la Querelle des Cérémonies chinoises sur l'évolution de ce problème - cette question sera traitée plus

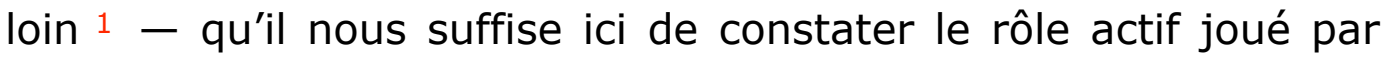
Bossuet dans cette querelle, bien qu'il s'efforce de ne pas paraître en personne, et le rôle à peine un peu moins actif du cardinal de Noailles, bien que souvent il n'agisse que sur les suggestions de M. de Meaux ${ }^{2}$. De, cette collaboration entre les deux prélats - sans parler de Le Tellier, archevêque de Reims, qui se répandait en injures violentes contre les Jésuites - les Jésuites firent tous les frais. Ils furent non seulement condamnés, mais honnis et vilipendés, et il n'est pas surprenant, si I'on juge les choses du seul point de vue humain, qu'ils aient pu songer à en tirer vengeance. Écoutons notre docteur de Sorbonne, dont le récit nous a été si précieux, pour apprécier I'acharnement des adversaires des Jésuites:

«Par tout ce qui m'en est rapporté, ce n'est qu'une cabale très p.107 grossière appuyée et soutenue de trois hommes

\footnotetext{
1 Voir II Partie, p. 309 sq.

2 Une lettre du P. Daubenton à Fénelon, du 23 mai 1711, qui annonce la saisie des papiers de Maille, agent du parti janséniste à Rome, précise le rôle de l'abbé Bossuet en 1690 et 1700 : « On connoit par ces lettres que cet abbé avoit eu à Rome de très étroites liaisons avec le sieur Maille. On y découvre tout le manège de l'assemblée de 1700 , le dessein de pousser à bout les Jésuites et d'épargner les Jansénistes, d'attaquer mais faiblement ceux-ci pour être en droit de tomber plus fortement sur ceux-là... [Dans ces lettres] on exagère fort le zèle de l'archevêque de Paris, et I'on fait surtout valoir I'union de cet archevêque avec celui de Reims et I'Université. Les Jésuites diton en enragent. L'abbé Bossuet n'oublie rien pour maintenir et augmenter cette union si nécessaire pour l'exécution de perdre les Jésuites qu'on a résolu de ne point épargner ». Fénelon, Corresp., t. II, p. 368-369.
} 


\section{La Chine et la formation de l'esprit philosophique en France}

ennemis des Jésuites, les archevêques de Reims et de Paris et l'évêque de Meaux.

«Ce n'est pas que les Jésuites ne méritent bien toutes les mortifications que cette censure leur peut causer. Ce sont des gens trop fiers et trop enflés, trop superbes ; quand on les détruirait même il n'y aurait pas grand mal ; il n'y avait pas moyen d'en venir à bout ; ce sont des animaux indomptés et quasi indomptables.

« Mais l'endroit n'est pas juste et l'on en devrait rougir.

« Les Jésuites au reste ne paraissent pas avoir sollicité personne pour être de leur sentiment ou leur être favorable.

«On ne peut pas croire la liberté que donne à certaines gens cette licence de parler contre les Jésuites. Il y en a qui disent tout haut que si on agitait aujourd'hui la question de M. Arnauld assurément il ne serait pas condamné. Cela est peut-être vrai, mais il est vrai aussi qu'il y a douze ans le P. Le Comte n'aurait pas été condamné et que peut-être sous un autre règne à venir il ne le serait pas non plus. Tout va ainsi, il n'y a rien de certain, de propre et de véritable. C'est toujours l'autorité qui l'emporte et l'avis qu'on a inculqué au souverain est toujours le meilleur ${ }^{1}$. »

1 Journal d'un Docteur de Sorbonne, p. 64. 


\section{La Chine et la formation de l'esprit philosophique en France}

Ces réflexions désabusées et mélancoliques trouveront une nouvelle confirmation après 1709 lorsque la fortune aura tourné et que les Jésuites auront retrouvé leur crédit ${ }^{1}$.

La décision de la Sorbonne qui condamnait les Jésuites ne termina pas les contestations, elle ne fit au contraire qu'envenimer l'affaire. Les presses de toute l'Europe furent mises à contribution et l'on vit paraître successivement l'Histoire de la Censure, la Censure réfutée, la Réfutation d'une prétendue réponse à l'écrit intitulé : Censure réfutée. De ces opuscules dont les titres p.108 menaçaient de s'allonger tous les jours on fit des recueils : Pour ou Contre le Culte chinois et les lecteurs même les plus acharnés, comme Bayle, finirent par se lasser de ce déluge. Et cependant le roi qui savait « qu'une guerre de plume en matière de religion peut avoir des suites plus fâcheuses qu'une guerre d'épée en matière d'État » avait interdit

\footnotetext{
1 Les Nouvelles ecclésiastiques écrivent en effet en 1731 à propos du livre de Silhouette : Idée générale du gouvernement et de la morale des Chinois, tirée particulièrement des ouvrages de Confucius, qu'elles croient inspiré sinon écrit par le P. Tournemine :

« L'on se demande naturellement si la nouvelle Sorbonne, censurera en 1731, dans le P. Tournemine, les mêmes erreurs que la vraie Sorbonne censura dans le P. Lecomte en 1700 . Si elle ne le fait pas, elle justifiera la pensée de M. de Montpellier dans sa dernière Lettre pastorale, p. 34 (Sur cette Lettre pastorale et sur cette polémique, voir plus loin, p. 408-9) : Si nous nous trouvions encore aujourd'hui dans les mêmes circonstances qu'en 1700, par rapport aux affaires de la Chine, on ne pourroit faire censurer en Sorbonne les propositions que la Faculté condamna alors. C'est qu'il ne reste dans cette ombre de Faculté aucun de ceux qui opinèrent en 1700 pour la Censure, et que ceux au contraire qui prirent la défense des propositions et qui avaient à leur tête feu $M$. Tourneli, ont tous reçu la Constitution Unigenitus. » (Silhouette, Idée générale du gouvernement et de la morale des Chinois, $2^{\mathrm{e}}$ édition, p. 43).
} 


\section{La Chine et la formation de l'esprit philosophique en France}

de rien publier en France sur cette question ${ }^{1}$. Mais ce qui ne se pouvait faire en France pouvait sans difficulté se faire en Hollande.

La première victime de cette affaire fut le $\mathrm{P}$. Le Comte, qui avait été la cause directe - ou seulement l'occasion ? - de cette levée de boucliers. Le roi le congédia parce qu'il était «alarmé, dit Saint-Simon, que la conscience de Madame la Duchesse de Bourgogne fût entre les mains du P. Le Comte 2 , et pour cela il n'attendit même pas que la Sorbonne eût rendu son jugement 3 . Mais en même temps, pour atténuer la blessure d'amour-propre du P. Le Comte, qui était, suivant l'abbé du Bos, le plus vain de tous les hommes ${ }^{4}$, le roi lui accordait une pension de 200 écus, et pour satisfaire les Jésuites, il créait douze places d'élèves orientaux dans la maison professe des Jésuites 5 , en même temps qu'il doublait leur pension ${ }^{6}$. Malgré sa disgrâce, le P. Le

1 Esprit des Cours, octobre 1700, p. 354. C'est sans doute pour avoir contrevenu à cet ordre du roi que fut enfermé à la Bastille un docteur de la Sorbonne qu'on appelait pour cette raison Le Fèvre de la Bastille : « Le $1^{\text {er }}$ de ce mois (juillet 1716) M. Le Fèvre, Docteur de Sorbonne et qu'on surnommait Le Fèvre de la Bastille parce qu'il y avait été renfermé autrefois pour avoir écrit contre les Jésuites au sujet des affaires de la Chine mourut âgé d'environ 75 ans (Nouvelles littéraires, $1^{\text {er }}$ août 1716, t. IV, p. 74). Le même journal (20 février 1717, t. $V$, p. 129-130) nous apprend que ce Le Fèvre était considéré comme l'auteur de I'Anti-Journal des assemblées de Sorbonne, c'est-à-dire comme l'auteur du libelle qui répondait au libelle des Jésuites, Journal des Assemblées tenues en Sorbonne et dont le titre exact est Lettres d'un Docteur de Sorbonne.

2 Saint-Simon, Mémoires, t. VII. p. 165.

3 L'abbé Le Dieu écrit dans son Journal, à la date du 8 juillet 1700 : «On a appris ici ce matin l'exil du P. Louis Lecomte » (t. II, p. 67).

4 Lettre à l'abbé de St Hilaire, R. H. L. 1907, p. 152.

5 Dangeau, Journal, 24 juillet 1700, t. VII, p. 345.

6 Papiers du P. Léonard, A. N. K. 1374, nº 17. 


\section{La Chine et la formation de l'esprit philosophique en France}

Comte restait encore un homme assez dangereux pour inquiéter l'agent de l'archevêque de Paris à Rome, le P. Roslet, et le délégué de la société des Missions étrangères, M. Charmot 1.

La seconde victime de la querelle fut le P. Le Tellier dont le livre Défense des nouveaux Chrétiens fut mis à l'index « donec ${ }_{p}$. ${ }_{109}$ corrigatur » en 1700 2. Mais les documents sur cette question semblent avoir été bien gardés ${ }^{3}$.

L'affaire réglée en France, il s'agissait pour les Missions étrangères d'aboutir en cour de Rome pour faire condamner les cultes chinois et les tolérances que les Jésuites permettaient, en se servant comme atout de la décision doctrinale que venait de prendre la Sorbonne. Cependant la mort du pape Innocent XII (7 septembre 1700) qui leur avait été favorable risquait de tout remettre en question. Heureusement pour eux, les Missionnaires avaient un fidèle soutien dans la personne de Mathieu de Noailles, nommé cardinal peu avant la mort du pape Innocent XII et qui allait à Rome pour chercher son chapeau et pour

1 Lettre du P. Roslet à I'archevêque de Paris, 27 juillet 1700, B. N. Fr. 23227, f. 37.

2 Sommervogel, op. cit., t. V, col. 1911.

3 Le Roy, La France et Rome de 1700 à 1715, p. 270. Il semble, d'après l'abbé Phélypeaux, Relation de l'origine du progrès et de la condamnation du quiétisme (t. I, p. 268), que le livre du P. Le Tellier échappa auparavant à une condamnation à Rome grâce au crédit du Cardinal d'Estrées : « On (Bossuet) n'ignorait pas son attachement aux Jésuites, qui protégeaient publiquement la doctrine de $M$. de Cambrai ; on avoit devant les yeux des faits erians où ce Cardinal [d'Estrées] n'avoit que trop favorisé la société contre son honneur et ses propres lumières, comme il arriva dans l'affaire du livre du P. Tellier. »

Ce témoignage de l'abbé Phélypeaux confirme les affirmations de SaintSimon, Mémoires, t. XVII, p. 58. 


\section{La Chine et la formation de l'esprit philosophique en France}

assister au conclave. Il était accompagné de l'abbé Renaudot, un savant orientaliste, qui devait être son conclaviste.

Le cardinal de Noailles arriva à Rome, le 11 novembre 1700, alors que le conclave était déjà ouvert. Il descendit chez le cardinal d'Estrées, l'ambassadeur, le prince de Monaco, s'étant retiré de Rome pour une affaire de peu d'importance. MM. Charmot, Maille et Tourreil, les agents du parti janséniste à Rome, allèrent, nous dit Quesnel ${ }^{1}$, saluer le cardinal de Noailles dès son arrivée, et le même Quesnel ajoute : « Les cardinaux d'Estrées et de Janson avoient fait complot pour le débaucher dans l'affaire de Chine ». C'est pour déjouer ce complot que les Jansénistes se précipitaient au-devant du cardinal. L'affaire de la Chine n'était donc pas oubliée même au milieu des importantes préoccupations du conclave.

Le cardinal de Noailles entra au conclave et, conformément à ses instructions, il dut soutenir la candidature du cardinal Albani (Clément XI) bien qu'il ne l'aimât guère, car on savait ce cardinal p.110 dévoué aux Jésuites 2. En effet, le conclave fini, le nouveau pape ne retint pas à Rome le cardinal plus qu'il n'était nécessaire ${ }^{3}$. De Noailles dut faire contre fortune bon cœur et, pour le représenter à Rome, il laissa un autre lui-même, l'abbé Renaudot.

\footnotetext{
${ }^{1}$ Quesnel, Lettres, t. II, p. 113-114.

2 Le P. Léonard prétend que «MM. des Missions étrangères ont été consternez » en apprenant l'élection du cardinal Albani. A. N. K. 1374, n 17.

3 Le Roy, La France et Rome, p. 91.
} 


\section{La Chine et la formation de l'esprit philosophique en France}

L'abbé Renaudot avait sans doute une mission officielle pendant son séjour à Rome, puisque de son propre aveu, il correspondait avec $M$. de Torcy ${ }^{1}$. Mais nous ne trouvons aucune trace de cette mission dans le livre d'Albert Le Roy, qui, cependant a dépouillé toutes les correspondances de Rome au ministère des Affaires Étrangères de Paris, de 1700 jusqu'à 1715. En tout cas il avait une mission officieuse qui lui était confiée par le cardinal de Noailles, et celle-là nous la connaissons par le Journal du Voyage à Rome ${ }^{2}$ de Renaudot, et surtout par ses lettres hebdomadaires adressées à l'archevêque. L'objet général de cette mission était de travailler contre les Jésuites, en particulier de chercher à faire pièce au cardinal de Bouillon, le

\footnotetext{
1 Le 14 avril 1701 il annonce au cardinal de Noailles qu'il vient d'écrire à M. de Torcy pour tâcher d'obtenir que l'on donne l'ordre au cardinal de Janson de parler en faveur des missions étrangères. Il est possible cependant que ce soit une requête à titre privé, Torcy n'étant pas ami des Jésuites. B. N. N. A. F. 6212, f. $8,1^{\circ}$. Mais quelques phrases de ses lettres semblent indiquer qu'il était à Rome, quoique officieusement, un agent diplomatique :

« Jugez... combien il m'est agréable de demeurer icy, éloigné de vous Monseigneur, (ce que je sens tous les jours) de mes amis, de mes livres et n'ayant aucune consolation que la bonté du Pape, qui véritablement est si grande que je ne puis assez la reconnoistre et la satisfaction de faire quelque chose pour le bien de l'Eglise et pour le service du Roy. Encore sur cet article j'ay eu une telle réserve, mesme à l'égard de $M$. de Torcy, avec lequel néanmoins je suis en quelque liberté, que j'ay laissé tout l'honneur aux Généraux, si ce n'est pour les choses qu'il avoit fallu faire soy-mesme. Ainsi je suis encore à scavoir si on a rendu au Roy quelque bon témoignage de moy. Car pour l'Église, il l'a fallu servir en fraude. » ibid., f. 43 ; et encore :

«...il est de l'interest du service de S. M. que les plus zélez serviteurs ne soient pas exposez à la calomnie, fondée sur les accusations de ceux qui n'ont de liaison en ce pais cy qu'avec ses plus grands ennemis. » ibid., f. $61, v^{\circ}$.

2 B. N. N. A. Fr. 7482.
} 


\section{La Chine et la formation de l'esprit philosophique en France}

protecteur des Jésuites et l'ennemi de la maison de Noailles ${ }^{1}$, et surtout de faire condamner les Jésuites dans l'affaire de la Chine.

p.111 A cet égard son activité fut grande. Il voit le pape une fois par semaine et il s'efforce sans cesse de diminuer les délais que les amis des Jésuites imposent pour les réunions du SaintOffice. Grâce à ces lettres, nous pouvons voir à quel point le cardinal de Noailles s'est intéressé à cette affaire des Cérémonies chinoises. Nous pouvons voir aussi quelle énergie dépensa pour faire condamner à Rome les idées des Jésuites sur les cultes chinois l'abbé Renaudot qui devait publier quelques années plus tard une traduction d'un auteur arabe : Anciennes Relations des Indes et de la Chine de deux voyageurs Mahométans, suivies de dissertations sur la Chine et la science des Chinois, pour essayer de ruiner l'idée de l'antiquité des sciences en Chine, idée dont les Jésuites se faisaient les actifs propagandistes.

L'abbé Renaudot précise à maintes reprises dans sa correspondance que tout ce qu'il fait à Rome, il le fait au nom et en vertu des ordres du cardinal de Noailles : « J'ay fait,

1 Sur la haine qui existait entre les deux maisons de Noailles et de Bouillon, on trouve chez Jordan le curieux renseignement que voici : « Le premier ouvrage que j'aye fait imprimer a pour titre Actes et Titres de la maison de Bouillon, à Cologne, 1698. Ce petit livre est véritablement imprimé à Berlin, à I'instance et aux dépens de $M$. de Gagnières qui $m^{\prime}$ engagea comme malgré moi, dans le tems même que je demeurois à Paris, à l'examen de ces titres. Dans le petit livre dont je vous parle, il n'y a de moi que la Préface, et l'écrit qui commence à la page 113. J'ai bien part au reste mais tout ce qui a paru a été interpolé par M. de Gagnières qui n'entendoit pas fort bien de quoi il s'agissoit. Aussi ce qui lui mit la plume à la main et ce qui le porta à me solliciter d'écrire fut uniquement la haine de la Maison de Noailles contre celle de Bouillon. Mr de Gagnières qui étoit tout dévoué à l'archevêque de Paris, son parent, m'obligea d'entrer dans cette dispute. Je m'en serois bien passé. » Jordan, Histoire de la vie et des ouvrages de M. La Croze. (Amsterdam, 1741), p. 64-5. 


\section{La Chine et la formation de l'esprit philosophique en France}

Monseigneur, écrit-il le 7 juin 1701, le meilleur usage qu'il m'a été possible de la. lettre de Votre Excellence du 16 de may. Je lus au pape dimanche matin l'article qui regardoit la Chine. Il loua fort le zèle de Votre Excellence et il me dit de vous mander qu'il n'avoit pas moins d'impatience que vous de voir cette affaire terminée... » ${ }^{1}$. Cependant le pape, malgré les assurances qu'il a données à Renaudot, espace de quinzaine en quinzaine, au lieu de les faire tenir chaque semaine, les séances de la congrégation, et Renaudot le rappelle à l'ordre. « Je dis que j'avois appris que les congrégations estoient remises de quinze en quinze jours, que je le suppliois de me dire si son intention estoit de ne pas les faire tenir plus souvent quand il seroit possible, que s'il n'y tenoit la main on les éloigneroit encore, sur quoi je luy prouvay de mon mieux la nécessité de finir et je luy montray ce que Votre Excellence me mandoit sur ce sujet $\gg 2$. Les jours de doute où Renaudot se prend à penser que son zèle est trop ardent, il se console et se tranquillise en se rappelant qu'il n'a fait qu'exécuter les ordres du cardinal de Noailles : «Ce que j'ay fait en cette affaire sera mon grand péché. p.112 C'est à Votre Excellence à m'en absoudre puisque je suis demeuré en partie sur ce qu'elle m'a ordonné, pour ce sujet-là. Faudra-t-il encore une persécution pour récompense ? J'ay mandé beaucoup de choses à Votre Excellence. Le détail qu'on ne peut écrire la persuadera encore plus que j'ay bien exercé les intentions... »3 .

\footnotetext{
${ }^{1}$ Lettre du 7 juin 1701, B. N. N. A. F. 6212, f. 34.

2 Lettre du 21 juin 1701, B. N. N. A. F. 6212, f. $43 v^{\circ}$.

3 Lettre du 26 juillet 1701, B. N. N. A. F. 6212, f. 55.
} 


\section{La Chine et la formation de l'esprit philosophique en France}

Et quand la situation devient très critique pour lui à Rome pour quelles raisons, nous ne le savons pas - Renaudot passant en revue les affaires qu'il a traitées, déclare en parlant de l'affaire des Cérémonies chinoises : « Vous estes instruit si j'ay rien fait que votre Excellence n'ait ordonné ou approuvé. Mais indépendamment de tout, je veux bien qu'on sache que je les crois dans l'erreur.. »1. Si par hasard les autres affaires peuvent prêter au doute ou à l'équivoque, « l'affaire de la Chine me laisse bien tranquille », ce qu'il exprime en une formule un peu familière mais énergique : «Si on attend que je me justifie sur Confucius, on attendra longtemps.... »2.

Renaudot n'a donc ni scrupule, ni remords à tâcher d'obtenir la condamnation des Jésuites. Pour cela il met à profit sa science personnelle et sa connaissance des langues orientales, il compose lui-même des traités. Il remet notamment au pape un mémoire de sa façon, « sur l'argument tiré de l'inscription Chinoise et Syriaque qui est dans la China Illustrata 3 où ces anciens Missionnaires Nestoriens voulant exprimer le nom de Dieu ne se sont servis ny des mots de Xamti ny de Tchien chu, mais du Syriaque : ce qui prouve démonstrativement qu'ils estoient persuadés que ces mots ne pouvoient convenir à l'idée que les Chrestiens doivent avoir de l'estre infini. Cet argument a frappé Sa Sainteté aussi bien que MM. les Cardinaux Ferrari Radolovix et Noris à qui j'ay donné des copies de cet

\footnotetext{
${ }^{1}$ Lettre du 2 août 1701, B. N. N. A. F. 6212, f. 57-8.

${ }^{2}$ Lettre du 9 août 1701, B. N. N. A. F. 6212, f. 61 vo.

3 Kircher, China illustrata, p. 59.
} 


\section{La Chine et la formation de l'esprit philosophique en France}

éclaircissement »1 Mais il ne dédaigne pas non plus de composer à I'occasion un pamphlet contre les Jésuites. Il remet, en effet, le même jour au pape la « Lettre à Madame de Lionne sur le libelle des Jésuites contre $M$. I'évesque de Rosalie son fils », dont « l'impression et l'estampe » étaient l'ouvrage de M. de Lyonne mais dont le texte était de Renaudot lui-même ${ }^{2}$.

p.113 Et le Saint-Père a daigné rire en voyant l'estampe représentant le P. Grimaldi.

Dans un grand nombre de ses lettres Renaudot insiste auprès du cardinal de Noailles pour qu'il tâche d'obtenir, en faveur des Missions étrangères, la protection déclarée de l'ambassadeur de France à Rome afin de contrecarrer l'influence des cardinaux Fabroni et de Bouillon, amis des Jésuites. Ce n'est pas chose facile à obtenir puisque le roi a décidé de rester neutre dans cette querelle entre les Jésuites et les Missionnaires. Et Renaudot en écrit aussi à $M$. de Torcy et à Brisacier. Par Brisacier peut-être pourrait-on agir sur Madame de Maintenon. Celle-ci, d'ailleurs, se récusa : «Le roy, répondit-elle à Brisacier qui lui demandait sans doute d'intervenir, ne parle point sur les affaires que vous avez avec les ministres ; il ne désire en cela qu'une décision du Saint-Siège pour finir des disputes qui blessent la charité. Quant à moi qui ne dois être comptée pour rien, surtout en pareille matière, je garde le silence qui me convient, mais si j'avais à

\footnotetext{
${ }^{1}$ Lettre du 19 avril 1701, B. N. N. A. F. 6212, f. $12 v^{\circ}, 13$ ro.

2 «On en dit I'abbé Renaudot auteur » (Note du P. Léonard). A. N. K. 1375, n $\circ 60$.
} 


\section{La Chine et la formation de l'esprit philosophique en France}

prendre un parti, vous ne pouvez douter que ce ne fût le vôtre $\gg 1$.

Renaudot, qui se méfiait de la Congrégation du Saint-Office où les Jésuites comptaient de nombreux amis, tenta un jour une démarche audacieuse auprès du pape pour lui suggérer l'idée de prendre comme confident secret le cardinal de Noailles dans I'affaire des Cérémonies chinoises. «Pourquoi donc Saint-Père, lui dit-il, ne pas mettre Mgr le cardinal de Noailles dans le secret de I'affaire, au moins pour Votre Sainteté seule. Car elle peut être assurée qu'il ne trahira pas la vérité. Credete, me dit-il en souriant, che no sappiamo il suo voto ? Non, lui répondis-je, Saint-Père, je ne doute pas que Votre Sainteté ne sache ce qu'il pense du fond de l'affaire, mais pourquoi ne luy demander pas son avis sur plusieurs détails que Votre Sainteté n'a pu traiter avec luy, et sur lesquels ayant sous les yeux Messieurs des Missions Étrangères qui ont quantité de pièces dans leurs archives qu'ils peuvent luy communiquer, il p.114 éclaircira Votre Sainteté plus que ne feront tous les gens de ce pais-cy. Il me répondit aussitôt qu'il approuvoit cette pensée et qu'il

\footnotetext{
1 Lettre du 29 septembre 1701. (Launay, Histoire de la société des missions étrangères, t. I, p. 399). Bien qu'elle refusât de prendre parti dans la querelle, Mme de Maintenon ne laissait pas cependant de s'intéresser activement à la Société des Missions étrangères. Valincour nous apprend qu'elle lui donna un jour rendez-vous à sept heures du matin aux Recollets : «Elle me fit entrer dans son carrosse, me dit que les missionnaires de la Chine, MM. Tiberge et Brisacier, voudroient bien avoir mille livres des Estats de Bretagne comme les Jésuites, et qu'elle avoit voulu me consulter pour savoir si cela estoit possible et ce qu'il falloit faire pour réussir. Je lui dis qu'il ne falloit que témoigner qu'elle le désirait et, que je la suppliois de vouloir bien me faire I'honneur de s'en reposer sur moi. »

Lettre de Valincour au duc de Noailles, R. H. L., 1903, p. 673-4.
} 


\section{La Chine et la formation de l'esprit philosophique en France}

I'exécuteroit incessamment. Je mande cecy à $M$. de Brisacier et je luy demande en même temps un très grand secret $\gg 1$.

Il peut sembler curieux de voir le gallican Renaudot batailler avec autant d'ardeur pour la Société des Missions qui était d'inspiration ultramontaine. Nous avons déjà vu que la formule du serment imposée aux missionnaires des autres ordres par les vicaires apostoliques contenait en réalité la reconnaissance de l'infaillibilité du pape. Un peu plus tard, pendant les affaires de la Constitution Unigenitus les directeurs du Séminaire destinèrent à l'usage de leurs missionnaires des instructions sur le respect et I'obéissance dus au Saint-Siège, et ces instructions disaient : «Pour ce qui regarde les propositions du clergé de 1689 , ou il ne faut point en parler du tout même par manière de dispute et d'entretien avec les missionnaires d'autres corps, ou prendre le parti le plus favorable au Saint-Siège en soutenant l'infaillibilité du Pape, et inspirer aux Chrétiens une haute estime et une profonde vénération pour l'Église romaine et le Saint-Siège apostolique) ${ }^{2}$.

Au contraire, en 1701, à l'époque où Renaudot se trouvait à Rome, les Missions étrangères étaient suspectes de gallicanisme, et Renaudot était obligé de les défendre auprès du Pape de I'intention qu'on leur supposait de vouloir constituer des missions nationales. Il remettait au pape un acte rédigé par les directeurs du Séminaire des Missions étrangères pour répondre à cette

\footnotetext{
${ }^{1}$ Lettre du 21 juin 1701, B. N. N. A. F. 6212, f. 44.

2 Launay, op. cit., t. I, p. 336.
} 


\section{La Chine et la formation de l'esprit philosophique en France}

accusation ${ }^{1}$. C'est que les Jésuites cherchaient alors à faire suspecter les Missions étrangères de jansénisme, accusation qu'ils avaient déjà portée, mais d'une manière plus précise, contre Pallu en 1673 et une seconde fois, en 1686 contre Maigrot 2. Cependant, il est assez étonnant de voir les Jésuites qui, au moment de l'affaire du serment, s'appuyaient sur les doctrines gallicanes pour résister aux Missions étrangères parce qu'elles imposaient avec le serment la doctrine de l'infaillibilité du pape, se faire maintenant les champions de I'ultramontanisme et accuser ces mêmes Missions étrangères de gallicanisme. Mais l'on n'est pas moins surpris d'ailleurs en voyant les Missions étrangères, nées du dessein de la papauté et de la Propagande de constituer à côté et en dehors des églises nationales une hiérarchie ecclésiastique relevant directement du p.115 pape, s'appuyer désormais sur les gallicans. C'est sinon un changement de principes du moins un renversement d'alliances, comme on en voit parfois en politique. Notre docteur de Sorbonne penserait sans doute que la faveur du prince explique ces faits en apparence contradictoires et qu'à la période Jésuites contre Missionnaires a succédé la période Missionnaires contre Jésuites parce que la faveur royale ne penche plus du même côté.

Brusquement, la mission de Renaudot à Rome fut interrompue par une lettre du cardinal de Noailles et de quelques-uns de ses amis, l'avertissant d'un grave danger qui le

\footnotetext{
${ }^{1}$ Lettre du 7 juin 1701, B. N. N. A. F. 6212, f. 34.

2 Launay, op. cit., t. I, p. 333.
} 


\section{La Chine et la formation de l'esprit philosophique en France}

menaçait : « Tout est perdu si je ne me tire d'ici promtement » écrit-il le 2 août $1701^{1}$. Il répondit à cette lettre du cardinal pour se justifier, mais il ne dut pas rester longtemps à Rome car sa dernière lettre au cardinal de Noailles est datée du 9 août. « Le pape, dit l'abbé Du Bos, lui fit présent de deux mille livres de rente en Bretagne avec tout l'agrément possible » 2.

$*$

La tentative faite par le cardinal de Noailles et I'abbé Renaudot pour emporter de haute lutte une condamnation rapide des Jésuites n'avait pas réussi. C'est que, outre les influences occultes qu'ils avaient pu faire agir en leur faveur, sans parler de l'appui du pape, les Jésuites avaient fait un coup de maître en s'adressant à l'empereur de Chine lui-même pour avoir une consultation autorisée sur le sens exact que les Chinois donnent aux mots qui servent à désigner Dieu. Les délais qu'ils demandaient sans cesse, les retards qu'ils faisaient apporter aux séances de la congrégation de la propagande n'avaient pour but que d'attendre cette fameuse consultation de l'empereur de Chine, car ils ne doutaient pas qu'elle ne leur fût favorable et qu'elle ne dût terminer toutes les contestations en leur faveur. Et de fait lorsque la réponse arriva en Europe, la cause sembla gagnée pour eux. Immédiatement un correspondant en avertissait Renaudot (10 novembre 1701) et lui annonçait en même temps « que le roy en voyant cet édit avait dit au P. de la

\footnotetext{
${ }^{1}$ Lettre du 2 août 1701, B. N. N. A. F. 6212, f. 57.

2 Lettre de Du Bos à Thoynard. 2 août 1701, in Denis, Lettres autographes de la collection de Troussures, p. 117.
} 


\section{La Chine et la formation de l'esprit philosophique en France}

Chaize que les Jésuites avaient gagné leur procès et qu'il n'y avoit plus rien à dire contre eux $\gg 1$.

Mais tel ne fut pas l'avis du pape, qui, ne se croyant pas encore suffisamment instruit sur les faits de la cause, choisit, le 2 juillet 1702, Charles Thomas Maillard de Tournon pour régler les points p.116 en litige, l'éleva à la dignité de patriarche

\footnotetext{
1 B. N. N. A. F. 7482, f. 375.
} 


\title{
La Chine et la formation de l'esprit philosophique en France
}

\author{
d'Antioche et lui donna le titre de légat a latere, puis l'envoya en
}

Chine trancher le différent 1.

En passant aux Indes, il devait aussi mettre fin aux discussions des Jésuites et des capucins qui troublaient les esprits à Pondichéry.

Le patriarche de Tournon s'embarqua avec douze religieux sur les vaisseaux du chevalier de Fontenay en avril 1703. Arrivé aux Indes, il se montra d'abord franchement favorable aux Jésuites,

1 Cette décision du pape était dans l'air depuis la fin de l'année précédente puisque I'abbé Le Dieu la signale à la date du 28 décembre 1701, en nous rapportant les objections que faisait Bossuet à une semblable décision. Bossuet et ses amis semblent avoir bien prévu les difficultés qui attendaient le légat du pape. «M. de Meaux s'est aujourd'hui déclaré que la conduite du pape est une illusion; que c'est ne vouloir pas finir l'affaire, mais la renvoyer aux calendes grecques ; que dans une matière si importante à la religion, il falloit au moins par provision défendre l'exercice d'un culte idolâtre, supposé qu'il se trouvât tel ; que c'est donner gain de cause aux jésuites, puisqu'ils ne demandoient pas autre chose ; que c'est leur ouvrir la porte aux cabales, puisqu'il sera bien plus aisé à ces pères de gagner par eux et par leurs amis un seul homme de qui on fait dépendre la cause que tout le consistoire; que les missionnaires apostoliques de la Chine, les vicaires apostoliques, les évêques mêmes, créés exprès par le St. Siège pour la Chine, sont de vrais juges compétens dans cette affaire, établis avec tout le pouvoir du St. Siège, autant que ce nouveau visiteur apostolique, avec cette différence néanmoins qu'un M. Maigrot, par exemple, aussi évêque de la Chine, n'en est venu à défendre le culte idolâtre des chrétiens chinois par provision, qu'après s'en être bien instruit par lui-même pendant douze et quinze ans, et non seulement par le commerce de tant d'années avec les gens du pays, les savans, les ignorans, les petits et les grands, mais encore par la lecture et la connoissance parfaite de leurs livres rituels; joint qu'il sait parfaitement leur langue, leurs mœurs et tout ce qui peut servir à la décision de cette affaire. Au lieu que le vicaire apostolique n'est pas en état même d'apprendre ces choses ; qui sait s'il fera seulement le voyage heureusement, s'il arrivera à la Chine, s'il obtiendra de l'empereur la permission d'y entrer et quand il l'aura obtenue, s'il obtiendra de faire une information juridique sur les sujets d'un empereur si jaloux de son autorité et qui a tant de mépris pour les étrangers ? Mais quels témoins écoutera-t-il ? Des chrétiens ou des idolâtres ? Des disciples des jésuites ou des autres missionnaires ? Trouvera-t-il des témoins dignes de foi ? Et comment s'assurera-t-il de leur foi ? M. de Meaux a écouté tranquillement toutes ces réflexions faites en sa présence dans la conversation, lui-même en faisant partie et approuvant les autres. » (Le Dieu, Journal, t. II, p. 260-1). 


\section{La Chine et la formation de l'esprit philosophique en France}

bien qu'il dût ensuite condamner les rites malabares comme les rites chinois. Il logea et officia chez eux pendant les neuf mois de son séjour à Pondichéry, excommunia plusieurs capucins de Madras et avant son départ pour la Chine, il laissa l'ordre à l'archevêque de Saint-Thomé de frapper de même tous les capucins indociles. Quelques mois après d'ailleurs, l'archevêque de Goa, primat des Indes, annula toutes les décisions du patriarche comme attentatoires à sa juridiction, et rétablit les capucins de Madras ${ }^{1}$.

p.117 Le légat arriva à Canton le 8 avril 1705 et à Pékin le 14 décembre. Il fut reçu en audience par l'empereur le 31 décembre. Lorsqu'après les banalités d'une conversation quelconque, le patriarche essaya d'aborder la question principale qui avait motivé son voyage et proposa de nommer un supérieur des missions, ou, si I'on préférait, un nonce à Pékin, Kang hi refusa, «à moins, dit-il, qu'on ne donne cette dignité à un des Européens qui habitent mon palais ». Le patriarche refusa ${ }^{2}$. On le comprend, de reste : c'eût été allumer une nouvelle guerre entre Jésuites français et Jésuites portugais qui, chacun de leur côté, auraient revendiqué cette dignité pour leur mission.

Sur ces entrefaites, le Légat reçut le décret de Clément XI, du 20 novembre 1704, condamnant - jusqu'à un certain point les Cérémonies chinoises. En même temps, on lui envoyait des ordres pour qu'il publiât en Chine les réponses de la Congrégation de la Foi aux différents points du mandement de

\footnotetext{
${ }^{1}$ Kæppelin, La Compagnie des Indes orientales, p. 557-8.

2 Launay, Histoire de la Société des Missions étrangères, t. I, p. 469.
} 


\section{La Chine et la formation de l'esprit philosophique en France}

Maigrot et pour qu'il fit respecter ce mandement par tous les missionnaires. Mais une importante restriction enlevait à ce décret ce qu'il pouvait avoir de trop absolu et de trop affligeant pour les Jésuites : «...Sa Sainteté, pour des causes justes et raisonnables dont elle a été touchée, a suspendu tant dans la Ville que dans les autres parties de l'Europe toute publication et toute divulgation de ces réponses ». L'intention du pape en ne publiant pas ce décret en Europe était, dit Dorsanne, « d'éviter les mauvaises critiques et le chagrin que l'une des parties aurait d'avoir perdu sa cause $\gg 1$.

Malgré toutes les précautions prises par le pape pour éviter les froissements, le décret de 1704 ne pouvait terminer toutes les contestations. Ce n'était pas en effet une condamnation formelle des cultes chinois, ce n'était pas une décision de fait, affirmant que ces cultes étaient superstitieux, c'était seulement une réponse de principe sur les faits allégués, laissant entière la question de savoir si les faits étaient conformes à la vérité. On comprend la prudence du Saint-Siège, qui ne voulait pas se mêler de juger une question dont les éléments lui échappaient,

\footnotetext{
${ }^{1}$ Lettre de Dorsanne à Gaston de Noailles, s. d. ; B. N. Fr. 23.308, f. 117.
} 


\section{La Chine et la formation de l'esprit philosophique en France}

mais on voit aussi quel facile échappatoire ce décret pouvait offrir aux Jésuites ${ }^{1}$.

p.118 Le légat ne put se résoudre à publier le décret de 1704 condamnant les cultes chinois. Il n'ignorait pas en effet que l'empereur de Chine était favorablement disposé pour les Jésuites. Mais l'existence de ce décret de condamnation était déjà connue à Pékin, car l'empereur, sans doute renseigné par les Jésuites, furieux qu'une assemblée de cardinaux et de théologiens tenue à Rome, eût condamné les cultes chinois,

${ }^{1}$ La Congrégation de la Foi avait été consultée par exemple sur cet article du mandement de Maigrot : «Nous déclarons que l'exposition qui a été faite autrefois au pape Alexandre VII sur les points controversés entre les ouvriers de cette mission ne dit pas la vérité en plusieurs choses : et qu'aussi les missionnaires pour permettre le culte qui est en usage dans la Chine à l'égard de Confutius et des Morts ne peuvent pas se prévaloir des réponses que le St. Siège a faites quoy qu'elles aient été rendues très sagement et conformément aux circonstances exprimées dans les doutes exposés » $A$ quoi la Congrégation répondait : «Sur la question du $3^{\text {e }}$ article renvoyée en cet endroit, la Sacrée Congrégation a jugé à propos de ne rien répondre, de crainte que le St. Siège ne fût obligé de s'éloigner de I'ancien usage qu'il a observé jusqu'à présent dans ces sortes de controverses de la Chine, selon lequel usage il a coutume de donner toujours des réponses à la vérité suivant que les choses lui sont exposées (quoy que ce soit différemment en des temps différents) mais de ne prononcer jamais sur la vérité ou sur la fausseté de ces sortes d'exposés. » Et les Jésuites d'en tirer cette conséquence : « Les jésuites demeurent en possession de soutenir, comme par le passé, la vérité de leur Exposé, qui est que les Chinois ne reconnoissent dans Confutius ny dans les morts aucune espèce de divinité ; qu'ils ne leur demandent rien, qu'ils n'attendent rien d'eux, et qu'il n'y a donc dans le culte qu'on leur rend ny idolâtrie ny superstition. » (Lettre à MM. du Séminaire des Missions étrangères sur ce qu'ils accusent les jésuites de ne s'être pas soumis sincèrement au nouveau Décret touchant let affaires de la Chine, p. 61-3). Les Jésuites ne se croyaient donc nullement condamnés. Couet écrivait en effet : « Je scay très certainement que les jésuites de Paris soutiennent encore aujourd'huy que le Pape n'a rien décidé d'absolu sur la question des cultes chinois, que son dernier jugement n'est que conditionnel et rendu sur un faux exposé, et il n'y a pas un mois qu'un de leurs Pères me dit à moimême que le décret de 1656 subsistait dans toute sa force et que si l'on avoit mal exposé au St. Siège les usages et les coutumes du Grand Empire, ils ne sont pas obligés pour cela, d'y perdre absolument la religion en observant des défenses faites à contre-tems de différentes pratiques qu'on peut tolérer. » (Lettres d'un théologien, $3^{\mathrm{e}}$ Lettre, p. 82-3). 


\section{La Chine et la formation de l'esprit philosophique en France}

interpella violemment le patriarche de Tournon dans I'audience solennelle qu'il lui donna : «Les Européens, dit-il, ne peuvent assez pénétrer le sens de nos livres, il est donc à craindre que le pape ne fasse quelque règlement, qui, fondé sur de fausses informations, attirera infailliblement la ruine du christianisme dans mon empire... »

Il demanda au Patriarche quels étaient les savants capables de renseigner le pape sur les cultes chinois. Le Légat désigna Maigrot. Celui-ci fut donc chargé par l'empereur de mettre par écrit ce qu'il trouvait dans les cultes chinois de contraire à la religion chrétienne. Maigrot signala dans sa réponse les deux antinomies essentielles qui existaient suivant lui entre la religion de la Chine et le christianisme : d'une part la religion chinoise n'admet, pour premier principe, qu'un être qui n'est ni intelligent ni subsistant par lui-même, tandis que la religion chrétienne croit à un seul p.119 Dieu éternel, créateur de l'homme et de l'univers. D'autre part, les sacrifices que l'on offre dans les cultes chinois ne s'adressent pas à Dieu seul, comme le veulent les Chrétiens, mais « au ciel, à la terre, au soleil, à la lune, aux étoiles et à des créatures beaucoup plus viles et plus indignes $\gg 1$.

L'empereur ayant été obligé de partir pour la Tartarie convoqua Maigrot en Tartarie pour entendre ses explications, et il lui donna audience le 2 août 1706. C'est le récit de cette audience que les Jésuites ont répandu à profusion en Europe

\footnotetext{
${ }^{1}$ Launay, op. cit., t. I, p. 471.
} 


\section{La Chine et la formation de l'esprit philosophique en France}

pour faire toucher du doigt l'ignorance de Maigrot 1. En effet, sur quatre caractères chinois que l'empereur lui donna à déchiffrer à l'improviste, il n'en put lire que deux. Les adversaires des Jésuites crièrent au guet-apens et ils en rendirent les Jésuites responsables, tout en niant que l'ignorance de Maigrot eût été étalée avec tant d'évidence. Cependant cette ignorance peut s'expliquer, pense M. Cordier, car Maigrot, vicaire apostolique du Fou-kien, où le dialecte est tout différent de celui de Pékin, ne pouvait guère rivaliser avec les Jésuites, versés dans les usages de la cour, habitués à manier la langue du nord, et soutenus au fond par l'empereur ${ }^{2}$. Le légat trouva pourtant un secours inattendu chez un Jésuite très savant, le P. Visdelou, qui, persuadé de l'athéisme et de l'idolâtrie des Chinois, fournit au légat tous les textes chinois paraissant contraires à I'opinion des Jésuites ${ }^{3}$. Mais il eut affaire à forte partie car les Jésuites, notamment les PP. Stumpff et Provana, déployèrent une vigueur dans leurs arguments qui produisirent le plus grand effet sur l'empereur ${ }^{4}$.

Le résultat de cette conférence fut que, le jour même, Kang hi ordonna à Maigrot de se retirer à Pékin dans la maison des religieux de la Compagnie de Jésus, et d'y demeurer jusqu'à ce qu'il eût statué entièrement. Par un décret du 3 août, il intima au

1 Notamment dans L'Etat présent de l'Église de Chine adressé à Monseigneur l'évêque de ... s. 1. n. d. C'est de cet opuscule que Voltaire s'est servi pour écrire son récit de l'entrevue de Maigrot avec l'empereur Kang hi. Cf. notamment p. 56 et 69 de cet opuscule.

2 Cordier, Histoire de la Chine, t. III, p. 326.

${ }^{3}$ Sommervogel, op. cit., art. Jouve, t. VIII, col. 839.

${ }^{4}$ Cordier, op. cit., t. III, p. 326. 


\section{La Chine et la formation de l'esprit philosophique en France}

patriarche de Tournon l'ordre de songer à son retour. Quelque temps après, Maigrot fut arrêté, puis conduit à Canton. Le patriarche de Tournon quitta Pékin le 28 août et s'achemina vers Nankin. Arrivé à Nankin, il n'osa pas encore publier le décret de Clément XI mais il convoqua les missionnaires et leur p.120 donna lecture du mandement qu'il avait projeté et qui prohibait tous les cultes chinois. Dès que Kang hi eut connaissance de cette déclaration, il fut tellement irrité contre le légat qu'il le fit aussitôt arrêter et conduire à Macao avec ordre aux Portugais de le retenir prisonnier. Le légat mourut le 8 juin 1710. Le chapeau qu'il reçut fut une consolation in extremis. Ainsi finit cette ambassade qui devait mettre fin aux querelles des missionnaires mais qui ne fit au contraire que les envenimer encore et qui eut pour résultat un édit de l'empereur interdisant dorénavant aux Européens qui étaient en Chine d'y demeurer sans avoir de lettres patentes de l'empereur, et ordonnant, à ceux qui voudraient venir en Chine de prendre des lettres patentes à Pékin ${ }^{1}$.

Les Jésuites interjectèrent appel du mandement du patriarche de Tournon. Maigrot expulsé de Chine vint à Rome défendre la cause des Missionnaires. La lutte devint alors aussi vive à Rome qu'elle l'avait été en France en 1700, lors de l'examen par la Sorbonne du livre du P. Le Comte.

Les Missions étrangères semblent avoir été disposées en 1709, à jouer le tout pour le tout. Elles adressèrent au pape, contre les écrits des Jésuites, une protestation dont les termes

\footnotetext{
${ }^{1}$ L'Etat présent de l'Eglise de la Chine, p. 95.
} 


\section{La Chine et la formation de l'esprit philosophique en France}

violents choquèrent un peu même les jansénistes comme Mathieu Marais : «Avez-vous vu, Madame, écrit-il à Madame de Mérignac, la protestation des missionnaires contre les libelles des jésuites ; elle est étonnante, foudroyante, dans l'éloquence de Démosthène. Ils seront, disent-ils, mahométans, juifs, sociniens, jansénistes et plus jansénistes que Jansenius lui-même pourvu qu'ils détruisent I'idolâtrie de la Chine. La figure est outrée, et je ne crois pas que les apôtres eussent ainsi parlé, mais le zèle devient fureur contre certaines gens ${ }^{1}$. Au même moment, Maigrot, à Rome, se servait des « écritures de $M$. le Patriarche $\gg 2$ pour essayer d'emporter à Rome une condamnation définitive des Jésuites.

Le Pape, qui voulait terminer cette querelle sans cesse renaissante, publia, le 25 septembre 1710, un décret qui confirmait son premier décret de 1701 et le mandement du cardinal de Tournon de 1707, cassait I'appel fait par les Jésuites contre ce mandement et interdisait en même temps d'écrire ou de publier quoi que ce fût sur l'affaire des Cérémonies chinoises, « à moins que d'en avoir obtenu dans la Congrégation de la Sainte et Universelle ${ }_{\text {p.121 }}$ Inquisition une permission expresse de Sa Sainteté ou du Souverain Pontife qui occuperoit alors le SaintSiège »3. Quelques jours plus tard, le 11 octobre, le pape faisait signifier le nouveau décret par l'assesseur du Saint-Office à tous

\footnotetext{
1 Mathieu Marais, Journal et Mémoires, t. I, p. 116.

2 Lettre du P. Daubenton au P. de Vitry, 24 mars 1709, in Fénelon, Correspondance, t. III, p. 204-5.

3 Second Décret de N. S. P. le pape Clément XI du 25 septembre 1710, p. 4-5.
} 


\section{La Chine et la formation de l'esprit philosophique en France}

les généraux des ordres religieux représentés en Chine ${ }^{1}$. Les Jésuites semblaient donc bel et bien condamnés; mais la souplesse dont ils avaient fait preuve jusque là laissait le public sceptique sur leur esprit de résignation. «Le pape, écrit Mathieu Marais, a publié sa constitution contre les cérémonies de la Chine. Tout le monde est dans l'attente du stratagème nouveau qui sauvera les bons Pères de ce pas. Car ils en trouveront un, infailliblement, et ce sera un beau spectacle que de voir la religion sacrifiée aux inventions humaines $\gg 2$. Comme le supposait Mathieu Marais, les Jésuites trouvèrent un moyen de se tirer d'affaire. Ils menacèrent le pape d'abandonner la mission de Chine. Le pape avoua qu'il n'y avait encore rien de fait, et il promit de donner une réponse nette et définitive, c'est-à-dire une constitution, un jugement motivé sur le fait des cultes chinois.

$\mathrm{Si}$, en 1711 , l'activité des deux partis hostiles dans l'affaire des Cérémonies chinoises est aussi grande à Rome qu'elle le fut en France et à Rome en 1700, la situation respective des deux partis a changé du tout au tout. Tandis qu'en 1700 le crédit des Missions étrangères était à son apogée grâce à l'appui du cardinal de Noailles et de Madame de Maintenon, en 1711, les Jésuites ont reconquis les positions perdues. Au P. de la Chaize a succédé près du roi le P. Le Tellier. Le cardinal de Noailles qui reste seul du «triumvirat est en demi-disgrâce et il a fort à faire pour se défendre contre les accusations de jansénisme que

\footnotetext{
1 Saint-Simon, Mémoires, t. XX, p. 200, n. 4.

2 Mathieu Marais, Journal et Mémoires, t. I, p. 135.
} 


\section{La Chine et la formation de l'esprit philosophique en France}

portent contre lui les Jésuites et leurs amis. En France, les Jésuites sont tout-puissants. A Rome, ils ont un point vulnérable : c'est l'affaire des Cérémonies chinoises. C'est donc de ce côté que les jansénistes vont les attaquer. Mais les Jésuites vont essayer de se servir de leur crédit en France pour éviter une condamnation définitive à Rome. La querelle continue donc, avec une violence accrue alors qu'elle semblait définitivement close ${ }^{1}$. p.122 Elle nous devient seulement à partir de ce moment un peu plus insaisissable, parce qu'à l'interdiction du pape de rien publier sur cette question s'ajoute une interdiction du roi du 20 octobre 1711, défendant aux supérieurs des congrégations religieuses de publier aucun écrit sur la question des rites 2 . Heureusement nous avons pour nous renseigner sur l'activité

\footnotetext{
1 Le marquis de Torcy a signalé en termes énergiques dans son Journal l'influence considérable que possédaient les Jésuites à la cour de France en 1710 : « Je marque seulement pour m'en souvenir que nous étions alors dans un temps où rien n'était plus facile que de' décrier auprès du roi ceux qu'on voulait perdre. Une accusation générale de penchant pour le jansénisme en faisoit l'affaire. Une liaison même éloignée avec quelque père de l'oratoire suffisait. Un homme qui n'aurait jamais entendu parler de la grâce était réputé l'un des plus ardents sectateurs de Jansenius et comme tel non seulement hérétique, mais malintentionné, mais ennemi personnel du roi et perturbateur du repos public. C'était un effet de douceur et de clémence que de ne lui faire aucun tort dans ce qu'il possédait, mais il était exclu de toute grâce pour lui et pour ses parents... Les ecclésiastiques ne trouvaient de voie pour parvenir que celle de servir les jésuites comme valets. » (Journal de Torcy, 25 juin 1710, p. 213). De son côté Quesnel écrivait à M. Schort le 12 septembre 1710 : «En France, le feu est plus violemment que jamais. Le Confesseur du roi Très Chrétien le P. Tellier, qui est l'apologiste des cultes chinois contre qui ont été faits les six derniers volumes de la morale pratique des Jésuites, ce Père, dis-je, est tout-puissant ; il fait introduire partout la signature du formulaire. » (Lettres, t. II, p. 308).
}

2 Launay, op. cit., t. I, p. 484. 


\section{La Chine et la formation de l'esprit philosophique en France}

des jansénistes à Rome dans cette affaire les lettres du P. Roslet au cardinal de Noailles ${ }^{1}$.

$*$

Les jansénistes commencent à mener l'attaque et ils exploitent la mort du cardinal de Tournon, dont on s'efforce de faire retomber la responsabilité sur les Jésuites.

Le P. Roslet ne manque pas d'envoyer au cardinal de Noailles, au début de novembre 1711, l'éloge que le pape a fait du cardinal de Tournon : « J'ay tardé à l'envoyer parce qu'on devoit I'imprimer avec la relation de sa mort faite par son Agent, mais on n'ose presque la donner au public parce que l'Autheur dit la vérité et il a pris le parti de l'envoyer à Turin au marquis de Tournon, frère du deffunt, qui le fera imprimer avec l'image du nouveau martir »2. On demande à Rome, dit le P. Roslet, la canonisation du cardinal et I'on presse l'abbé Fatinelli de publier sa relation de la mort du légat, de peur que le pape ne ${ }_{\text {p.123 }}$ révoque l'autorisation qu'il a donnée de l'imprimer ${ }^{3}$. Le 21 novembre, le P. Roslet envoie au cardinal de Noailles une lettre pleine de bonnes nouvelles : «Le grand pénitencier de la ville de Lecce, au royaume de Naples, a envoyé à l'abbé Fatinelli une relation authentique des miracles faits par l'intercession du

\footnotetext{
1 Sur l'activité du P. Roslet à Rome cf. la lettre de Daubenton à Fénelon, 23 octobre 1711, in Fénelon, Correspondance, t. III, p. 44.

2 Lettre du 7 novembre 1711. B. N. Fr. 23.227, f. 62. A partir de ce moment, ce nom de martyr devient une appellation que les jansénistes appliquent couramment au cardinal de Tournon. (Cf. Mathieu Marais, Journal et Mémoires, t. I, p. 150).

3 Lettre du 14 novembre 1711. B. N. Fr. 23.227, f. 69.
} 


\section{La Chine et la formation de l'esprit philosophique en France}

cardinal de Tournon, glorieux martir de Jésus-Christ. L'abbé Fatinelli a envoyé cette relation au pape avec une lettre très forte.. pour le porter à juger l'affaire de la Chine qu'il ne peut plus différer sans blesser sa conscience et sans s'attirer les reproches de Dieu et des hommes apostoliques qui soupirent après une bonne décision beaucoup plus importante que les obsèques qu'il veut faire à ce martyr. J'ay cru que cette nouvelle feroit plaisir à Votre Excellence ; Sa Sainteté a répondu de bouche qu'on a tort de se plaindre parce qu'il travaille actuellement à une bulle qui terminera cette controverse. On se flatte que cette bulle ou constitution pourra paroître dans le temps des obsèques ou peu après. Je le désire mais je n'ose I'espérer ou l'assurer »1. La semaine suivante, le P. Roslet annonce au cardinal que les obsèques du cardinal de Tournon ont eu lieu et il lui envoie l'oraison funèbre qui a été imprimée secrètement «avec les autres pièces qui y sont jointes », et il ne doute pas que cette relation ne puisse être aussi imprimée à Paris ${ }^{2}$.

Les Jésuites tendent le dos pour laisser passer l'orage. A tort ou à raison, tout le bruit fait autour de la mort du cardinal de Tournon et que les jansénistes savent si bien exploiter, I'approche des funérailles solennelles qui seront peut-être le prétexte d'un nouveau décret pour les condamner, les incitent à une soumission anticipée. Le 20 novembre 1711 ils se déclarent prêts à se soumettre au jugement du pape « contre ceux qui les

\footnotetext{
${ }^{1}$ Lettre du 21 novembre 1711, ibid., f. 78-9.

2 Lettre du 28 novembre 1711, ibid., f. 85.
} 


\section{La Chine et la formation de l'esprit philosophique en France}

persécutent de toutes parts $\gg 1$. Aussitôt après le pape publie son bref confirmant tout ce qu'avait fait le cardinal de Tournon contre les Jésuites. Et le P. Roslet triomphe, et il indique au cardinal de Noailles le parti qu'il peut en tirer : «Il seroit bon d'informer les Princes que le pape vient de confirmer par un Décret solennel tous les Décrets qu'avait prononcés le Légat contre les Jésuites rebelles à ses ordres qui se sont vus obligés à donner la déclaration que Sa Sainteté a ${ }_{\text {p.124 }}$ exigée. Cela feroit valoir les bonnes raisons que Votre Excellence a eu de suivre à leur égard l'exemple de ce Saint-Card. »2.

Le P. Roslet et le cardinal de Noailles ont donc toutes les raisons d'être satisfaits de la tournure que prennent leurs affaires à Rome contre les Jésuites. Une bonne condamnation des Jésuites à Rome serait une justification des mesures de rigueur que le cardinal de Noailles a prises contre eux en France. Mais une inquiétude perce cependant chez le $P$. Roslet. Le bruit court à Rome que le roi de France a fait demander au pape une constitution contre les erreurs contenues dans le Nouveau Testament du P. Quesnel. Le 5 décembre le P. Roslet espère encore que ce danger pourra être écarté, le pape lui ayant marqué une grande répugnance à donner une constitution, craignant «qu'elle ne lui attirât autant d'embarras que la précédente ${ }^{3}$ [la Bulle Vineam Domini] ». Quelques jours après

\footnotetext{
1 Même lettre, f. 82 .

2 Lettre du 5 décembre 1711, ibid., f. 94.

3 Lettre du 5 décembre 1711, ibid., f. 87-8.
} 


\section{La Chine \\ et la formation de l'esprit philosophique en France}

cependant (11 décembre) arrive à Rome la nouvelle officielle que le roi demande la constitution ${ }^{1}$.

L'affaire est d'importance pour le P. Roslet, et pour le cardinal de Noailles. Les Jésuites ont su intervertir les rôles. Pour se défendre là où ils sont faibles, et même on peut le dire battus d'avance, ils attaquent là où ils sont forts. C'est le premier principe et peut-être le seul de la stratégie. Mais usant d'une tactique semblable le P. Roslet et le cardinal de Noailles vont essayer de temporiser dans I'affaire de Quesnel pour emporter d'abord la condamnation des Jésuites dans l'affaire des Cérémonies chinoises, et ils ne vont pas craindre de frapper à la tête : ils vont essayer de compromettre le P. Le Tellier qui a fait demander au pape la condamnation du jansénisme.

En effet, dès le 28 novembre, le P. Roslet annonçait au cardinal de Noailles qu'il avait pu se procurer quatre exemplaires de la suite de l'Histoire de la Compagnie de Jésus du P. Jouvancy avant qu'on eût le temps de cartonner les passages qui pourraient sembler répréhensibles au Saint-Siège 2 .

Cet ouvrage contient, en effet, un long chapitre sur la Chine (Livre XIX, pp. 513-76) et notamment un paragraphe (18) De Sinarum religione, où l'on trouve toutes les idées avancées déjà par le P. Le Comte et condamnées autrefois par la Sorbonne. Les Jésuites, en effet, ne se croyaient pas définitivement condamnés, et dans un écrit qu'ils faisaient circuler à Rome en mars 1712, au p.125 moment même où s'amorce la campagne

1 Le Roy, La France et Rome, p. 380.

2 Lettre du 28 novembre, ibid., f. 83. 


\section{La Chine et la formation de l'esprit philosophique en France}

contre le P. Jouvancy, ils déclaraient qu'ils étaient toujours en droit de suivre leurs usages en Chine, même après les décrets du Saint-Siège et du cardinal de Tournon ${ }^{1}$.

Le pape confia à Maigrot que cet écrit contenait des propositions fausses et injurieuses pour le Saint-Siège et que cela lui ferait hâter la constitution « qui sera si précise qu'on ne pourra l'éluder » 2. Maigrot profita immédiatement de ces bonnes dispositions du Pape, et il composa « un bon écrit pour porter le Pape à donner une décision si claire que les Jésuites soyent obligez d'abandonner les mauvais rites de la Chine »3. Il faisait voir dans cet écrit que les Jésuites suivaient les principes des jansénistes, et qu'ils s'obstinaient à permettre les rites condamnés, « parce qu'ils ne croyent pas que l'église soit infaillible dans un fait de cette nature, comme si un culte idolâtrique dont il s'agit, estoit moins important à la religion qu'un mauvois sentiment sur la grâce $\gg 4$.

\footnotetext{
1 Lettre du 2 mars 1712. Ibid, f. 186. Une note qui se trouve dans les archives de la Société de Jésus et qui est citée par Sommervogel, op. cit., t. IV, col. 85, montre que les Jésuites soutenaient alors que les propositions condamnées par la Sorbonne n'étaient pas contraires aux décrets du pape : «Quidquid scripit (Jouvanci) approbatum est a Rmo Magistro Sacri Palati Apostolici. At credibile non est ab illo approbatum fuisse librum contrarium Decreto Summi Pontificis. Quod scripsit neque falsum, neque oppositum est Decreto Pontificio, ut patet a genuina propositions sequenti :

Ia propositio. - Sinæ veteres verum numen cognoverunt.

IIa propositio. - Sinæ recentes multi cognoscunt et colunt verum Deum.

C'est exactement ce que les Jésuites essayent de prouver dans leurs publications sur la Chine, Lettres édifiantes, Description de la Chine, etc.

2 Lettre du 9 avril 1712. ibid., f. 193-4.

3 Lettre du 14 mai 1712 . B. N. Fr. 23.228.

${ }^{4}$ Lettre du 14 mai 1712. ibid., f. 4.
} 


\section{La Chine et la formation de l'esprit philosophique en France}

Le livre du P. Jouvancy fut dénoncé secrètement au mois de juillet 1712. Le maître du Sacré Palais fit saisir tous les exemplaires de ce livre qui se trouvaient chez les Jésuites : «On convient, nous dit le P. Roslet, qu'elle [cette histoire] mérite condamnation et qu'on en doit au moins retrancher beaucoup de choses condamnées dans le livre du P. Le Tellier et du P. Le Comte ${ }^{1}$. A la fin du même mois le livre fut dénoncé dans les formes par le cardinal Tomasi qui joignit à sa dénonciation un écrit de sa propre main prouvant que «si ce que les jésuites ont avancé sur les affaires de la Chine est vrai, le pape et le SaintOffice illuserunt Ecclesice » 2. Le P. Le Tellier n'y était pas épargné, non plus que ${ }_{\text {p.126 }}$ son Apologie des nouveaux chrétiens. Et le P. Roslet se frotte les mains de satisfaction à l'idée de cette diversion si bien imaginée et qui va irriter les « grands frères $\gg 3$. Est-il besoin de rappeler l'affaire à laquelle le P. Roslet et le cardinal de Noailles jugeaient utile de faire diversion ? Mais étaitil de bonne politique de s'attaquer au plus puissant de tous les Jésuites, au P. Le Tellier, et de s'attaquer surtout à cette Défense des Nouveaux Chrétiens de la Chine qui pouvait rappeler au P. Le Tellier la condamnation que le Saint-Siège en avait faite, même s'il avait été disposé à l'oublier ? N'était-ce pas couper les ponts et engager une lutte sans merci qui ne pouvait se terminer que par la défaite complète de l'un ou de l'autre des deux adversaires ? D'ailleurs le P. Roslet prévint le cardinal de Noailles

\footnotetext{
${ }^{1}$ Lettre du 23 juillet 1712, ibid., f. 71, $v^{\circ}$.

2 Lettre du 30 juillet 1712, ibid., f. 79.

3 Lettre du 6 août 1712, ibid., f. 95.
} 


\section{La Chine et la formation de l'esprit philosophique en France}

le 12 novembre 1712, que le Jésuite considérait toutes ces querelles comme une lutte sans merci entre le cardinal et lui : « On dit qu'il [le P. Le Tellier] avoit assuré ses amis qu'il vous obligeroit de quitter vostre place ou qu'il quitteroit la sienne $\gg 1$.

En même temps on tâche de tirer parti de la mort du cardinal de Tournon, et jansénistes et Missionnaires signalent à qui mieux mieux les miracles que le cardinal de Tournon commence à faire. M. Charmot se trouve-t-il malade au mois de janvier 1712 ? Il « fait dire au Pape par le médecin qui l'est venu visiter de sa part qu'il a esté guéri par l'intercession du St-Martir de Tournon qu'il a invoqué et dont il a fait exposer l'image sur son lit $\gg 2$. D'ailleurs le P. Roslet détourne M. Charmot d'aller déclarer ce miracle à la Congrégation qui doit travailler à la béatification de cet homme apostolique, «parce que le témoignage y seroit contredit par la Société qui ne luy pardonnera pas plus qu'à Palafox »3. Quelques mois après c'est un M. Nicolaï qui a été très mal et qui assure qu'il est redevable de sa guérison à l'intercession du Saint Cardinal de Tournon qu'il avoit invoqué, et le Pape a consenti qu'on fasse là-dessus, une information selon les règles de la Congrégation des Rites ${ }^{4}$. Quand un peu plus tard l'abbé Fatinelli guérit d'une maladie grave contre toute attente, nul doute que ce brave ecclésiastique ne doive aussi sa guérison au cardinal, puisqu'il est chargé de ses intérêts posthumes et de

\footnotetext{
1 ibid., f. 191.

${ }^{2}$ Lettre du 23 janvier 1712. B. N. Fr. 23227, f. 133-4.

3 Même lettre, ibid., f. 134.

4 Même lettre de $1^{\text {er }}$ mars 1712 . B. N. Fr. 23227, f. 175-6.
} 


\section{La Chine et la formation de l'esprit philosophique en France}

la publication de ses papiers ${ }^{1}$. Le Jésuite Tolomei obtient-il le

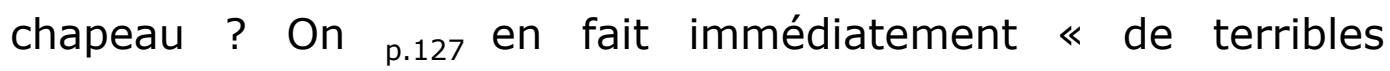
pasquinades ». On dit que les bourreaux ont eu les dépouilles du martir ; dans une autre pasquinade, on représente « un bourreau qui frappe la teste du Cardinal et fait tomber son chapeau et le Pape qui le ramasse et le met sur la teste du Jésuite $\gg 2$

Tandis que le P. Roslet signalait ainsi au cardinal de Noailles tous les points faibles des Jésuites et cherchait lui-même à les atteindre au défaut de la cuirasse, c'est-à-dire dans l'affaire des Cérémonies chinoises, il recommandait au cardinal de temporiser le plus possible dans I'affaire du Nouveau Testament de Quesnel. Il lui recommandait de «porter la cour et les magistrats à tenir ferme sur la demande de qualification des propositions déférées à Rome et à ne s'en point relâcher » 3 . Lui-même, il agissait près des cardinaux pour demander ces qualifications, ce qui prendrait plus de temps. Il faisait valoir la nécessité de bien réfléchir à ces qualifications pour quelles ne continssent rien que le clergé de France et les magistrats ne pussent recevoir. Et il ajoutait avec satisfaction : «Cette affaire doit naturellement occuper un grand temps étant comme celles qui, selon la maxime d'ici, ne finissent jamais mieux que quand elles ne finissent point $\gg 4$. Au contraire le roi, par l'intermédiaire de son ambassadeur ou de son

\footnotetext{
${ }^{1}$ Lettre du 2 juin 1712. B. N. Fr. 23228, f. 46.

2 Lettre du 28 mai 1712. B. N. Fr. 23228, f. 19-20.

3 Lettre du 24 décembre 1712. ibid., f. 230, vº.

4 Le Roy, La France et Rome, p. 382, n. I.
} 


\section{La Chine et la formation de l'esprit philosophique en France}

confesseur pressait le pape de donner la constitution. Or, brusquement, tout change. Le roi et le P. Le Tellier qui se montraient si pressés jusque-là, semblent vouloir reculer le dénouement. Au mois d'août 1712, en effet, ils défèrent à Rome soixante-dix propositions nouvelles extraites du livre du P. Quesnel, en plus des trente-trois qu'ils avaient déjà déférées. Et le pape lui-même ne peut s'empêcher d'en marquer son étonnement : «Je ne scais comme l'entend le P. Le Tellier, dit-il à La Trémoille ; il me fait escrire à tous les Ordres par le Roy et par l'ancien auditeur de la nonciature pour accélérer la Constitution et il fait faire par cette nouvelle dénonciation tout ce qu'il faut pour la reculer, parce que s'il a fallu tant de mois pour examiner trente-trois propositions il en faut bien plus pour en examiner cent-trois »1. La menace de censure du livre du P. Jouvancy n'était-elle pas venue juste à point pour inciter le P. Le Tellier à faire de la condamnation de Quesnel une affaire d'importance telle qu'à côté la condamnation du P. Jouvancy passerait inaperçue?

p.128 Quoi qu'il en soit, et malgré cette situation nouvelle, le P. Roslet ne lâche pas l'affaire du P. Jouvancy. Ce qui pour lui était autrefois un moyen d'attaque ne constitue plus qu'une diversion, mais elle lui paraît néanmoins fort utile. On poursuivait en effet le livre du P. Jouvancy devant le Parlement de Paris. Les Jansénistes espéraient qu'il serait lacéré et brûlé par la main du bourreau et I'on comptait sur cette condamnation pour emporter celle du pape : «Il [le pape] attent peut-estre que le Parlement

\footnotetext{
1 Lettre du P. Roslet, 3 septembre 1712. B. N. Fr. 23228, f. 124.
} 


\section{La Chine et la formation de l'esprit philosophique en France}

ait fulminé pour suivre son exemple, n'osant pas attaquer le premier la redoutable société ${ }^{1}$. »A Paris, la condamnation que les Jansénistes escomptaient se réduisit comme on le sait, grâce au crédit des Jésuites et du P. Le Tellier, à une simple suppression par deux arrêts du Parlement du 2 février et du 24 mars 1713, avec une admonestation « légère et honnête » 2 du premier président, condamnation fort douce, dont le P. Le Tellier « parut fort mécontent, ravi en secret d'avoir si bien fasciné le Roi et qu'il ne leur en eut pas coûté davantage »33. A Rome, peut-être à cause de cette condamnation trop douce du Parlement de Paris, I'affaire traîna en longueur. Maigrot publia bien en 1714 une critique virulente du livre du P. Jouvancy ${ }^{4}$, et le meilleur factum qu'il ait écrit d'ailleurs dans cette question des rites chinois. Le livre du P. Jouvancy fut seulement prohibé à Rome le 29 juillet 1722, en attendant que les passages concernant les rites chinois eussent été cartonnés « prohibentur quae concernunt ritus sinenses, quibus deletis, permittitur

1 Lettre du 19 janvier 1713, ibid., f. 245-246.

2 Saint-Simon, Mémoires, t. XXIII, p. 293.

3 Id., ibid. On connaît la réponse de l'abbé Pucelle, le plus intransigeant des Jansénistes du Parlement, au P. de Laistre, qui le remerciait : « Allez droit à Versailles, mes Pères ; c'est là que vous devez faire vos remerciements. Vous ne $m$ 'avez aucune obligation et je serois très faché que vous $m^{\prime}$ en eussiez en de pareilles matières. » Saint-Simon, Mémoires, t. XXIII, Appendice X, p. 515.

4 Examen des faussetez sur les cultes chinois avancées par le Père Joseph Jouvenci Jésuite dans l'histoire de la Cie de Jésus traduit d'un écrit latin composé par le P. Minorelli de l'ordre de St Dominique missionnaire à la Chine, s. I., 1714, in-12. 


\section{La Chine et la formation de l'esprit philosophique en France}

liber ${ }^{1}$. Il y avait longtemps à cette époque, que le P. Roslet était mort 2 .

Le P. Roslet aurait même voulu que le cardinal de Noailles, non content de dénoncer Jouvancy s'attaquât au P. Le Tellier luimême : « On est surpris que personne ne réveille la condamnation du livre du P. Le Tellier qu'il luy a esté impossible de justifier ny ${ }_{\text {p.129 }}$ de corriger et qu'il n'a pas rétracté ! Comment ose-t-il faire demander à Votre Excellence qu'elle rétracte l'approbation qu'elle a donnée à un livre que tant de Saints et sçavans Evesques avoient desja approuvé. Que diroit le Roy s'il estoit informé de ce fait ? Ne jugeroit-il pas qu'un Livre qui authorise l'idolatrie est aussy détestable que celuy qui favorise le Jansénisme ; ...Pourquoy ne le presse-t-on pas à le rétracter, pour faire une diversion dont ils [les Jésuites] sçavent si bien se servir, car ils éloignent le jugement de la Chine en occupant cette Cour d'un livre de Quesnel. On a raison de procéder contre I'histoire de Jouvancy qui offense I'Estat. Mais celui de Le Tellier est beaucoup plus mauvais puisqu'il attaque les fondemens de la Religion ${ }^{3}$.

La mort du P. Roslet, et la fin de sa correspondance avec le cardinal de Noailles, si précieuse pour nous faire connaître les agissements et les menées sourdes des jansénistes et des Jésuites à Rome, - attaques, ripostes et diversions - nous

\footnotetext{
1 Sommervogel, op. cit., t. IV, col. 853.

2 Une lettre du P. Francœur au cardinal de Noailles du 28 janvier 1713 annonce la mort du P. Roslet « survenue ce jour même ». B. N. Fr. 23228, f. 254.
}

3 Lettre du 17 décembre 1712. ibid., f. 226-227. 


\section{La Chine et la formation de l'esprit philosophique en France}

privent désormais de renseignements sur l'attitude du cardinal de Noailles et des jansénistes à l'égard de l'affaire des Cérémonies chinoises. Sans doute, cette affaire cède le pas, en France et à Rome, aux discussions qui s'élèvent au sujet de l'acceptation de la constitution Unigenitus. Mais si I'on songe que moins de deux ans après la fulmination de la Bulle Unigenitus, le pape fulmina une bulle de condamnation des Jésuites dans I'affaire des Cérémonies chinoises, on peut imaginer que le cardinal de Noailles et son parti purent y voir un succès pour eux et une revanche contre ceux qui avaient fait condamner Quesnel. Et désormais les jansénistes constateront, ironiquement, mais non sans aigreur, la double attitude des Jésuites qui, d'une part veulent obliger à l'acceptation de la Bulle Unigenitus et qui 


\title{
La Chine et la formation de l'esprit philosophique en France
}

\author{
d'autre part refusent d'accepter pour eux-mêmes la Bulle Ex illa \\ die ${ }^{1 .}$
}

\author{
$*$ \\ Le pape crut terminer en 1715 toutes les contestations sur les \\ rites chinois en publiant la Bulle Ex illa die (19 mars 1715). Cette \\ Bulle prescrivait d'observer le décret de 1704 sans avoir égard
}

1 A la fin de 1716 on vendait à la foire de Francfort un pamphlet contre les Jésuites intitulé «Traité de la nécessité de recevoir les constitutions des papes en France et de les rejeter en Chine par le R. P. Le Tellier » (Buvat, Journal de la Régence, t. I, p. 228). En 1718 le poète comique Destouches, dans une Requête d'un mandarin de la Chine au Pape Clément demandait au Pape de supprimer les deux Bulles, celle qui avait été apportée en Chine par le Cardinal de Tournon et la Bulle Unigenitus,

.... pour ne pas voir dans peu

A Loyola, morguant votre puissance

Faire chez nous ce qu'il déteste en France.

Et menaçant ironiquement le Pape d'un appel au concile s'il ne retirait la Bulle du Cardinal de Tournon, il concluait :

Bulles feront de I'Eglise un Sabat.

Bulles perdront toute la terre ronde.

Bulles ont fait que la moitié du monde

Du Paradis a banni l'autre part

Pour cela seul il mérita la Hart

Qui le premier en inventa I'usage.

N'en faites plus et vous serez bien sage.

(Nouvelles Littéraires, samedi 26 mars 1718, t. VII, p. 201-204).

En août 1720, Mathieu Marais signale le fait de deux missionnaires qui, allant en Chine, sont morts en route, et auxquels les Jésuites ont refusé la sépulture parce qu'ils n'ont pas voulu accepter la Constitution Unigenitus avant de mourir. Et Marais ajoute : « Ainsi ils se jouent des papes et de leurs bulles comme il leur plait et selon qu'elles leur conviennent » (Journal et Mémoires, t. , p. 405). Plus tard, en 1741, une publication d'inspiration janséniste, Anecdotes sur la Chine, consacre tout un volume à démontrer cette double attitude des Jésuites ; «...Par un contraste assez étonnant mais qui ne surprend que les personnes qui ignorent les ressorts de la politique des Jésuites, et leur entier dévouement à leur unique société, on voit à la Chine ces Pères Opposans. Appelans Réappelans même de plusieurs Décrets et Constitutions des Papes ; pendant qu'en Europe on leur en voit soutenir une par toute sorte de moyens, qui est aussi contraire à la vraie foi que celles qui regardent les affaires de la Chine sont nécessaires à I'honneur de la Religion et au maintien de la doctrine de l'Évangile; et il ne faut à un Jésuite qui ne connoit d'autre intérêt que celui de sa Société que passer rapidement d'Europe à la Chine, pour devenir son ennemi le plus déclaré et le plus indomptable. » (Avertissement, t. III, p. VI-VII). 


\section{La Chine et la formation de l'esprit philosophique en France}

aux prétextes dont on se servait pour en décliner ou en affaiblir I'autorité. Afin d'être assuré de l'exécution de sa volonté, le pape p.130 déclarait que tout acte contraire serait puni par le fait seul d'une déclaration majeure et il imposait le serment ${ }^{1}$. Mais cette constitution si catégorique dans la forme, laissait encore la porte ouverte à des discussions de toute sorte. Or les Jésuites avaient toujours prétendu que toutes les cérémonies du culte de Confucius et du culte des morts étaient des cérémonies purement civiles. C'est à convaincre le pape et l'opinion publique en France de la justesse de leurs idées sur les cultes chinois qu'ils vont s'employer dans leurs Lettres édifiantes et curieuses et dans la Description de la Chine, tandis que Renaudot les contredira dans les dissertations qui suivent la traduction des Anciennes relations ${ }_{\text {p.131 }}$ des Indes et de la Chine. La Bulle Ex illa die ne termina donc pas l'affaire des Cérémonies chinoises. Cependant la phase politique de cette affaire est close ; la bulle Unigenitus a relégué l'affaire des Cérémonies chinoises à I'arrière-plan.

Clément XI s'apercevant que sa bulle de 1715 n'avait pas terminé la querelle envoya en Chine, en 1720, le légat Mezzabarba. Lorsque le légat fut arrivé à quelques heures de Pékin, il fut invité par l'Empereur à s'arrêter et à faire connaître le but de sa mission. Il écrivit à l'empereur « qu'il était envoyé pour assurer l'exécution de la Bulle Ex illa die et qu'il désirait

\footnotetext{
${ }^{1}$ Launay, Histoire de la Société des Missions étrangères, t. I, p. 484-485. La traduction française in extenso se trouve dans A. Thomas, Histoire de la Mission de Pékin, p. 213-251. L'abbé Thomas, dont le livre est tout inspiré par l'esprit des Missions étrangères considère cette bulle comme étant « encore aujourd'hui la charte des Missions de l'Extrême-Orient », op. cit., p. 243.
} 


\section{La Chine et la formation de l'esprit philosophique en France}

être reconnu comme supérieur des missionnaires. Kang hi répondit qu'il acquiesçait volontiers à cette demande, mais à condition que le légat laissât les religieux attachés à la cour et emmenât tous les autres missionnaires à Rome, où il serait maître de leur signifier la Bulle et d'exercer ses fonctions de supérieur. Cette réponse ironique était accompagnée du refus de donner audience à l'envoyé du pape. L'empereur finit cependant par le recevoir mais il lui interdit de publier la Bulle. Ce qui fit que Mezzabarba envoya à l'empereur le texte de huit permissions qui exemptaient à peu près complètement de I'application des règles contenues dans la Bulle Ex illa die. Elles donnaient en effet aux missionnaires le droit de tolérer l'usage des tablettes avec le nom du défunt, les offrandes de viande, de fruits, de parfums et d'encens devant les tablettes, devant le cercueil des défunts et devant le tombeau, à la condition toutefois que les chrétiens protestent qu'ils écartaient toute idée superstitieuse. Le 3 mars 1721, Mezzabarba sortit de Pékin et il arriva le 27 mai à Macao, où il publia un mandement (4 novembre 1791) pour exhorter les missionnaires à se conformer aux décrets du Saint-Siège qu'il avait modifiés par les huit permissions particulières ${ }^{1}$.

Mezzabarba à son retour de Rome laissa publier un récit de son voyage, et on s'aperçoit que les concessions qu'il fit aux Jésuites n'étaient pas le fait d'un amour exagéré pour la Compagnie, mais plutôt une mesure opportuniste pour essayer de sauver la mission : il avait reconnu la nécessité de terminer à

\footnotetext{
${ }^{1}$ Launay, Histoire de la Société des Missions étrangères, t. I, p. 488.
} 


\section{La Chine et la formation de l'esprit philosophique en France}

tout prix ces rivalités entre missionnaires dont l'empereur commençait à être las, et qui risquaient de faire proscrire définitivement le christianisme de Chine. L'empereur soutenait les Jésuites: Mezzabarba s'en rendit compte, ce qui I'amena à composer. Il s'en vengea seulement dans le récit de sa légation,

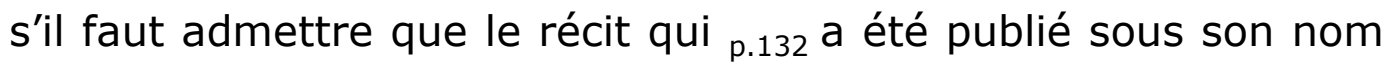
est son œuvre plutôt que l'œuvre du P. Viani : «Avez-vous lu, écrit le Président de Brosses, ce livre de la légation de Mezzabarba, qu'un Père Viani, servite, a fait imprimer à Milan ? C'est la plus violente satire que j'aie vue contre les Jésuites ; d'autant mieux qu'elle a un air de simplicité ne contenant que le détail des faits par de simples extraits des registres de l'ambassade, sans y joindre de réflexions, sinon sur la fin du livre, où l'auteur commence à montrer son venin contre la Société $\gg 1$.

Le 9 août 1742, le pape Benoit XIV publia la Constitution EX quo singulari, qui jugeait souverainement la question des rites chinois. Dans cette Bulle, le pape, après avoir fait l'historique de la controverse à partir des décrets de 1645, rapportait le mandement de Mezzabarba avec les huit permissions. Et il déclarait que le Saint-Siège n'avait jamais approuvé les concessions de Mezzabarba, qu'elles étaient contraires aux décrets pontificaux, qu'on devait les considérer comme nulles et non avenues et n'en faire aucun usage. Il confirmait le décret de Clément XI et défendait de l'interpréter autrement que le pape ne l'avait fait lui-même, c'est-à-dire que les cérémonies

\footnotetext{
${ }^{1}$ de Brosses, Lettres familières écrites d'Italie en 1739 et 1740, t. II, p. 249.
} 


\section{La Chine et la formation de l'esprit philosophique en France}

chinoises qui avaient fait l'objet de la querelle devaient être considérées sans exception comme idolâtriques et par conséquent illicites dans tous les cas possibles. Il portait les censures les plus sévères contre tous les missionnaires qui oseraient y contrevenir ; il ordonnait de renvoyer en Europe ceux qui ne se soumettraient pas, afin qu'ils fussent punis par le pape lui-même de leur désobéissance. Il prescrivait enfin la formule de serment à prêter par chaque missionnaire. Deux lettres de l'évêque de Pékin, écrites le 10 janvier 1743 et le 5 janvier 1744, ayant transmis au pape des observations sur les cérémonies chinoises, celui-ci écarta, dans un bref du 19 décembre 1744, tous les prétextes dont on pouvait colorer I'opposition aux constitutions apostoliques. Il montrait que les raisons de convenances alléguées contre l'opportunité de ses décisions n'étaient pas suffisantes quand il s'agissait de pratiques évidemment idolâtriques, et il faisait voir que les décrets, dont il établissait à la fois l'utilité et la convenance ne pouvaient nuire autant qu'on le prétendait à la propagation de la foi en Chine ${ }^{1}$. Ainsi pour la première fois depuis un siècle que durait la guerre des Cérémonies chinoises, un pape se risquait à prendre nettement ${ }_{\text {p.133 }}$ parti pour les condamner. Mais à cette époque, Voltaire avait déjà écrit le premier chapitre de son Essai sur les mœurs 2.

\footnotetext{
${ }^{1}$ Launay, Histoire de la Société des Missions étrangères, t. I, p. 539-540.

2 Ce premier chapitre, qui parut dans le Mercure de 1745 , mais avec des corrections et des atténuations, contient en réalité la matière des deux premiers chapitres de l'édition de 1753.
} 


\section{La Chine et la formation de l'esprit philosophique en France}

Enfin l'affaire des Cérémonies chinoises était close par la condamnation des Jésuites. Mais cette condamnation venait trop tard, car à cette époque tout le monde se désintéressait de la question des rites chinois, ou du moins si quelqu'un s'y intéressait encore dans le public, on n'y portait plus cette fureur théologique qui caractérise les premières années du XVIII siècle. La guerre de la Constitution Unigenitus suffit amplement à elle seule à occuper après 1713 ceux que pouvaient passionner les questions théologiques.

\section{$*$}

Au cours de cette histoire de l'affaire des Cérémonies chinoises, il est un témoignage qui peut être précieux pour juger les acteurs de cette querelle, mais que nous avons omis volontairement car c'est celui d'un adversaire acharné des Jésuites, et partant fort suspect - le témoignage de SaintSimon. On sait quelle est sa théorie sur cette affaire qui lui a inspiré quelques-unes de ses pages les plus virulentes et les plus pittoresques, tant dans ses Mémoires que dans ses Ecrits inédits, et I'on sait aussi comment il essaie d'établir une relation de cause à effet entre l'affaire des Cérémonies chinoises et l'affaire de la Constitution Unigenitus ${ }^{1}$. L'âme damnée de ces deux

\footnotetext{
1 Saint-Simon, Ecrits inédits, t. II, p. 473-6. Saint-Simon a été en relations par l'intermédiaire du cardinal de Gualterio avec Foucquet qui dut quitter la Compagnie de Jésus parce qu'il était d'un avis différent de celui de ses confrères sur l'interprétation des rites chinois. De Boislisle, dans ses Lettres de Saint-Simon au cardinal Gualterio (Extrait de l'Annuaire Bulletin de la Société de I'Histoire de France, t. XXV, 7.888, Paris, 1889) a signalé, p. 10, deux minutes de lettres de St-Simon adressées à l'évêque d'Eleuthéropolis (l'ex-jésuite Foucquet) existant dans la collection Morrison et relatives aux affaires de la Chine. Ces minutes n'ont pas été publiées par Thibaudeau dans son Catalogue d'autographes de la Collection Morrison.
} 


\section{La Chine et la formation de l'esprit philosophique en France}

affaires qui troublèrent l'Église et l'État pendant des dizaines d'années fut, suivant lui, le P. Le Tellier.

Saint-Simon signale avec raison le livre du P. Le Tellier, Défense des nouveaux chrétiens de la Chine en réponse à $L a$ Morale pratique des Jésuites et à Jurieu, et qui fut le premier engagement sérieux entre les Jésuites et leurs adversaires dans p.134 l'affaire des Cérémonies chinoises. Le gage de la réconciliation entre les Jésuites et les Missions étrangères en 1687 fut la lettre d'approbation donnée par le supérieur des Missions étrangères à cet ouvrage, et le signal des hostilités en 1700 fut la révocation de cette approbation. Le P. Le Tellier n'était pas cependant à cette époque confesseur du roi, et même il était peu connu. Mais Saint-Simon suppose, avec quelque raison qu'il était le porte-parole de son ordre tout entier : « Il [le P. Le Tellier] avoit été chargé de la défense du culte de Confucius et des cérémonies chinoises. Il en avoit épousé la querelle, il en avoit fait un livre qui pensa attirer d'étranges affaires à lui et aux siens et qui à force d'intrigues et de crédit à Rome, ne fut mis qu'à l'index ; c'est en quoi j'ai dit qu'il avoit fait pis que le P. Lecomte et qu'il est surprenant que malgré cette tare, il ait été confesseur du roi »1. Et ceci est juste, nous savons maintenant que c'est seulement grâce à l'entremise du cardinal d'Estrées que le P. Le Tellier ne fut pas condamné à Rome en 1692. Il dut venir à Rome pour apporter son livre corrigé ou pour I'y corriger.

1 Saint-Simon, Mémoires, t. XXII, p. 96-7. Suivant Saint-Simon, deux événements de la querelle des cérémonies chinoises auraient provoqué I'affaire de la Constitution Unigenitus, d'abord la Bulle de 1710 (Mémoires, t. XX, p. 199-201) et la mort du cardinal de Tournon (Mémoires, t. XXII, p. 57). 


\section{La Chine et la formation de l'esprit philosophique en France}

Il sut faire traîner les choses en longueur et c'est seulement en 1700, peu après la condamnation du P. Le Comte par la Sorbonne que son livre fut mis à l'index « donec corrigatur ». Nous avons donc des raisons de supposer comme Saint-Simon, que la personnalité seule du P. Le Tellier n'était pas en jeu, mais qu'il représentait son ordre et que de puissants appuis s'interposèrent pour empêcher sa condamnation qui aurait été la condamnation des Jésuites.

Mais Saint-Simon se trompe lorsqu'il prétend que le livre du P. Le Tellier fut déféré à la Sorbonne en $1700^{1}$. Seulement quelques docteurs, en opinant, rétractèrent l'approbation qu'ils avaient donnée au livre du P. Le Tellier ${ }^{2}$. Quant au P. Le Tellier, sans doute il resta dans la coulisse mais il fit tenir la plume par ses âmes damnées, les PP. Lallemant et Doucin, mal vus de I'archevêque de Paris ${ }^{3}$.

«Cette affaire [de la condamnation du livre du P. Le Comte par la Sorbonne et son renvoi de la cour] mortifia cruellement les Jésuites, continue Saint-Simon, d'autant plus que cette même ${ }_{\text {p.135 }}$ affaire leur bâtoit mal à Rome et remplit le P. Tellier d'une rage qui devint bien funeste dans la suite »4. Que les Jésuites aient été mortifiés du renvoi du P. Le Comte, cela est bien évident, et le témoignage de l'abbé du Bos nous montre qu'ils firent tous leurs efforts pour écarter toute interprétation

\footnotetext{
${ }^{1}$ Saint-Simon, Mémoires, t. VII, p. 166-7.

2 Le Dieu, Journal, t. II, p. 138.

${ }^{3}$ Saint-Simon, Mémoires, t. XX, p. 333, n. 4 et 5.

4 Saint-Simon, ibid., t. VII, p. 169.
} 


\section{La Chine et la formation de l'esprit philosophique en France}

humiliante pour eux. Mais Saint-Simon ne nous dit pas comment se manifesta la rage du P. Le Tellier. A-t-elle attendu onze ans pour se manifester, et le $P$. Le Tellier a-t-il tranquillement et patiemment attendu l'occasion d'une revanche Certains faits semblent indiquer qu'il n'en fut pas ainsi. Nous trouvons, en effet, le P. Le Tellier occupé à fonder en 1701 avec I'appui du duc du Maine, les Mémoires de Trévoux qui pendant la première moitié du XVIII ${ }^{\text {e }}$ siècle suivront avec une attention particulière les publications sur la Chine et défendront avec énergie, au sujet de la religion chinoise et de l'ancienne histoire de la Chine, les théories des Jésuites. L'année suivante, le duc du Maine - ici le nom du P. Le Tellier ne paraît pas - fonde les Lettres édifiantes et curieuses qui, à partir de ce moment paraîtront sinon périodiquement, du moins d'une manière assez régulière ; et à la tête de cette publication, où les lettres venant de Chine seront les plus nombreuses et les plus intéressantes, les Jésuites mettent le P. Le Gobien - dont un livre fut condamné par la Sorbonne en même temps que celui du P. Le Comte - et à sa mort en 1709, le P. Le Gobien sera remplacé par le P. du Halde, le secrétaire du P. Le Tellier. Dans ces recueils, et dans la Description de la Chine du P. du Halde, qui n'est qu'un ajustement des matériaux accumulés par les Lettres édifiantes et curieuses, nous trouvons la main de quelques-uns des hommes qui ont joué un rôle de premier plan dans l'affaire des Cérémonies chinoises. Nul doute par conséquent que cette querelle n'ait influé sur l'esprit qui anime ces recueils, d'autant plus qu'il ne s'agit pas pour les Jésuites de se justifier après coup d'une théorie définitive condamnée ; il s'agit de prouver la 


\section{La Chine \\ et la formation de l'esprit philosophique en France}

justesse de leurs idées dans une cause qui n'est pas encore tranchée.

Saint-Simon a vu juste en signalant le rôle du P. Le Tellier dans l'affaire des Cérémonies chinoises. Mais il va plus loin et cherche à établir un rapport de cause à effet entre I'affaire des Cérémonies chinoises et l'affaire de la condamnation de Quesnel : je fais seulement mention de cette bulle (d'octobre 1710) comme de la source de tout le fracas qui arriva bientôt après et dont la persécution dure encore et n'a fait que croître en fureur. Je parlerai en son temps de ce chef-d'œuvre du démon et des Jésuites et en ${ }_{\text {p.136 }}$ particulier du P. Le Tellier $\gg{ }^{1}$. En suscitant I'affaire de la Bulle Unigenitus, dit encore SaintSimon, le P. Le Tellier voulait faire oublier « I'opprobre » 2 de sa condamnation dans les affaires de la Chine. C'est donc la vanité du P. Le Tellier en particulier et des Jésuites en général qui les aurait poussés à monter la grande machine de la Bulle Unigenitus. Petite cause, il faut I'avouer si grande que puisse être la vanité pour un si grand effet.

Mais ce que Saint-Simon ne nous dit pas - on devine aisément pourquoi - et ce que ne nous dit pas non plus Albert Le Roy, qui d'ailleurs, a presque entièrement passé sous silence l'affaire des Cérémonies chinoises, c'est le rôle que l'archevêque de Paris a joué dans cette affaire. Ce rôle est un rôle actif. Le cardinal de Noailles s'est employé avec zèle pour obtenir la condamnation des Jésuites.

\footnotetext{
1 Saint-Simon, Mémoires, t. XX, p. 200-1.

${ }^{2}$ Id., ibid, t. XX, p. 333.
} 


\section{La Chine et la formation de l'esprit philosophique en France}

En 1697, il signe avec Bossuet et Le Tellier, archevêque de Reims, la lettre des cinq évêques, où les tolérances que les Jésuites accordent à leurs néophytes sont dénoncées. En juin 1700, I'agent du Séminaire des Missions étrangères à Rome, Charmot, considère l'archevêque de Paris comme un allié dans l'affaire des Cérémonies chinoises et sollicite de lui des lettres pour les cardinaux qui se montrent favorables aux Jésuites. En 1701, lorsque le cardinal de Noailles quitte Rome après le conclave, il laisse à Rome l'abbé Renaudot pour essayer d'enlever la condamnation des Jésuites. Nous n'avons pas malheureusement de lettres confidentielles d'agents du cardinal de Noailles entre 1709 et 1711 et nous ne pouvons savoir ce qu'il fit contre les Jésuites à Rome pendant cette période dans l'affaire des Cérémonies chinoises. Mais un document nous montre qu'en 1711, il n'avait oublié ni l'affaire des Cérémonies chinoises, ni le rôle du P. Le Tellier dans cette affaire. Aussi quand il écrit au roi pour le supplier d'enlever sa confiance au $P$. Le Tellier, le principal argument qu'il fournit, c'est le rôle du P. Le Tellier dans les affaires de la Chine : « Je savais qu'il avait fait un mauvais livre condamné deux fois à Rome, malgré la protection qu'il y eut, qui ne put qu'adoucir la condamnation ; je savais que loin de se soumettre à la censure de son livre, il en soutint toujours la doctrine et s'opposa plus fortement qu'aucun de sa compagnie aux décrets du pape sur les cérémonies de la Chine. $\mathrm{Au}$ lieu de cette soumission aveugle pour le Saint-Siège, dont il fait profession, il résiste toujours aux décisions du pape. p.137 Décret sur décret, explications sur explications n'ont pu encore le soumettre, non plus que le reste de sa compagnie. Et il tombe 


\section{La Chine \\ et la formation de l'esprit philosophique en France}

aujourd'hui, au grand scandale de toute l'église, dans la désobéissance qu'il reproche avec tant de raisons aux jansénistes $\gg 1$.

Puis de la fin de 1711 au début de 1713, nous savons, grâce au P. Roslet, ce qu'il a fait pour tâcher de faire pièce aux Jésuites, soit pour exploiter les circonstances de la mort du cardinal de Tournon, soit pour faire condamner le livre du P. Jouvancy. L'affaire des Cérémonies chinoises lui sert tantôt d'arme défensive tantôt d'arme offensive, mais il n'oublie jamais les Jésuites. Et d'autre part, les Jésuites n'ignoraient pas qui se cachait derrière le Séminaire des Missions étrangères. C'était au début le triumvirat soutenu par $\mathrm{M}^{\mathrm{me}}$ de Maintenon, puis Iorsque Bossuet fut mort et que $\mathrm{M}^{\mathrm{me}}$ de Maintenon évolua, avec l'aide de l'évêque de Chartres, du côté des Jésuites, le seul archevêque de Paris. Les Jésuites ne se méprirent donc pas et s'ils tâchèrent de faire condamner Quesnel, c'était pour prendre par son faible leur principal adversaire, comme l'avait fait le cardinal de Noailles à l'égard des Jésuites, au moyen des Cérémonies chinoises 2.

S'il y a un lien entre l'affaire des Cérémonies chinoises et I'affaire de la Constitution Unigenitus, ce n'est pas seulement la vanité personnelle du P. Le Tellier ou I'amour-propre froissé des Jésuites qui constitue ce lien. Mais ce lien c'est la nécessité pour les Jésuites en 1713 de discréditer, sinon d'abattre, un

\footnotetext{
1 Le Roy, La France et Rome, p. 363.

2 L'abbé Legendre (Mémoires) déclare que le P. Le Tellier et le P. Doucin voulurent perdre l'archevêque de Paris dans l'esprit du roi et des peuples ( $p$. 275). Mais il ne dit pas ce que de son côté l'archevêque avait fait pour essayer de perdre les Jésuites.
} 


\section{La Chine et la formation de l'esprit philosophique en France}

adversaire redoutable, et plus tenace qu'on ne le dit d'habitude, le cardinal de Noailles, qui poussa le pape à condamner les Cérémonies chinoises. Or, d'après les Jésuites, une condamnation définitive serait la ruine non seulement des missions des Jésuites en Chine, mais de toutes les missions catholiques ${ }^{1}$. Cet adversaire il faut donc p.138 l'occuper par la menace d'une condamnation de Quesnel qui l'atteindra par contre coup ; il faut aussi gagner du temps à Rome pour éviter une condamnation définitive qui semble imminente dans I'affaire des rites chinois : ici Saint-Simon semble avoir raison, la dénonciation de Quesnel ne fut qu'une parade des Jésuites, mais une parade destinée à sauver les missions de Chine.

\section{$*$}

Répétons-le encore, l'affaire des Cérémonies chinoises ne se termine qu'en 1742. Sans doute après 1713, elle passe à I'arrière-plan des préoccupations, depuis que l'affaire de la Constitution Unigenitus a divisé les consciences, heurté les différents partis. Mais il faut peu de chose pour faire flamber ce feu mal éteint : un livre de Silhouette (1729) sur la politique et la morale chinoises, pourtant bien anodin, mais qu'on croit inspiré par les Jésuites, et les Nouvelles ecclésiastiques partent

\footnotetext{
1 Dans une lettre du 12 août 1715 le roi de Portugal, vraisemblablement sous l'inspiration des Jésuites de sa nation, demande au Pape de convoquer un concile dans I'Inde sur la question des rites chinois, ou que du moins il ajoute à sa nouvelle constitution quelque instruction particulière par laquelle on puisse prévenir, s'il y a lieu de croire que de l'exécution de la constitution il s'ensuivra l'expulsion des Missionnaires. «Qu'on en rende compte à V. S. et, qu'elle en suspende l'exécution parce qu'il sera moralement Impossible d'introduire de nouveaux Missionnaires en la Chine après qu'on en aura chassé ceux qui y sont à présent ». B. N. Lat. 16980, f. 64.
} 


\section{La Chine et la formation de l'esprit philosophique en France}

en guerre ${ }^{1}$; une affirmation de l'évêque de Marseille en 1730 disant que le culte de la Chine a été approuvé par Alexandre VII, et l'évêque de Montpellier demande une réparation en forme pour Alexandre VII 2 ; la publication de la Description de la Chine du P. du Halde en 1735, pourtant si prudente en ce qui concerne cette querelle des Cérémonies chinoises, et cette publication provoque tout aussitôt une série de pamphlets jansénistes, les Anecdotes de la Chine (1733-1742) dont le ton nous ramène à l'époque de I'Anti-Cotton ${ }^{3}$.

Mais jusqu'à 1712 les Jésuites se croient en droit d'apporter des faits qui prouvent leurs affirmations. Et c'est précisément à ce moment que se publient leurs principaux ouvrages sur la Chine : Lettres édifiantes et curieuses, Description de la Chine du P. du Halde, sans oublier les Mémoires de Trévoux, qui s'intéressent tant à la Chine, qui signalent toutes les publications la concernant, qui les commentent et polémiquent au besoin. Sans doute, les Lettres édifiantes et curieuses et la Description de la Chine ne font pas d'allusions de près ou de loin à la Querelle des Cérémonies chinoises. Mais si I'on se rappelle l'attitude des Jésuites dans toute cette affaire, leur prétention à être de tous les missionnaires les seuls capables d'apporter des

${ }^{1}$ Silhouette, Idée générale due gouvernement et de la morale des Chinois, $2^{\mathrm{e}}$ éd., 1731 , p. 43.

2 Mathieu Marais, Journal et Mémoires, t. IV, p. 159.

3 Cf. par ex. I'Avertissement du t. II qui, rapportant le supplice du P. Morao, jésuite, au Siam, pour avoir essayé de faire détrôner l'empereur régnant ajoute : «...les pierres crieront et le public apprendra par la manifestation de tels excès que les Jésuites sont partout les mêmes, intrigans, factieux, portez à la sédition et à la révolte et capables des plus grands excez contre la personne sacrée des Souverains » (p. VI-VII). 


\section{La Chine et la formation de l'esprit philosophique en France}

faits précis et authentiques sur les cultes chinois et leur appel incessant du pape mal informé au pape mieux informé, on ne peut s'empêcher de penser que ces publications, malgré leur apparence d'impartialité, et quelquefois malgré leur air de simplicité naïve peuvent tout en affectant de n'apporter que des faits, accumuler en réalité des preuves en faveur des théories des Jésuites. Nous sommes donc en droit de nous demander d'où viennent ces faits et s'ils valent surtout comme preuves des théories des Jésuites ou comme éléments d'une connaissance impartiale de la Chine.

Et d'autre part, les partisans du séminaire des Missions étrangères n'ont pas désarmé. Alors que les Jésuites veulent voir en Chine, depuis la plus haute antiquité, une religion spiritualiste admettant un créateur et un monde distinct du créateur, leurs adversaires s'efforcent de prouver que les Chinois sont matérialistes et athées. Nous avons déjà signalé deux petits écrits, I'un du P. Longobardi et I'autre du P. Antoine de SainteMarie, dominicain, où la thèse spiritualiste est contestée. En 1708, Artus de Lionne, évêque de Rosalie, celui-là même que le P. d'Espagnac, au temps des affaires de Siam, appelait un « boute-feu », et qui certes n'a pas gardé un bon souvenir de ses relations avec les Jésuites, montre à Malebranche les rapports entre la doctrine des philosophes chinois et le spinozisme, et l'engage à écrire son Entretien d'un philosophe chrétien et d'un philosophe chinois. En 1718, l'abbé Renaudot, l'agent à Rome du cardinal de Noailles dans l'affaire des cérémonies chinoises, publie à la suite de ses Anciennes Relations des Indes et de la Chine, des dissertations sur la 


\section{La Chine et la formation de l'esprit philosophique en France}

science des Chinois où il s'efforce de démontrer la fausseté des affirmations des Jésuites sur l'antiquité des sciences des Chinois, sur l'élévation de leurs idées philosophiques et morales. Les livres favorables à la Chine sont écrits par des Jésuites. Les livres où I'on critique la Chine, sont publiés, écrits ou suggérés par les adversaires des Jésuites. Il y a motif de suspicion de part et d'autre.

Il était juste, avant d'apprécier la valeur des publications des Jésuites sur la Chine de les replacer dans l'atmosphère de combat où elles sont nées. Et si chemin faisant, au cours de notre examen critique nous trouvons des atténuations de faits ou des ${ }_{\text {p.140 }}$ déformations, voire même quelque chose de plus grave, nous ne devrons pas oublier, si nous voulons être complètement juste, que les Jésuites ont cru, en agissant ainsi, assurer non seulement le triomphe de leur ordre, mais le salut de leurs missions de Chine. Ce ne sera assurément pas une justification, mais à tout le moins une explication. 


\section{La Chine \\ et la formation de l'esprit philosophique en France}

\section{CHAPITRE III}

\section{Les Ecrits des Jésuites sur la Chine}

p.141 Si les Jésuites n'eurent pas autant qu'ils le voulaient le monopole des missions en Chine, qu'ils considéraient cependant comme leur appartenant en vertu d'un privilège historique, ils eurent à peu près le monopole des publications sur la Chine. Les Missionnaires en effet n'étaient pas, en règle générale, des savants, et en outre leurs instructions les mettaient en garde contre la science qui peut divertir le missionnaire de prêcher et de faire mission. Les Jésuites au contraire furent pour la plupart de grands savants que I'on choisit spécialement pour évangéliser cette nation qui mettait la science à si haut prix, et qui furent désireux de connaître dans le passé aussi bien que dans le présent ce pays nouveau qu'ils voulaient révéler au public européen. C'est à eux nécessairement que les hommes du XVIII siècle durent s'adresser pour avoir sur la Chine les connaissances qu'ils désiraient avoir. Il faut donc avant de se demander quelle fut l'influence de la connaissance de la Chine sur les philosophes du XVIII ${ }^{\mathrm{e}}$ siècle, savoir ce que les écrits des Jésuites sur la Chine pouvaient leur apporter, et dans quelle mesure ces écrits ne donnèrent aux gens du XVIII ${ }^{e}$ siècle qu'une connaissance fragmentaire - ou peut-être même déformée - de la Chine et des Chinois. Avant de juger les opinions des « philosophes » sur la Chine, il faut en bonne justice juger et apprécier la valeur des documents que les Jésuites leur apportaient. 


\section{La Chine et la formation de l'esprit philosophique en France}

Si nombreux que soient les tomes du recueil des Lettres édifiantes et curieuses, où la Chine tient la meilleure place, et si volumineuse que soit la compilation du P. du Halde avec ses quatre gros in-folios, il n'a paru dans la première moitié du $\mathrm{XVIII}^{\mathrm{e}}$ siècle qu'une ${ }_{\text {p.142 }}$ très minime partie des écrits composés par les Jésuites missionnaires en Chine. Ce n'est pas en vain que I'on avait choisi de savants Jésuites, astronomes, mathématiciens ou historiens, quelquefois même tout cela à la fois, pour les envoyer en Chine. Dès leur arrivée, ils se mirent résolument à l'ouvrage et leur production fut abondante. Ils entrèrent en correspondance avec les savants d'Europe, le P. Bouvet avec Leibniz, le P. de Prémare avec Vourmont et ensuite avec Fréret, le P. Parrenin avec Dortous de Mairon, le P. Gaubil avec l'astronome de I'Isle et avec Fréret, et aucun d'eux ne fut avare de ses trésors. Chaque année les vaisseaux de la compagnie des Indes apportaient aux savants français lettres et mémoires des Jésuites de Pékin, de Canton ou de Macao, et par suite, il serait inexact de prétendre que I'action des PP. Jésuites se réduit aux livres imprimés officiellement par les Jésuites de Paris, Lettres édifiantes ou Description de la Chine. Sans le P. Gaubil, il eût été difficile à Fréret d'écrire ses dissertations sur la chronologie chinoise. Quant à Fourmont qu'eût-il pu faire sans le P. de Prémare ? On s'en rend compte dès que I'on examine la correspondance des PP. de Pékin adressée aux savants français et qui se trouve conservée à l'Observatoire astronomique de Paris.

Pour juger de l'influence des Jésuites sur la connaissance de la Chine au XVIII ${ }^{e}$ siècle, il est non seulement équitable mais 


\section{La Chine et la formation de l'esprit philosophique en France}

même nécessaire d'examiner l'influence exercée par un savant jésuite sur un correspondant particulier, car ces lettres qu'apportaient annuellement les vaisseaux de la Compagnie des Indes n'étaient pas de simples lettres d'informations, mais de savantes dissertations que malheureusement les Jésuites de Paris laissèrent perdre en partie. De tout ce que les savants Jésuites envoyèrent de Chine au XVIII ${ }^{\mathrm{e}}$ siècle, la plus grande part fut ignorée des gens du XVIII ${ }^{\mathrm{e}}$ siècle. Nous aurons le droit de nous demander pourquoi il en fut ainsi, mais il est juste d'indiquer par avance que certains savants comme Fréret ou de Mairan furent en possession de documents originaux, tandis que le public n'eut à sa disposition que les écrits revus et corrigés par les Jésuites de Paris. Le public ne connut de la Chine que ce que les Jésuites de Paris voulurent bien lui faire connaître.

Des livres canoniques de la Chine on ne put rien connaître dans la première moitié du XVIII ${ }^{e}$ siècle sauf les très courts et très vagues extraits donnés par le $P$. du Halde dans sa Description de la Chine. Cependant, le P. Régis avait envoyé depuis longtemps déjà au P. du Halde une Introduction critique à l'étude des p.143 Kings dont le P. du Halde ne fit aucun usage. En 1740, le P. Gaubil envoyait à Fréret une traduction du Chou king. A la mort de Fréret, de I'Isle trouva cette traduction dans ses papiers, ainsi qu'un deuxième exemplaire de cet ouvrage et de I'Isle en fit une copie ${ }^{1}$. Cette traduction ne fut publiée qu'en 1770 par de Guignes, mais avec des inexactitudes volontaires

\footnotetext{
${ }^{1}$ Lettre de De I'Isle au P. Gaubil, Paris, le 15 novembre 1719 (Obs. Astr. A B ${ }^{1}$ $5, X-108$, f. 3).
} 


\section{La Chine et la formation de l'esprit philosophique en France}

que Pauthier a signalées ${ }^{1}$. Dans les papiers de Fréret se trouvait aussi une traduction de I'Yi King faite par le P. Régis (publiée seulement au XIX siècle par Pauthier) et une traduction du Che King due au P. Lacharme ${ }^{2}$.

Sans parler du premier traité de la chronologie chinoise du P. Gaubil, envoyé au P. Souciet en 1730 3, le savant traité de la chronologie chinoise en trois parties du P. Gaubil n'eut pas un meilleur sort. Il fut envoyé à Fréret en 1749. Quand il arriva en Europe, Fréret était mort ${ }^{4}$. Le P. Berthier en avait reçu aussi un exemplaire. Mais, remarque mélancoliquement Gaubil, « si ce Père est le même qui a fait l'extrait contenu dans l'article onze de 1750 (des Mémoires de Trévoux), mois de janvier, ma chronologie est comme vous le voyez en grand danger d'être abandonnée ».

Les craintes de Gaubil n'étaient que trop fondées. Il fallut attendre Silvestre de Sacy pour que ce traité fût imprimé.

En 1735, Fréret avait réussi à obtenir communication de la préface de I'Histoire générale de la Chine traduite par le P. de Mailla qui était déposée chez les Jésuites de Lyon, et il proposait aux Jésuites de faire des démarches auprès du comte de Maurepas pour faire imprimer cet ouvrage au Louvre, sachant

\footnotetext{
${ }^{1}$ Les livres sacrés de l'Orient, p. 51, col. 2 ; p. 53, col. L.

2 Les manuscrits de ces deux traductions se trouvent aux Archives du service hydrographique de la marine (Dépôt des cartes et plans).

${ }^{3}$ Lettre du P. Gaubil à Fréret, 5 novembre 1731 (Obs. Astr. A B ${ }^{1} 10,150,2$, $\left.15^{1}\right)$.

4 Ce manuscrit fut remis à Bougainville, exécuteur testamentaire de Fréret. De I'Isle en tira une copie (Obs. Astr. $B^{1} 6, X X, n^{\circ} 34$ ).
} 


\section{La Chine et la formation de l'esprit philosophique en France}

fort bien qu'aucun libraire ne consentirait à imprimer ces trente volumes sur I'histoire de la Chine, le public se montrant peu friand d'ouvrages semblables ${ }^{1}$. Les Jésuites firent la sourde oreille à cette proposition. Fréret revint à la charge en 1742 . Mais peine perdue. L'ouvrage ne commença à paraître qu'en 1777.

Semblable fut la destinée des travaux astronomiques. Sans doute il parut du P. Gaubil une Histoire de l'astronomie chinoise, avec des dissertations dans le recueil des Observations mathématiques, p.144 astronomiques, géographiques, chronologiques et physiques du P. Souciet en 1732. Mais plus tard, le P. Gaubil regrettait que cette Histoire eût paru ; et il constatait avec une certaine mélancolie que le seul ouvrage astronomique qu'il était prêt à désavouer eût vu le jour tandis que les autres restaient enfouis dans les cartons. En effet, de Mairan avait reçu de lui un Abrégé de l'astronomie chinoise depuis l'an de J. C. 1368 jusqu'à l'entrée des Jésuites dans le tribunal des mathématiques. Fréret avait dans ses papiers le Catalogue des comètes vues à la Chine depuis 613 av. J. C. jusqu'à 1539 2. De I'Isle possédait les Recherches astronomiques sur les constellations et les catalogues chinois des étoiles fixes, sur le cycle des jours, sur les solstices et sur les ombres

\footnotetext{
${ }^{1}$ Cf. notre thèse complémentaire, Documents inédits, p. 140 et 150.

2 Jos. Brucker, Correspondance scientifique d'un missionnaire, Revue $d u$ monde catholique, 1883, p. 218. Lettre de de I'Isle du 24 juin 1749. (Obs. Astr. $B^{1} 5$ X-89). Ce Catalogue, qui fut envoyé le 16 octobre 1737 à Fréret, fut utilisé par Pingré dans sa Cométographie.
} 


\section{La Chine et la formation de l'esprit philosophique en France}

méridiennes du Gnomon observées à la Chine 1, qui, enfouies à I'Observatoire astronomique de Paris avec les papiers de I'Isle furent découvertes par Laplace au XIXe siècle.

Que dire des autres missionnaires ? Il leur arriva la même aventure qu'aux PP. Régis, Gaubil et de Mailla. Le P. Visdelou, plus tard évêque de Claudiopollis Iorsqu'il eut quitté la Compagnie de Jésus, avait composé une Histoire de la Tartarie qui fut imprimée seulement dans le tome IV de la réédition de d'Herbelot (1777-9), longtemps après I' Histoire des Huns de de Guignes qui avait eu connaissance du manuscrit du P. Visdelou ; enfin une traduction du Chou king qui ne vit jamais le jour ${ }^{2}$. Les ouvrages du P. de Prémare sont innombrables. Quelques-uns comme le traité sur l'Athéisme des Chinois sont encore manuscrits ; d'autres comme les Vestiges des principaux dogmes des Chrétiens tirés des anciens livres des Chinois ne parurent qu'au XIXe siècle (1878). Et I'on pourrait encore allonger cette liste.

L'une des raisons qui empêchèrent au XVIII ${ }^{\mathrm{e}}$ siècle la publication de ces savants travaux est une raison très générale : le goût frivole du public qui n'aime pas ces ouvrages ardus ; «On ne veut pas ${ }_{\text {p.145 }}$ de Chine, écrit le P. Gaubil, des choses si abstraites, si sèches. On veut quelques descriptions, quelques

${ }^{1}$ Ce manuscrit fut envoyé le 23 juillet 1734 à J. N. de I'Isle, qui était alors à St. Petersbourg. Il en prit copie et envoya à Paris le manuscrit original, dont on perd la trace à partir de ce moment. De son côté, Fréret, dès 1735, signale 11 mémoires originaux du P. Gaubil, dont il donne l'énumération dans sa lettre au P. Gaubil de 1735. (Cf. notre thèse complémentaire, Documents inédits, p. 68-73).

2 L'orientaliste Deshauterayes en possédait le manuscrit. Cf. sa lettre au P. Gaubil. B. N. N. A. F. 6556, f. 175. 


\section{La Chine et la formation de l'esprit philosophique en France}

relations ; on veut surtout de quoi s'amuser agréablement ». Les savants comme Fréret gémissent de cette frivolité, car les libraires sont obligés de se conformer au goût du public et « ils se chargent mal volontiers d'ouvrages scientifiques dont le débit est dur en ce pays-ci et dont ils ne pourraient se défaire que par des échanges avec l'estranger, méthode qui leur est totalement inconnue »1. L'attention du public d'ailleurs était accaparée presque exclusivement par les Lettres édifiantes et curieuses qui tout en apportant bien des faits nouveaux, se présentaient un peu comme des relations de voyage et d'où I'on excluait d'ailleurs soigneusement tout ce qui aurait pu paraître trop ardu ou trop violent pour le goût du temps. Quand le P. Parrenin envoya à $M$. de Mairan une savante lettre de 108 pages, contenant notamment une traduction des annales des premiers temps de la monarchie chinoise, le P. du Halde ne balança pas à supprimer cette traduction dans les Lettres édifiantes et curieuses, « car les gens de goût ne la supporteraient pas ${ }^{2}$. Sans doute, il ne put omettre cette traduction, car c'est un texte important, dans sa Description de la Chine, ouvrage qui a la prétention de s'adresser aux savants autant qu'aux gens du monde, mais il y apporta des retouches, et il serait vain de chercher dans quelques-unes de ces corrections une intention autre que celle de ne pas heurter la délicatesse des lecteurs.

Les Jésuites missionnaires en Chine sont un peu responsables aussi du dédain témoigné pendant de longues années à leurs

1 Lettre de Fréret au P. Régis, 1737. Cf. notre thèse complémentaire, Documents inédits..., p. 84.

2 Lettres édifiantes et curieuses, XXI ${ }^{\mathrm{e}}$ R., p. 83. 


\section{La Chine et la formation de l'esprit philosophique en France}

travaux, car ils ont exagéré la modestie. Ils se sont considérés seulement comme les pourvoyeurs des savants d'Europe ; ils ont consenti à leur fournir des documents et des mémoires, tout en se retranchant derrière leur éloignement ou leur situation de missionnaires pour ne pas publier eux-mêmes ${ }^{1}$. Et de fait il leur était difficile de dire ce qu'ils voulaient, non seulement à cause des susceptibilités de leurs supérieurs ou de la cour de Rome p.146 la Querelle des Cérémonies chinoises étant toujours pendante - mais aussi à cause de leur situation privilégiée à la cour de Chine. Il y avait en effet des choses qu'un missionnaire ne pouvait dire à Pékin ni écrire en Europe sous peine de ruiner la mission. Il était impossible notamment de mettre en doute I'authenticité des anciennes annales chinoises, et le P. Gaubil demandait à Fréret d'admettre dans ses dissertations sur la chronologie chinoise qu'il y avait des empereurs en Chine vers 2500 avant Jésus-Christ. Par prudence et par modestie les Jésuites s'éclipsèrent devant leurs confrères d'Europe, membres de I'Académie des Sciences ou de I'Académie des Inscriptions et Belles-Lettres. Un jour Fréret proposa au P. Gaubil de lui faire donner le titre de correspondant honoraire de l'Académie des

\footnotetext{
1 « J'ay envoyé en France quantité de choses sur la chronologie chinoise, si je viens à savoir ce qu'on en pense je continueray et je tacheray de faire ce qu'on me proposera, il y aura sans doute bien des choses à retrancher, à éclaircir, à corriger, faittes s'il vous plait réflection, Monsieur, à l'état où nous sommes icy, aux secours qui nous manquent et à ce que nous pouvons savoir quand nous venons d'Europe, après cela vous jugerez aisément qu'il ne faut pas attendre de nous ce qu'on a droit d'attendre des doctes de profession d'Europe ». (Gaubil à Fréret. 7 septembre 1734, Obs. Astr. A B ${ }^{1} 10-(150,2$, 14 , f. 3-5).
} 


\section{La Chine et la formation de l'esprit philosophique en France}

Inscriptions pour lui permettre de faire imprimer ses travaux dans le recueil de I'Académie. Le P. Gaubil refusa ${ }^{1}$.

La correspondance de Fréret avec les missionnaires de Chine nous montre tous les efforts qu'il fit pour essayer de faire connaître en France les travaux des Jésuites. Il eût été disposé pour sa part à faire des démarches pour les faire imprimer au Louvre. Mais il aurait voulu aussi que les Jésuites de leur côté fissent un peu plus d'efforts pour se faire imprimer. Il s'efforce de les y intéresser, et pour cela aucun argument ne lui coûte. Il n'ignore pas que la passion de ces missionnaires, c'est leur mission, et lui qui n'aime guère les Jésuites ni les missions, il essaie de leur faire apercevoir l'intérêt que pourraient avoir pour leurs missions mêmes ces savantes publications : «Pourquoi faut-il que le public soit privé d'un ouvrage aussi important, écrit-il au P. Régis, non seulement pour donner une idée de la littérature chinoise mais encore de l'érudition et de la critique des missionnaires de la Chine ? Ce n'est pas pour leur intérêt que je parle mais pour celuy de la mission. Je l'ay desja dit. Il seroit important pour luy procurer la protection dont je vois par vos lettres qu'elle auroit besoin que les témoignages avantageux qui leur seroient rendus par les gens de lettres pussent aller jusqu'aux ministres et jusqu'aux puissances. Les sciences qui soutiennent la mission à la cour de l'Empereur pourroient luy attirer aussi les secours qui luy manquent. Cette innocente adresse seroit-elle contraire à la simplicité évangélique $\gg 2$.

1 Lettre du P. Gaubil à Fréret, 29 octobre 1736. Obs. Astr. A B ${ }^{1} 10-(150-2$, $\left.24^{2}\right)$.

2 Cf. notre Thèse complémentaire, Documents inédits..., p. 84. 


\section{La Chine et la formation de l'esprit philosophique en France}

Il semble d'ailleurs que Fréret ait prêché des convertis, car p. ${ }_{147}$ certains Jésuites missionnaires en Chine comme le P. Gaubil, étaient persuadés eux aussi de la nécessité de publier, dans l'intérêt de la mission, mais avec toutes les précautions nécessaires, et sous le contrôle des Jésuites de Paris. Il écrivait en effet au P. Souciet en lui envoyant différents travaux : « Si dans ce que je vous ay envoyé vous voyés quelque chose qui puisse passer, vous ne ferés pas mal de le produire, et il n'est pas mauvois qu'on voye dans les circonstances présentes que les Jésuites françois d'icy ne sont pas inutiles et il est bon de confondre l'envie et la malice de nos ennemis, soit publics, soit cachés »1. D'ailleurs, il laissait le P. Souciet entièrement libre de disposer de ses travaux en « omettant, retranchant, ajoutant » ce qu'il voudrait. Nous voyons aussi le supérieur de la mission de Pékin, le P. Jacques, s'inquiéter des travaux envoyés par le P. Parrenin à l'Académie des Sciences et s'informer de la raison pour laquelle ces travaux n'ont pas été publiés. Ces Messieurs seraient-ils mécontents ? «Et pourtant, ajoute-t-il, il faut qu'ils soient contens, car c'est par la liaison que nous aurons avec eux que nous serons toujours protégés à la cour, et que nous pourrons même obtenir des secours d'argent et des pensions qui nous seront toujours nécessaires $\gg 2$. Il indique en même temps une supposition qu'il a faite sur le sujet de ce mécontentement, c'est que le P. de Goville, avant de remettre les lettres du P. Parrenin à Fontenelle, en a tiré une copie qu'il a remise au P. du

\footnotetext{
${ }^{1}$ Le P. Gaubil au P. Souciet, 14 octobre 1729, Obs. Astr. A B ${ }^{1} 10(150-1,7)$.

2 Lettre du P. Jacques du $1^{\text {er }}$ novembre 1727 , p. p. H. Cordier, Histoire ecclésiastique de I'Extrême-Orient, Revue d'Extrême-Orient, t. III, p. 225.
} 


\section{La Chine et la formation de l'esprit philosophique en France}

Halde et que celui-ci en a publié des extraits dans les Lettres édifiantes et curieuses. Mais le supérieur des Jésuites de Chine, qui a la responsabilité de la mission, ne l'entend pas ainsi. Les académiciens doivent être satisfaits d'abord, dût le recueil du P. du Halde en souffrir un peu.

Le P. du Halde en effet semble avoir été un accapareur et avoir râflé au passage tous les mémoires qu'il pouvait trouver pour grossir son recueil des Lettres édifiantes. Les plaintes des Jésuites que nous pouvons surprendre à cet égard sont évidemment rares et toujours discrètes. Mais nous trouvons cependant de ci de là quelques traces de mécontentement. Le P. Orry apprend un jour aux PP. Jacques et Gaubil qu'il aurait bien voulu communiquer à différents membres de l'Académie des Sciences des cartes géographiques envoyées de Chine, mais il n'en a pu obtenir communication du P. du Halde, et il ajoute : «On croit qu'il faut tout ${ }_{\text {p.148 }}$ tenir serré de peur qu'on ne nous enlève la gloire de l'invention ; aussi nous ne communiquons rien que par nos Lettres édifiantes. Cependant tout le monde nous laisse et personne ne nous soutient, voilà ce qu'on gagne à vouloir faire toujours bande à part. Le P. Souciet en est mortifié comme moi »1. De son côté, le P. du Halde se plaignait en 1739 qu'on lui eût refusé de Pékin les mémoires qu'il sollicitait pour sa Description de la Chine. Il déplorait l'esprit de critique qui régnait alors à la mission de Pékin - ce qui veut dire sans doute que les Jésuites de Pékin se méfiaient un peu de lui et redoutaient son esprit d'accaparement - et il regrettait l'esprit des « anciens »,

\footnotetext{
${ }^{1}$ Lettre du P. Orry du 21 décembre 1722. Obs. Astr. A. B ${ }^{1} 10,150-7,2$.
} 


\section{La Chine et la formation de l'esprit philosophique en France}

les PP. Contancin et d'Entrecolles qui avaient si généreusement contribué à grossir les Lettres édifiantes et par suite la Description de la Chine ${ }^{1}$. Les PP. Gaubil, Parrenin, Regis, de Mailla se cachaient en effet un peu pour envoyer leurs écrits aux savants d'Europe, car ils ne pouvaient se contenter des Lettres édifiantes pour la publication de leurs savants travaux. Ils $n$ 'ignoraient rien en effet des déformations ou des mutilations que le P. du Halde leur faisait subir, et ils préféraient envoyer leurs travaux à des savants consciencieux, quitte à ne pas les voir publier. Les Lettres édifiantes et curieuses par le droit de regard que leur éditeur, le P. du Halde, s'attribua sur les publications au sujet de la Chine firent le vide autour d'elles.

Il ne faudrait, d'ailleurs pas croire que tous les Jésuites de Chine fussent toujours d'accord entre eux. Il y avait parmi eux des groupes bien distincts, et s'ils furent unis pour la mission, ils entretinrent cependant entre eux des luttes assez vives sur les questions d'exégèse chinoise. A la suite de la persécution de 1724 qui expulsait les Jésuites des provinces et les reléguait à Canton, ensuite à Macao après 1732 , il ne resta à Pékin que quelques Jésuites, ceux qui étaient particulièrement bien vus de l'empereur ; parmi ceux-là se trouvaient les PP. de Mailla, Gaubil, Régis et Parrenin. Le P. Bouvet eut I'autorisation de rester à Pékin, à cause de son grand âge et des services qu'il avait rendus à la mission, bien que ses théories sur l'ancienne histoire chinoise fussent suspectes à ses confrères et à l'empereur.

1 Lettre du P. du Halde au P. Foureau du 13 octobre 1739. B. N. N. A. F. 6556, f. 26-7. 


\section{La Chine et la formation de l'esprit philosophique en France}

Les Jésuites de Chine différaient en effet d'opinion sur I'interprétation des livres canoniques de la Chine et sur l'explication des faits historiques remontant à la plus haute antiquité chinoise. p.149 Tandis que les PP. de Pékin, à I'exception du P. Bouvet, considéraient les livres canoniques comme des livres historiques rapportant I'histoire des premiers siècles de I'empire, les PP. de Canton ne voulaient y voir que des livres symboliques, n'ayant aucun rapport avec I'histoire chinoise, mais contenant des traditions antérieures au Déluge et des allusions prophétiques à la venue d'un messie. Les PP. de Canton niaient donc l'antiquité des temps historiques de la Chine et déclaraient « chimériques » les trois dynasties Hia, Chang et Tcheou, ce qui, suivant le P. Gaubil, pouvait être un crime passible de la peine de mort en Chine si on en était accusé ${ }^{1}$.

Ces symbolistes, ou comme disait Fréret, ces figuristes, non seulement couraient des dangers pour eux-mêmes, mais ils étaient un péril pour la mission. Le plus ardent de ces figuristes, Foucquet, dut quitter non seulement la Chine mais la Compagnie et il alla s'établir à Rome, d'où il menaçait sans cesse de publier des textes accablants qui démontreraient jusqu'à l'évidence, I'erreur des PP. de Pékin 2. On ne vit jamais ces ouvrages merveilleux, mais Foucquet n'était pas fâché de laisser entendre qu'il avait à se défendre contre les cabales de ses anciens confrères, intéressés à faire disparaître ses ouvrages. Le P.

\footnotetext{
1 Lettre de Gaubil à Fréret, in Brucker, Correspondance scientifique d'un missionnaire, Revue du monde catholique, t. LXXVI, p. 374.

2 Foucquet à l'abbé Bignon, 31 août 1729. B. N. Fr. 22528, f. 162. (Cf. notre thèse complémentaire, Documents inédits..., p. 20).
} 


\section{La Chine et la formation de l'esprit philosophique en France}

Bouvet, autre figuriste, resta sans doute à Pékin et dans la Compagnie, mais ses confrères le surveillaient ${ }^{1}$, et nous ne connaissons sa doctrine que par ses lettres privées ou par quelques-uns de ses manuscrits. D'ailleurs le P. Gaubil, trop grand esprit pour donner dans le figurisme, avoue que les supérieurs des Jésuites avaient pris de bonnes mesures pour lutter contre ce mal 2 . Ces bonnes mesures, nous les connaissons par le P. de Prémare : c'est le refus de l'imprimatur. «Quand nous voulons faire paroitre quelque écrit dont ils ont peur, on dit qu'il faut des reviseurs, il faut attendre ces réviseurs des années entières, et après qu'ils sont nommez, l'un s'excuse sur son incapacité, l'autre sur ses occupations plus pressées et, si nous voulons y répondre voilà un nouveau procez; c'est par ces sales de manigances que ni le P. Bouvet ni le P. Foucquet ni moi n'avons jamais peu rien produire à la gloire de Jésus-Christ et ${ }_{\text {p.150 }}$ pour le salut des Chinois, tandis que les PP. de Pékin remplissent I'Europe de mille préjugés contre nous par la manière asseurée et le ton décisif dont ils débitent les plus grandes faussetez $\gg 3$.

Il ne faut pas trop regretter d'ailleurs que ces écrits figuristes des PP. Bouvet, Foucquet et de Prémare n'aient jamais vu le jour, puisqu'ils tendaient à montrer l'inutilité de l'étude des anciennes

\footnotetext{
${ }^{1}$ Lettre du P. d'Entrecolles, 13 février 1711. B. N. N. A. F. 6556, f. 83, sq.

2 Lettre du P. Gaubil à Fréret, in Brucker, Correspondance scientifique d'un missionnaire, op. cit., p. 374. Cf. la lettre du P. Contancin au P. Souciet (Obs. Astr. $A B^{1} 10(150-7,12)$ qui dénonce le caractère dangereux des écrits que le P. de Prémare envoie en Europe.
}

3 Lettre du P. de Prémare, 12 novembre 1730. B. N. Fr. 15195, f. 46, vº. 


\section{La Chine et la formation de l'esprit philosophique en France}

annales chinoises. C'est un service que les PP. de Pékin et de Paris ont rendu aux études orientales en surveillant leurs confrères figuristes.

On comprend d'ailleurs que ce fût pour eux une nécessité. Si on n'arrivait pas à démontrer l'antiquité de la nation chinoise et I'authenticité des annales énumérant les différentes dynasties depuis la plus haute antiquité, il devenait impossible de prouver que les cultes chinois remontaient aux premiers temps de I'antiquité, à l'époque où I'homme avait encore l'idée d'un Dieu unique, souverain maître du monde. Les cultes chinois comme les cultes des autres nations paiennes étaient donc des cultes idolâtriques. Par conséquent, les adversaires des Jésuites dans l'affaire des Cérémonies chinoises avaient raison, et par suite les figuristes devenaient leurs alliés. Il importait donc essentiellement de leur imposer silence. Pour cela les Jésuites de Pékin et les Jésuites de Paris étaient absolument d'accord.

Mais les Jésuites de Pékin avaient quelquefois des audaces que ceux de Paris ne pouvaient admettre. Les Jésuites de Pékin, en effet, pour concilier la chronologie chinoise, telle qu'ils l'admettaient, avec la chronologie de l'Écriture renonçaient résolument à la Vulgate qui était trop courte, et ils admettaient la version des Septante. Cette tolérance qui leur était accordée en Chine pour l'exercice de leur mission - car les Chinois n'admettaient pas qu'on retranchât rien de leur ancienne histoire - ne leur était accordée que difficilement pour les écrits qu'ils publiaient en France. Et nous trouvons dans la correspondance des missionnaires de Pékin des objurgations pour qu'on ne les 


\section{La Chine et la formation de l'esprit philosophique en France}

obligeât pas à suivre la chronologie de la Vulgate. Ils avaient pourtant fort à faire pour obtenir ce qu'ils demandaient, car les plus influents parmi les Jésuites de Paris, les PP. Souciet, et Tournemine étaient des partisans résolus de la Vulgate ; « Oserais-je espérer, écrit le P. Parrenin à M. de Mairan, que messieurs les ébraisant nous laisseront un peu allonger la durée du monde en dépit de la prétendue bonne foi des rabbins qui se sont permis de la raccourcir pour reculer l'avènement du Messie ? Nous ne pécherons en cela ni contre la ${ }_{\text {p.151 }}$ bonne foi ni contre les bonnes mœurs et nous serons plus larges pour prêcher notre sainte religion à une nation qui ne nous écouterait pas si, sans lui apporter de solides raisons, elle nous voyait retrancher ou rejeter ce qu'elle croit être certain dans son histoire $\gg 1$.

Entre ces deux théories opposées, entre les partisans de la Vulgate et les partisans de la version des Septante, le P. du Halde essaie de faire l'accord. La théorie du P. Tournemine qui propose d'interpréter la Vulgate pour allonger un peu la durée du monde lui en fournira les moyens, sans qu'il ait besoin d'avoir recours aux idées radicales des Jésuites de Pékin. Il veut sauver la chronologie traditionnelle et cependant accorder aux Jésuites de Pékin tout ce qu'il est possible de leur accorder dans l'intérêt de la mission. Son rôle est celui d'un modérateur et d'un conciliateur.

Ce n'est pas une tâche facile, car le public ne devait rien savoir de ces dissentiments entre Jésuites de Paris, Jésuites de

${ }^{1}$ Lettre du 20 septembre 1740, Lettres édifiantes et curieuses, t. XXVI. 


\section{La Chine et la formation de l'esprit philosophique en France}

Pékin, Jésuites de Canton. Il était donc bon qu'un seul Jésuite eût un monopole de fait sur toutes les publications de la Compagnie, pour faire disparaître les désaccords, pour donner au public l'idée d'une unité de doctrine conforme aux théories soutenues pendant des dizaines d'années par les Jésuites dans l'affaire des Cérémonies chinoises. Au prix de quels sacrifices le P. du Halde est-il arrivé à réaliser cet accord apparent ?

\section{$*$}

Pour les raisons que nous venons d'indiquer, les écrits sur la Chine, publiés par les Jésuites au XVII ${ }^{e}$ et au XVIII ${ }^{e}$ siècles ont été peu nombreux. Ils se réduisent à trois ouvrages principaux, ou trois recueils essentiels : le Confucius Sinarum philosophes des PP. Couplet, Intorcetta et Rougemont qui parut il est vrai à la fin du XVII ${ }^{e}$ siècle et qui est un peu antérieur à la phase aiguë de I'affaire des Cérémonies chinoises, mais qui est de l'année même où le P. Le Tellier faisait paraître sa Défense des nouveaux chrétiens de la Chine, et par conséquent en pleine lutte entre les jansénistes et les Jésuites. Les deux autres, les Lettres édifiantes et curieuses écrites des missions étrangères et la Description de l'empire de la Chine peuvent être mis au compte du P. du Halde. C'est la valeur de ces livres qu'il nous faut examiner pour savoir jusqu'à quel point les philosophes qui ont puisé à ces sources p. 152 portent la responsabilité de nous avoir donné une idée de la Chine peu conforme à la réalité. 


\section{La Chine et la formation de l'esprit philosophique en France}

Dès que parut I'ouvrage du P. Couplet, il sembla suspect. Des protestants comme Leclerc, dans sa Bibliothèque universelle ${ }^{1}$ et comme Basnage dans son Histoire des Ouvrages des savants 2 laissèrent entendre qu'ils soupçonnaient les Jésuites d'avoir embelli la philosophie de Confucius et d'avoir spiritualisé la religion des Chinois. Mais ils ne pouvaient émettre que des doutes, sans pouvoir en apporter la preuve. Un peu plus tard, en 1713, un certain Aymon affirma dans les Acta Eruditorum ${ }^{3}$ que les Jésuites avaient publié à peine le tiers de la traduction de Confucius qui avait été faite par les Jésuites de Chine. Il promettait de publier le manuscrit original d'une manière intégrale, et il prétendait que dans la préface, dont la moitié était écrite de la main du P. Couplet, on avouait que le bien de la Société des Jésuites n'avait pas permis d'éditer fidèlement cet ouvrage, que des changements étaient nécessaires pour faire condamner à Rome les autres missionnaires de la Chine, et pour engager le pape à approuver le culte mixte que les Jésuites avaient introduit dans cet empire, ainsi que les livres qu'ils avaient publiés en Europe sur cette question.

David Clément nous apprend ${ }^{4}$ que d'après d'Uffenbach 5 , la traduction de Confucius faite par les Jésuites occupait cinq volumes in-folio de deux doigts d'épaisseur chacun; qu'un

1 T. VII, p. 455.

2 T. I, p. 65.

31713 , p. 46.

4 Bibliothèque curieuse, historique et critique, ou Catalogue raisonné des livres difficiles à trouver, t. VII, p. 265, sq.

5 Merkwürdige Reisen, t. III, p. 481 sq. 


\section{La Chine et la formation de l'esprit philosophique en France}

évêque de Lyon, qui avait été huit ans à la Chine, avait remis ce manuscrit à M. Aymon, à la condition qu'il le ferait imprimer, car les parties supprimées par les Jésuites étaient très considérables.

Il existe à la Bibliothèque Nationale un manuscrit ${ }^{1}$ qui contient une partie de la préface du P. Couplet sur la philosophie, la religion chinoises, et la traduction des deux premiers livres de Confucius ainsi que la première partie du troisième livre. Une note manuscrite indique que le deuxième volume de cette traduction était entre les mains du P. Heschen, Jésuite à Anvers. Quant au volume de la Bibliothèque Nationale il a bel et bien été en la p.153 possession de cet Aymon. Une note manuscrite placée à la fin du volume et signée Aymon Theologus et Jurisconsultus nous apprend en effet que ce manuscrit a été donné à l'auteur de cette note, le 15 octobre 1706, par Artus de Lionne évêque de Rosalie (et non par un évêque de Lyon, mais voilà l'erreur d'Uffenbach expliquée) à condition qu'il le publiât intégralement pour l'instruction des savants et pour l'utilité publique, parce que les Jésuites en le publiant l'avaient mutilé. C'est donc bien l'exemplaire d'Aymon et ce manuscrit est certainement I'un des

1 B. N. Latin 6277. Fréret semble avoir eu connaissance en 1735, du manuscrit du $P$. Couplet, puisqu'il se dit à même de rectifier les assertions de la préface du livre imprimé Confucius Sinarum philosophus d'après le manuscrit original du P. Couplet. (cf. notre thèse complémentaire. Documents inédits..., p. 83). 


\section{La Chine et la formation de l'esprit philosophique en France}

manuscrits qu'il avait volés à la Bibliothèque du Roy ${ }^{1}$, car on comprendrait mal que ce volume ait pu tomber entre les mains d'Artus de Lionne, un ennemi déclaré des Jésuites. En tout cas c'est le manuscrit des Jésuites tout prêt pour l'impression, avec les corrections du reviseur que reproduit le texte imprimé, et à la fin du volume se trouve l'approbatur du censeur, le Président Cousin, daté du 29 avril 1687.

En examinant ce manuscrit on s'aperçoit immédiatement que les suppressions n'ont pas l'étendue qu'Aymon leur attribue. Certains chapitres sont rayés sans doute à l'encre noire, mais I'un d'eux tout au moins se trouve reporté à un autre endroit de l'imprimé (p. XXIV § 111). En somme, les corrections portent plutôt sur des détails que sur l'ensemble, ce qui ne veut pas dire que ces retouches soient sans importance. Mais ce sont des corrections, ce n'est pas une mutilation.

L'auteur du manuscrit avoue dans sa préface qu'il a fait cette traduction, non pas avec l'idée d'apporter aux savants d'Europe la connaissance de la sagesse chinoise, mais pour être utile aux futurs missionnaires et leur fournir les moyens de convertir plus

1 Renaudot écrit le 30 septembre 1707 au duc de Noailles : « Il y a une [affaire] qui fait beaucoup de bruit, pour des manuscrits volés à la Bibliothèque du Roy par un fripon d'apostat nommé Aymon, qui venoit icy se réconcilier et donner des avis importants. Les Hollandois n'ont pas fait jusqu'à présent ce qu'on attendoit de leur équité ; au contraire un, à qui $\mathrm{M}$. Clément avoit envoyé procuration pour agir contre le voleur, a été emprisonné comme ayant correspondance icy. Il y a un peu de la faute de $\mathrm{M}$. Brisacier et consorts, chez qui Monseigneur le Cardinat avoit logé cet honneste homme qui les a aussi volés », R. H. L., 1902, p. 292. 


\section{La Chine et la formation de l'esprit philosophique en France}

tard les Chinois ${ }^{1}$. Le correcteur, craignant sans doute que cette p.154 déclaration ne fît suspecter cet ouvrage par les savants et ne tendît à faire croire que les Jésuites avaient fait œuvre apologétique, justifiant leurs procédés en Chine, a supprimé ce passage. C'est une preuve de prudence. Il eût été étonnant que le reviseur eût avoué, comme I'affirmait Aymon, qu'il avait volontairement altéré le texte manuscrit pour faire condamner à Rome les autres missionnaires de la Chine. Nous n'avons pas trouvé trace de ce passage dans le manuscrit.

Le P. Couplet expliquait dans sa préface que les anciens Chinois avaient admis l'existence de Dieu. C'est Fou-hi, monarchiæ sinicæ conditor, qui leur a donné la connaissance de leur premier principe et de leur fin dernière. Mais I'expression dont se sert le P. Couplet en parlant de Fou-hi peut être ambiguë, car on pourrait se demander ce que pensaient les Chinois qui avaient vécu antérieurement à la fondation de la monarchie, et le reviseur corrige : Fo-hi sinicae gentis conditor. Les Chinois avaient donc dès leurs origines la connaissance de leur premier principe. Mais ceci ne paraît pas suffisant au correcteur qui ajoute supremœ spirituum intelligentiæ; ce qui est déjà une interprétation. Et de son propre chef il en tire une conclusion : Cui proinde vota et sacrificia jam tum offerebantur et quam ob rem Fo-hi alio nomine dictus Pao-hi quasi

1 Sinicæ et aliarum extremi Orientis Missionum candidatis, B. N. Latin, 6277, s. p. La préface du P. Couplet dans ce manuscrit n'est malheureusement pas paginée d'un bout à l'autre d'une numérotation continue. Ce sont des feuilles qui ont été réunies et reliées ensemble. On trouve des séries de numérotations 1-2, 1-4, etc. Nous donnerons donc comme références de cette préface, les numéros des paragraphes, qui ont été il est vrai biffés par le reviseur, mais qui restent cependant lisibles. 


\section{La Chine et la formation de l'esprit philosophique en France}

complectens victimas nominatur, quo evidentissime convincitur veri numinis in ipso gentis exordio extitisse ${ }^{1 .}$

Quelques pages plus loin, le correcteur précise et interprète de la même manière. Le P. Couplet cite Confucius qui déclare que I'Yi-King a été écrit pour que les hommes aient sous les yeux mandatum cœli, expression vague que le correcteur précise en ajoutant seu supremi numinis providentiam. Puis il développe : Quod ut clarius omnibus constet, lubet afferre quod in ipso statim exordio ad tabulam illam 64 mutationum disertis verbis pronotarunt duo illi et 40 Interpretes dum promuniut Lectorem totique posteritati cavent, docentes dari supremum Dominum quemdam et Gubernatorem cui nomen Imperator. Quis autem is est (inquiunt) qui dominus dicitur et gubernator ? Et protinus respondent : per se est dominus et gubernator. Nam coelum quidem res est quaepiam summe solida et perfecta quœ naturaliter volvitur absque interruptione; quod autem ita semper volvatur, procul dubio est aliquo Domino et Gubernatore qui id efficit : hoc posito fundamento necesse est ut homines eum per se noscant; non p.155 enim suppetunt verba, quibus possumus pertingere ad eum explicandam 》2. Et voilà démontrée la croyance des Chinois à un Dieu personnel, et créateur du monde.

C'est à peu près de la même manière que l'on démontre la croyance des anciens Chinois à l'immortalité de l'âme.

\footnotetext{
1 Préface, $\S 59$.

2 Préface, $\S 78$.
} 


\section{La Chine \\ et la formation de l'esprit philosophique en France}

Les Jésuites de Chine, dans une glose d'un texte de Confucius, interprétaient déjà la pensée du philosophe chinois, et d'une citation de Confucius déclarant que le roi Ven-Vam se trouvait à côté de l'Etre suprême, ils concluaient que selon les Chinois l'âme de Ven-Vam n'était pas morte avec le corps.

« Etenim cum dicatur Ven-Vam rex assistere Supremo numini, Utique perspicuum sit ipsius regis animam haudquaquam interiisse una cum corpore.... $\gg 1$.

Le reviseur est beaucoup plus audacieux et de cette phrase qui n'était encore tout d'abord qu'une glose d'un cas particulier, et une conclusion ne se rapportant qu'à ce seul cas, il fait une maxime générale et il conclut à une croyance générale des Chinois à l'immortalité de l'âme.

«Etenim cum introducatur ipse Supremi cœli Imperator verba proferens, ac deinde curry alibi dicatur Ven-Vam pii regis animam assistere ad supremi numinis loevam et dexterarn patet et Deum ab ipsis creditum et animam haudquaquam interire cum cor-pore... »2.

Le roi Ven-Vam devient donc chez le reviseur un roi pieux et, c'est pour cette piété qu'il siège à la droite... pour un peu le reviseur dirait « du Père ».

Le texte de Confucius au sujet de Ven-Vam disait que ce roi est à côté de Dieu, et les traducteurs prudemment en tiraient cette conclusion que les Chinois devaient croire par conséquent à

\footnotetext{
1 f. 224.

2 f. 224.
} 


\section{La Chine \\ et la formation de l'esprit philosophique en France}

la survie de l'âme après la mort. Mais quelquefois ils n'ont pas la même prudence. Heureusement le reviseur veille pour eux. Ils rapportent par exemple cette phrase de Confucius :

«...Quo pacto justissimas iras... effugiam... Atavi mei qui, in cœlo nune degit... » 1.

Le reviseur n'hésite pas à corriger

«...cujus anima in cælo nunc degit... »

Puisque la vie future n'est pas une survie du corps mais l'existence d'une âme immatérielle, les rites mortuaires ne sont p.156 pas des sacrifices et il n'y a pas de temples consacrés aux ancêtres - nous sommes ici au cœur même de l'affaire des rites chinois - et il faut être très précis. Voici de quelle manière le reviseur précise :

\begin{tabular}{|c|c|}
\hline Mst & $\operatorname{Im}$ \\
\hline $\begin{array}{l}\text { In majorum templis regio de } \\
\text { more et apparatu defunctis } \\
\text { majoribus sacrificabat (seu } \\
\text { verius parentabat)... . }\end{array}$ & $\begin{array}{l}\text { In majorum a ulis } \\
\text { parentalibus regio de more et } \\
\text { apparatu defunctis majoribus } \\
\text { parentabat... }\end{array}$ \\
\hline $\begin{array}{l}\text {... A posteris vicissim tanti avi. } \\
\text { memoria præsertim in gentilitiis } \\
\text { sacrificiis perpetuo conservata } \\
\text { fuit . }\end{array}$ & $\begin{array}{l}\text {... A posteris vicissim tanti avi } \\
\text { memoria præsertim in } \\
\text { parentalibus officiis ac ritibus } \\
\text { perpetuo conservata fuit. }\end{array}$ \\
\hline
\end{tabular}

Les traducteurs n'avaient pas pris garde qu'en rapportant quelques croyances des Chinois aux esprits, du temps même de Confucius, ils risquaient de ruiner toute l'argumentation des

\footnotetext{
1 f. 237.
} 


\section{La Chine et la formation de l'esprit philosophique en France}

Jésuites sur la pureté du culte transmis de génération en génération depuis les temps les plus reculés jusqu'à notre époque ; ils racontaient même qu'on donnait à Confucius pour I'honorer le nom d'une montagne où sa mère, disait-on, était allée invoquer l'esprit de la montagne pour le supplier d'être favorable à l'enfant qu'elle attendait. Aussi le reviseur n'hésite-til pas à supprimer ce passage :

«Confucius alio nomine honoris ergo Chùm-nhî dictus est : nhî porre montis nomen est, in quo præsidem loci spiritum mater Confucii precata dicitur ut sibi et desiderata, proli propitius foret $\gg 1$.

D'ailleurs d'autres textes prouvent aussi que les Chinois même dans l'antiquité ont cru aux esprits et qu'ils les ont eus en vénération. Les traducteurs rapportent un de ces textes et ils comprennent que ces esprits sont des intelligences - donc des êtres immatériels - qui peuvent apporter le bonheur aux hommes. Mais ceci est trop dangereux. L'ancienne religion chinoise doit être pure et exempte de superstitions. Les

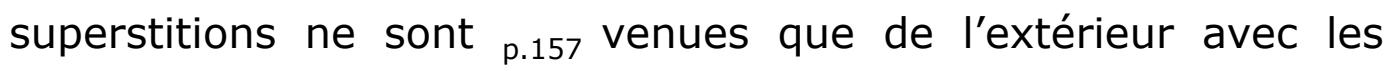
taoïstes. Aussi pas d'hésitations, il faut supprimer ce passage.

«...Spiritus olim jam Sinis fuisse notos atque in veneratione cum ex aliis locis quos in libro Chum-Yum explanamus tum ex hoc videtur posse convinci : quamvis enim deinde nonnulli Interpretum vel impie vel certe pinguiori, ut dicitur, Minerva, de iis philosophati sint : tamen et Intelligentias esse utpote quibus adulari homines queant et $a b$ is felicitatem mortalibus obvenire

1 f. 68. 


\section{La Chine \\ et la formation de l'esprit philosophique en France}

posse, nisi textum hunc imprimis negent, inficiari profecto non possunt $\gg 1$.

De même pas de prodiges ; on supprime la légende du cheval-dragon de Fou-hi ${ }^{2}$. On supprime de même la légende de la tortue qui du temps de Yao et de Yu apparut, apportant les hiéroglyphes. Il ne faut pas non plus insister sur le goût des Chinois pour les oracles, la divination, I'astrologie, qui pourraient indiquer une croyance à un pouvoir magique. Les traducteurs de Pékin discutaient longuement un discours de Chouen et ils s'efforçaient de montrer que I'on ne trouvait chez les anciens Chinois que la pratique des « sortes consultoriæ», mais aucune de ces pratiques qui supposent un pacte avec une puissance inférieure et hostile à celle de Dieu. Cependant il était dangereux d'insister, car si des Chinois ont pratiqué les «sortes consultoriæ » comme moyen de divination, ne croient-ils pas alors à la fatalité et cette croyance à la fatalité n'est-elle pas contraire au dogme de la Providence qu'on vient de si bien prouver ? Aussi faut-il supprimer sans hésiter ${ }^{3}$.

Il y a dans les théories des Jésuites sur les cultes chinois une difficulté qu'ils ont d'ailleurs bien aperçue. Si les anciens Chinois ont été, comme le répètent les Jésuites, si attachés d'une part à leurs traditions et à leurs usages, et d'autre part s'ils ont été spiritualistes par une tradition ininterrompue et ennemis de toute pratique superstitieuse, comment ont-ils pu accepter si

\footnotetext{
1 f. 368.

2 f. 170.

3 f. 174.
} 


\section{La Chine et la formation de l'esprit philosophique en France}

facilement les cultes idolâtriques de Lao Kiun et de Fo qui étaient contraires à leur nature et à toutes les traditions ? Le reviseur a vu le danger. Aussi lorsque son modèle parle de tous les malheurs quæ quantaque mala qui ont été introduits en Chine par l'idole des Indes il aime mieux insinuer que ce sont des dogmes (quæ dogmata) plutôt que des pratiques. Car les pratiques indiqueraient ${ }_{\text {p.158 }}$ une tendance du peuple à la superstition tandis que l'introduction des dogmes peut s'expliquer par un ordre royal. Aussi le reviseur glisse-t-il cette explication dans le texte du manuscrit :

« Ducentis septuaginta post annis quam Han familia rerum potiri cœperat, post Christum vero annis quinque et sexaginta teterrima pestis et quovis incendio perniciosior regia auctoritate Sinas invasit, Idoli Fe secta nefaria $\gg 1$.

Et dès lors tout s'explique. Il n'est pas nécessaire de développer pour des Français du XVII e siècle I'argument du Regis ad exemptum.

Ces remarques suffisent pour que nous puissions apprécier maintenant I'ouvrage des PP. Couplet, Intorcetta, Rougemont. Non que l'auteur de la préface ou que les traducteurs de Confucius en soient responsables, puisque c'est au contraire au reviseur qu'il faut attribuer les passages les plus significatifs. Mais il est désormais possible de voir que dès le premier grand ouvrage publié par les Jésuites sur la Chine les préoccupations de la Querelle des Cérémonies chinoises les absorbent et conduisent leur plume. Il faut défendre leurs méthodes

1 Mst, Préface, § 30, Imprimé, p. XXVII. 


\section{La Chine \\ et la formation de l'esprit philosophique en France}

d'évangélisation et les cultes qu'ils tolèrent aux nouveaux convertis. Quel meilleur moyen de le faire que d'exposer sous une forme en apparence impartiale l'ancienne religion des Chinois ? Ici pas d'attaques contre les adversaires, pas d'allusions à la Morale pratique des Jésuites. Mais comme ce livre rejoint bien cependant celui du P. Le Tellier, cette Défense des nouveaux chrétiens de la Chine. Le Confucius lui aussi est une défense, mais surtout une défense des Jésuites.

On a tenté plusieurs fois de tracer la physionomie des Lettres édifiantes et curieuses, de ces petits recueils périodiques qui eurent tant de succès au XVIII ${ }^{\mathrm{e}}$ siècle parce qu'ils apportaient non seulement des renseignements sur les missions et sur le nombre considérable des conversions que faisaient les Jésuites dans les pays lointains, mais aussi des faits nouveaux sur des pays mal connus. Jamais le goût des récits de voyage n'a été plus vif que pendant la première moitié du XVIII ${ }^{e}$ siècle, et les rédacteurs des Lettres édifiantes n'agirent pas sans intention en conservant à ce recueil son caractère de « choses vues», de récit direct adressé par un Jésuite de Chine ou d'ailleurs à un confrère de Paris et reproduit en toute simplicité dans le recueil.

p.159 M. Martino constate avec juste raison le caractère de naïveté de ces Lettres, qui fut une des causes de leur succès : « Le Livre, aussitôt ouvert, donne l'impression d'une merveilleuse candeur, d'une bonne foi naïve qui va souvent jusqu'à la maladresse... Les propos et le style, le récit comme les appréciations sont d'une simplicité, d'une médiocrité parfois, 


\section{La Chine et la formation de l'esprit philosophique en France}

qui doit ravir d'aise l'immense majorité du public et si les habiles directeurs de la Compagnie de Jésus qui eussent pu modifier à leur gré les termes de ces lettres, leur laissèrent ce ton si caractéristique, c'est qu'ils le savaient propre à attirer vers I'œuvre des missions toutes les sympathies des bonnes gens »1.

On ne saurait mieux dire, et de la naïveté du recueil on peut être tenté de conclure à sa véracité. Mais il nous faut essayer de pénétrer un peu dans la composition de ces lettres si simples en apparence, pour voir si Saint-Simon a eu raison de les appeler « d'artificieuses relations » 2. Il est possible que Saint-Simon soit seulement poussé par sa haine des Jésuites. Mais il est possible aussi qu'il ait formulé ce jugement d'après des renseignements précis en vertu des méritoires sur la Chine que lui fournissait l'ex-Jésuite Foucquet, et que nous ne connaissons pas ${ }^{3}$.

Nous savons par différents témoignages venant des intéressés eux-mêmes et qui s'en plaignent, que les lettres des missionnaires n'étaient pas publiées dans leur état original. Le P. de Mailla par exemple écrit de Pékin, le 17 septembre 1730 qu'à

1 Martino. L'Orient dans la littérature française au XVIII siècle, p. 114. Cependant des lecteurs de ces Lettres au XVIII ${ }^{\text {e }}$ siècle, étaient moins frappés par leur air de candeur que par l'élégance de leur style. « Ces recueils, comme vous le savez, sont non seulement bien écrits, (le stile en étant retouché par une nain habile) mais ils sont encore souvent remplis de faits singuliers. » (Nouvelliste du Parnasse, Lettre XLIX, t. IV, p. 7).

Pour se faire une idée de ces retouches, faites sur un texte qui ne présente aucun danger au point de vue religieux, on peut voir le mst.. du mémoire du P. Dentrecolles avec les corrections du P. du Halde. B. N. Fr. 17218, f. 75, sq.

2 Saint-Simon, Mémoires, t. XXV, p. 184.

3 Cf. les lettres de Foucquet publiées par H. Cordier, dans la Revue d'ExtrêmeOrient, t. I (1882), p. 21 sq. A trois reprises Foucquet annonce l'envoi de mémoires sur la Chine au duc de Saint-Simon par l'intermédiaire du cardinal de Gualterio. 


\section{La Chine et la formation de l'esprit philosophique en France}

la suite d'une de ses lettres qui a été publiée dans les Lettres édifiantes, le $P$. du Halde a ajouté au bout une autre lettre venant d'un autre missionnaire. Mais il s'est bien gardé d'en prévenir le public ou le P. de Mailla. Or la partie ainsi ajoutée

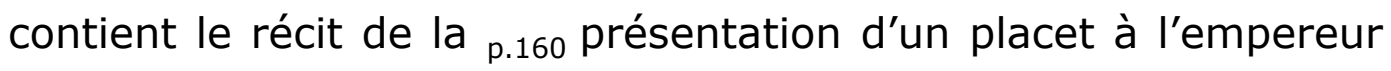
de Chine, ce qui est une fausseté ${ }^{1}$.

Vers la même époque, le 10 novembre 1730, le P. de Prémare écrit a Fourmont qu'il a trouvé dans le XIXe recueil des Lettres édifiantes un petit écrit de lui pour réfuter les Anciennes Relations de deux voyageurs mahométans de Renaudot. Le P. du Halde n'a pas publié la lettre entière qui était beaucoup plus longue. Il en a fait seulement, « assez bien d'ailleurs », un résumé. Mais il s'est permis à deux reprises (pp. 458 et 497 ) d'ajouter dix lignes au manuscrit du P. de Prémare et celui-ci ajoute : « C'est deux allonges dont l'éditeur auroit pu se passer $\gg 2$.

Foucquet apprend en 1736 de l'abbé de Rothelin que la lettre du P. Parrenin qui se trouve dans le XXIe tome des Lettres édifiantes n'a pas été publiée telle qu'elle se trouve dans I'original ; et Foucquet répond à l'abbé de Rothelin : « C'est le sujet d'une plainte ancienne que cette infidélité des éditeurs. Vers I'année 1702 ou 1703 j'écrivis une lettre à M. le duc de la Force qu'on s'avisa d'imprimer dans le second ou le troisième recueil et que j'ay vue absolument défigurée par les changemens

\footnotetext{
$1 \mathrm{H}$. Cordier. Documents inédits pour servir à I'histoire ecclésiastique de I'Extrême-Orient. Revue d'Extrême-Orient, t. III, p. 651-2.

2 B. N. Fr. 15195 , f. 51.
} 


\section{La Chine et la formation de l'esprit philosophique en France}

que l'éditeur de ce tems-là eut la hardiesse de faire. Aussi ay-je pris la résolution de ne rien écrire jamais de semblable. J'en avisay le procureur et je tins parole $\gg 1$. Comme on le voit, le P. du Halde ne faisait que suivre un usage déjà établi par son prédécesseur, le P. Le Gobien.

Pour nous rendre compte des procédés du P. du Halde, nous pouvons examiner en détail la manière dont il publie cette lettre du P. Parrenin à M. de Mairan dont parlait I'abbé de Rothelin à Foucquet. C'est une lettre dont le manuscrit nous a été conservé, ce qui nous permet d'apercevoir immédiatement que l'imprimé n'est pas identique à l'original 2 . Certains passages ont été supprimés. Mais, en outre, d'autres passages ont été ajoutés et nous pouvons en connaître la provenance, car les lettres du $\mathrm{P}$. Parrenin à $M$. de Mairan ont circulé parmi les savants au XVIII siècle ${ }^{3}$, un conseiller au Châtelet, Léonard des Malpeines, a pris soin de ${ }_{\text {p.161 }}$ noter toutes les différences entre les manuscrits des différentes lettres qu'il a eues sous les yeux et les textes imprimés ${ }^{4}$.

La lettre du P. Parrenin, telle qu'elle est imprimée dans le XXI recueil des Lettres édifiantes est en réalité une mosaïque. La véritable lettre du P. Parrenin commence seulement à la page 89

1 Lettre de Foucquet à l'abbé de Rothelin, à Rome, le mercredi 7 novembre 1736, la nuit. (Obs. A B 4 (149-5-9). La lettre à laquelle Foucquet fait allusion ici a été publiée dans Ve Recueil des Lettres édifiantes, p. 129-239.

2 Le manuscrit est à la B. N. Fr. 17240.

3 Fréret en avait eu communication, cf. sa lettre à M. de Mairan, B. N., p. 175-177, publiée dans notre thèse complémentaire, Documents inédits..., $\mathrm{p}$. 46.

4 B. N. Fr. 12215 , f. $171-174 ; 190-193$. 


\section{La Chine et la formation de l'esprit philosophique en France}

de l'imprimé. Les pages qui précèdent, que le P. du Halde donne comme faisant partie de la même lettre sont prises au commencement de la lettre du P. Parrenin à M. de Mairan du 12 octobre 1729. Quant aux extraits de la lettre de M. de Mairan au P. Parrenin qu'on trouve pp. 79-89, ce sont des citations faites par le P. Parrenin dans sa lettre à M. de Mairan du 12 octobre 1729 et dans celle du commencement du mois d'août 1730 . D'autre part, le P. du Halde supprime la partie la plus importante de la lettre du P. Parrenin donnant une traduction littérale des annales des premiers temps de la monarchie chinoise et il met cette note pour s'excuser : «On n'a pas jugé à propos de donner ici cette traduction. Outre qu'elle occuperoit une bonne partie de ce volume, elle ne seroit pas du goût de la plupart des lecteurs »1. Comme il a donné malgré tout cette traduction dans sa Description de la Chine, avec quelques modifications, nous verrons un peu plus tard jusqu'à quel point les questions de goût ont pu seules le déterminer à cette suppression. Enfin les pages 114-116 sont de la composition du P. du Halde ainsi que les pages 177-179.

Nous avons donc des raisons de nous méfier du P. du Halde. Son rôle n'est pas celui d'un simple éditeur, mais presque celui d'un collaborateur. Quels sont les principes qui I'ont guidé ?

Le P. du Halde corrige sans doute le style du P. Parrenin qui s'avance d'une allure un peu traînante. Mais ces corrections de style en général sont légères, et quand il y a une altération un peu importante nous pouvons toujours nous demander si c'est la

${ }^{1}$ Lettres édifiantes et curieuses, XXI ${ }^{\mathrm{e}}$ R., p. 83. 


\section{La Chine et la formation de l'esprit philosophique en France}

rudesse de l'expression de son texte qui l'a choqué ou l'idée défavorable que cette expression pourrait donner des Chinois. Le P. Parrenin parle par exemple d'une «forte et puante boisson » que boivent les Chinois. Le mot est peut-être un peu rude, mais le P. Parrenin le justifie et I'aggrave par une note : « Je dis puante et, de mauvais goût pour un nez et un gosier européen, car pour les Chinois elle leur plaît en toute manière et ils s'en enivrent à petits frais ». Le P. du Halde supprime le mot «puante » et la note. Est-ce le mot qui I'a choqué ? Est-ce la note qui lui a fait craindre que I'on sache que les Chinois s'enivrent ? ${ }^{1}$.

La Chine est le pays le plus heureux, parce qu'il n'y a ni guerre, ni peste, ni famine, ou tout au moins si rarement ! C'est le P. du Halde qui affirme cela en interprétant très librement, pour ne rien dire de plus, la pensée du P. Parrenin.

\begin{tabular}{|c|c|}
\hline Mst & Imprimé \\
\hline
\end{tabular}

1 B. N. Fr. 12215, f. 191. Le texte corrigé par le P. du Halde est dans les Lettres édifiantes, XXIVe R., p. 81. 


\section{La Chine et la formation de l'esprit philosophique en France}

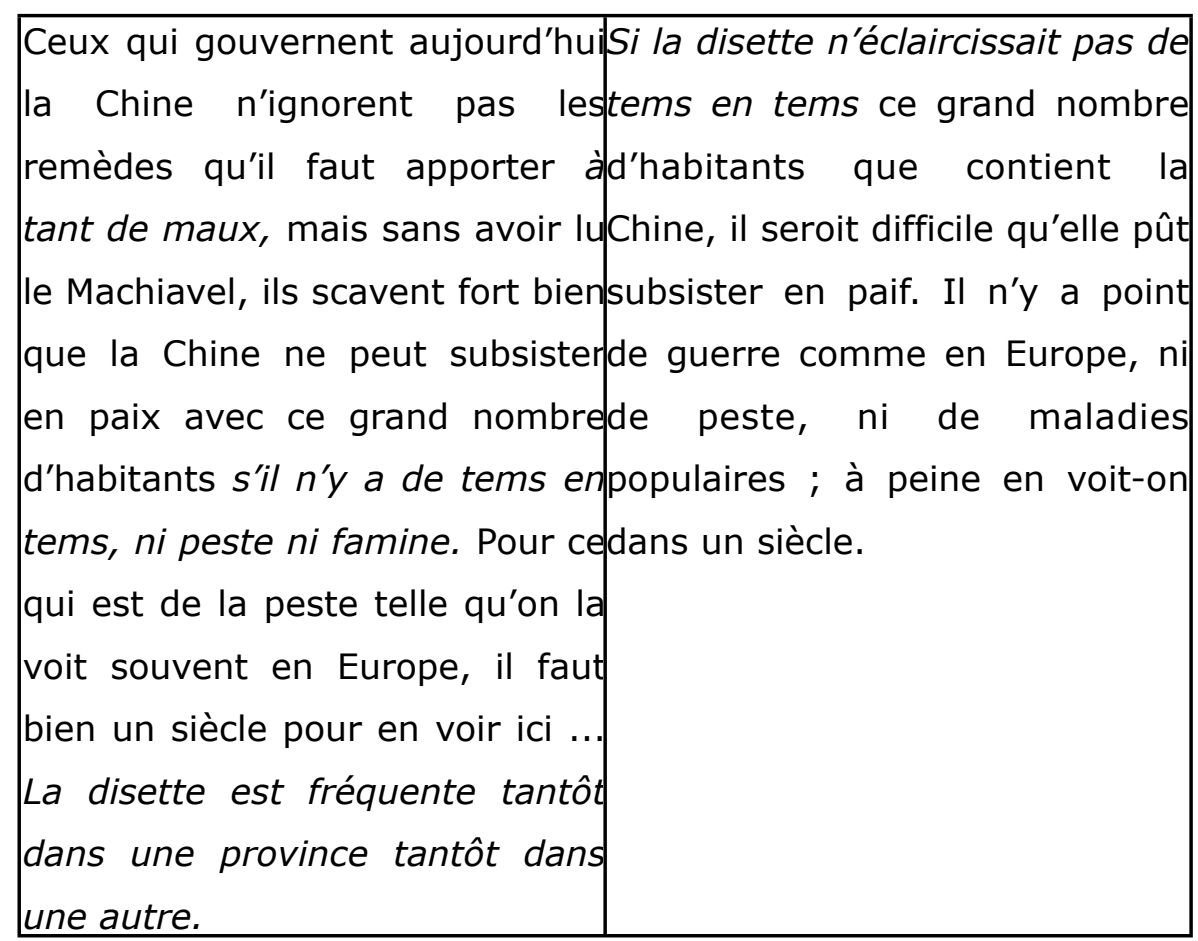

Le P. du Halde n'admet pas non plus qu'on mette en doute la science des Chinois. Ils ont apporté avec eux des plaines de Sennaar après la dispersion des peuples, les connaissances astronomiques, et cette science astronomique s'est maintenue sans interruption jusqu'à nos jours. Mais il ne faudrait pas que I'on pût en douter comme permettaient de le faire certaines expressions du P. Parrenin qu'il importe de préciser.

\begin{tabular}{|c|c|}
\hline Mst & Imprimé \\
\hline
\end{tabular}




\section{La Chine et la formation de l'esprit philosophique en France}

\begin{tabular}{|c|c|}
\hline $\begin{array}{l}\text { Cela supposé il est vraisemblable } \\
\text { que la colonie qui vint p.163 } \\
\text { d'abord à la Chine n'étoit pas } \\
\text { tout à fait dépourvue de gens } \\
\text { qui entendissent ces sortes de } \\
\text { sciences. S'ils en perdirent } \\
\text { quelque chose en chemin } \\
\text { faisant, cela n'alla pas jusqu'à un } \\
\text { oubli total et un peu } \\
\text { d'application suffit pour en } \\
\text { rappeler le souvenir. }\end{array}$ & $\left\{\begin{array}{l}\text { Cela supposé il est vraisemblable } \\
\text { que la colonie qui vint d'abord à } \\
\text { la Chine n'étoit pas tout à fait } \\
\text { dépourvue de gens capables } \\
\text { d'observer les astres, de } \\
\text { connoitre leurs mouvemens et } \\
\text { d'expliquer les phénomènes du } \\
\text { ciel. }\end{array}\right.$ \\
\hline
\end{tabular}

Une question sur laquelle le P. du Halde est encore plus chatouilleux est celle des croyances populaires des Chinois. Quelques missionnaires ont, il est vrai, dans la simplicité de leur cœur et en toute naïveté, exposé les difficultés qu'ils éprouvaient à convertir les Chinois. Mais les lettres de ce genre n'ont pas été publiées, c'est qu'elles ne sont rien moins qu'un panégyrique des Chinois. Ainsi le P. de Prémare lorsqu'il était jeune missionnaire en Chine et qu'il parlait librement, mais sans oser d'ailleurs envoyer sa lettre au P. de la Chaize ou au P. Verjus, supérieur des missions, disait franchement ce qu'il pensait des superstitions des Chinois : «Ils n'ont point de connaissances claires des créatures et du créateur et je n'en ai point trouvé qui sçussent ce que c'est de raisonner juste et avec méthode sur les effets de la nature qu'ils se mettent peu en peine de sçavoir, sur leur âme qu'ils ne connoissent pas, sur l'existence d'un premier être tout parfait, tâchant d'en effacer dans leur esprit toutes les idées, sur l'état d'une autre vie ne se mettant en peine que de 


\section{La Chine et la formation de l'esprit philosophique en France}

celle-cy, sur la nécessité d'une religion n'en ayant aucune qui les gêne ».

Ces Chinois qui ne se soucient aucunement de l'être suprême sont par contre extrêmement superstitieux : « Les Chinois ignorent la nature, c'est pourquoi ils attribuent quasi toujours ses effets les plus communs à quelque mauvais génie qu'ils tachent d'apaiser par des cérémonies impies et ridicules. Ils craignent et, rendent des respects aux démons sans sçavoir ce que c'est que ces diables qui les épouvantent si fort : il est comme seur qu'avant que d'être chrétiens ils ne connoissent point de substance purement spirituelle, aussi il faut qu'ils avouent que leurs diables sont corporels, tantôt ce sera quelque idole ou plutôt le diable qui habite dans l'idole, tantôt ce sera quelque haute montagne ou quelque gros arbre ou quelque dragon imaginaire qu'ils se figurent dans le ciel ou au fond des antres de la mer, tantôt enfin, ce qui est bien plus extravagant, ce sera comme la quintessence de quelque ${ }_{\text {p.164 }}$ bête comme un renard, un singe, une tortue, une grenouille, etc... $\gg 1$.

Il est certain que les ennemis des Jésuites n'en ont jamais tant dit sur les superstitions des Chinois. Et ce sont des lettres que le P. Le Gobien et le P. du Halde ont résolument écartées.

Un autre de ces missionnaires candides fut le P. d'Entrecolles qui envoya en France un assez long mémoire sur les écoles publiques à la Chine, imprimé en partie dans la Description de la Chine 2 . Le manuscrit nous en a été conservé avec de

\footnotetext{
${ }^{1}$ Lettre du 7 août 1700. B. N. Fr. 17239, f. 47, v․

2 Description de la Chine, t. II, p. 259-275.
} 


\section{La Chine \\ et la formation de l'esprit philosophique en France}

nombreuses ratures d'une tout autre encre que celle du manuscrit et dont aucune n'est passée dans les imprimés ${ }^{1}$.

Le P. d'Entrecolles avait I'audace de douter non seulement de la science des Chinois mais aussi de la valeur de l'enseignement donné dans ces nombreuses écoles chinoises dont les écrits sur la Chine avait rebattu les oreilles des Européens. Il cite une remarque qu'il a trouvée dans un livre assez récent et approuvé par deux Docteurs de la Cour :

« Un Professeur étant chargé de vingt écoliers tous de différens étages et quelquefois les uns lisant les livres pour les grades de la robe, et les autres pour les grades des armes (les livres sont en effet différens) peut-il luy seul fournir à les former à donner et exiger tant de leçons particulières à un chacun ; il n'y fourniroit pas quand il auroit dix yeux, dix oreilles, dix mains et dix bouches ».

Et le P. d'Entrecolles ajoute ce commentaire qui tout autant que le texte chinois va être impitoyablement coupé : «Voilà à mon avis la cause en partie pourquoy en Chine on étudie tant, et I'on avance si peu ; car enfin on n'a ni grec, ni latin, ni hébreu à apprendre comme dans nos collèges. En Chine on ne se met en peine d'aucune langue étrangère ; les maîtres n'enseignent pas même la langue mandarine à leurs disciples ; ils lisent pour la plupart et expliquent les livres dans le patois de leur province,

\footnotetext{
1 B. N. Fr. 17238. « Des écoles publiques de la Chine » (reçue le 12 juin 1718).
} 


\section{La Chine \\ et la formation de l'esprit philosophique en France}

chaque province a son jargon, comme qui diroit le Gascon par rapport au françois $\gg 1$.

Le P. d'Entrecolles doute également, ce qui est plus grave, de la valeur morale de l'enseignement des écoles chinoises : «Quant aux discours libres, souvent les écoles sont des écoles de Satan, p.165 soit parce que le maître est luy-même débauché, soit à cause des mauvais compagnons ; parmi des infidèles, il est rare qu'il ne s'y en trouve. L'auteur que je cite menace en vain de la colère des esprits, à qui on ne sçauroit cacher les désordres secrets, ils règnent étrangement parmi la jeunesse chinoise, et l'innocence des jeunes Chrétiens court d'étranges risques quand ils étudient sous un maître infidèle $\gg 2$.

Pas d'histoire de débauche chez les Chinois et surtout pas d'esprits et pas de prodiges. Le P. du Halde coupe toujours.

Le P. d'Entrecolles nous rapporte aussi qu'il a consulté des livres d'école pour voir les anecdotes qui servaient à l'instruction des enfants et il y trouve I'histoire d'un pauvre paysan qui sous la dynastie des Han se trouvant incapable de nourrir sa famille, se vit dans la nécessité de sacrifier ou sa vieille mère ou son fils. Conformément aux principes de la morale chinoise, il décida de garder sa mère et creusa une fosse pour enterrer son fils. Or en creusant cette fosse, il trouva une quantité de « très bel or » et sur cette «masse d'or » étaient écrits ces mots : «Le ciel donne cet or à Ko kiu, ce fils si attaché à sa mère. Le mandarin ni qui que ce soit n'a rien à voir à ce trésor ». Et le P. d'Entrecolles

\footnotetext{
${ }^{1}$ B. N. Fr. 17238, f. $26, v^{\circ}$.

2 ibid., f. $27, v^{\circ}$.
} 


\section{La Chine et la formation de l'esprit philosophique en France}

ajoute : «On sçut cet événement et l'on vit avec joye la vertu récompensée »1. La «vertu » de ce père qui enterre son fils était, il faut l'avouer, une vertu un peu forte pour des Français. Mais ce n'est pas la seule raison qui a poussé le correcteur à supprimer cette histoire. La véritable raison c'est que l'on y voit du prodige. Pourtant le P. d'Entrecolles a bien pris soin de déclarer que I'on peut voir des miracles arrivés parmi la gentilité. Il cite comme autorités le P. Grenade et Aristote. Mais rien n'y fait, les ciseaux de la censure sont impitoyables.

Si le P. du Halde ne croit pas aux prodiges que rapportent les histoires chinoises, il croit du moins aux miracles qui peuvent se produire en Chine pour favoriser la religion chrétienne. Au besoin même il en inventerait : il le faut pour satisfaire la clientèle pieuse des Lettres édifiantes.

Dans la lettre du P. Parrenin insérée dans le XXIe recueil des Lettres édifiantes et curieuses nous avons vu que certaines pages étaient de la main du P. du Halde lui-même et ne se trouvaient pas dans le manuscrit original. Or dans deux de ces pages p.166 (177179) ainsi ajoutées, le P. du Halde met au compte du P. Parrenin un développement sur les «croix de feu » environnées d'étoiles brillantes que I'on vit dans trois différentes provinces de la Chine en 1718, 1719 et 1722, et auxquelles on ne peut donner le nom d'aurores boréales. Et le P. Parrenin, transcrit par le P. du Halde, ajoute : « Ce spectacle qui attira tous les regards dura dans l'air un temps assez considérable pour qu'on pût l'examiner à loisir. On en grava une planche dans

\footnotetext{
1 ibid., f. 34.
} 


\section{La Chine et la formation de l'esprit philosophique en France}

la ville de Hang-tchéou, capitale de la province de Tche-kiang et les estampes qu'on en tira furent répandues dans tout l'empire, on y marque le lieu et le jour où chaque croix a paru, de combien de temps a été sa durée et la multitude des personnes qui I'ont considérée avec la plus grande attention. »1. Tout cela semble donc être l'énumération des circonstances qui peuvent rendre vraisemblable une observation de ce genre, et il est possible qu'un missionnaire dont le P. du Halde a eu la lettre sous les yeux ait interprété les faits de cette manière. Mais ce n'est certainement pas le P. Parrenin. Le P. Parrenin écrit en effet à M. de Mairan en septembre 1735 (lettre insérée dans les Lettres édifiantes, XXIVe Recueil, mais avec suppression de ce passage) : « Je crois, Monsieur, aussi bien que vous, que les croix de feu, les arcs lumineux qui parurent à Han-tchéou et dans le Chan-toun en 1718 et 1719 estoient des espèces d'aurores boréales. Les Chrestiens les prirent pour des prodiges qu'ils expliquèrent chacun suivant leurs souhaits. On nous en écrivit de là icy mais sans aucune observation sur laquelle on peut compter. Je ne sçai pas si les mandarins s'en apperçurent, du moins se gardèrent-ils bien d'en avertir la cour où on ne vit rien $\gg 2$.

Nous sommes donc obligés d'avouer avec Saint-Simon que les Lettres édifiantes sont légèrement artificieuses. C'est une œuvre d'apologétique. Ces lettres sont naïves sans doute mais d'une

\footnotetext{
1 Lettres édifiantes et curieuses : « Je ne voudrois pas donner le nom de lumières boréales aux globes de feu qui parurent ici, il y a trois ou quatre ans, ni à ce que nous vîmes trois jours devant et trois jours après l'équinoxe d'automne de cette année ». XXI ${ }^{\text {e }}$., p. 177-178.
}

2 B. N. Fr. 12215 , f. 140. 


\section{La Chine \\ et la formation de l'esprit philosophique en France}

naïveté plus feinte que réelle. La véritable naïveté des correspondants de Chine nous eût donné des Chinois une idée assez différente. Ils n'auraient pas aussi bien dissimulé que les Chinois étaient parfois ivrognes ou débauchés. Ils auraient vanté sans doute la vertu des Chinois, mais ils auraient mis quelques ombres au tableau. C'est le P. du Halde qui a fait du Chinois le parangon de vertu que le XVIIIe siècle admirera parce que ces Lettres sont ${ }_{\text {p.167 }}$ des lettres d'édification morale. Et non moins des lettres d'édification religieuse. Il faut montrer au public français l'importance de la mission de Chine, l'abondance de la moisson qui attend les missionnaires jésuites, puisque les Chinois qui ne sont ni superstitieux, ni idolâtres, semblent être tout prêts pour qu'on leur prêche l'évangile. Et Dieu lui-même ne semble-t-il pas favoriser la mission par ces miracles et ces croix de feu dont de nombreuses estampes répandues dans tout l'empire - véritables images de piété - apportent aux Chinois la nouvelle?

Ces Lettres édifiantes et curieuses, plus encore que curieuses sont édifiantes. Pour une publication de ce genre, il est nécessaire que les lettres des PP. Gaubil ou Parrenin passent par les ciseaux du P. du Halde.

Lorsqu'on parle de la Chine et des missionnaires jésuites au XVIII ${ }^{\mathrm{e}}$ siècle, le premier nom qui vient à l'esprit est évidemment celui du P. du Halde, et cependant il n'est jamais allé en Chine. Toute son érudition sur la Chine est de seconde main. Mais il a attaché son nom à ce monumental ouvrage : Description de 


\section{La Chine et la formation de l'esprit philosophique en France}

I'Empire de la Chine et de la Tartarie chinoise qui est la somme des connaissances sur la Chine dans la première moitié du XVIII siècle, et qui eut un grand succès ; trois éditions en français, deux éditions en anglais en quelques années.

Dans sa préface, le P. du Halde cite les autorités qui permettent d'ajouter foi à son ouvrage : ces nombreux missionnaires de Chine avec lesquels il est resté en correspondance pendant vingt-cinq ans, ou les missionnaires revenus de Chine avec lesquels il s'est entretenu pendant leur séjour à Paris. Lorsque son ouvrage fut terminé il eut la bonne fortune d'avoir à sa disposition pendant une année entière le $P$. Contancin qui « avait demeuré trente-deux ans à la Chine et dix ans à Pékin ». Donc, le P. du Halde nous offre des garanties sérieuses. Sans doute, comme nous l'avons vu, quelques mémoires qu'il aurait désiré consulter lui ont échappé ; parfois des missionnaires se sont cachés de lui pour envoyer leurs travaux en Europe, mais toutes les fois qu'il a pu saisir ces mémoires au passage, il n'a pas négligé de le faire. Si par hasard, un P. de Pékin, le P. de Mailla, par exemple, en envoyant un de ses mémoires aux PP. de sa province prenait des précautions pour que le $\mathrm{P}$. du Halde ne le vît pas, le mémoire tout au moins était communiqué au P. de Lignières, le confesseur du roi, et celui-ci p.168 s'empressait d'en faire part au P. du Halde ${ }^{1}$. Les sources du P. du Halde sont donc abondantes, et si nous consultons la liste des missionnaires dont les travaux ont servi de gré ou de force à la Description de la Chine, nous y

1 Lettre du P. du Halde au P. Foureau, Paris, 13 octobre 1739, B. N. N. A. F. 6556 , f. 26. 


\section{La Chine et la formation de l'esprit philosophique en France}

trouvons les meilleures têtes de la mission de Chine, depuis le P. Martin Martini, I'un des premiers missionnaires jésuites qui aient écrit sur la Chine jusqu'au P. Gaubil, qui ne faisait guère que de commencer ses travaux au moment où le $\mathrm{P}$. du Halde publiait son ouvrage. Nul plus que le P. du Halde n'était en mesure de donner en 1735 l'ouvrage attendu sur la Chine. Nul plus que lui n'avait eu plus de matériaux à sa disposition.

Un auteur anonyme qui écrit en 1747 une Dissertation sur l'Empire de la Chine, et qui semble avoir vécu dans le pays, relève chez Voltaire et chez son garant, le P. du Halde quelques erreurs matérielles : ils ont exagéré tous deux la population de la Chine et les revenus de l'Empereur. Mais I'anonyme déclare néanmoins : «M. de Voltaire a suivi le P. du Halde, c'étoit presque le seul guide qu'il pût suivre et il ne pouvoit pas en choisir un meilleur, la Description de la Chine faite sur les mémoires des missionnaires jésuites est un des plus beaux livres qui aient paru en ce genre. Les cartes seules sont un morceau précieux nous en avons peu qui soient aussi exactes, sans en excepter celles que nos plus habiles géographes nous ont données de la France même $\gg 1$.

C'est en effet le premier mérite de l'ouvrage du P. du Halde : la partie géographique est originale et nouvelle, et les cartes gravées par d'Anville sont précieuses non seulement par leur exactitude, mais aussi par leur nouveauté. Le P. du Halde avait eu en effet à sa disposition un mémoire très étendu, composé par le. P. Régis, I'un des missionnaires qui allèrent, sur l'ordre de

1 A. N. K. 1334 , f. 1. 


\section{La Chine et la formation de l'esprit philosophique en France}

l'empereur Kang hi, faire des levées géographiques en Tartarie, pour composer la carte. C'est de ce mémoire intitulé Nouvelle géographie de la Chine et de la Tartarie ${ }^{1}$ que le P. du Halde a tiré tout ce qu'il rapporte sur l'histoire de ce levé gigantesque aussi bien que de la meilleure partie des informations géographiques de sa Description.

Ce sont ces cartes que le P. du Halde tenait en réserve depuis longtemps et qu'il refusait même, comme nous l'avons vu, de p. ${ }_{169}$ communiquer aux membres de l'académie des sciences. C'est que les Jésuites français qui avaient eu la peine et le travail, voulaient avoir le mérite d'offrir ces cartes au roi de France pour contribuer à sa gloire. Mais les Jésuites de Chine s'inquiétaient et s'impatientaient des retards, car le roi de Portugal eût voulu être le premier souverain du monde à publier un atlas chinois. Le P. de Mailla prévient en effet en 1730 un de ses correspondants de Paris que le roi de Portugal a fait graver les cartes de chaque province et il importe de ne pas se laisser devancer, car, ajoutet-il « il seroit peut-être bon que le P. du Halde le sçeut, la carte de la Chine et de la Tartarie dans le fond est l'ouvrage des seuls jésuites françois. Les PP. Cardozo, portugois, et Fradely, allemant, qui ont accompagné quelques uns de nous n'y ont eu guère d'autre part que celle qui est inséparable du voyage $\gg 2$. Et de son côté Lange, l'envoyé de la Russie, n'eût pas mieux demandé que de conquérir cette gloire pour la nation qu'il représentait en Chine.

${ }^{1}$ B. N. Fr. 17242.

$2 \mathrm{H}$. Cordier, Documents inédits pour servir à I'histoire ecclésiastique de I'Extrême-Orient, Revue d'Extrême-Orient, t. III, p. 652-653. 


\section{La Chine et la formation de l'esprit philosophique en France}

Enfin le P. du Halde fut prêt avant ses rivaux, et s'il faut en croire son Epitre au Roi, c'est le plaisir que prit Louis XV à voir les cartes qui détermina le Jésuite à donner une Description détaillée de la Chine. En réalité, la Description est d'abord géographique, et la plus grande partie du premier volume, la presque totalité du quatrième sont consacrées à la géographie de la Chine et de la Tartarie.

Sans doute un savant comme Fréret, peu facile à satisfaire, regrettait que la carte générale de la Chine et de la Tartarie fût destituée de preuves et ne fût pas accompagnée du détail des opérations géographiques et astronomiques sur lesquelles elle est fondée. «On donne une liste des longitudes et des latitudes, écrit-il au P. Gaubil, sans remarquer les observations qui les ont données et sans désigner les longitudes déterminées astronomiquement, soit par les éclipses de lune, soit par celles des satellites, des longitudes déduites des opérations trigonométriques et de celles que I'on a conclu par voie d'estime des distances itinéraires... »1. Mais le P. Gaubil lui fait remarquer que les missionnaires qui ont fait la carte n'ont disposé ni du temps, ni des instruments nécessaires, et cette lettre toute simple du P. Gaubil nous donne de curieux renseignements sur cette existence des missionnaires, à la fois religieux et savants, et partageant leur temps entre leurs p.170 deux passions, la passion de la mission et la passion de la science : « Nos Pères profitoient de l'employ de mappistes pour faire mission, pour procurer des secours et de la protection aux

1 Fréret à Gaubil, voir notre thèse complémentaire, Documents inédits..., p. 77-8. 


\section{La Chine et la formation de l'esprit philosophique en France}

missionnaires des provinces et pour établir de nouvelles missions. Les mandarins chinois et tartares qui les accompagnoient les gênoient extrêmement et ne vouloient jamais donner le temps nécessaire pour ce que les PP. auroient voulu ajouter à l'observation des hauteurs méridiennes, à la mesure du chemin, à la variation de l'ayman, au rhumb et au calcul de ces éléments pour en conclure les positions. Quand cela étoit fait, il falloit vite envoyer à l'Empereur par des courriers »1.

Malgré ces difficultés et malgré les insuffisances des relevés qui tiennent à ces difficultés mêmes, la partie géographique de l'ouvrage du P. du Halde était en 1735 la partie la plus intéressante et la plus nouvelle de son immense ouvrage. Sous ce couvert, le P. du Halde pouvait offrir sa Description au roi comme un ouvrage digne de lui et de la mission qu'il patronnait. On ne possédait alors en effet que les cartes de Guillaume Delisle, la carte de la Tartarie éditée en 1706 et la deuxième édition de la carte d'Asie donnée en 1723, mais d'après des observations naturellement insuffisantes puisque Delisle n'était jamais allé en Chine ${ }^{2}$.

A cet égard, les reproches de Fréret n'étaient pas trop fondés. Mais il a parfois raison dans sa critique du livre du P. du Halde, notamment Iorsqu'il reproche au P. du Halde d'avoir grossi

1 Gaubil à Fréret, 5 novembre 1736 (Obs. 150-2-26). Cf. également la lettre du P. Gaubil du 29 octobre 1736 (Obs. 150-2-25).

2 Nicéron, Mémoires pour servir à la vie des hommes illustres, t. I, p. 220, montre les progrès réalisés par G. Delisle, sur ses prédécesseurs, dans l'établissement des cartes géographiques et les moyens de fortune qu'il employait pour tâcher de remédier à l'absence d'observations astronomiques. 


\section{La Chine et la formation de l'esprit philosophique en France}

démesurément son livre de choses inutiles ${ }^{1}$. D'ailleurs Fréret n'était pas seul de son avis, car le président Bouhier déclarait qu'il y avait un peu de « rhapsodie » dans cet ouvrage dont les quatre in-folios « auroient pu ou même dû estre réduits à un », mais il regrettait en même temps que «I'histoire fût réduite à de simples notes chronologiques et que l'article des loix, qui lui paraissait l'essentiel, eût été oublié ${ }^{2}$. Il est bien certain aussi que tout n'est pas nouveau dans la Description de la Chine; bien des mémoires antérieurement publiés ont été mis à contribution et les deux volumes qui traitent du gouvernement ou de la religion des Chinois ${ }_{\text {p.171 }} \mathrm{n}^{\prime}$ apprennent rien de plus - à quelques exceptions près - que les Mémoires du P. Lecomte ou que les Lettres édifiantes.

Le P. du Halde en est-il responsable, ou les documents lui ontils fait défaut?

Il est un cas tout au moins où le P. du Halde n'a pas cru devoir utiliser les documents précis qu'il avait à sa disposition. Il avait reçu en effet depuis longtemps du P. Régis, comme nous l'avons vu, une Introduction à I'histoire des King. Cette étude critique, composée par un des hommes les plus savants sur I'ancienne histoire chinoise et sur les livres canoniques eût pu être d'un grand secours à I'heure où I'on n'avait encore aucune traduction de ces livres, et où les figuristes, comme disait Fréret, essayaient de saper toute I'ancienne histoire chinoise et de

\footnotetext{
1 Fréret à Gaubil. Voir notre thèse complémentaire, Documents inédits..., p. 73.

2 Bouhier à Marais, 25 octobre 1735. B. N. Fr. 25542, f. 333.
} 


\section{La Chine \\ et la formation de l'esprit philosophique en France}

ramener la chronologie vérifiée aux siècles qui ont précédé Jésus-Christ. Malgré cela, le P. du Halde s'est contenté d'insérer dans son ouvrage quelques phrases vagues sur les King en général et une analyse plus que sommaire de chacun des livres canoniques. Pourquoi cela ?

Sans doute le P. du Halde écrit pour le public et non pour I'Académie des Inscriptions. Il cherche à conserver à son ouvrage le caractère d'une Description, ce qui est une condition de succès et il se garde avec soin des études trop savantes. Il faut que ces gros in-folios, malgré leur lourdeur, ne restent pas enfouis dans les bibliothèques, il faut qu'ils soient lus, et, pour qu'ils soient lus, il faut qu'ils plaisent. Il suffit d'ouvrir cet ouvrage pour voir tout ce que le P. du Halde a fait pour séduire le public : parfaite exécution typographique, gravures séduisantes, non seulement par le sujet mais aussi par la finesse du trait et du rendu, lettrines, culs-de-lampe, etc... Cette Description de la Chine est un plaisir des yeux. Or, la Dissertation du P. Régis, de l'aveu même de son auteur, était rébarbative « écrite en latin, non d'un style à plaire, mais propre à instruire ${ }^{1}$ et toute hérissée de citations d'auteurs chinois et de preuves.

Cependant le P. du Halde aurait pu en donner au moins un résumé substantiel et clair. Il semble qu'il ait eu une autre raison - et celle-ci moins défendable - pour supprimer cette dissertation.

\footnotetext{
${ }^{1}$ Régis à Fréret, 6 octobre 1736. Obs. Astr. A. B 10 (150-6-5).
} 


\section{La Chine et la formation de l'esprit philosophique en France}

Nous savons, toujours par le P. Régis, qu'il avait eu surtout pour intention en écrivant cette dissertation, d'attaquer les figuristes et de démontrer leurs erreurs : « J'aurais été plus court soit dans cet écrit, soit dans le commentaire sur I'Y-king si je n'avois p.172 pas voulu réfuter tacitement ceux dont vous parlez qui trouvoient dans les 5 King et surtout dans $L y$-king, les mystères de notre sainte religion et semblables choses qui ne pourroient venir que des anciens patriarches éclairés spécialement d'en haut. En peu de mots, je réponds partout à leurs objections et à leurs prétendues démonstrations tirées de l'analyse de quelques caractères chinoy, de certains éloges outrés, de 2 ou 3 passages de Ly-king, pris dans un sens tout contraire aux interprètes chinoy et à la suite du texte, car pour dire la vérité, les paradoxes qu'ils ont avancé ne méritent pas une longue réfutation $\gg 1$.

Or de tous les figuristes, celui que I'on avait le plus à redouter était l'ancien jésuite Foucquet, qui se trouvait alors à Rome avec le titre d'évêque d'Eleuthéropolis. Les PP. Gollet et de Prémare étaient sans doute aussi figuristes mais combien moins dangereux, puisqu'ils étaient encore Jésuites et qu'on disposait envers eux de moyens de contrainte. Foucquet au contraire, n'avait pas abdiqué ses rancunes contre ses anciens confrères et il ne se privait pas de déblatérer contre eux, contre leurs études sur la Chine et contre leurs procédés d'évangélisation, dans ses lettres à ses correspondants de France. L'adversaire était redoutable et le $P$. du Halde n'osa pas I'attaquer de front en

${ }^{1}$ Id., ibid. 


\section{La Chine et la formation de l'esprit philosophique en France}

publiant la dissertation du P. Régis ou en acceptant pour luimême les principes qui s'y trouvaient exposés. Il aima mieux essayer de gagner Foucquet et de le désarmer en lui faisant valoir les sacrifices qu'il lui faisait.

Le prétexte dont se servit le $P$. du Halde pour renouer avec l'évêque d'Eleuthéropolis des relations qui avaient été interrompues depuis que Foucquet avait quitté la compagnie, fut une rumeur qui circulait à Paris avant que ne parût la Description de la Chine et selon laquelle l'évêque d'Eleuthéropolis aurait déclaré que cet ouvrage ne vaudrait rien. La menace était grave, il fallait tâcher d'amener Foucquet à désavouer lui-même ce propos. Le P. du Halde devant le danger, n'hésita pas à écrire à Foucquet, et il lui avoue dans sa lettre - mais cette lettre n'était pas destinée au public - qu'il lui a fait le sacrifice des théories trop précises sur les King.

« Je regarde ce qui a été dit comme une pure invention de gens qui cherchent à nuire et qui empruntent votre nom parce que vous êtes éloigné d'eux pour détruire la fausseté de ce qu'ils avancent.

« Le seul soupçon qui me vient c'est que vous aurez pu juger que je ne suis pas une chronologie qui appuye votre système sur p.173 les King. Il est vrai, mais je ne dis rien qui donne atteinte à ce système et ce que j'avance vous donne la même liberté que 


\section{La Chine et la formation de l'esprit philosophique en France}

vous ont laissée ceux qui ont écrit antérieurement sur la chronologie chinoise $\gg 1$.

Foucquet répondit d'ailleurs très nettement que cette tolérance qu'on semblait aimablement vouloir lui concéder ne lui suffisait pas et il menaçait encore une fois de soutenir ses idées « dans des volumes plus amples peut-être et en plus grand nombre que ceux dont vous régalerez bientôt le public, et on y verra, si jamais ils paraissent, que le triple culte du ciel, de Confucius et des ancêtres, ce culte rempli d'impiétés, si justement flétri par les anathèmes du Saint-Siège n'a eu son origine que dans l'altération des King, altération dont les trois familles ne sont qu'un rejeton pernicieux $\gg 2$.

Au reçu de cette lettre, le $P$. du Halde dut se féliciter de sa prudence. La querelle des rites était assoupie depuis les permissions de Mezzabarba, mais elle pouvait reprendre à tout instant, et en cas d'une nouvelle alerte, Foucquet serait l'adversaire le plus dangereux. Pour cela on lui a sacrifié une étude sur les King et sur la chronologie chinoise, sacrifice immense. Les PP. de Pékin ne furent pas seuls à la regretter. Fréret eût donné tout l'ouvrage du P. du Halde pour la

1 Le P. du Halde à Foucquet, 5 juillet 1734. Obs. Astr. $B^{2} 4(149,3,2)$. Cet article de la chronologie donna prise aux critiques des protestants. Beausobre écrit en effet à Turrettini : «A propos de ces gens là [les Jésuites] $M$. des Vignoles qui, comme vous savez, s'est fort appliqué à la chronologie a lu depuis peu I'histoire de la Chine du P. du Halde et y a trouvé I'infidélité ordinaire à la Société. Je l'exhorterai à donner la critique de quelques endroits. Il l'a déjà faite et il me dit qu'il lui donneroit pour titre « Fides Jesuitica » (de Budé, Lettres à Turrettini, t. II, p. 239).

${ }^{2}$ Foucquet au P. du Halde. s. d. [1734 ]. Obs. Astr. B 4 (149, 3). 


\section{La Chine \\ et la formation de l'esprit philosophique en France}

dissertation sur les King et pour la traduction des livres canoniques ${ }^{1}$.

Le P. du Halde eut tout au moins I'audace de publier dans sa Description de la Chine le texte des anciennes annales de la Chine, qui avait été envoyé par le P. Parrenin à Dortous de Mairan et qui n'avait pas trouvé place dans les Lettres édifiantes. Évidemment, p.174 il nettoie ce texte, il le purge de ce qu'il a de trop archaïque et de trop chinois et qui pourrait choquer des oreilles françaises. D'ailleurs le P. Parrenin lui-même s'excusait d'envoyer à M. de Mairan un texte aussi grossier. Il ne peut venir à l'esprit des bons Pères, à cette date, que ces textes antiques puissent offrir un intérêt à cause de leur rudesse même. Seul de Mairan semble avoir regretté que le P. du Halde eût habillé ce texte chinois à la française. « Cette histoire chinoise, disait de Mairan, contient 50 ou 60 articles qui me font souvenir de ceux de nos vieilles chroniques, où on lit : Comment le bon roi livra illec sanglante bataille. Comment, etc., excepté qu'ici il n'est presque jamais fait mention de guerres ni de batailles et qu'après avoir mis à la tête de chaque règne le nom de l'empereur, toujours accompagné de son épithète, à peu près comme Achille aux pieds légers dans Homère, Fou-hi roi de la vertu des Bois, Yen-ty roi de la vertu du Feu, Hoam-ty roi de la

\footnotetext{
${ }^{1}$ Le président Bouhier dans une lettre à Marais (3 novembre 1735) constatait la prudence du P. du Halde au sujet de la religion chinoise : « Ce n'est pas dans le $1^{\text {er }}$ volume que le P. du Halde a parlé de la Religion des Chinois. Mais il en a suffisamment parlé dans les suivans et surtout sur le fameux Tien, qui a été la matière de tant de controverses. Il s'en est expliqué avec sagesse et modération et je ne vois pas qu'il ait trop donné de prises contre lui sur cet article. 》 B. N. Fr. 25542 f. 335, v 38.
} 


\section{La Chine et la formation de l'esprit philosophique en France}

vertu de la terre, on trouve simplement « il régla le mariage, il fit des mandarins pour regarder le Ciel $\gg 1$.

Le P. du Halde n'a pas le même amour pour les textes archaïques. La rudesse le choque et il craint qu'elle ne choque. Aussi il frise son mouton. Il n'est pas jusqu'au serpent de Fou-hi qu'il n'arrive à nous rendre aimable. Tout ce qu'une imagination française de cette époque peut supporter lorsqu'elle se représente un monstre, du moins selon le P. du Halde, c'est un Dragon-cheval, avec des ailes et des écailles, en somme un monstre classique, celui qu'a vu Hippolyte. Cependant, il était autrement singulier le monstre que dépeignait le P. Parrenin : « Le livre Che-y rapporte que Komngan Koué a dit que le Dragon-cheval était le suc du ciel et de la terre, qu'il avoit été nommé Dragon-cheval parce qu'il avoit la figure du Cheval et les écailles du Dragon, qu'il avoit 8 pieds et 5 pouces de haut, qu'outre qu'il ressembloit à un Chameau il avoit des ailes, qu'entrant dans l'eau il n'enfonçoit point et que parce qu'un sage (ou un saint) occupoit le throne cet animal portant une carte sur le dos sortit de la rivière nommé Morn »2.

Mais est-il bien sûr que ce soit la forme singulière de ce dragon-cheval, qui ressemblait à un chameau, qui ait fait peur au P. du Halde ? N'est-ce pas plutôt le prodige que redoute le P. du Halde?

Le P. du Halde, en effet, n'aime pas à laisser croire qu'il y a des prodiges dans l'ancienne histoire chinoise. Dans le cas du $\mathrm{p}$.

${ }^{1}$ Lettre du P. Parrenin à M. de Mairan, p. 27-8.

2 Lettre du P. Parrenin à M. de Mairan, B. N. Fr. 17240, f. 94, $a^{\circ}$. 


\section{La Chine et la formation de l'esprit philosophique en France}

${ }_{175}$ Dragoncheval de Fou-hi, le P. Parrenin lui tendait la perche car il émettait lui-même I'hypothèse que ce n'était peut-être qu'une supercherie de Fou-hi, quoique le texte des annales chinoises soit formel et donne le fait comme réel. D'ailleurs le P. Parrenin ajoutait aussitôt : « J'ai interrogé les Lettrés sur ce sujet et demandé ce qu'ils croient de cette fameuse apparition. Dans tous les tems, me répondit un d'eux, il a paru des monstres ou des animaux extraordinaires qu'on prenoit pour tels. Pourquoi voulez-vous que du tems de Fou-hi on n'ait rien vu de semblable et quel inconvénient y a-t-il de le croire ? »1. Le P. du Halde pour sa part y trouve de grands inconvénients et il aime mieux adopter résolument l'idée d'une supercherie. «Pour donner plus de crédit à ses nouvelles lois, il [Fou-hi] publia qu'il les avoit vu marquées sur le dos d'un Dragon-cheval qui sortait du fond d'un lac, il le nomma Dragon-cheval parce qu'il avoit la figure d'un cheval et les écailles d'un dragon avec les ailes $\gg 2$. Des deux hypothèses, entre lesquelles le P. du Halde devait choisir, ou laisser croire que Fou-hi a mystifié le peuple pour lui faire accepter ses lois, ou admettre que Fou-hi, et par conséquent les anciens Chinois croyaient aux prodiges c'est-à-dire qu'ils étaient superstitieux, le $P$. du Halde choisit la première hypothèse, ce qui profitera sans doute aux Jésuites et démontrera leur bonne foi dans l'affaire des Cérémonies chinoises. Mais les philosophes de leur côté pourront trouver leur compte, car ils y verront la preuve que les premiers législateurs furent des mystificateurs, et

\footnotetext{
${ }^{1}$ B. N. Fr. 17240, f. $94, v^{\circ}$.

2 Du Halde, Description..., t. I, p. 272.
} 


\section{La Chine et la formation de l'esprit philosophique en France}

qu'ils se sont servis des prodiges, c'est-à-dire de la religion, pour assurer leur domination.

Si le P. du Halde n'aime pas à rencontrer de prodiges dans I'ancienne histoire chinoise, il aime encore moins les faits qui pourraient laisser croire que les anciens Chinois croyaient aux « esprits et à la magie ».

Le P. Parrenin rapporte ${ }^{1}$ en effet que «...la mère de Yen-tychin-nom s'étant allée promener... elle fut agitée d'un esprit et fit Yen-ty ». Le P. du Halde supprime tout simplement ce passage.

Sous l'empereur Houang ti la boussole fut inventée. Cette invention selon le P. du Halde serait le fait du hasard. Mais le P. Parrenin traduisant littéralement les textes chinois, rapportait différemment l'origine de cette invention. p.176

\begin{tabular}{|l|l|}
\hline Parrenin & du Halde \\
\hline
\end{tabular}

1 B. N. Fr. 17240 , f. $96, v^{\circ}$. 


\section{La Chine et la formation de l'esprit philosophique en France}

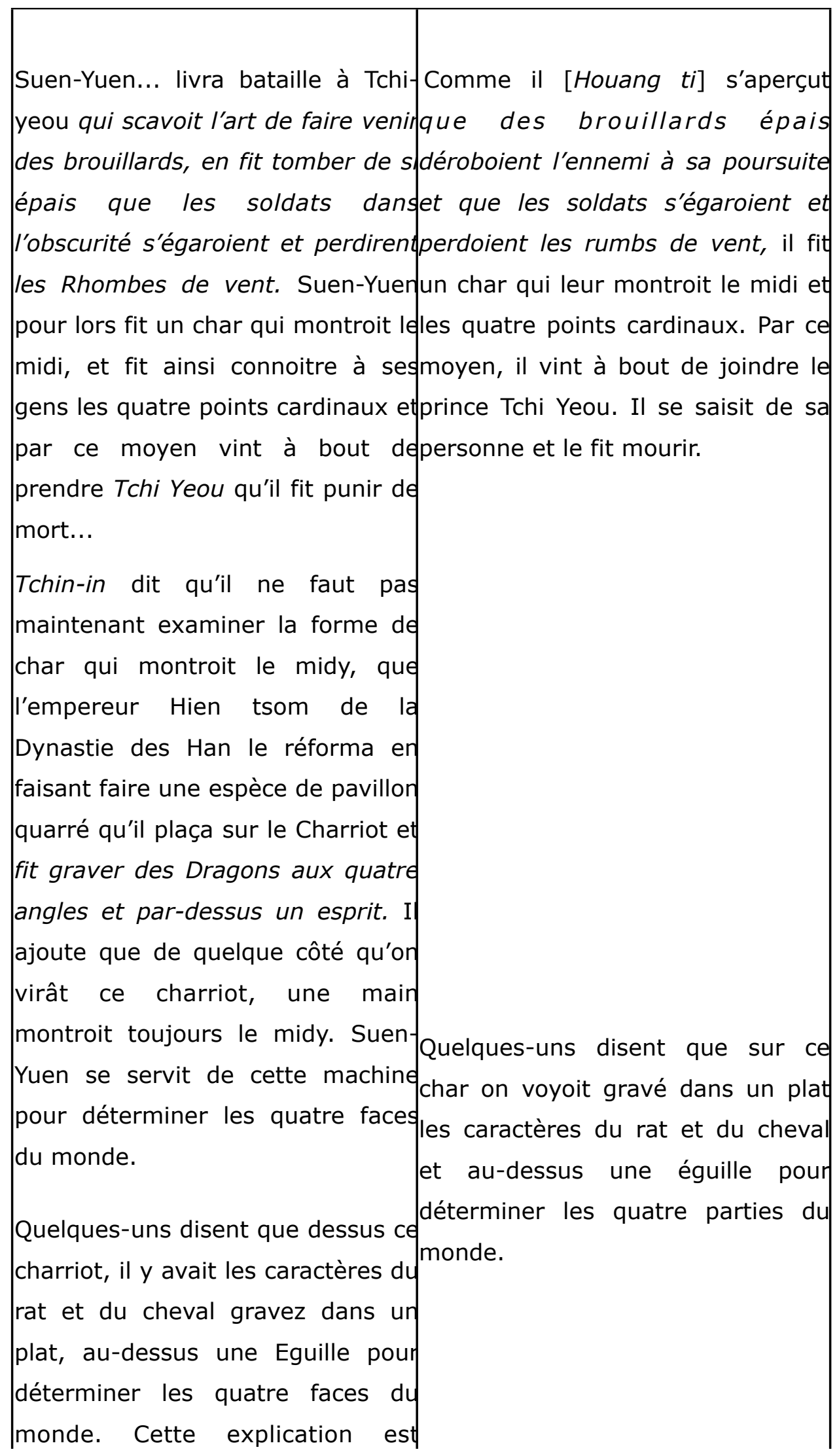




\section{La Chine et la formation de l'esprit philosophique en France}

p.177 Selon le P. Parrenin, les anciens Chinois croyaient donc à la magie. Dans une note ajoutée à ce texte il constate ce fait et le précise L'art magique est à peu près du même âge [que la boussole], c'est-à-dire que c'est la première fois qu'on en a fait mention, parce que Tchy yeou s'en servit dans cette fameuse bataille. Mais il est probable que ce prince avoit eu des maîtres là-dessus. Ce qui est de sûr c'est que la magie a été en vogue depuis ce temps-là et qu'on voit par I'histoire que les généraux d'armée s'en sont quelquefois servi, et qu'aujourd'hui les Lamas Tao-tse, Bonzes, etc. . en sont les dépositaires »1.

A quoi pensait donc le P. Parrenin en écrivant cela ? Les superstitions des Lamas et des Bonzes étaient-elles donc un reliquat de l'ancienne religion chinoise et non une importation relativement moderne venant des Indes ? Heureusement le P. du Halde veillait, et il supprime le passage.

Quelquefois le P. du Halde est encore plus audacieux. Il ne se contente pas de corriger ou de rogner le texte de son modèle, mais il invente, car il lui faut à tout prix retrouver dans ces premiers temps de la monarchie chinoise le culte d'un être suprême. Un texte suffira pour le prouver, mais nous pourrions en citer plusieurs.

\begin{tabular}{|c|c|}
\hline Parrenin & du Halde \\
\hline
\end{tabular}

${ }^{1}$ B. N. Fr. 17240 , f. 100. 


\section{La Chine \\ et la formation de l'esprit philosophique en France}

\begin{tabular}{|c|c|}
\hline $\begin{array}{l}\text { (à propos de l'empereun } \\
\text { Tchi) } \\
\text { Le Che-ky dit-il à répandu ses } \\
\text { bienfaits partout et sur tous sans } \\
\text { exception de qui que ce fût. Il étoit } \\
\text { éclairé, voyoit tout, examinoit tout } \\
\text { dans le détail jusques aux petites } \\
\text { choses, suivant l'équité du ciel, il } \\
\text { secouroit dans la misère, ouvroit les } \\
\text { voyes pour en sortir. Il aimoit sans } \\
\text { rien perdre de sa majesté. Il étoit } \\
\text { libéral et, fidèle. Il se réformoit luy- } \\
\text { même, étoit réglé dans sa dépense, i } \\
\text { aimoit tendrement ses p.178 peuples, } \\
\text { leur procurait tous les avantages } \\
\text { possibles. Il fit la distinction des bons } \\
\text { et des mauvais esprits qu'il servit } \\
\text { respectueusement. Son visage étoit } \\
\text { brillant, sa vertu éminante, il } \\
\text { n'agissoit qu'à propos et dans son } \\
\text { temps, gardant en tout un juste } \\
\text { milieu. }\end{array}$ & $\begin{array}{l}\text {.... Les écrivains chinois font de } \\
\text { grands éloges de ce prince : il étoit } \\
\text { éclairé, disent-ils, il voyoit tout, il } \\
\text { examinoit tout par lui-même, il } \\
\text { entroit dans les plus grands détails, } \\
\text { il étoit populaire sans rien perdre de } \\
\text { sa majesté. Il aimoit tendrement } \\
\text { ses sujets, il répandoit partout ses } \\
\text { bienfaits; il se réformoit lui-même, } \\
\text { il étoit religieux dans le culte du } \\
\text { Souverain Seigneur du Ciel qu'it } \\
\text { servoit respectueusement ; son air } \\
\text { grand et auguste attirait de la } \\
\text { vénération, sa vertu étoit éminente, } \\
\text { il n'agissoit qu'à propos et gardoit } \\
\text { en tout un juste milieu. }\end{array}$ \\
\hline
\end{tabular}

Et voilà donc la preuve - du moins selon le P. du Halde que les anciens Chinois ont cru à un Dieu unique et personnel. Le P. Le Comte avait donc raison contre la Sorbonne lorsqu'il affirmait que les Chinois avaient sacrifié au maître du monde dans le plus ancien temple de l'univers.

Mais il y a une difficulté qui avait déjà été signalée par un docteur de Sorbonne au moment des débats sur le livre du P. Le Comte et qui avait été reprise ensuite et avec force par Maigrot en 1714 ; difficulté que Renaudot n'avait fait que développer 


\section{La Chine et la formation de l'esprit philosophique en France}

dans ses dissertations ajoutées à sa traduction des Anciennes Relations de deux voyageurs mahométans : comment les Jésuites peuvent-ils soutenir que l'ancienne religion est un héritage direct de la religion primitive transmise par les descendants de Noé, puisque, au temps de Fou-hi, les Chinois étaient plongés dans la barbarie ? Or, le texte des anciennes annales chinoises, traduites par le P. Parrenin, prouve en effet, mieux que ne le faisait le P. Martini, que les Chinois étaient barbares au temps où Fou-hi leur donna leurs premières lois. Voyons donc comment le P. du Halde a traité ce texte essentiel du P. Parrenin.

\begin{tabular}{|c|c|}
\hline Parrenin & du Halde \\
\hline $\begin{array}{l}\text { Le livre Vay-kay dit que dans les } \\
\text { commencemens les hommes } \\
\text { n'étaient pas différents des } \\
\text { animaux; qu'ils connoisoient leur } \\
\text { Mère sans sçavoir qui étoit leur } \\
\text { Père ; qu'à la vérité ils sçavoient } \\
\text { aimer mais sans politesse, sans } \\
\text { urbanité, qu'étant couchez ils p.179 } \\
\text { ronflaient, renifloient et que } \\
\text { debout ils bailloient ; qu'ils } \\
\text { cherchoient à manger quand la } \\
\text { faim les pressuit et jettoient les } \\
\text { restes quand ils étoient rassasiez, } \\
\text { qu'ils avaloient le poil, buvoient le } \\
\text { sang et s'habilloient de peaux. }\end{array}$ & $\begin{array}{l}\text { Dans ces commencemens les } \\
\text { hommes n'étoient guère différens } \\
\text { des bêtes, dit un auteur chinois, ils } \\
\text { connaissoient leur mère mais ils } \\
\text { ignoraient qui était leur père, ils } \\
\text { étaient impolis et grossiers, ils ne } \\
\text { cherchaient à manger que quand la } \\
\text { faim les pressoit ; dès qu'ils étoient } \\
\text { rassasiés ils jettoient les restes; ils } \\
\text { avaloient le poil, buvoient le sang } \\
\text { et s'habilloient de peaux. }\end{array}$ \\
\hline
\end{tabular}

Le P. du Halde en somme n'a pas maltraité ce texte essentiel. Il a laissé tomber certains détails précis qu'il a résumés par les deux épithètes impolis et grossiers. Ses corrections portent plus 


\section{La Chine et la formation de l'esprit philosophique en France}

sur la forme que sur le fond ; ici sans aucun doute il craint de choquer la délicatesse de ses lecteurs. S'il en est ainsi, le P. du Halde avoue donc qu'il y a eu dans I'histoire chinoise à un moment donné une éclipse, momentanée sans doute, mais malgré tout une éclipse de la civilisation primitive, et par suite une interruption de la tradition religieuse. Mais si nous lisons attentivement le contexte nous pouvons nous apercevoir que le P. du Halde a pris ses précautions, et qu'il a essayé par avance d'enlever tout venin à ce texte. Il nous représente en effet Fouhi non comme un barbare au milieu d'une nation barbare, ni même comme un conquérant qui établit son pouvoir par la force, mais comme un homme d'un mérite tellement supérieur qu'il faut bien admettre qu'il a été spécialement marqué par Dieu pour donner des lois à ses compatriotes. Le P. du Halde écrit en effet ce qui suit, de sa propre autorité :

« Un mérite supérieur le fit choisir pour gouverner ses compatriotes qui l'appelèrent Tien-tse, c'est-à-dire fils du ciel, voulant marquer par là qu'il avoit été plus chéri du Ciel que les autres hommes puisque c'est du ciel qu'il avoit reçu ces qualités supérieures et extraordinaires qui l'avoient élevé sur le trône »1. Or le P. Parrenin ne dit pas du tout cela. Pour lui Fou hi n'est pas I'homme de Dieu ; c'est seulement un homme d'esprit et de bon sens, qui a été choisi pour gouverner ses compatriotes ou «se les est peut-être assujettis par force ou par un mérite supérieur $\gg 2$. Par conséquent peu importe désormais pour le $\mathrm{P}$.

\footnotetext{
${ }^{1}$ Du Halde, Description..., t. I, p. 271.

2 B. N. Fr. 17240 , f. $92, v^{\circ}$.
} 


\section{La Chine et la formation de l'esprit philosophique en France}

du Halde que la nation chinoise soit tombée dans la barbarie puisqu'elle avait pour l'en faire sortir un homme choisi par Dieu, qui assurait la tradition entre les premiers hommes et les générations p.180 postérieures. Fou hi, pour le P. du Halde, est un peu le Moïse chinois ${ }^{1}$.

$*$

Les quelques sondages que nous avons pu faire sur la Description de la Chine tendent à renforcer encore les constatations que nous avons faites en étudiant les Lettres édifiantes et curieuses. Comme les Lettres édifiantes, ainsi que

1 Il est curieux de constater que le P. du Halde, lorsqu'il a pris comme guide le P. Martini (Histoire de la Chine, Paris, 1692) pour continuer les Fastes de la Chine à partir du moment où s'arrêtait la lettre du P. Parrenin, l'a corrigé de la même manière et en vertu des mêmes principes.

Voici quelques passages du P. Martini qu'il supprime :

«Les Annales du pais rapportent que (sous le règne de Yao) le soleil fut dix jours sans se coucher, et qu'on craignit un embrasement universel. Il y eut en effet plusieurs incendies semblables peut-être à celui qui arriva aux environs du Po sous le règne de Phaéton. La terre produisit aussi quantité de serpents monstrueux : mais Yaus remédia à tous ces maux. (Histoire de la Chine, t. I, p. 60).

« Il (Yvo) choisit le noir entre toutes les couleurs pour la livrée de ses enseignes, mais il faisoit peindre de rouge et de jaune les victimes qu'il sacrifioit au Souverain être incompréhensible. » (T. I, p. 91).

«Ce prince observa de quelles constellations chaque Province recevoit les influences, et les observations qu'il a faites lui-même là-dessus subsistent encore aujourd'hui et s'appellent la division d'Yvo. » (T. I, p. 93).

Et voici un passage qu'il ne supprime pas mais qu'il corrige :

\begin{tabular}{|l|l|}
\hline Martini, t. I, p. 76 & Du Halde, t. I, p. 287 \\
\hline (Xuni) rentra dans le Palaisil trouva dans le palais quantité \\
impérial où il trouva quantité d'ord'or et de pierreries; il fit faire une \\
et de pierreries dont il fit faire unesphère qui représentoit les sept \\
Sphère qui représentoit les septPlanettes et il y employa les \\
Planettes, à chacune desquelles i|pierreries qui symbolisoient le \\
employa les Pierreries suivant Ifmieux avec chaque Planette. \\
rapport qu'avoient leurs différentes \\
vertus avec les influences de ces \\
astres.
\end{tabular}




\section{La Chine \\ et la formation de l'esprit philosophique en France}

le dit Saint-Simon ${ }^{1}$, c'est une « artificieuse relation » et pour les mêmes raisons. Les principes qui poussent le P. du Halde à corriger ou à altérer les textes qu'il a sous les yeux sont ceux-là mêmes qui guidaient autrefois le reviseur du Sinarum Philosophus; ce sont aussi les mêmes règles que suivait le $P$. du Halde pour la publication des Lettres édifiantes.

Il ne faut absolument pas laisser supposer que les Chinois sont superstitieux, qu'ils croient à la magie, aux esprits, aux démons. Il faut marquer très nettement qu'ils sont spiritualistes, qu'ils p.181 croient en un Dieu personnel, et cela depuis la plus haute antiquité, depuis I'origine même de la nation chinoise. En somme, il faut défendre à tout prix, même si les Jésuites de Pékin ou de Canton disent le contraire, les idées qui ont toujours été soutenues par les Jésuites depuis qu'il y a une Querelle des Cérémonies chinoises. La Description de la Chine est elle aussi une défense des Jésuites.

En même temps, c'est l'œuvre d'un homme prudent qui ne veut pas prendre parti dans les questions dangereuses, où tous les Jésuites eux-mêmes ne sont pas d'accord, comme celle de la chronologie chinoise, ou dans les questions épineuses comme celle de la rivalité des PP. de Pékin et des figuristes. L'ouvrage du P. du Halde perd par là beaucoup de sa précision. A cet égard,

1 St-Simon, Mémoires, t. XXV, p. 184. 


\section{La Chine et la formation de l'esprit philosophique en France}

nous devons approuver le jugement de Fréret ${ }^{1}$ : la Description de la Chine, à l'époque à laquelle elle parut, n'apportait rien de bien nouveau aux savants. C'était une mise au point pour les demi-savants ou pour les gens du monde de ce qu'il y avait de plus intéressant dans les écrits antérieurs des Jésuites sur la Chine : Nouveaux Mémoires du P. Le Comte ou Lettres édifiantes. C'était une somme des connaissances acquises mais dont quelques-unes étaient acquises depuis longtemps déjà : ce n'était pas une révélation. Le P. du Halde est dépassé par ses confrères de Pékin, et, grâce à eux, par des savants comme Mairan, Fréret, de I'Isle, qui ont été directement en relations avec les missionnaires. Quant au public qui n'a pas de correspondance avec Pékin, le P. du Halde reste malgré tout une source importante pour la connaissance de la Chine ancienne et moderne, d'ailleurs la seule qui soit accessible. Mais cette source n'est pas absolument pure, les philosophes qui y puiseront verront les Chinois, de gré ou de force, à travers les idées des Jésuites.

$$
*
$$

\footnotetext{
1 Fréret à Gaubil : «Ce que vos lettres m'apprennent des différents écrits envoyés en Europe me confirme dans la pensée que vos PP. d'Europe tiennent bien des thrésors enfouis. Je me flattois que le R. P. du Halde en auroit profité pour son grand ouvrage sur la Chine, mais mon attente a été trompée. Vous verrez sans doute cette collection cette année cy et vous jugerez par vousmeme si le public a tort d'être mécontent de ce qu'on luy fait payer 2001. d'un ouvrage dont on semble avoir cherché à grossir le volume sans en augmenter la matière et dans lequel il ne trouve presque rien qu'il n'eust desja dans les livres communs. » Lettre de 1735. Obs. (150, 2, 4). (Cf. notre Thèse complémentaire, Documents inédits..., p. 73).
} 


\section{La Chine et la formation de l'esprit philosophique en France}

Le mérite d'avoir découvert la Chine et de l'avoir fait connaître - du moins en partie - au XVIIIe siècle français revient incontestablement aux Jésuites.

Mérite à l'égard du développement des connaissances, p.182 voulonsnous dire, car sans aucun doute les Vicaires apostoliques ont poursuivi, avec autant d'ardeur que les Jésuites, l'évangélisation des âmes, bien qu'avec des méthodes différentes. Et même il y a eu parmi les Missionnaires du Séminaire des Missions étrangères, sinon de parfaits sinologues, du moins des hommes qui ont fini par connaître, à la suite d'un long séjour en Chine, les conditions de la vie sociale ainsi que les idées morales, philosophiques et religieuses des Chinois. Mais ils sont fort peu nombreux et n'ont publié que des écrits de circonstance, tel Maigrot ; le plus érudit de leurs partisans, Renaudot, ne savait pas le chinois et n'a jamais été en Chine. D'ailleurs I'instruction préalable des Missionnaires ne les rendait pas aptes à ce travail d'investigation qui exigeait tant de connaissances scientifiques, philologiques et philosophiques. On peut être un bon missionnaire et n'être pas capable de satisfaire à la curiosité d'un Cassini ou d'un Fréret. En outre les Monita que le Séminaire des Missions étrangères avait rédigés à l'usage de ces Missionnaires ne semblaient-ils pas les mettre en garde contre la tentation qu'ils pourraient avoir de céder au péché d'orgueil et au désir de savoir, en s'adonnant à des sciences vaines?

Au contraire les Jésuites n'ont pas hésité à envoyer sans cesse en Chine non seulement de bons missionnaires mais de 


\section{La Chine et la formation de l'esprit philosophique en France}

grands savants, capables de s'accommoder aussi bien de I'astronomie que de I'histoire ou de la philosophie. Et s'ils savaient par surcroît jouer de la trompette marine, ou réparer les horloges, c'était autant de gagné pour la mission, qui assurait par ces moyens accessoires sa faveur auprès de l'empereur. Les Jésuites n'ont pas cru que la pratique des arts libéraux et manuels fût nuisible aux missionnaires, et ils n'ont pas cru non plus que les résultats scientifiques acquis par leurs missionnaires pussent porter atteinte au prestige de leur ordre. Ils se vantaient d'avoir eu parmi eux un Sirmond et un Pétau, ils cherchèrent dans leurs collèges, pour les envoyer en Chine, des hommes capables de conquérir dans une science nouvelle un renom égal à celui de ces grands érudits.

Ayant découvert la Chine grâce à leurs missionnaires, les Jésuites auraient voulu conserver le privilège de la Chine, tant au point de vue des missions qu'au point de vue des connaissances qu'on en pouvait tirer : c'est un sentiment humain qui a fondé le droit ${ }_{\text {p.183 }}$ de premier occupant et le droit de propriété. Mais il serait injuste de n'attribuer qu'à cette faiblesse humaine l'âpreté que mirent parfois les Jésuites à défendre contre les autres missionnaires cette Chine qu'ils considéraient comme leur bien spirituel. Il y avait aussi l'intérêt de la religion. Il fallait démontrer par la christianisation des Indes, que le christianisme avait conservé sa force d'expansion des premiers siècles et que cette propagation de la foi, que l'islamisme avait faite par l'épée, le christianisme pouvait la réaliser par la parole. Pour cette grande œuvre les Jésuites se croyaient spécialement marqués 


\section{La Chine \\ et la formation de l'esprit philosophique en France}

par Dieu, et les succès qu'ils avaient remportés en Chine dès le début ne pouvaient que les enraciner dans cette croyance.

Il n'est pas dans nos intentions - parce que cela n'est pas de notre compétence - d'apprécier les mérites respectifs des procédés d'évangélisation des Jésuites et des Missionnaires. Tout ce que nous pouvons dire c'est qu'il est facile de constater que les Jésuites réussirent. Mais ce succès qu'ils obtinrent dans leur mission, s'il permit aux Européens de connaître quelque chose de la Chine, les priva par contre de toute une série de faits sur lesquels les Jésuites firent le silence, parce que ce silence était la condition de leur succès.

La faculté d'adaptation des Jésuites, qui leur permit de se glisser à la Cour, de vivre avec les Mandarins et les Lettrés, I'ambition et la certitude qu'ils eurent de convertir d'un seul coup la Chine tout entière par la conversion de l'empereur, ou de convertir indirectement le peuple par la conversion préalable des mandarins, nous ont laissés dans l'ignorance des idées, des traditions, des superstitions populaires, que les Jésuites tinrent pour négligeables. Sans doute la Querelle des Cérémonies chinoises les incitait aussi à glisser sur cette question dangereuse. Mais quelle que soit la raison du silence des Jésuites sur une question essentielle, il y a un fait certain : les Jésuites ont systématiquement exclu de l'esprit chinois cette croyance aux esprits, aux forces naturelles, aux monstres fantastiques qui, selon les croyances populaires des Chinois, peuplent la nature entière. Aussi l'art chinois échappa totalement aux hommes du XVIII ${ }^{e}$ siècle. Les dessins de costumes de mandarins 


\section{La Chine et la formation de l'esprit philosophique en France}

publiés par le P. Bouvet, les scènes de la vie chinoise enterrement ou mariage chinois - somptueusement éditées par le P. du Halde, dans sa Description de la Chine, ont pu fournir des détails pittoresques pour les chinoiseries de Boucher, mais à aucun degré, les éléments d'une connaissance de l'art véritable de la Chine. p.184 Les Jésuites, en excluant volontairement de leur enquête sur la Chine l'étude de l'âme populaire ont travaillé pour les chinoiseries de paravent.

De même, en cherchant dans les idées philosophiques et religieuses des Chinois, ce qui les rapprochait de l'esprit français et de l'esprit chrétien, ils n'ont pas voulu voir les spéculations originales des Chinois sur Dieu, sur la matière, sur I'origine du monde. Ou, s'ils les ont signalées, ils ne les ont données que pour des idées limitées à des sectes particulières. A cet égard d'ailleurs ils n'ont été que le reflet de l'opinion commune de leur temps, puisque tout le monde était encore persuadé - à part les libertins - que toute la vérité était dans la Bible. Il serait donc vain de chercher dans les écrits des Jésuites sur la Chine, du moins dans ceux qui furent publiés au XVIII ${ }^{\mathrm{e}}$ siècle, une étude impartiale sur les systèmes philosophiques ou religieux des Chinois qui pût servir de prolégomènes à une histoire comparée des philosophies ou des religions. Le XVIII ${ }^{e}$ siècle, encore tout embarrassé dans les querelles théologiques n'en demandait pas tant. Ce qu'il cherchait avant tout, s'il jetait un regard sur les exemples que lui fournissaient les peuples étrangers, c'était ou des raisons de croire ou des raisons de ne pas croire, c'était des arguments en faveur de la Bible ou contre la Bible. Or les Jésuites, en donnant il est vrai quelques coups de pouce aux 


\section{La Chine et la formation de l'esprit philosophique en France}

textes qui montraient le spiritualisme de la secte dominante des Lettrés de la Chine, pouvaient présenter la religion des anciens Chinois comme une religion spiritualiste qui ne répugnait pas à I'esprit chrétien, à condition de ne pas croire comme Arnauld à la nécessité de la foi explicite, ou de ne pas chercher, comme Bossuet, la preuve historique de la vérité du christianisme dans I'accord entre I'Ancien et le Nouveau Testament. Un spiritualisme un peu vague, et qui s'approchait suffisamment du déisme pour que Voltaire pût s'en contenter, mais un spiritualisme malgré tout, à condition de limiter et de restreindre l'influence, parmi les sectes chinoises, de la secte des Lettrés modernes, matérialistes et athées, telle est la religion des Chinois que les Jésuites nous ont décrite entre 1685 et 1735 . Pour un honnête homme de cette époque qui ne lisait que les Jésuites, les Chinois ne pouvaient être que des chrétiens à qui la grâce avait manqué.

Il reste à savoir pourquoi les Jésuites ont ainsi représenté les Chinois comme un peuple rationaliste, spiritualiste et déiste. Sans doute les nécessités de leur mission les y ont d'abord poussés. Puis la Querelle des Cérémonies chinoises, jointe au besoin de ${ }_{\text {p.185 }}$ maintenir la mission coûte que coûte les a obligés à soutenir, sans en rien retrancher, les idées qu'ils avaient d'abord proposées. Mais il y a sans doute autre chose. La méthode d'évangélisation des Jésuites, si flexible, si souple, au point qu'elle fut capable de s'adapter avec succès aux mœurs étrangères les plus différentes des mœurs européennes, rappelle I'attitude qu'ils ont prise en France dans les grands débats théologiques. Ils ont cédé à l'esprit du temps. Ils ont biaisé avec la morale et la religion des mondains. C'est qu'il fallait sauver la 


\section{La Chine et la formation de l'esprit philosophique en France}

religion chrétienne, même en faisant quelques sacrifices, des coups qui lui portaient les libertins. Et ainsi il nous faut chercher, en laissant de côté désormais les rivalités entre Jésuites et Missionnaires, comment les libertins pouvaient être tentés d'exploiter la découverte de la Chine pour nier l'histoire des origines du monde, telle que la rapportait la Bible ou pour invoquer l'exemple chinois en faveur de l'athéisme, ou pour essayer de trouver dans la morale primitive des Chinois les traces d'une morale indépendante de la religion. Éternité du monde, athéisme primitif, morale indépendante, sont les conclusions radicales que les libertins tireront de la découverte de la Chine. Contre ces conclusions tous les partisans de la Bible et tous les défenseurs du dogme chrétien vont engager la bataille, les uns sans faire aucune concession à leurs adversaires, les autres - et ce sont les Jésuites - en interprétant les faits nouveaux, en les adaptant au mouvement des esprits pour sauver malgré tout ce qui doit être sauvé, l'esprit chrétien et le christianisme, mais un christianisme atténué, adapté aux connaissances nouvelles. 
La Chine
et la formation de l'esprit philosophique en France

LIVRE DEUXIÈME

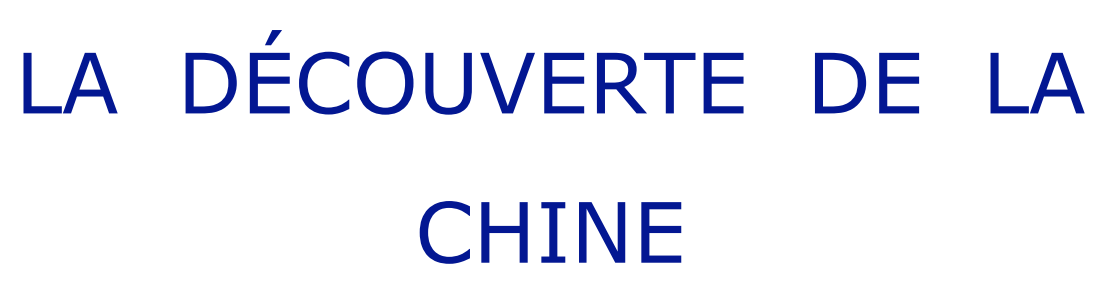

ET LA FORMATION

DE L'ESPRIT PHILOSOPHIQUE 


\section{La Chine \\ et la formation de l'esprit philosophique en France}

\section{CHAPITRE I}

\section{L'ANTIQUITÉ DE L'HISTOIRE CHINOISE ET LA CHRONOLOGIE}

p.189 Si les hommes du XVI ${ }^{\mathrm{e}}$ siècle ont découvert l'Amérique, ceux du XVII ${ }^{e}$ siècle ont eu l'avantage de découvrir la Chine.

Découverte relative d'ailleurs, car depuis Marco Polo on n'ignorait pas qu'il y avait en Extrême-Orient de riches nations d'une population surabondante, et d'une civilisation qui n'était pas inférieure à la civilisation des nations européennes les plus policées. Mais les merveilles que le Vénitien rapportait de l'immense Cathay et de Cambalu, la ville au peuple innombrable, si elles enchantaient l'imagination comme des descriptions de pays imaginaires et fabuleux ne trouvaient que peu de créance auprès des esprits sceptiques, enclins à se méfier de ces récits du voyageur, précisément à cause de ce caractère de merveilleux qu'ils y trouvaient. Un voyageur est souvent un imaginatif : c'est même pour cela qu'il aime à voyager. Et quand il revient chez lui, soit qu'il prenne plaisir à étonner, soit qu'il se laisse prendre encore une fois aux fantaisies de son imagination ou aux splendeurs de ses souvenirs, il a souvent tendance, tout en étant de bonne foi, à embellir la réalité. Le Cathay était-il la Chine ? La Chine était-elle ce pays fabuleux, grand et riche, dont parlait Marco Polo ? Voilà ce que les Européens, dès la fin du XVI siècle, mais surtout au XVII ${ }^{e}$ siècle vont s'efforcer de vérifier. 


\section{La Chine et la formation de l'esprit philosophique en France}

Découverte lente et progressive. Car ici l'esprit des Européens ne se trouve pas placé, comme pour la découverte de l'Amérique, devant un fait entièrement nouveau, l'existence brusquement révélée d'un continent jusqu'alors inconnu et même insoupçonné. Si I'on songe cependant que la découverte de l'Amérique, malgré ce caractère de révélation qu'elle a eu, n'a produit que peu à peu ses p.190 conséquences pour la transformation des idées européennes, au point que les hommes du $X V I I^{e}$ siècle et même du XVIII e ont continué à découvrir I'Amérique, on peut imaginer combien plus lente encore fut cette découverte de la Chine, non seulement à cause de la difficulté qu'on éprouvait à obtenir des faits certains et vérifiés sur ce pays lointain où les Européens ne pouvaient pénétrer, mais par suite de la nature des problèmes que posait la connaissance de la Chine. Il ne s'agit pas, en effet, pour la Chine, comme pour l'Amérique, de découvrir un continent nouveau. Les récits des voyageurs ou des missionnaires qui pénètrent en Chine ne modifient aucunement dans l'ensemble les connaissances géographiques que I'on possédait depuis Ptolémée. L'idée qu'on se faisait de la figure de la terre ou de la répartition des continents à travers le globe ne se trouve pas brusquement troublée par la découverte de la Chine, comme ce fut le cas pour I'Amérique. Si la Chine avait été un pays habité par des populations d'une civilisation primitive, sans traditions et sans histoire, la connaissance de la Chine eût été, pour les nations européennes, à peine plus importante que la connaissance du Groënland, et assurément moins que la découverte des terres australes. 


\section{La Chine et la formation de l'esprit philosophique en France}

Mais la Chine est un pays civilisé, ayant une civilisation toute différente de la civilisation européenne, qui a évolué en vertu de ses lois propres : ignorée de l'Europe, elle ne l'a pas connue, et comme l'Europe le croyait elle-même, elle s'est persuadée qu'elle était le centre du monde. La civilisation, qui était née dans les pays avoisinant la Méditerranée et qui avait si magnifiquement prospéré, n'était donc pas la seule qui existât. Il y en avait une autre en Extrême-Asie, qui ne le cédait en rien à la civilisation gréco-latine, non seulement pour la perfection, mais ce qui était plus grave, pour l'antiquité.

Pour les gens du XVII ${ }^{e}$ siècle, avant que la querelle des Anciens et des Modernes ne soit venue diminuer un peu la valeur de la notion d'antiquité, l'antiquité d'une nation, même indépendamment de l'importance qu'elle peut avoir pour les connaissances historiques, est un titre de gloire encore plus grand peut-être que sa perfection. Si pour les individus la noblesse est d'avoir des ancêtres qui ont participé aux Croisades, pour une nation la noblesse est d'avoir pour fondateurs des gens qui remontent au Déluge. Or, la Chine avait cette prétention. Voire, elle essayait de la justifier. Elle n'affirmait pas seulement son antiquité, elle se croyait en mesure de la prouver ; elle apportait en témoignage toute une histoire qui, disait-elle, n'était pas rédigée par des historiens p.191 modernes sur des documents douteux, mais une histoire écrite au jour le jour par des contemporains des événements et excluant par là toute idée de fraude, sinon sur les faits eux-mêmes, tout au moins sur les époques. On ne saurait trop dire combien cette idée de l'antiquité de la Chine, même indépendamment de ses 


\section{La Chine et la formation de l'esprit philosophique en France}

conséquences théologiques, séduisit ou choqua, en tout cas mit en branle, I'esprit français au XVII ${ }^{\mathrm{e}}$ siècle.

Mais les conséquences théologiques de cette antiquité de la Chine ne sont pas négligeables, loin de là. Si cette antiquité est bien prouvée, elle risque de rendre suspecte, ou même de détruire la chronologie de la Bible, car elle la dépasse. Et si cette histoire de la Chine est bien suivie et sans interruption depuis les origines, elle s'inscrit en faux contre l'idée du Déluge universel. Sans doute, il peut nous sembler à distance que toutes ces conséquences auraient pu être aperçues d'un seul coup, si bien que la découverte de la Chine aurait pris le caractère d'une révélation amenant comme conséquence une brusque transformation des notions consacrées. En réalité, il n'en fut rien. C'est qu'il n'y a pas pour l'esprit humain de fait brutal. L'idée de la rotation de la terre exposée en 1543 par Copernic, dans son ouvrage De revolutionibus orbium cœlestium, ne fut condamnée qu'en 1616. A la fin du XVII ${ }^{e}$ siècle, après un grand nombre de relations sur la Chine, dont quelques-unes étaient écrites, non par des voyageurs pressés, mais par des missionnaires qui avaient vécu longtemps dans le pays, une aventurière française put se faire passer à Paris pour une Chinoise. Rien d'extraordinaire sans doute que le public pût se laisser prendre, mais le P. Le Comte qui essaya de la confondre, tenta de le faire en lui montrant l'invraisemblance de ses affirmations. Il ne songea pas le moins du monde à lui faire remarquer qu'elle n'était pas de race jaune. Il ne savait pas luimême qu'il y avait une race jaune ; jusqu'à la fin du XVIII ${ }^{e}$ siècle 


\section{La Chine et la formation de l'esprit philosophique en France}

aucun des voyageurs ne s'est aperçu - à part Bernier ${ }^{1}-$ qu'il y $^{\prime}$ avait en Extrême-Orient une race différente des deux races connues, les blancs et les nègres. Les faits nouveaux ne s'imposent que peu à peu à l'esprit humain, délogeant successivement un préjugé puis l'autre, s'adaptant d'abord à I'en-semble des idées acquises, mais les effritant peu à peu jusqu'au jour où tout un système, qui semblait solide comme

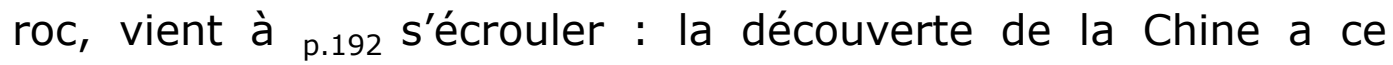
caractère d'un lent travail de sape et de mine.

Pas plus que le fait de la rotation de la terre, le fait de I'antiquité de la Chine n'émut les théologiens dès le début. Ou du moins cette antiquité ne les aurait pas émus, si vers le milieu du XVII ${ }^{e}$ siècle ne s'était trouvé ce fou de La Peyrère avec son hypothèse des Préadamites. Mais La Peyrère était peut-être venu trop tôt, à une époque où des négations aussi radicales ne pouvaient entamer des croyances sûres d'elles-mêmes et que n'avaient pas encore ébranlées des infiltrations d'idées nouvelles. Et à tout le moins La Peyrère donnait prise sur lui en essayant de tirer des conclusions extrêmes d'une interprétation nouvelle des textes bibliques, qu'il était d'ailleurs facile de contester. Sans doute, il invoquait à l'appui de sa théorie l'histoire des peuples chaldéen, égyptien et chinois qu'il opposait au peuple juif. Mais cette audace d'invoquer l'histoire des peuples profanes pour justifier une interprétation de la Bible apparaît alors comme une

\footnotetext{
1 Dans ses Etrenes adressées à Madame de la Sablière pour l'année 1688, Bernier distingue quatre races - ou couleurs différentes - dans le monde connu, ce qui correspond en gros à notre division actuelle. Cette observation de Bernier paraîtra remarquable si l'on considère les difficultés qu'ont éprouvées ses contemporains, ou même ses successeurs, pour ranger les peuples asiatiques dans I'un des groupes ethniques.
} 


\section{La Chine et la formation de l'esprit philosophique en France}

folle prétention. Il faudra que la connaissance de la chronologie et de l'histoire chinoise s'insinue peu à peu dans les esprits pour qu'apparaisse le danger de cette chronologie et pour qu'on sente le besoin de concilier I'histoire de la Chine avec I'histoire des Écritures. Lorsque La Peyrère eut été accablé sous de multiples critiques et qu'il se fut rétracté, les théologiens retrouvèrent leur tranquillité, car ils étaient trop sûrs du criterium qui leur servait à juger I'histoire du monde. Mais à mesure que la foi s'affaiblira et que la valeur de ce critère se trouvera diminuée par le fait des esprits forts, lorsque, d'autre part, des hommes comme Fréret préfèreront la critique des textes à l'autorité pour juger des faits anciens, alors apparaîtra le danger de l'antiquité de la Chine.

En outre, la chronologie généralement admise n'était pas article de foi. La science chronologique était au XVII ${ }^{e}$ siècle, comme d'ailleurs au début du siècle suivant, une science controversée où toutes les opinions restaient libres. C'était le domaine des hypothèses, où les imaginations fertiles avaient beau jeu. Différents calculs se présentaient qui permettaient de faire le monde plus vieux de quelques siècles, si besoin était. Etait-il donc nécessaire de s'inquiéter de l'ancienne histoire de la Chine ? Si elle ne s'accordait pas avec une hypothèse, elle pouvait du moins cadrer avec une autre. De plus chacun des systèmes généralement admis pour le calcul des époques depuis les origines du monde ne faisait pas un tout par lui-même qu'on devait accepter ou rejeter en bloc : il était possible de prendre dans I'un ou dans l'autre une période déterminée et de le rejeter pour le reste ; on pouvait donc de cette manière augmenter sans danger de plus d'un millier d'années la durée du monde, et 


\section{La Chine et la formation de l'esprit philosophique en France}

personne ne doutait au début que cette élasticité des systèmes chronologiques ne fût suffisante pour qu'on pût faire rentrer l'ancienne histoire chinoise dans le cadre de la chronologie de la Genèse. Le danger n'existera que le jour où l'histoire chinoise mais prouvée historiquement - apparaîtra plus ancienne que ne le permettent les différents systèmes chronologiques, ou les combinaisons diverses de ces différents systèmes. Pour cela il faudra ou que la preuve de l'antiquité de I'histoire chinoise soit faite de manière indubitable, ou que la croyance en la certitude de I'une ou de l'autre des hypothèses chronologiques, appuyées sur I'Ancien Testament, se soit affaiblie.

La découverte de l'antiquité de la Chine n'est pas le fait d'une journée : ce fut un lent travail d'initiation d'abord, puis de contrôle et de critique, et qui suscita parfois des réactions vigoureuses. Par là, cette découverte contribue à I'histoire du mouvement philosophique. Mais, remarquons-le, le mouvement philosophique ne commence pas avec Voltaire. Pour que Voltaire ait pu écrire les premières phrases de son Essai sur les Mœurs qui sont en réalité la négation du Déluge d'après les annales chinoises, ou du moins pour qu'il ait pu l'écrire sans susciter les plus vives protestations, il a fallu que des érudits, des théologiens, des philosophes se soient appliqués à connaître ces anciennes chroniques, et que ce travail critique ait habilité I'esprit des Français d'avant Voltaire à admettre I'antiquité de la nation chinoise malgré les dangers qu'elle pouvait présenter pour la religion. La Peyrère a risqué le bûcher en proposant sa théorie des Préadamites. Voltaire n'a pas risqué grand chose en niant I'universalité du Déluge. C'est qu'entre ces deux hommes il s'est 


\section{La Chine et la formation de l'esprit philosophique en France}

produit toute une évolution des idées qui a modifié l'esprit public, et qui est proprement le développement de l'esprit philosophique. La découverte de l'antiquité de la Chine a contribué à ce mouvement, mais elle a aussi été favorisée par lui. Elle a profité des progrès de l'esprit critique en général et de l'affaiblissement de la foi en la valeur de la Bible comme document historique sur les origines du monde. Elle est à la fois et à tout instant une des causes et une des conséquences du mouvement philosophique.

$*$

Avant 1650, les premiers écrivains qui nous donnent des relations sur la Chine - nous parlons seulement de ceux qui comptent et qui fournissent des renseignements de première main, Gonçales p.194 de Mendoce, Trigault et Semedo n'apportent que des faits peu précis sur l'antiquité de la Chine. Gonçales de Mendoce cependant, dès la fin du XVI siècle, donne une vague chronologie de I'histoire chinoise, ce qui permet à Montaigne qui l'a lu ${ }^{1}$ d'accepter l'idée de l'antiquité de la nation chinoise 2, mais Mendoce ne nous dit pas sur quoi se fonde cette chronologie : «Ce royaume est si antique, dit-il, qu'on estime que les premiers qui le peuplaient, ce furent les neveux et les petits-fils de Noé » 3 , et il énumère ensuite, sinon tous les rois, du moins les différentes familles avec la durée de leur règne, depuis « Vitey lequel a esté le premier qui a réduit ce Pays en

\footnotetext{
1 P. Villey, Les Sources et I'évolution des Essais, t. I, p. 138.

2 Montaigne, Essais, t. III, p. 12.

3 Gonçales de Mendoce, Histoire du grand Royaume de la Chine, p. 8, ro.
} 


\section{La Chine et la formation de l'esprit philosophique en France}

Royaume jusques au Roy qui est à présent régnant »1, ce qui fait remonter l'origine de la monarchie chinoise entre 2550 et 2600 avant Jésus-Christ, date antérieure au Déluge, suivant la version des Hébreux. Mais de cela, Gonçales de Mendoce semble n'avoir cure. Le P. Trigault ne disserte pas sur l'antiquité des Chinois, mais il cite en passant un petit fait qui prouve l'antiquité de la nation chinoise puisqu'on trouve « dans les Annales de la Chine l'artifice des ouvrages de soie deux mil six cens ans devant la nativité de Jésus-Christ »2. Quant à Semedo, tout en rapportant sommairement les opinions des Chinois sur les origines de leur monarchie, il les tient pour fabuleuses ou erronées, parce que leur chronologie ne peut s'accorder avec celle de la Bible : «Ils commettent des fautes remarquables pour le temps de leurs chronologies, pour ce qu'en supputant le plus favorablement qu'on peut les temps qui se sont écoulés depuis la création du Monde jusqu'à Noé, on trouve qu'ils font naistre leur empereur Yao douze ans avant le Déluge »3.

Mais s'il repousse cette chronologie à cause de sa trop longue durée, il lui accorde néanmoins une grande valeur, parce qu'elle est bien suivie : "Quoy qu'il en soit du mesconte des tems en I'histoire de cet Empereur [Yao] et de ses successeurs, il est certain que les choses s'accordent en leur suite »4. Quant aux polygraphes, Baudier ou Bellefleur, qui ne font que copier le P.

\footnotetext{
${ }^{1}$ Id., ibid., p. 40, $\mathrm{v}^{\circ}$.

2 Trigault, Histoire de l'expédition chrétienne en la Chine, p. 6.

3 Semedo, op. cit., p. 149-50.

${ }^{4}$ Id ibid., p. 150.
} 


\section{La Chine et la formation de l'esprit philosophique en France}

Trigault, s'ils font en passant une allusion à l'antiquité de la Chine, ils l'acceptent sur la foi de Ptolémée.

p.195 Donc jusque vers 1650 , la chronologie chinoise semble ne rien présenter qui soit de nature à inquiéter sérieusement les théologiens : elle est trop peu précise pour qu'on puisse ou I'accepter ou la rejeter, pour qu'on puisse même la critiquer. La seule impression qui reste de ces premières relations est que la Chine est une nation ancienne qui se dit même très ancienne, mais dont I'histoire des origines doit être entachée de fables, comme I'histoire primitive de beaucoup de peuples.

Malgré le peu d'indications certaines que l'on avait sur la chronologie chinoise, La Peyrère n'hésita pas cependant, en invoquant aussi il est vrai les chronologies chaldéenne et égyptienne ainsi que les anciennes civilisations mexicaine et péruvienne que Moïse n'avait pu connaître, sans parler des terres australes qui commençaient à piquer la curiosité mais qui n'étaient pas encore découvertes, à édifier sa théorie singulière des Préadamites. Sans doute, pour se couvrir, il invoque la nécessité d'admettre son hypothèse pour concilier la chronologie de la Bible avec elle-même et avec la chronologie des anciens peuples : « Conciliatur [historia Geneseos] cum se ipsa. Conciliatur item miris modis curn monumentis omnibus prophanis, sive antiquis sive recentioribus ; Chaldæis puta, 


\section{La Chine et la formation de l'esprit philosophique en France}

Ægyptiis, Scythis et Sinensibus... »1. Mais cette ${ }_{\text {p.196 }}$ précaution même ne pouvait être que le fait d'un franc libertin, puisqu'elle tendait en somme à laisser entendre que la Bible ne portait pas en elle-même un caractère de vérité qui la rendait l'arbitre des histoires profanes, et qu'elle devait au contraire être rectifiée ou du moins interprétée d'après ces histoires.

L'idée de La Peyrère, qui prétendait que le récit de l'origine des hommes, tel qu'on le trouve dans la Genèse, ne s'appliquait qu'à la nation juive et non aux autres peuples, n'était pas entièrement nouvelle puisque Giordano Bruno avait déjà prétendu «que la race seulement des Hébreux tire son origine d'Adam et d'Eve, et les autres nations de deux hommes que Dieu

1 La Peyrère. Præadamitæ, p. 19. Dans son Apologie, La Peyrère reprend cet argument et l'invoque comme une nécessité pour résoudre les difficultés que posent les histoires profanes et les théories des Gentils sur I'origine du monde : « Ce qui acheva de m'esblouir fut que j'accordois, ce me sembloit, sur mon hypothèse, I'histoire payenne avec I'histoire de la Genèse et la philosophie des Gentils avec la Théologie des Chrétiens touchant l'Éternité du monde, de la façon que j'entendois et que je posois cette Éternité. Et que je découvrois la véritable origine des peuples des Deux Indes qui nous sont connus et des peuples qui sont sous les deux pôles dont les terres nous sont tout à fait inconnues, et pour lesquels on demande encore tous les jours, d'où ils sont venus ? Et qui les a produits ? » (Apologie de La Peyrère, p. 18-9). On ne peut mieux marquer la difficulté d'accorder le récit de la création du monde avec la découverte des terres nouvelles, mais cette excuse que donne La Peyrère en faveur de son hypothèse des Préadamites, n'en sent pas moins le fagot. Cette Apologie, pleine de candeur, mais qui pose aussi nettement que le livre de J. F. Bernard (Dissertations mêlées. I Dissertation qui traite de I'origine du monde, 1740) l'opposition entre la sagesse païenne qui croit à l'éternité du monde et la Bible qui admet une création ex nihilo, n'est pas moins audacieuse lorsqu'elle critique l'idée du péché originel et qu'elle montre que cette notion est peu fondée historiquement : «Après avoir bien examiné tout ce qui se disoit sur ces versets 13 et 15 du chapitre $V$ de l'Epistre de St. Paul aux Romains) je fis cette réflexion en moy-mesme, que c'estoit une chose bien estrange de voir que la doctrine de la Religion Crestienne fust fondée sur la doctrine du péché originel, que la doctrine du péché originel fust fondée sur l'intelligence de ce passage de S. Paul. Car c'est le seul endroit de la Bible où il est précisément parlé de ce péché. Et toutefois que ce passage fust si obscur qu'il est comme impossible de l'entendre sur l'explication receue qu'on ne s'engage dans des difficultez inexplicables. »(Apologie..., p. 13-4). 


\section{La Chine et la formation de l'esprit philosophique en France}

avoir créez le jour précédent » ${ }^{1}$. Guy Patin nous apprend aussi que I'idée de La Peyrère était tout au moins dans l'air au moment où il publia son livre : «Paracelse même, dit-il, a fait un traité « de hominibus non Adamicis ». Mais il me semble que toutes ces matières sont bien difficiles et bien conjecturales. J'ai vu en cette ville un homme qui disoit qu'au-dessus de la lune il y avait un nouveau monde où étoient de nouveaux hommes, de nouvelles forêts et de nouvelles mers, aussi bien qu'en celui-ci. J'en ai vu un autre qui disoit que I'Amérique et tota illa terra Australis nobis incognita étoit un nouveau monde qui n'étoit pas de la Création d'Adam et que Jésus-Christ n'étoit pas venu pour le salut de ceux-là »2 2 . Le tort de La Peyrère nous voulons dire le tort qu'il risquait de se faire à lui-même - fut d'avoir systématisé cette idée en prenant des arguments de toutes parts pour la prouver.

La Peyrère soutient que c'est en lisant le Ve chapitre de l'Épitre aux Romains de Saint-Paul que cette idée lui est venue. Mais il y a tout lieu de se défier de cette affirmation et il est plus à supposer que La Peyrère ayant tiré d'ailleurs sa théorie s'est mis ensuite à lire la Bible et les Pères pour essayer de la confirmer. Quoi qu'il en soit de l'origine de cette thèse voici les arguments invoqués par La Peyrère.

D'après Saint-Paul le temps de la loi a commencé à Adam. Or Adam ayant transgressé la loi qui lui a été donnée a commis un

\footnotetext{
1 La Croze, Entretiens sur divers sujets d'histoire. Dissertation sur l'athéisme et sur les athées modernes, p. 295. Cf. R. Charbonnel, La pensée italienne au $X V I^{e}$ siècle et le courant libertin, p. 559, n. 1.

2 Guy Patin, Correspondance, Ed. Réveillé-Parise, t. I, p. 296-7.
} 


\section{La Chine et la formation de l'esprit philosophique en France}

péché qui a été imputé à tous les hommes : avant ce temps, p.197 quoique les hommes péchassent, ce péché ne leur était pas imputé, parce qu'il n'y avait pas encore de loi, mais depuis la loi donnée à Adam, le péché a été imputé, ce qui suppose, suivant La Peyrère, qu'il y avait des hommes avant Adam, mais qu'ils n'ont souffert du péché originel que par la faute d'Adam et d'une manière rétrospective. En tout cas Adam n'est pas le premier homme.

Le deuxième argument consiste à signaler et à mettre en valeur les contradictions qui existent entre le premier et le second chapitre de la Genèse et à démontrer qu'il est impossible que la Création de I'homme se soit faite telle qu'elle est rapportée au second chapitre.

Il est impossible en effet que la création de l'homme se soit faite en un jour, et encore moins en une demi-journée comme il le faut supposer $d^{\prime}$ après le $2^{\mathrm{e}}$ chapitre, si Dieu créa ce jour-là les animaux et les hommes. Il est dit en effet dans ce chapitre qu'en ce jour Dieu créa premièrement les animaux et ensuite les hommes, qu'il créa l'homme du limon de la terre et qu'il lui donna le souffle de vie et qu'il le transporta dans le Paradis, que ce Paradis avait été planté dès le commencement, terme qui désigne un temps fort reculé, qu'il lui donna des lois et qu'il lui fit défense de manger du fruit de l'arbre de la science du bien et du mal, au lieu que dans le premier chapitre de la Genèse il est dit qu'il avait donné à I'homme pour sa nourriture toutes les graines des herbes et des fruits de tous les arbres sans exception ; que Dieu vit ensuite qu'il n'était pas à propos de laisser cet homme seul et qu'il résolut de lui donner une aide 


\section{La Chine et la formation de l'esprit philosophique en France}

semblable à lui ; qu'avant cela il fit venir tous les animaux devant lui afin qu'il leur donnât des noms. Or, remarque La Peyrère, comment tous les animaux avaient-ils pu être rassemblés de tous les points du monde en si peu de temps et comment Adam aurait-il pu en moins d'une heure donner des noms propres et convenables à tant de différentes espèces ? Ensuite, Dieu envoya le sommeil à Adam qui s'endormit, et pendant qu'il dormait Dieu tira une de ses côtes pour en former la femme. Enfin Dieu lui amena cette femme et I'homme lui parla. Toutes ces choses, conclut l'auteur des Préadamites, n'ont pu se faire non seulement en un jour, ou en une demi-journée, ni même en une semaine ou en un mois. Donc le premier chapitre qui rapporte des événements bien antérieurs à ceux du second chapitre, est l'histoire de la création des premiers hommes dans diverses parties du monde, tandis que le second, bien postérieur au premier, est I'histoire de la création d'Adam et de la race juive.

Enfin le troisième argument, plus vigoureux destiné à servir p. ${ }_{198}$ de preuve au premier, sera repris par Bayle, sous une forme un peu différente et deviendra par la suite un des arguments essentiels de ceux qui voulurent faire le monde plus vieux que ne le marque la Genèse ${ }^{1}$.

Adam, chassé du Paradis terrestre, dit La Peyrère, eut deux enfants, Caïn et Abel. Il partagea entre eux ses biens, donna à Caïn les terres à cultiver et à Abel des troupeaux. L'un fut laboureur, l'autre pasteur. Pour labourer on a besoin de quantité

\footnotetext{
${ }^{1}$ Bayle, Dictionnaire critique. Art. Caïn, note A, t. II, p. 226.
} 


\section{La Chine et la formation de l'esprit philosophique en France}

d'instruments. Comment Caïn aurait-il pu les avoir, si les arts n'étaient pas encore inventés ? Comment aurait-il pu, à lui seul, creuser des mines, faire des forges ? Comment aurait-il pu, sans minerai et sans forges, faire des enclumes et des marteaux ? S'il avait fait du pain avec le blé qu'il récoltait, où avait-il appris à le moudre, à le pétrir et à le faire cuire et comment pouvait-il seul suffire à tant de travail ? Abel était pasteur. Il gardait ses troupeaux. En quoi était-ce nécessaire ? Il n'y avait point de voleurs à craindre, puisqu'il n'y avait point d'habitants sur la terre. Quand Caïn tua son frère Abel, il fallait qu'Abel fût dans une ville entourée de murs puisque Caïn lui dit : Sortons dehors. Il craignait donc d'être vu s'il commettait son crime dans un lieu habité et peuplé. Mais ce qui est encore plus difficile à expliquer c'est que Caïn, après avoir tué son frère, s'en va vers I'Orient en exprimant la crainte que ceux qu'il rencontrera ne le tuent [c'est le point précis sur lequel Bayle insistera]. Il y avait donc dès lors des habitants en grand nombre dans les pays éloignés. Joseph dit que Caïn ramassa une troupe de marchands et de voleurs et qu'ils exercèrent le brigandage. Il ne faut pas s'arrêter à cette conjecture qui n'est pas certaine, mais l'Écriture nous apprend que Caïn se maria, qu'il eut un fils nommé Hénoch, et qu'étant venu d'Orient, il bâtit une ville à laquelle il donna le nom de son fils. La terre était donc déjà peuplée d'hommes, et d'autres hommes que des descendants d'Adam car Abel était mort. Seth ne naquit que la cent huitième année d'Adam et ce fut le premier enfant qu'Adam eut après la mort d'Abel. Ève dit en effet, en le nommant : «Dieu m'a donné un autre fils en la place d'Abel que Caïn a tué » ce qui prouve manifestement qu'il n'y avait pas eu 


\section{La Chine et la formation de l'esprit philosophique en France}

d'autres enfants entre la mort d'Abel et la naissance de Seth. Donc Caïn épousa une femme qui n'était point de la race d'Adam ${ }^{1}$.

p.199 Ce livre qui avait l'audace d'examiner la Bible avec l'esprit critique et qui la réduisait à n'être que I'histoire des Juifs et non plus I'histoire universelle du monde primitif, qui d'autre part laissait entendre que le monde avait une prodigieuse antiquité, fit un grand scandale. Et non seulement en France mais en Hollande, en Allemagne et en Suède. A la date du 13 septembre 1656, Guy Patin 2 comptait déjà dix-sept critiques qui s'étaient acharnés sur le pauvre La Peyrère, qui fut incarcéré à Anvers sur I'ordre de I'Inquisition, et ne fut relâché que grâce à la protection du Prince de Condé, pour aller se rétracter à Rome. Tout le monde évidemment n'était pas de l'avis de Guy Patin qui trouvait que l'auteur avait mis de la « gentillesse » 3 dans ses preuves et qui semblait disposé à adopter la thèse principale. « Cette opinion me plaît et me lairois volontiers persuader qu'elle est vraie. Au moins est-elle belle » 4 . Guy Patin cependant ne fut pas le seul qui fût prêt à adopter cette opinion, car si nous en

\footnotetext{
1 Guy Patin qui, décidément, semble avoir été lui aussi préadamite, écrit le 20 novembre 1656 à J. B. de Salins : «...Lisez au commencement de la Genèse chap. 4 ce que dit Caïn à Dieu qui l'avoit maudit pour avoir tué son frère Abel, et de là vous pourrez tirer une forte conjecture qu'Adam n'a pas été le premier homme du monde, mais seulement dans la Palestine, etc... ». A. Chéreau, Quelques lettres inédites de Guy Patin (1651-1661), p. 23-4.

2 Guy Patin, Correspondance, Ed. Réveillé-Parise, t. II, p. 252.

${ }^{3}$ Id. . Lettre à Spon du 10 novembre 1656. ibid., t. II, p. 263-4.

${ }^{4}$ Id., Lettre à Spon du 11 mai 1655. ibid., t. II, p. 175.
} 


\section{La Chine et la formation de l'esprit philosophique en France}

croyons Buddeus ${ }^{1}$, l'athée Knutzen, qui fonda à Lena la secte des conscientiaires, et qui professait de ne croire ni à Dieu ni à diable, admettait l'idée des Préadamites et il avait de nombreux disciples. Bayle, nous l'avons vu, reprit dans I'article Caïn de son dictionnaire le principal argument de La Peyrère pour signaler et mettre dans son jour une des difficultés de la Bible, et reculer I'origine du monde. En 1711, Ellies du Pin jugeait nécessaire de réfuter dans ses Dissertations critiques cette théorie des Préadamites, et, nous le verrons plus loin en détail, I'abbé Renaudot publiait en 1718 ses Anciennes Relations de deux voyageurs Mahométans aux Indes et à la Chine, suivies de cinq dissertations, tendant à combattre l'idée de l'antiquité de la Chine, pour enlever cet argument de poids aux libertins, qui voudraient s'en servir pour faire le monde plus vieux que ne le permet la Bible, et par là ruiner la valeur historique de la Bible.

La théorie de La Peyrère, bien que suggérée peut-être par des faits, chronologie des Chaldéens, des Égyptiens et des Chinois et par la découverte, qui semblait à cette époque sinon probable, tout au moins possible, d'un continent nouveau, l'Australie, reste p.200 cependant, tout au moins dans la forme, plus encore qu'une démonstration positive appuyée sur des faits nouveaux, une réfutation au nom de la raison du récit biblique des origines du monde et de I'humanité. Mais les conclusions de La Peyrère risquaient de devenir singulièrement dangereuses, si I'on découvrait en Australie une race et une civilisation toutes

1 Buddeus, Traité de l'athéisme et de la superstition., p. 95, n. 1. Cf. aussi Bayle, Dictionnaire... Art. Knutzen, note A, t. III, p. 556. 


\section{La Chine et la formation de l'esprit philosophique en France}

différentes des races et des civilisations déjà connues ou si l'antiquité de la nation chinoise était prouvée.

En 1658, trois ans après le livre de La Peyrère, le P. Martini, Jésuite missionnaire en Chine, publia la première chronologie chinoise que nous ayons, chronologie qu'il tirait des annales chinoises compulsées par lui-même dans les textes chinois ${ }^{1}$. Laissant de côté les temps antérieurs à Fou hi que beaucoup de Chinois estiment fabuleux, il commence à cet empereur et énumère ensuite tous les empereurs qui lui ont succédé sans interruption jusqu'à Jésus-Christ. Un court chapitre consacré à chacun d'eux énumère les principales actions de leur vie. Mais I'intérêt principal de ce livre réside, plus encore que dans les faits qu'il rapporte, dans la manière dont il marque les époques, c'est-à-dire au moyen du cycle sexagénaire des Chinois.

Quelques années auparavant (en 1650) Greaves avait publié les Epochæ celebriores d'Ulug Beig, où se trouvaient des indications, selon un auteur persan, sur un cycle en usage chez les Cataiens. Lorsque le P. Martini revint en Europe et s'arrêta à Amsterdam pour faire publier son Atlas sinensis, I'orientaliste Golius lui expliqua les caractères persans des tables d'Ulug Beig, et le P. Martini reconnut sous les caractères persans qui les déformaient, les notations du cycle sexagénaire des Chinois. Golius 2 écrivit une dissertation sur le cycle sexagénaire, ce qui ne contribua pas peu à donner une haute idée des capacités des

\footnotetext{
1 Martini (le P.), Historiæ sinicæ decas prima.

2 Renaudot, Anciennes relations de deux voyageurs Mahométans, p. 395.
} 


\section{La Chine et la formation de l'esprit philosophique en France}

Chinois en astronomie, et par suite à créer un préjugé favorable en faveur de l'exactitude de la chronologie chinoise.

C'est au moyen de ce cycle sexagénaire que le P. Martini marque les époques de l'ancienne histoire chinoise, et il fait remonter le cycle à la première année du règne de Houang ti, troisième empereur, ce qui correspond à I'an 2697 avant J.-C. Ce cycle, dit-il, fut inventé par Houang ti lui-même et c'est la raison pour laquelle les Chinois ont appliqué pour la première fois à son règne des notes cycliques. Mais il y a eu avant lui deux autres empereurs qui p.201 régnèrent 255 ans, si bien que I'histoire authentique de la Chine remonte à I'an 2952 av. J.-C. ; et nous avons pour garant de la certitude de cette date le soin avec lequel les Chinois, même avant I'emploi du cycle, ont noté les différents événements de leur histoire ${ }^{1}$. Or, cette date est antérieure de six cents ans à l'époque fixée par le texte hébreu pour le Déluge. Le P. Martini a vu la difficulté et il se défend, dans sa préface, d'être obligé d'indiquer pour les origines authentiques de I'histoire chinoise une date qui semble en contradiction avec la Vulgate, mais il laisse le soin aux chronologistes de s'en arranger, puisqu'ils ont à leur disposition ou le texte samaritain ou le texte des Septante 2. Pour sa part, comme les annales chinoises parlent d'un déluge qui se serait produit environ trois mille ans avant J.-C. et dont les

\footnotetext{
1 «Ab illo tamen tempore [ante Fu hium] certissima Sinis habentur, ea maxime, quæ ad annorum supputandum rationem spectant, qua in re mirabile Sinarum semper studium emicuit. Hinc est illa continua temporum et fide optima deducta series etiam antequam annorum cyclo utebantur. »op. cit., p. 3.

2 Id., op. cit., p. 3.
} 


\section{La Chine et la formation de l'esprit philosophique en France}

circonstances semblent assez voisines de celles du Déluge de Noé, il n'hésite pas sur la foi des annales chinoises à fixer I'époque du Déluge de Noé au troisième millénaire avant J.-C. ${ }^{1}$. Mais il y a plus : le P. Martini croit à la haute antiquité de la science astronomique en Chine puisque Fou hi fut habile en astrologie judiciaire : « Hic Imperator magnis virtutibus eluxit, et Astrologiæ cumprimis peritus, cœlestium juxta humanarumque rerum curam exacte habuit »2. Si donc l'astronomie était développée en Chine à l'époque du Déluge, si d'autre part, I'histoire de la Chine remonte plus haut que Fou hi, il faut nécessairement que la Chine ait été habitée avant le Déluge. Le P. Martini n'élude pas cette conséquence et il l'accepte en toute bonne foi : « Hanc enim qua de scribo, extrernam Asiam ante diluvium habitatam fuisse pro certo habeo $\gg 3$ et il déclare que ce n'est pas son affaire d'expliquer comment a pu se conserver le souvenir des faits antédiluviens, s'il est vrai que toute la race humaine, à l'exception de la famille de Noé, fut détruite par le Déluge ${ }^{4}$.

Le P. Martini a donc mis dans tout leur jour les difficultés de la chronologie chinoise. Mais il a tant d'admiration pour l'histoire $\mathrm{p}$. 202 chinoise et pour les annalistes de la Chine, non moins que pour ses anciens astronomes, qu'il établit et affirme la certitude

\footnotetext{
1 « Illud pro certo compertum, Sinensium de Diluvio historiam non multum a Noetico abesse ; quippe quæ ter mille circiter annis vulgarem Christi epocham prægreditur. »op. cit., p. 3.

2 Id., op. cit., p. 10.

${ }^{3}$ Id., op. cit., p. 10.

${ }^{4}$ Id., op. cit., p. 10.
} 


\section{La Chine et la formation de l'esprit philosophique en France}

de cette chronologie sans tenir compte des conséquences qu'elle peut avoir pour la critique de la chronologie des Écritures.

Jamais plus après le P. Martini, les Jésuites, qui seront pourtant d'ardents défenseurs de l'antiquité de la Chine, ne pousseront l'audace aussi loin, du moins dans les ouvrages qu'ils feront imprimer. Il n'en reste pas moins que I'Histoire du P. Martini fut un livre toujours consulté même après la chronologie du P. Couplet, ou celle du P. Gaubil, et que les adversaires des Jésuites se plairont à montrer les divergences entre les affirmations du P. Martini et celles de ses successeurs.

Quoi qu'il en soit il n'y avait plus après le P. Martini, si I'on voulait conserver le récit des origines du monde, tel que nous le rapporte la Bible, qu'à soumettre à une étude critique I'histoire du P. Martini pour examiner le bien-fondé de ses affirmations, mais qui était capable de le faire à cette époque - ou à accepter la version des Septante pour faire cadrer la chronologie chinoise avec la chronologie biblique. C'est ce que fit Isaac Vossius moins encore peut-être pour défendre la Bible que pour reculer l'origine du monde et à coup sûr pour justifier l'admiration frénétique qu'il avait pour la Chine ${ }^{1}$.

Curieuse figure que celle de ce savant qui dès l'âge de 19 ans était en relation épistolaire avec les hommes les plus marquants de son temps, Saumaise, Gronovius, Hensius, qui lui

\footnotetext{
1 Dans son livre Variarum Observationum liber il consacre quelques chapitres à la Chine qui témoignent de son admiration sans réserves pour ce pays. Ce qu'il dit de l'antiquité de cette nation, de ses arts, de ses sciences, de la grandeur, de la beauté de ses villes, de son immense population dépasse même le récit de Marco Polo.
} 


\section{La Chine et la formation de l'esprit philosophique en France}

prodiguaient encouragements et compliments. Après une jeunesse aventureuse - si du moins I'on taxe d'esprit d'aventure ce brûlant désir de savoir qui faisait parcourir à ces jeunes hommes les différents pays d'Europe pour copier dans les bibliothèques des manuscrits grecs et latins - il se laissa séduire après beaucoup d'autres par les offres de la reine Christine et il partit pour Stockholm. Il fit pour la reine, en différents pays d'Europe, divers voyages, pour lui acheter livres et manuscrits, et au cours de ses achats, paraît-il, il ne s'oublia pas lui-même. Il se brouilla ensuite avec Saumaise et dut quitter la Suède, mais il y revint lorsque la reine qui d'abord avait pris parti pour Saumaise, ne voulut plus ensuite en entendre parler. Il fut toute sa vie un errant n'ayant pour patrie que les p.203 pays où il trouvait des faveurs et des dignités et des souverains honorant les savants. Il fut historiographe en Hollande, reçut une pension de Louis XIV, finit par devenir chanoine de Windsor. L'Europe fut sa véritable patrie, tous les savants ses compatriotes, et les souverains ses bailleurs de fonds.

D'après les contemporains, ce Vossius était un franc libertin. « Heinsius, dit Chaufepié, marque à Gronovius qu'on étoit universellement persuadé que Vossius, Saumaise et Bourdelot, avaient perdu la reine [Christine] ; qu'il ne doutoit pas que cela ne fût vrai des deux derniers ; qu'il défendoit le premier autant qu'il lui étoit possible mais avec peu de succès ; et il ajoute qu'il auroit souhaité que Vossius se fût davantage opposé aux 


\section{La Chine et la formation de l'esprit philosophique en France}

libertins $\gg 1$. Lorsqu'il fut en Angleterre il fit partie de la société de Saint-Evremond et de la duchesse de Mazarin, et I'on connaît ce jugement du roi Charles II sur Isaac Vossius : « Ce savant théologien est un étrange homme; il croit tout hors la Bible ». Il mourut, dit Chaufepié ${ }^{2}$, d'une manière très peu édifiante n'ayant fait paraître aucun sentiment de piété.

A peine I'Histoire de la Chine du P. Martini eut-elle paru que Vossius s'empara de la chronologie que cette histoire lui apportait pour démontrer que le monde devait être plus ancien de 1400 ans que ne le prétend le texte hébreu, et son intention n'était nullement de sauver par un pis aller I'histoire mosaïque en montrant que la chronologie de la Bible pouvoit s'accorder à la rigueur avec I'histoire chinoise. Mais bien plutôt cette chronologie chinoise nouvellement révélée se présentait à lui comme un merveilleux argument pour démontrer la nécessité de reculer les origines du monde.

Dans sa Dissertatio de ætate mundi, il commence par examiner les différentes hypothèses sur l'origine du monde. Le monde est-il éternel ? S'il a été créé, a-t-il été créé par Dieu, ou s'est-il créé lui-même ? Cette dernière hypothèse ne semble pas absurde à Vossius, mais il la repousse néanmoins, pour des raisons il est vrai qui n'ont pas grande valeur, et il conclut qu'il

1 Chaufepié, Dictionnaire... Art. Vossius, t. IV, p. 622. Cf. aussi Nicéron, Mémoires..., t. XIII, p. 130. «Il publioit des livres pour prouver que la Version des Septante est divinement inspirée et il témoignoit par ses entretiens particuliers qu'il ne croyoit point de révélation. La manière peu édifiante dont il est mort ne nous permet pas de douter de ses sentiments. » Des Maizeaux, Vie de St Evremond, 4e éd. des Fuvres de St Evremond, 1726, p. 224.

${ }^{2}$ Chaufepié, ibid., t. IV, p. 631. 


\section{La Chine et la formation de l'esprit philosophique en France}

faut accepter comme pis aller le récit mosaïque des origines du monde, qui nous fournit les principes de la foi et de la chronologie ${ }^{1}$.

p.204 Cependant ce récit doit être examiné de près, car il présente plus que des invraisemblances : il contient des impossibilités manifestes. En effet d'après le texte hébreu, la période comprise entre la fin du Déluge (époque où il n'y avait sur la terre que Noé et sa famille, en tout huit personnes) et la dispersion des peuples (alors une partie du monde était peuplée et des nations étaient constituées) ne comprend en tout et pour tout que 101 ans. Pour les théologiens du XVII siècle cette difficulté ne pesait guère, depuis que le P. Pétau, une autorité décisive en faveur de la chronologie traditionnelle, avait montré qu'aux temps heureux du Déluge, alors que la fécondité des hommes était grande, I'humanité avait pu pulluler en cent ans au point de comprendre des millions d'hommes. Mais Vossius ne I'entend pas ainsi. Il remarque que pour admettre que la terre ait été peuplée en partie en si peu de temps, il faut supposer que les patriarches ont été d'une fécondité extrême, qu'ils ont dû en outre commencer à engendrer à 19 ans, et il fait à ce sujet une plaisanterie qui annonce celles de Lenglet Dufresnoy, de d'Argens et de Voltaire sur le même sujet : «Etiam si concedatur vos cucurbitarum instar pullulasse, non tamen efficient ut hæc computandi ratio non sit prorsus ridicula $\gg 2$.

\footnotetext{
1 Vossius, Dissertatio de ætate mundi, p. 4.

${ }^{2}$ Id., ibid., p. XVIII.
} 


\section{La Chine et la formation de l'esprit philosophique en France}

Cette impossibilité d'expliquer le peuplement de la terre en un si court laps de temps oblige Vossius à adopter pour la chronologie le texte des Septante qui s'accorde d'ailleurs avec la chronologie des Chaldéens, des Égyptiens et des Chinois. Ces derniers notamment, ont une histoire continue qui remonte à 4.500 ans, et cette histoire est appuyée sur des monuments et sur les annales de la Chine : «Les Chinois ont des écrivains plus anciens que Moïse lui-même »1. Donc nécessité historique d'admettre la version des Septante, mais aussi nécessité pratique car cette « fausse opinion sur l'antiquité des nations » que I'on trouve dans le texte hébreu a été la raison déterminante qui a poussé La Peyrère a écrire son livre des Préadamites. Or, malgré les nombreuses réfutations qui ont été faites de la thèse de l'auteur, malgré la rétractation à laquelle il s'est soumis, ses idées sont encore acceptées par une secte de gens qui s'attachent à rechercher toutes les contradictions de l'Écriture. Ce n'est pas à dire que Vossius accepte entièrement les idées de La Peyrère, mais il avoue qu'à son avis le Déluge n'a pas été universel 2. En effet pour l'admettre il faudrait p.205 supposer un grand nombre de miracles. Comme les eaux du monde entier n'auraient pas suffi à recouvrir la terre, même si les mers avaient été desséchées, il faudrait supposer que les masses d'eaux ont été créées pour cet objet particulier ou qu'elles ont été empruntées à d'autres « globes du ciel », où elles ont dû

\footnotetext{
${ }^{1}$ Vossius, Dissertatio de ætate mundi, p. XLIV-V.

2 Il a circulé un peu plus tard une dissertation qui était une négation du déluge De Diluvii universalitate que Bayle, dans son Dictionnaire, art. Vossius, attribue à Vossius, tandis que Ellies du Pin, dans ses Dissertations historiques et critiques, l'attribue à La Peyrère. (Voir plus bas, p. 246).
} 


\section{La Chine et la formation de l'esprit philosophique en France}

retourner à la fin du Déluge. Dieu ne fait pas de miracles en vain. Quelle nécessité avait-il donc d'inonder des pays où il n'y avait pas d'hommes, où il n'y en a pas encore maintenant ? C'est une folie de penser que le genre humain avait tant pullulé avant le Déluge qu'il se trouvait à l'époque du Déluge des hommes dans tous les coins de la terre. La preuve que même à cette époque les hommes procréaient lentement c'est que Noé n'était que le neuvième homme depuis Adam. Sans doute les huit personnes qui ont échappé au déluge ont pu multiplier plus rapidement que le couple Adam et Ève, mais il n'en reste pas moins qu'avant la dispersion des peuples, la race humaine n'occupait qu'une petite partie de l'Asie ; elle ne dépassait peutêtre pas les limites de la Syrie et de la Mésopotamie ${ }^{1}$.

Vossius, malgré ses dénégations, malgré ses critiques de la théorie des Préadamites, rejoint donc La Peyrère. L'histoire du Déluge, I'histoire de la Tour de Babel et de la Dispersion des peuples, sont pour lui des faits locaux qui sont historiques seulement pour une toute petite région de l'univers et pour un tout petit peuple. Il réduit donc la Bible à la valeur d'un livre d'histoire locale, d'ailleurs plein de difficultés et d'hypothèses inadmissibles et qui ne peut avoir par suite la prétention de relater I'histoire des origines du monde entier. Pour connaître la Chine, il faut consulter, plutôt que la Bible, I'histoire chinoise qui est suivie et confirmée par des monuments.

Telle est l'impression que l'on éprouve à la lecture de cette dissertation qui, tout en voulant rester prudente et semblant

\footnotetext{
1 Vossius, op. cit., p. 53-4.
} 


\section{La Chine \\ et la formation de l'esprit philosophique en France}

chercher une conciliation entre I'histoire profane et l'histoire biblique, montre en réalité la difficulté d'une conciliation entre elles.

Vossius trouva un contradicteur en la personne de Georges Horn, un homme d'imagination avec un léger vernis de science et auquel aucun argument ne coûtait pour défendre les vérités traditionnelles, tellement il était sûr que rien ne pouvait les ébranler. Cet érudit s'était efforcé notamment quelques années auparavant d'expliquer le peuplement de I'Amérique en excluant p.206 l'idée d'une race autochtone car alors comment comprendre le récit de la création tel que le fait la Bible, ou comment admettre I'universalité du Déluge ? Et pour cela, il faisait de l'Amérique une sorte de rendez-vous de différents peuples d'Occident ou d'Orient : d'abord les Phéniciens, les anciens Cantabres, d'autres encore, puis plus tard les Chinois, les Huns et diverses nations de I'Orient ${ }^{1}$.

Dans sa réponse à Vossius, Dissertatio de ætate mundi, Horn établit un lien entre le livre de La Peyrère et la dissertation de Vossius, pour souligner le caractère dangereux de cette dernière. Suivant lui, la théorie de La Peyrère conduisait tout droit à l'athéisme parce qu'elle essaye de prouver que le monde n'a pas été créé. C'était peut-être l'idée de derrière la tête de La Peyrère, mais La Peyrère, malgré ses audaces se contentait de montrer que le monde n'avait pas été créé comme le rapportait la Genèse. Quant à la théorie de Vossius, qui se couvre de desseins honnêtes puisqu'elle s'efforce de faire concorder la

${ }^{1}$ G. Horn, De originibus Americanis libri quatuor, Hagæ, 1652, in-8. 


\section{La Chine et la formation de l'esprit philosophique en France}

chronologie des peuples nouvellement connus avec la chronologie biblique, elle ne cache pas moins, suivant Horn, un danger très grave : «Si le texte hébraïque ne doit pas être préféré aux textes grecs, il en résulte que jusqu'ici dans aucune église d'occident on n'a admis une véritable version des Saintes Écritures, puisque toutes sont tirées des manuscrits hébreux $\gg 1$. Donc cette suspicion que I'on vient jeter brusquement sur la version hébraïque rend inutiles les efforts et le travail de tous les rois, princes et magistrats qui se sont efforcés de procurer des versions exactes de la Bible et les ont fait recevoir dans les églises et les écoles. Donc puisqu'il n'y a qu'une version de la Bible qui soit en usage et que Vossius la sape, c'est à la Bible même qu'il s'attaque.

Mais il ne suffit pas de rester dans les généralités, il faut aussi répondre aux arguments de Vossius, et notamment à l'argument de la chronologie chinoise. Or la réponse de Horn est extrêmement faible ou à vrai dire ce n'est même pas une réponse : c'est un lourd badinage sans esprit et sans valeur qui tend à nier purement et simplement le fait précis apporté par Vossius : «Que pensons-nous des Sérès, vulgairement appelés chinois et dont la chronologie très précise précède le déluge de sept ou huit siècles, selon Vossius ? S'il en est ainsi nous penserons que leur chronologie très précise est fausse, tout autant que ce qu'ils rapportent de l'éternité du monde et de Panzon et Panzone, de Tahomus, Tecesicomus, p.207 Tuhacomus, Lotzizamus, Azolomus. [J'abrège cette fastidieuse énumération

\footnotetext{
${ }^{1}$ Id., Dissertatio de ætate mundi, p. 3.
} 


\section{La Chine et la formation de l'esprit philosophique en France}

qui est longue, parce que Horn pense sans doute que le grotesque de ces noms suffit à prouver que ces personnages n'ont pas existé]. Si les Cataiens sont les Chinois, conformément à leur chronologie très précise, il s'est écoulé jusqu'à cette année 1659, 88.640.075 années solaires complètes comme on le voit d'après Ulug Beig. Mais bien loin que cette chronologie des Sérès précède le déluge de sept à huit siècles, elle lui est postérieure de 237 ans, d'après les annales de cette nation et d'après les affirmations des jésuites $\gg 1$. Horn ne nous dit pas d'ailleurs sur quelles affirmations des Jésuites il se fonde : on sent fort bien que pour lui son siège est fait, la version hébraïque doit sortir saine et sauve de l'aventure, à n'importe quel prix.

Mais Vossius ne se tint pas pour satisfait et répondit. Horn répliqua à son tour et la polémique continua un certain temps. Nous ne suivrons pas les deux antagonistes dans leur polémique parce qu'aucun d'eux ne modifia sa position et n'apporta d'arguments nouveaux. Pour les savants, tels que Bochart, qui pourtant ne partageait pas les idées de Vossius sur la population à l'époque du Déluge 2, l'avantage restait incontestablement à Vossius : « Je me doutois bien que votre homme vous donneroit belle prise, lui écrivit-il. Il a bien vérifié ce qui se dit, que les meilleures causes deviennent mauvaises entre les mains d'un mauvais Advocat. On aura sujet de croire qu'il est à vos gages, et que vous le payez pour prévariquer et trahir sa cause. Je n'avois jamais veu en un si petit escrit un tel ramas

${ }^{1}$ Id., ibid., p. 34.

${ }^{2}$ Chaufepié, Dictionnaire... Art. Vossius, t. IV, p. 624, note T. 


\section{La Chine et la formation de l'esprit philosophique en France}

d'impertinences. Au lieu qu'au vostre et les raisons et la façon de les exprimer me surprennent si fort, qu'encore que j'aye toujours fait grand cas de tout ce que j'ay veu de vous, je trouve qu'en ce petit escrit vou vou surpassez vous-mesme.. $\gg 1$.

Quelques années plus tard d'ailleurs (1666) Horn reprit la question plus sérieusement. Il ne lui fut plus possible alors dans son Area Noæ, qui est à la fois une histoire des origines du monde et une défense de la Bible, de traiter avec mépris l'argument de l'antiquité de la Chine et il essaya cette fois d'interpréter cette antiquité dans le cadre des données fournies par la Bible.

D'abord il s'en prend encore une fois à ses deux ennemis La Peyrère et Vossius. Vouloir réfuter Moïse d'après des histoires fabuleuses de quelques nations, dit-il, c'est passer dans le camp de p.208 l'impiété et des Préadamites. Vouloir corriger le texte hébreu d'après les annales des Chinois et des Égyptiens et préférer à ce texte les versions des Grecs et des Samaritains qui ne s'accordent pas entre elles, tant pour les années que pour la supputation des époques, c'est confondre les choses divines avec les choses humaines 2.

Mais les annales chinoises, qui n'ont été mises au jour que dans notre siècle, et qui ont fourni le moyen aux uns et aux autres de commettre de graves erreurs contre la foi des Écritures, présentent cependant des faits intéressants en ce qui concerne l'époque antédiluvienne. Les Chinois disent qu'il y a eu

\footnotetext{
${ }^{1}$ Id., ibid., Art. Vossius, t. IV. p. 623, note T.

2 G. Horn, Arca Noæ, p. 12-3.
} 


\section{La Chine et la formation de l'esprit philosophique en France}

avant le Déluge sept empereurs, le premier étant Fou-hi, le septième Yao, à l'époque duquel se produisit le Déluge de Noé. D'autre part sous le cinquième empereur, «Chuenhoius », se produisit cette conjonction de cinq planètes avec le soleil et la lune que quelques astrologues européens prétendent s'être produite à l'époque de Noé avant le Déluge. Il est donc évident que ces premiers empereurs chinois, depuis Fou-hi ou Xinnung doivent être reportés après le Déluge. Si donc les annales chinoises remontent plus haut que le Déluge, il suit de là que toute I'histoire de cette nation jusqu'au Déluge est fabriquée ou bien qu'elle rapporte les choses qui se sont passées avant le Déluge de Noé, dont le souvenir a pu se conserver dans l'arche. Il n'est donc pas impossible que le Fou-hi des Chinois soit I'Adam de Moïse, ce que certaines traditions des Chinois laissent supposer assez clairement. Ils disent en effet que Fou-hi est né d'un père mais qu'il n'a pas eu de mère. Sa mère fut la terre, ou la poussière dont Adam lui-même a été formé. Les époques non plus ne rendent pas la chose invraisemblable. Si donc Fou-hi est Adam, Xunnung sera Caïn. Les noms ne diffèrent pas absolument, et il y a un rapport assez étroit entre Caïn et Xin (sic). En outre Caïn a été laboureur. On rapporte la même chose de Xinnung qui a, dit-on, inventé la charrue et les autres instruments aratoires, ce qui lui a valu son nom qui signifie « le laboureur d'esprit ». Le fils de Caïn fut Hanoch, dont le nom fut donné par Caïn à la première ville qu'il fonda. Le successeur de Xinnung fut Hoangtius. Or ces noms de Hanoch et de Hoang ti sont tellement voisins l'un de l'autre (sic) que l'on pourrait supposer que ce nom de Hoang ti a été tiré de Hanoch. 


\section{La Chine et la formation de l'esprit philosophique en France}

L'empereur chinois Yao est évidemment Noé. Cela ressort d'une foule d'indices. Tous les livres chinois représentent en effet Yao comme un homme très saint et très pieux. En p.209 outre c'est sous son règne que se produisit le Déluge, fait qui a tellement frappé Martini : «Je n'aurai pas scrupule de dire que ce Yao est notre Janus, qui pour beaucoup de gens a été considéré comme étant Noé »1. Par conséquent, il ne saurait y avoir de désaccord entre l'ancienne histoire chinoise et la Bible, puisque l'ancienne histoire chinoise et la Bible, c'est la même chose.

Si curieux que puisse paraître cet argument qui consiste à assimiler les premiers empereurs chinois aux patriarches - nous reverrons ce procédé bien souvent par la suite - ce livre de Horn marque cependant un progrès intéressant sur ses dissertations antérieures. Il ne croit plus pouvoir désormais rejeter en bloc comme fabuleuses ou contraires à la Bible, les origines de l'histoire chinoise. Il ne lui suffit plus de les tourner en ridicule pour les repousser, il lui faut les comprendre pour pouvoir les interpréter, et en somme, les admettre. Mais le fait d'admettre une semblable histoire, pour un défenseur à tous crins de la Bible, tel que l'était Horn, est l'indice du danger que I'on commençait à entrevoir dans cette antiquité chinoise, si on ne l'interprétait conformément aux principes traditionnels. Mieux valait la rendre inoffensive que d'avoir l'air de l'ignorer ou de la dédaigner.

A la suite de la chronologie de I'Histoire de la Chine du P. Martini, la Chine dut trouver sa place dans toute chronologie :

\footnotetext{
${ }^{1}$ G. Horn, Arca Noæ, p. 17.
} 


\section{La Chine et la formation de l'esprit philosophique en France}

elle s'est conquis un droit de cité. Aussi le P. Riccioli l'admet dans sa Chronologie réformée. Mais il ne se contente pas de se référer aux auteurs chinois pour prouver l'antiquité de la Chine. Il rapporte que le $\mathrm{P}$. Sabatino de Ursis, un des Jésuites missionnaires à Pékin, a trouvé dans les observations faites du temps de Yao, I'indication de la position de deux étoiles fixes avec leurs lieux qui se trouvaient près des points solsticiaux et équinoxiaux. Or, en examinant le lieu où se trouvaient ces étoiles en 1612 et en tenant compte du mouvement annuel des fixes, le Jésuite s'aperçut qu'il s'était passé depuis ce temps 3.970 années solaires, ce qui lui permettait de reporter cette date de Yao à I'année 2.358 avant Jésus-Christ. Le P. de Ursis ne donne cependant cette date qu'avec hésitation et avec crainte à cause de son respect pour l'Écriture et parce que dans les annales chinoises on trouve un certain nombre de faits fabuleux, notamment celui-ci, à savoir que sous Yao le soleil s'arrêta dix jours. Cependant, le P. Riccioli n'hésite pas à inscrire cette date dans la liste chronologique, parce qu'il constate que « ni ce Père [de Ursis] ni les autres n'ont osé infirmer la chronologie chinoise qu'ils voyoient être tenue pour indubitable par les p.210 Chinois, d'autant plus que Julius Africanus fait remonter I'origine du royaume de Chaldée à 2401 avant Jésus-Christ ». Mais cela est impossible, à cause du Déluge, du moins d'après la Vulgate. On peut cependant, pense le P. Riccioli, allonger la Vulgate en y insérant Caïnan, on aurait alors pour la date du Déluge l'année 2973. Malgré cela, si cette date est vraiment celle du Déluge, ni Fou-hi, ni Xinnung ne peuvent avoir régné en Chine avant cette année, ni même Hoang $t i$, car il faut supposer plus d'un siècle 


\section{La Chine et la formation de l'esprit philosophique en France}

entre le Déluge et Phaleg. Cependant les règnes de ces empereurs sont assurés d'après les annales chinoises. Il ne reste donc que deux hypothèses : ou le Déluge n'a pas été universel, comme le voulait Vossius (mais le P. Riccioli répugne à admettre cette hypothèse comme contraire à la Bible) ou ces trois empereurs ont régné avant le Déluge. Mais d'autre part cette supposition est impossible parce que le propre des annales chinoises est de nous donner une histoire suivie et sans interruption depuis les origines jusqu'à nos jours. On est obligé en fin de compte pour conserver la chronologie chinoise, qu'il semble désormais bien difficile de repousser, d'accepter la Version des Septante qui fait le monde plus ancien que la Vulgate, et cela permet de conserver du même coup la chronologie des Chaldéens et des Égyptiens ${ }^{1 .}$

Cette rapide esquisse de la chronologie chinoise que donne le P. Riccioli est intéressante, non pour les dates qu'il admet, car il n'en donne que quelques-unes, et il les emprunte au P. Martini, sans même leur adjoindre les indications cycliques, mais parce qu'il montre que certaines dates très anciennes de la chronologie chinoise ont pu être vérifiées par les astronomes modernes, les annales chinoises rapportant des observations astronomiques d'époques très lointaines, ce qui garantit l'exactitude de la chronologie chinoise et en même temps renforce le respect des Européens pour l'habilité des Chinois en astronomie. Mais aussi commence à se faire jour une autre idée dont se préoccuperont

1 Cette Table chronologique de Riccioli (Chronologiæ reformatæ et ad certas conclusions redactæ) est rapportée par Chevrau à la suite de son Histoire du monde, et, à cette occasion, il donne une description sommaire de la Chine, de son antiquité, de son étendue, de ses richesses et de ses plus belles villes. 


\section{La Chine et la formation de l'esprit philosophique en France}

les écrivains postérieurs : c'est que le danger que présente la chronologie chinoise pour l'idée du Déluge, ce n'est pas seulement son antiquité, c'est aussi sa continuité. Nul trou, nulle rupture dans cette succession d'empereurs depuis Fou-hi jusqu'à nos jours.

Un court Aperçu chronologique de la monarchie chinoise, publié par Thévenot dans le tome II de son Recueil des Voyages curieux ${ }_{\text {p.211 }}$ qui n'ont pas été publiés ${ }^{1}$, mais sans qu'il nous dise d'où il le tient, ne nous apprend rien de nouveau. Il ne mériterait guère d'être signalé s'il ne marquait l'intérêt sans cesse accru que le public portait à la chronologie chinoise. Cependant cette chronologie publiée par Thévenot, n'est pas identique à celle du P. Martini ou aux tables du P. Riccioli, puisqu'elle fixe la première année de Fou-hi à 2944 au lieu de 2952, différence d'ailleurs peu importante.

La seule nouveauté est que l'auteur de cette chronologie adopte résolument la version des Septante : il nous indique en regard des dates importantes des premiers empereurs chinois, les dates correspondantes, par rapport au Déluge, fixé suivant la version des Septante : «Anno Fohi 76 juxta septuaginta interpretum computum obiit Noe, anno post Diluvium $350 \gg 2$. L'auteur de cet article indique que Fou-hi a posé les fondements du calendrier et du cycle sexagénaire, mais c'est seulement à partir du règne de Yao que les temps sont comptés d'après ce

\footnotetext{
1 Ce recueil de Thévenot n'est pas paginé d'un bout à l'autre du volume, chaque article a une pagination spéciale.
}

2 Aperçu chronologique de la monarchie chinoise, p. 1. 


\section{La Chine et la formation de l'esprit philosophique en France}

cycle, et la première année marquée de cette manière se trouve être la $41^{\mathrm{e}} \mathrm{d}^{\prime} u n$ cycle.

En 1686, parut la Table chronologique de la monarchie chinoise, du P. Couplet. Le P. Couplet n'était pas alors un inconnu pour les Français. Il avait paru à la cour, en 1684, alors qu'il se rendait à Rome, escorté d'un jeune Chinois qu'il ramenait en Europe. Il avait été présenté au Roi ${ }^{1}$. Le parti des Jésuites, le duc du Maine en tête, avait profité de sa présence à Paris pour lui faire vanter la Chine et les merveilleux progrès qu'on pouvait faire pour la religion au moyen des mathématiques et de l'astronomie, afin de tâcher de décider le roi à envoyer des Jésuites mathématiciens en Chine. L'issue de cette négociation semblant douteuse, on avait remis provisoirement au P. Couplet un questionnaire sur la Chine où la chronologie n'était pas oubliée ${ }^{2}$. Entre le moment où le p.212 P. Couplet se trouvait à Paris et le moment où parut sa chronologie, les Jésuites étaient partis, nantis de brevets de mathématiciens du Roi, et I'on attendait d'eux des révélations sur l'astronomie et sur l'antiquité de la Chine.

\footnotetext{
1 Voir plus haut, p. 44.

2 Dans la liste des Questions à proposer au R. P. Couplet sur le Royaume de la Chine et qui lui fut remise à son passage à Paris en 1684, on trouve les questions suivantes sur la Chronologie :

- S'il a mis au net sa chronologie chinoise depuis J. C. qui sert de continuation au livre du P. Martinius.

- Quelle est I'autorité et la fidélité de leurs historiens et de leur histoire et si on continue à présent d'y travailler avec le même soin.

- Si les RR. PP. Jésuites n'ont pas fait quelques observations considérables des longitudes et des latitudes de la Chine.

- Des sciences des Chinois et de la perfection et des défauts de leur mathématique, astrologie, philosophie, etc.

Voir notre Thèse complémentaire, Documents inédits..., p. 7.
} 


\section{La Chine et la formation de l'esprit philosophique en France}

La chronologie du P. Couplet, qui fut publiée en 1686 mais qui fut reliée ensuite avec sa traduction de Confucius qui parut l'année suivante - livre qui fut soumis, comme nous l'avons vu, à un épluchage minutieux ${ }^{1}$ - est en somme un livre plein de prudence. Avec lui nous commençons à nous écarter du $P$. Martini qui non seulement était de bonne foi dans ses audaces, mais qui ne croyait même pas qu'il fût audacieux. Dès l'époque du P. Couplet, les Jésuites - ou du moins les éditeurs des écrits des Jésuites - ne veulent plus être audacieux qu'avec prudence : ils ont dès ce moment une doctrine sur la Chine.

Le P. Couplet dans la préface de sa chronologie distingue d'abord deux périodes dans I'histoire chinoise : I'histoire antérieure à Fou-hi, qui est regardée par les historiens chinois comme fabuleuse, et la période qui commence avec cet empereur et qui est considérée comme historique. Puisque la première partie est fabuleuse, de l'aveu même des historiens chinois, nous serions en droit d'attendre que le P. Couplet cesse de s'en occuper. Mais il n'en est rien. Il se plaît à rapporter quelques-unes des fables de cette époque préhistorique et notamment les idées que les Anciens Chinois avaient sur la création du monde : le monde fut créé entre la onzième et la douzième heure de la nuit ; la terre, entre la première et la deuxième heure de la nuit ; I'homme, entre trois et quatre heures du matin, la femme, entre trois et quatre heures de I'après-midi. Rêveries sans doute, mais qui ne sont pas sans importance, car elles prouvent à tout le moins que les Chinois

\footnotetext{
1 Voir plus haut, p. 153-8.
} 


\section{La Chine et la formation de l'esprit philosophique en France}

n'ont pas cru, comme tant d'anciens philosophes, que les libertins se plaisent à rappeler, que le monde est éternel ${ }^{1}$. En outre, au milieu de ces légendes on trouve quelques traces des vérités premières. Ne dit-on pas par exemple, que le premier homme des Chinois, Puon-Cu, est né d'une terre stérile, mais qu'il était pourvu dès l'origine d'une admirable connaissance des choses ? Sans doute, pense le P. Couplet, les premiers Chinois ont reçu des descendants de Noé quelques connaissances des vérités essentielles qui se sont affaiblies ensuite en se transmettant de génération en génération ${ }_{\text {p.213 }}$ ou qui ont été obnubilées par l'idolâtrie qui s'est établie postérieurement 2 .

Si dans la période historique on cherche chez les écrivains chinois des souvenirs du Déluge, on ne trouve guère de faits précis semblant indiquer nettement que les Chinois ont gardé la mémoire d'une inondation générale, à part le déluge de Yao, qui fut une inondation particulière à la Chine. Mais en consultant les anciens livres des Chinois, on trouve certaines traditions qui, bien interprétées, peuvent rappeler l'idée de ce Déluge. Les anciens Chinois pensent en effet que le monde à l'origine était une masse d'eau, animée d'un violent mouvement, grâce auquel les parties les plus dures et les plus solides venaient se rassembler et se concréter au centre. Par suite de ce mouvement et par suite du flux et du reflux, les montagnes sont sorties peu à peu de cette masse aqueuse. Et la preuve que la terre a

\footnotetext{
1 Præfatio ad Tabulam chronologicam Sinicæ monarchiæ, p. IV.

2 ibid., p. IV.
} 


\section{La Chine \\ et la formation de l'esprit philosophique en France}

émergé peu à peu de l'eau c'est qu'on trouve encore des coquillages sur le sommet des montagnes ${ }^{1}$.

Donc, à regarder de près, en se servant surtout des lumières bibliques, on trouve dans I'histoire chinoise des souvenirs de la création du monde, du premier homme et du Déluge. Mais les Chinois qui sont privés de ces lumières particulières, confondent la période préhistorique, qu'ils ne savent interpréter, et la période historique. Ils racontent notamment qu'avant Fou-hi, il y a eu plusieurs rois, hommes habiles à calculer les temps et à observer le mouvement des astres, qui furent les inventeurs du calendrier et du cycle sexagénaire, alors qu'à cette époque les hommes étaient sauvages et vivaient dans les bois comme les bêtes fauves. Mais ces conducteurs de peuples les réunirent et les assujettirent aux lois.

Or les historiens qui font tous commencer I'histoire certaine et indubitable de la Chine à Fou-hi, rapportent les événements des règnes de Fou-hi et de Xin nun [Cheu nong], les deux premiers empereurs, de la même manière et à peu près dans les mêmes termes que les événements de l'époque préhistorique. Les Chinois ont donc attribué par erreur à des personnages de leur histoire authentique des souvenirs de l'époque antérieure. Cependant, ils ont eu conscience qu'il y avait entre leurs traditions préhistoriques et leur histoire authentique une coupure très nette, et. pour cela ils n'ont pas marqué dans leur chronologie les années antérieures à Fou-hi ${ }^{2}$. Mais, d'après le P.

\footnotetext{
1 ibid., p. IV.

2 ibid., p. VI-VII.
} 


\section{La Chine et la formation de l'esprit philosophique en France}

Couplet, celle coupure doit se p.214 placer non pas avant Fou-hi, mais avant Houang ti, troisième empereur. Aussi dans sa table chronologique des empereurs chinois dont les règnes sont datés, le P. Couplet n'inscrit pas les deux empereurs Fou-hi et Cheu nong, mais il les met à part sans indiquer le commencement ou la durée de leur règne, même d'après la supputation des annales chinoises, comme le faisaient les PP. Martini et Riccioli, et il se contente d'indiquer les principaux événements de leurs règnes ${ }^{1}$, qui peuvent être à ce qu'il dit dans sa préface, des souvenirs des anciennes traditions chinoises. Suivant lui, la période historique ne commence donc qu'avec Houang ti en 2697 avant JésusChrist.

La chronologie du P. Couplet ne s'accorde donc pas plus que celle des PP. Martini et Riccioli avec la Vulgate. La date qu'il fixe pour le début de l'époque historique est encore antérieure de 300 ans environ au Déluge, suivant cette version. Ceux qui adopteront sa chronologie et voudront concilier l'histoire biblique avec I'histoire profane seront obligés d'adopter la version des Septante. Il semble donc que les conclusions du P. Couplet s'accordent d'une part avec celles de Vossius et d'autre part avec celles des PP. Martini et Riccioli. Et cependant la position du P. Couplet est sensiblement différente de celle de Vossius et de celle des deux Jésuites. Nous avons vu en effet le soin avec lequel le P. Couplet note dans I'ancienne histoire les souvenirs de la création du monde, pour ôter aux libertins dans le genre de La Peyrère, et peut-être aussi de Vossius, la tentation de se servir

\footnotetext{
1 ibid., p. X.
} 


\section{La Chine \\ et la formation de l'esprit philosophique en France}

de l'argument de l'antiquité chinoise pour insinuer l'idée de l'éternité du monde.

Au contraire, le P. Couplet pense que les anciennes traditions des Chinois sur la création apportent non seulement des faits contre l'hypothèse d'un monde éternel, mais encore des faits concordant avec ceux de la Genèse. Donc bien loin d'être dangereuse, I'histoire chinoise devient une sorte de confirmation de I'histoire biblique.

Et d'autre part, si les PP. Martini et Riccioli montraient dans I'histoire chinoise une longue suite d'événements historiques sans aucune interruption, le P. Couplet prend grand soin de marquer cette interruption pour conserver la possibilité du Déluge universel. Sans doute les Chinois ont grand'peine à interpréter les premiers temps de leur histoire, précisément parce qu'il leur manque celle idée du Déluge universel, mais tout s'éclaire si l'on se sert des lumières que fournit la Bible. La Bible est le livre nécessaire qui peut seul aider les Chinois à débrouiller les périodes obscures de ${ }_{\text {p.215 }}$ leur primitive histoire : la chronologie du P. Couplet devient une sorte de catéchisme à I'usage des futurs missionnaires.

Ainsi se trouve fixée, dès 1686, l'attitude des Jésuites à l'égard de la chronologie chinoise. Ils ne trouveront pas dangereux, au contraire, même en présence des libertins, d'accepter, mais avec quelques précautions, I'antiquité de la nation chinoise. Et d'autre part, ils feront mission en Chine, non pas en imposant les enseignements de la Bible comme des vérités révélées, mais en proposant aux Chinois lettrés I'histoire 


\section{La Chine et la formation de l'esprit philosophique en France}

que fournit la Bible comme une histoire générale seule capable d'élucider les obscurités des histoires particulières, notamment I'histoire de la Chine. Pour accorder les deux chronologies, la seule concession qui leur semblait nécessaire était d'accepter la version des Septante au lieu de la Vulgate pour le calcul des temps, concession qui leur semblait d'autant plus facile qu'ils étaient habitués et qu'ils étaient autorisés dans leur mission en Chine à admettre cette version qui leur permettrait de reconnaître l'existence des premiers empereurs chinois, ce qu'ils n'auraient pas pu faire avec la Vulgate.

Si aucun article de foi n'empêchait d'adopter la version des Septante, cette version comptait néanmoins de nombreux adversaires, notamment tous les Juifs qui avaient intérêt à faire remonter le moins haut possible les origines du monde, pour laisser à leur Messie attendu le plus de temps possible pour se manifester (la durée totale du monde étant, comme on le sait, fixée à six mille ans), et en général les protestants, qui étaient fort attachés à la Vulgate. Aussi nous trouvons peu de temps après que le $P$. Couplet eut publié sa chronologie, mais sans qu'il I'eût connue d'ailleurs, semble-t-il, un protestant, Allix, qui, dans ses Réflexions sur les cinq livres de Moïse, fait une étude critique très serrée des principes sur lesquels repose la chronologie chinoise, telle qu'il pouvait la connaître d'après le P. Martini.

Un homme de bonne foi d'ailleurs. Il ne dissimule rien des arguments qu'apporte le P. Martini pour démontrer la certitude de la chronologie chinoise. Elle marque exactement, dit-il, la suite et la succession des rois de la Chine depuis l'origine de 


\section{La Chine et la formation de l'esprit philosophique en France}

cette nation. Elle marque en quelle année du cycle chaque roi a commencé de régner et a fait, telle et telle chose. Elle note les observations faites sur les mouvements des astres plus anciennes que celles qui ont été faites par des plus anciens Astrologues qui nous soient connus »1. Enfin elle a été écrite par une autorité ${ }_{\text {p.216 }}$ publique et par des auteurs qui ont vécu dans les temps où les choses se sont passées.

Allix ne peut songer évidemment à vérifier les affirmations du P. Martini, car il ne dispose que du texte même de ce Père, mais il va en faire la critique au nom de la raison, en démontrant le caractère fabuleux de la plupart des traditions ou des faits qui sont rapportés. Critique en somme facile mais assez dangereuse, arme à deux tranchants dont on peut se servir aussi bien pour réfuter la Genèse - comme I'avait fait La Peyrère - que pour repousser I'ancienne histoire chinoise. Mais en même temps, comme le P. Couplet, Allix va montrer que les plus anciennes traditions des Chinois ne diffèrent pas essentiellement de ce que rapporte Moïse de l'origine des peuples.

Les intentions d'Allix ne relèvent ni de la philosophie ni de la théologie : il a seulement des prétentions historiques. Il veut prouver, en étudiant les diverses périodes de l'histoire chinoise, que ces histoires que le P. Martini donne comme authentiques, ne sont pas d'une certitude absolue. Et d'abord la période fabuleuse. Si l'on examine de près ce que rapportent les historiens chinois, on s'aperçoit que ces traditions, loin d'infirmer

\footnotetext{
1 Allix, Réflexions sur les cinq Livres de Moïse pour établir la vérité de la religion chrétienne, p. 116.
} 


\section{La Chine et la formation de l'esprit philosophique en France}

les récits de Moïse, ne font en somme que les confirmer. Les Chinois, en effet, depuis les premières époques soutiennent que le monde a eu un commencement. Ils reconnaissent un Dieu qu'ils appellent «Xang-ti » qui est non pas le nom propre mais l'épithète de la divinité ${ }^{1}$. Ils reconnaissent un premier homme sorti du chaos ; ils ont eu l'usage des sacrifices ; ils croient à l'existence de peines et de récompenses dans l'autre vie ; enfin, ils ont le souvenir du Déluge, « d'où il est aisé de juger en comparant ces vérités avec le récit de Moïse que les premiers Chinois convenoient avec les autres nations dans la créance des premiers principes de la Religion que Moïse a posés »2. Et ce ne sont pas seulement les principes qui s'accordent, mais aussi les faits : « La généalogie des treize successeurs du premier homme, nommé Puoncus, revient assez à I'Histoire de la Genèse qui marque la succession des Patriarches de père en fils ${ }^{3}$. La tradition d'après laquelle le second roi aurait soumis à des lois les peuples barbares s'accorde avec I'histoire de Seth qui commença à former les hommes au culte de Dieu, en se séparant de la famille de Caïn » ${ }^{4}$. Enfin ils s'imaginent que sous un de leurs p.217 rois Guihohang, il y a eu une espèce de siècle d'or, la terre produisant d'elle-même avec une fertilité admirable, alors que les hommes étaient dans une simplicité étrange et dans une extrême ignorance des arts nécessaires à la vie. Donc

\footnotetext{
1 Id., ibid., p. 117.

2 Id., ibid., p. 118.

${ }^{3}$ Id., ibid., p. 118.

${ }^{4}$ Id., ibid., p. 119.
} 


\section{La Chine et la formation de l'esprit philosophique en France}

rien qui ne s'accorde, dans cette période préhistorique, avec les enseignements de Moïse sur la «nouveauté du monde ».

Si I'on passe à l'époque historique qui commence à Fou-hi et qui compte environ 3.000 ans avant J. C. on peut remarquer d'abord qu'elle n'est incompatible qu'avec la chronologie de Moïse selon I'hébreu, et non avec les autres versions. Mais I'histoire de ces premiers empereurs est pleine de fables qui la rendent suspecte, comme par exemple I'histoire de Fou-hi, né d'une mère sans père, qui fut conçu au bord d'un lac où sa mère en se promenant « vit les traces d'un Homme dans le sable et fut environnée d'un Arc-en-ciel »1. Non moins fabuleuse I'invention qu'on attribue à Fou-hi d'un instrument de musique à 36 cordes, ou des caractères qu'il vit gravés sur le dos d'un dragon. Mais on fait naître ce Fou-hi à l'occident de la Chine, ce qui indique que les premiers habitants de la Chine sont venus de l'occident et qu'ils descendent de Sem, comme le marque Moïse au chapitre $X$ de la genèse. On attribue au successeur de Fou-hi l'invention de tous les arts, mais on déclare qu'il ne mourut point et qu'il fut enlevé vivant dans le lieu que les Chinois assignent au bonheur éternel. Habitude fort ancienne, suivant Pline, de déifier après coup les inventeurs des arts, mais qui rend ces histoires plus que suspectes. Et notre auteur passe ainsi au crible I'histoire des cinq premiers empereurs, marquant ce qu'il y a d'invraisemblable dans le récit de la vie de chacun d'eux, mais notant en même temps avec soin dans ces traditions ce qu'elles ont de conforme avec les récits mosaïques. Ayant ainsi réduit les

\footnotetext{
1 Id., ibid., p. 121.
} 


\section{La Chine et la formation de l'esprit philosophique en France}

premiers temps de I'histoire chinoise jusqu'à l'époque de Yao, qui vivait à peu près au moment où la Vulgate place le déluge, - ce qui établit la concordance entre la chronologie chinoise et la chronologie du texte hébreu - Allix cherche à montrer que les Chinois, ayant pu connaître, par le canal des Chaldéens ou des Juifs, établis en Tartarie après leur captivité en Assyrie, le récit que fait Moïse des origines du monde, ont mis au compte des prétendus empereurs Chinois des évènements qui ont marqué la vie des patriarches d'avant le déluge.

Allix se distingue donc nettement de Horn qui prétendait que Fou-hi était Adam, et que Yao était Noé ; il ne lente pas p.218 d'identification entre les premiers rois de la Chine et les Patriarches. Il montre seulement, qu'il y a conformité de traditions entre I'histoire chinoise et la Bible, conformité qui résulte de relations historiques de peuple à peuple. Sans doute, il ne prouve pas l'existence de ces relations, mais pour la première fois il invoque cet argument des Juifs qui auraient transporté en Asie les traditions mosaïques, fait qu'au XVIII siècle s'efforceront de ruiner ou tout au moins de limiter les philosophes qui, comme Voltaire, voudront montrer l'indépendance de l'histoire chinoise par rapport à I'histoire juive.

Les moyens de rendre inoffensive I'ancienne histoire chinoise ne manquaient donc pas, et chacun des chronologistes, dont nous avons examiné les théories, semble avoir eu un de ces moyens dans son sac. Il n'en reste pas moins que dès cette époque le danger apparaît : on ne peut plus guère traiter par le mépris l'ancienne histoire chinoise. Aussi un bénédictin de St- 


\section{La Chine et la formation de l'esprit philosophique en France}

Maur, le P. Pezron, propose résolument de substituer à la Vulgate pour les calculs des premiers temps de l'histoire, la version des Septante : « La connoissance [de cette chronologie] en est si nécessaire, même pour le soutien de la Religion, que si l'on ne donne aux tems leur juste étendue, il est difficile de répondre solidement aux arguments que font les Préadamites, les Libertins et ceux qu'on appelle esprits forts, contre les livres de Moïse et contre ce qu'il dit de l'établissement du Monde. Ils prétendent montrer que les premiers Empires, surtout ceux des Chaldéens, des Égyptiens et des Chinois devancent le temps de Noé de beaucoup de siècles; et qu'ainsi tout ce que ce Saint Législateur a dit du Déluge universel, de la confusion des Langues et de la dispersion des peuples, n'est pas soutenable $\gg 1$.

Comme c'est au nom de l'antiquité des anciens peuples, Chaldéens, Égyptiens et Chinois que les esprits forts attaquent I'autorité de Moïse, c'est précisément l'antiquité de ces peuples qui va devenir le meilleur argument pour le P. Pezron en faveur de la version des Septante. En ce qui concerne la Chine, le seul argument qui nous importe ici, il accepte purement et simplement la chronologie que lui fournit le P. Martini (il ne connaît pas le P. Couplet), et il ne manque pas de mettre en relief les arguments qui prouvent la certitude de cette chronologie : c'est une histoire continue qui marque les rois et les dynasties depuis plus de quatre mille ans, et cette histoire remonte à l'an 2952 av. J.-C., date à laquelle Fou-hi a été placé

\footnotetext{
${ }^{1}$ Pezron, L'Antiquité des tems rétablie.
} 


\section{La Chine et la formation de l'esprit philosophique en France}

sur le trône et dont les Chinois ne disputent pas. Pour le reste, le P. Pezron s'efforce de montrer la vraisemblance de cette p.219 antiquité et la conformité de cette histoire avec les Écritures. Comme il y avait sur la terre, 400 ans après le déluge, des millions d'hommes et que la Chine est le plus beau pays du monde, est-il vraisemblable qu'elle n'ait pas été peuplée à cette époque, alors que les autres parties de I'Asie, I'Égypte et même I'Afrique avaient des colonies quelque temps après la mort de Noé ? Et pour convaincre les adversaires de l'antiquité de la Chine, le P. Pezron emploie un argument tout à fait nouveau, la nécessité de se débarrasser du préjugé grec et romain : «Cette longue suite de familles et de Roys paraîtra presque incroiable à ceux qui ne jugeront que par leur propre sens ou par rapport à I'histoire des Grecs et des Romains. Mais ce n'est point par là qu'il en faut juger, et on ne doit nullement s'étonner si l'on ne voit rien de semblable parmy les nations de l'Europe qu'on peut appeler récentes au prix de celles de l'Asie. L'Orient a commencé d'être habité trois ou quatre siècles après le Déluge, et il y avoit déjà des royaumes dans cette partie de la terre, peut-être avant qu'il y eût des peuples dans la Grèce et dans l'Italie. L'Asie a été le berceau des hommes et ils n'ont pas manqué de s'y répandre incontinent qu'ils ont commencé à se multiplier $\gg 1$.

Les théories du P. Pezron trouvèrent d'énergiques contradicteurs notamment le P. Martianay qui pour enlever à son antagoniste ses arguments essentiels en faveur de la version des Septante, s'efforça de ruiner l'idée de l'antiquité des peuples

\footnotetext{
${ }^{1}$ Id., ibid.
} 


\section{La Chine et la formation de l'esprit philosophique en France}

autres que les Juifs. Mais s'il déclara « fabuleuse » I'antiquité des Égyptiens, il fit grâce du moins à la chronologie chinoise. Il essaya cependant de l'interpréter et pour cela il ne fit pas de grands efforts d'imagination : il se contenta de reprendre la théorie de G. Horn : Fou-hi c'est Adam. Mais là-dessus le P. Pezron n'eut pas de peine à triompher. Si Fou-hi est Adam, comme la Chine était déjà à cette époque un pays habité, puisque Fou-hi a donné des lois à ces peuples barbares, il doit y avoir eu des hommes avant Adam et I'on retombe dans I'erreur des Préadamites. Et si Noé est Yao, cet empereur chinois sous lequel se produisit une forte inondation, que I'on veut considérer comme le Déluge, on ruine en réalité I'idée du Déluge universel, car cette inondation ne fut que partielle et les Chinois, sous le commandement de $Y u$, travaillèrent à faire entrer ces eaux dans la mer. En outre, malgré ce prétendu Déluge, Yao eut un empire florissant, et pour alléger le fardeau du gouvernement il s'adjoignit « un collègue nommé Xun » [Chouen] qui régna avec lui pendant vingt-huit ans. Voit-on dans cela quelque chose qui ressemble à I'histoire de Noé ? p.220 Est-ce par de semblables rapprochements qu'on peut défendre le Texte hébreu ? Et le $\mathrm{P}$. Pezron conclut en un grand mouvement d'indignation oratoire : « Et moi je dis que si le texte hébreu ne peut sauver son autorité que sur ces rapports feints et imaginaires, il est en danger de la perdre sans ressource. Ce n'est nullement par des voyes de cette nature qu'on doit soutenir la majesté de nos Écritures. Elles s'accordent aisément avec ce qu'il y a de véritable dans les histoires profanes, et il ne faut point les forcer pour cela. Qu'on suive celles que les Apôtres nous ont laissées et qui ont été 


\section{La Chine et la formation de l'esprit philosophique en France}

suivies par les Pères et les Églises, et l'on verra un parfait accord entre les Livres Saints et ceux des Nations, en ce qui n'est point visiblement fabuleux »1. Et le P. Pezron reprend encore la démonstration de la certitude de la chronologie chinoise, en s'appuyant cette fois, non plus seulement sur le P. Martini mais aussi sur la Nouvelle Relation de la Chine du P. Magaillans qui venait de paraître.

Le P. Pezron montrait ainsi avec vigueur et d'une manière plausible la difficulté d'accorder la chronologie biblique avec la chronologie chinoise et en outre, il marquait la niaiserie des gens qui, à la mode de Horn, essayaient de retrouver dans I'histoire chinoise les personnages de la Bible, sur de fantaisistes ressemblances. Mais en même temps, il apportait une sécurité, la version des Septante, qu'aucun article de foi n'empêchait d'accepter. C'était « un mol oreiller » dont pouvaient se contenter tous ceux qui étaient incapables d'examiner par euxmêmes la certitude de la chronologie chinoise. Aussi l'abbé Fleury, qui rédigea, à la demande du Séminaire des Missions étrangères, des instructions à l'usage des futurs missionnaires, leur recommandait de suivre pour la chronologie la version des Septante : «Que si dans notre chronologie vous vous trouvez embarrassé à cause des histoires de la Chine dont vos Indiens ont sans doute une grande opinion, vous pouvez suivre la chronologie des Septante, qui vous donnera sept ou huit cents

1 Pezron, Défense de l'Antiquité des Temps. 


\section{La Chine et la formation de l'esprit philosophique en France}

ans de plus et vous mettra fort au large. Elle a été depuis peu fort bien expliquée par le P. Pezron, de l'ordre de Citeaux »1.

D'après cette analyse des réactions produites par la découverte de l'ancienne histoire chinoise, il semble qu'il n'y ait pas eu jusqu'aux dernières années du XVII ${ }^{e}$ de négation absolue ni même de critique bien vive de la chronologie chinoise. Sans doute on manque des p.221 éléments nécessaires pour faire la critique de cette chronologie et il faut bien accepter les données fournies par le P. Martini. Mais on ne cherche même pas à faire cette critique, on n'en sent pas le besoin ; on croit disposer de trop de moyens faciles pour faire cadrer I'histoire chinoise avec I'histoire biblique, de trop de systèmes chronologiques pour qu'il n'y ait pas un qui puisse s'accorder avec l'antiquité de la Chine. Vers la fin du siècle, on commence à s'attaquer au contraire, à la chronologie chinoise elle-même.

Ce n'est pas dans les Relations sur la Chine qui paraissent à la fin du siècle que nous trouvons cette critique, car elles sont trop admiratives pour cela, notamment celle du P. Magaillans ; mais c'est à la suite de la relation de La Loubère sur Le Royaume de Siam.

Dans un court chapitre qu'il consacre aux Chinois « Du soin des mœurs chez les Chinois et de l'ancienneté de leur histoire », il indique en quelques mots, contre la certitude de l'ancienne histoire chinoise, l'argument essentiel contre lequel se heurtera le P. Gaubil malgré toute sa science, et que Voltaire tournera,

\footnotetext{
1 Abbé Fleury, Mémoires pour les études des missions orientales. Lettres édifiantes et curieuses (Ed. du Panthéon Littéraire), t. I, p. 11.
} 


\section{La Chine et la formation de l'esprit philosophique en France}

pour esquiver la difficulté dans l'impossibilité de la résoudre : « Une raison particulière jette un grand doute sur I'Histoire chinoise depuis le commencement de leur monarchie jusqu'à environ 200 ans avant Jésus-Christ, parce que Xin, le premier Roy de la race Cina, qui regnoit environ 200 avant Jésus-Christ, fit bruler autant qu'il lui fut possible tous les Livres de la Chine qui ne traitoient pas de Médecine ou de Divination. Leur histoire marque qu'il exerça de grandes cruautés contre ceux qui cachoient des Livres, et qu'ainsi il en échappa peu à sa fureur et qu'il n'en échappa presque point d'entiers : événement fort singulier parmi ceux qui détruisirent de temps en temps la mémoire des choses passées. Cela suffit donc à mon avis pour douter si l'on veut que ce grand Empire se soit formé sans aucune guerre $\gg 1$. Conclusion inattendue à vrai dire, mais qui s'explique cependant par I'opinion des Chinois sur la formation de leur empire et qui a semblé si invraisemblable à La Loubère qu'il cherche des raisons d'en douter. La Chine, lui ont dit les Chinois, s'est formée par l'agglomération d'un grand nombre de provinces qui n'ont pas été réunies par la force des armes mais par le prestige qu'exerçait la civilisation chinoise. Ce prestige ne s'est exercé que lentement et suppose donc une longue continuité de siècles. C'est donc malgré tout à cette idée de la continuité de I'histoire chinoise que s'attaque La Loubère. Seulement les arbres lui ont un peu caché la forêt.

Non content de cela, La Loubère met aussi en doute les connaissances astronomiques des Chinois, et ici il s'appuie sur

\footnotetext{
${ }^{1}$ La Loubère, Du royaume de Siam, t. II, p. 376-7.
} 


\section{La Chine et la formation de l'esprit philosophique en France}

les Observations de Cassini, insérées à la fin de son Royaume de Siam : «Réflexions sur la chronologie chinoise ». Cassini, comparant les tables chinoises des constellations avec celles de Tycho s'aperçut qu'elles concordaient presque entièrement à peu près dans la même minute, ce qui donne lieu de juger que ces Tables ont été calculées par les Pères Jésuites qui depuis un siècle sont allés à la Chine. Car, quelle apparence y a-t-il que sans être tirées des tables de Tycho, elles y fussent si conformes ? »1. Et voilà mise en doute la grande réputation des Chinois pour l'astronomie. En outre, examinant la conjonction des cinq planètes dans la constellation $\mathrm{Xe}[\mathrm{Che}]$, qui aurait été observée sous le cinquième empereur entre 2513 et 2435 , dates extrêmes de son règne, Cassini s'aperçoit que cette conjonction n'a pas pu se produire à l'époque indiquée, mais qu'elle doit être placée en 2012, ce qui réduit la chronologie chinoise de 500 ans environ. Cassini n'en tire pas de conclusions, mais son observation ne tardera pas à être reprise par ceux qui auront intérêt à cette réduction de plusieurs siècles dans la chronologie chinoise.

Voltaire n'avait pas un grand respect pour Vallemont et pour sa chronologie, Les éléments de l'Histoire 2. Avec raison, d'ailleurs. C'est cependant un esprit fertile en ressources et il n'est jamais à court d'arguments, bons ou mauvais, surtout mauvais peut-être, pour prouver à toute force ce qu'il veut prouver. Il commence par déclarer qu'il ne se serait pas occupé

\footnotetext{
1 ibid., t. II, p. 390-1.

2 Voltaire, Lettre à l'abbé Moussinot, 27 décembre 1738, t. XXXV, p. 83.
} 


\section{La Chine et la formation de l'esprit philosophique en France}

de la Chine s'il n'avait remarqué que depuis quelque temps on était devenu extrêmement curieux de tout ce qui touchait à ce grand empire. Curiosité très légitime si l'antiquité de la Chine était une chose bien prouvée. Mais, ajoute-t-il, nous ne connaissons la Chine que par les Jésuites et nous ne pouvons les contrôler. Tout ce qu'ils nous racontent, nous le lisons « comme on lirait un roman $\gg 1$. Or la chronologie chinoise n'est pas certaine « car nous apprenons même de leurs histoires qu'il est arrivé des désastres dans la Chine qui y ont fait périr un grand nombre d'anciens monuments. Il est parlé d'un certain Yven-ti, troisième empereur de la $10^{\mathrm{e}}$ famille qui, vers l'an 552 de Jésus-

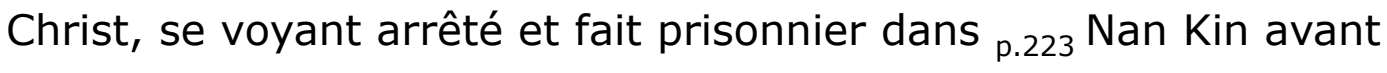
que de se rendre rompit son épée et brûla sa Bibliothèque, où il y avait plus de cent quarante mille volumes, dans la pensée que son épée et ses livres lui alloient devenir inutiles $\gg 2$. Si notre auteur avait lu moins vite le P. Martini, il y aurait trouvé l'indication d'un autre incendie de livres infiniment plus ancien, qui lui eût été beaucoup plus utile pour étayer son affirmation. Quoi qu'il en soit, suivant Vallemont, cette chronologie n'est pas assurée, mais si I'on tient malgré tout à la considérer comme authentique, cela ne présente aucune difficulté : il n'y a qu'à supposer que Fou-hi, c'est Noé ! «Ce n'est pas une chose extraordinaire que plusieurs Peuples aient regardé Noé comme leur fondateur. N'est-il pas le Saturne dont parle le Poète et dont les trois fils, Jupiter, Neptune et Pluton sont Sem, Cham et

\footnotetext{
${ }^{1}$ Vallemont, Les éléments de I'histoire, t. II, p. 264.

${ }^{2}$ Id., ibid., t. II, p. 263.
} 


\section{La Chine et la formation de l'esprit philosophique en France}

Japhet, les trois fils de Noé ? »1. Mais allons plus loin, s'il n'y a pas de conciliation possible entre la chronologie chinoise et la chronologie de la Bible, il faut préférer la Bible, qui est révélée, aux historiens profanes. Et Vallemont montre qu'il serait dangereux de renoncer à la Vulgate pour la version des Septante : «On ne sauroit trop admirer la pensée de certains Auteurs, qui ne pouvant pas concilier la Chronologie de la Vulgate avec I'Histoire des Chinois, prétendent qu'il faut abandonner la Vulgate et suivre la chronologie qui se trouve aujourd'hui dans la Version des Septante. Quiconque y pensera bien trouvera beaucoup de raison pourquoi I'histoire de la Chine qu'on a publiée dans ces derniers tems ne doit porter à faire une démarche de cette conséquence. Que diroient de nous les impies et les Libertins si, sur des mémoires venus de la Chine nous allions corriger nos sentiments et abandonner une Bible consacrée dans l'Église par son ancienneté et par les Décrets du Concile de Trente »2. L'argument avait déjà été esquissé, comme nous l'avons vu, par Horn dans sa réponse à Vossius.

Plus courte mais plus solide est la critique du P. Hardouin. En quelques phrases, il indique les arguments essentiels qui peuvent faire suspecter la chronologie chinoise. Les historiens chinois, dit-il, ont rapporté les événements de leur histoire, mais la Chine étant un pays isolé du reste du monde, ils ont pu écrire tout ce qu'ils ont voulu, sans être contrôlés par les historiens d'autres nations. En outre, 200 ans avant Jésus-Christ, tous les

\footnotetext{
${ }^{1}$ Id., ibid., t. II, p. 257-8.

2 Vallemont, Les éléments de l'histoire, t. II, p. 259-60.
} 


\section{La Chine et la formation de l'esprit philosophique en France}

livres historiques ont été brûlés. Les Chinois notent dans leurs histoires des p.224 observations d'éclipses et de faits astronomiques, mais Cassini, qui a vérifié la conjonction des Planètes qu'ils rapportent à I'an 2490, a constaté qu'elle a dû se produire en I'an 2012. Enfin, une autre observation astronomique qu'ils prétendent avoir été faite sous Yao en 2347, n'a pu être faite que 495 ans plus tard, en 1852. On voit donc par ces deux faits que la chronologie chinoise doit être réduite de 500 ans environ ${ }^{1}$.

La tendance à douter de la certitude des temps préhistoriques de la Chine s'affirme donc de plus en plus : on n'accepte plus, avant de les avoir vérifiés, du moins autant qu'on peut le faire, les faits rapportés par les Jésuites. Ni leur état ni leur réputation de savants ne semblent désormais des garanties suffisantes. L'hostilité grandissante contre les Jésuites, à mesure que se développera la Querelle des Cérémonies chinoises, va augmenter cette propension au doute, au point que l'idée de la certitude de I'antiquité de la Chine risquera de sombrer avec le prestige des Jésuites.

Parmi ceux qui n'étaient pas disposés à croire les Jésuites sur parole se trouvaient les Missionnaires de la Société des Missions étrangères, leurs adversaires en Chine et à Rome. Comme quelques-uns d'entre eux avaient fait un long séjour en Chine et pouvaient connaître I'histoire chinoise d'après les sources mêmes, il est intéressant de savoir ce qu'ils pensaient de l'antiquité de cette histoire.

\footnotetext{
${ }^{1}$ Hardouin, Chronologia Veteris Testamenti, p. 21-22.
} 


\section{La Chine et la formation de l'esprit philosophique en France}

Nous avons la bonne fortune de posséder la copie d'une lettre de Maigrot, évêque de Conon qui revint en Europe pour mener la lutte à Rome contre les Jésuites, lettre adressée à l'abbé de Lyonne, qui eut lui aussi des démêlés avec les Jésuites au Siam en 1685 et 1686, et qui ne croyait pas à l'ancienneté de la nation chinoise.

Cette lettre ${ }^{1}$ expose avec bonne foi les raisons que I'on a de douter de l'ancienne histoire chinoise, et les raisons que I'on peut avoir d'y croire. Sans doute, Maigrot ne perd pas de vue qu'il y a certains faits que la foi ne permet pas d'accepter même s'ils semblent justifiés rationnellement. Mais la foi ne lui est pas un argument suffisant pour les nier : il cherche à les interpréter historiquement.

Il commence par exposer ses doutes au sujet de la haute antiquité des Chinois. D'abord cette histoire tant vantée ne présente pas le caractère de certitude qu'on lui attribue généralement : «Le premier historien que nous ayons qui ayt fait un corps d'histoire et ayt donné les noms des anciens empereurs des Chinois depuis p.225 Hoang ty vivoit encore 100 ans devant l'ère vulgaire », et nous n'avons pas les mémoires dont il s'est servi. De plus, il n'a pas marqué la durée des règnes. Quant au cycle chinois de soixante ans que I'on attribue généralement à Hoang ty, on n'en trouve nulle trace dans la vie de cet empereur écrite par cet historien. Les Chinois avouent qu'on ne peut compter comme certain le nombre d'années que I'on donne aux anciens empereurs des deux premières races et

1 B. N. Fr. 14687. 


\section{La Chine et la formation de l'esprit philosophique en France}

aux premiers de la troisième « la seule perte des livres dans l'embrasement général a été plus que suffisante pour que la connaissance de I'histoire ne vint pas jusqu'à nous ». Les livres canoniques parlent de quelques anciens Rois, mais ils n'en donnent pas la chronologie. Le Xu-king [Chou king], qui est I'ancienne histoire de la Chine, ne dit rien des empereurs audessus de Yao et de Xun [Chouen] auxquels cette ancienne histoire commence ; il n'indique pas tous les empereurs qui les ont suivis et il ne marque pas non plus par conséquent les années de leurs règnes. Cependant on trouve dans Montius [Mong tseu], disciple de Confucius, une chronologie abrégée qui remonte jusqu'à Yao, et d'après cette chronologie la Chine aurait été habitée plus de 2000 ans avant l'ère vulgaire, puisqu'elle I'était du temps de Yao et de Xun. Les Chinois ont une tradition fort claire d'un déluge, « mais si c'est le déluge universel, c'est une autre difficulté qui marque sûrement la fausseté de leur histoire, car il faudroit que les Roys ou Empereurs qui ont précédé Yao, sous lequel arriva le déluge chinois, fussent devant le déluge et ce déluge mesme n'empeschoit pas que la Chine ne fust habitée, ce qui est bien contre la foy ». Comme ce fait est d'importance, Maigrot cite le texte même de I'historien chinois qui rapporte cet événement, et confrontant les conditions historiques qui ont accompagné le déluge chinois et celles qui donnent au Déluge de Noé ses caractères particuliers, il en tire cette conclusion que ce sont deux événements tout à fait différents et qui ne peuvent être confondus. Il est donc vraisemblable que les Chinois ayant connu d'ailleurs cette 


\section{La Chine et la formation de l'esprit philosophique en France}

tradition relative au Déluge I'ont appliquée après coup à leur ancienne histoire. C'était déjà I'idée d'Allix.

Malgré tous ces doutes, Maigrot croit que la Chine est une nation très ancienne et il en apporte des preuves en somme convaincantes : Confucius, dit-il, vivait certainement 600 ans avant Jésus-Christ, sous la troisième race des Empereurs qui régnait depuis longtemps déjà, et la Chine était alors et même depuis longtemps, «toute formée ». A moins de nier ce qu'il y a de plus clair dans la tradition et dans l'histoire des peuples (chose à éviter de peur d'encourager les Libertins qui nient ce qu'il y a de plus certain ${ }_{\text {p.226 }}$ dans la tradition et dans I'histoire biblique) il faut avouer qu'avant la troisième race sous laquelle vivait Confucius, il y en a eu deux successivement, car les détails qui marquent la fin de chaque race et l'avènement de la suivante sont si nettement indiqués qu'on ne saurait douter de la réalité de ces faits qui en plus sont assurés par une « tradition constante parmi ce peuple ». Enfin il paraît certain aussi qu'il y a eu avant les deux premières races deux Empereurs, Yao et Xun « dont la mémoire est aussy constante parmy les Chinois que l'est parmy nous celle d'Auguste et de Tibère ». Et il conclut : « Je ne prétends pas que I'on doive donner à ces Empereurs un aussi long règne que font les Chinois, mais deux races successives d'Empereurs avec quelques Empereurs qui les ont précédés, jointes à la $3^{e}$ race dont le commencement ne se peut guère mettre au-dessous de 500 ans avant Confucius, tout cela joint au tems que la nation était encore toute barbare, ce dont conviennent généralement tous les Chinois, et les plus anciens livres marquants le commencement de la police et des arts, tout 


\section{La Chine et la formation de l'esprit philosophique en France}

cela joint ensemble est une démonstration morale que la Chine a été habitée peu de siècles après le déluge ».

Lettre de bonne foi, nous l'avons dit, parce que les rancunes de Maigrot contre les Jésuites ne l'incitent pas à nier l'antiquité de la Chine sur laquelle ils avaient édifié toutes leurs théories sur I'ancienneté des cultes chinois qui provoquèrent la Querelle des Cérémonies chinoises, mais lettre habile aussi parce que, sans accepter la rigueur des calculs des Jésuites qui liaient les événements de chaque règne avec une année d'un cycle (surtout le P. Martini, le P. Couplet un peu moins déjà), Maigrot fonde sa démonstration sur des preuves morales, l'antiquité des arts et des sciences, et surtout la tradition constante d'un ancien peuple, ce qui est en somme la plus grande preuve de l'authenticité des faits rapportés par le Pentateuque, qui lui non plus n'est pas contemporain des événements qu'il rapporte, mais dont la certitude historique cependant repose sur une tradition constante entre les événements et la rédaction des livres qui les relatent. Sans pouvoir dire exactement quel fut l'effet de cette lettre sur les partisans de Maigrot, il nous est permis de penser qu'elle ne modifia guère leur opinion sur l'antiquité de la Chine puisque c'est précisément aux «preuves morales » de cette antiquité que Renaudot, le redoutable adversaire des Jésuites dans la Querelle des Cérémonies chinoises, va s'attaquer en publiant quelques années plus lard ses Anciennes Relations de deux voyageurs Mahométans.

Si les Jésuites missionnaires en Chine avaient obtenu de Rome le droit de se servir de la Version des Septante pour leurs 


\section{La Chine et la formation de l'esprit philosophique en France}

p.227 catéchumènes chinois - car aucun Chinois n'eût accepté une religion dont les livres sacrés tendaient, par leur chronologie trop courte des origines du monde, à nier l'existence des premiers empereurs chinois, crime puni de mort en Chine - les Jésuites de France étaient des partisans déterminés de la Vulgate. Est-ce le désir de favoriser les missions des Jésuites en Chine en lui donnant des coudées plus franches sur la chronologie, est-ce une autre cause inconnue qui poussa les Jésuites de Paris à se relâcher de leur intransigeance à cet égard, nous ne saurions en décider ; toujours est-il qu'en 1703, un Jésuite des plus savants et des plus influents, le $P$. Tournemine, tenta, du moins en partie, une conciliation entre la Vulgate et la Version des Septante. En effet, dans un article des Mémoires de Trévoux de mars 1703, il augmente de 650 ans la durée des patriarches qui ont suivi le Déluge. Constatant, en effet, qu'il était d'usage à son époque de supprimer le premier chiffre d'un nombre lorsqu'on avait eu I'occasion de citer antérieurement un nombre de même grandeur (si bien qu'on disait 670 au lieu de 1670 si l'on avait dit antérieurement 1650) il suppose que dans la durée de la vie des patriarches le chiffre des centaines a été omis. Argument qui paraîtrait singulier s'il n'était étayé d'autre part. Mais le P. Tournemine remarque que de cette manière le texte des Septante s'accorde avec le texte samaritain, si bien que pour cette période la Vulgate a deux autorités contre elle. Comme par ailleurs il a déjà accepté la durée que donne le texte des Septante pour la période du Déluge, il se trouve très au large pour placer dans la chronologie 


\section{La Chine et la formation de l'esprit philosophique en France}

des Écritures les premiers temps de l'histoire chinoise, ce qui est peut-être la raison de son infidélité à la Vulgate.

Cette théorie parut séduisante, et le P. Tournemine fit des adeptes. Nous voyons en effet, quelques années plus tard, en 1706, un protestant, Duhamel, dans ses Prolégomènes de I'Écriture Sainte comparer entre elles les diverses versions et s'efforcer de les combiner. Sans doute, il préfère le texte des Septante, non pas que ce texte soit inspiré, comme le croyait Vossius, mais parce qu'il lui paraît avoir une exactitude plus grande. Mais dans un Appendice à ses Prolégomènes il examine pour les différentes périodes les versions diverses et il adopte dans chaque cas le texte de l'une ou de l'autre selon le rapport de convenance qu'il lui semble présenter avec la période qu'il examine. Il se réfère au $P$. Tournemine et il accepte comme lui la durée qu'indique la version des Septante pour la première période du monde qui va d'Adam au Déluge. Ainsi de tous côtés,

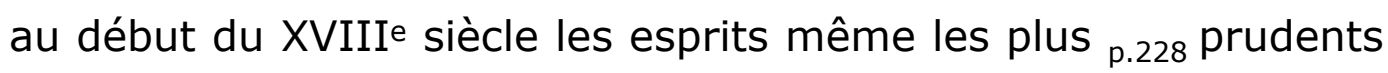
semblent enclins à augmenter quelque peu la durée du monde.

Mais en même temps la résistance s'organise. Les conservateurs à tous crins adoptent une attitude intransigeante et refusent de faire aucune concession aux novateurs, tel Dom Calmet qui va rompre de nombreuses lances en faveur de I'histoire biblique contre les histoires profanes. Dans sa Dissertation sur l'excellence de l'Histoire des Hébreux qu'il met en tête de son Histoire de l'ancien et du nouveau Testament, il accumule toutes les raisons qu'il peut trouver en faveur de la supériorité de I'histoire des Juifs sur les histoires profanes. Après 


\section{La Chine et la formation de l'esprit philosophique en France}

avoir examiné l'ancienne histoire des Chaldéens et des Égyptiens, il en arrive à la Chine. Il commence par déclarer que le premier roi Fou-hi vivait 2352 ans av. J.-C. (Où a-t-il pris cette date, le P. Martini indiquant la date de 2952, et le P. Couplet n'en donnant aucune ?) Mais comme dans cette histoire ancienne il n'y a qu'incertitude et obscurité, au jugement même des Chinois, leur monarchie ne commence en réalité qu'à l'année du monde 2048 et 31 ans avant la vocation d'Abraham. Il reste donc 300 ans entre le Déluge et les premiers Empereurs chinois. L'histoire de la Chine peut donc s'expliquer par le récit de Moïse si I'on admet les idées du P. Pétau sur la fécondité des premiers hommes. Mais pour répondre aux critiques qu'on pourrait lui faire en lui objectant la certitude des annales chinoises qui sont rédigées au moment même où se passaient les événements, et qui ne sont jamais corrigées par les écrivains postérieurs, Dom Calmet indique les règles de critique que les Européens devraient observer avant de proclamer la certitude des annales chinoises: « il vaudroit peut-être mieux traduire en une langue connue dans l'Europe les Annales des Chinois, faire la critique de leur histoire et de leurs historiens, nous apprendre leur âge, les circonstances de leur vie, leur caractère, le lieu d'où I'on a tiré les exemplaires de leurs écrits, comment ils sont parvenus jusqu'à nous parmi tant de révolutions, marquer les précautions que I'on a prises pour les conserver. Il seroit agréable de sçavoir ces particularitez et elles serviroient beaucoup à affermir la créance que I'on auroit en ces histoires ». Ce programme de travail était précisément celui qu'allaient suivre les savants 


\section{La Chine et la formation de l'esprit philosophique en France}

Jésuites qui étaient en Chine, les PP. Gaubil, Parrenin, Régis et de Mailla.

En fait d'antiquité, comme en fait de certitude, Dom Calmet croit à la supériorité de I'histoire des Juifs sur I'histoire des Chinois. Mais il croit, en outre, que la connaissance de la Chine ne peut nous être d'aucune utilité. La Chine est, en effet, un monde à part sans communication avec l'Europe ; elle a ses idées à elle, sa religion à elle : «Or, qui s'est jamais avisé de vouloir étudier à fond I'histoire d'un peuple très éloigné de nous par sa situation, par ses mœurs, par ses intérêts, par sa religion ? » Les « philosophes » précisément s'en aviseront, et Voltaire dans les deux premiers chapitres de son Essai sur les Mœurs montrera la nécessité d'une semblable étude ${ }^{1}$.

Les plus rudes coups qui furent portés contre I'antiquité de la Chine, contre l'ancienneté de ses arts et de ses sciences, le furent par un ennemi des Jésuites, Eusèbe Renaudot. Nous connaissons, par ailleurs 2, son activité contre les Jésuites au moment de la Querelle des Cérémonies chinoises, et nous avons pu constater que pendant son séjour à Rome, il avait composé

\footnotetext{
1 Dom Calmet fut toute sa vie un adversaire déterminé de la chronologie et de l'antiquité chinoises. Lorsqu'il publia, quelques années plus tard (1735), son Histoire Universelle, le chapitre qu'il consacre à la Chine ne se trouve qu'au Livre III, qui traite de l'ancienne histoire de la Grèce et après le chapitre consacré au « roiaume de Sicyone ». Ses arguments contre I'authenticité des annales chinoises méritent à peine d'être cités : «...ceux qui ont examiné les choses avec le plus de soin et de scrupule sont obligez d'avouer que tout ce qu'on dit de l'origine et de l'antiquité de ce fameux Empire et de la longue suite des Rois de la Chine qu'on nous produit au nombre de deux cens neuf, sortis de vingt deux familles qui ont succédé les unes aux autres, est très peu certain et n'est fondé, à l'exception des derniers tems, sur aucun monument digne de foy » (t. I, p. 232).

2 Voir ci-dessus, p. 111.
} 


\section{La Chine et la formation de l'esprit philosophique en France}

un petit écrit, à propos du monument nestorien en Chine, où il s'efforçait de démontrer que les Chinois n'ayant pas dans leur langue de mot pour désigner Dieu, avaient été obligés d'emprunter le syriaque. Il s'efforçait de cette manière de réfuter la théorie des Jésuites qui voulaient prouver que depuis la plus haute antiquité les Chinois avaient eu une religion spiritualiste et qu'ils avaient conservé depuis les premiers hommes, sans interruption, I'idée d'un Dieu créateur.

Mais en publiant en 1718 ses Anciennes Relations de deux voyageurs Mahométans, tirées d'un manuscrit arabe de la Bibliothèque du Roy, et qui sont des relations des voyages faits

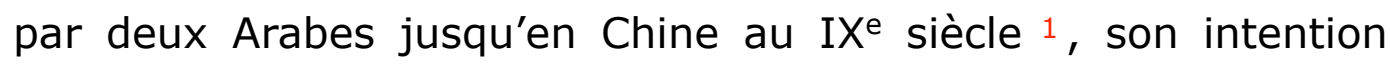
n'est pas seulement d'atteindre les Jésuites : il veut aussi confondre les Libertins. Il veut montrer non seulement par le texte qu'il traduit mais encore par un long Éclaircissement sur la science des Chinois qu'il ajoute à la fin de son volume, que les arts et les sciences ne sont pas aussi anciens en Chine que les Jésuites veulent le prétendre, et que, de cette antiquité des arts, les Libertins ne sauraient conclure à une plus grande antiquité que ne le permettent les Écritures.

L'antiquité des arts était en effet un des arguments des

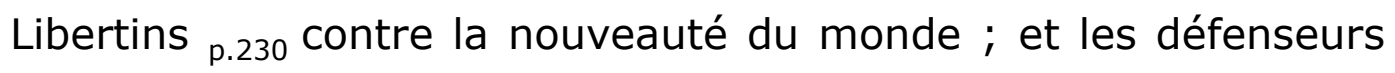
de la religion prenaient grand soin de la réfuter. Abbadie par exemple, dans son traité De la Vérité de la Religion chrétienne 2 , s'efforçait de montrer que tous les arts, la philosophie,

\footnotetext{
${ }^{1}$ Quérard, La France littér., art. Renaudot, I, VII, p. 526.

2 Abbadie, De la Vérité de la Religion chrétienne, Livre I, ch. IX.
} 


\section{La Chine et la formation de l'esprit philosophique en France}

I'astronomie, la médecine, non moins que les lois étaient d'une date relativement récente, et il ne manquait pas de s'en prendre à l'auteur du système des Préadamites qui avait voulu prouver que la découverte des lois astronomiques supposait un grand nombre de siècles, et que ni Abraham ni même Moïse n'auraient été capables de connaître la composition de la sphère si l'antiquité du monde n'était pas plus grande que nous ne I'imaginons. Les défenseurs de la religion se trouvaient obligés de se faire les champions de l'idée de progrès pour réfuter l'idée de l'éternité du monde. Si les arts, disaient-ils, ont fait tant de progrès depuis peu de temps, à quelle perfection seraient-ils portés si le monde était éternel ? Ce qui postule évidemment l'idée d'un progrès constant dans le passé - sinon d'un progrès indéfini - idée contre laquelle les Libertins s'inscrivaient en faux. «Les incrédules, dit Abbadie, ne pouvant contester la vérité de tous ces faits auront recours à leur défaite ordinaire qui est de dire qu'il est arrivé au genre humain des accidens qui I'ont empêché de croître, de peupler la terre et de faire des progrès dans les arts et dans les sciences. Et afin que nous ne soyons pas surpris de trouver tant de caractères de nouveauté dans la société des hommes, ils nous diront qu'il est survenu des pestes, des guerres et des inondations qui ont diminué le nombre des hommes et changé l'état et la face des choses ${ }^{1}$. » Et de son côté, Buddeus, dans son Traité de l'Athéisme et de la Superstition 2, répondait de cette manière à l'argument des Libertins sur l'intermittence du progrès des arts et des sciences :

${ }^{1}$ Id., ibid. t. I, p. 87.

2 Buddeus, Traité de l'Athéisme et de la Superstition, p. 217. 


\section{La Chine et la formation de l'esprit philosophique en France}

«Que si vous dites que plusieurs Arts se sont perdus par les guerres ou par les autres malheurs des tems, comme Guido Pancirellus le montre dans son traité : de rebus deperditis, j'en conviendrai sons peine si vous parlez de quelques arts superflus peu nécessaires à la vie, car pour celles (sic) dont nous ne pouvons nous passer dans la vie civile, je le nierai ${ }^{1}$. »

p.231 Les Jésuites qui prouvaient l'antiquité de la Chine par I'antiquité des arts, qui se sont conservés intacts depuis les premiers empereurs jusqu'à nos jours, apportaient donc un excellent argument aux libertins et un argument d'autant plus

1 Fontenelle était de ceux qui tout en croyant à la supériorité des modernes sur les anciens ne pensaient pas que le progrès des sciences et des arts se fût fait sans interruption :

Sans doute la Nature se souvient bien encore comment elle forma la tête de Cicéron et de Tite-Live. Elle produit dans tous les siècles des Hommes propres à être de grands Hommes, mais les siècles ne leur permettent pas toujours d'exercer leurs talens. Des inondations de Barbares, des Gouvernemens ou absolument contraires ou peu favorables aux Sciences et aux Arts, des préjugés et des fantaisies qui peuvent prendre une infinité de formes différentes, tel qu'est à la Chine le respect des cadavres qui empêche qu'on ne fasse aucune Anatomie, des guerres universelles établissent souvent et pour longtemps l'ignorance et le mauvais goût ». Digression sur les anciens et les modernes. - Euvres complètes (1758), t. IV, p. 189.

Au cours de cette Querelle des Anciens et des Modernes, l'anglais Wotten, examinant la question de la supériorité des anciens ou des modernes sous l'angle de la religion pensait que I'hypothèse d'un progrès constant depuis I'antiquité était le meilleur argument à opposer aux Libertins qui affirmaient l'éternité du monde : «En effet parmi les hypothèses dirigées contre la foi il n'en est pas de plus grave que celle de l'éternité du monde. Les histoires fabuleuses qu'on a faites des Égyptiens, des Chaldéens et des Chinois tendent à fortifier cette supposition. On essaye de résoudre les objections qui s'élèvent contre elle, en disant que des déluges, des invasions, des barbares et des guerres ont détruit tous les monuments de l'ancien monde jusqu'aux cinq ou six premiers milliers d'années. Cette réponse trop facile donneroit à penser que la révélation n'est qu'un vain mot. Or peut-on mieux réfuter cette hypothèse de l'éternité du genre humain qu'en démontrant que le monde a fait des progrès d'âge en âge et qu'aujourd'hui I'humanité est plus avancée qu'autrefois ? » (Rigault, La Querelle des Anciens et des Modernes, p. 305) Grotius croit aussi que la lenteur du progrès des sciences et des arts est une preuve très claire que «les hommes n'ont pas esté de toute éternité. » (De la religion révélée, traduit par de Beauvoir, p. 26-7). 


\section{La Chine et la formation de l'esprit philosophique en France}

grave qu'il permettait de laisser entendre que si les arts tels que l'astronomie, dont les progrès sont les plus lents, existaient dès le règne de Hoang ti, 2697 av. J.-C., il fallait encore supposer un grand nombre de siècles antérieurs, si bien que toute conciliation entre I'histoire chinoise et I'histoire biblique devenait impossible. N'était-on pas fondé alors à donner quelque créance à certaines traditions des Chinois qui faisaient remonter leurs origines à plusieurs milliers d'années avant Fou-hi ? Ne glissait-on donc pas peu à peu à l'idée de l'éternité du Monde ?

On y glissait sans nul doute et nous connaissons quelquesuns de ces Préadamites, qui, se servant de la chronologie chinoise que leur fournissaient les Jésuites, cherchaient à faire remonter les origines du monde, assurément beaucoup plus haut que le déluge, et peut-être jusqu'à l'éternité. Préadamite - en ce sens plus large - était certainement Tyssot de Patot, I'auteur des Voyages et aventures de Jacques Massé, qui ne sont que de nom et d'apparences des voyages imaginaires ${ }^{1}$. Jacques Massé nous raconte en effet qu'il a disséqué ${ }_{\text {p.232 }}$ un nègre, et qu'il a trouvé ce corps tout semblable à celui d'un blatte, sauf audessous de l'épiderme où se trouve placée une légère membrane, qui doit avoir pour effet d'émousser et d'absorber les

\footnotetext{
1 Tyssot de Patot a lu certainement des récits de voyages qui ne sont pas imaginaires. C'est ainsi que Jacques Massé et son compagnon sont appelés à la cour du roi des Australiens parce que la nouvelle s'est répandue qu'ils savent fabriquer des horloges. (Voyages..., p. 199-200 [css : édition/rechercher : 'p200']). C'est exactement I'aventure de l'arrivée du P. Ricci en Chine. Cf. cidessus, p. 21-2.

Tyssot de Patot a lu aussi Dellon. Sa description de la prison de Goa est empruntée à celle que Dellon a donnée dans sa Relation de I'Inquisition de Goa, au tome II des Voyages de M. Dellon. (Cf. notamment les passages suivants des Voyages et Aventures de Jacques Massé, p. 411, p. 438, p. 439, correspondant respectivement aux pages 38-9, 41, 127 de Dellon).
} 


\section{La Chine et la formation de l'esprit philosophique en France}

rayons de la lumière : « ce qui donna matière à bien des raisonnements sur l'origine des Éthiopiens qui semble ne devoir pas être celle des autres hommes, vu cette remarquable différence. Suivant ce principe, je voulus insister sur les conséquences qui n'allouent pas moins qu'au renversement entier du Sistème de l'auteur sacré que nous traitons. Mais on me ferma la bouche en disant qu'il y avoit bien des choses que Dieu veut que nous admirions, qu'il nous deffend d'approfondir »1.

Dans les Terres australes on croit sinon à l'éternité du monde, du moins à une origine du monde qui remonte si haut que personne n'en peut fixer l'époque : « Je vous ai déjà dit, répondit le Prêtre, que personne de nous ne s'émancipe de déterminer l'âge du monde : nous sommes persuadés qu'il a eu un commencement, mais nous en ignorons le tems : tout ce que je puis dire, c'est que ce tems-là est extrêmement reculé »2. Jacques Massé se fait l'avocat du christianisme près de ce Prêtre des Terres australes et il invoque les arguments que l'on opposait aux libertins. Sans doute, dit-il, les Chinois et les Égyptiens se vantent eux aussi d'une haute antiquité, n'allant pas à moins de quarante mille ans, « mais tout cela a été avancé sans fondement, et suivant un principe de vanité, par où ils prétendoient se mettre au-dessus des autres Nations de la terre ». Une preuve incontestable que le monde n'est pas si ancien est que nous n'avons point d'histoire qui remonte au-

\footnotetext{
${ }^{1}$ Voyages et Aventures de Jacques Massé, p. 32-33. ['p38']

2 ibid. , p. 174-7. ['p177']
} 


\section{La Chine et la formation de l'esprit philosophique en France}

dessus de quatre mille ans. Et d'autre part, les arts sont en général fort récents : «Nous ne savons point qu'avant cinq cens ans on ait eu aucune connoissance de la Boussole pour la Navigation, de l'impression des Livres, de la Poudre à canon, des armes à feu, des Lunettes d'approche, des microscopes, et autres telles inventions. Les horloges sonnantes, les Montres, le verre, le papier, la trempe de l'acier et une ${ }_{p .233}$ infinité d'autres choses sont de fort nouvelle date. Ainsi je conclus que là, aussi bien qu'ailleurs, il s'en faut tenir à la parole de Dieu ». Argument que le Prêtre rétorque de deux manières : d'une part les arts sont seulement des choses utiles qui ne s'inventent qu'au fur et à mesure des besoins, si bien qu'un peuple a pu vivre « un million d'années » sans les connaître parce qu'ils ne présentaient pour lui aucune utilité, et d'autre part les arts sont sujets, comme les autres choses humaines, aux mêmes vicissitudes : « Je remarque fort bien ici que les Sciences s'avilissent ; mon bisayeul étoit beaucoup plus habile que mon Père dans I'astronomie ; j'en sai encore bien moins qu'eux et à leur dire les lumières qu'ils en avoient n'étoient que ténèbres au prix de ce qu'en savoient leur Ancêtres. Il en est ainsi de toutes les autres familles. Il y a des sciences qui se cultivent dans de certains Tems, comme si elles étoient à la mode, et qui se négligent entièrement dans l'autre : et on les peut même tellement oublier que ceux qui naissent après n'en trouvant aucune trace, et venant à s'y exercer jugent qu'ils en sont les premiers Auteurs $\gg 1$.

1 ibid., p. 178-9. 


\section{La Chine et la formation de l'esprit philosophique en France}

Ni moins libertins ni moins dangereux que Tyssot de Patot est I'auteur de L'Espion dans les cours des princes chrétiens ${ }^{1}$. Il ne croit pas au Déluge ou du moins l'incertitude des faits préhistoriques l'empêche de rechercher la vérité de choses «si éloignées et de si vieille date $\gg 2$. Il est aussi préadamite : il s'efforce de démontrer d'après la dissection d'un nègre que les noirs et les blancs ne peuvent avoir même origine : "Si Adam avoit été blanc, ses Enfants l'auroient été aussi. S'il eût été noir, ses descendans auroient été de la même couleur. Par conséquent ou les blancs ou les noirs ne sont point de la postérité d'Adam » 3 . Il confronte I'histoire mosaïque avec les annales des anciens peuples, notamment des Chinois, et il constate que les Chinois regardent le récit de la Bible sur l'origine des hommes « comme un roman plus nouveau que les chroniques qui portent que les extrémités de l'Orient étoient le séjour des premiers hommes. Ils soutiennent que les premiers parens du genre humain s'apeloient Panzon et Panzona, et non Adam et Eve ou Alileth. Ils disent que les descendans de Panzon et de Panzona subsistèrent dix millions d'années et qu'enfin le Ciel envoya une tempête qui les détruisit $\gg 4$.

\footnotetext{
1 Ou du moins de la Suite de l'Espion qui, à partir du tome III, paraît avec cette adjonction : Traduit de I'Anglois.

2 ibid., t. V, p. 65.

3 ibid., t. VI, p. 353.

4 ibid., t. III, p. 294.
} 


\section{La Chine et la formation de l'esprit philosophique en France}

p.234 Il ne croit pas à la nouveauté ni même à la création du monde, car il semble spinoziste ${ }^{1}$ et persuadé de l'éternité de la matière ${ }^{2}$; et il note avec intérêt les traces de l'antiquité des arts chez les Chinois, « notamment quelques canons de Pékin sur lesquels étaient gravés en caractères chinois la date de leur âge, qui allait à plus de deux mille ans $\gg 3$.

Mais les Juifs, et après eux les Chrétiens, nient la grande antiquité des peuples orientaux. C'est que les Juifs sont de toutes les nations de la terre celle qui a le plus essayé d'en imposer au monde pour se faire valoir aux dépens de tous les autres descendants d'Adam. Les historiens hébreux ont réduit l'âge du monde à six mille ans, « au lieu que, s'il en faut croire les autres chronologies, il peut avoir plus de six cens mille ans ». En effet les chroniques des Égyptiens font I'histoire de dix-sept dynasties successives, longtemps avant l'époque que les Juifs et les Chrétiens prennent pour le commencement du monde. Les Assyriens se vantent d'avoir eu une race de rois longtemps avant le déluge de Noé. Quant aux Chinois et aux Indiens, ils « surpassent tous les autres peuples de la terre du côté de la prodigieuse antiquité de leur histoire ». Mais, diront Juifs et

\footnotetext{
1 «Qu'adorerai-je donc ou à qui rendrai-je grâces des biens dont je jouis ? Est-ce ou n'est-ce pas une partie de l'Univers ? Non. Est-ce à tout I'Univers ensemble ? Non. Mon âme et l'âme du monde sont unissons. Mais c'est la profonde profondeur de l'éternité, l'infini et l'immortel qui est le diapason et qui fait une parfaite harmonie. A cet être qui n'a point de ressemblance, qui n'est ni divisé ni borné, dont le centre est partout et la circonférence nulle part, au seul Tout Puissant d'où émanent toutes les autres choses, et auquel elles retournent, à cet Être, dis-je, je suis redevable de tout ce que j'ai. » (T. III, p. 301-302).

2 ibid., t. VI, p. 355.

3 ibid., p. 116.
} 


\section{La Chine et la formation de l'esprit philosophique en France}

Chrétiens, comment peut-il subsister des histoires des époques antédiluviennes, à part les monuments qui furent conservés dans l'arche ? Et l'auteur de l'Espion Turc est ainsi amené à nier I'universalité du Déluge. Il est bien évident, dit-il, que Noé qui prêcha cent-vingt ans avant le Déluge ne put aller prêcher toutes les nations de la terre si l'on admet que la terre était tout entière habitée. D'ailleurs Noé construisit I'Arche pendant le temps de sa prédication « et I'Alcoran fait mention de l'eau qui bouilloit dans son pot », preuves convainquantes qu'il ne sortit point de son pays, « à moins qu'on ne suppose qu'il portoit avec lui l'Arche et son pot. Le premier est impossible, l'autre ridicule et tous deux pleins d'absurdité ». En outre Noé ne put construire une Arche

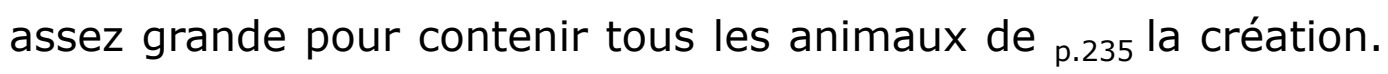
Et même s'il avait pu le faire, comment tous les animaux auraient-ils pu venir jusqu'à l'Arche et s'en retourner ? Donc il faut conclure que le Déluge, s'il a eu lieu, a été limité à l'Arménie et aux pays voisins et que « d'autres Nations comme les Égyptiens, les Chinois et les Indiens ont pu conserver leur chronologie incorruptible depuis le commencement du tems $\gg 1$.

L'idée de l'ancienneté, ou de l'éternité, du monde n'est sans doute pas la conséquence unique de la découverte des anciennes annales chinoises - car le développement des idées philosophiques sur l'éternité de la matière la favorise sans nul

\footnotetext{
1 ibid., t. VI, Lettre LXVII, p. 342-6.
} 


\section{La Chine et la formation de l'esprit philosophique en France}

doute, sans parler des observations scientifiques ${ }^{1}$, mais il n'en

reste pas moins que le fait de l'antiquité de la Chine, de l'ancienneté de ses arts et de ses sciences, vient fournir un argument sérieux à tous ceux qui sont tentés de nier la vérité des livres mosaïques. La révélation que font les Jésuites de ces annales chinoises peut donc présenter un grave danger et c'est contre ce danger que Renaudot va s'efforcer de prémunir le public en publiant ses Anciennes Relations des Indes et de la Chine de deux voyageurs mahométans. Dans sa préface, il déclare sans ambages à qui il s'en prend : aux Jésuites d'abord - p.236 mais en les excusant, et ensuite surtout à La Peyrère et à Vossius, et à d'autres libertins qu'il ne nomme pas mais dont

1 Notamment la découverte faite par le Chevalier de Louville des variations de I'obliquité de l'écliptique. D'autre part la découverte des fossiles ou des «pétrifications » semblait aux orthodoxes un excellent argument en faveur de I'universalité du Déluge. C'est ainsi qu'il parut en 1709 à Zurich un Herbarium antediluvianum de J. J. Scheutzer, docteur en médecine et professeur de mathématiques, dont les Mémoires de Trévoux signalent le caractère apologétique : «Monsieur Scheutzer qui a pu donner de l'éloquence aux poissons, parle ici-même en Philosophe et en chrétien. Notre siècle, dit-il, a donné un grand éclat, et même une grande perfection aux sciences : mais par je ne sçai quel malheur l'impiété a fait aussi de grands progrès ; la curiosité indiscrète excitée par l'éclat où sont les sciences, le faux sçavoir, ont fort avancé ce progrès de l'impiété ; c'est aux vrais Sçavans d'opposer les connoissances solides aux connoissances superficielles, la vérité à l'impiété. Rien n'a été sacré pour les critiques téméraires : ils ont osé nier l'universalité du Déluge si clairement marqué dans l'Écriture, la nature vient heureusement au secours de l'Écriture, et la terre ouvre son sein, pour en faire sortir des preuves de l'universalité du déluge, dans ce grand nombre d'animaux et de plantes pétrifiés qu'on trouve tous les jours. 》 (Janvier 1713, p. 69-70). L'année suivante parut à Leipzig un autre livre sur les fossiles dont le titre Rudera diluvii testes, suffit à marquer les tendances. Un peu plus tard le savant anglais Halley indiquait une méthode scientifique pour déterminer l'âge du monde : constatant que la mer est salée par le sel que charrient les fleuves, il proposait qu'on fit des expériences pour déterminer de combien chaque année augmentait le degré de saturation de la mer. Une fois cette augmentation bien établie il serait devenu facile de constater combien il avait fallu d'années pour atteindre à son degré de saturation. (Transactions Philosophiques, 1715, n. 344, p. 290sq. Compte rendu dans les Acta Eruditorum, mars 1717 , p. 117-8). 


\section{La Chine et la formation de l'esprit philosophique en France}

nous connaissons désormais quelques-uns. « Les Missionnaires, dit-il, ont cru se pouvoir servir de l'autorité des Philosophes chinois pour les disposer aux lumières de l'Évangile, et leur dessein étoit louable. Mais quelques autres, surtout des libertins, ont estrangement abusé des louanges excessives qu'on a données aux antiquitez chinoises pour attaquer l'autorité de la Sainte Écriture et la religion chrétienne, dont elles sont le fondement, pour combattre l'universalité du déluge et pour trouver que le monde estoit plus ancien qu'on le croyoit. Les fables dont I'histoire de Perse est remplie, toutes absurdes qu'elles soient, leur ont paru mériter quelque attention. Les ignorants, tel qu'estoit l'Auteur du système des Préadamites, croyent tout ce qui peut favoriser leur imagination, principalement quand ils entendent débiter sérieusement de pareilles histoires à des hommes sçavants, comme nous en avons entendu plusieurs qu'on a néanmoins reconnu depuis n'avoir connu que par les titres les livres dont ils faisoient valoir I'autorité : M. Vossius, qui étoit sans contestation très sçavant dans la littérature Grecque et Latine, trouvoit des preuves dans les Auteurs anciens, pour soutenir tout ce qu'il lisoit ou entendoit dire sur les Chinois. Enfin sur de pareilles autorités, des Libertins gastés par une fausse métaphysique ont respandu des opinions qui leur ont paru nouvelles quoyque la plus part soient des anciens Philosophes ou des hérétiques des premiers siècles, et 


\section{La Chine \\ et la formation de l'esprit philosophique en France}

qui ne vont pas à moins qu'à un renversement général de toute 


\section{La Chine et la formation de l'esprit philosophique en France}

Religion »1.

1 Anciennes Relations..., p. XXVIII-XXIX. La conclusion de Renaudot précise encore non seulement I'influence exercée dans la seconde moitié du XVII siècle par la connaissance de l'antiquité de la Chine, mais aussi la part importante de la découverte de cette antiquité dans la formation des idées de La Peyrère, et I'action que sa théorie des Préadamites exerça à son tour sur les Libertins : «Les écrivains du dernier siècle s'en sont un peu éloignés [des bornes de la vérité], en préférant quelques légères étincelles de raison et de certaines veritez enveloppées d'énigmes à celles qui ont été découvertes par les autres Nations, et excusant les défauts essentiels de leur Philosophie. Ces louanges excessives pourroient estre indifférentes si les conséquences n'en estoient pas trop périlleuses. La plus grande consiste dans les difficultés qu'elles font naistre sur l'autorité des Livres sacrez laquelle indépendamment de la Religion ne peut estre mise en parallèle avec lez histoires chinoises. Il est vray que ceux qui les font le plus valoir les abandonnent sur cet article, mais reconnoissant et establissant mieux, autant qu'il leur est possible, la vérité de ces histoires, les réponses qu'ils font aux difficultez sont beaucoup plus faibles que les objections, et donnent des armes aux impies et aux libertins. On en a veu un exemple de nos jours dans l'Auteur du système des Préadamites. Cet homme que ceux qui l'ont connu sçavoient être très ignorant, puisqu'il entendoit à peine le Latin, ayant d'abord formé son système sur des passages de l'Ecriture interpretez à sa manière, grand questionneur s'il en fut jamais, ayant appris de quelques hommes plus sçavants que luy, ce qu'on disoit de la grande antiquité des Chinois et estant confirmé par I'histoire du P. Martini qui parut presque en mesme tems s'en servit comme d'une preuve considérable, non seulement de ce qu'il avoit imaginé mais aussi de ce nombre infini d'années des Assyriens, des Babyloniens et des Egyptiens que les Payens même avoient rejetté comme fabuleux. Il trouva des gens qui luy fournirent des mémoires employez dans sa seconde Dissertation où cette matière est traitée plus amplement, et il n'est que trop vray que plusieurs s'y sont laissez surprendre, non pas pour devenir Préadamites, mais pour se former d'autres idées aussi dangereuses et qui tendent au renversement de toute religion. Car ces prétendues antiquitez chinoises diminuent insensiblement le mépris que non seulement les Chrétiens mais les Philosophes avoient eu des traditions des Egyptiens et des Babyloniens. On apprend d'ailleurs que les Persans ont de pareilles histoires qui remontent beaucoup plus haut que celles des Livres sacrez ; des esprits légers et d'une érudition médiocre, ou d'autres qui croyent tout sçavoir, parce qu'ils ont beaucoup leu [ceci n'est-il pas à l'adresse de Bayle ?] ne reçoivent pas absolument toutes ces fables mais ils supposent qu'elles sont fondées sur quelque vérité. (Ibid., p. 372-3).

Un de ces libertins préadamites auxquels Renaudot fait peut-être allusion est Collins dont Bentlay disait (La friponnerie laîque des prétendus Esprits forts d'Angleterre, p. 21) : « Cet écrivain... panche fort a croire qu'il y avoit des hommes avant Adam ». En effet, dans son Discours sur la Liberté de penser [qui ne fut traduit en français qu'en 1727], Collins citant Joseph, rapporte que Caïn, après avoir traversé divers pays « établit sa demeure en un lieu nommé Nais, où il eut plusieurs enfants. Mais tant s'en faut que son châtiment le 


\section{La Chine et la formation de l'esprit philosophique en France}

p.237 La véritable raison pour laquelle il publie ce texte des deux voyageurs arabes, c'est que cette relation montre qu'au moment où elle fut faite $-c^{\prime}$ est-à-dire au IX siècle après J.-C. - les Chinois ne connaissaient pas encore la boussole et qu'ils ont reçu cette connaissance des Européens par l'intermédiaire des Arabes. Que devient donc l'argument, si souvent répété, des arts inventés et pratiqués par les Chinois bien avant qu'ils le fussent par les Européens ? Mais ce fait de la boussole ne suffit pas à lui seul à renverser l'argumentation des libertins, et I'Eclaircissement sur la science des Chinois que Renaudot ajoute à la publication de son texte arabe tend à compléter et à renforcer la démonstration. Il veut montrer dans cette dissertation que la philosophie des Chinois est la philosophie d'un peuple primitif.

La fable de l'œuf dont naquit Puon-Cu, le premier homme des Chinois se trouve par exemple chez les Iroquois. Leur physique $\mathrm{p}$. 238 n'est guère plus raisonnable, « et on ne peut avoir aucune estime de l'esprit de ceux qui establissent, comme il font, cinq éléments : le bois, le métal, l'eau, la terre et le feu $\gg 1$. Vossius vante la médecine des Chinois et leur habileté à découvrir les maladies en tâtant le pouls. «Mais cela ne veut pas dire qu'ils aient raisonné plus juste qu'Hippocrate et mieux appliqué les principes que Galien »2. On dit aussi qu'ils font des cures merveilleuses avec des simples. « Mais en cela ils ne surpassent pas les sauvages de I'Amérique les plus barbares qui font des

\footnotetext{
${ }^{1}$ Renaudot, op. cit., p. 345.

${ }^{2}$ Id. . ibid., p. 348-9.
} 


\section{La Chine et la formation de l'esprit philosophique en France}

cures étonnantes, soit pour des blessures, soit pour des maladies »1. On vante leur astronomie ? Mais Cassini a trouvé leurs tables si conformes à celles de Tycho-Brahe qu'on a toutes les raisons de s'en méfier. On invoque le cycle sexagénaire pour prouver l'authenticité des annales chinoises ? Mais à cet égard le P. Martini et le P. Couplet ne sont pas d'accord. Le premier prétend qu'il fut mis dans sa perfection par Hoang ti, et le second déclare que ce même empereur l'inventa 2. Et cependant ces deux Jésuites travaillent sur les mêmes livres. Et Renaudot continue ainsi ne faisant aucune grâce aux Chinois, ne leur laissant aucun avantage, ni celui de la morale ni celui de la politique. Ils ont eu peut-être, dit-il, de belles maximes de politique, mais elles n'ont guère servi à former de grands principes, comme on a pu le voir quand les Tartares ont conquis la Chine. « Tous les défauts qui ont été considérez comme la cause de la ruine des plus grands empires en Orient, le pouvoir despotique, le luxe des princes enfermez dans un palais avec des femmes et des Eunuques, la négligence pour les affaires publiques, le mépris de l'art militaire et la mollesse se trouvent dans le gouvernement de la Chine. Les Tartares sans philosophie se sont rendus maistres de ce grand Empire en fort peu de temps lorsqu'ils l'ont attaqué, et quand ils ont pris les mœurs chinoises ils se sont trouvez dans la suite exposez aux mêmes disgrâces que leurs prédécesseurs $\gg 3$. On croirait entendre les

\footnotetext{
1 Id. . ibid., p. 349.

2 Id.. ibid., p. 355.

3 Id. . ibid., p. 377-8.
} 


\section{La Chine \\ et la formation de l'esprit philosophique en France}

paroles éloquentes par lesquelles J.-J. Rousseau écartera I'argument de la Chine dans son Discours sur les sciences et les arts.

Renaudot avait-il tort de signaler le danger que pouvait provoquer la connaissance de la Chine ? Cela est douteux. Mais pouvait-il écarter ce danger en essayant de contester cette antiquité par des p.239 arguments secondaires, c'est-à-dire par la critique des preuves morales alors que restait intacte le preuve essentielle : I'antiquité de I'histoire fondée sur des observations astronomiques ? On peut en douter encore davantage. Mais l'âpreté de Renaudot dans ses dissertations, et le souci qu'il manifeste de rabaisser les Chinois au niveau des sauvages de I'Amérique - chose qui même de son temps pouvait paraître singulière - prouvent à tout le moins, en même temps que la haine de Renaudot pour les Jésuites, I'inquiétude désormais provoquée chez les théologiens par la chronologie, grâce aux arguments des Libertins, héritiers spirituels de La Peyrère.

L'ardeur combative de Renaudot ne fut pas suffisante pour décourager les Libertins, et bien loin d'atténuer leur audace, ceux-ci désormais se sentent assez forts pour critiquer la Genèse, sans plus emprunter le voile de la fiction. C'est ainsi que Tyssot de Patot, en 1722, ose prononcer devant une Université allemande qui venait de l'appeler au rectorat et publier ensuite dans le Journal Littéraire un discours dont le titre prolixe marque nettement à lui seul, malgré quelques restrictions, les opinions de son auteur sur la chronologie de la Genèse » : Discours de $M$. Simon Tyssot de Patot, où dans la vue de concilier les différentes 


\section{La Chine et la formation de l'esprit philosophique en France}

Nations au sujet de la Chronologie, il prétend démontrer philosophiquement, et sans intéresser l'Écriture Sainte, que le Ciel et la terre qu'il croit d'une ancienneté inexprimable, n'ont point été creez en six jours naturels ; que les animaux ont aussi été produits depuis un temps immémorial ; que le monde doit vraisemblablement encore durer des millions d'années ; et il finit par faire voir quelle doit être naturellement la cause de la fin de ce globe terrestre. Fait à l'occasion de son avènement au Rectorat ${ }^{1 .}$

C'est le désir ardent qui le possédait de trouver un moyen d'accommodement entre des opinions différentes sur la chronologie des anciens peuples, déclare-t-il tout d'abord, qui l'a encouragé à lire le Pentateuque, et à cette lecture, il s'est senti transporté d'admiration en faveur de « I'Écrivain » Si bien qu'il lui fut impossible désormais de douter que Moïse « qui avoit passé pour le Petit-Fils de Pharaon, n'eût été élevé dans le grand monde, et n'eût eu pour Maître dans le cours de ses études, ce qu'il y avoit de plus habile parmi les Philosophes, les Mathématiciens et les Poètes de son tems ; et qu'ainsi s'il n'avoit pas sceu, comme cela pouvoit être, que les Chinois montroient déjà alors une liste chronologique d'un nombre innombrable de Princes, qui les avoient gouvernez, p.240 il n'étoit pas vraisemblable qu'il eût ignoré que les Caldéens et ses compatriotes entre autres fussent en possession de tables astronomiques où l'on voyoit au juste la quantité des Eclipses qu'ils avaient observées et calculées depuis plus de cent mille

\footnotetext{
1 Journal Littéraire 1722 , p. 154, sq.
} 


\section{La Chine et la formation de l'esprit philosophique en France}

ans ». Mais Moïse qui était un savant, parlait à « des idiots » 1 et il se trouve obligé d'emprunter leur langage pour être compris d'eux. C'est ainsi qu'ayant été mis par Dieu à la tête des Israélistes pour les ramener d'Égypte en Palestine, il se vit, chemin faisant, obligé de leur donner des lois, et il leur imposa notamment la nécessité de travailleur six jours consécutifs, de se reposer le septième, et de l'employer entièrement au service divin. Pour donner de la force à ce commandement et l'appuyer d'un grand exemple, il déclara que « l'esprit universel a employé autant de tems à créer tout I'Univers ». Le récit de la création, tel que le fait Moïse dans la Genèse, ne doit pas être pris au sens propre ou littéral, mais au sens figuré ou allégorique, et les six jours désignent évidemment six époques, dont il nous est difficile d'apprécier la durée ${ }^{2}$. Et pour le démontrer, Tyssot de Palot se permet « de tenir le langage, dont je suppose qu'il (Moïse] se seroit servi, s'il avoit eu à faire à des philosophes $\gg 3$. Pour cela il fait la critique de l'idée du temps, mesure créée par l'esprit borné des hommes qui ne peut s'appliquer aux créations de I'Être infini et éternel : «Le tems qui s'est écoulé depuis la production des unes et des autres [créatures], doit être considéré comme intérieur ou extérieur ; et d'autant que le tems extérieur est proprement la durée du mouvement journalier ou annuel du Globe que nous habitons, par le moyen duquel on

1 ibid., p. 160.

2 Cette idée du sens allégorique de la Genèse est développée en termes à peu près identiques par Tyssot de Patot dans une de ses lettres, Lettres choisies, lettre LXXVII, t. I, p. 414-5.

${ }^{3}$ Discours..., p. 162. 


\section{La Chine et la formation de l'esprit philosophique en France}

mesure précisément l'espace qu'a parcouru une substance, de quelque nature qu'elle soit, à conter depuis le moment de son entrée jusqu'à celui de sa sortie, il est clair qu'avant que la terre fût, il n'y a eu qu'un Tems intérieur, qu'il n'est pas en notre pouvoir de déterminer ; comme il seroit impossible à un Arpenteur de déterminer les dimensions intérieures de cet apartement, pour m'exprimer de la même manière, sans se servir d'instruments extérieurs, de la grandeur desquels on est convenu, pour les mesurer précisément ${ }^{1}$. Cela étant, il est impossible de marquer « dans quel tems a paru le premier homme ; nous en sommes peut-être si éloignez, qu'à peine la distance en pourroit être mesurée ou exprimée par aucun nombre $\gg 2$.

Il ne nous appartient pas de relever ici toutes les audaces libertines que renferme ce Discours, les contradictions que signale Tyssot de Patot dans la Bible au sujet d'Adam et du Paradis terrestre, I'opinion qu'il émet sur l'esprit borné d'Adam qui n'avait même pas « autant de pénétration et de lumière que ses descendans en ont eu après lui »3, l'impossibilité d'admettre la fable de l'Arche de Noé, à une époque où l'on n'avait pas assez d'industrie pour construire un vaisseau d'une si prodigieuse étendue » ${ }^{4}$. Qu'il nous suffise de remarquer que

\footnotetext{
1 ibid., p. 163. du soleil », t. I, p. 417-8.

3 ibid., p. 180.

${ }^{4}$ Lettres choisies, t. I, p. 285, sq.
}

2 ibid., p. 175. Cf. Lettres choisies : «Dieu étant infini à tous égards, il est indubitable qu'à proportion de la brièveté de notre vie, non seulement mille mais cent millions d'années lui sont moins qu'à nous le terme d'une révolution 


\section{La Chine et la formation de l'esprit philosophique en France}

Tyssot de Patot, s'il ne peut être rangé, à cause de ce discours, parmi les écrivains qui ont cru à l'éternité du monde (il semble avoir cru à un Dieu créateur, si l'on en juge d'après une de ses lettres) ${ }^{1}$ est du moins de ceux qui pensent que l'origine du monde doit être reportée à un temps que nous ne pouvons déterminer, et que rien ne permet de repousser à priori la chronologie des Chinois, des Chaldéens et des Égyptiens ${ }^{2}$. C'était en somme ce qu'avait déjà dit le Prêtre des Terres Australes à Jacques Massé et c'était peut-être aussi l'idée de La Peyrère.

\footnotetext{
1 Dans ses Lettres, il témoigne d'une audace plus grande et laisse entendre que c'est le seul désir de ne pas contredire les Écritures qui empêche d'accorder aux Chinois leur antiquité : « Ces peuples [les Chinois]... prétendent avoir subsisté de tout tems ; les chrétiens qui ont examiné leurs monumens et leur chronologie avouent franchement qu'on ne peut pas nier qu'ils ont été près de cinq mille ans consécutifs gouvernés par des têtes couronnées dont les noms, la vie et les actions sont exactement marquées. Les principes de notre Religion ne leur permettant pas de leur en accorder davantage, ils mettent le reste au rang des fables. » (Lettre LVIII, t. I, p. 306).
}

2 Levesque de Burigny, dont nous avons l'occasion de nous occuper plus particulièrement lorsque nous examinerons les opinions des philosophes sur la philosophie et la religion des Chinois, signale en passant dans son Histoire de la Philosophie payenne, certaines idées des Chinois et des Siamois qui ont cru à l'éternité du monde : «...Les Chaldéens, plusieurs Chinois et les Siamois croyoient le monde éternel. C'est du moins ce qu'en dit le P. Tachard, dont voici les paroles : Ils estiment que le Ciel et la Terre sont incréés et éternels et ne comprennent pas que le Monde ait jamais commencé ni qu'il puisse jamais finir. Et cette autorité d'un homme qui a demeuré longtems dans le Pais parait préférable à celle de Barros et de Schoouten, qui assurent que les Siamois reconnoissent un Dieu, Créateur du Ciel et de la Terre. » (T. I, p. 244). Il note cependant « I'erreur » de certains philosophes chinois ou siamois qui ont cru que le monde était le produit du hasard : «...[autre erreur] : ceux qui pensoient que cet admirable arrangement qui paroit dans toutes les parties de l'univers est l'effet d'un hazard aveugle. - Il y a des philosophes chinois dans la même erreur, selon Martinius. - M. de Choisi assure que les Siamois croyoient que le Monde s'est fait par lui-même : ou il y a différentes sectes chez ces Peuples, qui ont des sentimens différens, ou il contredit le P. Tachard. » (T. I, p. 245-246). 


\section{La Chine et la formation de l'esprit philosophique en France}

p.242 Renaudot n'a donc pas tout à fait tort de combattre sous

le nom de préadamites les philosophes qui, à découvert ou sous le voile de la fiction, s'efforçaient en réalité de prouver l'éternité du monde ${ }^{1}$. Un de ceux-là fut encore un peu plus tard LengletDufresnoy, qui sous le prétexte d'exposer la Méthode d'enseigner

1 Bien que Montesquieu dans ses Lettres Persanes n'ait pas invoqué l'argument de la Chine, il n'est pas hors de propos de marquer qu'il a semblé en 1721 partisan de l'éternité du monde, comme en témoigne la lettre 114 de cette édition (lettre 113 de l'édition Barkhausen qui reproduit les corrections de 1754) : « Ceux qui connoissent la nature et qui ont de Dieu une idée raisonnable, peuvent-ils comprendre [1754 : Il y a des philosophes qui distinguent deux créations, ils ne peuvent comprendre...] que la matière et les choses créées n'aient que six mille ans. Que Dieu ait différé pendant toute l'éternité ses ouvrages, et n'ait usé que d'hier de sa puissance créatrice. Serait-ce parce qu'il ne l'aurait pas pu ou parce qu'il ne l'aurait pas voulu ? Mais s'il ne l'a pas pu dans un temps, il ne l'a pas pu dans l'autre. C'est donc parce qu'il ne l'a pas voulu. Mais comme il n'y a pas de succession dans Dieu, si l'on admet qu'il ait voulu quelque chose une fois, il l'a voulu toujours et dès le commencement [1754, supprime : Il ne faut donc pas compter les années du monde : le nombre des grains de sable de la mer ne leur est pas plus comparable qu'un instant ]. Cependant tous les historiens nous parlent d'un premier père ; ils nous font voir la nature humaine naissante. N'est-il pas naturel de penser qu'Adam fut sauvé d'un malheur commun comme Noé le fut du déluge, et que ces grands événements ont été fréquents sur la terre depuis la création du monde ? » Montesquieu semble avoir été un de ces libertins qui se servaient du préadamisme, moins par fidélité aux théories de La Payrère que pour le plaisir de faire échec à Moïse. 


\section{La Chine et la formation de l'esprit philosophique en France}

I'Histoire montra surtout l'impossibilité de connaître l'histoire des origines, si I'on tient compte du récit de Moïse ${ }^{1 .}$

p.243 La première difficulté, dit Lenglet-Dufresnoy, pour arriver à connaître l'origine des peuples est le manque d'historiens contemporains des événements «Étudier I'Histoire ancienne de ces circonstances, c'est étudier les sentiments et les imaginations des modernes et non la vie et les actions de nos premiers pères $\gg 2$. L'Écriture n'échappe pas à ce défaut ; c'est un moderne que Moïse, si du moins on le compare aux origines, et il expose les origines du monde par rapport au seul peuple qui

1 L'édition de 1729 (Paris, Pierre Gandouin) a de nombreux cartons. Il y a en effet peu de livres aussi audacieux, non seulement en ce qui concerne la religion mais encore au sujet de l'origine du pouvoir des rois. Cependant l'exemplaire de la Bibliothèque Nationale n'est pas cartonné, et c'est d'après cet exemplaire (G. 3616) que nous citons. Tous les passages subversifs qui ont été cartonnés ont été rassemblés dans le livre de Beyer : M. Augusti Beyeri, Memorice historico-criticae Librorum rariorum. Dresdaæ et Lipsiæ, apud Fredericum Hekel, 1714. Une note manuscrite jointe au prospectus de cet ouvrage, qui parut en 1728 (B. N. G.-1142) donne d'assez curieux renseignements sur le profit que l'abbé Lenglet-Dufresnoy sut tirer de ces cartons : «M. le Garde des sceaux ayant souhaité qu'on examinât de près cet ouvrage, dont l'auteur est un homme suspect en tout genre, on a trouvé dans la partie où il traite de I'histoire de la Religion sous I'ancienne et la nouvelle loy, beaucoup de choses contraires à la pureté des mœurs, aux principes de la foy et aux traditions orthodoxes ; dans la partie qui traite de l'estat présent de l'Europe, plusieurs réflexions capables de choquer les puissances, et dans celle où l'auteur porte un jugement sur divers ouvrages particuliers, nul égard aux bienséances de la société civile. Ces observations ont donné lieu à une infinité de changemens et de cartons, et comme c'est peut estre icy un des seuls exemplaires conservés dans sa première forme on a jugé à propos pour le rendre encore plus utile et plus curieux d'y joindre une note sommaire des changemens qui y ont été faits. Et premièrement il faut remarquer qu'avant que I'ouvrage ait été remis au censeur nommé par $M$. le Garde des sceaux (Gros de Boze) l'auteur y avoit déjà fait de lui-même, surtout dans le premier volume, les changemens marqués cy après; et que comme il ne vouloit pas qu'on l'ignorât, il avoit lui même indiqué ces changemens par des étoiles ajoutées aux chiffres courans des pages changées. On comprend que c'estoit pour faire rechercher davantage les Cartons et les vendre séparément un bon prix. »

2 T. I, p. 77. 


\section{La Chine et la formation de l'esprit philosophique en France}

l'intéresse, le peuple juif : «Dira-t-on pour cela qu'il n'y avoit alors que cet unique peuple ? Moïse à la vérité ne marque rien des premiers Égyptiens, des Éthiopiens, des Scythes et des Chinois. Cependant on n'oseroit avancer que les fragments si sûrs qui nous restent de leur histoire soient des fables inventées après coup pour honorer chacune de ces nations. Il nous suffit seulement de penser que les Saints-Livres n'ayant parlé d'Adam, que comme un chef des Israélites, cela n'empêche point qu'il n'y eût du tems de Moïse d'autres hommes, qui ne faisant rien au but que ce législateur s'étoit proposé n'ont pas trouvé place dans son histoire »1. La seconde difficulté de I'histoire ancienne vient de I'antiquité des temps : «Que peut-on dire de certain, que peut-on circonstancier exactement quand il faut pénétrer l'obscurité de cinquante ou soixante siècles ? »2 [Remarquer l'audace de cette estimation de la durée du monde]. Une troisième difficulté est de trouver par la dispersion des peuples I'origine et la source des empires. On peut comprendre comment se sont formés les peuples qui ont pris naissance aux environs de I'Euphrate. Mais comment se sont formés les Scythes, les Tartares, les Éthiopiens ? Comment deux ou trois cents ans après le Déluge, l'Égypte pouvait-elle être peuplée au point de contenir vingt mille villes ? « La Chine n'était pas moins peuplée que I'Égypte. La Scythie ou la Tartarie l'étoit autant que l'une et l'autre » ${ }^{3}$. Il n'y a que le P. Pétau, lui qui p. 244 « fait des hommes

\footnotetext{
${ }^{1}$ Id., ibid., p. 77-78.

${ }^{2}$ Id., ibid., p. 78.

${ }^{3}$ Id., ibid., p. 79.
} 


\section{La Chine et la formation de l'esprit philosophique en France}

à coups de plume ${ }^{1}$ qui soit capable de peupler le monde, en deux cents ans, de plusieurs milliards d'habitants. Le seul moyen de résoudre cette difficulté de la constitution des anciens peuples serait de dire que le Déluge n'a pas été universel : « Trouveroitt-on des peuples rassemblés, des Empires formés peu après le Déluge ? On diroit que ce sont les restes de ceux sur les terres desquels cette inondation ne s'est pas fait sentir. La Chine, l'Égypte, I'Éthiopie, I'Afrique et l'Europe même auroient été peuplées par des hommes que Dieu leur auroit destinés avant ce naufrage. Il paroit que Scaliger qui fait remonter plusieurs Monarchies avant le Déluge, ne s'éloigne pas de ce sentiment qui a été soutenu ouvertement par quelques auteurs célèbres. Mais quand l'Écriture Sainte ne parleroit pas du Déluge, l'autorité des Pères seroit suffisante pour en établir I'Universalité. Ainsi nous préjugeons que cet expédient, quoique favorable, ne sera pas suivi .... $\gg 2$.

Le Déluge est donc, selon Lenglet-Dufresnoy, une inondation locale, et ne dépassant pas la région que les Juifs étaient capables de connaître. Mais les autres régions et les autres peuples, Moïse les a complètement ignorés. Les livres de Moïse ne concernent donc que la nation juive, et « c'est un abus de chercher dans ses livres tout ce qui concerne les autres peuples et de regarder comme supposés tous les faits historiques qu'on peut apprendre par d'autres monumens que ceux qu'ils nous ont laissés ».

1 D'Argens et après lui Voltaire ont repris la plaisanterie dans les mêmes termes.

2 Lenglet-Dufresnoy, ibid., p. 80. 


\section{La Chine et la formation de l'esprit philosophique en France}

Lenglet-Dufresnoy, malgré ses prémisses pyrrhoniennes aboutit donc à une conséquence positive. Il semble d'abord vouloir démontrer la difficulté - voire l'impossibilité - de connaître l'origine des différents peuples, mais peu à peu, il laisse percer le bout de l'oreille : s'il y a tant de difficultés c'est que I'histoire des anciens peuples ne concorde pas avec la Bible, qui se dit un livre inspiré et qui a la prétention d'être I'histoire de toutes les nations. En réduisant le récit de la Bible au rôle d'histoire de la nation juive, et Moïse au rôle d'historien de cette nation, on peut admettre l'antiquité des Chinois et des Égyptiens. Des difficultés subsisteront pour pénétrer dans les temps lointains de leurs origines, mais il n'y aura plus d'impossibilité absolue et préalable de connaître cette antiquité.

Plus audacieux que Lenglet-Dufresnoy, l'auteur de I'Examen critique des Apologistes de la Religion chrétienne - il est vrai p. 245 que son livre ne parut pas, même avec des cartons au moment où il l'écrivit - invoque l'ancienne histoire chinoise pour faire échec à la Bible, parce que cette histoire « contredit ouvertement celle des Juifs ». Sans tenir compte en effet des temps immenses que les Chinois adoptent dans leurs livres historiques, il est constant, d'après les Jésuites que la Chine était peuplée en 2155 av. J.-C., puisqu'une éclipse fut observée cette année-là en Chine : «M. I'abbé Renaudot rejette cette éclipse sur le témoignage de $M$. de Cassini, mais il n'a pas compris ce qu'il a cité de ce célèbre astronome. On a envoyé au P. Souciet des observations astronomiques tirées de l'histoire et des livres chinois qui prouvent et leur habileté en fait d'astronomie et 


\section{La Chine et la formation de l'esprit philosophique en France}

I'antiquité de leurs observations. Il est certain comme l'avoue M. l'abbé Renaudot, que cette antiquité a des conséquences funestes puisqu'elle donne atteinte à I'Universalité du Déluge et à l'authenticité du texte hébreu, suivant lequel la terre n'étoit habitée que par des enfants de Noé, 2155 ans av. J.-C. Pendant ce tems, il ne devoit point y avoir d'astronome en Chine »1. Il tient à cette date ancienne qui lui garantit l'existence d'une astronomie en Chine à une époque voisine du Déluge parce que c'est un argument positif et historique pour nier le Déluge. Citant une Histoire du monde de Boulainvilliers, qui n'a jamais vu le jour, il démontre l'impossibilité de la création d'une assez grande quantité d'eau pour noyer le monde entier. Il rappelle un argument de Vossius contre l'universalité du Déluge à savoir qu'il auroit fallu plus de vingt mille ans à certains animaux qu'on nomme paresseux pour arriver jusqu'à I'Arche. Enfin il reprend les arguments de Lenglet-Dufresnoy contre la rapide multiplication des hommes et il n'oublie pas la plaisanterie de I'abbé contre le P. Pétau. Les nègres, enfin, dont la nature physiologique lui semble ${ }_{\text {p.246 }}$ totalement différente de celle des

1 P. 221-2. Ce livre a dû être écrit entre 1729 et 1732 . Il n'est pas antérieur à 1729 puisque I'auteur cite La Méthode pour enseigner I'Histoire (1729) de Lenglet-Dufresnoy, ainsi qu'une lettre du P. Fauque, Jésuite, qui parut dans le XIXe Recueil des Lettres édifiantes et curieuses, 1729. D'autre part l'auteur annonce les observations astronomiques, reçues de Chine par le P. Souciet, qui les publiera. Or le $\mathrm{P}$. Souciet a publié deux tomes d'Observations mathématiques en un seul volume en 1732.

La citation que nous avons faite de cet ouvrage et relative à l'éclipse de 2155 est une preuve que ce livre ne peut être attribué à Fréret, puisque ce savant, malgré les critiques et les objurgations des PP. Gaubil et de Mailla s'est toujours entêté à nier non certes la réalité de cette éclipse mais la date de 2155 que les Jésuites lui donnaient. En 1729, Fréret était déjà en correspondance avec les PP. de Canton, ceux qu'il appellera plus tard les « figuristes » qui ne croyant pas à l'authenticité de l'ancienne histoire chinoise, essayaient de prouver que cette éclipse n'avait pu être observée en Chine à l'époque indiquée, mais qu'elle avait été calculée après coup. 


\section{La Chine et la formation de l'esprit philosophique en France}

blancs prouvent encore que tous les hommes ne descendent pas d'Adam.

Des libertins, nous l'avons vu, ont argué de la couleur des nègres, pour prétendre qu'il ne peuvent être de la race d'Adam, favorisant ainsi la thèse de La Peyrère. Cet argument de la différence de couleur des peuples (on ne profère pas encore le mot de race) paraît assez dangereux aux environs de 1730, pour que des défenseurs de la Bible essayent d'expliquer l'origine des peuples de couleur, nègres et américains d'après les données de la Bible. C'est ainsi que nous trouvons dans les Mémoires de Trévoux, de 1733, un mémoire d'un P. Jésuite, Sur l'origine des Nègres et des Américains qui combat nettement la théorie de La Peyrère, mais en faisant un sacrifice important, le sacrifice de I'universalité du Déluge ${ }^{1 .}$

« Les différentes couleurs des hommes qui sont sur la terre, dit le P. Auguste [Malfert] ont fait croire à quelques auteurs que des peuples entiers n'étaient pas de la race d'Adam, que Dieu dans le commencement, les créa en toute contrée de la terre, comme il avait créé les animaux pour la peupler, que ces hommes n'avaient vécu que d'une vie animale, sans connaissance d'un vrai Dieu, et que leurs races s'étant multipliées comme à I'infini, Dieu créa enfin Adam auquel il

\footnotetext{
1 Dans un article de la Revue des Questions scientifiques, t. XXI, Bruxelles, 1887, I'abbé Robert énumérant les adversaires de la théorie de I'universalité du Déluge entre 1650 et 1740, ne cite, outre La Peyrère et le P. Malfert, que Abraham Mill : De Diluvii universalitate (1667) et Guillaume Whiston : Supplément au Traité de l'accomplissement littéral des Prophéties. Il ne connaît ni Vossius, ni Tyssot de Patot, ni l'auteur de L'Espion Turc, ni LengletDufresnoy lesquels, il est vrai, n'ont pas écrit de traité en forme sur le Déluge.
} 


\section{La Chine \\ et la formation de l'esprit philosophique en France}

donna une Loi, voulant se former de sa race un peuple $d$ 'adorateurs, et renfermer dans lui tous les hommes de la terre sous le nom de Gentils ».

C'est à cette thèse que le P. Malfert va s'attaquer. L'argument essentiel de La Peyrère, dit-il, suivant lequel la parole de Caîn à Dieu : «Quiconque me trouvera me tuera », n'aurait pas été possible s'il n'y avait pas eu d'autres hommes sur la terre, peut s'expliquer d'une autre manière. Avec un peu d'attention, il aurait remarqué que Caïn ne tua Abel que longtemps après la naissance de l'un et de l'autre et qu'ainsi il devait y avoir un grand nombre d'hommes qui descendaient d'Adam, de Caïn et d'Abel et de plusieurs autres que l'Écriture comprend sous le nom de fils et de filles qu'Adam engendra. Mais Dieu donna un signe à Caïn pour qu'il ne fût pas tué, et ce signe, c'est la couleur noire. Caïn, muni p.247 de ce signe, s'établit et fonda sa race en Orient jusqu'aux Indes, d'où un rameau est allé coloniser l'Afrique. Quelques écrivains - notamment des esprits forts prétendent que la couleur noire peut être produite par le climat. Mais le $\mathrm{P}$. Malfert ne le pense pas et il estime qu'il est prouvé que : $1^{\circ}$ Caïn devint nègre comme punition de son crime ; pour être mis à couvert de la vengeance des descendants d'Abel ; $3^{\circ}$ que ce sont les différentes couleurs des hommes qui les ont obligés de se séparer avant le Déluge.

Reste à expliquer l'origine des Américains (car les Chinois même à cette époque ne sont pas considérés par les Européens comme un peuple de couleur). Or, remarque le P. Malfert, on trouve dans la Bible que Lamech, descendant de Caïn, dit à ses 


\section{La Chine et la formation de l'esprit philosophique en France}

deux femmes, Ada et Scelle : «Femmes de Lamech, entendez ma voix, écoutés ce que je vais dire : j'ai tué un homme l'ayant blessé, j'ai assassiné un jeune homme d'un coup que je lui ai donné, on vengera sept fois la mort de Caïn et celle de Lamech septante fois. Après ces paroles, l'Écriture ne parle plus de Lamech. Mais on voit bien d'après la punition plus grande qu'aurait méritée celui qui l'aurait tué, que son crime était plus grand que celui de Caïn. En effet, il était doublement coupable du crime d'homicide et il a dû avoir une plus grande peur que n'avait eu Caïn d'être tué par les siens, et cette crainte a dû l'obliger à fuir encore plus vite que n'avait fait Caïn. Mais comme son péché était plus grand que celui de Caïn, Dieu l'a puni doublement d'abord en lui imposant une troisième couleur - ce qui d'ailleurs mettait sa vie à couvert - et en privant « toute sa race jusques à la fin du quinzième siècle, de la manifestation qui s'est faite de Dieu notre sauveur dans la plénitude des tems, à tous les hommes de l'Asie, de I'Europe et de I'Afrique, par la prédication des Apôtres ».

Si les nègres et les Américains sont des Caïnites, il faut nécessairement, puisque le Déluge détruisit la race de Seth, que les Caïnites, nègres et américains, aient échappé au Déluge, c'est-à-dire que le Déluge n'ait pas été universel. Et le P. Malfert va jusqu'à cette extrême conséquence de sa théorie. Reste cependant une objection possible qui risque de renverser cette théorie, malgré tous les sacrifices que son inventeur lui a faits, et cette objection c'est l'existence des Chinois, qui ne sont ni des nègres ni des américains. Avec une hypothèse de plus, notre Jésuite se tire d'affaire : «Nous croyons, et il nous paroit très 


\section{La Chine et la formation de l'esprit philosophique en France}

vraisemblable, que les Chinois et autres peuples d'alentour, tiennent leur origine des mariages que firent les filles de Seth qui étoient blanches avec une partie des enfants de Caïn ; car il est probable qu'elles ont dû prendre ce p.248 parti, se voyant méprisées et rejettées par ceux de leur race »1. Rien en effet dans la Bible n'empêche d'admettre cette hypothèse puisque Moïse a ignoré complètement les Chinois.

Enfin il faut, pour que cette théorie tout entière tienne debout, expliquer comment Lamech ou ses descendants sont passés en Amérique, car on ignorait encore en 1733 si I'Amérique était une île, ou si elle était jointe par le nord au continent asiatique. Grotius avait il est vrai soutenu autrefois que les Américains étaient venus d'Europe en Amérique par la Norvège et le Groenland, et qu'ils provenaient d'Allemagne, hypothèse inadmissible dans la théorie du P. Malfert puisque les Caïnites se sont étendus vers l'Orient : il faut donc qu'ils soient passés directement d'Asie en Amérique. Malgré les incertitudes géographiques, le $\mathrm{P}$. Malfert croit cependant que ce voyage a pu se faire facilement : « Le premier moyen qui se présente est celui de la navigation, car il ne faut pas croire que les premiers hommes aient ignoré cette science si nécessaire pour le commerce de la vie, étant instruits par Adam qui n'ignorait rien. Secondement, I'Amérique a pu être autrefois jointe à l'Asie et que peut-être elle l'est encore, quoique cela nous soit inconnu, ou séparée seulement par quelque petit bras de mer, très aisé à passer ; et c'est cette conjoncture qui a porté le feu Czar Pierre

\footnotetext{
1 P. 1970.
} 


\section{La Chine et la formation de l'esprit philosophique en France}

$1^{\text {er }}$ à envoyer en Amérique des hommes de génie et propres à faire cette découverte. Troisièmement, la mer étant sortie de son lit pour couvrir la moitié du globe terrestre dans le tems du Déluge et ayant laissé l'autre moitié à sec, ces Peuples ont pu y passer aisément. Quatrièmement, I'Amérique a pu être jointe aux autres parties de la terre, ce qui seroit conforme à l'opinion de Platon ; et ce qui est certain, c'est que ces Peuples y ont passé par quelqu'une de ces quatre voyes. Il nous suffit d'avoir démontré qu'ils y ont pu passer par plusieurs voyes et que ces Peuples, les Blancs et les Nègres, et toutes les autres Nations de différentes couleurs qui ont du mélange de ces trois races différentes, tiennent leur origine d'Adam, de Caïn, de Lamech et des enfants de Noé et que Dieu ne les a pas crées en toutes ces différentes Régions longtemps avant Adam, comme I'a prétendu l'auteur des Préadamites »1.

Et voilà La Peyrère, la bête noire des Théologiens, réfuté une fois de plus. On peut en effet admettre, sans renier la Bible, que Moïse n'a pas parlé des Chinois - simple péché d'omission - $\mathrm{p}$. ${ }_{249}$ ou qu'il a semblé parler d'un Déluge universel - procédé emphatique des Orientaux. Mais il est impossible d'admettre, sans renier les deux premiers chapitres de la Genèse, que des hommes ont existé avant Adam. Le préadamisme, négation de la Genèse, est pour les Chrétiens qui voient dans la Genèse le seul récit authentique de l'origine du monde et de la naissance de l'homme, une négation absolue de la création. Aucun sacrifice,

\footnotetext{
1 P. $1976-7$.
} 


\section{La Chine \\ et la formation de l'esprit philosophique en France}

même le sacrifice de l'universalité du Déluge, ne doit coûter à un Chrétien pour réfuter La Peyrère.

@

La première période de commentaires et de critiques sur I'ancienne histoire chinoise est close aux environs de 1730. A partir de ce moment commence une nouvelle période qui ne se signale par aucune œuvre imprimée de premier plan, comme le furent de leur temps I'Histoire de la Chine, du P. Martini, ou le livre des Préadamites, de La Peyrère, mais qui a d'autant plus d'importance pour I'histoire des idées qu'elle consiste en un commerce épistolaire fréquent entre savants, entre les Jésuites de Chine et des érudits comme Fourmont et Fréret. Ces lettres circulaient non sous la forme châtiée et expurgée que les Jésuites de Paris leur ont donnée quand ils les ont fait imprimer, mais avec toutes leurs audaces tranquilles, audaces de savants appliqués, malgré leur qualité de missionnaires, à leur tâche scientifique. Sans doute ces petits faits historiques patiemment contrôlés, examinés, interprétés par les Jésuites de Chine, passés ensuite au crible de la raison par les savants de France, ne forment pas au total une thèse comme celle de La Peyrère, capable d'exciter la verve des érudits du monde entier, de provoquer des répliques innombrables ou de susciter en réponse des théories plus audacieuses encore. Mais ces petits faits dont la certitude est affirmée par un travail critique forment peu à peu une conviction que ne sauraient ébranler les théories fallacieuses les mieux présentées, les thèses les plus séduisantes : c'est la période de la découverte historique de I'« ancienne histoire 


\section{La Chine et la formation de l'esprit philosophique en France}

chinoise qui commence avec cette correspondance entre les Jésuites de Chine et les savants de France.

Nous avons raconté plus haut ${ }^{1}$, en faisant la critique des écrits des Jésuites sur la Chine, I'histoire des altérations ou des mutilations que les Jésuites de Paris, sous la menace de la Querelle des Cérémonies chinoises, firent subir aux documents qui leur p.250 étaient envoyés de Chine par leurs PP. de Pékin. Dans ce chapitre, seule nous importe la question de la chronologie, et nous sommes obligés de constater que les PP. de Paris ne se montraient pas disposés à accepter une chronologie des premiers temps de la Chine qui pût mettre en échec la Vulgate. Un seul fait 2 - mais il est significatif - nous en sera une preuve convaincante. Le P. de Mailla, jésuite missionnaire à Pékin avait envoyé à la maison professe des jésuites de Lyon, aux fins de publication, une Histoire de la Chine, où il démontrait dans la préface la certitude de l'ancienne histoire chinoise qu'il faisait remonter d'une manière certaine à une date qui pouvait être gênante pour les tenants de la Vulgate. Un des PP. de Lyon

\footnotetext{
1 Voir p. 151 sq.

2 Ou peut cependant rappeler aussi que le P. Gaubil donnait comme argument pour que I'on acceptât la version des Septante la nécessité d'admettre l'existence des empereurs chinois, Yu, Chun [Chouen], et Yao dont personne ne doutait en Chine, mais dont les dates ne pouvaient se concilier avec la Vulgate, et il écrivait dans son Histoire de l'astronomie chinoise : "Ceux qui regardent la chronologie de la Vulvate comme la seule qu'on puisse suivre, ne pourroient le dire sans exposer la religion; le gouvernement chinois procéderoit contre eux... puisqu'il s'ensuivroit de la que les empereurs Yu, Chun Yao par exemple n'ont jamais été en Chine. Cela révolteroit les esprits. » Mais ce passage n'a pas été imprimé par le P. Souciet. (Brucker. Correspondance scientifique d'un missionnaire, Revue du monde catholique, $\mathrm{t}$. LXXVI, p. 366-7).
} 


\section{La Chine et la formation de l'esprit philosophique en France}

ou de Paris - et vraisemblablement le P. Souciet ${ }^{1}$ - lui demanda sans doute d'apporter des corrections ou des atténuations à cette préface pour tâcher d'arriver à une conciliation entre la chronologie chinoise et la chronologie de la Bible, et si nous n'avons pas la lettre du Jésuite de France, nous avons une réponse du P. de Mailla qui est assez claire pour que nous comprenions la nature des demandes qui lui étaient faites :

«.... V. R. voit assez, parce que j'ay eu I'honneur de lui dire ${ }_{p}$. 251 jusqu'ici, s'il n'est pas impossible de réduire la chronologie chinoise à celle du texte hébreu et de la Vulgate. Ce n'est pas qu'à luy parler ingénument je n'entends pas trop bien ce qu'elle prétend par réduire la chronologie chinoise à etc.... ; voudroitelle dire que pour la diminuer et l'accourcir, il faudroit en retrancher quelques règnes ou en diminuer la longueur; cela ne se pourroit faire qu'au-dessus du règne de Tchong kang, car l'éclipse de 2155 est un point auquel on ne pourroit toucher ; or M. R. P. il me paroit impossible, sans renverser tout ce que nous lisons dans le Chu-king ou sans le supposer faux, de pouvoir

1 Il fait remonter en effet I'histoire certaine de la Chine jusqu'à Fou hi, dont l'existence et le règne en Chine lui semblent certifiés par le témoignage de Confucius. Moyriac de Mailla, Histoire Générale de la Chine, p. p. I'abbé Grosier, Paris, 1777, t. I, p. xxv sq. Le P. Souciet au contraire dans ses Fastes du Monde ou Abrégé de chronologie depuis la Création jusqu'à Jésus-Christ admet les dates de la Vulgate : il fixe le Déluge à 2365 av. J. C., la naissance de Phaleg et la dispersion des peuples à 2264, la conjonction des cinq planètes, qui se serait produite en Chine sous le cinquième empereur à 2003 (suivant les observations de Cassini). Cette période de 261 ans peut paraître un peu courte pour que les Chinois aient eu le temps de passer des plaines de Sennar jusqu'en Chine, de s'organiser en corps de nation, de construire des observatoires pour faire des observations astronomiques. Mais ces difficultés que précisément feront valoir les philosophes n'existaient pas pour les chronologistes qui ne raisonnaient que sur des chiffres, et se trouvaient toujours fort à l'aise, pourvu qu'il n'y eut pas de contradiction formelle entre les dates elles-mêmes. (Recueil de Dissertations du P. E. Souciet de la Compagnie de Jésus, t. II). 


\section{La Chine et la formation de l'esprit philosophique en France}

faire la diminution qui seroit nécessaire et ce qui est infaisable pour peu d'esgard qu'on ait au sentiment général, constant et invariable de la nation dans tous les temps.

«Mais recourir, dit V. R., a celle des $L X X \ldots$, on pourro it compter qu'en Europe généralement parlant cela seroit mal reçu. Nous ne saurions qu'y faire et je crois que V. R. ne me conseilleroit pas de débiter à l'Europe des faussetez pour I'engager à mieux recevoir I'histoire que je traduis, je dis faussetez parce que après les diligences et les examens que j'ay faits, dont je rends raison dans ma préface, je crois impossible de trouver chez les chinois quoy que ce soit de raisonnable qui favorise I'opinion de la Vulgate $\gg 1$.

Le résultat fut que I'histoire du P. de Mailla ne fut pas publiée, malgré les efforts de Fréret pour la faire imprimer ${ }^{2}$ et qu'elle dut attendre jusqu'en 1777 pour trouver un éditeur. Nous avons vu d'ailleurs ${ }^{3}$ que le P. Parrenin réclamait à cor et à cri qu'on voulût bien permettre aux Jésuites qui publiaient des travaux sur la Chine d'augmenter la durée du monde. Le P. Gaubil dans sa correspondance faisait les mêmes demandes pressantes. Les Jésuites de Paris, notamment le P. du Halde, leur répondaient seulement en laissant de côté, sans les publier et sans en tirer parti, les écrits qui leur venaient de Pékin.

\footnotetext{
$1 \mathrm{H}$. Cordier, Documents inédits pour servir à I'histoire ecclésiastique de I'Extrême-Orient, Revue de l'Extrême-Orient. t. III, p. 70.

2 Voir notre thèse complémentaire, Documents inédits, p. 150.

3 Voir plus haut, p. 150-1.
} 


\section{La Chine et la formation de l'esprit philosophique en France}

Parmi les Jésuites missionnaires en Chine qui s'adonnèrent aux études chinoises il faut distinguer deux groupes bien marqués : ceux qui crurent à l'antiquité de la Chine en tant que nation, et ceux qui n'y crurent pas. Au premier groupe appartiennent les PP. Gaubil, Parrenin, Régis, de Mailla ; au second, les PP. Bouvet, de Prémare et quelques autres, en mettant à part le P. p.252 Foucquet qui quitta la compagnie de Jésus dès $1723^{1}$. Les premiers, à la suite de la mort de l'empereur Kang hi et de la persécution qui s'éleva sous son successeur, eurent malgré tout la permission de rester à Pékin, tandis que les autres, à part le P. Bouvet, furent relégués à Canton d'abord et ensuite à Macao. Tous avaient évidemment pour principe de favoriser du mieux qu'ils pouvaient la diffusion du christianisme, et tous ils pensaient aussi que le moyen le plus favorable de faire une moisson fructueuse était de montrer aux Chinois que les traditions judaïques pouvaient être admises par eux, et que les livres de Moïse n'étaient pas en contradiction avec les livres canoniques de la Chine. Mais tandis que les premiers, acceptant I'ancienne histoire chinoise, telle qu'elle se trouve établie par la tradition, essayaient de faire entrer I'histoire de la Chine dans le cadre de I'histoire des peuples, telle que la rapporte Moïse, les autres niaient qu'on pût trouver dans les livres canoniques de la Chine I'histoire de la Chine à ses origines et ils y cherchaient des traces des enseignements des premiers hommes et l'annonce d'un Messie. Les uns étaient des

\footnotetext{
1 Sommervogel, op. cit., art. Fouquet, t. III, col. 903. Le P. Sommervogel orthographie mal le nom de ce Jésuite qui signait toujours Foucquet, avant qu'il fût nommé évêque d’Eleuthéropolis.
} 


\section{La Chine et la formation de l'esprit philosophique en France}

historiens, les autres des théologiens symbolistes, ou comme disait Frérot, des figuristes.

Le plus audacieux et le plus radical de ces figuristes fut assurément Foucquet, qui niait toute authenticité de I'histoire chinoise jusqu'au Ve siècle av. J.-C. et qui dut pour cette raison (et aussi pour son attitude dans la Querelle des Cérémonies chinoises) quitter la mission, car il la mettait en danger, les Chinois pensant que c'était un crime digne de mort de nier l'ancienne histoire chinoise. Foucquet, lorsqu'il ne fut plus jésuite, et qu'il se fut établi à Rome avec le titre d'évêque d'Eleuthéropolis que le Pape lui donna, publia une Tabula chronologica historiæ sinicae où il voulait montrer que I'histoire authentique de la Chine ne pouvait remonter plus haut que le ve siècle av. J.-C. Cette table chronologique n'était en réalité que la traduction d'une table chinoise établie par un certain chronologiste Niau, d'une grande famille chinoise sans doute, mais qui vivait au $X V I I^{e}$ siècle, et qui n'était même pas bachelier ${ }^{1}$. Le peu d'autorité de cet historien, que les autres Jésuites traitaient d'ignorant, n'était pas pour embarrasser Foucquet, et il p.253 avouait même un jour à l'abbé de Rothelin qu'à son avis personnel la chronologie certaine de la Chine ne pouvait remonter plus haut que 296 ans av. J.-C. : «Pour moi, je suis persuadé qu'avant Tsin chin houng [Ts'in che Houang] il n'y a jamais eu dans la Chine aucun empereur. Elle estoit partagée

\footnotetext{
1 Le P. Parrenin l'écrivit à de Mairan en 1732 et 1735 : « ce mandarin encore en vie pour lors n'était pas même bachelier et ne pouvait en aucune manière être considéré comme représentant l'opinion des lettrés de son pays. » Jos. Brucker, Correspondance scientifique d'un missionnaire, Revue du monde catholique, t. LXXVI, p. 372.
} 


\section{La Chine et la formation de l'esprit philosophique en France}

en plusieurs Roiaumes. Ce Prince maistre d'un Roiaume appelé Tsin dont la province de Chensi faisoit partie, dompta six autres Rois et se fit monarque. Il prit alors le titre de Chi Hoang comme qui diroit le Premier Auguste »1. Mais il ne donne pas plus de raisons de cette persuasion intime qu'il n'indique les autorités sur lesquelles il s'appuie pour accepter une semblable chronologie. Ses principes sont la norme de sa chronologie et non la chronologie la norme de ses principes.

Quelle est donc sa théorie sur l'ancienne histoire chinoise ? Son principe fondamental est que la langue chinoise est composée de caractères hiéroglyphiques. Et qui dit hiéroglyphe dit symbole. Tout caractère chinois peut donc être considéré de deux manières : ou dans son sens vulgaire, tel que l'entendent les non-initiés ou dans son sens symbolique que seuls sont capables de comprendre les initiés, c'est-à-dire ceux qui ont le privilège de la révélation du christianisme. Les premiers, c'est-àdire tous les Chinois, étant incapables de comprendre le sens véritable de ces livres leur donnent une interprétation erronée et ils y veulent trouver le récit des événements de l'ancienne histoire chinoise. Les autres, en décomposant les caractères chinois pour en analyser les éléments retrouvent des symboles qui ne peuvent s'expliquer que par le christianisme.

«Chaque charactère représentant l'idée au moins d'un Être si le charactère est très simple, ou les idées de quelques Êtres s'il se trouve plus composé, en tant que ces Êtres eux-mêmes sont images en quelque sorte de leur Autheur ou de leur Réparateur,

1 Lettre du 3 novembre 1738 . Cf. notre Thèse complémentaire, Documents inédits, p. 34. 


\section{La Chine et la formation de l'esprit philosophique en France}

il s'ensuit que chaque charactère renferme toujours quelque sens qui a rapport à la Religion, et ainsy qu'il signifie quelque chose de sacré, mais ce sens sacré qui est foncier, primitif, essentiel, est voilé par le sens usuel et secondaire qui est superficiel comme l'écorce du premier. Ces deux sens sont fort différens I'un de l'autre quoiqu'ils ayent entre eux de la liaison » 1.

p.254 Et voici comment en partant de ce principe, Foucquet raisonnait pour en tirer des conséquences contre la chronologie chinoise. Il trouve par exemple dans le Chou-king le nom d'un personnage Heou tcie dont le hiéroglyphe, interprété symboliquement veut dire : né d'une Vierge mère. Or, il n'y a qu'un Être qui soit né d'une Vierge mère : «il est impossible que cet homme soit né ou ait vécu dans la Chine. Notre foi ne permet pas de le penser, nul Docteur ne l'admettra... ». Cela posé, on peut en tirer de multiples conséquences qui se déduisent logiquement avec une rigueur que nous craindrions d'affaiblir en ne citant pas textuellement :

$\ll \ldots$... hi heou tcie ne fut jamais un Chinois, $s^{\prime} i l$ ne nacquit jamais dans la Chine, ce corollère redevenant principe fécond, que d'importantes véritez n'en vont pas naitre ?

$\left.1^{\circ}\right)$ Donc tout ce que les Chinois depuis qu'ils sont aveugles, c'est-à-dire depuis plus de deux mille ans, appuient sur ce heou Tcie comme un héros de leur pais, tout cela, dis-je, est appuyé sur un fondement ruineux et ne peut plus subsister.

1 Foucquet, Essai d'introduction préliminaire à l'étude des Kings, B. N. Fr. 12009 , f. 14. 


\section{La Chine \\ et la formation de l'esprit philosophique en France}

$2^{\circ}$ ) Donc Tice que I'on fait son père et un prétendu Empereur chinois est un homme chimérique.

$\left.3^{\circ}\right)$ Donc ces personnages qui s'entretiennent avec Heou Tcie dans le Chu king, comme Chuh, comme Yu, ne furent jamais à la Chine des hommes réels.

$4^{\circ}$ ) Donc Yao qui dans le même Chu King transmet I'Empire à Chun ne luy transmet point I'Empire chinois mais un Empire d'un ordre plus élevé et I'Empire chinois n'eut jamais cet Yao pour son fondateur.

$5^{\circ}$ ) Donc $\mathrm{Yu}$ que le Chu king dit avoir remédié au Déluge sous Yao par ordre de Chun ne fut point un Chinois et cet Écoulement des eaux fait à la Chine par le grand Yu est encore une fabuleuse imagination.

$\left.6^{\circ}\right)$ Donc la prétendue Dynastie ou première famille Impérialle appelée des Hia dont on veut que cet Yu fut le fondateur, doit être comme le reste réléguée dans I'Empire des fables.

$\left.7^{\circ}\right)$ Donc Wen Wang que les Interprètes et autres écrivains modernes font descendre de Heou Tcie à la $15^{\mathrm{e}}$ génération est ainsi que les précédens un héros imaginaire que l'ignorance, I'orgueil, la témérité des Interprètes ont enfanté ».

Donc de l'interprétation symbolique d'un seul caractère chinois résulte par voie de déduction la négation de l'existence des trois premières dynasties chinoises. 


\section{La Chine et la formation de l'esprit philosophique en France}

Ce n'est pas le lieu d'examiner ici les conclusions que Foucquet tirait de ses principes pour démontrer que les cérémonies chinoises p.255 étaient des cultes idolâtriques, puisque selon lui l'idolâtrie était née dans le monde depuis que les peuples avaient perdu le sens symbolique de leurs anciens livres pour les interpréter historiquement. Cette divergence d'idées avec ses confrères les Jésuites sur les cultes chinois fut une des causes pour lesquelles il dut quitter la Compagnie de Jésus. Nous aurons aussi l'occasion d'examiner dans un autre chapitre les opinions de Foucquet sur les idées religieuses des peuples primitifs. Contentons-nous de constater pour l'instant qu'il fut un adversaire résolu de l'antiquité chinoise, mais un adversaire qui ne fut guère dangereux. Sa Table chronologique ne fut imprimée qu'à Rome et en Chine, I'Explication de cette table ne trouva place que dans une collection anglaise ; quant à son Essai d'Introduction à l'intelligence des Kings, bien qu'il en eût envoyé des exemplaires en France ${ }^{1}$, il ne fut jamais publié. D'ailleurs Foucquet aimait à s'entourer de mystère. Il demandait à ses correspondants, I'abbé Bignon ou l'abbé de Rothelin, le secret sur ce qu'il leur envoyait : « Je crains trop le grand jour, disait-il, la matière est des plus jalouses » 2 .

D'ailleurs Foucquet se heurtait à une difficulté insurmontable qu'il n'ignorait pas. S'il niait en effet l'authenticité de la chronologie et de l'histoire chinoises, il ne niait pas l'existence en Extrême-Orient d'un peuple qui dès les temps préhistoriques

1 Lettre à l'abbé Bignon, 27 novembre 1729. B. N. Fr. 22228, f. 165.

2 Lettre à l'abbé de Rothelin, 27 avril 1735. Voir notre Thèse complémentaire, Documents inédits.... p. 22. 


\section{La Chine et la formation de l'esprit philosophique en France}

avait recueilli les traditions des premiers hommes. Il niait I'antiquité du peuple chinois, mais il ne niait pas I'antiquité du monde et il conférait à un peuple établi en Chine le privilège d'avoir recueilli la parole de Dieu par la tradition des patriarches. Tout comme le P. Le Comte, il dépouillait donc le peuple juif de son privilège, mais tandis que le $\mathrm{P}$. Le Comte prétendait que la tradition s'était conservée pure depuis la plus haute antiquité, Foucquet pensait qu'elle s'était altérée au point que la clef de la doctrine s'était entièrement perdue pour le peuple chinois : « La principale [des objections] se tire des prérogatives du peuple juif sur tous les autres peuples de l'univers. Il sera question de montrer que ces prérogatives ne peuvent empescher de trouver chés une nation infidèle, mais la plus ancienne qui soit dans le monde, des Livres chiffrés mystérieux, sacrés, altérés pourtant et dans lesquels sont voilées sous des symboles impénétrables à l'esprit humain les plus hautes vérités de la Religion. Si on disoit que ces vérités sont connues ${ }_{\text {p.256 }}$ de cette nation, qu'elle entend les livres mystérieux et scellés, alors l'objection aurait sa force et pourroit embarrasser, mais quand on dit que cette nation est aveuglée sur cette vérité et que depuis des milliers d'années elle est à l'égard des livres comme dans une nuit obscure, quelle atteinte donne-t-on aux prérogatives de la nation des Hébreux, à leurs Prophètes, à leur culte, à leur sacerdoce et surtout l'inestimable avantage d'avoir veu naistre le messie chez eux ? Depuis trois mille ans et peut-être plus, la nation chinoise conserve des monumens beaucoup plus anciens qu'elle, où est voilé le système des vérités que nous croions. Elle avoue ellemesme qu'elle en a perdu l'intelligence et il est de fait qu'elle n'y 


\section{La Chine et la formation de l'esprit philosophique en France}

peut plus rien comprendre parce qu'une erreur fatale lui a fait appliquer à son pais ce qui désignoit I'empire universel du Saint des Saints $\gg 1$.

Quel était donc ce Saint Patriarche qui avait rassemblé dans les livres - les premiers livres que I'humanité eût possédés les enseignements de Dieu transmis par Adam à ses successeurs ? Quel était ce Patriarche que les Chinois, dans leur aberration, appelaient Fou-hi ? Le P. Bouvet pensait que c'était le patriarche Enoch, qui d'après la tradition était l'auteur de ces anciens livres pré-mosaïques que personne n'avait jamais vus, mais que des savants, comme Peiresc, avaient fait rechercher à

1 Lettre à l'abbé de Rothelin. Voir notre Thèse complémentaire, Documents inédits, p. 12. 


\title{
La Chine et la formation de l'esprit philosophique en France
}

\author{
grands frais dans différents pays du monde ${ }^{1}$. Foucquet trouve
}

1 Cette révélation reçue par les Chinois des patriarches antérieurs au Déluge semble au P. Bouvet la raison pour laquelle la morale et la politique de la Chine se sont conservées pures, malgré l'écoulement des siècles, et la raison aussi qui a préservé la religion chinoise de toute idolâtrie - théorie qui lui permettait d'adhérer aux idées officielles de l'ordre des Jésuites dans la Querelle des Cérémonies chinoises et de rester dans la Compagnie, ce que ne pouvait faire Foucquet : «...Parce que la Chine est une des plus anciennes nations du monde, et qu'elle est sans contredit celle qui de tout tems a montré le plus d'attachement et de respect pour l'antiquité et pour tout ce qu'elle a reçu de ses premiers patriarches ; il est manifeste qu'elle doit avoir conservé dans chacun des susdits chefs plus d'affinité que toutes les autres avec ce peuple primitif et avec la famille de Noé, d'où on doit inférer que ses lois, ses coutumes, la forme de son gouvernement, de sa langue, ses caractères et ses livres canoniques qu'elle conserve depuis plus de 4 mil ans dans une si grande intégrité, si on en croit la tradition générale, doivent avoir retenu jusqu'à présent, au moins quant à l'extérieur qui est moins sujet au changement, presque toute la mesme forme où Noé et ses enfants les laissèrent à leurs descendants, avant la division des peuples : c'est-à-dire dans le mesme estat à peu près où ils les avaient reçus eux mesme avant le Déluge, immédiatement des premiers patriarches du monde, qu'on doit assurément regarder comme l'unique et vraie origine à laquelle il faut rapporter la Religion, les loix, les coutumes, les arts, les sciences, les langues et les caractères de toutes les Nations de I'univers et surtout de la Chine, de toutes les nations n'y en ayant eu aucune, si on en excepte les hébreux, qui paroisse s'être moins éloignée de la pureté de cette commune origine et s'être maintenue plus longtemps dans la connoissance et l'observance de la Loy naturelle. » (B. N. Fr. 17240, $\mathrm{n}^{\circ} 4$, f. 5). Suivant une autre lettre du P. Bouvet et datée du 12 octobre 1729, le P. Tournemine, qui avait d'abord semblé favorable à ces théories qui assimilaient Fo-hi à Enoch, s'était ensuite rétracté et était devenu « un des plus opposés aux nouvelles découvertes de ceux qui prétendent que tous les plus profonds mystères de la loy évangélique se trouvent dans les anciens monumens de la Chine. » (Lettre du P. Bouvet au P. Souciet. Obs. Astr. $(150,7,5)$. Cependant le P. Bouvet n'avait rien ménagé pour essayer de convaincre les PP. Souciet et Tournemine, et il les avait accablés de ses mémoires qui essayaient d'interpréter symboliquement les anciennes annales chinoises. (Cf. H. Cordier, Documents inédits sur I'histoire ecclésiastique de l'Extrême-Orient, Revue de l'ExtrêmeOrient, t. III, p. 219-20). Pour le P. Bouvet, le Déluge, que le Chou-king rapporte au temps de l'empereur Yu, serait le Déluge de Noé. Cependant le P. Bouvet tenait pour la chronologie des Septante. Mais suivant le P. Gollet, un autre symboliste, qui identifiait l'empereur Yao avec le patriarche Jectan, descendant de Sem à la quatrième génération et frère de Phaleg, la chronologie chinoise concorde entièrement avec celle du texte hébreu et de la Vulgate. Pour le P. de Prémare - qui est celui des Jésuites dont les idées se rapprochent le plus de celles de Foucquet - I'histoire authentique et la chronologie certaine de la Chine ne commencent que trois ou quatre siècles avant l'ère chrétienne. (Jos. Brucker, Correspondance scientifique d'un 


\section{La Chine et la formation de l'esprit philosophique en France}

admirable ${ }_{\text {p.257 }}$ cette découverte du P. Bouvet, mais pour luimême il va plus loin. Ce patriarche Enoch, suivant lui, n'est que I'Hermes Trismégiste. «Le plus ancien Mercure Trismégiste dont il s'agit n'est pas différent du Saint Patriarche Enoch ; c'est ce que d'habiles gens ont avancé et imprimé surtout dans Rome même avec l'approbation des puissances et l'applaudissement des sçavants. Or Enoch paraît caché sous le symbole de Fou-hi et d'Hermanubis ou de Cynocéphale : et on ne doit pas s'effraier ou s'effaroucher d'entendre qu'Henoch fut appelé Fou-hi. Il a eu des noms fort différens et aussi extraordinaires que celuy la chez les diverses nations, Mercure chez les Latins, Hermes chez les Grecs, Adaris et Adris et Edris chez les Arabes, Ouriaj et Douvanaj chez les Chaldéens, Taaut chez les Phéniciens, Thoyt et That chez les Égyptiens; Teutates et Esus chez les Gaulois. Pourquoy ne pourroit-on pas dire qu'il fut appelé Fou-hi chez les Chinois ? »1. En outre, Foucquet pense qu'il y a des arguments positifs qui prouvent l'identification de Fou-hi avec Énoch, étant admis comme il le croit qu'Enoch et le Trismégiste ne sont que le même personnage sous deux noms différents. Enoch et Fou-hi en effet ont vécu tous les deux avant le Déluge. Dans la suite des patriarches, Enoch est le septième. Or, on trouve dans la vieille chronologie de la Nation chinoise (il ne ${ }_{\text {p.258 }}$ faut jamais chercher chez le P. Foucquet d'indications ni de références plus précises) une suite de personnages célèbres dont le « chef » n'a rien avant luy et ressemble fort à Adam : le septième est Fou-hi. Enoch fut le maître de I'ancien monde et autheur de toute la

\footnotetext{
${ }^{1}$ Foucquet, Essai..., f. 10.
} 


\section{La Chine et la formation de l'esprit philosophique en France}

Littérature. Or les Chinois en disent autant de Fou-hi. Enoch laissa plusieurs livres, les Chinois en attribuent aussi un fort grand nombre à Fou-hi. Donc Enoch est certainement Fou-hi. Mais ce dernier fait ne concorde pas, malgré toute l'habileté de Foucquet à étirer les faits en tous sens pour les faire cadrer avec ses théories, avec l'identification de Fou-hi et d' d'Hermes, car d'après la tradition, le « vieux Hermes » aurait composé 36.225 livres, et les Chinois n'en attribuent pas un nombre aussi grand au premier de leurs empereurs. Qu'à cela ne tienne, Foucquet n'est jamais à court d'arguments : ces livres peuvent être des caractères chinois, et selon le calcul que fait Foucquet, le nombre des caractères chinois originaires atteindrait à peu près à ce chiffre.

Il n'est pas ici question d'examiner les conclusions que les Jésuites « figuristes » tiraient de cette interprétation symbolique des anciens livres, au point de vue des idées religieuses ou philosophiques des anciens Chinois. A cet égard, ils différeront d'avis - comme nous le verrons dans le chapitre suivant - non seulement avec leurs confrères de Pékin et de Paris, mais même entre eux. Actuellement, ce qu'il nous importe de constater en étudiant les opinions sur la chronologie chinoise, c'est que ces « figuristes » ne cherchaient pas dans les anciennes annales chinoises I'histoire de la Chine, mais une histoire des origines de I'humanité, analogue à celle que I'on trouve dans les livres mosaïques bien qu'avec un caractère d'authenticité et de certitude plus grand, parce que l'origine en était plus lointaine. Pour ces théologiens symbolistes, la chronologie qu'ils adoptent est une sorte de postulat qui rend possible leur interprétation 


\section{La Chine et la formation de l'esprit philosophique en France}

figurative des anciens livres chinois. La chronologie chinoise ne les intéresse pas pour elle-même. Ils cherchent seulement en montrant l'incertitude de cette chronologie, à ruiner l'opinion avantageuse que I'on commençait à se faire en Europe de I'antiquité de la nation chinoise. Ils sont théologiens, plus encore qu'historiens. Mais ils furent en relation avec des savants d'Europe, notamment Fourmont et Fréret et à cet égard leur action ne fut pas négligeable.

Les Jésuites de Pékin ont eu pour préoccupation dans leurs études historiques de prouver contre leurs confrères de Canton - ceux que Fréret appelait les figuristes - l'authenticité des anciennes annales chinoises et la certitude de la chronologie chinoise. Fuvre ${ }_{\text {p.259 }}$ difficile sinon dangereuse, puisqu'ils avaient à lutter d'abord contre l'indifférence ou l'ignorance des savants d'Europe, ensuite contre I'hostilité de leurs confrères de Canton, et contre les préjugés des Jésuites de Paris, qui dans leur admiration aveugle pour la Vulgate, ne tenaient pas à voir reculer l'origine du monde. A cette tâche pleine de difficultés se sont appliqués avec des aptitudes diverses et un inégal bonheur mais avec une ardeur semblable les PP. Gaubil, Parrenin, Régis et de Mailla.

Sans entrer dans le détail des diverses études de ces PP. et pour n'en retenir que les préoccupations essentielles, du moins au point de vue de la chronologie, on peut dire que leur effort porta principalement sur les preuves de fait qui certifiaient la réalité de l'éclipse dont parle le Chou king et qui pouvait être rapportée à I'année 2155 av. J.-C. Mais tandis que le P. Gaubil 


\section{La Chine et la formation de l'esprit philosophique en France}

S'attachait aux preuves astronomiques, le P. de Mailla faisait la critique des textes anciens qui rapportaient les circonstances de cette éclipse.

Déjà, dans son Histoire de l'Astronomie chinoise, publiée par le P. Souciet, en 1732, le P. Gaubil s'était servi de l'argument que fournissait la certitude de cette éclipse pour juger les différentes chronologies chinoises, et notamment pour rejeter la chronologie du Tchou chou, qui ignorant cette éclipse, ou la passant du moins sous silence, permettait de douter de l'existence des trois premières dynasties chinoises, les familles Hia, Chang et Tcheou, ce qui était d'une aide précieuse pour les figuristes. « L'éclipse de Chouking, dit le P. Gaubil ${ }^{1}$, est une grande preuve pour la durée que Pan-kou donne aux trois familles Hia, Chang, Tcheou ». Et d'autre part cette éclipse « rapportée par Confucius sous Tchong-kang, et trouvée selon les règles du calcul et Chinois et Européen au 12 octobre à la Chine, I'an 2155 avant Jésus-Christ, est une très grande preuve contre la chronologie de Tsou-chou »2. Mais avec son esprit critique habituel qui ne faisait pas de lui l'esclave même de ses propres idées, le P. Gaubil indiquait ce qui manquait à sa démonstration : «...dans le fonds ce n'est pas une démonstration absolue. Car, $1^{\circ}$ il faudroit savoir démonstrativement si la neuvième lune d'alors étoit la neuvième lune d'aujourd'hui ; $2^{\circ}$ il faudroit savoir démonstrativement si la Constellation Fang d'alors est celle d'aujourd'hui, et si elle avoit la même étendue. Je sai que le

\footnotetext{
1 Histoire abrégée de l'Astronomie chinoise, p. 41.

2 ibid., p. 43.
} 


\section{La Chine et la formation de l'esprit philosophique en France}

commun des Chinois depuis les Han asseurent ces deux points ; mais je sai aussi que depuis les Han jusqu'à l'Éclipse, il y a plus p.260 de 2000 ans : or qui oseroit assurer que les Han ont su certainement ces deux choses $\gg 1$. Et ces restrictions qui sont tout à I'honneur du P. Gaubil, parce qu'il était en lui-même persuadé que cette éclipse avait été observée à l'époque indiquée - devaient plaire au P. Souciet qui eût préféré beaucoup que cette éclipse n'eût été calculée qu'après coup, ne conférant par suite aucun caractère d'authenticité aux anciennes chronologies chinoises. Mais le P. Gaubil possède assez de ressources d'esprit pour tirer avantage même des critiques qu'il peut faire à ses propres théories. S'il s'est écoulé 2000 ans entre le moment de l'éclipse et le moment où elle a été rapportée ; d'autre part, si les Han ont été ignorants en astronomie et n'ont pas eu de principes suffisants pour calculer une éclipse si ancienne, ne pouvant en aucune manière rapporter juste à une constellation le lieu du soleil pour un temps si ancien, « puis donc que ces auteurs rapportent I'Éclipse de Soleil à un lieu d'une Constellation que le calcul vérifie plus de 1900 ans avant leur dynastie, il faut que ces auteurs ayent rapporté fidèlement ce qu'ils ont trouvé sur une observation si ancienne »2.

Un autre argument en faveur de la certitude de la chronologie chinoise est l'invention du cycle de 60 ans. « Ce cycle, dit le P. Gaubil ${ }^{3}$, est de la première antiquité. L'Histoire chinoise que

\footnotetext{
1 ibid., p. 43.

2 Histoire de I'Astronomie chinoise, p. 142.

3 Appendice à l'Histoire de l'Astronomie chinoise, p. 137.
} 


\section{La Chine et la formation de l'esprit philosophique en France}

I'Empereur Cam-hi [Kang hi] a fait traduire en Tartare, commence à mettre les caractères du cycle à l'an 2357 avant Jésus-Christ ». Sans doute le P. Souciet, dans les notes qu'il met au texte du P. Gaubil suggère que cette raison n'est pas démonstrative « car on a pu après coup et depuis que ce cycle est inventé, l'appliquer aux années qui ont précédé son invention, comme nous avons appliqué l'ère de Jésus-Christ à tous les siècles qui ont précédé Denis le Petit qui en est I'inventeur »1. Mais le P. Gaubil ajoute en faveur de l'ancienneté de ce cycle un autre argument qui, pour les Jésuites de Chine, est « démonstratif » sans qu'il ait ce caractère pour le $P$. Souciet : le tribunal des Mathématiques, autorité souveraine en Chine pour les questions d'authenticité des antiquités chinoises, fixe la première année du premier cycle à cette année 2357 avant J.-C. ${ }^{2}$.

Le P. Gaubil, qui ne veut s'avancer que sur un terrain solide est trop prudent pour fixer la date du premier empereur chinois, p.261 que ce soit Yao, que ce soit Fou-hi, mais cette certitude qu'il a d'une observation d'éclipse en Chine en 2155 et de l'invention d'un cycle sexagénaire en 2357 l'oblige à mettre des empereurs en Chine au moins en 2400 av. J.-C. C'est-à-dire avant le Déluge, du moins d'après la Vulgate.

Cette publication du P. Gaubil, malgré toutes les restrictions, toutes les objections apportées par l'éditeur, le P. Souciet, était audacieuse en son temps puisqu'elle tendait à établir

\footnotetext{
1 ibid., note 1.

2 ibid., p. 137.
} 


\section{La Chine et la formation de l'esprit philosophique en France}

I'authenticité de l'ancienne histoire chinoise jusqu'à une date qui la mettait en contradiction avec I'histoire biblique, et cela non seulement sur la foi de textes chinois, toujours sujets à chicanes, mais d'après des vérifications de calculs astronomiques. Ce livre parut si curieux à Fréret, qui depuis de nombreuses années s'intéressait à la Chine, qu'il se mit en relations directement avec le P. Gaubil.

C'est de 1732, I'année même où parut le livre du P. Gaubil que datent les brouillons de la première lettre adressée par Fréret à ce Père ; brouillons incomplets malheureusement, mais suffisants malgré tout pour marquer que c'est lui qui a sollicité cet échange de lettres qui devait être si fructueux, et pour nous laisser entrevoir la nature des questions sur lesquelles il avait besoin d'éclaircissements, au moment où il préparait son Mémoire de 1733, De l'antiquité et de la certitude de la chronologie chinoise ${ }^{1}$.

Fréret, cependant, était en relations avec d'autres Jésuites de Chine, les PP. de Prémare et Collet, tous deux de Canton et tous deux figuristes. Un hasard, un ami commun les avait mis en relations. Sans doute Fréret, en lisant les mémoires que lui fournissaient ces Jésuites ne se départait jamais de son attitude critique, comme en témoignent certaines de ses lettres à ses correspondants de Chine 2, mais il n'en resta pas moins influencé, même après les renseignements que lui transmit le $P$. Gaubil, par les premières indications qu'il avait reçues du P. de

\footnotetext{
1 Mémoires de l'Académie des Inscriptions, t. X (1736), p. 377, sq.

2 Voir notamment la lettre au P. Gaubil de 1736, Documents inédits..., p. 140.
} 


\section{La Chine et la formation de l'esprit philosophique en France}

Prémare et du P. Gollet. Jamais il ne put admettre la réalité de cette éclipse de 2155 av. J.-C. que les figuristes avaient intérêt à nier, car s'il était vrai qu'une éclipse dont les anciens livres chinois donnaient les détails s'était réellement produite en Chine dans les circonstances indiquées par ces livres, et à l'époque désignée, il ne pouvait plus être question de prétendre que les livres ne racontaient pas I'histoire de la Chine et qu'ils étaient des livres transmis par les premiers patriarches et dont les Chinois avaient perdu la clef.

p.262 Ce n'est pas que Fréret fût devenu lui-même figuriste, comme il le disait. Il a trop sévèrement qualifié cette méthode, non seulement dans ses lettres au P. Gaubil mais encore au P. de Prémare, pour qu'il puisse y avoir le moindre doute à cet égard : «Est-il possible, écrit-il au P. de Prémare 1, que de bons esprits se laissent gaster par cette maladie et qu'elle devienne assez générale pour infecter également aux deux bouts de la terre des gens plus éloignés encore par leurs sentiments que par les lieux qu'ils habitent, les Jésuites et les Jansénistes ? » Et bien que Fréret s'excusât de cette « franchise peut estre trop grande », cela sans aucun doute ne devait pas faire plaisir au P. de Prémare.

Rien en effet n'était plus étranger à l'esprit critique de Fréret que cette méthode - si I'on peut dire - des figuristes qui, sur les moindres ressemblances entre I'histoire biblique et I'histoire de la Chine, cherchaient à ramener celle-ci à celle-là. L'histoire

\footnotetext{
1 Lettre de 1732 . Cf. notre thèse complémentaire, Documents inédits..., p.
} 45. 


\section{La Chine et la formation de l'esprit philosophique en France}

chinoise rapporte-t-elle par exemple qu'il y eut en Chine deux famines sous des empereurs chinois que les figuristes prétendent supposés, le P. Collet émet I'hypothèse que ces deux famines de sept ans et de trois ans, sont celles qui sont marquées par l'Écriture au temps de Jacob et au règne d'Achaz. Mais Fréret avant d'entrer dans le détail de cette argumentation invoque d'abord un argument de bon sens - première condition de l'esprit critique - qui à lui seul rendrait inutile toute discussion ultérieure : « ...on se persuadera très difficilement que ces deux famines se soient estendues depuis la Judée et l'Égypte jusques à la Chine, la distance de ces pais et la hauteur des montagnes qui les séparent ne permettant guère de supposer que la même intempérie des saisons ait régné en même temps sur plus de la moitié de notre hémisphère ... ${ }^{1}$. Bien qu'il

puisse sembler que cet argument eût dû venir à l'esprit de tout le monde et qu'il n'y ait pas lieu d'en louer Fréret, le bon sens était cependant la chose qui manquait le plus aux chronologistes, et pas plus qu'ils ne tenaient compte dans leurs calculs du temps nécessaire pour la multiplication des hommes à I'origine, ils ne voulaient s'embarrasser de la difficulté qui résultait de l'immensité des distances entre la Judée et la Chine.

Esprit précis et qui veut de solide raisons pour se laisser convaincre, Fréret ne pouvait se satisfaire des analyses tendancieuses des caractères chinois que faisaient les allégoristes et qui leur p.263 permettaient de trouver « tout dans

\footnotetext{
${ }^{1}$ Lettre au P. Collet, ibid., p. 51.
} 


\section{La Chine et la formation de l'esprit philosophique en France}

tout »1, c'est-à-dire des symboles des histoires rapportées par Moïse jusque dans les caractères chinois. Esprit historique, pourrait-on dire, il avait trop le sens de la diversité des époques, pour adopter, comme le faisait le P. Foucquet certaines traditions des Tao-sseu comme d'anciennes traditions chinoises : «Par quelques passages des écrits du R. P. Foucquet que j'ay vus il me semble qu'il se sert beaucoup de ces sortes de Livres. Il est important de mettre les Européens au fait là-dessus et de prévenir l'impression que pourroient faire les ouvrages que le $P$. Foucquet a composés et qu'il promet de publier. Il faut montrer d'avance que les difficultés contre l'histoire et la chronologie chinoise fondées sur de semblables autheurs n'ont pas plus de force qu'en auroient contre la certitude de I'histoire de France des difficultés tirées de nos vieux romans de chevalerie $\gg 2$.

Prouver la certitude de la chronologie et de l'ancienne histoire chinoises malgré les difficultés et les obscurités qui résultent du recul du temps fut le but de Fréret lorsqu'il composa sa première Dissertation lue en 1733 à I'Académie des Inscriptions et Belles Lettres, donc avant même qu'il ait pu recevoir des renseignements des PP. de Pékin, et d'après les seuls documents que lui fournissaient les PP. de Canton ou I'Histoire de I'Astronomie Chinoise du P. Gaubil. Mais pour prouver

\footnotetext{
1 Outre la question de méthode il est bon de remarquer que Fréret qui, du temps où il travaillait avec le Chinois Hoang, avait cherché à découvrir le caractère particulier de la langue chinoise, ne croyait pas du tout que les caractères chinois étaient des hiéroglyphes ; mais il était persuadé que ces caractères étaient des combinaisons d'idées et non des représentations d'objets concrets. Cf. son mémoire sur l'Ecriture des Chinois (Mémoires de I'Académie des Inscriptions, t. VI).
}

2 ibid., p. 143. 


\section{La Chine et la formation de l'esprit philosophique en France}

I'authenticité de l'ancienne histoire chinoise il fallait avant tout donner une méthode, et une méthode historique indépendante de tout système religieux, ne se prévalant pas d'une affirmation de la Bible pour repousser un fait d'une histoire profane contraire à cette affirmation. Établir la chronologie chinoise sur les seuls documents chinois, mais après en avoir fait une étude critique, fut le principe de la méthode de Fréret, sans qu'il cherchât, comme le faisaient tous les chronologistes, une conciliation entre la chronologie chinoise et la chronologie sacrée : «Par rapport à la conciliation de la chronologie chinoise avec la chronologie sacrée, je croy que le préliminaire absolument nécessaire est de commencer par les establir l'une et l'autre séparément et indépendamment l'une de l'autre, après quoy vous les p.264 comparerez ensemble et vous verrez quels points elles auront de commun entre elles $\gg 1$.

Et pour justifier son principe même devant des religieux comme les Jésuites de Pékin, il ne craignait pas d'invoquer l'intérêt qu'il pouvait y avoir à employer cette méthode afin de convaincre les esprits forts : «Cette naissance [de Phaleg] est le point fixe duquel les Chrétiens, les Juifs, les Mahométans ne peuvent s'écarter sans donner atteinte aux fondements de leurs Religions qui supposent également la certitude et l'inspiration des Livres écrits par Moïse. Cette raison qui est décisive pour vous et pour moy n'est pas cependant celle sur laquelle il faut appuyer dans un siècle où règne le libertinage d'esprit. Ce seroit prester des armes aux esprits forts, ils prendroient cela pour un

\footnotetext{
1 ibid., p. 39.
} 


\section{La Chine et la formation de l'esprit philosophique en France}

aveu de l'opposition de la chronologie chinoise à celle de I'Écriture. Il faut establir la chronologie chinoise pour elle-même et que la convenance de cette chronologie avec celle de l'Écriture paroisse seulement un corollaire du système. Il ne faut pas laisser même soupçonner quel a esté l'objet que I'on s'est proposé $\gg 1$.

Son but et sa méthode une fois fixés, comment Fréret va-t-il échapper aux graves dangers qui attendent I'historien assez audacieux pour prouver la certitude d'une histoire qui remonte au Déluge ? Il lui faut d'abord désarmer les sceptiques, qui ne manquent pas, surtout à une époque où le « pyrrhonisme historique $\gg 2$ semble si répandu. Quant à Fréret il n'est rien moins que sceptique. Déjà quelques années auparavant, il avait rompu des lances contre Levesque de Pouilly devant I'Académie des Inscriptions ${ }^{3}$ pour démontrer qu'il était possible d'arriver à quelques connaissances certaines sur les origines du peuple romain ; et, généralisant les observations qu'il avait faites par un travail minutieux et précis sur une période particulière de I'histoire, il posait en principe certaines conditions nécessaires et suffisantes pour qu'il fût possible de prouver l'authenticité des faits anciens : ou l'existence de témoignages authentiques contemporains des faits, ou l'existence d'une tradition

\footnotetext{
${ }^{1}$ Lettre au P. de Mailla, 1737. ibid., p. 180.

2 Lettre au P. de Prémare, 1735. Ibid, p. 110.

3 Tous les mémoires relatifs à cette question de I'histoire des 4 premiers siècles de Rome, celui de Levesque de Pouilly qui voulait en prouver I'incertitude, et ceux de l'abbé Sellier et de Fréret ses contradicteurs, se trouvent au tome VI des Mémoires de l'Académie des Inscriptions et BellesLettres.
} 


\section{La Chine et la formation de l'esprit philosophique en France}

ininterrompue depuis les faits jusqu'à nous ${ }^{1}$. Aucun théologien évidemment ne pouvait refuser ces p.265 principes, car ces conditions nécessaires mais suffisantes étaient celles-là même qui permettaient de prouver la certitude des faits bibliques. Que si les théologiens refusaient aux histoires profanes qui offraient ces garanties d'authenticité tout caractère de certitude historique, les libertins pouvaient trouver dans ce refus un excellent argument pour nier à leur tour la certitude des faits rapportés par la Bible, qui ne pouvait plus dès lors s'imposer que par l'autorité de la foi, en vertu de la révélation, et perdait par là même son caractère de livre historique. Dans sa correspondance avec les missionnaires ${ }^{2}$, et dans ses mémoires lus à l'Académie ${ }^{3}$ Fréret fait toucher du doigt ce grave danger, allant même jusqu'à prétendre que la foi religieuse est fondée sur la certitude historique ${ }^{4}$. Pour sa part, il est et veut rester historien : il

1 «Par traditions historiques, j'entends ces opinions populaires en conséquence desquelles toute une nation est persuadée de la vérité d'un fait sans en avoir d'autre preuve que sa persuasion même et celle des générations précédentes et sans que cette persuasion soit fondée sur aucun témoignage contemporain subsistant séparément de la tradition même. Pour que ces traditions aient une autorité suffisante, on demande que les faits dont elles déposent aient été publics et éclatants, qu'elles soient anciennes, qu'elles remontent jusqu'au temps des événements mêmes et que du moins on ne puisse en montrer le commencement, qu'elles soient constantes et générales, qu'elles s'accordent avec les témoignages positifs de l'histoire, qu'au moins elles n'y soient point opposées, qu'elles ne soient point détruites par d'autres traditions mieux prouvées ou plus anciennes et par des coutumes et des pratiques religieuses ou politiques établies en conséquence. 》 Réflexions sur l'étude des anciennes histoires et sur le degré de certitude de leurs preuves. Fuvres complètes, Ed. Champollion Figeac., t. I, p. 11-12.

2 Lettre au P. de Prémare, Documents inédits..., p. 110-1.

3 Mémoires de l'Académie des Inscriptions et Belles Lettres, t. XVIII, p. 93.

4 Lettre au P. de Prémare, Documents inédits..., p. 110. 


\section{La Chine et la formation de l'esprit philosophique en France}

applique à l'ancienne histoire chinoise les mêmes principes de critique qu'il applique à I'histoire romaine ou à la Bible.

Loin de partager le pyrrhonisme historique de quelques-uns de ses contemporains - et non des moins savants - il croit à la certitude des anciennes histoires des peuples profanes malgré toutes les difficultés qu'elles présentent, et cette croyance personnelle, il veut la propager. Il ne pense pas comme Fontenelle qu'il doive tenir enfermées dans la main les vérités qu'il a découvertes - tout au moins en ce qui concerne I'histoire, car il en irait peut-être autrement pour la religion - ; au contraire, il veut persuader. Mais pour persuader de la vérité d'un fait particulier il faut accepter d'abord les modes de pensée, les principes de ceux auxquels on s'adresse : il faut couler les idées nouvelles dans le moule des idées admises. Ce principe dialectique, nécessaire à qui veut persuader, Fréret l'a exposé nettement à la fin de son mémoire de p.266 1739 : « La pluspart de nos théologiens en écrivant sur ces matières raisonnent comme si les adversaires dont ils entreprennent de réfuter les opinions avoient les mêmes opinions qu'eux sur ce qui fait le fond de la dispute, et ils ne pensent pas que les principes qu'ils leur opposent pour les obliger de recevoir les traditions des Juifs et de rejeter celles des autres Nations ne sont pas admis par ceux qu'ils combattent. Une des premières règles de la Critique est de n'employer que des principes communs aux deux partis, surtout que ceux que nous attaquons ne puissent pas se servir contre nous des principes d'où nous partons $\gg 1$. Conformément à cette règle, Frérot dans sa première dissertation, lue à

1 Mémoires de l'Académie des Inscriptions, t. XVIII, p. 294. 


\section{La Chine et la formation de l'esprit philosophique en France}

l'Académie des Inscriptions au mois de novembre 1733, part d'un principe que les théologiens les plus rigoureux ne peuvent lui contester : il admet pour le calcul des temps le calcul de la Vulgate et il montre que rien dans la chronologie chinoise ne vient contredire ce système chronologique de la Bible. Non qu'il fût persuadé lui-même de la supériorité du manuscrit des Massorètes sur les manuscrits grecs ou samaritains. Mais de cette manière sa démonstration de la certitude de l'antiquité de la Chine ne risquait pas d'être attaquée dans son principe même par les théologiens les plus rigoureux sur la chronologie : Si j'ay paru suivre le calcul abrégé de la Vulgate dans ma dissertation c'est que, me proposant d'establir la certitude de la chronologie chinoise par sa partie historique qui ne remonte pas au-delà du règne de Yao, il me suffisoit de montrer que ce Prince estoit au plus contemporain des Roys Elamites qui possédoient alors un assez grand Empire et qu'on ne pouvoit proposer contre l'existence de la monarchie au temps d'Abraham aucune difficulté qui ne tombast également sur celle des Elamites prouvée cependant par l'Écriture »1. La démonstration acquiert plus de force si la chronologie chinoise peut se concilier avec le calcul chronologique le plus court, mais cette conciliation n'est pas le but de Fréret ; ce n'est qu'une garantie préliminaire ${ }^{2}$.

L'objet essentiel est de prouver la certitude de la chronologie chinoise contre les « figuristes » qui veulent voir dans les

\footnotetext{
${ }^{1}$ Lettre au P. Gaubil, 1935, Documents inédits..., p. 90.

2 Le P. de Mailla, qui n'a pas très bien compris les intentions de Fréret, lui a reproché d'avoir cru aveuglément des auteurs (c'est-à-dire les Jésuites de Canton) « prévenus que la seule chronologie du texte hébreu est celle que I'on doit suivre. » Histoire générale de la Chine, t. I, p. XcII.
} 


\section{La Chine et la formation de l'esprit philosophique en France}

premiers empereurs chinois Noé et ses ancêtres, et d'autre part, contre ceux qui, désespérant d'establir la conciliation entre la chronologie p.267 chinoise et la chronologie sacrée ne veulent voir dans I'histoire des premiers temps de la Chine qu'« un amas de traditions confuses et peu assurées que les écrivains des siècles postérieurs ont liées les unes aux autres pour en former un seul corps $\gg 1$.

Mais ceci posé, Fréret croit que la chronologie chinoise est susceptible de réductions par elle-même et « indépendamment des raisons que le système religieux veut que nous $y$ fassions » 2. Deux faits le prouvent : d'abord l'étude critique des historiens chinois, qui à mesure qu'ils s'éloignent des origines augmentent la durée des premières époques ${ }^{3}$, ce qui témoigne du désir chez les chronologistes les plus modernes, de faire remonter le plus haut possible leurs origines (et la différence ne va pas à moins de 150 ans environ pour le commencement du règne de Yao, c'est-à-dire pour le commencement de la période historique de la Chine) ; d'autre part, l'éclipse rapportée par le Chou king, qui se serait produite sous le règne de l'empereur Tchong K'ang, cinquième successeur de Yao, ne peut être l'éclipse de 2155 av. J.-C., que le calcul sans doute certifie s'être produite en Chine, mais dans des conditions toutes différentes de celles qui sont rapportées par le Chou king. Et ici Fréret,

1 Mémoires de l'Académie des Inscriptions..., t. X, p. 378-9.

2 Lettre à M. de Mairan, 1733, Documents inédits..., p. 47. Cette lettre serait à citer tout entière, car elle nous révèle d'une manière très nette les intentions de Fréret lorsqu'il écrivit son mémoire de 1733.

3 Mémoires de l'Académie des Inscriptions..., t. X, p. 389. Cf. aussi la lettre à M. de Mairan de 1733. 


\section{La Chine et la formation de l'esprit philosophique en France}

abusant un peu de l'esprit critique, mais influencé d'ailleurs par les Jésuites de Canton, croit trouver dans I'exposé des circonstances qui ont accompagné l'éclipse, non certes une raison de douter de la réalité de cette éclipse, mais tout au moins une raison de douter du règne de cet empereur Tchong Wang, et une preuve que I' « éclipse dont parle le Chou king » ne peut être l'éclipse de 2155 . Le P. Gaubil qui tient à la réalité de cette éclipse lui objecte : « Les difficultés qu'on fait ne rendent pas toujours un fait douteux, il faut voir d'où et de qui vient la difficulté ». Et Fréret rétorque : « Je pense comme vous que les difficultés proposées contre un fait ne rendent pas toujours le fait douteux. C'est pour cela que je ne rejette pas absolument l'observation d'une éclipse sous l'empire de Tchong cang, mais je crois que les difficultés auxquelles certaines circonstances de ce fait donnent lieu nous mettent en droit d'estre un peu plus rigoureux sur les preuves de ces circonstances. C'est là un des premiers principes de la critique $\gg 1$.

p.268 Pour contrôler son hypothèse sur cette éclipse, il se met en relations avec Cassini, par l'intermédiaire de Maupertuis, et il lui fait demander de vérifier par le calcul à quelle époque a pu être observée en Chine une éclipse correspondant par ses circonstances à celle que décrit le Chou king. Cassini trouve l'éclipse de 2007 av. J.-C., ce qui confirme les conclusions de l'analyse critique que Fréret avait faite des historiens chinois et

\footnotetext{
${ }^{1}$ Fréret au P. Gaubil, Documents inédits..., p. 87.
} 


\section{La Chine et la formation de l'esprit philosophique en France}

lui fournit un argument de plus pour diminuer de 150 ans la chronologie chinoise.

La vérification de cette hypothèse qui devait emplir de vanité un savant comme Fréret, entièrement voué à sa tâche d'érudit, semble le laisser indifférent et ne semble même pas avoir chatouillé agréablement son amour-propre. Mais il constate avec satisfaction que la chronologie de la Chine se trouve maintenant établie depuis I'an 2200 avant J.-C. environ, avec la plus grande certitude dont ces matières soient susceptibles ${ }^{1}$. Donc tous les arguments des figuristes deviennent sans valeur, et d'autre part les historiens comme don Calmet qui laissaient de côté I'histoire chinoise, arguant du caractère fabuleux de cette histoire ou de I'incertitude de ses origines, n'auront plus de prétexte pour la passer sous silence puisque Fréret en a établi la certitude historique.

Cependant cette méthode de Fréret qui, passant du connu à l'inconnu remonte l'ordre des temps, semblait aux Jésuites de Pékin vétilleuse, trop chicanière et trop prudente. Ils s'efforçaient pour leur part, comme tous les chronologistes, de fixer le début, la première époque qui pût être datée d'une manière certaine, que ce fût celle de Fou-hi ou celle de Houang ti. Ainsi procède également d'ailleurs le P. du Halde dont le livre parut entre la première et la seconde dissertation de Fréret, au moment où l'échange de lettres entre les missionnaires de Pékin et de Fréret était le plus actif, et dont les Fastes de la Monarchie chinoise, énumérant les différents empereurs, fixent les dates du

\footnotetext{
${ }^{1}$ Fréret à Maupertuis, ibid., p. 60.
} 


\section{La Chine et la formation de l'esprit philosophique en France}

règne de chacun d'eux. Nous avons examiné plus haut ${ }^{1}$, en faisant l'étude critique des écrits des Jésuites sur la Chine, les raisons de convenance pour lesquelles le P. du Halde ne se servit pas pour sa chronologie des écrits du P. Gaubil et du P. Régis qu'il avait pourtant entre les p.269 mains. Il voulait que la chronologie de la Chine pût s'adapter au cadre de la Vulgate car il ne voulait aucunement déplaire aux PP. Souciet et Tournemine, - il voulait aussi que sa chronologie des premiers temps fût assez élastique pour que le P. Foucquet pût y insérer ses explications symboliques. Aussi sa chronologie, loin d'être en progrès sur celle du P. Couplet, est-elle singulièrement plus vague et moins audacieuse. Tandis que le P. Couplet faisait partir I'histoire certaine de la Chine du règne de Houang ti en 2697 av. J.-C., le P. du Halde ne fait commencer le cycle sexagénaire, donc I'histoire certaine de la Chine, qu'au règne de Yao en 2357 av. J.-C., et nous n'essaierons pas d'expliquer comment le P. du Halde peut concilier cette notation du Cycle I qu'il met en marge en face du nom de Yao avec cette remarque incorporée dans le texte : «Ce fut la quarante-unième année du cycle précédent que ce Prince monta sur le trône »2. Bornons-nous à constater que l'audace des Jésuites en ce qui concerne la chronologie chinoise, loin de croître avec le temps ne faisait que diminuer. Il

\footnotetext{
1 Voir p. 171 sq. Frérot, nous l'avons vu, pensait que ce livre n'apportait rien de nouveau. Le P. de Mailla, dans une lettre au P. Combes du 5 novembre, déclare également qu'il n'est pas satisfait de cet ouvrage : «On nous écrit que celui (le livre) du P. du Halde a été bien reçu du public; si vous aviez vu l'ouvrage que j'ay envoyé, vous jugeriez comme nous que, les cartes mises à part, on lui a fait plus d'honneur qu'il ne mérite. » Histoire générale de la Chine, t. I, p. CXCI.

2 Description de l'Empire de la Chine, t. I, p. 284.
} 


\section{La Chine et la formation de l'esprit philosophique en France}

suffit, pour s'en rendre compte de remarquer que du P. Martini au P. Couplet et du P. Couplet au P. du Halde, la chronologie chinoise se trouvait réduite de six siècles et qu'elle tendait de plus en plus à satisfaire les chronologistes les plus intransigeants et les plus conservateurs. Elle s'adaptait de plus en plus au calcul des temps le plus court ; elle tendait à rendre impossible désormais la négation du Déluge universel en vertu de l'exemple chinois, et la dissertation de Fréret, bien qu'inspirée d'un tout autre esprit que les écrits des Jésuites, et conduite avec une méthode toute différente, agissait dans le même sens, les précautions dont il s'entourait dissimulant son véritable objet.

Ainsi donc Jésuites de Canton, Jésuites de Paris, Fréret en apparence, pour des raisons diverses et avec des méthodes différentes, enlevaient tout venin à la chronologie chinoise. Les seuls qui eussent voulu faire remonter plus haut qu'on ne le faisait en France l'origine des temps historiques de la Chine étaient les Jésuites de Pékin, comme le prouve leur correspondance, mais à Paris, on ne les écoutait pas et leurs écrits restaient manuscrits. Les lettres adressées par ces Jésuites à Fréret entre sa première dissertation (1733) et la seconde (lue dans la séance du 20 février 1739 et dans les suivantes) vont tendre à persuader le savant français qu'il s'est laissé égarer par les faux mémoires qu'il a reçus de Canton et à l'engager à renoncer à la Vulgate, chronologie qui ne peut p.270 S'accorder avec I'ancienne histoire chinoise. Deux Jésuites notamment, et des plus savants, les PP. Gaubil et de Mailla, vont I'entreprendre sur ce point, l'un avec une science plus précise et plus sûre, l'autre avec plus de brillant et d'ardeur combative ; et de leurs 


\section{La Chine et la formation de l'esprit philosophique en France}

critiques la dissertation de Fréret de 1733 sortira fort mal en point. Mais il avait lui-même sollicité ces critiques et n'avait publié son premier mémoire que pour exciter les Jésuites de Chine à faire part de leurs connaissances aux savants d'Europe. Il acceptera donc toutes les corrections des erreurs de fait que lui signaleront les Jésuites et ne restera intransigeant que sur sa méthode qu'il croit « la seule propre à éclaircir la matière » 1 .

Le principe de la méthode - nous l'avons vu - est d'écarter de I'ancienne histoire chinoise toute la période fabuleuse et de n'accepter dans la chronologie chinoise que les règnes des anciens empereurs qui peuvent être prouvés historiquement. C'est la raison pour laquelle Fréret, dans sa première dissertation ne croyait pas pouvoir remonter plus haut que Yao. Mais le P. Gaubil et le P. de Mailla s'accordent à lui faire remarquer que Confucius a parlé des règnes antérieurs à Yao et qu'il fait remonter I'histoire de la Chine à Fou-hi et même au delà. Cette autorité de Confucius semble suffisante à Fréret pour qu'il accepte les règnes de Fou-hi, de Cheu nong et de Houang ti : «Lorsque j'écrivis ma dissertation, dit-il au P. Gaubil en 1735, j'ignorois ce que j'ay appris par votre notice que Confucius oust fait expressément mention dans son commentaire sur I'Ye king des règnes de Fou-hi, de Chin nong et de Hoang ti et que Tso kieou nine [Tso Kieou ming,] contemporain de ce philosophe, parloit de ceux de Chao hao, de Tchouen hio [Tchouan Hiu], de Tito [Ti-Kou] et de Yao. Si je l'avois seu je me serois exprimé différemment. Je croyois que par ce que Confucius commence

${ }^{1}$ Lettre au P. Parrenin. 6 octobre 1735, Documents inédits..., p. 94. 


\section{La Chine et la formation de l'esprit philosophique en France}

son Chou king au règne d'Yao ce prince estoit ce qu'il connoissoit de plus ancien. La préface du P. de Mailla dit que Confucius qui remonte jusqu'à Fou-hi parle encore des temps antérieurs où I'on se servoit de cordelettes nouées en guise de caractères et même de ceux dans lesquels la plus forte Barbarie règnoit à la Chine puis que non seulement on ignoroit l'art de bastir mais que l'on se nourrissoit des herbes et de la chair crue des animaux et que I'on buvoit le sang. Tout cela feroit remonter bien haut le passage de la première colonie à la Chine, car ceux de cette colonie n'ont pu tomber tout d'un coup dans cette profonde barbarie »1. Mais p.271 s'il accepte l'existence de Fou-hi et de Cheu nong sur la foi de Confucius, il ne croit pas pouvoir admettre la durée de 184 ans que certains historiens chinois donnent à leurs deux règnes parce que cette longue durée est contraire à toutes les observations faites sur la durée moyenne des règnes à différentes époques et dans différents pays. Aussi il fixe la première date certaine de I'histoire chinoise au début du règne de Houang $t i$, date que lui fournit la chronologie du Tchou chou, mais en admettant que d'autres empereurs ont pu régner en Chine antérieurement.

Il faut donc désormais renoncer aux efforts de conciliation entre la chronologie chinoise et la Vulgate. Il faut nécessairement adopter la chronologie des Septante pour qu'une conciliation reste encore possible entre la chronologie chinoise et la chronologie sacrée. Sans doute Fréret était déjà persuadé en 1733, que I'histoire des anciens peuples, Égyptiens el Chaldéens,

\footnotetext{
1 Lettre au P. Gaubil, 1736, Documents inédits..., p. 88.
} 


\section{La Chine et la formation de l'esprit philosophique en France}

obligeait à admettre cette chronologie plus longue, mais il croyait que I'histoire authentique de la Chine plus courte que celle de l'Égypte et de la Chaldée - c'était la conclusion de son mémoire de 1733 - pouvait, elle du moins, s'adapter au calcul plus strict de la Vulgate. Il ne fait donc nulle difficulté d'abandonner sa première hypothèse et il donne cette satisfaction en 1739 à tous les Jésuites de Pékin. Comme le lui demandait le P. Gaubil ${ }^{1}$, il place des empereurs en Chine vers I'an 2500 avant J.-C.

Mais s'il accorde des concessions sur les faits que lui révèlent les Jésuites de Pékin, et sur les dates qu'ils lui démontrent être d'une telle certitude que l'esprit critique le plus difficile ne peut les repousser, il reste intransigeant sur la méthode. Il continue à penser que l'éclipse du Chou king ne peut être l'éclipse de 2155 et qu'elle est celle de 2007 calculée par Cassini ; et d'autre part, malgré les critiques véhémentes du P. de Mailla, il s'en tient à la chronologie du Tchou chou, ce qui lui permet encore de diminuer de 150 ans la chronologie des premiers temps de l'histoire chinoise. En effet, malgré l'adoption de la version des Septante, et même en choisissant dans les différents manuscrits ceux qui donnent les intervalles les plus longs, il devient difficile, si I'on place des empereurs en Chine vers 2500 av. J.-C., d'établir une conciliation entre la chronologie chinoise et la chronologie sacrée. Dans son mémoire lu à l'Académie et destiné à être publié, il fait toucher ${ }_{\text {p. } 272}$ du doigt la principale difficulté : la

\footnotetext{
1 « Vous me marquez dans un des écrits sur ma dissertation qu'il seroit à propos que I'on pust mettre des Empereurs en Chine avant Yao et au temps qui repond à I'an 2400 ou même 2500 av. J. C. » Fréret au P. Gaubil, 1737, Documents inédits..., p. 174.
} 


\section{La Chine et la formation de l'esprit philosophique en France}

nécessité de faire remonter assez haut la naissance de Phaleg, date de la dispersion des peuples, pour obtenir un intervalle assez long entre cette dispersion et la fondation de la monarchie chinoise, si I'on veut tenir compte des réalités, c'est-à-dire de la longueur de temps nécessaire à cette migration d'un peuple entre les plaines de Sennaar et la Chine, peu de temps après le Déluge, alors que la terre était encore bouleversée. « Cette considération semble bien simple et paroit s'être présentée d'abord, cependant aucun des chronologistes qui dans des ouvrages publiez ont examiné l'ancienne Histoire, et en particulier celle de la monarchie chinoise n'y a fait attention ; ils semblent avoir craint de toucher cette difficulté et n'avoir cherché qu'à s'étourdir eux et leurs lecteurs sur cet article $\gg 1$. Une autre difficulté, et non moins grave est celle de la multiplication des hommes. Mais, comme nous l'avons vu, cette difficulté n'existait pas davantage pour les chronologistes, grâce au P. Pétau. Au contraire, Fréret connaît toute la gravité de ces difficultés. Or même en abaissant de 150 ans environ d'après le Tchou chou l'avènement de Houang ti, même en renonçant à fixer la durée des règnes entre Fou-hi et Houang ti, c'est-à-dire en diminuant de plus de deux siècles la chronologie chinoise des origines, Fréret ne trouve qu'un intervalle de 436 ans entre la dispersion des peuples et l'empereur Houang ti. Cet intervalle lui paraît-il suffisant ? Dans son mémoire il ne l'affirme pas expressément, mais il se borne à constater que « les défenseurs de la chronologie des Massorethes sont obligés de supposer que l'intervalle des 314 ans écoulés depuis la naissance de Phaleg

\footnotetext{
1 Mémoires de l'Académie des Inscriptions..., t. XV, p. 548.
} 


\section{La Chine et la formation de l'esprit philosophique en France}

jusqu'à la vocation d'Abraham avoit été suffisant pour remplir la terre d'habitans qui étoit alors partagée entre plusieurs Nations qui formoient des états policés, qui avoient des loix et des différens, qui connoissoient plusieurs arts, qui bâtissoient des villes, en un mot qui étoient en général à peu près au même état où elles sont aujourd'hui ; ce qu'on est obligé de supposer s'être fait en 314 a pu se faire en 436 que je compte entre Phaleg et Houang ti »1. Donc si l'intervalle de 314 ans peut sembler suffisant aux chronologistes pour qu'ils acceptent la chronologie chinoise, a fortiori celui de 436 ans ne doit nullement éveiller leurs susceptibilités. Et ainsi aucune raison tirée de la religion ne peut empêcher d'accepter la chronologie chinoise.

Mais cette démonstration que faisait Fréret en adoptant les $\mathrm{p}$. 273 principes des chronologistes chrétiens exprimait-elle sa véritable pensée ? Autrement dit, cet intervalle de 436 ans entre la dispersion des peuples et l'existence d'un peuple nombreux en Chine, qui était suffisant pour les chronologistes, paraissait-il tel à Fréret ? Il ne le semble pas, si du moins nous en jugeons par un passage d'une de ses lettres au P. Gaubil : « Dans le manuscrit des Samaritains et dans quelques-uns de ceux de la version des Septante l'intervalle de la naissance de Phaleg à la vocation d'Abraham est de 646 ans et selon d'autres manuscrits, de 796 ans. Suivant les premiers la dispersion des Homes et I'origine des nations sera de I'an 2822 av. J.-C., suivant les autres elle sera de I'an 2942. Si le commencement de Fou-hi est de I'an 2456, il sera postérieur de près de 500 ans à la

1 Ibid, t. XVIII, p. 295. 


\section{La Chine et la formation de l'esprit philosophique en France}

dispersion des peuples et certainement il ne faut pas un moindre temps pour que les Homes qui n'ont pu peupler la terre que de proche en proche ayant pénétré jusques à la Chine en traversant des montagnes impraticables et des fleuves aussi considérables que ceux qui se trouvent sur la route de Babylonie à la Chine, y ayent multiplié pour former une nation nombreuse et soient tombés dans la Barbarie où ils estoient avant le temps d'Yao. J'avoue même que 500 ans ne me paroissent pas suffisants pour tout cela dans un temps où la puberté estoit tardive et où la vie des Homes estant très longue, les Pères estoient en estat de communiquer à leurs descendants toutes les connoissances qu'ils avoient aportées du pays dont ils sortoient. Cette difficulté qui est générale pour l'origine de tous les peuples me semble encore plus forte pour les Chinois que pour les autres nations »1. Or, si I'on songe que Fréret n'avait obtenu cet intervalle de 500 ans qu'en diminuant la chronologie chinoise de 150 ans. il est bien évident qu'à son avis la chronologie plus longue que cherchaient à établir les PP. Gaubil et de Mailla rendait impossible toute conciliation avec I'Écriture. Et nous en trouvons une preuve en lisant les réflexions que Fréret note à la lecture de la lettre du $P$. de Mailla du 23 may 1735, qui, critiquant sa dissertation, attaquait véhémentement I'autorité du Tchou chou et défendait l'éclipse de 2155 av. J.-C. : «Chronologie des Annales. - Son opposition avec toutes ( $\mathrm{sic}$ ) les systèmes de la chronologie juive - Incompatible absolument avec celle du texte hébreu. Difficulté de la concilier même avec celle des Septante, parce qu'elle remonte nécessairement jusqu'à Fou-hi. - Il est donc

${ }^{1}$ Lettre au P. Gaubil, 1735, Documents inédits..., p. 90. 


\section{La Chine et la formation de l'esprit philosophique en France}

nécessaire d'examiner la chronologie chinoise et ses fondements p.274 dans un esprit de critique et avec la disposition de ne se rendre qu'à des preuves solides $\gg 1$.

Est-ce à dire que Fréret se soit fait le défenseur de la chronologie sacrée et que les journalistes qui ont rendu compte de son mémoire de 1739 aient eu raison en affirmant qu'il avait cherché une conciliation entre les deux chronologies, la chronologie de la Bible restant en réalité la loi suprême et intangible dont ne pouvaient s'écarter les histoires profanes ? 2, Peut-être auraient-ils raison s'ils ajoutaient que Fréret a cherché cette conciliation non pour défendre la vérité religieuse, mais parce qu'il a cru à la valeur historique des Livres Saints, valeur historique qui lui est garantie par leur ancienneté. N'ajoute-t-il pas, en effet, cette remarque à la note que nous venons de citer, et qui lui a été suggérée par la lecture de la lettre du P. de Mailla : «La chronologie hébraïque est establie non seulement sur des livres extrêmement anciens, mais nous savons que des livres sont, quelque supposition que I'on veuille hazarder, au moins du temps de David et de Salomon. Le Pentateuque est entre les mains des Samaritains. Or ces Samaritains sont establis en Judée dès le huitième siècle avant J.-C. » 3 . Et ainsi lorsqu'il étudie les histoires profanes qui s'attribuent une antiquité capable de contredire l'Écriture, à savoir la Chaldée,

\footnotetext{
1 Remarques de M. Fréret sur la lettre du P. de Mailla du 23 May 1735, ibid., p. 130.

2 Journal des Sçavans, mai 1754, p. 28-30. - Lettres sur quelques écrits de ce tems, 1753, t. XII, p. 35-6.

3 Remarques de M. Fréret, Documents inédits..., p. 130.
} 


\section{La Chine et la formation de l'esprit philosophique en France}

l'Égypte, la Chine et I'Inde, il a l'esprit particulièrement en éveil pour découvrir dans les traditions de ces peuples la ligne de démarcation entre les faits historiques et les légendes fabuleuses. Il est persuadé qu' « en remontant dans I'histoire de chaque Nation, on rencontre toujours, plus ou moins haut, une époque au-dessus de laquelle les traditions cessent d'être historiques, c'est-à-dire de présenter des faits du même genre que ceux qui se passent sous nos yeux »1. Alors les événements sont des prodiges, les hommes deviennent des dieux, des Génies ou des Géants. Déterminer la limite entre I'histoire et la fable, en partant des dates les plus récentes pour remonter jusqu'aux plus reculées en s'aidant de tous les documents authentiques, tel est le rôle de I'historien, ainsi que l'entend Fréret. Mais la chronologie de l'Écriture est un avertissement qui nous indique à peu près à quelle p.275 époque doit se trouver cette ligne de démarcation, non parce que le Pentateuque est un livre révélé, mais parce que c'est un document historique certain. Voilà pourquoi la chronologie de la Chine doit être plus courte que la chronologie de la Bible, et voilà pourquoi l'histoire des Chinois qui ont dû émigrer des plaines de Sennaar jusqu'en ExtrêmeOrient doit être nécessairement plus récente que celle des Égyptiens et des Chaldéens qui se sont établis plus près que les Chinois du lieu d'origine de l'humanité.

Fréret est le premier historien qui ait essayé d'étudier I'histoire de la Chine ancienne en historien véritable, c'est-à-dire

\footnotetext{
${ }^{1}$ Recherches sur les traditions religieuses et philosophiques des Indiens pour servir de préliminaires à l'examen de leur chronologie. (Histoire de l'Académie des Inscriptions et Belles-Lettres, t. XVIII, 1753, p. 24).
} 


\section{La Chine et la formation de l'esprit philosophique en France}

en laissant de côté toutes les préoccupations religieuses et tous les préjugés d'Européen. S'il a essayé de fixer la chronologie chinoise pour replacer les origines de cette nation dans l'histoire générale de I'humanité, il n'a jamais eu pour intention, même quand il a diminué cette chronologie, de l'adapter à la chronologie sacrée, pas plus qu'il n'a voulu, en établissant la certitude de I'antiquité de la Chine ruiner l'autorité de la Bible. Ses intentions diffèrent autant des intentions des libertins que sa méthode contraste avec la méthode des théologiens ${ }^{1}$. De même, s'il a su se garder de cette faiblesse trop humaine qui fait que I'on accorde un trop grand prix aux choses que l'on étudie et $s^{\prime}$ il n'est pas tombé dans ce piège que tend la vanité, comme son contemporain de Mairan par exemple y est tombé, en surfaisant les Chinois, en vantant avec exagération leurs historiens et la certitude de leurs annales, il a cru cependant que ces annales, mais étudiées avec un esprit critique et avec la ferme volonté de ne se rendre qu'à des raisons certaines, permettaient d'affirmer la certitude de l'antiquité de la Chine, et par là projetaient une grande lumière sur les origines de I'humanité. Avant Voltaire, il a

\footnotetext{
1 Pour apprécier le mérite de la méthode historique de Fréret, il suffit de la comparer avec celle de son émule et antagoniste Fourmont, qui, voulant prouver l'antiquité de la Chine le faisait en prenant les arguments de toutes mains, les bons et les mauvais, et allait jusqu'à nier, malgré les témoignages historiques concordants, la réalité de l'incendie des livres. Cf. son mémoire à l'Académie des Inscriptions de 1734 «Sur les Annales chinoises où I'on examine leur époque ou la croyance qu'elles méritent. 》 (Mémoires de l' Académie des Inscriptions, t. XIII, p. 507, sq.) dont nous ne pouvons dire avec Alfred Maury (L'Ancienne Académie des Inscriptions et Belles-Lettres, p. 260) qu'il n'est pas sans valeur. Les idées essentielles de cette dissertation furent reprises l'année suivante et développées par Fourmont dans son grand ouvrage Réflexions critiques sur les histoires des anciens Peuples, p. 390-460, où il ne craint pas, selon la méthode de Horn et des figuristes, d'identifier Puon ku, le premier homme des Chinois, avec Japhet, t. II, p. 437.
} 


\section{La Chine et la formation de l'esprit philosophique en France}

compris l'importance pour l'histoire, de la découverte de la Chine.

p.276 Mais chez Fréret, à côté des timidités critiques et des scrupules d'historien, il y a aussi, en ce qui concerne la chronologie chinoise, des doutes sur la réalité de la chronologie biblique, qui sont des audaces de philosophe. Nous avons eu l'occasion chemin faisant d'en marquer deux : la difficulté d'expliquer comment en un court espace de temps un peuple a pu émigrer des plaines de Sennaar jusqu'en Chine, et la difficulté d'admettre comment le peuple chinois, si peu de siècles après le Déluge, a pu constituer un peuple immensément nombreux. Mais il y en a une autre, encore plus grave, s'il est possible. Pour admettre coûte que coûte une conciliation entre la chronologie chinoise et la chronologie sacrée, on est obligé de poser comme postulat que les sciences, notamment l'astronomie, sur laquelle est fondée la chronologie chinoise, ont pu être intentées brusquement et même d'un seul coup, du temps de l'empereur Yao. Dès 1733, dans sa lettre à $M$. de Mairan, Fréret marquait cette difficulté : «On suppose que de leur temps [des premiers empereurs chinois] les sciences, etc. étoient non seulement inventées mais même portées au point de perfection dont ils n'ont fait que déchoir depuis ; cette supposition absurde par elle-même puisque cette perfection ne peut jamais être que le fruit d'une suite d'années et de générations qui marchent longtemps dans la même route avec la même ardeur, cette 


\section{La Chine et la formation de l'esprit philosophique en France}

supposition, dis-je, est démentie par les textes formels des King $\gg 1$.

Sans doute les PP. de Pékin avaient vu la difficulté. Le P. Parrenin, dans sa lettre à M. de Mairan où il relatait I'histoire de la monarchie chinoise d'après les historiens chinois, et où il ne dissimulait rien des textes qui prouvaient l'état de barbarie des anciens Chinois, d'où les avaient fait sortir les premiers empereurs, essayait d'expliquer cette rapide floraison de l'astronomie en Chine p.277 par des connaissances que les premiers hommes avaient transmises à leurs descendants, mais qui s'étaient obscurcies pendant l'époque des migrations, pas assez cependant pour qu'elles fussent oubliées totalement, « si bien qu'un peu d'application suffit pour en rappeler le

\footnotetext{
1 Lettre à M. de Mairan, Documents inédits..., p. 47. L'Histoire Universelle anglaise, dont le $1^{\mathrm{er}}$ volume a paru en 1732 , a compris la difficulté qu'il y avait à trop rapprocher la fondation des empires de la dispersion des hommes et c'est la raison pour laquelle elle accepte le texte samaritain qui lui donne un intervalle plus long : «Les Sçavans à qui nous sommes redevables de cette Histoire mettent entre le Déluge et la dispersion des hommes sur la terre un intervalle beaucoup plus grand que celui qui paroit par le Texte Hébreu et par la même raison ils reculent moins la fondation des Empires et l'invention ou la restauration des Arts et des Sciences. Les premiers Rois, selon eux, n'ont été que des chefs de Peuplades et n'étoient Rois que d'une seule ville et d'un seul canton et non de plusieurs, la réunion forcée de plusieurs Républiques ou états en un seul corps étant un ouvrage selon eux qui a exigé un tems considerable, ils sont persuadez que ceux qui placent l'origine de plusieurs grandes Monarchies doux ou trois siècles après le Déluge se trompent manifestement et se fondent sur un système impossible. » (Le Pour et Contre, 1733, t. II, p. 87-7).
} 


\section{La Chine et la formation de l'esprit philosophique en France}

souvenir »1. Le P. Gaubil soutenait la même idée dans ses lettres à Fréret, mais Fréret lui répondait : « Je connois ce que Joseph et les premiers écrivains chrétiens ont débité de la grande habileté d'Abraham en astronomie, et ce que feu $M$. Cassini a dit après eux du culte des premiers patriarches, mais ce sont toutes choses avancées gratuitement et sans que I'on en trouve le moindre vestige dans l'Écriture où nous voyons que les descendants d'Heber et ceux de la famille d'Abraham si attentifs à conserver les traditions de leurs ancestres, ont ignoré pendant longtemps les principes les plus communs de l'astronomie et connoissoient si peu les mouvements lunaires qu'ils étoient obligés de régler leurs mois lunaires sur les phases mesme de la lune et sur la première apparition de cette planette.... ».

« Je suis persuadé que les anciens Chinois ont été théistes ou adorateurs du souverain être, et très éloignez de l'athéisme de ceux des siècles postérieurs... Mais de ce que les hommes d'après le déluge avoient conservé l'idée d'une divinité et de la nécessité du culte religieux, s'en suit-il qu'ils avoient aussi conservé des connoissances et des principes scientifiques que

\footnotetext{
1 B N. Fr. 17240 , f. 123 , v․ Comme nous l'avons vu (cf. ci-dessus, p. 1623) le P. du Halde en publiant ce texte du P. Parrenin dans sa Description de la Chine a cru bon de le modifier, ne voulant pas admettre, ce qui lui paraissait dangereux, que ces connaissances astronomiques aient pu se perdre ou s'obscurcir pendant la période de la migration. ce qui l'aurait obligé à faire remonter beaucoup plus haut qu'il ne le faisait l'origine de l'histoire chinoise, car il est bien évident que l'observation des phénomènes célestes suppose l'existence d'un peuple sorti de la barbarie depuis plusieurs siècles. Il est bon de rappeler aussi que c'est en niant l'antiquité des arts et des sciences en Chine que Renaudot voulait faire douter de I'antiquité de la Chine. (Cf. cidessus, p. 237-8).
} 


\section{La Chine et la formation de l'esprit philosophique en France}

I'on ne voit pas trop avoir esté connus avant le Déluge »1. Et ainsi Fréret se trouvait avoir marqué sous forme de doutes ou d'objections les difficultés essentielles qui rendaient à peu près impossible une conciliation entre la chronologie sacrée et la chronologie de la Chine, et qui deviendront chez Voltaire des arguments positifs pour affirmer l'antiquité de la Chine bien au-`delà des dates que permettrait I'Écriture. La notion de I'antiquité des arts, et de la lenteur du progrès, plus encore que la chronologie positive, rend dangereux le fait de I'antiquité de la Chine.

p.278 Cette étude sur la découverte de la chronologie chinoise en France nous a menés, du milieu du XVII ${ }^{e}$ siècle jusque vers 1710 au moment où Voltaire s'apprête à écrire son Histoire Universelle. En suivant au jour le jour l'effet produit par la révélation de cette chronologie apportée par les divers ouvrages des Jésuites, nous avons pu constater deux phénomènes très nets : d'une part, les théologiens, catholiques ou protestants, ne se sont pas inquiétés au début de cette chronologie, malgré la date dangereuse qu'indiquait le P. Martini pour l'origine de I'histoire authentique de la Chine, et malgré les audaces de La Peyrère et de Vossius. On croyait pouvoir parer à tous les dangers au moyen de la Version des Septante. Mais à partir de 1686, lorsque les écrits sur la Chine sont publiés par les Jésuites de Paris, cette chronologie se resserre, sensiblement déjà chez le P. Couplet, un peu plus encore chez le P. du Halde, au point qu'elle peut s'adapter désormais, à peu près aux calculs de la

\footnotetext{
${ }^{1}$ Lettre de Fréret au P. Gaubil, 8 août 1737, Documents inédits..., p. 170.
} 


\section{La Chine et la formation de l'esprit philosophique en France}

Vulgate, si du moins I'on accepte la correction qu'y apporte le P. Tournemine. D'autre part, les esprits forts qui, dès le début, ont accaparé la chronologie chinoise pour essayer de démontrer l'éternité du monde ou pour reculer les origines de I'humanité, semblent pendant de longues années la dédaigner. C'est seulement après 1700 notamment à partir de 1710 qu'ils se servent de I'antiquité de la Chine - plus encore que de la chronologie proprement dite - pour attaquer la Bible et lui enlever toute valeur historique. Or, à mesure que le nombre et l'audace de ces esprits forts augmentent, leurs adversaires deviennent plus rigoureux sur la chronologie, et les théologiens, pour enlever aux libertins l'argument de la Chine, vont jusqu'à nier son antiquité. Et ainsi nous discernons en 1740 trois attitudes d'esprit à l'égard de l'antiquité de la Chine : d'abord ceux qui la nient sans même vouloir la discuter comme les auteurs de I'Histoire universelle anglaise, et ceux qui l'acceptent sans même l'examiner, pour faire pièce à la Bible, mais entre ces deux partis extrêmes, les Jésuites et Fréret qui, persuadés de cette antiquité, cherchent pour des raisons différentes, en la diminuant à la faire accepter.

Or adopter le fait de l'antiquité de la Chine, c'est modifier de fond en comble I'histoire universelle : désormais il ne sera plus possible de limiter avec Bossuet I'histoire universelle à I'histoire des peuples avoisinant la Méditerranée ; il faudra y annexer tous les peuples d'Asie et d'Extrême-Orient avec leur civilisation particulière. Et d'autre part l'antiquité de la chronologie chinoise pose, qu'on le veuille oui non, cette question redoutable : où se place le berceau de I'humanité, de quelle contrée la civilisation 


\section{La Chine et la formation de l'esprit philosophique en France}

est-elle ${ }_{\text {p.279 }}$ originaire ? Ainsi l'histoire universelle se trouve modifiée dans l'espace et dans le temps.

En 1740, I'argument de I'antiquité de la Chine est une arme dangereuse entre les mains des libertins et une arme qui a déjà beaucoup servi. Mais personne n'a fait de la Chine une étude spéciale. Cet argument de la chronologie chinoise fait seulement partie de l'arsenal de guerre contre le Déluge et contre la Bible : il trouve place à côté de l'argument de la couleur des nègres, ou de la question du peuplement de l'Amérique. C'est moins à la certitude de I'histoire de la Chine qu'à la fausseté du récit de Moïse que s'intéressent les esprits forts. Il n'y a pas avant 1740 d'histoire universelle qui, dans le développement de I'humanité, place, en tête de toutes les nations, la Chine, à cause de son antiquité. Ce sera I'originalité de Voltaire dans le premier chapitre de son Essai sur les Mœurs. Il prendra aux Jésuites des faits et des dates prouvant l'antiquité de la Chine et aux libertins des arguments pour porter cette antiquité beaucoup plus haut que ne le faisaient les Jésuites, et de cette manière toute conciliation devenant impossible, entre la chronologie sacrée et la chronologie chinoise, la Chine, qui remonte beaucoup plus haut que la date assignée par la Bible aux ancêtres du peuple juif, prendra la première place à laquelle lui donne droit ce titre de noblesse, I'antiquité. 


\section{La Chine}

et la formation de l'esprit philosophique en France 


\section{La Chine \\ et la formation de l'esprit philosophique en France}

\section{CHAPITRE II}

\section{LA PHILOSOPHIE ET LA RELIGION DES CHINOIS}

p.281 Les Chinois sont-ils matérialistes ou spiritualistes ? Sontils athées ou déistes ? Telles sont les questions qui vont se poser à partir du milieu du XVII ${ }^{e}$ siècle, à mesure que la Chine commencera d'être connue.

Questions passionnantes non seulement pour les théologiens mais aussi pour les historiens, pour les philosophes, car le peuple chinois se trouve être un des plus anciens de la terre. Questions passionnantes aussi, non pas in abstracto, mais par suite d'une nécessité immédiate et pratique, pour de simples particuliers, des honnêtes gens qui dans cette période critique procèdent à la revision des valeurs religieuses et morales. La foi du charbonnier ne suffit plus : il faut un support à la foi, que ce soit la raison, que ce soit l'expérience qu'apporte I'histoire, ou la découverte des pays nouveaux. La philosophie et la religion des Chinois peuvent fournir, suivant la manière dont on les jugera ou des raisons nouvelles de croire, à ceux qui veulent étayer leur foi chancelante, ou des arguments en faveur de leur incrédulité à ceux qui cherchent à échapper aux obligations de la croyance. Questions d'autant plus passionnantes qu'elles sont d'un intérêt pratique autant que théorique.

En effet, pendant que s'élabore la connaissance de la Chine dont la physionomie n'est pas révélée en un seul livre, mais dont 


\section{La Chine et la formation de l'esprit philosophique en France}

les différents traits se précisent ou s'atténuent au cours de livres successifs qui s'échelonnent sur près de cent cinquante ans, des problèmes importants, dont la solution importe pour la vie spirituelle sont débattus par les théologiens, telle la question du salut des infidèles ; d'autre part des problèmes à données historiques ou géographiques, tel le problème du consentement universel des peuples sont posés par les historiens, les philosophes et encore les théologiens. C'est p.282 au milieu de ces préoccupations que viennent se glisser les documents apportés par les Jésuites sur la philosophie et la religion des Chinois.

Un examen impartial et désintéressé - nous dirions aujourd'hui une étude critique - des faits qu'ils apportaient en faveur de leurs conclusions était-il donc possible ? La nécessité pour chacun de conclure, et de conclure vite, était trop grande pour qu'on pût se livrer à un examen rigoureux des faits invoqués, même si on l'eût voulu. Mais pouvait-on même le vouloir?

D'autre part, la Querelle des Cérémonies chinoises, avec ses violences et les haines qu'elle suscite dans les camps adverses empêche que ces problèmes soient résolus avec sérénité. Les Jésuites, par tous leurs écrits, tendent à démontrer le spiritualisme - ou comme le disent quelques docteurs de Sorbonne - le déisme des Chinois. Mais leurs adversaires s'efforcent de prouver, avec une ardeur non moins grande, I'athéisme des Lettrés de la Chine : et les philosophes Leibniz, Malebranche, auront quelque peine à démêler la vérité au milieu de ces affirmations contradictoires. Violences égales des deux 


\section{La Chine et la formation de l'esprit philosophique en France}

côtés, qu'expliquent en partie des rivalités d'ordre à ordre, une égale recherche de l'influence politique ou des avantages matériels, mais en partie seulement, car dans cette lutte entre Jésuites et Missionnaires, il y a en réalité deux doctrines contraires qui s'affrontent et que I'on trouve toujours dressées I'une contre l'autre dans les luttes entre Jésuites et Jansénistes : d'une part un libéralisme assez large pour que Voltaire lui-même puisse s'en accorder, d'autre part une rigidité de principes qui pose d'abord et au-dessus de toute discussion, comme le faisait Arnauld, la nécessité de la foi.

La connaissance de la philosophie et de la religion des Chinois ne s'est pas élaborée dans le silence ouaté du cabinet de travail d'un philosophe mais bien plutôt au milieu des agitations de la place publique. Aussi, il nous faut dès l'abord abandonner l'idée - ou l'illusion - que les philosophes qui s'occupaient de la Chine au milieu du XVIII ${ }^{\mathrm{e}}$ siècle ont pu se faire une idée, conforme à la réalité, de la philosophie et de la religion des Chinois. Mais telles qu'elles furent connues, cette philosophie et cette religion ont permis à chacun d'en tirer des conclusions pour sa vie intellectuelle, conclusions différentes sans doute suivant le criterium adopté, mais toujours importantes, soit qu'elles modifient radicalement les idées anciennes, soit au contraire qu'elles les fortifient, mais en les élargissant.

\section{I. - Les Missionnaires et les Théologiens}




\section{La Chine et la formation de l'esprit philosophique en France}

p. 283 Les premières relations sur la Chine n'ont apporté que de très vagues renseignements sur la religion des Chinois, des notations parfois curieuses, plutôt qu'un exposé suivi, des notes prises au hasard des impressions, et sans qu'il fût tenu compte des différentes sectes religieuses de la Chine : «Ils croient à l'immortalité de l'âme et à la rémunération des vertus et des vices », dit Mendoça ${ }^{1}$. Et cependant ces Chinois sont idolâtres. Mais ils se laisseraient facilement convertir parce qu'ils sont « tous dociles et gens de bon esprit qui se soumettent à la raison » 2 . Outre les possibilités de conversion, question primordiale pour ces missionnaires, ce que cherchent à découvrir ces voyageurs dans les cultes chinois, ce sont - déjà - des rapports et des analogies avec le christianisme. La Chine n'a-telle pas été peuplée par Noé ou par ses descendants ? Les cultes chinois ne gardent-ils pas, mais avec des déformations et sans que les Chinois s'en rendent compte eux-mêmes, la trace de la révélation primitive ? Mendoça nous décrit notamment une idole boudhique, mais qu'il croit chinoise, qui lui semble une image de la Trinité : «Entre les figures des idoles qu'ils ont, les Chinois disent qu'il y en a une de merveilleuse et étrange facture qu'ils tiennent en très grande révérence. Ils la dépeindent avec un corps, des épaules duquel sortent trois testes se regardant l'une I'autre, qui signifie, ce disent-ils, que toutes les trois n'ont qu'un mesme vouloir et que ce qui desplait à l'une desplait aussi aux deux autres. Cecy estant interprété chrestiennernent se peut

\footnotetext{
1 Mendoça, Histoire du grand Royaume de la Chine, p. 29.

${ }^{2}$ Id., ibid., p. 24.
} 


\section{La Chine et la formation de l'esprit philosophique en France}

entendre du mystère de la Très Saincte Trinité que nous autres adorons et confessons par foy $\gg 1$.

Il croit même que les Chinois ont quelques notions du culte de la Vierge puisqu'ils ont « une peinture d'une femme belle à merveille tenant un petit enfant, entre ses bras, qu'ils disent qu'elle enfanta demeurant vierge $\gg 2$.

Le polygraphe Michel Baudier - qui d'ailleurs suit Mendoça insiste sur les mêmes faits : idolâtrie des Chinois, mais survivance dans les cultes païens de la Chine de cérémonies ou de pratiques p.284 qui semblent se rapporter au culte primitif. Cependant il note au passage qu'à côté des adorations pour les idoles de bois ou de pierre il y a un culte des grands hommes : «Ils révèrent et prient un grand nombre d'hommes desja morts, qui ont dans leur Royaume surpassé les autres en la valeur des armes, en la lumière des lettres ou en la sainteté d'une vie austère et recluse dans les solitudes de leurs monastères religieux $\gg 3$. Le nom de Confucius n'est pas prononcé et les Lettrés de la Chine, qui plus tard, vont devenir si célèbres, se trouvent confondus avec les mandarins de guerre ou avec les Bonzes, mais c'est déjà l'indication de ce culte des grands hommes qui suscitera tant d'admiration au XVIII ${ }^{\mathrm{e}}$ siècle.

Le premier livre qui nous apporte des faits précis sur la religion des Chinois est celui du P. Trigault, composé sur les mémoires ou les écrits du P. Mathieu Ricci. Livre de bonne foi, où

${ }^{1}$ Id., ibid., p. 19.

${ }^{2}$ Id., ibid., p. 20.

3 Baudier, Histoire de la cour du roy de la Chine, p. 49. 


\section{La Chine et la formation de l'esprit philosophique en France}

l'auteur n'essaie pas de surfaire les Chinois mais au contraire expose en termes souvent dénués d'aménité les superstitions de toutes les classes sociales de la Chine : « ils s'enquestent souvent et curieusement des choses à venir. Ils consultent les démons et les esprits familiers. Tout est plein d'imposteurs. Les rues, tavernes, marchez, sont pleins de ces Astrologues, Géologues, devins et pronosticqueurs. Et non seulement les lieux particuliers sont remplis de cette racaille, mais les villes capitales mesmes et les Cours sont farcies de cette ordure »1. On voit que le P. Trigault écrivait avant le début de l'affaire des Cérémonies chinoises.

Mais si tous les Grands et les petits, les nobles et les roturiers, les doctes et les ignorants s'adonnent à ces superstitions honteuses, la classe des Lettrés tout au moins fait une honorable exception. Car ces lettrés « n'ont aucun Temple pour l'adoration de leur Dieu et ne luy ordonnent aucune cérémonie $\gg 2$. Ils révèrent Confucius « pour auteur et prince des philosophes »3, mais dans le temple qui lui est dédié « ils ne luy font aucune prière, ni demandent ou espèrent rien de luy $\gg 4$.

Quant à la doctrine, les Lettrés se distinguent en deux classes dont la première, qui est la plus nombreuse, est celle qui maintient la véritable tradition. Ceux-ci adorent une seule déité

\footnotetext{
1 Nicolas Trigault, Histoire de l'expédition chrestienne au Royaume de la Chine, p. 151-2.

${ }^{2}$ Id., ibid., p. 169.

${ }^{3}$ Id., ibid., p. 167.

${ }^{4}$ Id., ibid., p. 172.
} 


\section{La Chine et la formation de l'esprit philosophique en France}

parce $q^{\prime}$ « ils croient que toutes ces choses inférieures sont maintenues p.285 et gouvernées par icelle ». Cependant ils « n'enseignent ni la manière de la création du monde, ni l'auteur, ni le temps d'icelle »1. Donc la croyance à la Providence, mais non la croyance à la création. Ils parlent aussi « de la récompense des bons et des mauvais, mais ils croyent la pluspart qu'elle est donnée en cette vie et qu'elle revient ou à l'autheur ou à sa postérité selon ses mérites »2. Par conséquent il n'est pas soufflé mot de l'enfer. Quant à la seconde secte des Lettrés, celle des Lettrés modernes, elle est matérialiste et athée : «Ils croyent que cet univers est composé d'une seule substance $\gg 3$. Le P. Trigault ne cherchait pas, il va sans dire, à établir des rapports entre les traditions religieuses des Chinois et les traditions judaïques.

Jusqu'au livre du P. Martini (1659), aucun ouvrage intéressant et documenté aux sources mêmes, n'apportera de renseignements nouveaux. Il est inutile de citer Bellefleur, qui n'est qu'un polygraphe et s'inspire de Trigault tout en le déformant, tout autant que Fernand Mendez Pinto qui a plus d'imagination que de scrupules intellectuels et ne peut inspirer

\footnotetext{
${ }^{1}$ Id., ibid., p. 167.

${ }^{2}$ Id., ibid., p. 168.

${ }^{3}$ Id., ibid., p. 168.
} 


\section{La Chine et la formation de l'esprit philosophique en France}

confiance ${ }^{1}$, ou même Semedo qui est de bonne foi mais n'apporte rien de neuf. Or, dès avant que le P. Martini eût relaté des faits précis sur la doctrine des Lettrés chinois, Confucius était placé au paradis par La Mothe le Vayer, en compagnie d'autres philosophes païens, tels que Pythagore et Socrate.

Le problème du salut des infidèles qui ont observé la loi naturelle et qui ont vécu moralement bien n'était pas un problème nouveau au XVII ${ }^{e}$ siècle, et depuis longtemps, les théologiens s'en préoccupaient. Tandis qu'Abailard, Erasme voulaient sauver les païens vertueux, c'est-à-dire les sages de I'antiquité et que Dante dans sa Divine Comédie les plaçait en différents endroits, soit au p.286 Paradis comme Trajan, sur la foi des légendes, soit dans un brillant Elysée, près du purgatoire, comme Caton, qui en garde l'entrée, soit dans un séjour de paix et de gloire, même lorsqu'ils sont aux enfers, comme Aristote, Socrate et Platon, les protestants au contraire et notamment Luther, les damnaient sans rémission.

Il ne nous appartient pas d'exposer les diverses solutions qu'aux différentes époques les théologiens ont données de ce

\footnotetext{
1 Citons seulement, mais en l'abrégeant, et à titre de curiosité (car dans les relations suivantes nous ne trouverons rien d'équivalent), la description d'un monstre d'un temple chinois : « Un de ces monstres... s'y void là soubs la figure d'un serpent de hauteur excessive avec des couleuvres fort difformes et monstrueuses qui luy sortent de l'estomach, toutes couvertes d'écailles vertes et noires, où se voyent encore force espines qui ont plus d'un pan de longueur tout ainsi que celles des porcs espics. Chacune de ces couleuvres avoit une femme au travers de sa gueule, avec les cheveux espars et pendants en arrière, comme grandement effrayée. Le monstre portoit aussi en sa gueule qui estoit fort grande et demesurée, un lézard qui luy sortoit dehors plus de trente pieds de longueur et de grosseur... entre ses pattes ce lézard entrainoit un grand éléphant... » Voyages adventureux de Fernand Merdez Pinto, p. 408-9.
} 


\section{La Chine et la formation de l'esprit philosophique en France}

problème - Capéran l'a fait excellemment 1 - mais il nous importe de constater qu'en 1624, au moment où le P. Garasse publiait son livre La Doctrine curieuse des beaux esprits de ce temps ou prétendus tels, ce problème ne suscitait pas seulement des discussions d'école, mais aussi des discussions dans les cercles d'honnêtes gens, où les libertins, « les athéistes 》, apportaient naturellement les solutions les plus favorables aux anciens philosophes et essayaient de prétendre que « les Grecs et les Payens qui n'ont pas cogneu toutes ces petites particularitez de nostre Religion, ainsi qu'elles sont qualifiées par les Athéistes, comme sont I'Incarnation du Fils de Dieu. sa Passion, le Paradis et l'Eucharistie sont néanmoins sauvés sur la créance commune d'un seul Dieu »2. Dans ces réunions sans doute tout le monde n'était pas libertin, mais de bons catholiques, « de sçavans hommes », montraient aussi par des citations des Pères que les Philosophes païens ont pu être sauvés par la philosophie seule « comme nous l'espérons estre en vertu de nostre créance en Jésus-Christ ${ }^{3}$. Il n'est pas étonnant que l'idée soit venue, quelques années plus tard à La Mothe le Vayer, d'examiner cette question pour les honnêtes gens, moins en théologien qu'en philosophe, et d'introduire pour la première fois dans le Paradis des philosophes, à côté des philosophes de l'antiquité grecque et latine, le chinois Confucius.

\footnotetext{
1 Capéran, Le Problème du salut des Infidèles.

2 Garasse, La Doctrine curieuse..., p. 254.

${ }^{3}$ Id., ibid., p. 252
} 


\section{La Chine et la formation de l'esprit philosophique en France}

La Mothe le Vayer était alors déjà connu par ses Discours Sceptiques d'Horatius Tubero, ce qui ne l'avait pas empêché d'être nommé précepteur du duc d'Anjou, frère du Roi, malgré les avertissements d'Antoine Arnauld ${ }^{1}$. Dans son livre De la Vertu des Payens, il p.287 examine le problème du salut des Infidèles dans un esprit tout nouveau, qui est le résultat de la découverte de l'Amérique et de la Chine.

Si I'on doit accorder, dit-il, que les philosophes païens qui ont bien vécu, conformément à la loi naturelle, avant la loi de Moïse ont pu être sauvés, on doit accorder aussi que les sages des nations chez qui les apôtres n'ont pas prêché le christianisme peuvent être sauvés eux aussi. Mais le christianisme a-t-il été prêché à toute la terre dès le temps des Apôtres, comme le prétendent certains Pères de l'Église, et comme le dit Saint-Paul dans l'Épitre aux Romains, où il adapte à la parole de Dieu ce que David a dit de la parole des Cieux, qui a été entendue de toute la terre ? S'il en était ainsi, tous les Américains, tous les Chinois vertueux seraient damnés. Mais que veulent dire les

\footnotetext{
1 « Je ne m'étonnerois pas de trouver ces choses (les idées exprimées par Huet dans ses Quæstiones de concordia rationis et fidei) dans quelque ouvrage de La Mothe le Vayer. Ses discours sceptiques sous le nom de Horatius Tubere, ainsi que son livre De la Vertu des Payens font assez voir qu'il n'étoit pas chrétien ; et cependant quelque avertissement que j'en eusse donné, je ne pus empêcher qu'il ne fut pris pour précepteur de Monsieur. » (Lettre du $1^{\text {er }}$ novembre 1601 à M. Dodart. - Fuvres, éd., 1775, t. III, p. 401). La Mothe le Vayer ne semble pas avoir trouvé la sympathie de certains hommes comme Guy Patin, dont il devait cependant être parent par les idées : «M. de la Mothe le Vayer a été depuis peu appelé à la Cour et y a été installé précepteur de Monsieur frère du roi. Il est âgé d'environ soixante ans, de médiocre taille, autant stoïque qu'homme du monde, homme qui veut être loué et ne loue jamais personne, fantasque, capricieux et soupçonné d'un vice d'esprit dont étoient atteints Diagoras et Protagoras. » (Lettre à Falconet, 13 juillet 1649. Correspondance de Guy Patin. Ed. Reveillé-Parise, t. II, p. 523-44).
} 


\section{La Chine et la formation de l'esprit philosophique en France}

Pères par cette expression : toute la terre ? Ils parlent du monde entier, mais tel qu'il était connu de leur temps. Or ils n'avaient jamais entendu parler de l'Amérique, de la Chine et des terres Australes. D'ailleurs les Japonais se sont plaint à Saint FrançoisXavier d'avoir été les derniers à recevoir la prédication de I'évangile. Quant à l'Amérique, «c'est tout ce qu'on peut faire de croire pieusement et parce que la foy nous y oblige, que les hommes qu'on a trouvez dans cet autre hémisphère soient venus d'Adam et n'ayant eu qu'une mesme origine avec nous »1. La Mothe le Vayer est donc préadamite, même avant que La Peyrère eût formulé la théorie du préadamisme, mais c'est la preuve que cette théorie était dans I'air au milieu du XVII ${ }^{\mathrm{e}}$ siècle. Et La Mothe le Vayer conclut, en arguant des nouvelles découvertes faites en Afrique, où I'on n'a trouvé nulle trace de christianisme, que la loi n'a pas été prêchée par toute la terre et que par conséquent les philosophes des nations infidèles peuvent, même d'après la théologie la plus orthodoxe, espérer leur salut éternel.

Ceci posé, et s'appuyant sur une opinion de Saint-Augustin, d'après laquelle la croyance en la puissance et en la bonté d'un seul Dieu, créateur de toutes choses, est ce qui approche le plus de la foi chrétienne, La Mothe le Vayer constate que la religion p. ${ }_{288}$ chinoise est plus pure que celle des Grecs, des Romains ou des Égyptiens, puisqu'elle n'est pas remplie de prodiges, et que

\footnotetext{
${ }^{1}$ La Mothe le Vayer, De la Vertu des Payens, p. 47.
} 


\section{La Chine et la formation de l'esprit philosophique en France}

« les Chinois n'ont reconnu de temps immémorial qu'un seul Dieu qu'ils nomment le Roy du Ciel $\gg 1$.

Or, parmi tous les Chinois de tous les temps, l'homme le plus célèbre est sans contredit Confucius, que l'on peut appeler le Socrate de la Chine. Comme Socrate en Grèce, et à peu près à la même époque, il a fait descendre la philosophie du ciel sur la terre. Alors que les Chinois s'adonnaient aux arts libéraux et à toutes les sciences «qui ont eu cours à la Chine aussi bien que parmi nous 2, il leur montra la valeur de l'Éthique, si bien « qu'on escrit que depuis luy il ne s'est plus fait de Bacheliers ny de Docteurs à la Chine qu'en les examinant sur la morale »3. Et comme tous ces gradués qui ont été nourris dans la doctrine de Confucius occupent toutes les situations de l'État, on peut dire que c'est la doctrine même de Confucius qui gouverne la Chine : « Certes ce n'est pas une petite gloire à Confucius d'avoir mis le sceptre entre les mains de la Philosophie et d'avoir fait que la force obéisse paisiblement à la raison $\gg 4$.

Quant au principe de la morale de Confucius, c'est le principe même de la morale naturelle qui est « de ne faire jamais à autruy ce que nous ne voudrions pas qui nous fût fait »5. Donc Confucius, qui, d'une part, a cru à l'existence d'un Dieu unique, créateur de toutes choses, et qui a pris comme centre de son

\footnotetext{
${ }^{1}$ Id., ibid., p. 280.

2 Id., ibid., p. 282.

3 Id., ibid., p. 282.

${ }^{4}$ Id., ibid., p. 283.

5 Id., ibid., p. 291.
} 


\section{La Chine et la formation de l'esprit philosophique en France}

éthique le précepte essentiel de la loi de nature, peut être sauvé, « Dieu luy conférant ceste grâce spéciale qu'il ne refuse jamais à ceus qui contribuent par son moyen tout ce qui est de leur possible pour l'obtenir $\gg 1$.

Pour répondre à ce traité « qui tendoit au déisme et à la destruction entière de la Religion chrétienne »2, Arnauld composa une longue dissertation qu'il ne publia pas, peut-être pour des raisons politiques, mais qu'Ellies du Pin jugea bon de faire paraître en 1701 aussitôt après la Querelle des Cérémonies chinoises, n'étant sans doute pas mécontent de montrer de cette manière que la p.289 doctrine des Jésuites sur les Cultes chinois ne différait pas essentiellement des théories d'un sceptique.

Or, d'après Arnauld, le principe destructeur du christianisme que I'on trouve dans le livre de La Mothe le Vayer, ou du moins le postulat que suppose cet ouvrage, c'est l'idée de la bonté de la nature. Et cette idée tend à détruire la croyance au péché originel. Croire que les hommes, plus ils remontent loin dans l'antiquité et plus ils se rapprochent des origines, conservent quelque chose de cette innocence première que Dieu avait créée avant la chute d'Adam, c'est oublier que le premier homme, depuis qu'il s'est révolté contre Dieu « est devenu la source non plus de la vertu et de la probité mais de la malédiction et de I'iniquité $\gg 3$. Croire que les philosophes de l'antiquité ont pu se

1 Id., ibid., p. 291.

2 L'expression est d'Ellies du Pin qui publia en 1701 l'ouvrage d'Arnauld, De la nécessité de la foy en J. C. Avertissement, s. p.

3 Antoine Arnauld, De la nécessité de la foy, t. I, p. 98-100. 


\section{La Chine et la formation de l'esprit philosophique en France}

sauver par les seules forces de la nature, c'est tomber dans l'erreur des Pélagiens et croire comme eux « que la grâce se donne selon les mérites et les bonnes œuvres faites par les forces de la nature et ainsi faire que la grâce ne soit plus la grâce »1.

Cette idée de la nécessité de la grâce ou de la nécessité de la révélation pour le salut, sera en somme la question essentielle qui divisera les théologiens au moment de la Querelle des Cérémonies chinoises, et nous la retrouverons un peu plus tard. Mais bien avant I'année 1700, apparaît un autre argument que théologiens et libertins vont se renvoyer comme balle au jeu de paume, un argument que la connaissance de la Chine, mieux que la connaissance d'un autre pays, à cause de son antiquité, peut servir à confirmer ou à repousser, l'argument du consentement universel, qui sera longtemps encore invoqué, mais sous des formes nouvelles, même bien après que Bayle I'aura ruiné théoriquement.

Que les missionnaires en Chine aient eu tendance à chercher des rapports entre les idées religieuses des anciens Chinois et les vérités admises par les Chrétiens, rien de plus naturel ; mais tout d'abord on n'a pas cru, avant que l'argument du consentement universel ne devînt un argument de l'école, que l'aveu de l'athéisme des Chinois pût être une preuve contre le spiritualisme chrétien, comme le montre l'exemple du P. Martini.

Le P. Martini qui le premier fournit des documents précis, et que I'on croyait pouvoir tenir pour assurés, sur les cultes chinois,

${ }^{1}$ Id., ibid., t. I, p. 107. 


\section{La Chine et la formation de l'esprit philosophique en France}

avoue dans la préface de son Historiæ Sinicæ Decas Prima que la plupart des philosophes chinois croient que tout a été produit par p.290 le hasard, ou que le monde est éternel ; et d'autre part, qu'il n'y a pas dans la langue chinoise de terme pour désigner Dieu. Mais, ajoute le P. Martini, comme leurs livres sont remplis d'une doctrine qui établit des peines et des récompenses, et qu'il est invraisemblable que les espaces immenses remplis de corps lumineux dont ils parlent soient capables d'exercer cette justice distributive, il faut croire que les Chinois sous-entendent l'existence d'un Souverain Être qui prend soin de toutes les choses créées : c'est le Xang-ti qui gouverne souverainement le Ciel et la Terre. Si I'on ajoute que la Chine a dû avoir la connaissance de Dieu dès le temps du patriarche Noé, ou peu après, il sera possible de trouver dans les annales primitives de l'empire chinois, des faits qui pourront s'interpréter facilement à la lumière de la religion chrétienne. Ainsi le livre du P. Martini pourra servir, et aux libertins qui y chercheront des arguments en faveur de l'éternité du monde, et à ceux qui voudront trouver dans les idées religieuses d'un peuple très ancien des analogies avec les idées bibliques.

Le premier théologien qui, à notre connaissance, se soit servi de l'exemple de la Chine pour prouver l'universalité, et par suite la vérité des traditions judéo-chrétiennes, est le P. Beurrier, curé de Saint-Etienne du Mont. Et le fait est d'autant plus curieux que ce théologien n'est pas un homme qui, à l'ombre de l'école, cherche l'absolu, mais un curé de paroisse qui a charge d'âmes, et qui pense que parmi ses paroissiens, il y a trop de libertins : il lui faut donc trouver, pour ramener au bercail les ouailles 


\section{La Chine et la formation de l'esprit philosophique en France}

égarées, moins des arguments philosophiques que des preuves de fait de la vérité du christianisme.

Les différentes religions du monde sont le miroir de la religion chrétienne, pense le P. Beurrier, et il s'efforce de prouver que la religion primitive des Chinois comporte la croyance à tous les dogmes fondamentaux du christianisme : «Il est très certain, dit-il, que les Chinois ont possédé les mêmes vérités sur la création du monde, sur la naissance du premier homme, sur sa chute, sur le Déluge, la Trinité, la Rédemption, les Anges et les démons, le Purgatoire, la récompense éternelle des justes et le châtiment des coupables qu'avaient aussi les Patriarches »1. Et cela, malgré les p.291 apparences, n’a rien d'étonnant, puisque Fou-hi, - qui en pourrait douter ? - est l'un des fils ou des petits-fils de Sem, qui, suivant la Genèse, habitèrent en Orient après la dispersion des peuples. Ou même Fou-hi n'est-il pas Sem en personne, Sem qui a vécu cinq cents ans après le Déluge et a pu fonder ce royaume de la Chine comme beaucoup

1 Beurrier, Speculum christianæ religionis in triplici lege, t. I, p. 259 . - Ce petit livre était destiné aux missionnaires d'Extrême-Orient et il fut dédié aux évêques d'Héliopolis et de Metellopolis qui partaient pour la Chine. (Cf. Mémoires du R. P. Beurrier, ap. Ernest Jovy, Pascal inédit, t. III, p. 150). Le P. Beurrier nous rapporte aussi dans ces Mémoires qu'ayant à convertir à I'heure de la mort un médecin philosophe dont les trois principes philosophiques étaient ceux-ci : que la plus grande de toutes les fables c'est la religion chrétienne, que le plus ancien de tous les romans c'est la Bible, que le plus grand de tous les fourbes et de tous les imposteurs c'est Jésus-Christ, il y réussit en lui démontrant que tous les philosophes et les sages de la gentilité, Zoroastre, Trismégiste, Orphée, Pythagore, Platon, etc. ont reconnu le dogme de la Trinité, et que Trismégiste a annoncé la venue d'un Dieu-homme, qui sera l'auteur de la régénération (Ibid., p. 173). Le P. Beurrier, par l'importance qu'il donne à la loi des trois états et au souci qu'il témoigne de rechercher dans les textes païens non seulement des analogies avec le christianisme mais les dogmes chrétiens eux-mêmes est le précurseur des missionnaires symbolistes, tels que le P. de Prémare, qui ne se fera pas faute de l'invoquer, et de certains philosophes comme Ramsay, qui d'ailleurs fut également influencé par le P. de Prémare. (Voir infra, p. 352 sq). 


\section{La Chine et la formation de l'esprit philosophique en France}

d'autres ? Comme il a été pendant cinq cents ans le grand pontife de la loi de nature, il a pu aller jusqu'aux bornes de l'Orient comme pieux zélateur du culte divin pour prêcher la religion du vrai Dieu. Nous avons déjà vu Fou-hi identifié avec Adam ou avec Noé pour les besoins de la chronologie. Le P. Beurrier qui ne se préoccupe pas des difficultés de chronologie peut ne faire de Fou-hi qu'un descendant de Noé.

Mais, ajoute le P. Beurrier, I'ancienne religion des Chinois ne contient pas seulement des dogmes identiques à ceux de I'Ancien Testament, elle a, elle aussi, son prophète qui annonce la loi nouvelle, ce prophète, c'est Confucius. Le philosophe Confucius a pratiqué une morale pure, il a posé comme principe essentiel de la morale qu'il fallait se rendre parfait soi-même avant de vouloir rectifier les autres; il a dit souvent : Ne fais pas aux autres ce que tu ne voudrais pas qu'on te fît à toi-même. Mais s'il a enseigné une morale aussi pure et dont les principes se rapprochent étrangement des principes de la morale chrétienne, c'est parce qu'il a été un véritable prophète. Il a annoncé, en effet, qu'il fallait chercher le Saint en Occident, ce qui veut dire : à Jérusalem et à Rome, pense le P. Beurrier. Il a prévu que le Verbe se ferait chair et il a prévu cet événement pour l'année même où il se produisit. Enfin avant de mourir, Confucius « versa des larmes amères, soit de joie (sic) à cause de la venue future du Messie, soit de pitié pour sa passion $\gg 1$.

1 Id., ibid., t. I, p. 271, « Flevit amare, sive præ gaudio ob futurum Christi adventum, sive præ compassione super futuram ejus passionem. » 


\section{La Chine et la formation de l'esprit philosophique en France}

p.292 Le P. Beurrier croit donc, comme le feront plus tard les Jésuites symbolistes que les anciens Chinois ont été en possession des prophéties ce qui explique l'accord singulier que I'on découvre entre leurs croyances et les croyances judéochrétiennes. Ce n'est donc pas la religion naturelle, c'est la religion judéo-chrétienne que le $\mathrm{P}$. Beurrier croit découvrir chez les Chinois, mais toute son interprétation repose sur cette hypothèse fragile que Fou-hi est un descendant de Noé. Si I'hypothèse s'écroule ou même si elle ne peut être vérifiée, toutes les concordances que l'on trouvera, loin de servir à la défense du christianisme, ne feront que profiter au déisme.

Les libertins, en effet, ne se faisaient pas faute de signaler les analogies entre les religions païennes et le christianisme et leur intention, en le faisant, était de montrer l'inutilité de la révélation.

Dès 1639, un déiste anglais, Herbert, baron de Cherbury, dans un ouvrage publié en français ${ }^{1}$, distinguait les vérités historiques de la vérité révélée : «Les choses que l'on sçait par I'histoire, disait-il, ne sont pas seulement distinguées par l'action du sentiment des choses que l'on pourra recevoir par le moyen de la foy divine, mais elles en sont aussi esloignées comme le Ciel l'est de la terre et comme le sont semblablement les vrayes révélations d'avec les fantastiques et trompeuses $\gg 2$. Une fois cette distinction bien établie entre les vérités révélées et les

\footnotetext{
${ }^{1}$ De la vérité, en tant qu'elle est distincte de la Révélation, du Vraysemblable, du possible et du faux. Sur Herbert de Cherbury, cf. Albert Chéret, André Michel Ramsay, p. 155.

2 Cherbury, op. cit., p. 9.
} 


\section{La Chine et la formation de l'esprit philosophique en France}

vérités positives, Herbert de Cherbury se trouve tout à fait à l'aise pour chercher la vérité dans l'opinion « la plus receue dans toute sorte de Philosophie, de religion et de temps »1. Cette distinction qui, sous couleur de respect pour la religion, borne en réalité le domaine de la foi, pour constituer un domaine où la raison soit libre de rechercher les vérités positives, n'est en fait qu'une habileté dont se serviront aussi les philosophes français au commencement du XVIII ${ }^{\mathrm{e}}$ siècle.

Ce principe de recherche des vérités communes à toutes les religions, Herbert de Cherbury I'applique encore trente-quatre ans plus tard dans son livre De Religione Gentilium. Il y étudie les religions païennes, pour dégager les vérités universelles des enseignements particuliers que les prêtres des différentes religions ont pu $\mathrm{y}$ insérer et il arrive ainsi à déterminer cinq principes qui lui semblent la base de la religion : « Il y a un Dieu - il faut I'honorer - La ${ }_{\text {p.293 }}$ vertu est l'essentiel du culte divin Il faut s'abstenir du péché - Il faut des récompenses et des peines tant dans cette vie que dans l'autre ». C'est un livre libertin parce que l'auteur cherche à découvrir les principes essentiels des religions à travers les déformations que leur font subir les cultes «qui sont l'œuvre des prêtres avares et intéressez $\gg 2$, mais c'est aussi un livre qui professe un pur déisme, puisque les principes essentiels du christianisme sont

\footnotetext{
${ }^{1}$ Id., ibid., p. 9.

2 L'expression est de Lenglet du Fresnoy dans sa Méthode pour étudier I'histoire, t. I, p. 35-36, où il déclare qu'on doit faire une particulière attention à ce livre.
} 


\section{La Chine et la formation de l'esprit philosophique en France}

considérés comme communs à toutes les religions même non révélées.

En 1678 parut en Angleterre le livre de Cudvorth, True Intellectual System of the Universe, qui, dirigé contre les athées, montrait que I'unité de Dieu avait été reconnue par les Anciens, Zoroastre et les Mages, Orphée et les Égyptiens 1. L'année suivante Huet publiait sa Demonstratio evangelica.

C'est à la suite d'un voyage en Hollande oit il passa tout un mois à Amsterdam à discuter sur les Écritures avec un juif qui n'est pas Spinoza, comme le prétend Vigneul-Marville 2, qu'il décida d'attaquer la forteresse de l'impiété et cette catégorie d'hommes qui à cause de leurs mœurs dépravées ou de leurs opinions corrompues ont tout intérêt à détruire le nom de Dieu, du Christ, de la religion et de la foi ${ }^{3}$. Il voulut prouver contre les libertins I'antiquité, et par suite l'authenticité des Écritures, par le témoignage même de tous les peuples venus après la nation juive, et il ne crut pas trouver de meilleur moyen de le faire que de rechercher, dans la mythologie des Égyptiens, des Grecs ou des Romains, des traces ou des souvenirs oblitérés des livres

\footnotetext{
1 Ce livre fut seulement traduit en latin en 1733 mais Leclerc en donne de longs extraits dans sa Bibliothèque choisie entre 1703 et 1711 . Voir notamment l'extrait inséré au t. III de la Bibliothèque choisie : "Que les Payens les plus éclairez ont cru qu'il n'y a qu'un Dieu Suprême. »

2 Vigneul-Marville, Mélanges d'histoire et de littérature, t. II, p. 331. C'était un juif très érudit nommé Mantisse ben Israël, auteur d'un livre en hébreu sur les Écritures qui fut traduit en latin sous le titre Conciliator sive de convenentia locorum Sanctæ Scripturæ, Amsterdam, in-4․ (Cf. Huet, Mémoires, p. 86).

3 Huet, Demonstratio evangelica. Préface de 1690, f. 1.
} 


\section{La Chine et la formation de l'esprit philosophique en France}

bibliques ${ }^{1}$. Si ces peuples anciens, les plus anciens de I'Occident, ont reconnu les livres judaïques, ils ont dû avoir aussi une certaine connaissance de Moïse. Si donc on peut retrouver dans les caractères que présentent leurs divinités des traits qui rappellent Moïse et qui prouvent qu'ils I'ont divinisé, comme ils sont les peuples les plus anciens de la terre après les Juifs, et qu'ils n'ont rien dans leur histoire de comparable comme p.294 antiquité à leur mythologie, on aura démontré par là-même l'antiquité de Moïse et des livres mosaïques.

Pour faire cette démonstration, Huet déploie des trésors d'érudition et il s'efforce de prouver que Moïse est le Theuth des Égyptiens et par suite le Taautus des Phéniciens, I'Hermès des Grecs, le Mercure des Romains, le Teutatès des Gaulois. Il est aussi Bacchus, il est de même Zoroastre. La méthode de Huet pour prouver l'identité entre Moïse et ces différents personnages n'est pas supérieure à celle qu'employait Horn pour essayer de démontrer que Fou-hi était Adam.

Les arguments de Huet pour faire ces assimilations, qui sont désormais sans valeur, n'ont pas lieu de nous retenir. Ce qu'il nous importe de relever, c'est l'intérêt qu'apporte Huet à prouver I'antiquité de Moïse, et par suite l'antiquité du Pentateuque, par le consentement unanime des peuples anciens, Il ne s'agit pas pour lui de montrer, comme les libertins aimaient à le faire, que tous les peuples ont cru à un Dieu unique et ont eu une morale naturelle analogue en ses principes essentiels à la morale chrétienne. Il s'agit de montrer que tous les peuples ont reçu les

\footnotetext{
${ }^{1}$ Id., ibid., f. 2.
} 


\section{La Chine et la formation de l'esprit philosophique en France}

enseignements de Moïse et que des traces en sont restées dans leur mythologie. S'il en est ainsi, quoi d'étonnant que I'on puisse retrouver dans la philosophie païenne des enseignements analogues à ceux que nous tenons du christianisme ? L'accord unanime des peuples permettrait donc de conclure non au déisme mais à la vérité, prouvée historiquement, de la révélation mosaïque.

Cette idée de la diffusion du mosaïsme chez les anciens peuples n'eut pas grand succès et Huet constata son échec dans une préface désabusée qu'il mit à la troisième édition de son livre, où, pour justifier sa méthode, il s'efforça de s'abriter derrière de grands savants, comme Bochart, qui en avaient usé avant lui. En cette même année 1690, dans un livre qui avait la prétention d'accorder la foi et la raison, il voulut démontrer « que soit à l'égard de la croyance, soit à l'égard de la pratique, il n'y a rien de tellement opposé au sens commun dans ce qui nous est commandé par notre sainte religion que les nations les plus policées n'aient également cru ou n'« aient pratiqué, qu'il ne reste donc aux impies aucun prétexte pour les répudier $\gg 1$. La foi était-elle donc si chancelante en 1690 qu'il fallait à cette date faire de la religion, pour qu'elle fût acceptée un « christianisme raisonnable », suivant le titre donné à la traduction de l'ouvrage de Locke?

p.295 Pour démontrer sa thèse de l'accord de la foi et de la raison Huet revient au simple argument du consentement universel : tous les philosophes anciens ont cru en Dieu ; les

\footnotetext{
1 Huet, Mémoires, p. 205.
} 


\section{La Chine et la formation de l'esprit philosophique en France}

poètes ont dit des choses justes et pieuses de la Divinité ; il n'y a pas de nation même barbare qui ait mis en doute l'existence des dieux, tels les habitants de la Guinée, d'Angola et du Congo. Quant aux nations les plus civilisées elles ont cru en outre à un Dieu créateur du monde, comme les Perses qui sous le nom du feu et du soleil adorent les formes sous lesquelles se manifeste le Dieu suprême, principe et auteur de toutes choses, comme les Brahmanes de l'Inde, comme encore les Chinois - le peuple le plus civilisé de l'Orient - dont une secte appelle du nom de Tao le Créateur du monde, nom qui vient évidemment du Theut Égyptien ${ }^{1}$.

Non seulement les païens s'accordent sur l'existence de Dieu, mais ils s'accordent aussi sur l'époque de la création du monde. C'est ainsi que les Chinois les plus érudits fixent cette création à une date qui concorde très bien avec les Écritures, si du moins on adopte la version des Septante ${ }^{2}$. Ils croient aussi Égyptiens, Chaldéens, Perses, Brahmanes et Chinois - que le dieu ou les dieux qu'ils révèrent s'occupent de la direction du monde, si bien qu'Elien a eu raison de dire « qu'il n'y a pas de peuple barbare qui n'ait cru à l'existence de dieux et qui n'ait été persuadé que ces dieux sont la providence de l'humanité »3. Quant aux plus instruits des peuples orientaux, ils ont eu connaissance, tels que les Chinois par exemple, des histoires relatives au paradis terrestre, et I'on retrouve dans leurs

\footnotetext{
${ }^{1}$ Huet, Alnetanæ questiones de concordia rationis et fidei, p. 100-1.

${ }^{2}$ Id., ibid., p. 143.

${ }^{3}$ Id., ibid., p. 145.
} 


\section{La Chine et la formation de l'esprit philosophique en France}

traditions religieuses le souvenir des aventures d'Adam et d'Ėve au paradis, ce qui fut la cause du mal pour l'humanité $\gg 1$.

Huet ne s'était pas aperçu qu'à chercher ainsi un accord entre la foi et la raison, mais pour justifier la foi devant la raison, il faisait du sens commun ou de la raison le juge de la foi, et, que d'autre part en voulant prouver l'existence de Dieu par la créance unanime des peuples en un dieu ou en plusieurs dieux, il aboutissait en réalité à l'indifférence en matière de religion. Sa tentative dans la Demonstratio evangelica n'était évidemment pas soutenable historiquement, mais elle était tout au moins d'intention orthodoxe.

Arnauld, après avoir lu dans l'Histoire des Ouvrages des p.296 Savans 2 un compte rendu de cet ouvrage, s'aperçut immédiatement des conclusions dangereuses qu'en pouvaient tirer les libertins, et il écrivit à son ami Dodart pour décharger son cœur : «Si l'auteur protestant n'a point altéré ce qu'il rapporte de la seconde et de la troisième partie de ce livre, ce sont d'horribles choses et capables d'inspirer à de jeunes libertins qu'il faut avoir une religion mais qu'elles sont toutes bonnes et que le Paganisme même peut entrer en parallèle avec le Christianisme »33. Il comparait ce livre de l'abbé d'Aunay, évêque désigné d'Avranches, au livre de la Vertu des Payens du sceptique La Mothe le Vayer, et il y répondait de la même manière, en marquant que le christianisme se distinguait de

${ }^{1}$ Id., ibid., p. 172.

2 Juin 1691.

3 Arnauld, Fuvres, t. III, p. 400-1. 


\section{La Chine et la formation de l'esprit philosophique en France}

toutes les autres religions par la nécessité de la foi, ce qui ne le rendait pas tributaire de la raison, et que le chrétien devait avoir une vertu essentielle, ignorée des sages du paganisme, I'humilité : «On ne sauroit disconvenir que la morale des sages du Paganisme n'ait beaucoup de rapport à celle de l'Évangile. Peut-être que I'humilité qui est le caractère spécifique du chrétien étoit la vertu qu'ils cultivoient le moins $\gg 1$.

Que le livre de Huet fût dangereux, c'est très vraisemblable, mais qu'il soit faible, on n'en peut douter. Sans doute, Huet est persuadé que les peuples les plus civilisés de l'Orient, Brahmanes et Chinois, ont pu avoir connaissance des vérités bibliques par les navigateurs anciens, qui ont mis en relation I'Europe et l'Asie. Mais lui qui s'est tant intéressé aux relations de voyages, comme le prouvent les livres de sa bibliothèque que conserve la Bibliothèque Nationale, s'est contenté d'affirmer le fait de ces rapports entre l'Orient et l'Occident, sur la foi de quelques auteurs anciens, et il n'a pas cherché à les préciser d'après les auteurs modernes. Il s'est contenté aussi d'indications très vagues sur la philosophie et la religion des Chinois dont il voulait pourtant tirer argument pour sa thèse, et il a totalement ignoré la traduction de Confucius des PP. Jésuites, avec la préface du P. Couplet, œuvre capitale dans I'histoire de la connaissance de la Chine en Europe et qui avait paru trois ans auparavant.

Nous avons vu avec quel soin la traduction de Confucius et la préface du P. Couplet furent expurgées et corrigées par les

\footnotetext{
1 Id., ibid., p. 401.
} 


\section{La Chine et la formation de l'esprit philosophique en France}

rédacteurs de Paris ${ }^{1}$, pour qu'il n'y eût aucun doute sur le caractère spiritualiste de la religion des anciens Chinois. Souci méticuleux p.297 qu'expliquent le développement des connaissances à ce moment sur l'ancienne chronologie chinoise, et le danger qu'aurait pu faire courir à la religion la découverte d'un peuple athée, tout près des origines du monde, à une époque où les enseignements des premiers hommes ne pouvaient être oubliés. Mais souci que provoquent peut-être aussi les publications sur le Siam, du Chevalier de Chaumont et du P. Tachard, qui nous parlent de la religion des Siamois, peuple qui n'est pas éloigné de la Chine, qui a peut-être la même antiquité qu'elle, et qui, lui, est athée.

Le Chevalier de Chaumont sans doute déclare que les Siamois ne sont pas superstitieux, qu'ils n'adorent pas les idoles qui sont dans leurs temples, mais qu'ils leurs rendent seulement des honneurs comme à des hommes d'un grand mérite « dont l'âme est à présent en quelque Roy, vache ou Talapoin »2. Mais il ajoute : «Voilà en quoy consiste leur Religion qui à proprement parler ne reconnoit aucun Dieu, et qui n'attribue toute la récompense de la vertu qu'à la vertu même qui a par elle le pouvoir de rendre heureux celuy dont elle fait passer l'âme dans le corps de quelque puissant et riche Seigneur ou dans celuy de quelque vache ${ }^{3}$. Le P. Tachard use de plus de prudence en affirmant tout d'abord que les Siamois croient en un Dieu, mais

\footnotetext{
${ }^{1}$ Cf. supra, p. 151 sq.

2 Chaumont, Relation de l'ambassade, p. 158.

3 Id., ibid., p. 158.
} 


\section{La Chine et la formation de l'esprit philosophique en France}

la description qu'il donne de ce dieu nous permet d'apercevoir que ce dieu sans passions et par conséquent sans bonté, sans mouvement et sans action sur le monde, n'est pas un Dieu Providence et que d'autre part, ce n'est pas non plus un dieu créateur puisque le ciel et la terre sont incréez et éternels $\gg 1$. Ce dieu n'a donc aucun des attributs qui selon le christianisme doivent être ceux de la divinité et il est possible que le P. Couplet et les reviseurs de Paris aient tenu particulièrement à justifier les Chinois de doctrines semblables qui frisent en réalité l'athéisme. Justification d'autant plus nécessaire que le P. Martini avait prétendu que les Chinois n'avaient pas de mot pour désigner Dieu.

Le P. Couplet écrit en effet sa préface à la traduction de Confucius à l'usage des jeunes missionnaires qui vont en Chine pour catéchiser les Infidèles, mais surtout pour tâcher de convertir les Lettrés, les mandarins, et, s'il est possible, I'Empereur. Or, les Chinois cultivés ne veulent se rendre qu'à la raison, ce qui ne veut pas dire qu'ils soient rationalistes, c'est-àdire prêts à renoncer aux p.298 principes de leurs raisonnements, si on leur démontre qu'ils sont faux ; mais ils veulent que les vérités qu'on leur apporte cadrent avec leurs principes immuables. Le P. Couplet essaie donc de montrer aux jeunes missionnaires qu'ils peuvent prêcher sans crainte le christianisme aux Lettrés de la Chine, et même avec des chances de succès, s'ils sont assez habiles pour faire apercevoir aux Chinois la concordance entre les témoignages des annales

\footnotetext{
1 Tachard, Voyage de Siam des PP. Jésuites. Ed, in-4º, p. 390.
} 


\section{La Chine et la formation de l'esprit philosophique en France}

chinoises et les témoignages de la Bible sur les origines du monde et la religion des premiers hommes. Les concordances de temps, prouvées par le P. Couplet dans sa Chronologie mènent à des concordances de principes philosophiques et d'idées religieuses que le $P$. Couplet dégage et que le reviseur accentue, dans la préface du Confucius Sinarum philosophus.

Par sa Chronologie, le P. Couplet s'efforçait de prouver ${ }^{1} \mathrm{qu}^{\prime i l}$ y a dans l'histoire de la Chine deux périodes distinctes, une période fabuleuse et une période historique, mais que les Chinois ont souvent confondues, parce qu'ils ont perdu le souvenir du Déluge universel. Établis en Chine peu de temps après le Déluge, deux seuls ans à peine, sous la conduite de Noé ou de l'un de ses descendants. ils ont pu conserver dans leurs traditions des idées saines sur la formation du monde et la création du premier homme. Mais comme l'origine de ces idées leur a bien vite échappé, ils ont placé au début de leur histoire une période fabuleuse à laquelle ils ont rapporte ces traditions antédiluviennes dont ils ne trouvaient pas I'explication. D'où nécessité de ramener le début de la période historique à une époque où suivant les données de la Genèse, Noé et ses descendants ont pu se trouver en Chine. Et c'est la raison pour laquelle le P. Couplet exclut de la période historique les deux premiers empereurs.

Mais une fois l'origine de cette période historique fixée à une époque légèrement postérieure au Déluge, tout se suit dans I'histoire chinoise, et les Chinois, sans aucun commerce avec les

\footnotetext{
1 Voir supra, p. 212.
} 


\section{La Chine et la formation de l'esprit philosophique en France}

autres peuples du monde, ont pu conserver inaltérées les idées philosophiques et religieuses qu'ils ont reçues de Noé ou de ses descendants.

Si Fou-hi, premier empereur de la Chine a reçu des descendants de Noé la connaissance du vrai Dieu, Hoam-ti [Houang ti], troisième empereur, éleva un temple au Souverain Empereur du ciel, qui fut, probablement le premier temple du monde. Il régla les sacrifices que ses successeurs maintinrent inchangés pendant ${ }_{\text {p.299 }}$ de nombreux siècles, persuadés que le Souverain Empereur du ciel ne les accepterait pas s'il n'y avait outre «le culte pur de l'âme » l'exactitude des pratiques traditionnelles ${ }^{1}$. Mais ce culte ne s'adressait pas à des idoles, car un auteur dont le livre a échappé à l'incendie de Ym Hoam Ti déclare qu'avant l'entrée en Chine de I'Idole Fo il n'y avait pas d'images de faux dieux, il n'y avait pas de statues en Chine. De cette affirmation on ne peut conclure que deux choses : ou que les Chinois étaient athées, ou qu'ils reconnaissaient le vrai Dieu. Athées, ils ne l'étaient pas, témoin ces sacrifices que les empereurs faisaient à des dates fixes, car « si l'on avait vu Aristote ou un autre philosophe fléchir les genoux à des époques déterminées, adresser des prières en levant les yeux et les mains vers le ciel, ne penserait-on pas que ce philosophe a reconnu l'existence d'un dieu, même s'il n'en a jamais fait mention dans ses ouvrages ? »2. Or ce Dieu ne peut être que le vrai Dieu, comme le prouve l'antiquité de l'empire chinois et de

${ }^{1}$ Confucius Sinarum Philosophus, Préface, p. 80.

${ }^{2}$ Id., ibid., p. 81. 


\section{La Chine et la formation de l'esprit philosophique en France}

sa religion, preuve que viennent corroborer encore toute sorte d'autres arguments : les Chinois en effet n'ont jamais eu dans leur religion de sacrifices sanglants tels que les Priapées et les Saturnales des Romains. Ils sont toujours restés étrangers aux superstitions ridicules que I'on trouve par exemple chez Homère et Hésiode, que pourtant on considère comme des sages. Ils ont toujours eu une morale très pure, où I'on retrouve même certains préceptes du christianisme, tel le précepte de Confucius : «Ne fais pas aux autres ce que tu ne voudrais pas qu'on te fit à toi-même »1. Donc les Chinois qui ne sont ni athées ni superstitieux et qui ont une morale pure ont certainement adressé leurs sacrifices au vrai Dieu, et I'on peut admirer la Providence « qui a favorisé la nation chinoise plus que presque toutes les autres $\gg 2$.

Ensuite le P. Couplet examine les termes dont les Chinois se servent pour désigner Dieu. Il faut en effet répondre à I'affirmation du P. Martini. Il faut aussi détourner le sens dangereux que I'on pourrait être tenté de donner au mot Tien qui, suivant certains interprètes, désigne le ciel matériel. Ce terme est très ancien, le P. Couplet ne le nie pas, mais il escamote la difficulté que pose la signification de ce mot, et, par une pétition de principe, supposant démontré le spiritualisme de

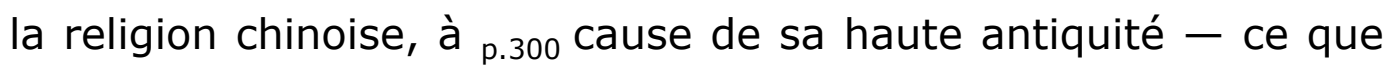
précisément il devrait prouver - il en tire la conséquence que le mot Tien ne peut désigner le ciel matériel : « Si on accorde que

\footnotetext{
${ }^{1}$ Id., ibid., p. 85.

${ }^{2}$ Id., ibid., p. 81.
} 


\section{La Chine et la formation de l'esprit philosophique en France}

les Chinois existaient en des temps voisins du Déluge et qu'ils ont dû avoir la connaissance de Dieu, et par suite le nom servant à le désigner, qu'ils se soient servis du mot Tien ou du mot Xamti, on devra toujours conclure qu'ils n'ont pas compris sous ces désignations et qu'ils n'ont pas voulu désigner par elles autre chose que le vrai Dieu $\gg 1$.

Le P. Couplet voulait en somme démontrer que les Chinois avaient participé à la révélation primitive, qu'ils avaient dès I'origine connu le vrai Dieu, qu'ils lui avaient élevé un temple et rendu un culte, que ce culte était demeuré inaltéré pendant une longue suite de siècles, qu'il exigeait non seulement la pureté du cœur, mais encore la modestie et I'humilité 2 - la vertu essentielle du chrétien suivant Arnauld -, toutes conditions qui prouvent que les Chinois ont connu la véritable religion. Si I'on ajoute qu'ils ont eu de tout temps une morale très pure dont le principe est la charité et l'amour du prochain, ne peut-on proposer aux Chinois la religion et la morale chrétiennes, et les

\footnotetext{
${ }^{1}$ Id., ibid., p. 90.

2 Ce texte est assez curieux pour que nous le citions en entier : « Jam vero illa principum in deprecando cœlo modestia animique demissio, qua se parvulos et infantulos coram suprema majestate vocitabant ; illa caritas qua se reos agebant omnium quæ forte peccaverant subditi, sibique unis ultro deposcebant ea supplicia quæ cunctis ab irato cœlo timebantur : illa sollicitudo, ille angor timor ac tremor in cultu et veneratione etiam privata, supremi imperatoris, de quibus sæpe in libris fit mentio, hæc, inquam, omnia nonne declarant veram in eorum animis Religionem insedisse »Id., ibid., $\mathrm{p}$. 81.
} 


\section{La Chine et la formation de l'esprit philosophique en France}

Chinois risquent-ils de trouver une contradiction entre leurs principes religieux et les principes du christianisme ${ }^{1}$ ?

C'était la conclusion à laquelle le P. Couplet voulait aboutir à l'intention des futurs missionnaires pour lesquels cette préface était écrite, mais en même temps, de cette analyse de la religion chinoise, résultait une autre conclusion qui n'importait pas moins p.301 aux Jésuites - comme le montre le soin que mirent les Jésuites de Paris à en corriger les moindres détails - c'est que les cultes chinois ne peuvent être idolâtriques, puisque les empereurs, et par suite le peuple, n'ont adoré de tout temps qu'un Dieu immatériel. Le P. Couplet ne fait pas l'étude des différents cultes pour démontrer qu'ils sont exempts de superstition ; il n'avait pas à le faire puisque la même année le $P$. le Tellier s'en chargeait dans sa Défense des nouveaux chrétiens de la Chine. Ces deux livres se complètent I'un l'autre, ils sont tous deux une apologie des Jésuites et de leurs missions en Chine. Mais tandis que le P. Le Tellier ne cherche qu'à réfuter ou à expliquer les faits signalés par la Morale pratique, le $\mathrm{P}$. Couplet se réfère seulement aux principes.

\footnotetext{
1 Le Journal des Sçavans, dans le compte rendu qu'il fait de la préface du P. Couplet, marque exactement l'intention de ce livre, tout ou moins en ce qui concerne la propagande religieuse en Chine : «Quand les Jésuites furent parvenus à ce point de connoissance, ils se proposèrent d'examiner la Philosophie des Chinois, où n'ayant rien trouvé qui répugnant à la loi naturelle, ils résolurent d'en apprendre les maximes et de s'en servir pour confirmer les véritez de la Religion Chretienne; ce qu'ils firent avec tant de succez que les Chinois reçurent ces véritez non avec mépris comme auparavant mais avec confiance et les regardèrent comme des conséquences qui se déduisoient de leurs principes et qui estoient confirmées par l'autorité de leurs propres philosophes. » (Janvier 1688. Ed. de Paris, p. 100).
} 


\section{La Chine et la formation de l'esprit philosophique en France}

La préface du P. Couplet sur la religion des Chinois était audacieuse. Elle disait déjà et dans les mêmes termes, tout ce que dira quelques années plus tard le P. Le Comte qui pour ce fait fut chassé de la Cour et condamné par la Sorbonne. Elle dépassait de beaucoup les conclusions de La Mothe le Vayer qui ne faisait en somme qu'entrebâiller la porte du Paradis aux païens vertueux, et, chose plus grave, les idées qu'elle exprimait n'étaient pas proposées par un sceptique ou un libertin, voire même par un laïc, mais par un religieux et, un théologien. La théorie que supposaient les allégations du P. Couplet tendait en somme à dépouiller le peuple juif de sa dignité de nation élue, à rendre inutiles pour le salut la révélation, la foi et la grâce. Cependant le livre du P. Couplet ne fut pas interdit ; il fut au contraire imprimé jussu Ludovici Magni et les idées exprimées par le P. Couplet ne semblent même pas avoir suscité à leur époque de protestations. Arnauld ne jugea pas utile de reprendre contre ce livre les arguments qu'il avait entassés contre La Mothe le Vayer, mais il se revancha sur le P. Le Tellier en essayant de faire condamner son livre à Rome et en lui assénant six volumes de la Morale pratique, dont les deux derniers sont consacrés aux affaires de la Chine. Mais ces deux volumes ne traitent que des rites chinois et s'attaquent seulement aux tolérances que permettent les Jésuites aux catéchumènes : les questions de doctrine sont laissées de côté ; ce n'est donc plus ici notre affaire.

Si le silence que I'on peut constater au sujet de la préface du P. Couplet peut S'expliquer par le crédit des Jésuites à la Cour à cette époque, par l'attente où l'on était aussi des révélations sur 


\section{La Chine et la formation de l'esprit philosophique en France}

la Chine que devaient apporter les missionnaires jésuites envoyés spécialement par le roi, sans parler de la trêve qui semblait s'être p.302 faite momentanément entre Jésuites et Missionnaires, trêve dont le prix avait été l'approbation donnée par Brisacier au livre du P. Le Tellier ${ }^{1}$, il n'en reste pas moins que l'explosion de critiques haineuses qui se produisirent lorsque parurent les Nouveaux Mémoires de la Chine du P. Le Comte ne pourrait pas s'expliquer seulement par un affaiblissement, qui fut cependant très réel, du crédit des Jésuites entre 1687 et 1696 . Mais dans l'intervalle avait sévi une autre querelle théologique, où les Jésuites faisaient encore une fois figure de libéraux et d'accusés, l'affaire du péché philosophique.

En 1686, un Jésuite du Collège de Dijon, I'abbé Musnier, soutint une thèse publique où il s'efforçait de prouver que les péchés les plus contraires à la nature et à la droite raison n'étaient point des péchés mortels qui méritassent la peine éternelle, lorsque ceux qui les commettaient ne connaissaient pas Dieu ou ne pensaient pas actuellement à lui ; que, dans ce cas, ces péchés n'étaient que des péchés philosophiques et nullement une offense à Dieu. Autrement dit, en dépouillant ces formules de leur gaine théologique, commettre le péché philosophique, c'est contrevenir à la morale naturelle, commettre le péché théologique c'est contrevenir à la loi religieuse. Mais on ne contrevient pas à cette loi si on ne la connaît pas, si l'on ne sait pas qu'il y a un Dieu, et pour cela on ne peut être damné. Cette thèse tendait donc à libérer du péché théologique tous les

1 Voir supra, p. 66-9. 


\section{La Chine et la formation de l'esprit philosophique en France}

peuples auxquels le christianisme n'a pas été prêché, et les Jésuites ouvraient ainsi toutes grandes les portes du paradis à des peuples entiers, notamment aux Chinois, qui vivaient conformément à la droite raison, et qui par suite ne commettaient même pas le péché philosophique. Et dans ce paradis où pénètreront les Chinois entreront aussi les Américains et autres «Barbares » à qui la loi religieuse n'a pas été prêchée.

Cette thèse très libérale, en ce qui concerne les infidèles, (c'est la seule question qui nous importe) tendait en somme à nier la nécessité de la foi et de la grâce pour le salut. Arnauld qui en ce moment était occupé à rédiger ses volumes de la Morale Pratique se crut obligé de prendre la plume, toutes affaires cessantes, pour combattre cette doctrine.

L'ignorance de la foi religieuse, dit-il, ne peut être un argument en faveur du salut des infidèles car « l'écriture est pleine de témoignages de la colère de Dieu contre les peuples qui ne le ${ }_{\text {p.303 }}$ connoissent point $\gg 1$. Colère de Dieu qui est la règle de sa sagesse car les hommes « dégénèrent d'autant plus de la dignité de leur nature par la malice de leur volonté qu'ils sont dans une plus grande ignorance de Dieu et de sa loy »2. La connaissance du vrai Dieu est donc nécessaire pour le salut, comme elle est nécessaire pour la morale : et, poussant à bout les Jésuites, Arnauld leur fait admettre ce principe. Mais cela posé, comment peut-on, comme les Jésuites, vouloir sauver tous

1 Arnauld, Nouvelle Hérésie dans la morale (Seconde, troisième, etc., dénonciation d'une nouvelle hérésie, p. 32).

2 Id., ibid., p. 32. 


\section{La Chine et la formation de l'esprit philosophique en France}

les hommes ? Bien des païens sont morts avant d'avoir été « prêchés »; bien d'autres n'ont pas encore reçu de prédicateurs. Prétendra-t-on qu'ils ont connu la vérité par des grâces intérieures ? Mais ces grâces sont de deux sortes, ou des grâces « congrues », c'est-à-dire suffisantes pour que les peuples barbares arrivent à connaître Dieu (or il ne semble pas qu'ils y soient arrivés) ou bien des grâces « incongrues » qui ne leur ont pas permis de parvenir à la vérité parfaite, mais les ont fait tomber dans le péché théologique, si bien que les Jésuites en prétendant que la miséricorde de Dieu a voulu sauver tous les hommes arrivent à cette conclusion que Dieu « laissant là ces grâces par lesquelles il auroit exécuté cette intention a choisi à dessein les grâces seules qu'il sçavoit avant que de les donner qui n'auroient point d'autre effet que de les rendre plus criminels $\gg 1$.

Bien que la thèse du péché philosophique eût été condamnée par Alexandre VIII 2, il parut en 1696, I'année même des Nouveaux Mémoires de la Chine du P. Le Comte, un livre posthume du Cardinal Sfondrati qui, reprenant I'argument de la miséricorde divine qui doit s'exercer sur tous les peuples, ne faisait en somme que renforcer l'argumentation des Jésuites en repoussant la critique d'Arnauld.

La connaissance de Dieu, dit Sfondrati, est naturelle à I'homme. Mais, répond-t-on, il y a des peuples barbares qui n'ont pas connu Dieu, tels que les Brésiliens qui ne savaient pas

\footnotetext{
${ }^{1}$ Id., ibid., p. 145.

2 Le 24 août 1690.
} 


\section{La Chine et la formation de l'esprit philosophique en France}

même que Dieu existât avant d'en être instruits par les Portugais. C'est une chose que d'ignorer Dieu, répondait Sfondrati, et c'est une autre chose que de l'ignorer invinciblement. Puisque Dieu ne refuse à aucune créature les ressources et les facultés nécessaires pour atteindre sa fin, qui pourrait croire que ce bienfait ait été refusé à l'homme seul ? Mais, poursuivait-il, concédons l'ignorance invincible : cela p.304 même est un grand bienfait et une grande grâce. En effet, comme le péché est essentiellement une offense et une injure faite à Dieu, une fois la connaissance de Dieu supprimée, il s'en suit nécessairement qu'il n'y a plus ni injure ni péché, ni éternelle peine ${ }^{1}$.

La lettre des cinq évêques, adressée au Pape pour lui demander une condamnation formelle des affirmations du Cardinal Sfondrati, s'efforçait d'établir des rapports entre cette théorie et la doctrine du péché philosophique. Elle insistait, pour en marquer le danger, sur l'argument des peuples infidèles qui n'ont pu pécher puisqu'ils n'ont pas eu la connaissance de Dieu, et elle rappelait qu'en 1674, la Congrégation romaine de I'Inquisition, consultée sur le fait de savoir si les Chinois qui n'ont pas connu Dieu ont pu échapper aux peines éternelles, avait répondu catégoriquement qu'ils ont dû être damnés ${ }^{2}$.

Le problème du salut des infidèles, ou comme disait La Mothe le Vayer de la vertu des païens, c'est-à-dire en somme de l'indépendance de la morale par rapport à la religion, se pose

\footnotetext{
${ }^{1}$ Capéran, Le Problème du Salut des Infidèles, p. 358.

2 Bossuet, Correspondance, t. VIII, p. 164-165.
} 


\section{La Chine et la formation de l'esprit philosophique en France}

avec acuité et à propos de toute sorte de questions, entre 1688 et 1700 ; et ce n'est pas par hasard que l'Assemblée du clergé de 1700 renouvelle la condamnation du péché philosophique, songe un moment à condamner la thèse du Cardinal Sfondrati, et fait condamner par la Sorbonne les ouvrages des PP. Le Comte et Le Gobien sur la Chine. Les défenseurs de l'orthodoxie aperçoivent nettement alors ce que ces théories, d'autant plus dangereuses qu'elles sont soutenues par des théologiens, peuvent apporter d'appui aux idées des libertins. En 1687, I'exposé que faisait le P. Couplet de la philosophie et de la religion des Chinois pouvait sembler inoffensif. En 1700, les idées des PP. Le Comte et Le Gobien, qui ne font cependant que systématiser, mais en supprimant certaines atténuations, les idées du P. Couplet, prennent une importance tout autre, parce qu'elles semblent venir confirmer par l'expérience d'un pays très ancien la thèse du péché philosophique et celle du Cardinal Sfondrati. En outre, avec les PP. Le Comte et Le Gobien, la théologie sort de l'ombre de l'école pour affronter le soleil de la place publique, car leurs ouvrages ne s'adressent plus seulement aux théologiens et aux érudits comme le lourd in-folio du P. Couplet qui était écrit en latin, mais au public qui peut y trouver dans un format commode et en un français élégant, des faits et des idées sur une des plus anciennes religions du monde. Or, c'est là qu'est p.305 le grand danger, car non seulement les libertins, mais les gens qui ne sont pas des esprits forts, vont pouvoir se faire juges dans un débat théologique où s'affrontent les éternels adversaires, molinistes et augustiniens. 


\section{La Chine et la formation de l'esprit philosophique en France}

Danger d'autant plus grand que la Sorbonne était obligée, qu'elle le voulût ou non, de décider une question de fait, le fait de la religion des Chinois : en effet, condamner les affirmations du P. Le Comte sur le spiritualisme des Chinois, c'était décider en somme que leurs adversaires avaient raison de croire à l'athéisme des Chinois. Si bien qu'elle se trouvait dans une impasse : en condamnant les Jésuites et en prenant parti pour l'athéisme des anciens Chinois, elle ruinait l'argument du consentement universel, et l'idée si souvent exprimée contre les libertins de la dépendance nécessaire entre la religion et la morale; en ne les condamnant pas, elle glissait elle aussi vers le déisme.

La théorie du P. Le Comte sur l'ancienne religion des Chinois, empruntée en grande partie, comme nous l'avons dit, au P. Couplet, se résume en quelques formules : le peuple de la Chine a conservé près de deux mille ans la connaissance du vrai Dieu, il l'a honoré d'une manière qui peut servir d'exemple et d'instruction même aux chrétiens. Il lui a sacrifié dans le plus ancien Temple de l'univers. Il a pratiqué le culte intérieur et extérieur. Il a eu des prêtres, des Saints, des Hommes inspirés de Dieu, pleins de son esprit, et des miracles. Sa morale a été aussi pure que sa religion. Et non seulement l'esprit de la religion s'est conservé parmi ce peuple, mais encore les maximes de la plus pure charité, ce qui en fait la perfection et le caractère. La première conséquence que l'on tire de ces faits est que dans la sage distribution des grâces que la Providence divine a faite parmi les nations de la terre, la Chine n'a pas sujet de se plaindre puisqu'il n'y en a aucune qui ait été plus constamment 


\section{La Chine et la formation de l'esprit philosophique en France}

favorisée. Et la seconde, que I'ancienne religion chinoise est la même que la religion chrétienne, dans ses principes et dans ses points fondamentaux, puisque les Chinois adorent le même Dieu que les Chrétiens, et le reconnaissent aussi bien qu'eux pour le Seigneur du Ciel et de la terre ${ }^{1}$.

Les deux conséquences sont naturellement les deux points $p$. 306 essentiels sur lesquels porteront principalement les débats puisque la première tend à déposséder la nation juive du privilège de peuple élu, et que la seconde, en assimilant la religion chinoise, même du temps de Noé, à la religion chrétienne, tend à rendre inutile la révélation chrétienne et par suite la foi en Jésus-Christ.

C'est sur la seconde de ces conséquences que s'acharnèrent avec le plus d'âpreté les adversaires des Jésuites, et ils s'efforcèrent de montrer qu'elle tendait à favoriser le déisme ${ }^{2}$. Mais répondaient les partisans des Jésuites, la religion de Noé conduisait-elle donc au déisme ? Assurément non, rétorquaient leurs contradicteurs : du temps de Noé, la foi implicite du mystère de la Sainte Trinité et de l'incarnation suffisait ; mais « c'est introduire le déisme que de vouloir faire accroire

\footnotetext{
1 Ellies du Pin, Défense de la Censure, p. 4. Les différentes affirmations des PP. Le Comte et Le Gobien qui ont été soumises à la censure, ainsi que les qualifications qui leur ont été appliquées par la Sorbonne se trouvent publiées dans ce livre d'Ellies du Pin, ainsi d'ailleurs que dans de nombreuses publications de l'époque que l'on peut retrouver facilement d'après le Catalogue de l'histoire d'Asie de la Bibliothèque Nationale, art. Cultes Chinois.

2 Voir dans la Lettre d'un Docteur sur ce qui se passe dans les assemblées de la faculté de théologie de Paris, l'énumération des Docteurs demandant à la Faculté de déclarer que cette proposition tend à favoriser le déisme (lettre II, p. 35 ; lettre III, p. 14, 19, 20, 27 ; lettre IV, p. 59, etc.). Cependant la Faculté n'a pas inséré ce reproche dans la censure de cette proposition.
} 


\section{La Chine et la formation de l'esprit philosophique en France}

aujourd'hui à un Prince athée que sa Religion, qui est la même que l'ancienne, soit la même dans le fonds que la Religion Chrétienne »1. Le déisme est donc l'ennemi qu'il faut combattre, cet ennemi auquel les Jésuites donnent des armes en vantant comme une religion analogue à la religion chrétienne la religion naturelle des Chinois, qui n'avait connu ni la loi écrite ni la loi de grâce. C'était rendre inutile et Moïse et Jésus-Christ.

Le P. Le Comte dans un Éclaircissement sur la dénonciation faite à N. S. P. le Pape des Nouveaux Mémoires de la Chine, publié en 1700, un peu avant la réunion de la Faculté de théologie, avait essayé de se disculper, sans rien retirer d'ailleurs de ses affirmations. Il y déclarait qu'il n'avait fait que rappeler une doctrine très orthodoxe de l'école en prétendant que les Gentils aussi bien que les Juifs ont eu des prophéties, des miracles, la sainteté, et par conséquent l'esprit de Dieu, la charité et les autres vertus surnaturelles qui en sont inséparables, puisque les Pères ont considéré les Sibylles comme inspirées par Dieu, et que d'autre part, Saint-Justin a prétendu que Socrate et Héraclite peuvent passer pour de véritables Chrétiens, et qu'il les a comparés même à Abraham et à Elie ${ }^{2}$. A ce compte le livre de La Mothe le Vayer n'avait rien que de très orthodoxe.

Mais c'est une chose d'affirmer que quelques philosophes de la gentilité, par une vertu spéciale ou par une grâce particulière, ont eu des mérites analogues aux vertus chrétiennes, et c'est

\footnotetext{
${ }^{1}$ Lettre d'un Docteur... Lettre IV, p. 18.

2 Le Comte, Eclaircissement..., p. 22.
} 


\section{La Chine et la formation de l'esprit philosophique en France}

une tout autre chose de prétendre qu'un peuple entier, comme le peuple chinois a conservé intacte et pure pendant deux mille ans la religion naturelle, alors que le peuple juif lui-même était tombé à diverses reprises dans I'idolâtrie. De ce grief, le P. Le Comte ne cherchait pas à se défendre par des raisons théologiques, mais il invoquait l'autorité de I'histoire dont il avait été, disait-il, le fidèle porte-parole : «Quand j'ay parlé de I'ancienne Religion des Chinois, je I'ay toujours fait en Historien qui rapporte ce que les anciens Livres de ces peuples nous ont laissé. Et je n'ay jamais prétendu que le public donnât à mon Livre plus de croyance que n'en mérite I'Histoire même de la Chine »1. Mais invoquer I'histoire contre des arguments théologiques, c'est faire de l'histoire le juge de la théologie, c'est mettre les faits au-dessus de la doctrine. Ainsi I'histoire d'une nation profane devenait un critérium de vérité, supérieur même à la révélation.

Enfin le P. Le Comte se défendait en invoquant un argument d'occasion, la nécessité d'enlever une arme aux libertins : « Ne serait-il pas bien plus dangereux de condamner ce qu'on reprend icy dans mon Livre, en disant que les anciens Chinois, comme ceux d'à présent, étoient athées. Car les Libertins ne tireroientils pas avantage de l'aveu qu'on leur feroit, que dans un empire si vaste, si éclairé, établi si solidement, et si florissant, soit par la multitude de ses habitants, soit par l'invention de presque tous les arts, ou n'auroit jamais reconnu de Divinité. Que deviendroient donc les raisonnements que les Saints-Pères, en

\footnotetext{
1 Id., ibid., p. 9.
} 


\section{La Chine et la formation de l'esprit philosophique en France}

prouvant l'existence de Dieu ont tiré du consentement de tous les peuples, auxquels ils prétendent que la Nature en a imprimé l'idée si profondément que rien ne la peut effacer $\gg 1$.

Démontrer l'accord de la foi avec la raison ne suffit plus en 1700 après la révélation de l'ancienne religion des Chinois : il faut prouver l'accord de la foi avec I'histoire, il faut démontrer I'universalité chez tous les peuples, dès leur origine, des enseignements mosaïque et chrétien. Pour y arriver, il faut sans doute apporter au dogme quelques atténuations, - sans parler des retouches que I'on fait subir aux textes chinois - si bien que la tradition des peuples civilisés se réduit à quelques principes généraux : croyance à l'existence d'un Dieu créateur, à la Providence, à l'immortalité de p.308 l'âme. Quant à l'attente d'un Messie rédempteur, principe essentiel de la religion juive, on n'en trouve sans doute pas de traces bien nettes chez les anciens Chinois, mais s'ils ont eu, sinon une foi explicite du moins une croyance implicite en ce Rédempteur, on peut néanmoins assurer leur salut.

Cette idée n'alla pas sans protestations. Un des Docteurs, Coulau, qui adopta entièrement la thèse des Jésuites et publia ensuite son jugement longuement motivé - ce qui faillit le faire incarcérer 2 - put s'en apercevoir. Il voulut démontrer qu'il n'y avait presque point de nation qui n'eût reconnu l'Être suprême. Les Gaulois adoraient Teutatès, mais c'était le vrai Dieu ; ils étaient exacts observateurs de la loi naturelle, reconnaissaient

\footnotetext{
${ }^{1}$ Id., ibid., p. 14.

2 Voir supra, p. 106.
} 


\section{La Chine et la formation de l'esprit philosophique en France}

l'immortalité de l'âme et la vie future. Quant aux Américains, on a cru longtemps qu'ils étaient polythéistes, mais Laët a montré que les Péruviens croient en un Dieu créateur, à l'immortalité de l'âme et à la vie future. Il en est de même pour les anciens Perses dont le législateur Zoroastre enseignait qu'il y a un principe éternel du bien qu'il appelait Dieu, et un principe du mal, mais qui devait périr, et qu'il appelait le Diable. Il était persuadé aussi qu'il $y$ avait une vie future où les justes trouvaient leur récompense ${ }^{1}$. Il en est ainsi des Germains et des Éthiopiens. Pourquoi ne pourrait-on pas dire la même chose des Chinois qui sont des descendants de Noé ? Dans son discours Coulau alla jusqu'à prétendre «qu'il importait peu de quels noms les historiens se servissent pour exprimer l'Être souverain $\gg 2$. Cette affirmation provoqua un violent tumulte : «On prétendoit qu'il avoit avancé qu'on pouvoit appeler Dieu, Jupiter ou Mars. M. Coulau dit qu'on lui imposoit et qu'il n'avait dit autre chose sinon qu'il nous importoit peu que les Historiens profanes eussent donné à Dieu le nom de Mars ou de Jupiter, s'il étoit constant que ces historiens par ces différents noms n'eussent entendu que le même Estre souverain » 3 .

Le livre de Thomas Hyde, Histoire de la Religion des Persans, qui parut en cette même année 1700 - mais Coulau ne l'a pas connu (il cite Huet et non Hyde au sujet de Zoroastre), - était une importante contribution en faveur de ceux qui cherchaient

\footnotetext{
${ }^{1}$ Coulau, Judicium unius..., p. 26.

2 Journal historique des Assemblées tenues en Sorbonne pour condamner les Mémoires de la Chine. (V. Lettre, p. 17-8).

3 ibid., loc. cit.
} 


\section{La Chine et la formation de l'esprit philosophique en France}

des traces de la véritable religion dans les doctrines religieuses des anciens peuples. Ce que les Jésuites prétendaient de l'ancienne p.309 religion des Chinois, Hyde I'affirmait aussi de I'ancienne religion des Persans. Les anciens Perses, disait-il, croyaient en un Dieu unique, omnipotent et éternel. Ils commençaient tous leurs livres par cette formule : Au nom du Dieu bienfaisant. Ils lui adressaient des prières. Ils lui accordaient tous les attributs que nous lui donnons. Ils croyaient à la résurrection générale, à la récompense des bons et à la punition des méchants ${ }^{1}$. En somme c'était un argument précieux en faveur des croyances spiritualistes des anciens peuples. Sans doute Hyde affirmait que toutes ces ressemblances qu'il trouvait entre les doctrines des anciens Persans et les idées juives, tenaient à ce fait que les Persans les avaient empruntées aux Juifs. Mais cela n'était pas une atténuation pour les théologiens intransigeants, pour lesquels tous les peuples anciens étaient idolâtres, hormis le peuple juif.

Voilà donc un certain nombre de faits qui indiquent une tendance assez générale des esprits à sauver des nations entières, comme auparavant les philosophes ou les théologiens libéraux s'efforçaient d'assurer le salut de certains sages du paganisme. Mais s'il est possible d'expliquer théologiquement, en s'appuyant sur des témoignages des Pères de l'Église, que certains philosophes privilégiés ont pu être inspirés par Dieu, comment pouvoir déclarer que des nations entières ont trouvé le chemin du salut sans avoir eu connaissance de la véritable

\footnotetext{
${ }^{1}$ Ch. XXXIII.
} 


\section{La Chine et la formation de l'esprit philosophique en France}

religion ? N'est-on pas amené à conclure de ces exemples historiques, si on les interprète ainsi, que la religion naturelle est suffisante, puisque tous les peuples ont trouvé en eux-mêmes les principaux enseignements du judaïsme et du christianisme ? On aboutirait ainsi à l'indifférence des religions ce qui aurait pour conséquence la tolérance. Si l'on n'y prend garde la tolérance va devenir la conclusion nécessaire de la découverte de la religion des anciens peuples.

Bossuet qui, au témoignage de l'abbé Le Dieu ${ }^{1}$, avait agi pour faire déférer à la Sorbonne les propositions du P. Le Comte, vit le danger du discours de Coulau. Il commença, pour y répondre, à rédiger trois mémoires pour Brisacier et Tiberge, mémoires rapides qui sont des notes plutôt qu'une rédaction définitive, mais qu'il n'acheva pas de mettre au point parce que Ellies du Pin dans sa Défense de la Censure et par sa publication du livre d'Arnauld De la nécessité de la foy répondait à ses intentions. En même temps, comme il s'agissait de combattre l'idée de l'indifférence ${ }_{\text {p. } 310}$ des religions, conséquence qui pouvait résulter du fait du spiritualisme de l'ancienne religion chinoise, Tiberge et Brisacier essayèrent de prouver la fausseté de ce fait en publiant deux opuscules de deux missionnaires en Chine, les PP. Longobardi et de Sainte-Marie, sur I'athéisme des Chinois 2. C'était une offensive concertée pour essayer de rendre au peuple

\footnotetext{
1 Voir supra, p. 105.

2 Par grâce et Privilège du Roy, donné à Versailles le 28 décembre 1700... il est permis aux Sieurs Supérieurs et Directeurs du Séminaire des Missions Etrangères de faire imprimer un livre qui a pour titre Anciens Traitez de divers auteurs sur les Cérémonies de la Chine... Achevé d'imprimer pour la première fois le 25 février 1701.
} 


\section{La Chine et la formation de l'esprit philosophique en France}

juif son privilège de peuple élu, qui seul a eu la connaissance du vrai Dieu et de son culte.

Plus que l'athéisme, l'indifférence en matière de religion qui, sous sa forme théologique et philosophique peut s'appeler déisme, et qui sous sa forme civile et politique n'est autre chose que la tolérance, semble à Bossuet l'ennemi le plus dangereux qu'il faut combattre, parce que répandue chez les nations protestantes, cette indifférence des religions tend à s'insinuer aussi chez les nations catholiques : « Je dis.... en général que ce livre [le livre de Coulau] est fait pour appuyer l'indifférence des religions qui est la folie du siècle où nous vivons. Cet esprit règne en Angleterre et en Hollande trop visiblement, mais par malheur pour les âmes, il ne s'introduit que trop parmi les catholiques. Ce livre autorise ce sentiment en faisant tous les hommes, de quelque religion qu'ils soient, capables de salut. L'auteur fait servir à cette doctrine la volonté générale de sauver tous les hommes, d'où il conclut que la religion véritable a pu être dans tous les peuples, et comme cette volonté subsiste toujours, il doit tirer la même conséquence du temps présent comme il a fait de celui qui a précédé l'Évangile ${ }^{1}$.

Cette indifférence des religions est une idée fausse, parce qu'elle suppose, contrairement à la tradition et aux enseignements des Pères, que les anciens peuples - Persans et Chinois - ont pu avoir le même privilège que la nation juive : la connaissance et le culte du vrai Dieu. Or, de telles affirmations

\footnotetext{
1 Bossuet, Lettre du 30 août 1701, Correspondance, t. XIII, p. 44.
} 


\section{La Chine et la formation de l'esprit philosophique en France}

sont des hérésies ${ }^{1}$. Sans doute l'auteur part de deux idées très orthodoxes, l'une qu'il y a des fidèles dispersés par ci par là hors de l'enceinte du peuple juif, la seconde que Dieu veut que tous les hommes soient sauvés « mais que des peuples entiers aient ouvert les yeux à la vraie religion, c'est de quoi l'on ne voit aucun exemple »2. p.311 Quelle est donc l'idée de Bossuet sur la religion de ces peuples primitifs tant vantés ? En général, mais avec quelques exceptions individuelles, il pense qu'ils sont idolâtres et que, comme tous les idolâtres, ils sont athées » 3 .

Ellies du Pin, développant et complétant les idées de Bossuet et insistant, comme l'eût fait Arnauld, sur la nécessité de la foi et sur la nécessité de la grâce pour le salut, examine la religion chinoise au regard des principes du judaïsme et du christianisme, et $n^{\prime} y$ trouve pas les caractères qui sont nécessaires pour constituer la véritable religion. En effet, la véritable religion doit être fondée sur la révélation et non pas seulement sur des connaissances naturelles. Ce n'est point sur les faibles lumières de la raison qu'est appuyée la religion, c'est sur l'autorité infaillible de Dieu qui ne peut être trompé ni trompeur. Quant au culte, comment les Chinois I'ont-ils reçu ? Pour que ce culte fût vrai, il faudrait que les Chinois l'eussent reçu directement de Dieu par une révélation spéciale ou indirectement de Dieu par l'intermédiaire des Juifs. Mais Dieu leur a-t-il donné des Prêtres ? Ou a-t-il fait passer des Juifs dans

\footnotetext{
${ }^{1}$ Id., Lettre du 8 septembre 1701, Correspondance, t. XIII, p. 161.

${ }^{2}$ Id., ibid., p. 170.

${ }^{3}$ Id., ibid.
} 


\section{La Chine et la formation de l'esprit philosophique en France}

leur pays ? Non, dira-t-on, mais ils ont eu l'ancienne religion de Noé qu'ils ont conservée par tradition. Or c'était en cela que consistait formellement I'hérésie des Pélagiens dont la plus grande erreur était de soutenir que I'homme pouvait rendre à Dieu le culte qu'il lui devait, par les seules forces de la nature. Ainsi ceux qui soutiennent le système de la pureté de l'ancienne religion de la Chine établissent sans y penser le pur pélagianisme ${ }^{1}$. Donc la théorie des Jésuites sur les cultes chinois est inspirée dans son principe par I'hérésie pélagienne, et par ses conséquences, elle tend à assimiler la religion naturelle aux vérités révélées du christianisme.

Bossuet et Du Pin discutent en théologiens ; c'est au nom des principes de la vérité révélée qu'ils combattent les Jésuites. Et si par hasard Bossuet fait appel à I'histoire pour contester les affirmations de Coulau, c'est à l'Écriture qu'il emprunte des faits et des textes. Mais si la doctrine peut condamner les théories des Jésuites, elle n'infirme pas les faits qu'ils ont allégués sur la religion et les cultes chinois. Même si les Jésuites sont pélagiens, il peut être vrai, comme ils le prétendent, que la religion chinoise est une religion spiritualiste, qui s'est conservée telle depuis les origines p.312 jusqu'à nos jours. Chaque chose a son ordre, comme aurait dit Pascal.

C'est ici qu'interviennent les deux petits traités publiés par le Séminaire des Missions étrangères.

Les deux petits traités des PP. Longobardi et de Sainte-Marie, qui n'ont ni préface ni lettre liminaire, semblent à première vue

${ }^{1}$ Ellies du Pin, Défense de la Censure, p. 324-341. 


\section{La Chine \\ et la formation de l'esprit philosophique en France}

n'être que des documents impartiaux, sans intention de polémique, sur la question controversée de la religion des Chinois. Mais quand on connaît les éditeurs et le rôle qu'ils ont joué dans la Querelle des Cérémonies chinoises, il n'est pas besoin d'être grand clerc pour deviner que les intentions ne sont pas aussi anodines que la modestie de la présentation de ces opuscules semblerait le faire croire. Ils veulent en réalité prouver pour faire pièce aux Jésuites et d'après le témoignage même de certains Jésuites, comme le P. Longobardi, que la théorie du spiritualisme de l'ancienne religion chinoise est un fait insoutenable.

Le P. de Sainte-Marie et le P. Longobardi, qui n'ont pas été persuadés de la vérité des théories du P. Ricci sur les cultes chinois ont étudié la religion chinoise à deux points de vue différents : tandis que le P. de Sainte-Marie étudiait le détail des cultes, culte de Confucius, culte des ancêtres et culte des morts, le $P$. Longobardi s'attaquait aux doctrines métaphysiques des philosophes chinois. Or le P. de Sainte-Marie arrivait à cette conclusion que les cultes populaires n'étaient en réalité que des cérémonies idolâtriques, et le P. Longobardi concluait à l'athéisme des philosophes chinois.

Dans les théories des philosophes, le P. Longobardi discernait deux doctrines différentes : une doctrine apparente, faite pour le peuple, pour la police intérieure, pour le culte divin, pour le culte civil et fabuleux, et « de cette manière, disait-il, ils conduisent le peuple au bien ou le détournent du mal »1. Mais la véritable

\footnotetext{
${ }^{1}$ Longobardi, Traité sur quelques points de la religion des Chinois, p. 26.
} 


\section{La Chine et la formation de l'esprit philosophique en France}

doctrine doit être cherchée sous les symboles, les énigmes, les figures dont les philosophes se plaisent à l'envelopper pour la mieux dissimuler.

Or, cette doctrine cachée, dangereuse pour le peuple, et qui n'est réservée qu'aux Lettrés, est la pure doctrine matérialiste. Ils n'ont pas cru à l'existence « d'une puissance infinie qui eût le pouvoir de tirer toutes choses de rien », mais, considérant d'un autre côté qu'il y avoit des choses qui existoient dans un temps et qui dans un autre n'existoient plus », ils ont imaginé une cause éternelle ${ }_{\text {p.313 }}$ et ils lui ont donné le nom de $L i$, c'est-à-dire raison ou fondement de toute nature ; « ils ont conçu que cette cause étoit une entité infinie, incorruptible, sans principe et sans fin $\gg 1$. Cette cause de tous les éléments, et de tout ce qui existe, « n'a ni vie ni sçavoir, ni aucune autorité, mais elle est pure, quiète, subtile, diaphane, sans corps et sans figure, qui ne se peut connoître que par l'entendement, de la même manière que nous autres nous connoissons les choses spirituelles, et quoiqu'elle ne soit pas spirituelle, elle n'a pourtant aucune des qualitez actives ni passives des élémens »2. Et de cette analyse du Li, le P. Longobardi tire ces deux conclusions : que les Chinois n'ont point connu de substance spirituelle distincte de la matérielle, mais une seule substance matérielle. « en différens degrez $\gg 3$ et que tous les esprits que les Chinois adorent sont « une même substance avec les choses auxquelles ils sont

\footnotetext{
${ }^{1}$ Id., ibid., p. 31.

${ }^{2}$ Id., ibid., p. 32.

${ }^{3}$ Id., ibid., p. 47.
} 


\section{La Chine et la formation de l'esprit philosophique en France}

unis $\gg 1$. Donc un matérialisme absolu qui sent furieusement son spinozisme, et qui exclut toutes les idées soutenues par les Jésuites sur le spiritualisme de la religion des anciens Chinois.

\section{$*$}

La Querelle des Cérémonies chinoises n'a pas seulement mis en lumière et exaspéré les intérêts rivaux des différents missionnaires qui voulaient ou conserver ou acquérir le privilège des missions en Chine ; par la nature des problèmes qu'elle souleva, comme le problème de la religion des anciens Chinois, elle mit les théologiens dans un grand embarras. Admettre avec les Jésuites que les Chinois depuis la plus haute antiquité, par les seules forces de leur raison naturelle ont adoré un seul Dieu, créateur de l'univers, et lui ont rendu un culte exempt d'idolâtrie, c'est être obligé d'accepter I'hypothèse du salut de cette nation infidèle, ce qui supprime la nécessité de la révélation et de la grâce et mène, comme le dit justement Bossuet, à l'indifférence en matière de religion et au déisme. Mais, d'autre part, s'il était prouvé que les anciens Chinois étaient athées, I'argument du consentement universel était réduit en poudre ; car peu importait désormais de trouver chez des peuplades sauvages de I'Afrique ou de l'Amérique une croyance à une divinité quelconque, si un des peuples les plus anciens et, les p.314 plus cultivés de la terre avait dès l'origine, ignoré l'existence d'un Dieu créateur. En outre, conclure avec les adversaires des Jésuites, que les Chinois sont athées, c'est porter une forte atteinte au dogme de l'interdépendance de la morale et de la

${ }^{1}$ Id., ibid., p. 52. 


\section{La Chine et la formation de l'esprit philosophique en France}

religion, puisque les Chinois ont la réputation méritée d'être le peuple le plus moral de la terre. Comment peuvent-ils donc pratiquer la plus pure morale s'ils sont athées, à moins que la morale n'ait aucunement besoin du support de la religion ? Idée dangereuse, surtout au moment où Bayle, qui d'ailleurs ne s'est pas encore occupé de la Chine, sauf accidentellement, commence à montrer que les idées religieuses et les idées morales constituent deux groupes différents, sans lien entre eux et qui ne se conditionnent pas l'un à l'autre. Faudra-t-il donc, pour avoir conclu à l'athéisme des Chinois, être obligé d'admettre la possibilité d'une morale indépendante ?

Difficultés de part et d'autre pour les théologiens.

Mais la Querelle des Cérémonies chinoises, par le retentissement qu'elle a eu, par les débauches de publications auxquelles se sont livrés les partis adverses, a intéressé le public à ces problèmes, parce que ces publications voulaient le prendre pour juge. Alors le débat prit plus d'ampleur, et une portée plus générale. Ce ne fut plus seulement une querelle de moines », comme dit Voltaire; ce ne fut même plus un simple débat théologique. Ce fut, avec toutes ses conséquences, un problème philosophique (déjà au sens du XVIII ${ }^{\mathrm{e}}$ siècle) où nous allons voir de nombreux philosophes prendre position et en tirer des conséquences.

\section{II. - Les Philosophes}




\title{
La Chine \\ et la formation de l'esprit philosophique en France
}

\author{
1. - BAYLE
}

Bayle semble avoir été attiré à l'étude de la Chine, moins par l'intérêt que présentait la chronologie chinoise que par le souci qu'il avait aux environs de 1685, soit immédiatement avant, soit aussitôt après la Révocation de l'Édit de Nantes, de combattre I'intolérance de Louis XIV. Or, la Chine vint lui offrir tout à point un exemple de tolérance, puisque selon la lettre du P. Verbiest, l'empereur de Chine se déclarait prêt à accepter les missionnaires dans son empire. « Je ne sçai pourquoi, écrivait-il dans ses Nouvelles de la République des Lettres ${ }^{1}$, les Chrétiens font si peu p.315 de réflexions sur l'esprit de tolérance qui règne dans ces Rois païens que nous traitons hautement de barbares et de féroces. Voilà un empereur chinois très persuadé que la Religion des Jésuites est fausse et tout à fait opposée à celle dont lui et tous ses sujets font profession, qui ne laisse pas de souffrir des missionnaires et de les traiter fort humainement $\gg$. Le ton même de cette observation marque l'étonnement de Bayle, à constater que la tolérance est possible, puisqu'elle existe. Il se contente de cette constatation, il ne recherche pas cette fois quels sont les fondements intellectuels de la tolérance.

Les mois qui suivent lui fournissent des faits qui vont lui permettre d'observer le contraire de la tolérance, à savoir I'intolérance : d'abord et surtout, c'est la Révocation de l'Édit de Nantes, avec les persécutions qu'elle provoque, conversions de

1 Nouvelles de la République des Lettres, février 1685, Fuvres diverses (1707), t. I, p. 232. 


\section{La Chine et la formation de l'esprit philosophique en France}

force et Dragonnades, ensuite l'envoi de missionnaires jésuites en Chine ${ }^{1}$. Ainsi Louis XIV semble se contredire, puisqu'il réclame de l'empereur de Chine pour ses missionnaires cette tolérance qu'il refuse à ses sujets.

Or, à y regarder de près, il n'y a pas contradiction. Car le principe du « papisme », c'est la conquête ${ }^{2}$ et le moyen de la réaliser, I'intolérance et la persécution. Louis XIV en obligeant par la force ses sujets à se convertir, et en introduisant ses missionnaires en Chine, ne fait qu'obéir au même principe qui est de conquérir les âmes. Sans doute le papisme ne fait encore que se glisser en Chine, mais s'il réussit à s'y implanter, il aura vite fait par son esprit persécuteur de détruire les autres religions. Faut-il donc conseiller à l'empereur de Chine d'accepter le papisme au nom de la tolérance ? Que non pas. Ce serait le meilleur moyen de la détruire. Un souverain tolérant, et précisément parce qu'il l'est, doit examiner les religions qui veulent pénétrer dans ses États, et se montrer intolérant des

\footnotetext{
1 Dans la France toute catholique. Bayle esquisse I'argument qu'il développera dans son Commentaire philosophique : « Je ne doute point que les loix d'humanité n'obligent un honnête homme à faire savoir à l'empereur de la Chine ce qui vient de se passer en France, afin qu'il prenne ses mesures pour recevoir comme il faut les missionnaires que le Roi vient d'envoier en ce pais là sur le pié de grands mathématiciens. » Euvres diverses, t. II, p. 350.

2 Bayle n'a pu connaître en 1686 la lettre du P. de la Chaize au roi de Siam (elle ne fut publiée que l'année suivante par le $P$. Tachard) où il célèbre comme deux grandes conquêtes du christianisme et de Louis XIV I'extirpation de I'hérésie en France et la conversion attendue du roi de Siam.
} 


\section{La Chine et la formation de l'esprit philosophique en France}

religions intolérantes, c'est le premier principe et la condition d'existence de la tolérance ${ }^{1}$.

p.316 C'est donc à l'intolérance qu'il faut d'abord s'attaquer. Bien qu'elle paraisse, par le nom même dont on la désigne, n'être que la négation de la tolérance, c'est elle en réalité qui est le principe agissant, c'est à elle qu'on doit la disparition de la tolérance, qui sans elle régnerait. Mais pourquoi donc?

Bayle part de ceci que le principe essentiel du papisme est une fausse interprétation du précepte chrétien Contrain-les d'entrer. En effet, tandis que le christianisme des trois premiers siècles interprétait ce précepte en esprit et convertissait par la persuasion, le catholicisme ensuite n'a plus voulu le prendre que dans son sens littéral, d'où les Croisades, les Guerres de religion,

\footnotetext{
1 Un peu plus tard, dans une note écrite en novembre 1700 (c'est lui-même qui I'indique, Dictionnaire..., éd. 1734, t. IV, p. 121), Bayle examinant la doctrine de la tolérance de Milton montre que d'après Milton, « le papisme doit être entièrement privé du bénéfice de la Tolérance, non pas en tant que c'est une Religion, mais en tant que c'est une faction tyrannique qui opprime toutes les autres. » Et reprenant à son compte l'idée de Milton qui concorde si bien avec celle qu'il exprimait en 1686 dans son Commentaire philosophique, Bayle déclare que « les Tolérans les plus outrez », c'est-à-dire les plus fidèles amis de la tolérance, concluent à l'expulsion du papisme qui est « de tems immémorial le Parti qui persécute le plus » et « ne cesse de tourmenter le corps et l'âme des autres Chrétiens partout où il le peut faire. »Comment donc concilier l'édit de tolérance accordé par l'empereur de Chine aux missionnaires chrétiens avec la haute sagesse dont on le loue ? Son excuse est qu'il ignore que le papisme est persécuteur. Mais en souverain éclairé et sage, il aurait dû s'informer (Dictionnaire, art. Milton, note 0 ). Il est à remarquer que Montesquieu, après avoir étudié les religions du Japon et de la Chine est arrivé à une conclusion analogue à celle de Bayle, à savoir que l'intolérance est le propre du judaïsme : « Une marque que l'intolérance est un dogme de la religion des Juifs, c'est qu'au Japon où il y a (je crois) soixante-dix sectes, il n'y a aucune dispute entre elles sur la prééminence quoyque le Déiro soit le chef d'une secte et considéré par l'Empereur plus que le Pape ne l'est par nos rois. Je ne scache pas qu'il y ait des disputes à la Chine entre les sectes différentes. Il y en a bien contre les Chrétiens : car nous commençons par dire : « Toutes religions sont mauvaises, excepté la nôtre., (Pensées et fragments inédits, t. II, p. 511).
} 


\section{La Chine et la formation de l'esprit philosophique en France}

la Révocation de l'Edit de Nantes. Or, dans son sens littéral ce précepte est faux, ce qu'il s'agit de démontrer, non pas au nom de la raison - Bayle l'a fait dans un autre chapitre - mais au nom des vrais principes du christianisme même.

Pour rendre plus forte son argumentation, et mieux convaincre ses adversaires, Bayle met son argument « en forme », suivant la méthode qui lui est chère, c'est-à-dire sous la forme de syllogisme. Sa majeure ne peut être contestée, elle s'inspire d'un précepte essentiel du christianisme qui doit être prêché dans tout l'univers, puisque la connaissance de la loi de Jésus-Christ a été promise à tous les hommes. Donc « tout sens littéral de l'Écriture qui fournit aux Infidèles un sujet légitime et raisonnable de défendre l'entrée et le séjour de leurs États aux

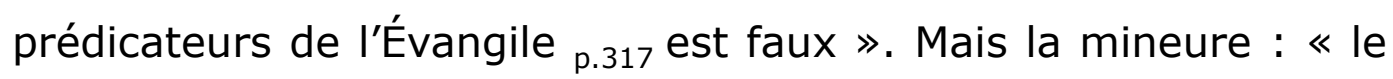
sens littéral de ces paroles Contrain-les d'entrer fournit ce prétexte aux infidèles » a besoin d'être démontrée.

$\mathrm{Si}$ la mission consistait à prouver rationnellement la supériorité de la religion que l'on apporte sur les religions existantes, rien n'empêcherait les Chinois de recevoir les missionnaires chrétiens, de même que nous devrions recevoir une flotte des Terres Australes, qui viendrait chez nous pour nous apporter une religion que ces Australiens croient supérieure à la nôtre. (Ainsi le roi de Siam avait accueilli avec faveur I'ambassade que le roi de France lui avait envoyée pour lui demander de se convertir au christianisme, mais il avait ajouté qu'il recevrait de la même manière une autre ambassade venant lui proposer le mahométisme). Il devrait en être ainsi s'il ne 


\section{La Chine et la formation de l'esprit philosophique en France}

s'agissait que de persuasion. Mais le principe Contrain-les d'entrer ne s'adresse pas à la raison ; il fait appel à la force pour venir à bout de la résistance opiniâtre des hommes. Et cette violence deviendra de plus en plus grande à mesure que les nouveaux chrétiens auront augmenté en nombre par la prédication. En outre, si le principe du christianisme est de convertir, il importe encore plus de convertir les rois que les particuliers, mais le même principe de violence s'exercera contre eux, si le sens littéral du Contrain-les d'entrer doit être accepté pour vrai. Car on les menacera du refus d'obéissance, de la déposition, de la croisade, s'ils ne se font eux-mêmes intolérants. Et ainsi l'empereur de Chine, tant pour le bien de ses sujets que pour lui-même, doit interdire l'entrée de son empire aux missionnaires, dès qu'il sera informé de leurs principes. De cette manière le peuple chinois, qui n'aura pas encore été prêché, ne portera pas la peine de son ignorance du christianisme. Mais comme il faut que le christianisme soit prêché, le sens littéral du Contrain-les d'entrer est faux et le christianisme exclut l'intolérance ${ }^{1}$.

Au cours de cette longue argumentation, où Bayle considère la tolérance non comme une résultante de l'indifférence en matière de religion, mais comme une conséquence nécessaire du christianisme, il s'élève parfois à des généralités et il s'efforce de montrer que l'intolérance de l'intolérance, c'est-à-dire la nécessité de chasser les Chrétiens de son empire, est imposée à l'empereur de Chine par un principe de conscience « loi éternelle

\footnotetext{
${ }^{1}$ Commentaire philosophique sur ces paroles de J.-C. : Contrain-les d'entrer,
} 


\section{La Chine et la formation de l'esprit philosophique en France}

et antérieure à toutes les religions de droit positif ». Contraindre par le crime, c'est favoriser les hypocrisies de religion, les actes qui vont « contre les p.318 instincts et les lumières de la conscience ». L'empereur ne doit donc pas hésiter à chasser ces missionnaires, pour éviter à ses peuples la tentation presque insurmontable de commettre le plus grand de tous les crimes », l'apostasie d'une religion qu'ils croient vraie.

Ainsi ce traité de Bayle sur la tolérance s'inspire des événements contemporains. La lettre du P. Verbiest sur l'édit de l'empereur de Chine, autorisant l'entrée des missionnaires chrétiens dans son empire, lui a appris que la tolérance était un fait, puisqu'elle existait en Extrême-Orient, et que c'était son contraire, I'intolérance qu'il s'agissait de définir, pour pouvoir l'extirper.

Jusqu'en 1700 Bayle ne semble plus s'être occupé de la Chine. Aucun article, aucune note de l'édition de 1697 de son Dictionnaire ne témoigne de son intérêt pour ce pays. Ni la fin de I'article Brachmanes, où Bayle expose les principes de la secte de Fo, ni la note 18 de l'article Cesalpin sur la secte des Lettrés de la Chine, ni la note $O$ de l'article Milton sur la tolérance et l'édit de l'empereur de Chine ne se trouvent dans cette édition de 1697. Et ceci ne serait pas pour nous surprendre, si dans l'intervalle n'avait paru le Confucius Sinarum philosophus du P. Couplet, dont Bayle ne paraît pas s'être soucié ${ }^{1}$. Par contre

\footnotetext{
${ }^{1}$ Il ne l'a connu que par les extraits qu'en ont donnés certains journaux (Acta Eruditorum 1688, p. 257, Bibliothèque universelle, t. VII, p. 403-4, références que I'on trouve dans la note $B$ de l'article Spinoza, t. V, p. 203. Cette note ne se trouve pas dans l'édition de 1697.
} 


\section{La Chine et la formation de l'esprit philosophique en France}

avant 1700 , il s'informe de la religion des Siamois ; il connaît les relations du P. Tachard et de La Loubère, et il s'en sert dans I'article Sommona-Codom et dans la note $\mathbf{X}$ de I'article Spinoza, qui se trouvent dans cette édition de 1697.

Les relations du P. Tachard et de La Loubère I'informent que les Siamois sont athées : « ils n'ont pas moins perdu que les Chinois l'idée de la divinité », et cependant ils vivent bien, ils croient à la récompense de la vertu et au châtiment du crime. Il est donc faux comme l'avait prétendu Bayle ${ }^{1}$ que la foi en la Providence n'est pas moins nécessaire que la foi en Dieu pour exciter à la vertu. Du Rondel ayant lu La Loubère, fait remarquer son erreur à Bayle et conclut pour sa part que ce n'est pas la croyance en une divinité déterminée qui est nécessaire pour la vertu, mais seulement le fait que I'on parle des Dieux « et que I'on attache à ces idées-là toute la beauté des mœurs », ce qui suffit pour qu'il se trouve parmi les hommes « force gens qui aspirent à ce degré de gloire ${ }^{2}$. C'est donc l'idée des rapports

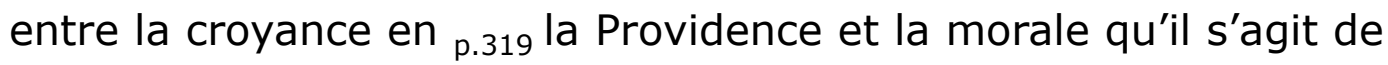
tirer au clair, puisque d'une part les théologiens déclarent que l'idée de la Providence doit être admise comme soutien de la morale, et que d'autre part, les Siamois, qui ne croient pas en Dieu, ont mis à la place d'un Dieu, juge de nos œuvres, une fatalité aveugle, qui fait, à leur avis, ce que pourrait faire une justice toute puissante et toute éclairée. «Ils prétendent que c'est une chose toute conforme aux Principes de la Nature, que

\footnotetext{
${ }^{1}$ Article Lucrèce, Remarque K.

${ }^{2}$ Article Sommona-Codom, note A, t. V, p. 179.
} 


\section{La Chine et la formation de l'esprit philosophique en France}

par des sympathies secrètes, mais certaines, entre la Vertu et le Bonheur et entre le Vice et le Malheur, la Vertu soit toujours heureuse et le vice toujours malheureux »1. Or, Bayle, examinant en détail les arguments qui plaident contre « la loi d'une providence éclairée », doit avouer que la croyance en une liaison indissoluble et nécessaire entre les actes et leurs conséquences est un gage de certitude plus assuré que la croyance en la Providence qui « dispose de toutes les choses selon son bon plaisir », et ne peut par suite donner aucune garantie d'une exacte récompense ou d'un juste châtiment. Mais, pense Bayle, cette croyance des Siamois ne provoque qu'une vertu mercenaire, puisque la notion pure de l'honnêteté n'en est pas le principe, de même d'ailleurs que la croyance en la Providence, sur laquelle elle a seulement l'avantage de n'être pas une duperie. Il est donc à croire que ce dogme de la rétribution des actes humains a été inventé seulement par les Lettrés siamois, qui, du moment qu'ils niaient la Providence, ont voulu la remplacer par autre chose, par utilité sociale, et pour contenir le peuple. Ils ont donc dû avoir - tout comme en Chine les sectateurs du dieu Fo - une double doctrine, l'une réservée aux philosophes et à leurs adeptes, mais qui reste secrète, l'autre faite pour le peuple, et qui se contente d'exposer quelques principes utiles à la société.

Quant à la doctrine métaphysique des Lettrés chinois - Bayle ne dit pas siamois, bien que La Loubère soit toujours sa source - cette doctrine qui « met un grand nombre d'âmes dans

\footnotetext{
${ }^{1}$ Article Spinoza, t. V, note X, p. 219 h.
} 


\section{La Chine et la formation de l'esprit philosophique en France}

I'univers, distinctes les unes des autres, dont chacune existe par elle-même et agit par un principe intérieur et essentiel », il la croit plus acceptable que la théorie de l'éternité de la matière, qui doit nécessairement conduire à l'atomisme, « car s'il peut y avoir deux êtres coéternels et indépendans quant à l'existence, il $y$ en peut avoir cent mille millions et à l'infini. "L'hypothèse métaphysique des substances coéternelles n'est pas absurde, puisque c'est l'opinion de l'antiquité entière, et parce qu'elle peut

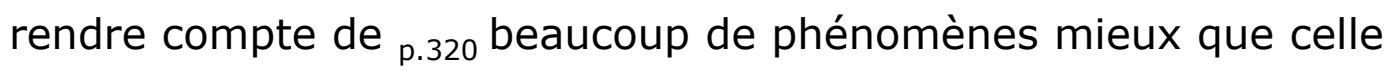
de Spinoza, en assignant à chaque chose un principe actif, aux unes plus fort, plus petit aux autres. Quant à I'homme cette doctrine rendrait compte de la nature de l'âme qui, n'étant point sortie du sein du néant, existe et agit par elle-même. Mais ceci serait du socinianisme et Bayle n'insiste pas.

En somme en 1697, avant le moment critique de la Querelle des Cérémonies chinoises, Bayle a peu connu la philosophie des Chinois : il ne connaît que la doctrine des Siamois d'après La Loubère, les hypothèses des disciples de Fo en Chine d'après un extrait de la préface du P. Couplet. Mais ces faits si peu nombreux et si fragmentaires qu'ils soient, l'avertissent qu'en Extrême-Orient il y a des doctrines matérialistes, donc des doctrines athées.

Mais de cela que peut-on conclure pour les rapports de la religion et de la morale ? Les Siamois et les Lettrés de la Chine sont athées, mais cet athéisme n'est que la doctrine philosophique d'une petite caste : ces philosophes ont inventé pour le peuple, à la place de la Providence, l'idée d'une fatalité 


\section{La Chine et la formation de l'esprit philosophique en France}

aveugle qui récompense ou punit, ce qui semblerait indiquer qu'ils ont cru à la nécessité sociale de quelques idées religieuses comme fondement de la morale. Mais cette morale ainsi constituée n'est qu'une morale « mercenaire » c'est-à-dire utilitaire. Son principe est l'intérêt et non l'obéissance aux suggestions les plus rares de la raison et de la conscience. Les athées chinois pratiquent-ils une morale non utilitaire et cette morale peut-elle se concilier avec l'athéisme ? Il semble qu'en 1697 Bayle ne se soit pas encore posé la question. Tout au plus peut-on dire qu'à la suite des critiques de Du Rondel et à cause de l'exemple des Siamois, il ne croit plus à la nécessité absolue de la croyance en un Dieu Providence comme fondement de la moralité.

Cependant Bayle, en grand lecteur qu'il était, s'intéressait aux rivalités entre Jésuites et Missionnaires, bien qu'il ne prît pas encore définitivement parti pour les uns ou pour les autres sur le fait des cultes chinois. En 1699, il écrit à Minutoli qu'il a lu le VI ${ }^{\mathrm{e}}$ volume de la Morale pratique, qui lui semble « plus curieux que les deux précédents ; car il traite du culte qu'on rend à Confucius à la Chine et des démélez que les Dominicains ont suscitez aux Jésuites, prétendans et soutenans par leurs subtilitez que ce culte n'est point de Religion mais civil, et en quelle manière on y peut participer sans idolâtrie »1. Cependant en 1701, son p.321 opinion semble se modifier, à cause de l'ouvrage de Hyde, où il trouve une confirmation des idées du P. Le Comte ${ }^{2}$. Tout en

\footnotetext{
${ }^{1}$ Lettre du 11 novembre 1692, Fuvres diverses, t. III, p. 473.

2 Lettre à X... du 12 septembre 1701, Fuvres diverses, t. IV, p. 802.
} 


\section{La Chine et la formation de l'esprit philosophique en France}

déclarant qu'on est las de la multitude d'écrits qui ont paru coup sur coup touchant les disputes des Missionnaires de la Chine et des Jésuites, il avoue qu'il les lit, non sans plaisir, parce qu'il trouve que «le feu de la passion [y] éclate beaucoup ». Notamment il a eu entre les mains un recueil en cinq tomes grand in-12 de ce que les Jésuites ont publié « et il y a là des Traités dont le tour est fort adroit $\gg 1$. C'est le moment où le contradicteur auquel il aura affaire dans la Continuation des Pensées diverses sur la Comète se plaint à lui, dans les lettres qu'il lui adresse, que la Sorbonne ait censuré les propositions du P. Le Comte qui apportaient un argument si fort en faveur du consentement universel ${ }^{2}$. Or Bayle, bien qu'il connaisse dès lors les principaux écrits des Jésuites, notamment ceux du P. Le Comte et du P. Le Gobien va se séparer de son correspondant et conclure à l'athéisme des Chinois, pour ruiner l'argument du consentement universel.

\footnotetext{
${ }^{1}$ Lettre à Ancillon, 3 août 1702, Euvres diverses, t. III, p. 13-4.

2 La seconde partie de la Continuation des Pensées diverses, dont fait partie le paragraphe où Bayle rappelle cette correspondance, est datée de 1705. Dans ce paragraphe, Bayle dit, en parlant de ces lettres, qu'il les a reçues « il y a trois ans », donc en 1702. C'est le moment où il insère dans la $2^{\mathrm{e}}$ édition de son Dictionnaire les fragments d'articles et les notes où il expose la doctrine des Lettrés de la Chine. Or dans la première partie de cette Continuation, §XXVIII datée du 30 novembre 1703, Bayle avoue à son contradicteur qu'il est peu renseigné sur les affaires des cultes chinois, et qu'il a suspendu son jugement dans le démêlé entre les Jésuites et leurs adversaires. C'est donc seulement en 1705 qu'il prend nettement position en faveur de l'athéisme des Chinois : il ne s'agit plus désormais d'une secte particulière de philosophes, mais du peuple entier. Alors Bayle se trouve obligé de démontrer que l'athéisme, doctrine philosophique de tout un peuple n'empêche pas ce peuple d'avoir une organisation sociale admirable et une morale qui égale tout au moins la morale des Européens. Bayle a été ainsi poussé par ses contradicteurs à généraliser sa pensée, et il l'a fait sans augmenter ses connaissances sur la Chine; alors seulement il a conclu. L'important dans l'histoire de sa pensée est d'arriver à déterminer en vertu de quel criterium il a conclu à l'athéisme des Chinois.
} 


\section{La Chine et la formation de l'esprit philosophique en France}

Dans ses Pensées diverses sur la Comète, il avait cherché à montrer que l'athéisme est supérieur à l'idolâtrie contre les théologiens qui pensaient que l'idolâtrie étant un théisme, devait encore être préférée à la négation absolue d'une divinité ; l'athéisme en effet provenant d'une « corruption du cœur », ne pouvait être le soutien de la morale, et par conséquent avait un caractère antisocial. Cependant les Siamois dont parle La Loubère sont une preuve de fait du contraire. Peu importe que la doctrine de la fatalité aveugle qui fait l'office de justice p.322 distributive soit une invention des philosophes pour maintenir le peuple. Le peuple et les Lettrés n'en sont pas moins athées, donc une société d'athées peut avoir une morale ; une société d'athées peut exister.

L'argument du consentement universel - argument de fait puisqu'il consiste à découvrir chez tous les peuples connus des traces d'une croyance à une divinité - n'est en somme que l'ancien argument des théologiens qui cherchaient dans l'antiquité païenne des traces du christianisme - mais adapté aux préoccupations nouvelles, provoquées par les nombreux récits de voyages en Orient et en Occident. Dans ces relations de voyageurs chez les peuples civilisés d'Extrême-Orient ou chez les sauvages d'Amérique on croyait trouver un sentiment religieux quelconque, si bien que la religion devenait une sorte d'instinct naturel et nécessaire à l'homme.

Pour ruiner cet argument, Bayle fait deux objections, I'une rationnelle, l'autre de fait. 


\section{La Chine et la formation de l'esprit philosophique en France}

En raison, si l'on veut conclure du consentement de tous les peuples que la religion est vraie, il faut admettre ce postulat « qu'un instinct de la nature ne peut estre faux estant si universel »1. Or cela n'est nullement prouvé, l'expérience montrant que la nature comporte plus de mal que de bien. Les contradicteurs de Bayle, Jaquelot, Bernard, invoquent la raison « qui rend impossible à l'homme de se passer d'une Divinité », mais en raisonnant ainsi ils admettent comme prouvé ce qu'il s'agit précisément de démontrer : I'universalité de la croyance ${ }^{2}$.

L'objection de fait est plus importante, et c'est de ce côté que Bayle fait porter tout son effort. Pour que l'argument du consentement universel fût valable, il faudrait que I'enquête fût complète dans toutes les parties du monde, et qu'on eût examiné tous les peuples. Or cela est impossible car il reste

1 Continuation des pensées diverses, t, XXXIII. Fuvres diverses, t. III, p. 220.

2 Continuation des pensées diverses, $t$, XXXIII. Fuvres diverses, t. III, p. 220. 


\section{La Chine et la formation de l'esprit philosophique en France}

encore des terres à découvrir, notamment les Terres Australes ${ }^{1}$. Conclure sans p. 323 attendre des faits dignes de foi sur ces terres neuves, c'est faire preuve de la même témérité que l'épicurien Velleius qui «se vantoit du consentement de tous les peuples avant de connoître l'histoire de l'Orient »2. Mais il ne suffit pas que le consentement des peuples soit universel dans l'espace, il faut aussi qu'il soit universel dans le temps. Il faut que tous les peuples, de tout temps, aient conservé I'idée d'un Dieu unique, car s'il est prouvé qu'il y eut un temps, comme à l'époque des Apôtres et de leurs disciples, où le polythéisme était répandu sur toute la terre, l'argument du consentement universel peut être retourné contre ses défenseurs : « Si le consentement général des nations à reconnoitre l'existence divine est une preuve de

1 La découverte des terres australes qui était attendue avec impatience depuis le milieu du XVII ${ }^{\mathrm{e}}$ siècle, comme pierre de touche des théories de La Peyrère, attire de plus en plus l'attention à la fin du siècle, lorsque le bruit se répand en Europe que les Hollandais y ont débarqué. L'abbé du Bos, en 1698, fut admis à examiner en Hollande les tableaux de la Compagnie des Indes représentant des hommes et des animaux de ces terres nouvelles (Lombard: I'abbé du Bos, p. 81-2 ; Dampier : Voyage aux Terres Australes fait en 1699, Amsterdam, 1705. Nouvelles de la République des Lettres, juillet 1705, p. 98, sq.). Il apprit ainsi que les terres australes étaient peuplées d'oiseaux extraordinaires et de cygnes noirs, d'hommes qui, tout en se rapprochant de la race nègre, conservaient cependant figure humaine et n'avaient rien de commun avec les êtres fantastiques que l'on supposait pouvoir se trouver dans ces pays, « ayant le corps semblable à celui d'un chien ou d'une grue, ou de quelque espèce d'animal que nous ne connoissons pas » (J. Bernard, Nouvelles de la République des Lettres, 1705, t. I, p. 133-3). Puisque les hommes nouveaux ainsi découverts ressemblaient au reste de I'humanité connue, les partisans du consentement universel espéraient que l'on découvrirait aussi chez eux des traces d'une croyance à la divinité, ce qui eût confirmé leur théorie par l'expérience.

2 Continuation des pensées diverses, XXV. Fuvres diverses, t. III, p. 222. 


\section{La Chine \\ et la formation de l'esprit philosophique en France}

vérité il faudroit rejetter l'unité de Dieu et embrasser le polythéisme qui est pire selon quelques-uns que l'athéisme » 1.

Dans la première partie de la Continuation des Pensées diverses, Bayle se contentait de montrer qu'il était impossible de faire la preuve de l'argument du consentement universel. Dans la seconde partie et dans la Réponse aux Questions d'un Provincial, il va démontrer que cet argument est faux. Mais comme c'est l'argument essentiel, il faut apporter des faits qui en fassent apparaître la fausseté. Or il n'est pas d'exemple plus probant que l'exemple chinois, exemple probant parce que la Chine est une nation très ancienne, et qui pratique la plus pure morale ${ }^{2}$. Bien loin que son athéisme ait empêché la nation chinoise de se former et de subsister, il semble que cet athéisme I'ait aidée à se maintenir et à prospérer. Mais il faut prouver son athéisme, ce qui est précisément la pomme de discorde entre les Missionnaires et les Jésuites.

Bayle qui a déjà signalé dans son Dictionnaire ( $1^{\mathrm{e}}$ édition, 1697) I'athéisme des Siamois et I'athéisme de la secte des Lettrés de la Chine ( $2^{\mathrm{e}}$ éd. du Dictionnaire, 1702) veut montrer en 1705 que l'athéisme en Chine n'est pas seulement une doctrine particulière à un petit groupe de philosophes, mais la théorie philosophique dominante. Sans doute parce qu'il ne se sent pas assez sûr de lui, n'ayant pas lu la préface du P. Couplet,

\footnotetext{
1 ibid., t. III, p. 222.

2 Il est digne d'être noté que J. Bernard qui ergota tant autour des intentions cachées de Bayle pour essayer de prouver son athéisme ne lui conteste aucunement le fait de l'athéisme des Chinois. (Nouvelles de la République des Lettres, janvier 1707 , p. 5, sq. ; février 1707, p. 139, sq. ; mars 1707, p. 256 , sq. ; mai 1707 , p. 532 , sq. ; juin 1707 , p. 636 , sq.).
} 


\section{La Chine et la formation de l'esprit philosophique en France}

qui d'ailleurs eût infirmé sa thèse au lieu de la vérifier, il jette allègrement par-dessus bord la question de l'athéisme ou du spiritualisme des disciples de Confucius : « Je ne vous dirai pas que Confucius qui a laissé d'excellens préceptes de morale était athée. Ceux qui l'affirment trouvent des contredisans ; je passe donc à des faits non contestés $\gg 1$.

L'athéisme de la nation chinoise se démontre par une affirmation du P. Le Gobien dans sa Préface de I'Histoire de l'Edit de l'Empereur de la Chine en faveur de la religion chrétienne. C'est une source non suspecte puisque le P. Le Gobien est Jésuite, et que les Jésuites se sont fait condamner pour avoir nié I'athéisme des Chinois. Or le P. Le Gobien énumérant les quatre principales sectes de la Chine avoue que le nombre de ceux qui « reconnoissent dans le monde un esprit supérieur, éternel, toutpuissant » n'est pas fort grand, tandis que la secte « dominante, quoique moins étendue que quelques autres, est celle des nouveaux philosophes. Ces philosophes « ne reconnaissent dans la Nature que la Nature mesme, qu'ils définissent le principe du mouvement et du repos. Ils disent que c'est la Raison par excellence, qui produit l'ordre dans les différentes parties de I'univers et qui cause tous les changements qu'on y remarque. La matière, selon eux, est éternelle, incréée, infiniment étendue et en quelque manière toute-puissante, quoique sans discernement et sans liberté. Ils ajoutent que cette matière, toujours occupée au Gouvernement de I'Univers est néanmoins aveugle dans ses actions les plus réglées qui n'ont d'autre fin

${ }^{1}$ Continuation ..., $\S 145$. Fuvres diverses, t. III, p. 397. 


\section{La Chine et la formation de l'esprit philosophique en France}

que celle que nous donnons et qui par conséquent ne sont utiles qu'autant que nous savons en faire un bon usage. Quant à la divinité ils en parlent comme si ce n'était que la nature même, c'est-à-dire cette force ou cette vertu naturelle qui produit, arrange et conserve toutes les parties de l'univers. En somme par cette divinité ils entendent « je ne scay quelle âme insensible du monde qu'ils se figurent répandue dans la matière, où elle produit tous les changemens ». Donc ces philosophes, qui sont la secte dominante de la Chine professent « un athéisme raffiné », et p.325 S'abstiennent « de tout culte religieux »1. Or ces philosophes athées s'opposent précisément par la pureté de leurs mœurs au libertinage des bonzes et des prêtres des idoles. Les voyageurs s'étonnent précisément que des philosophes si aveugles aux vérités de la vraie religion soient de tous les Chinois ceux qui pratiquent le mieux l'honnêteté. Ce sont donc des athées spéculatifs et non des athées pratiques ${ }^{2}$, et par là est démontré qu'il n'y a pas contradiction de fait entre l'athéisme et la morale.

J. Bernard, remarque Bayle, est bien obligé de s'apercevoir que des voyageurs toujours plus nombreux découvrent dans les différentes parties du monde des peuples sans aucune connaissance de la divinité comme le P. Le Gobien aux îles Mariannes par exemple, mais il critique la sincérité ou la perspicacité des voyageurs. Les récits de voyages deviennent pour lui « les romans des honnêtes gens ». Sur quoi donc veut-il

\footnotetext{
${ }^{1}$ Continuation ..., Fuvres diverses, t. III, p. 343-4.

2 Continuation ..., Fuvres diverses, t. III, p. 413-4.
} 


\section{La Chine et la formation de l'esprit philosophique en France}

édifier son argument du consentement universel ? D'ailleurs, ajoute Bayle, la découverte de l'athéisme de ces peuples primitifs n'a qu'une importance secondaire, car ce sont des « athées négatifs », tandis que l'exemple chinois a une importance capitale, car les Lettrés de la Chine sont des philosophes, qui « ont comparé ensemble le système de l'existence de Dieu et le système opposé ». Ce sont des « athées positifs $\gg 1$.

Mais ici Bayle risque d'achopper à une difficulté qu'il avait luimême signalée à Bernard dans la première partie de la Continuation des pensées diverses, lorsqu'il examinait en soi l'argument du consentement universel et l'impossibilité d'arriver à une certitude, si l'on ne connaît parfaitement la langue, les traditions des peuples que I'on cite comme exemples. Cette objection, valable contre les théologiens qui affirmaient une croyance universelle à la divinité était également valable contre Bayle qui la niait. Or Bayle ignorait tout de la Chine. Allait-il donc se contenter de choisir, parmi les récits des missionnaires, des garants favorables à sa thèse, quitte à ignorer ou à repousser ceux qui ne l'étaient pas ? Il eût fait la partie trop belle à Bernard. Et d'ailleurs, cela eût répugné à son esprit critique. Il lui fallait donc trouver un criterium de vérité, extérieur pour ainsi dire aux faits eux-mêmes, qui lui permît d'affirmer la vérité de ces faits. Ce fut la Querelle des Cérémonies chinoises qui le lui fournit. En effet, comme les Jésuites et les Missionnaires ont été

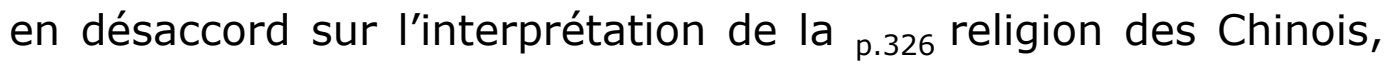

${ }^{1}$ Réponse aux Questions d'un Provincial. Fuvres diverses, t. III, p. 925. 


\section{La Chine et la formation de l'esprit philosophique en France}

toutes les fois que sur cette question particulière ils sont d'accord en quelque point, ce point peut être considéré comme vrai. Or certains Jésuites célèbres parlent positivement de I'athéisme qui règne à la Chine parmi les Lettrés. Mais ce témoignage est confirmé par celui de leurs antagonistes : « Cette confirmation est d'un grand poids parce que les Missionnaires qui ont des différens avec les Jésuites ne leur pardonnent rien : il faut donc qu'une chose soit certaine et évidente dans la Chine lorsqu'aiant été racontée par les Jésuites, elle n'est point contestée par leurs ennemis ». La Querelle des Cérémonies chinoises apporte donc à Bayle en 1706 un criterium qui lui permet de conclure à l'athéisme des Chinois $\gg{ }^{1}$.

Ainsi se trouve fixée, grâce à Bayle et à la diffusion de ses ouvrages 2 l'opinion du public cultivé sur la religion des Chinois. Voltaire lui-même, jusqu'au moment où il se sera reporté aux écrits mêmes des Jésuites pour écrire les premiers chapitres de son Essai sur les Mœurs, c'est-à-dire jusqu'à 1742 environ,

\footnotetext{
${ }^{1}$ Réponse aux Questions d'un Provincial. Fuvres diverses, t. III, p. 295.

2 D. Mornet, L'enseignement des Bibliothèques privées, R. H. L. 1919, p. 463-4.
} 


\section{La Chine et la formation de l'esprit philosophique en France}

partagera les idées de Bayle sur l'athéisme des Chinois ${ }^{1}$. A I'égard de I'opinion publique dans la première moitié du XVIII siècle, les Jésuites sont grâce à Bayle les vaincus de la Querelle des Cérémonies chinoises.

Et cependant, nous l'avons vu, à aucun moment de sa vie, Bayle n'a fait une étude particulière de la philosophie ou de la religion des Chinois. Il n'a même pas lu le P. Couplet, et il s'est contenté p.327 d'un creterium tout extérieur pour conclure à l'athéisme. La Chine pour lui n'a été qu'un exemple, un argument dans le débat sur la valeur du consentement universel. Mais en établissant même de cette manière détournée l'athéisme des Chinois, alors que personne ne doutait d'autre part de leur grande valeur morale, il a montré qu'il n'y avait pas antinomie entre l'athéisme et la morale, d'où il résultait, par une conséquence toute naturelle, que la morale est indépendante de la religion.

1 Dans I'ode sur le Fanatisme, qui s'appelait d'abord Ode sur la Superstition, Voltaire avait écrit cette strophe qui subsiste jusqu'à l'édition de 1742 :

Au vaste empire de la Chine

Il est un peuple de Lettrés

Qui de la nature divine

Combat les attributs sacrés.

$O$ vous, qui de notre hémisphère

Portez le flambeau salutaire

A ces faux sages d'Orient

Parlez; est-il plus de justice

Plus de candeur et moins de vice

Chez nos dévots de l'Occident?

Voltaire, t. VIII, p. 431. Bengesco, Bibliographie..., t. IV, p. 20-1. Cf. Lanson, éd. crit. des Lettres philosophiques de Voltaire, t. I, p. 149. La note de l'édition de Kehl au sujet de cette strophe a tort lorsqu'elle prétend que Voltaire croyait à l'athéisme des Chinois sur la foi de « quelques ouvrages de moines ». Il y croyait sur la foi de Bayle. A cet égard on ne saurait trop remarquer l'importance qu'ont pu avoir les index de Bayle, tant du Dictionnaire que des Fuvres diverses, aux articles Ame, Athéisme, Chinois, pour répandre l'idée de l'athéisme des Chinois, dans la première moitié du XVIII ${ }^{\mathrm{e}}$ siècle. 


\section{La Chine et la formation de l'esprit philosophique en France}

Une autre conséquence, et non moins importante, de cette polémique entre Bayle et Bernard, est que I'argument du consentement universel, du moins sous la forme que lui avait donnée Bernard, est devenu désormais sans valeur. Qu'importait, en effet, d'aller chercher chez les sauvages « abrutis » de vagues notions d'une divinité quelconque, pour prouver l'existence de Dieu, si une nation, des plus anciennes, des plus civilisées, des plus soucieuses de la morale comme la Chine, professait l'athéisme ? La preuve de l'existence de Dieu par le consentement universel dans l'espace avait fait son temps. Elle s'écroulait à son tour, après la méthode de Beurrier et de Huet.

Mais cela ne veut pas dire que toute preuve par le consentement universel soit désormais abandonnée. Comme c'est un argument historique, plutôt qu'un argument rationnel, non seulement il peut être saisi par tous les esprits, même les plus simples, mais, en outre, il peut convaincre mieux que la conclusion d'un syllogisme. Aussi les théologiens n'abandonnent pas cet argument après Bayle, mais il le modifient pour échapper à ses objections.

Elie Benoist, dans la préface de son livre, où sous le nom de Toland, il combat Bayle, reprend en effet, l'argument du consentement universel, mais en le posant d'une autre manière ${ }^{1}$, il ne s'agit pas, dit-il, de savoir si tous les peuples actuellement croient en Dieu, et en un Dieu unique, mais si tous

\footnotetext{
1 Les arguments d'Elie Benoist contre Toland et Bayle ont été repris d'une manière presque identique un peu plus tard par de Crousaz dans son Examen du Pyrrhonisme ancien et moderne, p. 675-6.
} 


\section{La Chine et la formation de l'esprit philosophique en France}

les peuples à l'origine ont eu cette double croyance. Le fait que les peuples sauvages n'ont plus actuellement cette double croyance n'est pas une preuve qu'ils ne l'ont pas eue. Car le souvenir de cette croyance primitive peut s'être effacé peu à peu au cours du temps, ou par suite de la vie errante de ces peuplades. Donc l'athéisme actuel des nations sauvages - ou même des peuples des terres australes, si l'on y trouve des nations athées - ne prouverait rien contre p.328 l'argument du consentement universel. Il faut savoir que ces peuples ont pensé et. ce qu'ils ont cru à l'origine. Pour cela il faut rechercher des témoignages approchant le plus près possible des origines du monde. A cet égard, le témoignage de Cicéron, plus vieux que nous de deux mille ans, a plus de poids que tous les témoignages actuels. Or, Cicéron constate que tous les peuples que l'on connaît et que peu à peu on découvre de son temps ont la connaissance d'une divinité. Quant à Moïse, beaucoup plus ancien que Cicéron, il peut nous fournir un témoignage beaucoup plus autorisé, sans même qu'il soit besoin de le considérer comme un prophète inspiré. Or, par son témoignage deux faits sont prouvés : que le monde a été créé et que la connaissance de la divinité s'est trouvée dans le monde dès son origine.

Mais, dira-t-on à Elie Benoist, comment percer l'obscurité des temps primitifs et fabuleux ? Par quel moyen saisir cette idée originale d'un Dieu unique ? Benoist répond que c'est par la fable : « Il n'y a point de fable qui ne suppose cette connoisance et dans laquelle on ne voie une idée de Divinité d'où dépend tout le tissu de l'événement. D'où il s'ensuit que ceux qui ont les premiers obscurci la vérité par l'enveloppe des fables, avoient 


\section{La Chine et la formation de l'esprit philosophique en France}

l'idée de la Divinité plus nette et moins confuse qu'elle n'est passée d'eux à leurs successeurs $\gg 1$.

C'est un peu l'hypothèse de Huet qui voulait retrouver Moïse dans toutes les divinités du paganisme. Mais I'hypothèse de Huet était aventureuse en ce qu'elle voulait assimiler un personnage historique comme Moïse avec des divinités fabuleuses. Ce n'est pas le personnage de Moïse qu'il faut chercher à découvrir sous les fables païennes, c'est son esprit et sa doctrine ; ce sont ses idées qui sont des témoignages autorisés sur Dieu, sur l'origine du monde et des hommes. Mais les peuples païens ayant perdu de vue I'unité de cette doctrine, ont donné à un grand nombre de divinités particulières des attributs qui n'appartiennent qu'au Dieu unique. Pour retrouver les idées primitives des hommes sur la religion, il faut donc retrouver l'unité sous la multiplicité, le monothéisme sous le polythéisme. Si I'on dépouille les fables de leur enveloppe extérieure, que seule les peuples ont été capables de voir et de comprendre, et de laquelle ils ont conclu à un infinie diversité de dieux ou de déesses, on trouvera partout la même idée, l'idée d'un Dieu unique.

Dépouiller les fables, les traditions de leur écorce extérieure pour en extraire la vérité cachée - et cette vérité c'est naturellement celle que l'on veut trouver - va être désormais la préoccupation d'un certain nombre de théologiens dont nous aurons un peu plus tard l'occasion de nous occuper. Une fable ou une tradition ne sera pour eux qu'un symbole qui, interprété par

1 Elie Benoist, Mélange de remarques critiques, historiques, philosophiques, théologiques, sur les deux Dissertations de M. Toland intitulées I'une «I'homme sans superstition », et l'autre « Les origines judaïques ». Préface, p. 80-1. 


\section{La Chine et la formation de l'esprit philosophique en France}

les lumières de la révélation, permettra de retrouver dès I'origine, pour les peuples qui ont une histoire, ou à notre époque, pour les peuples sauvages, non seulement l'idée d'un Dieu unique, mais encore l'idée du Dieu des Chrétiens.

\section{2. - MALEBRANCHE}

Malebranche n'a pas choisi la forme du dialogue, dans son Entretien d'un philosophe chrétien avec un philosophe chinois, pour piquer la curiosité, comme le feront par la suite, tant d'auteurs de Lettres de pays exotiques, à la suite des Lettres persanes, ou d'auteurs d'Espions orientaux à la suite de l'Espion du Grand Seigneur dans les cours de l'Europe. Dans ces ouvrages, l'intention satirique est évidente et le plus souvent I'oriental triomphe des mœurs et des idées européennes. Au contraire dans l'Entretien de Malebranche, le philosophe chinois n'a pas le beau rôle et c'est lui qui doit être convaincu par les raisons du philosophe chrétien.

Le choix d'un philosophe chinois comme interlocuteur et la forme dialoguée adoptée par Malebranche sortent tout naturellement des raisons qui ont donné naissance à cet Entretien.

Le P. Malebranche, dans son Avis touchant l'Entretien d'un Philosophe chrétien avec un philosophe chinois, publié quelques 


\section{La Chine et la formation de l'esprit philosophique en France}

mois après I'Entretien lui-même, et son biographe, le P. André ${ }^{1}$, nous ont fait I'historique de cet opuscule.

En 1707, Malebranche reçut la visite de l'évêque de Rosalie, de Lyonne, que nous connaissons déjà pour ses démêlés avec les Jésuites, tant au Siam qu'en Chine. Il avait dû quitter la Chine à la suite de l'expulsion des Missionnaires et des vicaires apostoliques provoquée par la proclamation du cardinal de Tournon. Il se lia d'amitié avec le P. Malebranche, et lui représenta que ses principes métaphysiques étaient les seuls capables de toucher les Chinois. Il lui exposa les principes de la Religion et de la philosophie des Chinois et il le pria enfin « de réfuter leurs erreurs dans quelque ouvrage, de manière toutefois qu'il employât les véritez qu'ils reçoivent pour leur faire admettre celles qu'ils ne reçoivent pas ». p.330 Malebranche accepta. Son Entretien est donc une sorte d'aide-mémoire métaphysique à l'égard des futurs Missionnaires en Chine, mais sous forme de dialogue pour qu'ils aient plus rapidement présentes à l'esprit les réponses à faire aux arguments ou aux objections des philosophes chinois. C'est en principe un traité d'apolégétique du christianisme d'après les idées métaphysiques de Malebranche.

Malebranche fait exposer par le philosophe chinois certains principes de sa doctrine, pour avoir l'occasion de les réfuter, mais l'exposé de la philosophie chinoise n'est pas l'essentiel de son ouvrage ; ce qui lui importe avant tout c'est la démonstration de sa propre métaphysique. Sur la philosophie chinoise, il est peu renseigné ; il en connaît seulement certains

\footnotetext{
1 Vie de Malebranche, pp. Ingold.
} 


\section{La Chine et la formation de l'esprit philosophique en France}

principes qui lui ont été exposés par l'évêque de Rosalie ; il n'y a que deux genres d'êtres, le $L y$, qui est la souveraine Raison, et la matière. Le $L y$ et la matière sont éternels. Le $L y$ ne subsiste point en lui-même et indépendamment de la matière, (les Chinois le considèrent sans doute comme une forme ou comme une qualité répandue dans la matière) le $L y$ n'est ni sage ni intelligent, quoiqu'il soit la sagesse et l'intelligence souveraines. Le $L y$ n'est point libre et n'agit que par la nécessité de sa nature. Il rend intelligentes, sages, justes, les portions de matière disposées à recevoir l'intelligence, la sagesse, la justice, car l'esprit de I'homme n'est que de la matière épurée ou disposée à être informée par le $L y$ et par là rendue intelligente ou capable de penser : «C'est apparemment pour cela qu'ils accordent que le $L y$ est la lumière qui éclaire tous les hommes et que c'est en lui que nous voyons toutes choses $\gg 1$. Voilà un certain nombre d'erreurs et de paradoxes que Malebranche va essayer de réfuter dans son écrit.

Mais il importe d'abord de savoir au nom de quel principe général Malebranche va juger ce système philosophique des Chinois. Quelle est I'idée directrice qui va être le fil de ses arguments ? Autrement dit pense-t-il que les Chinois sont athées ou qu'ils sont spiritualistes ? Car suivant l'une ou l'autre hypothèse les arguments ne seront sans doute pas les mêmes. Or, si le P. André appréciant cette métaphysique chinoise, la

\footnotetext{
1 Avis..., p. 3.4.
} 


\section{La Chine et la formation de l'esprit philosophique en France}

considère comme un déisme grossier mélangé d'idolâtrie ${ }^{1}$, Malebranche l'estime être un p.331 athéisme ayant de grands rapports avec celui de Spinoza. Les Jésuites lui ayant en effet reproché de mettre l'athéisme au compte d'un philosophe chinois 2, il leur répond : «Ainsi puisqu'il n'y a pas un seul

Chinois qui donne dans l'athéisme et qui sans blesser la vraisemblance puisse me servir d'interlocuteur pour réfuter I'impiété, il n'y a pour contenter la délicatesse de l'Auteur qu'à changer Chinois en Japonois ou Siamois ou plutôt en François ; car il convient que le Système de l'impie Spinoza fait icy de grands ravages; et il me paroît qu'il y a beaucoup de rapport entre les impiétés de Spinoza et celles de notre philosophe chinois. Le changement de nom ne changeroit rien dans ce qui est essentiel à mon écrit $\gg{ }^{3}$. Et dans une lettre à M. de Mairan ${ }^{4}$, Malebranche précise un peu plus tard que c'est dans cet

1 André, Vie du P. Malebranche, B. N.-N. A. F. 1038, f. 472. Ce passage emprunté à l'analyse de l'Entretien... que fait le P. André n'a pas été édité par Ingold.

Ce manuscrit est intéressant, non seulement parce que la vie du $P$. Malebranche qu'il contient est plus détaillée que celle qui a été publiée par Ingold, mais parce qu'on $y$ trouve aussi un fragment de lettre, malheureusement sans date, du chancelier d'Aguesseau, sur certains manuscrits libertins qui couraient sous le manteau. Ce fragment de lettre n'a sans doute rien à voir avec la Chine, je le cite cependant parce qu'il peut être important pour la formation de l'esprit philosophique.

2 Mémoires de Trévoux, juillet 1708.

3 Avis..., p. 6-7.

4 Malebranche écrit à Dortous de Mairan le 29 septembre 1713 : «Quoy que je n'aye point écrit ex professo contre l'auteur (Spinoza) vous pourriez peutêtre trouver quelque éclaircissement sur vos difficultez dans un Entretien entre un philosophe chrétien et un chinois que je fis il y a deux ou trois ans qui est de la nature et de l'existence de Dieu... ». Méditations métaphysiques et Correspondance de M. Malebranche prêtre de I'Oratoire avec J. J. Dortous de Mairan sur des sujets de métaphysique, pp. Feuillet de Conches, p. 100-1. 


\section{La Chine \\ et la formation de l'esprit philosophique en France}

Entretien qu'il faut chercher sa critique du Panthéisme spinoziste.

Traité d'apologétique, pour démontrer aux philosophes chinois la vérité du spiritualisme chrétien, ce dialogue est donc aussi une arme pour les missionnaires de l'intérieur qui veulent combattre Spinoza, non moins qu'un moyen pour Malebranche de préciser contre ses ennemis déclarés ou secrets sa propre position par rapport à Spinoza.

A quel point les ennemis de Malebranche étaient prêts, pour le compromettre, à établir une confusion entre son système et celui de Spinoza, nous en trouvons une preuve dans le compte rendu que firent les Mémoires de Trévoux de son Entretien, et notamment au sujet de la définition qu'il donnait de Dieu : «Ce Roy du Ciel que vous regardez comme notre Dieu, ne seroit qu'un tel être, qu'un être particulier, qu'un être infini, Notre Dieu est I'Être sans aucune restriction ou limitation. Il renferme en lui-même d'une manière incompréhensible à tout esprit fini, toutes les perfections, tout ce qu'il y a de réalité véritable dans tous les êtres p.332 créés et possibles »1. Or en supprimant de cette définition les trois mots que nous avons soulignés, les Jésuites pouvaient répondre triomphalement, en faisant venimeusement suspecter l'orthodoxie de Malebranche : «S'il [le Chinois] se convertit et qu'il lise les Saintes Écritures, il sera bien étonné d'y trouver à chaque page que Dieu est le Seigneur et le Roi du Ciel et de la terre, et surtout que Dieu est un tel Estre, un estre particulier, absolument distingué de tous les

\footnotetext{
${ }^{1}$ Entretien..., p. 2-3.
} 


\section{La Chine et la formation de l'esprit philosophique en France}

autres et infiniment élevé au-dessus d'eux et dont par conséquent, il ne renferme point en soi la réalité, quoiqu'il en contienne éminemment toutes les perfections. Comme tout ce qui est créé participe en sa manière aux perfections de Dieu et non à sa réalité, de même, Dieu en sa manière renferme les perfections qu'il a données et non la réalité de son ouvrage ».

Le journaliste de Trévoux insinue donc que, selon Malebranche, Dieu peut contenir formellement la réalité propre des créatures, même avec leurs imperfections, et que par conséquent Dieu n'est que l'assemblage de tous les êtres, idée qui s'apparente aux doctrines spinozistes. Ainsi le Jésuite se plaît à rejeter sur Malebranche l'athéisme panthéiste que Malebranche critiquait chez les philosophes chinois. Il ne nous appartient pas d'examiner en quoi les doctrines de Malebranche se rapprochaient ou différaient de celles de Spinoza, ni les raisons pour lesquelles ses adversaires, de même que les amis de Spinoza, pour des raisons diverses, cherchaient à le rejeter ou à l'attirer dans le camp spinoziste. Au point de vue de la philosophie chinoise, Malebranche adoptait en somme les idées de Bayle, contre les affirmations des Jésuites, et son petit livre, suivant son biographe, eut un grand succès, puisqu'on « en tira des copies avant qu'il fût imprimé, et qu'on le lut dans les assemblées de sçavans »1. En somme ce furent les Lettrés de la Chine qui payèrent les frais de l'aventure et ce ne fut plus seulement l'athéisme qui leur fut attribué mais aussi le spinozisme : « Tous ceux qui étoient au fait des matières

\footnotetext{
1 André, op. cit., pp. Ingold, p. 313.
} 


\section{La Chine et la formation de l'esprit philosophique en France}

chinoises y applaudirent comme à un ouvrage qui exposoit fort juste le système de religion propre de la Chine et qui refutoit excellemment le libertinage d'Europe »1.

Reste à savoir si cette démonstration de Malebranche qui admettait après Bayle l'athéisme des Lettrés chinois, et qui, en outre, marquait les rapports d'idées qu'ils pouvaient avoir avec le p.333 spinozisme n'était pas un succès que I'on pourrait qualifier de victoire à la Pyrrhus.

\section{3. - LEIBNIZ}

Leibniz est de tous les savants du XVII ${ }^{e}$ siècle, celui qui s'est intéressé le plus tôt - à part Colbert peut-être - et avec le plus d'opiniâtreté et de constance, à la Chine. Dès $1675^{2}$, en effet, dix ans avant le départ des Jésuites mathématiciens pour la Chine, il loue Colbert d'être le promoteur de découvertes réelles dans tous les lieux et dans tous les temps et il semble, dès cette époque, être informé exactement des projets précis - s'il n'en est pas l'instigateur - qui ne seront réalisés qu'après la mort de Colbert : «Un roy de Perse se récriera sur l'effet de la lunette et un Mandarin de la Chine sera ravi d'étonnement quand il aura compris I'infaillibilité d'un Missionnaire géomètre ».

1 Id., ibid., p. 313.

2 Si du moins il faut admettre la date de 1675 que donne à cette lettre son éditeur (en effet la lettre n'est pas datée). Die werke von Leibnitz. Erste Reihe, bd. III, p. 211. 


\section{La Chine et la formation de l'esprit philosophique en France}

Ces nouvelles découvertes dont il louait Colbert, c'était la découverte des plus anciens vestiges de I'antiquité du monde, permettant de faire I'histoire du genre humain. L'antiquité grecque et latine était suffisamment connue, mais il manquait la connaissance des nations orientales : «Dans peu il faudra aller fouiller chez les Chinois et les Arabes, pour achever I'histoire du genre humain, autant qu'on la peut tirer des monuments qui nous restent, soit par écrit, soit sur les pierres ou les métaux, soit même dans la mémoire des hommes, car il ne faut pas négliger entièrement la tradition et je tiens que de tout ce qui est non écrit, les langues mêmes sont les meilleurs et les plus grands restes significatifs de l'ancien monde dont on pourroit tirer des lumières sur les origines des peuples et souvent pour celles des choses $\gg 1$.

La langue chinoise l'intéressait, non seulement parce qu'il était avide de connaître le mécanisme encore ignoré de l'écriture chinoise, mais parce qu'il se demandait si le chinois n'était pas la langue primitive. Il note dans sa correspondance 2 qu'un Anglais Joh. Webbe a cru que le chinois était la langue-mère, et d'autres lettres de ses correspondants, qui lui donnent leur avis sur cette question de la langue primitive, indiquent que cette idée p.334 continuait à le préoccuper ${ }^{3}$. En 1701 il encourage La Croze à cultiver la langue chinoise ; il lui apprend que l'empereur de Chine fait faire un dictionnaire tartare-chinois et lui-même il

\footnotetext{
1 Davillé, Leibniz historien, p. 385, n. 1.

2 Ed. Kortholt, t. I, p. 53.

3 ibid., t. I, p. 352.
} 


\section{La Chine et la formation de l'esprit philosophique en France}

pousse les Jésuites à y joindre une explication dans quelque langue d'Europe ${ }^{1}$. Lorsque La Croze travaille à son dictionnaire arménien, Leibniz le loue, mais il ajoute : «...Les Chinois mériteroient bien davantage vos soins $\gg 2$. L'année suivante il apprend avec joie que le dictionnaire de La Croze est terminé et il I'en félicite, mais à ses félicitations se mêle un regret : « Je reconnois la conséquence de la langue arménienne et je suis assuré que vous en tirerez de belles pour l'Histoire ecclésiastique et la Sainte Ecriture, mais je trouve la recherche du chinois infiniment plus utile $\gg 3$.

Il incitait aussi les PP. Bouvet et Grimaldi, Jésuites missionnaires en Chine, avec lesquels il était en correspondance, à faire connaître l'histoire de la Chine, et à donner des éditions critiques de leurs auteurs ${ }^{4}$. L'histoire de la Chine lui semblait importante, non moins que sa langue, à cause de sa haute antiquité. En décembre 1687, en annonçant au Landgrave Ernest la chronologie du P. Couplet, il lui écrivait : « La chronologie chinoise qu'on a ajoutée à cet ouvrage est extrêmement considérable. Car il semble selon le calcul ordinaire des temps que les premiers monarques chinois comme Fohi et Hoangti approchent trop du déluge. Cela nous obligera sans doute de préférer les 70 interprètes au texte hébreu, car les Jésuites avouent eux-mêmes qu'au moins I'histoire de Hoangti ne sauroit

\footnotetext{
1 Jourdan, Histoire de la vie et des ouvrages de M. La Croze, p. 119.

2 Ed. Kortholt, t. I, p. 414-5. Cf. Davillé, op. cit., p. 586, n. 6.

3 Jourdan, op. cit., p. 119.

4 Davillé, op. cit., p. 343, n. 9.
} 


\section{La Chine et la formation de l'esprit philosophique en France}

être révoquée en doute »1. Il pensait que « excepté les Juifs, les Chinois surpassent tous les peuples dans l'exactitude et I'ancienneté de leurs histoires, parce que leur gouvernement a toujours subsisté presque sans interruption nonobstant les changements qui y sont arrivés $\gg 2$. Donc la connaissance de la Chine, à cause de sa haute antiquité, était un bien inestimable «pour l'accroissement des sciences et des arts chez nous aussi bien que chez les Chinois. Car c'est un commerce de lumières qui nous peut donner d'un seul coup leurs travaux de p.335 quelques milliers d'années, et doubler pour ainsi dire nos véritables richesses de part et d'autre $\gg 3$.

Si Leibniz se montra ainsi toute sa vie préoccupé de découvrir les secrets de la plus haute antiquité, ce n'est pas seulement curiosité historique ; mais il était persuadé aussi que l'ancienne histoire, et I'histoire des peuples les plus éloignés de nous, concourait à la démonstration de la religion : « L'histoire de I'Antiquité est d'une nécessité absolue pour la preuve de la vérité de la religion et mettant à part l'excellence de la doctrine, c'est par son origine toute divine que la nôtre se distingue de toutes les autres qui n'approchent en aucune façon. C'est là peut estre le meilleur usage de la plus fine et de la plus profonde critique que de rendre un témoignage sincère à ces grandes vérités par des anciens auteurs exactement vérifiés et si les Mahométans et payens et même les libertins ne se rendent point à la raison, on

\footnotetext{
1 Id., op. cit., p. 425, n. 3.

2 Id., op. cit., p. 425, n. 3.

3 Lettre au P. Verjus du 2 décembre 1697, citée par Baruzi, Leibniz et l'organisation religieuse de la terre, p. 98.
} 


\section{La Chine et la formation de l'esprit philosophique en France}

peut dire que c'est principalement faute de ne pas sçavoir I'histoire ancienne, aussi ceux qui l'ignorent entièrement sont toujours enfans, comme cet Égyptien qui parla à Solon jugea fort bien les Grecs »1.

Donc démonstration de la vérité de la religion par I'histoire. Mais cette démonstration doit être valable et pour les Européens et pour les Chinois. Leibniz, toujours féru de l'idée d'unité religieuse, pense qu'il est possible de révéler aux Européens comme aux Chinois, grâce à la connaissance d'une des plus anciennes histoires du monde, les principes de la théologie naturelle. Le moyen sur lequel il comptait pour réaliser cette unité entre I'Europe et I'Extrême-Orient, c'était l'ordre des Jésuites.

S'il n'eut pas lui-même l'idée de l'envoi des Jésuites mathématiciens en Chine, il célébra du moins cet important résultat. Il vanta comme un éclatant succès l'édit de tolérance de 1697 qui accordait en Chine la liberté du culte chrétien et son admiration pour la Chine ne connut plus de bornes : Si cela continue, je crains fort que les Chinois ne nous surpassent bientôt dans les Sciences et dans les Beaux Arts, ce que je ne dis pas pour leur envier cette gloire puisque je m'en réjouis avec eux ; mais pour nous porter aussi nous-mêmes à apprendre d'eux la politesse, et cet art admirable de gouverner qu'aucune nation du monde ne possède comme eux. Car nous vivons avec si peu d'ordre qu'il me semble que, comme nous leur envoions des missionnaires pour leur apprendre la véritable p.336 théologie,

1 Couturat, Opuscules, p. 226. 


\section{La Chine et la formation de l'esprit philosophique en France}

il seroit nécessaire qu'ils nous envoiassent aussi de ces sages politiques qui nous apprissent l'art de gouverner et toute cette théologie naturelle qu'ils ont portée à un si haut point de perfection $\gg 1$.

Il se mit en relation avec les missionnaires de Pékin, notamment avec le P. Bouvet qui lui donna des indications sur les caractères primitifs inventés par Fou-hi, d'où il voulut conclure à une analogie avec le système numérique dyadaire, où tous les nombres peuvent s'exprimer par I et par $O$. Il correspondit aussi avec le P. Verjus, procureur général des missions ; il partagea en somme toutes les espérances que les Jésuites mirent dans leurs missions de Chine.

Il n'est pas nécessaire d'exposer longuement les raisons de cette sympathie de Leibniz pour les Jésuites missionnaires en Chine après l'excellent exposé qu'en a fait Baruzi : à la suite de l'échec de sa tentative près de Louis XIV, en 1672, mais ne cessant pas d'être préoccupé de l'unification religieuse de la terre, il crut trouver dans l'ordre des Jésuites, discipliné et hiérarchisé comme il l'était, l'instrument nécessaire pour amener l'Extrême-Orient aux vérités du christianisme. Il est possible aussi qu'il se soit senti attiré vers les Jésuites à cause de la lutte qu'ils menaient contre le cartésianisme, et qu'il ait eu l'espoir de

\footnotetext{
${ }^{1}$ Extrait de la Préface que M. Leibnitz, protestant, conseiller aulique à la Cour d'Hanovre a mise à la tête du Livre qu'il a fait imprimer touchant l'édit que I'Empereur de la Chine a donné en faveur de la Religion chrétienne, ap. Lettre sur les Progrez de la Religion à la Chine à Monsieur l'abbé de X..., p. 7. (La lettre préface est datée du 21 novembre 1697). Dans la préface de ses Novissima Sinica ( $2^{\mathrm{e}}$ édition. 1699) Leibniz est toujours enthousiaste de la Chine, mais il semble juger plus sainement : il accorde toujours aux Chinois la supériorité sur les Européens dans la morale et dans la politique, mais il constate leur infériorité dans les sciences spéculatives.
} 


\section{La Chine et la formation de l'esprit philosophique en France}

faire triompher par eux le leibnizianisme. Mais ce qui est certain, c'est que la souplesse des Jésuites, leur facilité d'adaptation aux mœurs étrangères, leur libéralisme à l'égard des cérémonies et des traditions chinoises, et les efforts qu'ils faisaient pour élucider les points obscurs de l'ancienne théologie et de I'ancienne histoire chinoises au moyen des lumières de la révélation - ce qui répondait si bien à ses propres désirs et à ses propres efforts - toutes ces raisons sont plus que suffisantes pour expliquer et justifier la sympathie de Leibniz à l'égard des Jésuites.

Aussi il prit parti pour eux dans la Querelle des Cérémonies chinoises, et il ne s'en cachait pas : « Je suis, écrivait-il à Madame, Duchesse d'Orléans, également partisan de la doctrine des jésuites par rapport aux croyances des Chinois et j'ai eu sur ce sujet une p.337 petite discussion avec le Prince Eugène de Vienne. Il s'étonnoit que moi protestant, je me range à l'avis de Rome, mais je suis impartial $\gg 1$.

Un peu plus tard, Bouhier et Marais qui pourtant n'étaient rien moins que partisans des Jésuites, rendaient hommage à cet esprit libéral de Leibniz : « Je viens de lire avec plaisir, écrivait Bouhier, les lettres de $M$. de Leibniz qu'on a imprimées depuis peu en Allemagne. Il y a des choses assez curieuses et surtout par rapport à ses sentiments sur l'autorité du Pape et sur les rites de la Chine. On est surpris de voir que tout protestant qu'il étoit, il reconnoissoit que l'autorité et la Primauté du Pape sont d'institution divine, et que la condamnation des rites de la Chine

\footnotetext{
${ }^{1}$ Lettres de Madame Duchesse d'Orléans, éd. Jaeglé, t. III, p. 166.
} 


\section{La Chine et la formation de l'esprit philosophique en France}

est une pure ignorance qui tôt ou tard attireroit l'expulsion des Missionnaires de ce beau royaume. En quoi sa prédiction ne s'est trouvée que trop vraye »1. Et Marais approuvait : « Il est singulier que $M$. de Leibniz ait parlé du Pape en catholique et des rites de la Chine en Prophète » 2.

La sympathie de Leibniz pour les Jésuites était une sympathie intellectuelle qui ne tenait nullement, comme cherchait à le faire croire La Croze 3, aux flatteries que les Jésuites lui adressaient. La preuve est qu'il prit aussi parti pour eux non seulement dans l'affaire des rites mais dans la question de l'ancienne religion des Chinois, problèmes de métaphysique et de théologie qu'il essaya d'interpréter et de résoudre à la lumière de ses propres idées, et dont la solution qu'il donna est très voisine de celle que les Jésuites essayèrent de faire triompher.

Il lut et annota les traités du P. Longobardi ${ }^{4}$ et du P. SainteMarie qui s'efforçaient de démontrer l'athéisme des Chinois et

${ }^{1}$ Lettre de Bouhier à Marais, 14 octobre 1734, B. N. Fr. 25542, f. 259.

2 Lettre de Marais à Bouhier, 17 octobre 1734, B. N. Fr. 24414, f. 363, v.

3 Nimirum hoc habuit, vir alias incomparabilis, ut facile blanditiis et adulationibus expugnaretur. Atqui a nullis unquam hominum tantopere laudatus et commendatus fuit, qua privatis litteris, qua etiam testimoniis compluribus passim in lucem emissis. (Lettre de La Croze à Kortholt, décembre 1720, in Kortholt, t. II, p. 495).

${ }^{4}$ La Croze prétendait que Leibniz n'avait pas lu ce traité du P. Longobardi et qu'il avait adopté un peu à la légère l'opinion des Jésuites (Id., ibid., t. II. p. 495). Pour sa part il croyait que les Chinois étaient panthéistes (ibid., p. 497). 


\section{La Chine et la formation de l'esprit philosophique en France}

ensuite dans une longue lettre à $M$. de Bémond, il exposa ses idées sur l'ancienne religion de la Chine ${ }^{1 .}$

p.338 Le grand principe de Leibniz dans cette étude, est de chercher à saisir le sens exact que les anciens Chinois donnaient aux textes en les dépouillant des gloses et des commentaires qui ont été ajoutés par les philosophes modernes, de même qu'il faudrait se garder de juger du christianisme d'après les interprétations qu'en ont données les philosophes scolastiques. Or comme ce sont les commentaires qui prévalent, et que ces commentaires proviennent des philosophes modernes qui sont athées, on est porté tout naturellement à conclure à l'athéisme des anciens Chinois, ce qui n'est peut-être pas la vérité. En effet l'Empereur qui est «le chef des sages et la vie de la Loy » semble autoriser I'opinion des anciens ${ }^{2}$.

Ce principe critique une fois posé, la question importante est de savoir si les Chinois ont cru ou non à des substances spirituelles : « Je juge qu'ouy, quoy qu'ils n'ayent peut entre point reconnu ces substances comme séparées et tout à fait hors de la matière... il n'y auroit point de mal en cela à l'égard des Esprits créés, car je panche moy même à croire que les Anges ont des corps, ce qui a été aussi le sentiment de plusieurs Anciens Pères de l'Église. Je suis d'avis aussi que l'âme

\footnotetext{
1 Ces deux traités avec les notes de Leibniz et la lettre à $M$. de Rémond ont été publiés par Kortholt, Epistulæ ad diversos, t. II. Ils ont ensuite été réédités par Dutens dans son édition de Leibnitz (t. IV) en 1768. Comme les philosophes entre 1735 et 1768 n'ont pu consulter que l'édition Kortholt, c'est d'après cette édition que nous citerons car nous avons des raisons de croire que Voltaire notamment a connu cette lettre à $M$. de Rémond avant 1768.

2 Kortholt, Epistulae ad diversos, t. II, p. 414.
} 


\section{La Chine \\ et la formation de l'esprit philosophique en France}

raisonnable $n^{\prime}$ est jamais dépouillée entièrement de tout corps $\gg 1$.

Mais Dieu ? Certains Chinois n'ont-ils pas été d'avis de lui donner un corps, de le considérer comme l'âme du monde et de le joindre à la matière ? Sans doute, mais les plus anciens auteurs attribuent au $L i$ ou premier principe, la production du Ki ou de la matière. Ce $L i$ non seulement est distinct de la matière mais il la produit. Il est la règle, le premier Acteur et il répond à notre Divinité 2 . Ses attributs en effet sont les mêmes : infini, éternel, incréé, il est « le principe physique du Ciel, de la Terre et des autres choses corporelles mais il est aussi « le principe moral des vertus, des habitudes et des autres choses spirituelles $\gg 3$. Ils appellent cette substance Unité sommaire parce qu'elle n'est point capable de division quant à son entité ; mais elle est en même Temps la plus parfaite multitude, parce que dans l'entité de ce principe sont renfermées toutes les essences des choses

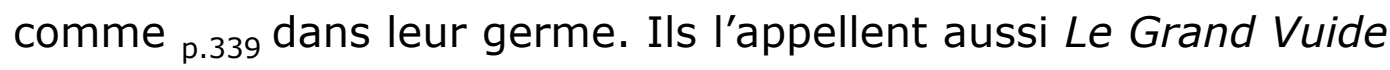
ou la Souveraine Plénitude, ce qui peut s'expliquer « dans un bon sens » si l'on conçoit l'espace non pas comme une substance qui a des parties hors des parties, mais comme l'ordre des choses en tant qu'elles sont considérées comme existantes ensemble, provenant de l'immensité de Dieu en tant que toutes les choses en dépendent dans chaque moment $\gg 4$.

\footnotetext{
${ }^{1}$ Ib., ibid., t. II, p. 415.

${ }^{2}$ Ib., ibid., t. II, p. 416.

3 Ib., ibid., t. II, p. 420.

${ }^{4}$ Ib., ibid., t. II, p. $420-422$.
} 


\section{La Chine et la formation de l'esprit philosophique en France}

Le $L i$ produit le $K i$ et ainsi la philosophie chinoise approche plus de la théologie chrétienne que de la philosophie des anciens Grecs, qui considéraient la matière comme un principe parallèle à Dieu, que Dieu ne produit point, mais qu'il forme seulement. Il est vrai que les Chinois ont cru que le $\mathrm{Li}$ a toujours produit son $K i$, si bien que les deux principes seraient éternels. «Mais ne faut point s'en étonner puisqu'apparemment ils ont ignoré cette Révélation, laquelle seule peut nous apprendre le commencement de I'univers, St-Thomas et d'autres Docteurs ayant jugé que ce dogme ne peut point être démontré par la seule raison... il y a des gens [des Européens] qui croyent que le commencement de leur Empire [I'Empire des Chinois] tombant dans le temps des Patriarches, ils pourront avoir appris d'eux la Création du Monde $\gg 1$.

Si le $L i$, tel qu'on vient de le définir est la même chose que Xang-ti [Chang ti], le P. Ricci a eu raison de dire que sous le nom de Xang-ti les Chinois ont connu le vrai Dieu. Les anciens sages de la Chine ont appelé ce Dieu Seigneur du Ciel, et ils ont eu raison car les découvertes astronomiques ont montré que le ciel est tout I'univers connu : «C'est pourquoy comme ils ont si bien rencontré, sans en savoir la raison, il se peut qu'ils ayent appris une partie de leur sagesse de la tradition des Patriarches $\gg 2$. Enfin, examinant certaines expressions chinoises, concernant Xang-ti [Chang ti] ou le Ciel, Leibniz leur trouve des équivalents tout à fait orthodoxes dans le langage européen et il conclut :

\footnotetext{
${ }^{1}$ Ib., ibid., t. II, p. 440-1.

${ }^{2}$ Ib., ibid., t. II, p. 451.
} 


\section{La Chine et la formation de l'esprit philosophique en France}

« Je crois que ce n'est que par des interprétations forcées et des interpolations qu'on y peut trouver à redire. C'est le christianisme tout pur en tant qu'il renouvelle la loy naturelle gravée dans nos cœurs. Sauf tout ce que la révélation et la grâce y ajoutent, pour mieux redresser la nature $\gg 1$.

Leibniz est donc une exception au milieu des philosophes de son p.340 temps, français comme Bayle et Malebranche, ou anglais comme Toland, qui ont cru à l'athéisme ou même au spinozisme des Chinois. Il croyait trop à la connaissance naturelle de Dieu chez tous les hommes même indépendamment des enseignements de l'Écriture et à la nécessité d'une religion spiritualiste comme principe et soutien de la vertu, soit pour admettre les idées de Socin, soit pour concéder aux adversaires des Jésuites que les anciens Chinois avaient pu être athées, ou à Bayle que l'athéisme dans une nation entière pouvait se concilier avec la morale la plus pure. Il ne niait pas sans doute qu'un particulier pouvait être homme de bien, « soit par tempérament, par coutume ou par un heureux préjugé », mais il pensait qu'il ne le saurait être entièrement par un principe solide de la «droite raison » 2 . Or la droite raison exige la connaissance d'un «Souverain Seigneur de l'univers », qui seul peut nous faire comprendre «que son service nous peut obliger en bien des rencontres à préférer le bien d'autrui à nos intérêts présents ». La croyance en Dieu est donc non seulement le support mais la

\footnotetext{
${ }^{1}$ Ib., ibid., t. II, p. 451.

2 Cf. La Croze, Réflexions historiques et critiques sur le Mahométisme et le Socianisme, in Dissertations historiques sur divers sujets, p. 147-151, et la réponse de Leibniz in Kortholt, t. I, p. 179-I81.
} 


\section{La Chine et la formation de l'esprit philosophique en France}

condition première de la moralité. Au contraire, plusieurs écrivains, avant Leibniz, ont cru trouver la preuve dans l'exemple chinois, qu'il existait une morale naturelle indépendante de la religion, et d'après laquelle l'intérêt particulier s'efface devant I'intérêt général. D'autres encore le croiront même après Leibniz et malgré lui, mais ses idées ne seront peut-être pas sans influence cependant sur l'évolution des idées de Voltaire entre 1760 et 1764 .

\section{4. - LEVESQUE DE BURIGNY}

Seul Leibniz s'oppose parmi les philosophes du premier quart du XVIII ${ }^{e}$ siècle à l'opinion de Bayle sur I'athéisme des Chinois qui semble devenue en France, grâce à lui, un fait incontesté. Mais les idées de Leibniz ne furent pas connues dès d'abord et ne purent l'être qu'après la publication du deuxième volume de Kortholt en 1735. Et d'autre part les adversaires des Jésuites ne se trouvant satisfaits ni de la condamnation de la Sorbonne, ni de l'Édit du Cardinal de Tournon, continuèrent la démonstration de l'athéisme des Chinois, qui leur avait si bien réussi avec la publication des opuscules du P. Longobardi, et du P. de SainteMarie, en 1701.

p.341 Renaudot dans ses Éclaircissemens, qui suivent ses Anciennes Relations des Indes et de la Chine, essaie notamment de prouver que les Chinois n'ont qu'une métaphysique 


\section{La Chine et la formation de l'esprit philosophique en France}

incohérente, qu'ils n'ont « aucune idée du Souverain Estre et pas mesure de nom pour signifier Dieu $\gg 1$.

C'est une affirmation du P. Martini, mais Renaudot croit pouvoir la prouver par un argument qui lui a déjà servi dans la Querelle des Cérémonies chinoises, lorsqu'il était à Rome : l'inscription que les Syriens laissèrent en Chine, comme un monument de leur mission, alors qu'ils avaient passé dans le pays cent quarante-six ans et qu'ils ne pouvaient ignorer le Chinois, a dû emprunter du syriaque un mot pour désigner Dieu, parce qu'ils n'en trouvaient pas dans la langue chinoise ${ }^{2}$. Toutes les expressions figurées du ciel et du soleil que I'on veut rapporter au Souverain Estre ne prouvent rien en faveur des Chinois puisqu'on les retrouve chez les Américains ou les Iroquois les plus barbares qui certainement n'ont jamais eu aucune connaissance de Dieu 3. Quant à leurs idées sur l'origine du monde - les uns pensent que le monde est éternel, les autres qu'il s'est formé par hasard - elles sont plus grossières que celles des Grecs et des Latins qui n'avaient d'autres lumières que celles de la raison. Enfin « ils n'ont aucune idée juste de l'immortalité de l'âme et une grande partie de leurs cérémonies funèbres fait voir clairement qu'ils n'ont aucun système de doctrine sur un article aussi important. et qui est le fondement de toute religion $\gg{ }^{4}$. En somme les idées métaphysiques des

\footnotetext{
1 Anciennes Relations..., p. 342.

2 Id., ibid., p. 343.

3 ibid., p. 343-4.

4 ibid., p. 347.
} 


\section{La Chine et la formation de l'esprit philosophique en France}

Chinois sont des idées grossières et ils doivent les quelques lueurs de raison que I'on découvre dans leur métaphysique soit aux Arabes, soit aux philosophes d'Occident qui allaient aux Indes pour s'instruire de la sagesse orientale $\gg 1$.

p.342 Levesque de Burigny, pour se renseigner sur la théologie des Chinois s'est adressé à Bayle et à Renaudot ; c'est dire qu'il conclut comme eux à l'athéisme. Conclusion d'ailleurs qui ne devait pas lui déplaire 2 , puisque sous les apparences d'un exposé impartial des doctrines des anciens philosophes, il cherche surtout à montrer que l'athéisme a été très répandu dans I'antiquité à travers le monde ; I'exemple chinois vient à point pour prouver que l'athéisme a été la doctrine dominante des philosophes, non seulement dans notre Occident mais jusqu'en Extrême-Orient. A la preuve par l'antiquité vient donc se joindre la preuve par l'extension dans l'espace. C'est le

\footnotetext{
1 Le voyageur Le Gentil qui a éprouvé en Chine l'impolitesse et la grossièreté des foules chinoises, et qui a pu se rendre compte des pirateries des mandarins, toutes choses qu'il nous rapporte d'ailleurs avec bonne humeur. et qui auraient pu édifier Montesquieu, sans qu'il eût eu besoin d'attendre le récit de l'amiral Anson, croit sans doute augmenter la valeur de sa relation en nous donnant son appréciation sur les cultes et sur la religion des Chinois. Sur les cultes il a pris l'avis d'un missionnaire jésuite et il en adopte toutes les idées : sur la science et sur la philosophie des Chinois il se contente de prendre des citations à Renaudot, de démarquer ses arguments ou quelquefois tout bonnement de les copier. (Cf. notamment Nouveau Voyage autour du monde, t. II. p. 768-171). Il ne s'est pas inquiété - ou ne s'est pas aperçu - de cette contradiction.

2 Il m'est impossible d'admettre l'opinion émise par Chéret dans son livre, d'ailleurs si plein d'enseignements, sur André-Michel Ramsay (p. 161-2) où il range Levesque de Burigny parmi les initiateurs de Ramsay, ou du moins dans cette famille d'esprits qui peuvent expliquer la formation du déisme de Ramsay. Pour se convaincre que les contemporains ne jugeaient pas ainsi, il n'y a qu'à lire les Acta Eruditorum (septembre 1724, p. 416-7) qui montrent par leur compte rendu que Levesque de Burigny cherche à prouver la presque universalité de l'athéisme chez les anciens philosophes, et se plaît à énumérer toute la foule, longum agmen, des prédécesseurs de Spinoza.
} 


\section{La Chine \\ et la formation de l'esprit philosophique en France}

consentement universel en faveur de l'athéisme. C'est l'argument du consentement universel retourné.

Dans son premier chapitre De l'existence de Dieu, Levesque de Burigny semble vouloir démontrer que « I'existence de Dieu a été reconnue de presque tous les philosophes », ce qui est le sommaire de son premier paragraphe. Mais quinaud serait celui qui s'y laisserait prendre, car les deux paragraphes suivants montrent «qu'elle a été ignorée de quelques Peuples » et par quelques-uns des plus importants comme le peuple chinois, et qu'« elle a été niée par quelques philosophes ». Le premier paragraphe sert seulement à mettre en confiance, les deux autres qui le suivent apportent le venin.

Or le second paragraphe qui tente de démontrer l'athéisme des Chinois n'est pas un simple hors-d'œuvre, mais Levesque de Burigny fait feu de tout bois pour arriver à la conclusion que manifestement il cherche. Bayle et Renaudot sont ses garants pour les arguments qu'ils apportent, mais surtout pour la conclusion à laquelle ils tendent. Aux arguments de Bayle et de Renaudot, notre auteur joint encore des citations de Jésuites qui prouvent l'athéisme des Chinois, des listes de Jésuites qui avouent cet athéisme. et l'on conçoit qu'à son avis ces témoignages ne sont pas suspects, mais qu'ils sont des preuves d'autant plus fortes de l'athéisme des Chinois ${ }^{1}$.

p.343 Dans le second chapitre, Levesque de Burigny examine «les diverses descriptions de la nature divine par les Payens », puis il traite « de la Spiritualité de Dieu», et enfin et surtout il

1 Lévesque de Burigny, Histoire de la philosophie paienne, t. I, p. 16-36. 


\section{La Chine et la formation de l'esprit philosophique en France}

disserte « de ceux qui avant Spinoza ont enseigné l'erreur qu'il a renouvelée ». Erreur qu'il a renouvelée et non inventée, car il a de nombreux prédécesseurs à toutes les époques et dans tous les pays du monde. Les philosophes chinois sont naturellement parmi ces prédécesseurs, d'après une autorité non suspecte, le Jésuite Trigault. Et Levesque de Burigny conclut ce chapitre de cette manière : «Nous finirons ce chapitre en remarquant avec M. Bayle, qu'on ne peut assez admirer qu'une idée si extravagante et si remplie de contradictions absurdes ait pu s'introduire chez tant de gens, si éloignez les uns des autres et si différens entre eux en humeur, en éducation, en coutume et en génie »1. Quoi qu'il en soit on doit conclure, si I'on veut lire entre les lignes, que l'argument du consentement universel, s'il est valable, joue plus en faveur de l'athéisme que du spiritualisme.

L'idée de Lévesque de Burigny apparaît encore plus nette, si I'on examine ses opinions sur la morale des anciens philosophes, et notamment le chapitre où il essaie de démontrer « qu'il n'y a aucune action de vertu qui n'ait été pratiquée par quelque payen ». Les deux grands devoirs de I'homme, dit-il, se réduisent à aimer Dieu plus que toutes choses, et le prochain comme soi-même. C'est dans l'exercice de ces deux préceptes que consiste toute la morale. Le premier de ces préceptes a été négligé des Payens, quoique Porphyre rapporte que Plotin aimait Dieu de toute son âme. Mais le second, qui exprime la nécessité d'aimer les autres hommes, a été connu de presque tout le

\footnotetext{
${ }^{1}$ Id., ibid., t. I, p. 84-86.
} 


\section{La Chine et la formation de l'esprit philosophique en France}

monde : «Dans les premiers temps, cette vertu fut pratiquée dans tous les Pais. L'hospitalité pour laquelle on avoit tant de respect en est une preuve bien sensible »1. Ainsi, malgré les opinions différentes sur la nature de Dieu, et malgré l'athéisme qui semble dominant, il y a cependant quelque chose d'universel, une règle morale, lien des sociétés, qui n'est pas inspirée par la religion, mais semble inhérente à la nature même de I'homme. La morale est donc indépendante de la religion; c'est la conclusion à laquelle déjà tendait Bayle.

\section{5. - FRÉRET}

p. ${ }_{344}$ Personne plus que Fréret ne s'est intéressé à la Chine. Sa correspondance avec les missionnaires jésuites en Chine en est une preuve suffisante, non moins que ses mémoires publiés dans le recueil de I'Académie des Inscriptions et Belles-Lettres. Mais à lire ces mémoires ou cette correspondance on serait tenté de croire que Fréret ne s'est intéressé qu'aux questions de chronologie ou d'histoire et que la recherche patiente qu'il a faite inlassablement des origines de la monarchie chinoise ne procède que de son goût d'érudit et d'historien. Cependant à l'occasion, dans sa correspondance avec le P. Gaubil, Fréret exprime son opinion sur la religion des premiers hommes et en 1737 - mais c'est peut-être pour plaire au P. Gaubil - il déclare qu'il croit qu'ils ont été théistes ${ }^{2}$. Cependant, dans une note qui n'était

${ }^{1}$ Id., ibid., t. II, p. 240-2.

2 Documents inédits..., p. 170. 


\section{La Chine et la formation de l'esprit philosophique en France}

destinée ni à la publicité ni à la correspondance avec les missionnaires, où par suite nous avons des chances de trouver l'expression de la pensée véritable de Fréret, et qui est antérieure à la lettre de 1737 adressée au P. Gaubil ${ }^{1}$, Fréret analysant et critiquant la préface du P. Couplet sur la religion des anciens Chinois conclut comme Bayle à l'athéisme, et même à un panthéisme de genre spinoziste, des anciens Chinois.

Examinant d'après le $P$. Couplet les événements de la vie de Confucius, Fréret semble croire, comme Bayle le croyait des Lettrés de la Chine, qu'il avait une doctrine secrète 2 : «a vie de ce philosophe, dit-il, estoit une comédie perpétuelle ». Il masquait « ses sentimens et tous les mouvements de son cœur sous les apparences d'une tranquillité et d'une espèce d'impassibilité entière ». Son enseignement portait sur quatre parties de la philosophie, morale, logique, politique, éloquence, mais il « n'admettoit ni métaphysique ni physique, ni théologie, aussi disoit-il lui-même, qu'un homme sage ne se devoit pas inquiéter de toutes ces choses ». Sa doctrine est donc essentiellement morale, la science des p.345 mœurs étant chez les Chinois « la dernière et la plus estimée » de toutes les sciences. Il ne parle donc jamais ni du Souverain Être ni de l'immortalité

\footnotetext{
${ }^{1}$ Documents inédits..., p. 117-8.

2 Cette idée de l'existence d'une doctrine secrète des anciens philosophes semble avoir été une idée chère aux libertins. L'auteur de la Lettre de Thrasybule à Leucippe, qui certainement n'est autre que Fréret, était persuadé que le philosophe devait se garder de livrer sa doctrine au premier venu et ne devait en faire part qu'aux esprits capables de la comprendre, si du moins il faut accepter le témoignage de Duclos rapporté par G. Lanson, $R$. H. L. 1912 , p. 300.
} 


\section{La Chine et la formation de l'esprit philosophique en France}

de l'âme ni de l'autre vie, « il exorte à la vertu pour elle-même et pour les avantages qu'elle entraîne nécessairement avec elle par une suite naturelle ». C'est la constatation qu'avait faite Bayle au sujet des Siamois. Donc la morale et la religion sont deux choses indépendantes.

Le P. Couplet ne peut esquiver certains passages où Confucius parle des esprits, mais il s'efforce de démontrer que ce sont des êtres réels intermédiaires entre la divinité et le monde. Or Fréret confrontant la traduction du P. Couplet avec celle du P. Noël qu'il croit plus exacte conclut : « Cet esprit qui est uni intimement à toutes choses et qui n'en peut estre séparé, cet esprit qu'on ne connoit que par ses effets, cet esprit qui produit et qui détruit n'est-il pas certainement très différent de ce que nous appelons les Esprits et ne doit-on pas le prendre pour quelque chose de semblable à l'âme du monde ou à la vertu active des Spinozistes ». Les divinations de la religion chinoise que le $P$. Couplet s'efforce d'excuser mènent Fréret à la même conclusion : «Ces divinations n'estoient pas fondées sur les décrets d'une providence mais sur des raisons sympathiques et antipathiques qui s'accordent avec l'âme du monde ». S'il en est ainsi on comprend la distinction que les Chinois font entre I'homme saint et I'homme sage. Le sage est celui dont la lumière naturelle est offusquée par les taches et les imperfections de sa nature et qui s'efforce par le travail de toute sa vie de se rétablir dans l'état de perfection originelle. Mais le Saint « est rempli et pénétré de la lumière raisonnable du ciel dont il n'y a qu'une portion dans les autres hommes. Ces saints sont le ciel même et la souveraine raison et après leur mort ils n'en sont plus 


\section{La Chine et la formation de l'esprit philosophique en France}

distingués ». C'est à peu près l'idée que nous avons de JésusChrist et que les Bramines ont de leurs Dieux, et Confucius « passe pour estre de cette espèce avec un petit nombre d'autres... Le Saint est lui-même sa perfection, sa lumière, sa vertu ». Et Fréret de conclure ironiquement : « Je ne sçay comment le P. Couplet peut faire cadrer ce système avec la vraye métaphysique ou du moins celle du christianisme ». Il examine ensuite avec esprit critique les différentes raisons que le P. Couplet allègue pour prouver que les Chinois ont cru à l'immortalité de l'âme et nous ne le suivrons pas dans cette longue discussion point par point, car son intention est manifeste, à savoir de monter, en interprétant avec critique les arguments mêmes du P. Couplet que les Chinois n'ont pas cru à l'immortalité de l'âme. Tout cela montre p.346 bien que Fréret peut être rangé au nombre des philosophes qui, à la suite de Bayle, mais avec des raisons plus solides, ont cru à l'athéisme des Chinois.

L'argument du consentement universel semble donc bien ruiné par l'exemple chinois, non pas seulement sous sa forme traditionnelle de consentement de tous les peuples du monde mais aussi sous la forme nouvelle que lui avait donnée Elie Benoist. Car à mesure que se prouve et se précise l'antiquité de la Chine, il devient de plus en plus difficile de prétendre que la Bible apporte le témoignage le plus ancien et par suite le plus autorisé sur la création et les origines de I'humanité, puisque Confucius est contemporain de Socrate et que Fou-hi et plusieurs 


\section{La Chine et la formation de l'esprit philosophique en France}

de ses successeurs sont les aînés de Moïse. Le témoignage de Moïse - si on ne le considère que comme témoignage historique - est donc infirmé par le témoignage des anciens Chinois. On peut, il est vrai, prétendre que Moïse est inspiré tandis que les anciens Chinois ne le sont pas, mais c'est précisément ce qu'il faut prouver, et ni les historiens ni les philosophes ne peuvent admettre comme axiome un principe dont ils cherchent la vérification. Les adversaires des Jésuites qui se sont efforcés de prouver l'athéisme des Chinois ont donc travaillé pour les philosophes.

Mais les Jésuites ne s'avouent pas battus : la Querelle des Cérémonies chinoises en effet n'est pas terminée et il leur faut se justifier en même temps que les Chinois ; aussi ils accumulent dans leurs Lettres édifiantes et curieuses des faits qui tendent à prouver le spiritualisme de l'ancienne religion chinoise. Mais ils risquent comme le leur reprochaient certains docteurs de Sorbonne d'établir ainsi plutôt les titres de noblesse du déisme que ceux du christianisme. Or dans l'ordre des Jésuites, toute une école de théologiens, notamment parmi les missionnaires de la Chine, s'efforçait de retrouver dans les anciens livres des peuples primitifs non les traces d'une philosophie ou d'une religion spiritualiste quelconque, mais l'annonce des vérités particulières du christianisme, autrement dit les traces d'une révélation primitive dès la plus haute antiquité. Si cette démonstration pouvait être faite, tous les arguments des philosophes devaient tomber. Mais cette démonstration ne pouvait être faite qu'en interprétant symboliquement les anciens livres chinois. C'est donc la théorie 


\section{La Chine et la formation de l'esprit philosophique en France}

des théologiens et des philosophes symbolistes ou comme dira Fréret « figuristes » qu'il nous faut maintenant examiner.

\section{III. - Les Figuristes}

p.347 Lorsque certains Jésuites essayèrent d'expliquer symboliquement les anciens livres de la Chine, pour y découvrir, non le sens vulgaire ou la réalité historique que les Chinois croyaient y trouver, mais les mystères les plus secrets du christianisme, ils s'efforcèrent de montrer que le texte chinois pouvait avoir deux sens, un sens apparent que les Chinois interprétaient d'une manière fautive parce qu'ils étaient ignorants du christianisme, et un sens religieux que les missionnaires seuls étaient capables de comprendre parce qu'ils en avaient la clef, à savoir la Bible. Dépouiller les anciens textes de leur enveloppe extérieure, de leurs symboles, de leurs figures, pour permettre d'arriver jusqu'au sens enveloppé mais véritable, ruiner la lettre pour pénétrer l'esprit, telle fut l'intention des Jésuites « figuristes ». Pour eux, il ne s'agissait plus de montrer chez les anciens Chinois une croyance vague à une divinité quelle qu'elle fût, mais de faire apercevoir dans les anciens textes chinois le christianisme pour ainsi dire préformé et annoncé bien qu'en termes enveloppés.

Ils avaient été devancés dans cette voie par Pascal, qui par le système des « figuratifs » avait voulu montrer que l'Écriture pouvait avoir deux sens, ce qu'il appelle le sens «charnel», 


\section{La Chine et la formation de l'esprit philosophique en France}

auquel les Juifs, préoccupés uniquement des réalités matérielles s'étaient laissé prendre, et l'autre le sens spirituel, en apparence contraire au premier. Or dans la dialectique de Pascal ce système des figures est une preuve de la vérité de l'Écriture parce qu'il explique les « contradictoires ». Soit par exemple la loi et les sacrifices au sujet desquels l'Écriture rapporte des affirmations contradictoires $\mathrm{Si}$ le sens littéral est vrai on pourra conclure, suivant les textes, que les sacrifices plaisent ou déplaisent à Dieu. Mais en admettant le système des figuratifs, tout s'éclaircit, car on comprend dès lors que les sacrifices qui déplaisent à Dieu sous leur forme matérielle lui plaisent par I'esprit qui les vivifie, si bien que dans cette contradiction même nous trouvons une preuve de la vérité de l'Écriture qui est capable d'en rendre compte.

Ce principe des figuratifs qui aveugle ceux qui aiment « les choses figurantes » et qui éclaire ceux qui cherchent les « figurées »1. p.348 Pascal semble avoir voulu l'appliquer à I'histoire profane. C'est du moins l'explication que I'on peut donner du fragment où il paraît avoir aperçu l'importance de I'ancienne histoire chinoise, favorable aux libertins si on la prend à la lettre, favorable au christianisme au contraire si elle est interprétée selon le système des figuratifs :

«(Lequel est le plus croyable des deux, Moïse ou la Chine).

« Il n'est pas question de voir cela en gros ; je vous dis qu'il y a de quoi aveugler et de quoi éclairer.

\footnotetext{
1 Pascal, Pensées, fragment 685, t. III, p. 123-4.
} 


\section{La Chine et la formation de l'esprit philosophique en France}

«Par ce seul mot, je ruine tous vos raisonnements. Mais la Chine obscurcit, dites-vous, et je réponds : La Chine obscurcit, mais il y a clarté à trouver, cherchez-la »1.

Si Pascal employa cette méthode des figuratifs, chère aux rabbins, c'est comme le remarque le savant éditeur des Pensées qu'il voulait battre les théologiens juifs sur leur propre terrain et opposer à leur système figuratif de I'Ancien Testament un système semblable prouvant par des figures la vérité du Nouveau Testament déjà figuré dans I'Ancien. Mais ce système n'était pas inconnu dans la théologie catholique ni surtout dans la théologie janséniste 2 .

En dehors de la théologie, dans la seconde moitié du XVII siècle, les critiques et les poètes eux-mêmes ont une tendance à donner une explication allégorique des poèmes de I'antiquité. Les poètes et les philosophes anciens ne sont plus seulement des sages qui par une intuition qui leur est personnelle ont mieux compris que les autres hommes les principes de la loi naturelle, mais ils sont comme le prétend le P. Thomassin, des garants de

${ }^{1}$ Id., ibid., fragment 593, t. III, p. 33.

2 L. Brunchwig dans son Introduction aux Pensées de Pascal (p. xcII-xcIII) indique que le caractère figuratif de la loi juive est une doctrine fondamentale de Saint-Paul, de Saint-Augustin, de Jansenius, et il rappelle que I'Histoire de la Bible de Nicolas Fontaine, connue sous le nom de Bible de Royaumont, est « d'un bout à l'autre présentée comme un système de figuratifs. » Longtemps auparavant le poète Charles Fontaine, l'auteur du Quintil Horatian, avait publié à Lyon chez Jean de Tournes les Quadrins historiques de la Bible (1558) où chaque quatrain était illustré suivant un principe que l'auteur expliquait ainsi dans son Avis au Lecteur : « Et quand ce ne seroit que pour témoignage et te réduire à mémoire que tout le Vieil Testament n'estoit que I'image et figure de celui que nous tenons, je te l'ay bien voulu figurer ici : à cette fin aussi que ayant souvent devant tes yeux I'histoire de la vie des saincts Patriarches tu puisses si bien conformer la tienne a leur exemple qu'elle soit à l'accomplissement de la volonté de Dieu et de ton salut. Ainsi soit. 》 


\section{La Chine et la formation de l'esprit philosophique en France}

la vérité judéo-chrétienne, parce qu'ils ont pu recueillir par la tradition « beaucoup de restes de la Théologie des Patriarches avant le Déluge ». Cette tradition qui s'est conservée par Noé, plus de trois cents ans avant le Déluge et par Sem qui vit les

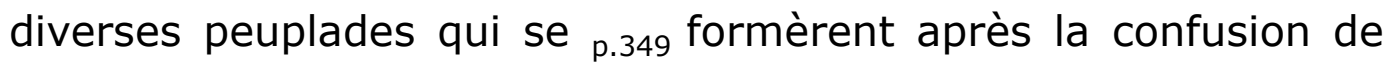
Babel a été fortifiée, amplifiée ensuite par les enfants de Noé, par les fils et les petits-fils de ses enfants, ce qui nous mène jusqu'à l'âge d'Homère ou peu s'en faut. « Mais ces poètes ou philosophes n'ont pas toujours puisé à des sources pures, car ils ont été parfois inspirés par les « Démons » qui en «profanes imitateurs de la Divinité ont pu leur communiquer ce qu'ils sçavoient des mystères de la véritable Religion et les porter à les contrefaire dans leurs Poésies »1. En débarrassant ces fables de leur enveloppe extérieure on peut donc arriver à saisir des vérités originelles, si bien que les poètes de l'antiquité, bien interprétés, deviennent de véritables Prophètes. Aussi le P. Thomassin n'hésite pas à écrire : « La philosophie profane a appelé Sages ou Philosophes ceux que l'Écriture nomme prophètes $\gg 2$. L'Iliade, par exemple, pour qui sait la lire et l'interpréter comme il sied, n'est pas un poème plein d'histoires fabuleuses et qui choquent la raison, c'est au contraire un livre plein d'enseignements «Si Hector fait un discours à ses chevaux pour les amener au combat, cet exemple peut avoir esté

\footnotetext{
1 Thomassin, Méthode d'étudier et d'enseigner chrétiennement les poètes, $\mathrm{t}$. I, p. 219-220.

2 Id., Méthode d'étudier et d'enseigner chrétiennement et solidement la Philosophie par rapport à la Religion chrestienne et aux Escritures, p. 61.
} 


\section{La Chine et la formation de l'esprit philosophique en France}

emprunté de l'entretien d'Eve avec le serpent »1. Quant à l'épisode du cheval d'Achille qui parle à son maître, par la permission de Junon, pour lui annoncer l'époque de sa mort, c'est l'équivalent de l'épisode de l'Ange ouvrant la bouche de I'ânesse et s'en servant pour instruire Balaam ${ }^{2}$.

La Querelle des Anciens et des Modernes n'eut pas seulement pour conséquence de poser et de préciser l'idée de progrès sur laquelle s'appuyaient naturellement les Modernes pour soutenir leur cause, elle eut aussi ce résultat d'accentuer chez les partisans des anciens la tendance à l'explication allégorique des fables anciennes et notamment du poème épique ${ }^{3}$. Les Modernes, disaient Perrault et Fontenelle, ont toutes les idées des Anciens et en outre toutes celles qui ont pu être acquises par I'humanité au cours des siècles. Donc ils sont supérieurs aux Anciens par le seul fait qu'ils sont les Modernes. Vérité qui serait incontestable, répondaient le partisans des Anciens, si certaines vérités ne se perdaient pas en route et s'il était démontré que la vérité peut être découverte par ${ }_{\text {p.350 }}$ un effort constant de I'intelligence humaine. Mais si la vérité est au point de départ et non au terme de l'humanité ? Dans ce cas les sages, les philosophes, les poètes de l'antiquité ne peuvent-ils donc mieux que les Modernes donner des idées justes sur la religion et sur la morale ? «Ils ont enfermé dans des fictions, disait Massieu en 1706, à I'Académie des Inscriptions, presque tous les secrets de

\footnotetext{
1 Méthode d'étudier chrétiennement les poètes, t. I, p. 341.

2 Id., ibid., t. I, p. 345.

3 Voir les textes et les références rassemblés par Lombard, La Querelle des Anciens et des Modernes, p. 21, et Id., L'Abbé du Bos, p. 185.
} 


\section{La Chine et la formation de l'esprit philosophique en France}

la théologie, de la morale et de la physique »1. C'est en vertu de ce principe que $\mathrm{M}^{\mathrm{me}}$ Dacier dans la préface de sa traduction de I'Iliade faisait d'Homère un élève du roi Salomon et que son mari s'efforçait de retrouver dans les paiens les vestiges de l'Écriture sainte $\gg 2$.

Les Jésuites qui partirent en Chine en 1685, comme le P. Bouvet, et ceux qui partirent un peu plus tard comme le P. de Prémare, bons humanistes s'il en fut, ne pouvaient ignorer cette tendance des esprits qui depuis Scudéry et sa préface d'Alaric et surtout depuis le Traité du poème épique, du P. Le Bossu, voulaient retrouver dans les poèmes de l'antiquité une inspiration nettement chrétienne. Qu'ils aient été tentés d'appliquer le même principe à l'interprétation des Livres primitifs de la Chine il n'y a guère lieu de s'en étonner, d'autant plus que l'intérêt de la mission les y incitait encore ! S'ils arrivaient en effet à démontrer à l'Empereur et aux Lettrés chinois que les Livres sacrés de la Chine, dépouillés des interprétations et des gloses postérieures que des commentateurs ignorants des vérités premières y avaient ajoutées, contenaient les mêmes prophéties que I'Ancien Testament, l'Empereur et avec lui tous les Lettrés ne pourraient que se convertir en voyant dans le Nouveau Testament la réalisation des prophéties de leurs anciens Livres, et ainsi seraient confondus tous les libertins d'Europe.

${ }^{1}$ Lombard, l'Abbé du Bos, p. 185.

2 Rigault, La Querelle des Anciens et des Modernes, p. 362-3. 


\section{La Chine et la formation de l'esprit philosophique en France}

Il y eut donc toute une école de Jésuites missionnaires en Chine qui voulurent prouver, par l'étude des anciens livres chinois, non la vérité d'une religion spiritualiste quelconque, mais la vérité du christianisme, annoncé, prophétisé dès les origines du monde dans ces livres primitifs où se retrouve la sagesse des patriarches et les révélations faites par Dieu aux premiers hommes. Pour que cette théorie fût valable, il fallait admettre deux postulats, le premier que l'écriture chinoise était une écriture hiéroglyphique, dissimulant sous ses symboles des vérités religieuses essentielles qui échappaient aux Chinois les plus savants, parce qu'ils manquaient de la clef nécessaire pour les interpréter, à savoir la révélation, et p.351 le second que les faits rapportés par les Livres sacrés de la Chine n'étaient pas des faits particuliers à I'histoire chinoise, comme le croyaient les commentateurs, mais des faits plus généraux qui étaient I'histoire de l'origine du monde et des hommes. Sur le premier point il n'y avait guère de difficulté, car tout le monde ignorait alors le véritable caractère de l'écriture chinoise et l'on pouvait y voir à volonté, suivant sa fantaisie ou ses théories, ou la langue originelle de I'humanité, ce que I'on appelait alors la languemère, ou une langue dérivée de I'hébreu, ou une altération de caractères hiéroglyphiques égyptiens. Seuls Leibniz et Fréret supposèrent que l'écriture chinoise était une écriture idéographique, mais cette supposition qui n'était pas étayée de faits assez sûrs n'avait que la valeur d'une hypothèse au milieu des autres hypothèses. Le second point était plus difficile à admettre, parce qu'il fallait pour cela nier la chronologie chinoise dont les Jésuites de Pékin s'efforçaient précisément de marquer 


\section{La Chine et la formation de l'esprit philosophique en France}

l'exactitude par la concordance entre les détails rapportés dans les anciennes histoires et les vérifications des astronomes modernes.

Ces deux axiomes posés, il ne restait plus qu'à démontrer au moyen de l'interprétation symbolique des caractères que les principaux mystères du christianisme se trouvent annoncés dans les anciens livres chinois : « Si j'avois loisir d'entrer ici dans quelque détail, écrivait le P. Bouvet à Leibniz ${ }^{1}$, vous auriez le plaisir d'apprendre par la lecture de cette lettre que le système presqu'entier de la vraye Religion se trouve enfermé dans les livres classiques des Chinois; et que les principaux mistères de I'Incarnation du Verbe, de la vie et de la mort du Sauveur et les principales fonctions de son saint ministère sont contenues comme d'une manière prophétique dans ces précieux monumens de l'antiquité chinoise. Vous seriez étonné aussi bien que moi, de voir que ce n'est que comme un tissu continuel d'ombres, de figures ou de prophéties des vérités de la loi nouvelle ». Et le P. de Prémare lui non plus n'hésite pas à prétendre que les livres chinois sont des livres inspirés : «Par ce seul système [le système d'interprétation symbolique des livres chinois] non seulement on sauve les livres King, mais ce qui est plus

\footnotetext{
1 Kortholt, op. cit., p. 78-9.
} 


\section{La Chine et la formation de l'esprit philosophique en France}

important, on les élève après des ténèbres de tant de siècles, au rang des Livres Prophétiques »1.

p.352 Mais lorsqu'ils parlent de livres prophétiques, ni le P. Bouvet, ni le P. de Prémare ne pensent que ces livres ont été inspirés par le Saint-Esprit au moment où ils ont été composés ; ils croient tous deux que ces livres sont prophétiques en ce sens qu'ils transmettent les enseignements de la révélation primitive. Le P. Bouvet essayait de démontrer que sous le nom de Fou-hi, auteur de I'Yi-King, ce livre mystérieux, on devait reconnaître le patriarche Henoch, et le P. Prémare allait encore plus loin, car rappelant la tradition d'après laquelle Seth, longtemps avant Enoch, inventa l'écriture et composa des livres, il ajoutait que Henoch n'a fait que rassembler des traditions orales antérieures dont l'origine remonterait à Seth ou même à Adam 2.

Les PP. Bouvet et de Prémare concluaient de cette interprétation symbolique des livres chinois, non seulement que les anciens Chinois avaient été monothéistes, mais que les Lettrés modernes mêmes ne sont pas athées. En cela ils se distinguaient de leur confrère en symbolisme, le P. Foucquet qui,

\footnotetext{
1 Vestiges des principaux dogmes chrétiens tirés des anciens Livres chinois, $\mathrm{p}$. 475. Cet ouvrage, dont I'original est en latin, est daté : Cantone, die 21 mai anno 1725. De nombreuses années auparavant, le $P$. de Prémare, dans une lettre adressée au P. Verjus le 25 octobre 1707, essayait de démontrer que les anciens livres chinois contenaient les deux dogmes essentiels du christianisme : un Dieu créateur et Seigneur de toutes choses et un Dieu sauveur de tous les hommes. Il prétendait même que « si on mettait sur une colonne tous nos dogmes fondamentaux » et si on développait tant soit peu les principaux endroits des King, où ces mêmes dogmes se trouvent marqués d'une manière comme prophétique et divine on retrouverait dans cette seconde colonne «le plan tout entier de notre Ste Religion. » B. N. $-N$. A. Lat. 156 , f. 20-2.

2 De Prémare, Vestiges..., p. 27. Cf. aussi, du même missionnaire, Catalogue de livres chinois. B. N. - N. A. Fr. 4754, f. 8.
} 


\section{La Chine et la formation de l'esprit philosophique en France}

lui, était persuadé de l'athéisme des Lettrés modernes et de I'idolâtrie des cérémonies cultuelles. Les PP. Bouvet et de Prémare purent donc rester dans leur ordre puisqu'ils partageaient les idées de leurs confrères sur l'interprétation des cultes chinois mais leurs théories symbolistes les rendirent suspects, et, comme nous l'avons vu, ils ne trouvèrent jamais de réviseurs pour obtenir un permis d'imprimer. Et cependant ils étaient convaincus que la démonstration - indéniable à leur avis qu'ils faisaient de leur théorie, non seulement devait enlever aux esprits forts un argument précieux, l'argument de l'athéisme des Chinois ${ }^{1}$, mais en outre prouver contre les hérétiques I'unité de l'Église et I'universalité du catholicisme. « [Cela] fera voir, écrivait le P. Bouvet en envoyant en France un de ses écrits, que les Prophètes et les Saints docteurs de la loy naturelle doivent

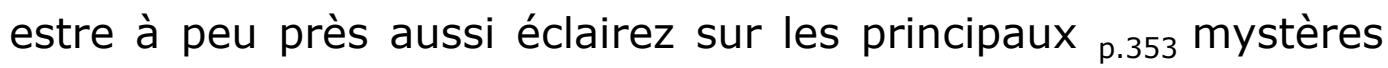
de la loy de Jésus-Christ que I'ont esté les Saints Pères et que l'Église, que le fils de Dieu a établie sur la terre, est véritablement catholique et universelle aussi bien pour tous les tems que pour tous les lieux du monde $\gg 2$.

Malgré ces belles espérances pour la religion, et pour le christianisme en particulier, que laissaient entrevoir les figuristes, si l'on acceptait leurs méthodes d'exégèse des anciens livres chinois, leurs théories eurent peu de succès. Non seulement ils se heurtèrent à l'opposition de l'école historique des missionnaires de Pékin, mais leurs théories ne furent pas du

\footnotetext{
1 De Prémare, Lettre à l'abbé Raguet, 24 novembre 1731. B. N. - N. A. Fr. 4756, f. 1.

2 Lettre du 15 septembre 1704. B. N. Fr. 17210 , n 4, f. 2.
} 


\section{La Chine et la formation de l'esprit philosophique en France}

tout goûtées de leurs confrères et de leurs supérieurs de Paris. Sans doute, la condamnation de la Sorbonne suggérait-elle la prudence, car si le P. Le Comte avait soulevé contre lui toute une armée de théologiens pour avoir accordé aux Chinois quelquesuns des privilèges du peuple élu, l'antiquité du culte, les prophéties et les miracles, mais sans en apporter des preuves trop précises et trop convaincantes, combien plus grosse encore de polémiques et de violences théologiques était la théorie des PP. Bouvet et de Prémare, qui faisaient des Chinois les dépositaires des enseignements transmis par Dieu même à Adam et par Adam à Seth. Si vraiment Seth et Henoch étaient les deux premiers législateurs de la Chine, et s'ils étaient les auteurs de l'Yi-king qui contenait sous ses caractères symboliques I'annonce des vérités essentielles du judaïsme et du christianisme, quel air de nouveauté allait prendre l'Ancien Testament à côté des livres chinois antérieurs au Déluge, et combien jeune apparaîtrait Moïse à côté de Seth !

Mais d'autre part les théories des figuristes risquaient d'avoir des conséquences plus graves parce qu'elles semblaient favoriser le manichéisme. Manichée en effet examinant les idées religieuses et morales de I'Ancien Testament, trouvait que ces idées impures ou imparfaites étaient indignes de la Sainteté de Dieu, ou même fausses et injurieuses à Dieu. Il concluait de là que le Dieu des Hébreux n'était pas le vrai Dieu, que leurs Prophètes n'étaient pas de véritables Prophètes, ou enfin que leurs Livres avaient été corrompus par les Juifs ${ }^{1}$. Il pensait donc

\footnotetext{
${ }^{1}$ Beausobre, Histoire critique de Manichée et du manichéisme, t. I, p. 269.
} 


\section{La Chine et la formation de l'esprit philosophique en France}

que toutes les Nations avaient eu leurs Prophètes, et que par suite il n'y avait aucune raison de préférer les prophètes des Hébreux à tous les autres. En conséquence, il supposait que Seth, Henoch et d'autres patriarches, ayant été instruits par les bons Anges, avaient transmis à leurs p.354 descendants les vérités qu'ils avaient apprises, et que ces instructions s'étaient conservées, soit dans des Livres qui subsistaient encore, soit dans les écoles de philosophes orientaux de qui tous les autres avaient appris la sagesse ${ }^{1}$. Sans doute les Jésuites figuristes étaient bien loin d'être manichéens, mais, comme Manichée, ils semblaient déposséder le peuple juif de son privilège de dépositaire de la vraie religion et ils transféraient à un peuple oriental le dépôt de la sagesse première et des livres primitifs. Il est vrai qu'il restait en Europe, ou du moins en France très peu de manichéens, mais à en croire Voltaire, il en restait encore au moins un, même en 1759, et c'était le Docteur Martin.

En apparence les Jésuites figuristes n'eurent pas d'influence sur le public au XVIII ${ }^{e}$ siècle, puisque leurs écrits ne furent pas publiés. Mais leurs idées furent connues des savants avec lesquels ils étaient en correspondance, le P. Bouvet avec Leibniz, le $P$. de Prémare avec Fréret, Fourmont et très probablement Ramsay, si bien que cette influence s'exerça malgré tout, bien que par des intermédiaires. En revanche, ils trouvèrent un disciple inattendu dans le P. Lafitau, I'auteur des Mcurs des Sauvages Amériquains, qui appliqua à l'interprétation des

${ }^{1}$ Id.. ibid., Préface, p. XII. 


\section{La Chine et la formation de l'esprit philosophique en France}

mythes et des cérémonies des peuples primitifs les principes symbolistes des PP. Bouvet et de Prémare.

« Le P. Lafitau, nous dit, le P. Gaubil, à I'occasion de son livre sur les sauvages américains, eut grand rapport avec quelques Jésuites françois qui avoient un système singulier sur l'antiquité chinoise, les livres classiques et la mythologie chinoise »1. Le P. Gaubil ayant lu le livre du P. Lafitau lui dit ce qu'il pensait sur la méthode des figuristes « de même que sur son ouvrage des mœurs des sauvages ». Mais le P. Lafitau n'en tint pas compte, et son ouvrage publié, il en rédigea un autre beaucoup plus général «sur la religion révélée à nos anciens et dont on voit des vestiges dans toutes les nations $\gg 2$. Ce livre ne vit jamais le jour et le manuscrit a disparu.

p.355 Le P. Lafitau semble donc avoir été entièrement convaincu des principes des figuristes qui, croyant à une révélation primitive, pensaient qu'il était possible d'en trouver des « vestiges » chez tous les peuples à condition de dépouiller les textes, les mythes ou les cérémonies cultuelles de tout ce que l'ignorance ou les superstitions ont pu y ajouter ultérieurement. Mais pour l'Amérique, à laquelle le P. Lafitau voulait appliquer ces principes, il y avait une difficulté préliminaire qui tenait à

1 Cette lettre publiée par le P. Brucker, Correspondance scientifique d'un missionnaire, Revue du monde catholique, t. LXXVI, p. 376-7, précise d'une manière lumineuse la différence de méthode entre les figuristes et l'école historique, celle des PP. Gaubil, Parrenin, etc... qui dans les idées religieuses s'efforcent de découvrir l'époque à laquelle elles se sont introduites en Chine et le lieu d'où elles viennent : «Avec cette critique, ajoute le P. Gaubil, on voit souvent que ce qu'on appelle chinois, est dans son origine persan ou sabéen ou juif ou chrétien, mais habillé à la chinoise. »

2 Fragment de lettre du P. Gaubil. du 19 octobre 1752, Sommervogel, op. cit., t. IV, c. 1363. 


\section{La Chine et la formation de l'esprit philosophique en France}

l'ignorance où l'on se trouvait alors de la forme géographique de I'Amérique. C'est la difficulté à la laquelle on s'était heurté dès le XVII ${ }^{e}$ siècle. L'Amérique était-elle une île ? Mais dans ce cas quelles communications avait-elle pu avoir avec l'Asie, et comment avait pu se transmettre la révélation primitive ? Ou fallait-il admettre pour l'Amérique une création différente de celle d'Adam, ce qui ramenait à I'hypothèse des préadamites ? Le P. Lafitau crut que ce problème était résolu le jour où il trouva au Canada quelques exemplaires de cette plante chinoise le gin seng [Jen $\sin$ ] dont le P. Jartoux venait de célébrer les mérites dans le $X^{\mathrm{e}}$ Recueil des Lettres édifiantes et curieuses.

Cette trouvaille lui paraît une découverte essentielle, moins pour la plante elle-même que pour le nom qu'elle porte en chinois et en iroquois. En Chinois, gin seng veut dire «Ressemblance de I'homme » ou comme l'explique le traducteur du P. Kircher, «Cuisses de I'homme»; or en iroquois le nom de la plante est composé de deux mots dont l'un signifie « les cuisses et les jambes » et l'autre « deux choses séparées ». Et de cette analogie, dont le moins qu'on en puisse dire est qu'elle n'est pas très frappante, le P. Lafitau tire de très grandes conséquences : «Faisant alors la même réflexion que le $P$. Jartoux sur la bizarrerie du nom qui n'a été donné que sur une ressemblance fort imparfaite qui ne se trouve point dans plusieurs plantes de cette espèce et qui se rencontre dans plusieurs autres d'espèce fort différente, je ne pus m'empêcher de conclure que la même signification n'avoit pu être appliquée au mot chinois et au mot iroquois sans une communication d'idées et par conséquent de personnes. Par là je fus confirmé 


\section{La Chine et la formation de l'esprit philosophique en France}

dans l'opinion que j'avois déjà et qui est fondée sur d'autres préjugez que I'Amérique ne faisoit qu'un mesme continent avec I'Asie à qui elle s'unit par la Tartarie au nord de la Chine $\gg 1$.

Donc des relations de personnes ont pu exister entre l'Asie et p.356 l'Amérique, et la révélation primitive a pu se transmettre d'homme à homme entre les Chinois et les Américains. Il n'est donc pas impossible à priori de trouver des analogies entre les mythes chinois et les mythes des sauvages américains, comme on peut en trouver entre les mythes chinois et les mythes européens. Une mythographie comparée est donc possible en principe. Et non seulement possible mais souhaitable, car elle prouvera l'universalité des dogmes judéo-chrétiens.

Cette idée essentielle du P. Lafitau s'aperçoit dans le frontispice qu'il a imaginé pour son livre et dans la manière dont il I'a commenté. Une femme assise compare les différents monuments de l'antiquité des diverses parties du monde. «Deux génies rapprochent ces monuments les uns des autres, lui aident à faire cette comparaison, en lui faisant sentir le rapport qu'ils peuvent avoir ensemble ». C'est le consentement universel dans l'espace. « Mais, ajoute le P. Lafitau, le temps à qui il appartient de faire connoître toutes choses et de les découvrir à la longue, lui rend ce rapport encore plus sensible en la rappellant à la source de tout, et lui faisant comme toucher au doigt la connexion qu'ont tous ces monumens avec la première origine

1 Mémoire présenté à S. A. R. Mgr le Duc d'Orléans.,. concernant la précieuse plante du gin-seng de Tartarie, découverte au Canada, par le P. JosephFrançois Lafitau, p. 16-18. 


\section{La Chine et la formation de l'esprit philosophique en France}

des hommes, avec le fond de notre Religion et avec tout le système de révélation faite à nos premiers Pères après leur péché, ce qu'il lui montre dans une espèce de vision mystérieuse »1. Consentement dans le temps qui vient confirmer le consentement dans l'espace, c'était I'idée du P. Bouvet.

Reste à prouver ce consentement. Or, d'après le P. Lafitau, la foi nous enseigne et la raison nous dicte «qu'il ne peut y avoir qu'une Religion, et cette Religion étant pour les hommes, doit avoir commencé avec eux et doit subsister autant qu'eux $\gg 2$. Mais cette religion, pure et simple dans son origine, s'est déformée dans la suite des temps. Des fables diverses, selon les diverses nations, ont altéré le fond primitif. Il importe donc à I'historien de découvrir sous la diversité de ces fables quelque chose de permanent, et, s'il est habile, on verra « comment malgré l'altération de la religion, malgré les changemens qui s'y sont faits chez les différents peuples du monde, il s'y trouve néanmoins partout une certaine uniformité dans les fables qui ont rapport à la Vérité dans certains points de la morale et dans plusieurs observances légales qui supposent des principes semblables à ceux de la véritable ${ }_{\text {p.357 }}$ religion et dont on peut tirer des argumens très forts contre ceux qui l'ont altérée » 3 . Ceux qui ont altéré cette religion primitive, ce sont les ignorants qui n'ont pas compris que toutes les religions sont

\footnotetext{
1 Lafitau, Mœurs des sauvages amériquains, t. I, s. p.

2 Ib., ibid., Dessein et plan de l'ouvrage, p. 14-15.

${ }^{3}$ Id., ibid., p. 15-16.
} 


\section{La Chine et la formation de l'esprit philosophique en France}

hiéroglyphiques et que leur théologie est pleine de symboles, comme le prouvent les religions des Indes orientales et occidentales, mais ce sont aussi les athées qui ont trouvé avantage à tirer parti contre la religion de l'absurdité apparente des fables et des mythes.

Si I'on applique le principe symboliste du P. Lafitau pour l'interprétation de ces fables, on découvre, sous la diversité apparente, des idées communes et qui se rapportent toutes à la vraie religion. Par exemple si les Tybareniens se mettent au lit aux couches de leur femme « c'est une pratique de religion qui semble avoir une connexion naturelle avec le péché originel et qui paroist estre une pénitence pour les parens, instituée pour l'expiation de ce péché »1. Si de nombreux peuples ont adoré le feu, c'est qu'il « représente le mieux cette suprême intelligence dégagée de la matière $\gg 2$.

Ce n'est donc pas seulement l'éducation classique du P. Lafitau, comme le prétend Chinard 3, qui lui a fait chercher des comparaisons ou des assimilations audacieuses entre les fables des Américains et les fables de I'antiquité classique. Car ces comparaisons ou ces assimilations il va les chercher en Chine aussi bien qu'à Athènes ou à Rome. Quand par exemple les sauvages américains partent pour la guerre ils échangent leur robe ou leur couverture avec ceux qui restent au village. Cette

\footnotetext{
1 Id., ibid., t. I, p. 257.

2 Id., ibid., t. I, p. 252.

3 Chinard, L'exotisme américain dans la littérature française au XVIIe et au XVIIIe siècles, p. 320-1.
} 


\section{La Chine et la formation de l'esprit philosophique en France}

coutume semble au P. Lafitau avoir des analogies avec celle du départ d'un mandarin chinois à qui l'on enlève les bottes pour conserver quelque chose qui lui ait appartenu, et des analogies aussi avec cet échange mutuel de leurs armes que font Glaucus et Diomède dans I'Iliade avant de se combattre ${ }^{1}$. Les Mémoires de Trévoux dans le compte rendu qu'ils ont fait du livre du P. Lafitau ont clairement exposé le principe de sa méthode et nettement marqué ses intentions : «Comme il avoit consacré ses premières années à l'étude de l'ancien monde et de ce qu'on appelle l'Antiquité, il vit d'abord que les distances des lieux étant toutes analogiques aux distances des tems, les Américains se trouvoient à peu près dans le même point de vue pour p.358 nous et dans le même rapport de distance que les anciens Romains, Grecs, Gaulois, Perses, Curetes, Scytes, Sarmates lesquels, malgré les diversitez qu'on y trouve ou qu'on y imagine, ont toujours marché sur des lignes fort parallèles pour le fonds de la Religion, des Mœurs et mil usages civils et politiques $\gg 2$.

Il ne nous appartient pas de rechercher l'influence du livre du P. Lafitau sur les philosophes qui ont cru à la vertu des sauvages et qui ont pensé trouver dans l'étude des civilisations primitives les idées essentielles de I'humanité et des vertus naturelles que la civilisation n'était pas venue oblitérer ${ }^{3}$. Ils ont sans doute tiré de ce livre des conclusions auxquelles le P. Lafitau n'aurait pas souscrit. Mais il est certain qu'il a contribué à détruire la notion

\footnotetext{
${ }^{1}$ Lafitau, op. cit. , t. II, p. 192-3.

2 Mémoires de Trévoux, septembre 1724, p. 1569-70.

3 Cf. Chinard, op cit., p. 324-5.
} 


\section{La Chine et la formation de l'esprit philosophique en France}

du sauvage, du barbare inculte qui ne présente aucun intérêt pour le civilisé. Il a fait du sauvage le témoin d'une très ancienne civilisation, un témoin sans doute qui ignore la valeur du témoignage qu'il apporte mais qui a conservé malgré tout, sans le savoir, dans ses mythes et dans ses traditions qu'il ne sait même plus interpréter, le souvenir des origines de I'humanité. D'autre part, les influences subies par le P. Lafitau, et par suite la genèse de ses idées nous permettent de constater que la théorie de la religion des peuples primitifs n'est pas une hypothèse philosophique admettant que Dieu est révélé immédiatement à la conscience de tous les hommes, mais une hypothèse théologique, se prétendant appuyée sur I'histoire et d'après laquelle tous les peuples, si anciens qu'ils soient, et quel que soit leur éloignement du berceau de I'humanité, ont conservé même sans le savoir, la révélation qui a été faite aux premiers hommes.

Ramsay lui aussi fut un disciple du P. de Prémare. Sans doute nous ne voulons pas dire par là qu'il fut uniquement le porteparole du missionnaire symboliste ; il a subi l'influence de toute la lignée des théologiens ou des philosophes qui ont cru à la vertu des Payens, de tous ceux qui ont cherché chez les Poètes et les philosophes du paganisme des traces d'une foi en un Dieu distinct de la matière, d'une croyance en la Providence et en l'immortalité de l'âme. Le P. de Prémare d'ailleurs avait subi lui aussi l'influence de tous les Jésuites qui ne fermaient pas aux Payens les portes du Ciel, et des théologiens comme le $P$. Beurrier qui voulaient prouver aux impies et aux libertins la vérité du christianisme en s'efforçant de montrer l'antiquité de ses dogmes. Mais à l'époque où p.359 Ramsay publiait ses 


\section{La Chine et la formation de l'esprit philosophique en France}

Voyages de Cyrus, il ne s'agissait pas seulement d'invoquer la tolérance en faveur des Païens qui s'étaient moralement bien conduits, ni de montrer par des citations des poètes du paganisme que le christianisme n'était pas contraire à la raison, puisque les plus grands des poètes ou des penseurs de I'antiquité païenne avaient pu trouver par les seules forces de leur raison, des idées se rapprochant des dogmes judéochrétiens ; il fallait en outre, contre Bayle, Toland, Levesque de Burigny et autres, montrer que l'athéisme n'était pas congénital à I'homme et d'autre part, contre les déistes, montrer que l'on retrouve dans les annales des peuples primitifs non les traces d'une religion spiritualiste quelconque, mais, sous forme enveloppée l'annonce des vérités essentielles du christianisme, la loi des trois états successifs de l'homme et l'annonce du Rédempteur.

Le P. de Prémare fut enthousiasmé par les Voyages de Cyrus : «Puisque vous estes des amys de M. Ramsay, écrit-il à Fréret, le 20 septembre $1731{ }^{1}$, vous me ferez un grand plaisir de luy présenter mes très humbles respects. Son livre me paroit en vérité un chef-d'œuvre. Rien de mieux écrit, rien de plus solide, rien de plus nécessaire dans un tems où la religion est en danger de se perdre. Mentor apprend à un jeune prince la fable des Grecs et l'art de régner. M. Ramsay en instruisant Cyrus instruit I'univers dans ce qu'il y a de plus indispensable qui est la religion. Mais la manière dont il instruit me paroit tenir de celle d'Homère. La vérité entre bien agréablement dans l'esprit quand

1 Obs. Astr. A B ${ }^{1} 10(150-4,9)$. 


\section{La Chine et la formation de l'esprit philosophique en France}

on la propose sous des enveloppes si charmantes. Circée avoit un breuvage pour changer les hommes en bêtes, et M. Ramsay en a un encore plus puissant pour changer les hommes impies en de parfaits chrétiens $\gg 1$.

Ce ne sont pas seulement les mérites littéraires que le $\mathrm{P}$. de Prémare loue chez Ramsay, mais ce sont aussi et surtout les mérites de l'apologie du christianisme contre les athées et les déistes. « J'ay esté charmé, écrit-il, à Fourmont le 27 août 1732, de trouver dans les voyages de Cyrus les trois états de la nature humaine si p.360 bien marquez dans les précieux restes de la théologie de toutes les anciennes et les plus célèbres nations de I'univers sans en excepter la chinoise par laquelle finit le beau discours qui est à la fin. J'ay été seulement affligé de voir qu'on ne fait qu'effleurer une si belle et si abondante matière... Ce n'est pas une petite joye pour moi de voir que dans un ouvrage parfaitement bien écrit comme celuy-la on confond les athées et les déistes par le témoignage des plus anciennes nations du monde et, ce qui est encore plus consolant, on fasse voir que depuis la chute d'Adam le dieu homme a toujours esté l'espérance des hommes... Il y a plus de trente ans que je fouille dans les vieux monuments qui ne se trouvent qu'icy et je me

\footnotetext{
1 Tous les contemporains n'ont pas été de cet avis, témoin cette opinion inédite - de Bouhier : « Il faut estre fou... de vouloir faire une espece de second tome de Télémaque. Ce sont des ouvrages originaux que personne n'imitera, non plus que les Fables de votre ami La Fontaine. Ramsay fait comme ces valets de chambre qui après avoir eu la garde robe de leurs maitres veulent se parer de leurs habits. Mais ils ne peuvent attraper ni leur air ni leur taille. C'est justement le rôle de Mascarille dans les Précieuses Ridicules. 》 Rouhier à Marais, 22 décembre 1727, B. N. Fr. 25541, f. 178, vº $179, r^{\circ}$.
} 


\section{La Chine et la formation de l'esprit philosophique en France}

suis toujours proposé le même dessein qu'a eu M. Ramsay en ramassant les antiques traditions de l'univers $\gg 1$.

Les Jésuites symbolistes de Chine ne furent donc pas scandalisés des audaces philosophiques de Ramsay, comme le furent certains critiques en France, bien au contraire ils durent trouver en lui un allié contre l'athéisme, voire contre le déisme et ils avaient de bonnes raisons pour le croire, puisque c'était le P. de Prémare qui avait fourni les éléments du Discours sur la mythologie qui traite des mythes des anciens Chinois et où I'on retrouve les deux idées essentielles que ce Discours expose et que le livre illustre, à savoir que les philosophes de tous les temps et de tous les pays ont eu l'idée d'une Divinité suprême, distincte de la matière, et que « les vestiges des principaux dogmes de la Religion révélée sur les trois états du monde se rencontrent dans la théologie de toutes les nations »2. Ramsay dit en effet que pour étendre son enquête sur la mythologie des anciens peuples jusqu'en Extrême-Orient il s'est adressé « à ceux qui entendaient la langue de ce Pays, qui y avoient demeuré plusieurs années de suite et qui en avoient étudié les livres originaux ». Mais ce n'est pas aux Jésuites de Pékin qu'il s'est adressé, c'est aux Jésuites symbolistes de Canton.

Une phrase importante du Discours sur la Mythologie qui résume la doctrine de Ramsay se retrouve, sous une forme un peu abrégée, comme épigraphe d'un manuscrit du P. de Prémare

\footnotetext{
1 B. N. Fr. 15195 , f. $63-4$.

2 Ramsay, Voyages de Cyrus, t. II - (pagination spéciale pour le Discours) p. 1-2.
} 


\section{La Chine et la formation de l'esprit philosophique en France}

Lettre sur le monothéisme des Chinois. Ramsay avait écrit « Une fausse idée sur la Divinité ne forme point l'athéisme, ce qui constitue l'athée n'est pas de soutenir avec les Stoïciens que l'étendue et la p.361 pensée peuvent être des propriétés de la même substance, ni avec Pythagore et Platon que la matière est une production éternelle de la Divinité. Le véritable athéisme consiste à nier qu'il y ait une intelligence souveraine qui ait produit le monde par sa puissance et qui le gouverne par sa sagesse $\gg 1$. Le P. de Prémare met en épigraphe cette formule plus concise qui ne cherche à justifier ni les Stoïciens, ni Pythagore, ni Platon : «Une fausse idée sur la Divinité ne forme point l'athéisme. Le véritable athéisme consiste à nier qu'il y ait une intelligence souveraine qui ait produit le monde par sa puissance et qui le gouverne par sa sagesse »2. Mais il nous est impossible de savoir si Ramsay a développé une formule du P. de Prémare en I'aggravant, ou si au contraire le P. de Prémare n'a

\footnotetext{
${ }^{1}$ Id., Discours sur la Mythologie, p. 81-2.

${ }^{2}$ Les Voyages de Cyrus, dont le privilège est du 8 mai 1727, ont dû paraître dans les derniers mois de 1727. Le manuscrit du P. de Prémare qui porte cette épigraphe est daté du 10 septembre 1728, il est donc très douteux que l'ouvrage de Ramsay ait pu lui parvenir à cette date. D'ailleurs les lettres que nous avons citées et dans lesquelles le P. de Prémare vante les intentions de I'auteur de Cyrus sont datées de 1730 et 1731 . Il y a donc eu entre Ramsay et le P. de Prémare des relations plus étendues qui nous échappent. Mais d'après les textes que nous avons confrontés on ne saurait douter de ces relations.
} 


\section{La Chine et la formation de l'esprit philosophique en France}

fait que condenser et atténuer une phrase de Ramsay ${ }^{1}$. Peutêtre le $P$. de Prémare n'eût-il pas pris sur lui de considérer comme inoffensives ou l'idée de l'âme du monde des Stoïciens ou celle de l'éternité de la matière de Pythagore et de Platon.

Cette différence qui n'est pas négligeable est peut-être ce qui sépare un Jésuite, même figuriste, d'un franc-maçon. Mais à cet égard nous en sommes réduit, comme $A$. Chérel, aux conjectures 2 .

L'idée générale de Ramsay sur les trois états successifs du monde, dont il s'efforce de rechercher des traces dans les livres chinois ${ }_{\text {p.362 }}$ à la suite du P. de Prémare ne fut pas du goût de ses contemporains. Desfontaines et Granet dans leurs Entretiens sur les voyages de Cyrus, remarquent que « cette doctrine des trois états quoique révélée dans l'Écriture n'étoit connue que de peu de Juifs et que le Peuple de Dieu en général n'avoit pas sur cela des idées bien distinctes $\gg 3$.. Et Montesquieu, dans une note

1 Dans sa Défense de la chronologie, qui est postérieure aux Voyages de Cyrus, Fréret semble avoir voulu critiquer les opinions de Ramsay. Il prétend en effet que les Stoïciens « avec leurs discours spécieux sur la vertu et sur la Providence, ramenoient tout au Physique et à la fatalité d'une force aveugle et nécessaire » et qu'en réalité ils « avoient les mêmes principes que les Hylozoïstes établissant l'unité de l'Estre » (p. 259). C'était donc des matérialistes. Quant aux théories pythagoriciennes ou platoniciennes, où I'on croit voir des analogies avec les dogmes chrétiens, c'est en réalité la transposition métaphysique de certaines idées religieuses qui provenaient des Égyptiens et que les philosophes pythagoriciens et platoniciens furent dans l'obligation de formuler pour défendre l'ancienne religion contre les chrétiens. (Ibid., p. 3634 ). Les Stoïciens ne peuvent donc pas plus servir à improuver le fait de l'athéisme allégué par Bayle que les Pythagoriciens et les Platoniciens ne peuvent être invoqués en faveur de l'universalité dans les métaphysiques du paganisme, des dogmes judéo-chrétiens.

${ }^{2}$ Albert Chéret, André-Michel Ramsay, p. 163.

3 P. $107-8$. 


\section{La Chine et la formation de l'esprit philosophique en France}

énigmatique, où il insinue que Fréret partageait les idées de Ramsay sur cette loi des trois états repousse cette doctrine mais sans en donner de raisons : «C'est mal à propos que M. de Ramsay, Fréret et les siens font leur système de l'idée des trois états de I'homme chez tous les peuples : de la félicité et innocence, de la dégradation et corruption après la chute, et de la réparation ${ }^{1}$. Si le rédacteur du Journal des Sçavans voyait dans cet ouvrage de Ramsay, et notamment dans la Dissertation sur la Mythologie un « germe de tolérantisme », la démonstration de Ramsay permettant une confusion, favorable aux libertins, entre « le foible ressouvenir d'une révélation presque oubliée », et « le progrez d'une opinion qui s'établit peu a peu »2, Desfontaines, même après les arguments des défenseurs de Ramsay, et même après la préface justificative de l'édition de Londres établissait l'impossibilité de trouver dans le consentement universel des peuples un argument décisif en faveur du spiritualisme chrétien ${ }^{3}$. L'année suivante le Nouvelliste

\footnotetext{
1 Montesquieu. Pensées et fragments inédits, t. II, p. 201. Bien que Fréret ait laissé publier une Lettre sur la chronologie à la suite des Voyages de Cyrus, nous n'avons trouvé dans ses œuvres ou dans ses papiers inédits aucune indication qui puisse laisser supposer qu'il ait partagé les idées de Ramsay sur les trois états successifs du monde. Il n'aimait pas les Jésuites figuristes (comme le prouve sa correspondance avec le P. Gaubil) qui faisaient de cette doctrine des trois états le principe essentiel de leur méthode dans leurs recherches sur les antiquités chinoises. Et d'autre part lorsqu'il n'écrivait que pour lui-même, comme dans cet examen critique de la préface du Sinarum Philosophus du P. Couplet, il cherchait dans les anciens livres chinois non des preuves d'une révélation primitive mais des arguments en faveur de I'athéisme comme Bayle et Levesque de Burigny. Reste à savoir ce que Montesquieu entend par l'expression : Fréret et les siens. A cet égard nous ne pouvons même pas proposer une conjecture. Le seul fait qui soit certain est que Montesquieu n'aimait pas Fréret, et mettait même en doute sa science, qui pourtant est incontestable. (Cf. Correspondance, L. I, pp. 77-8).

2 Journal des Sçavans, février 1728. Ed. de Paris, p. 111.

3 Nouvelliste de Parnasse, Lettre XX, t. II, p. 138-141.
} 


\section{La Chine et la formation de l'esprit philosophique en France}

du Parnasse, c'est-à-dire Desfontaines, rendant compte du livre de Silhouette Idée générale du Gouvernement et de la Morale des Chinois, inspiré par le P. Tournemine, reprochait à l'auteur de n'avoir pas admis l'idée de l'athéisme des Chinois : «Ce qui m'a donné lieu de lui reprocher cet entortillement est sa manière de révoquer en p.363 doute l'athéisme des Lettrés de la Chine. Comme ce qu'il ajoute dans sa réponse n'est qu'un amas de vaines subtilités, permettez-moi de n'entrer dans aucun détail et de vous renvoyer à des témoins ingénus et non suspects qui les déclarent hautement athées. Vous trouverez leurs propres paroles dans le tome I de I'Histoire de la Philosophie Païenne, p. 22. Ce témoignage historique est préférable à toutes les imaginations d'un jeune écrivain $\gg 1$. Il était donc entendu que les Chinois étaient athées ; prétendre le contraire semblait même un paradoxe qui n'avait pas besoin d'être combattu. Ainsi s'évanouissait l'argument du consentement universel, de quelque manière qu'il fût présenté.

Il semble bien après 1730 que le fait de l'athéisme des Chinois soit considéré comme démontré. La preuve en a été faite non seulement par des philosophes comme Bayle, mais par des théologiens ennemis des Jésuites comme Renaudot, qui se sont plu à rechercher dans les écrits mêmes des Jésuites des faits tendant à prouver cet athéisme. En 1739, d'Argens, dans ses Lettres chinoises, tout en protestant qu'il a rendu presque tous ses Chinois très bons Déistes, ne peut cacher que l'un de ses Lettrés chinois professe l'athéisme, « puisqu'il est certain que

\footnotetext{
${ }^{1}$ Nouvelliste du Parnasse, Lettre XXXVIII, t. III, p. 143.
} 


\section{La Chine et la formation de l'esprit philosophique en France}

plusieurs savans chinois font profession de l'être [athées] et que leur nombre en est si considérable que $M$. de la Croze a prétendu que les Lettrés étoient athées, qu'ils admettoient ainsi que les anciens Égyptiens une force aveugle répandue dans tout I'Univers qui le vivifioit et le gouvernoit et que leur Li n'étoit que le chaos ou la matière première ${ }^{1}$. Il va sans dire que d'Argens se croit obligé de faire réfuter par un de ses Lettrés les doctrines athées de la Chine, mais cette réfutation précède l'exposé de la doctrine 2 : de cette manière l'aiguillon a plus de chance de rester dans la plaie. Il critique le spinozisme, doctrine qui, dit-il, a un si grand nombre de partisans en France, en Allemagne, en Angleterre, en Hollande et surtout en Italie ${ }^{3}$, mais il le critique en lui opposant la doctrine de Gassendi ${ }^{4}$, un de ces maîtres devant le portrait desquels son valet Mathieu était obligé de se découvrir chaque matin ${ }^{5}$. En 1743, I'auteur de Réflexions sur l'argument de M. Pascal et de M. Locke concernant la possibilité d'une autre vie à venir, insérées dans les p.364 Nouvelles libertés de penser (qui ont été mises à tort sous le nom de Fontenelle) veut mettre en face d'un missionnaire un philosophe païen qui réfutera ses théories sur la vie future et l'immortalité de l'âme, et il choisit un philosophe chinois « qui ne croit pas à une vie à venir (étant presque tous dans ce sistème) qui jouit dans sa

\footnotetext{
${ }^{1}$ Lettres chinoises, t. I, Préface, s. p.

2 ibid., Lettre VII, t. I, p. 31-5.

3 ibid., Lettre XIV, t. I, p. 108.

4 ibid., Lettre XIV, t. I, p. 108-112.

5 ibid.. Epître dédicatoire à son valet Mathieu, t. II, p. 3.
} 


\section{La Chine et la formation de l'esprit philosophique en France}

façon de penser d'un bonheur parfait en ce monde et qui est moralement certain qu'il en jouira toute sa vie $\gg 1$. Ce Chinois athée réfute l'argument du pari de Pascal que lui propose le missionnaire et il ne conclut pas seulement qu'il se trouve bien de son athéisme et qu'il ne veut pas l'abandonner, mais que le « sistème », c'est-à-dire la doctrine religieuse du missionnaire, est erroné comme contraire à la « raison immuable » 2 .

Bayle l'emporte donc. Avant la Querelle des Cérémonies chinoises il avait montré par des arguments théoriques, non seulement qu'il pouvait y avoir des athées de bonne foi, contrairement à l'avis des théologiens, mais encore qu'il pouvait exister des nations athées, c'est-à-dire que l'athéisme n'était pas inconciliable avec une morale ni avec une organisation sociale. Les adversaires des Jésuites, par les textes qu'ils apportèrent en faveur de l'athéisme des Chinois, vinrent fournir à Bayle la preuve et la vérification par le fait de la justesse de ses arguments. Preuve d'autant plus décisive que les Chinois étaient une des plus anciennes nations du monde et que leur état social, depuis des millénaires était resté fixe, immuable, et n'avait pas connu ces vicissitudes que les empires de l'ancien monde avaient subies. Ainsi Bayle avait ruiné l'argument du consentement universel, et, ce qui plus est, en posant le fait de l'athéisme des Chinois il avait montré l'indépendance de la morale et, de la politique par rapport à la religion. Par cette brèche les philosophes passèrent, Toland d'abord qui s'efforça de démontrer

\footnotetext{
${ }^{1}$ Nouvelles libertés de penser, p. 11.

2 ibid., p. 44-45.
} 


\section{La Chine et la formation de l'esprit philosophique en France}

le panthéisme de Moïse ${ }^{1}$, ensuite Levesque de Burigny qui nota soigneusement toutes les traces d'athéisme qu'il put trouver chez les anciens philosophes des différentes nations du monde, tentative pour retourner l'argument du consentement universel. D'autres, comme Fréret, ne se contentant pas du criterium tout extérieur que Bayle avait adopté pour décider en faveur de l'athéisme des Chinois, cherchèrent dans les textes chinois p.365 euxmêmes, traduits par les Jésuites, des preuves directes de cet athéisme.

Mais les théologiens et les défenseurs des idées traditionnelles ne se tinrent cependant pas pour battus. Ils modifièrent l'argument du consentement universel : au lieu de chercher des traces de religion chez les différentes nations du globe, ils remontèrent l'ordre des temps pour trouver le plus près possible des origines du monde des témoignages décisifs et concordants en faveur de l'existence de Dieu : telle fut la riposte d'Elie Benoist à Bayle et à Toland, et telle fut aussi l'idée du P. Lafitau pour qui les mœurs et les cérémonies des sauvages n'étaient que des survivances des mœurs et des cérémonies des peuples primitifs. De leur côté, les Jésuites figuristes essayèrent de trouver dans les anciens livres chinois des vestiges d'une révélation primitive, mais nous savons que leurs théories ne furent pas admises par leurs confrères de Pékin et de Paris, et tout ce que le public put en connaître ce fut seulement le pâle Discours sur la mythologie de Ramsay, qui d'ailleurs ne trouva

1 Dans ses Antiquitates judaicæ. (Cf. le compte rendu du Journal des Sçavans, avril 1709, t. II, p. 85-98). Un protestant français, de la Faye, essaya le rétorquer les arguments de Toland dans une Defensio religionis (compte rendu dans le Journal des Sçavans, octobre 1709, t. IV, p. 107-113). 


\section{La Chine et la formation de l'esprit philosophique en France}

pas audience ${ }^{1}$. Vers 1740, l'argument du consentement universel a fait son temps : I'athéisme des Chinois lui a porté un coup mortel.

Cependant le fait de l'athéisme des Chinois ne fut pas admis sans une énergique et tenace résistance des Jésuites. Déjà en 1687 le reviseur de la préface du P. Couplet avait pris soin de souligner, mieux que ne l'avait fait le P. Couplet, les croyances des Chinois à un Dieu personnel et à l'immortalité de l'âme. En 1696, le P. Le Comte alla plus loin : il crut trouver dans la doctrine des anciens philosophes chinois des principes analogues à ceux du judaïsme, tells qu'ils résultent de l'enseignement de Moïse, et dans la religion chinoise un culte pur, sans aucun mélange d'idolâtrie. Ainsi non seulement le P. Le Comte dépouillait le peuple juif de son privilège, mais il plaçait les Chinois sur un plan supérieur puisque, eux du moins, ils n'avaient pas adoré le veau d'or. Condamnés par la p.366 Sorbonne, à demi condamnés par le pape, harcelés par leurs adversaires, Vicaires apostoliques et Dominicains, les Jésuites n'en continuèrent pas moins leur croisade en faveur du. spiritualisme des Chinois. Ils auraient pu sans doute avoir un

\footnotetext{
${ }^{1}$ Bouhier répondant à Marais au sujet de Ramsay marque I'influence de Bayle et l'importance que lui attribuaient même ses adversaires : «Pour ce qui est de Bayle il est absurde de dire qu'il ne fait qu'effleurer les matières, surtout celles de Religion et de Métaphysique. Il ne les enfonce que trop et je me souviens d'avoir ouy dire cet été au $P$. de Tournemine qui travaille à une Réfutation des Athées qu'il ne trouvoit rien de plus difficile à résoudre que certaines objections proposées par votre ami et que je suis seur que Ramsay n'entend seulement pas. Je ne sçais même si feu M. de Cambray son maître les entendoit bien aussi. Car vous sçavez que les raisonnements philosophiques n'étoient pas son fort. » Lettre du 22 décembre 1727, B. N. Fr. 25511, f. $178, v^{\circ} 179 r^{\circ}$.
} 


\section{La Chine et la formation de l'esprit philosophique en France}

allié en la personne de Leibniz qui partageait en partie leurs idées, mais ils menèrent la lutte à eux seuls, sans se compromettre avec un protestant. En 1731, le livre de Silhouette Idée générale du gouvernement et de la morale des Chinois, inspiré par le P. Tournemine, n'est que le résumé des idées soutenues de tout temps par les Jésuites sur la religion chinoise.

Mais I'argument qui les a fait condamner en 1700 subsiste dans toute sa force et ils ne peuvent y échapper. Supposer une religion dans laquelle on a connu et adoré le vrai Dieu deux mille ans av. J.-C., une religion qui imposait les plus pures maximes de la morale et de la charité, « c'est, comme le disait en 1700 un

Docteur de St-Dominique, établir un Système qui conduit au Déisme et au Socinianisme. Car les Déistes et les Sociniens reconnoissent et adorent un Dieu. Ils croyent qu'on doit garder ses commandemens c'est-à-dire la Loy de nature dont le Décalogue n'est qu'un renouvellement et que cela suffit sans qu'il soit nécessaire de croire en Jésus-Christ, Médiateur entre Dieu et les hommes » ${ }^{1}$. Pour sauver les Chinois de l'athéisme, les Jésuites ont dû, bien que malgré eux, en faire des déistes.

Vers 1740, au moment où Voltaire commence à se documenter pour son Histoire universelle et à s'intéresser à la Chine, il va se trouver placé entre ces deux grands courants d'opinion, et il va lui falloir choisir entre l'athéisme et le déisme des Chinois.

\footnotetext{
1 Lettre d'un Docteur de l'ordre de St. Dominique sur les Cérémonies de la

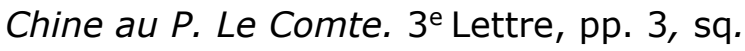




\section{La Chine}

et la formation de l'esprit philosophique en France

@

561 


\title{
La Chine \\ et la formation de l'esprit philosophique en France
}

\author{
CHAPITRE III
}

\section{LA MORALE ET LA POLITIQUE DES CHINOIS}

p.367 Lorsqu'on parle de la Chine, il est impossible de séparer la politique de la morale, la morale n'étant pas en Chine une spéculation pour la détermination de notions abstraites, pour la recherche du bien en soi, du bonheur en soi, mais seulement la codification des règles traditionnelles qui fixent les devoirs des hommes dans leur vie privée, ce qui est la morale, ou dans leur vie publique, quelle que soit leur condition sociale, ce qui est la politique.

Il eût été peut-être même plus exact, c'est-à-dire plus conforme à l'esprit de la Chine, de ne pas séparer dans cet exposé la morale de la religion, étant donné I'absence en Chine de tout dogmatisme même religieux, étant donné aussi le caractère social d'un grand nombre de cérémonies religieuses. Mais nous avons dû, moins nous adapter à l'esprit chinois que nous conformer aux tendances d'esprit des Français ou des Européens qui ont observé la Chine au XVII ${ }^{e}$ siècle et dans les premières décades du siècle suivant. Or ils ont remarqué parfois sans doute avec étonnement - mais du moins ils ont bien vu que le principe de la politique est exactement le même que celui de la morale, tandis qu'ils n'ont pas aussi bien compris le caractère social des cultes chinois, pas même les Jésuites, qui pourtant se sont évertués à prouver que les cérémonies du culte 


\section{La Chine et la formation de l'esprit philosophique en France}

de Confucius ou du culte des morts ne sont que des cérémonies civiles. Ils ont cru à la duplicité des philosophes de la Chine, qui, athées en fait, n'en pratiquaient pas moins un culte extérieur « pour maintenir le peuple dans le devoir ». C'est que pour ces voyageurs qui étaient à peu près tous des missionnaires, une religion véritable ne pouvait se limiter à l'exercice d'un culte, elle devait être tout d'abord une spéculation métaphysique sur la nature et les attributs de Dieu, sur les origines du p.368 monde, sur les rapports entre Dieu et l'homme. Il n'est donc pas étonnant qu'ayant été en général incapables de comprendre l'absence de dogmatisme de l'esprit chinois (à part peut-être le P. Martini quand il a constaté que les Chinois manquaient de terme pour désigner Dieu) ils n'aient pu comprendre le caractère à la fois religieux et civil des cérémonies cultuelles des Chinois.

Au contraire ils ont marqué avec netteté, souvent avec finesse, la dépendance de la politique par rapport à la morale, telle qu'elle existe en Chine. Ils ont compris que la morale chinoise n'était pas une morale dogmatique et qu'elle ne dérivait pas de principes abstraits, mais qu'elle était seulement un code de prescriptions - résumé d'expérience humaine - destiné à procurer le bonheur de l'individu, de la famille et de la société. Ce qui leur a paru curieux, c'est que ce fût le même principe qui réglât la vie individuelle et la vie sociale, autrement dit que la politique ne fût autre chose qu'une morale collective. Et cela fut peut-être la plus grande révélation qu'apporta la découverte de la Chine. 


\section{La Chine et la formation de l'esprit philosophique en France}

Aucun des missionnaires qui allèrent en Chine à l'époque qui nous occupe n'avait en effet la moindre intention de chercher dans ce pays lointain des exemples capables de vérifier - ou d'infirmer - ses notions morales traditionnelles. La seule morale qui fût vraie, à savoir la morale chrétienne, chacun d'eux voulait au contraire la faire connaître, la répandre, tâcher de la rendre universelle. Cette morale n'avait donc pas besoin de la pierre de touche de l'expérience : la morale chinoise ne pouvait en aucune manière ou l'infirmer ou même la rectifier. Quant à la politique, ces missionnaires n'avaient pas à s'en préoccuper. Pour des Européens de ce temps, qu'ils fussent sujets du Roi Très Chrétien ou du roi de Portugal, la politique était l'affaire du souverain. Mais, sans avoir aucune intention critique à l'égard du gouvernement de leur pays respectif, ils ne purent s'empêcher de constater en Chine la fertilité des campagnes, I'abondance de la population, le nombre, la grandeur et la richesse des villes qu'ils traversaient et ils cherchèrent l'explication de ces faits. Or la Chine était un pays monarchique, tout comme la France ou le Portugal. Comment se faisait-il donc que le principe monarchique, qui n'obtenait en Europe que des résultats médiocres ou déplorables, produisait en Chine des effets merveilleux ? Cette explication, ils crurent la trouver dans cette forme particulière du gouvernement chinois, dont le principe est le même que celui de la famille, dont la politique en somme n'est que l'adaptation à la vie nationale des principes mêmes qui régissent la vie individuelle et la vie familiale. Quoi ${ }_{\text {p.369 qu'il en }}$ soit, sans avoir eu eux-mêmes aucune intention critique ils apportèrent aux Européens des faits permettant de corriger le 


\section{La Chine \\ et la formation de l'esprit philosophique en France}

principe monarchique, tel qu'on le trouvait en Europe, et que jusque-là on avait pu croire immuable.

En bons missionnaires qu'ils étaient, habitués à lier la morale à la religion et à faire de la morale la condition, non certes suffisante mais du moins nécessaire, de la religion, ils ont été surpris et choqués de constater que les Chinois liaient la morale à la politique et ne s'efforçaient de déterminer les principes d'une morale parfaite que pour des fins politiques. C'est ainsi que Magaillans, après avoir exposé les trois principes de. la morale de Confucius, qui sont d'éclairer la nature raisonnable, de renouveler le peuple et finalement de parvenir au souverain bien, ajoute ce commentaire. « On peut remarquer ici qu'il n'y a peut estre rien qui soit plus propre que ces paroles de Cum fu cius pour expliquer les fonctions d'un Prédicateur de l'Évangile ; dont l'obligation est premièrement de se perfectionner soymême, ensuite le prochain, afin que nous arrivions au souverain bien qui est Dieu, dernière et suprême fin de toutes choses. Toutefois les Chinois Payens et mondains ont accomodé ces trois points au gouvernement du Royaume, en quoy comme politiques ils mettent tout leur bonheur et leur fin dernière $\gg 1$.

D'autres missionnaires, et des voyageurs qui n'étaient pas des missionnaires, ont aussi constaté que les Chinois, tout en étant préoccupés de la morale et de la recherche du souverain bien n'entendent par là rien d'idéal, mais seulement des avantages matériels. « Le P. Ricci, nous raconte I'Italien Gemelli Careri, parlait un jour à un mandarin du christianisme et de la

\footnotetext{
1 Magaillans, Nouvelle Relation de la Chine, p. 103-7.
} 


\section{La Chine et la formation de l'esprit philosophique en France}

félicité éternelle. Taisez-vous, lui répondit le mandarin, laissez-là ces vérités ; que toute votre gloire et votre félicité soit pour vous qui êtes étranger ; quant à moi toute ma gloire et toute ma félicité consiste dans cette ceinture et dans cet habit de mandarin ; tout le reste ne sont que des fables et des paroles que le vent emporte; ce sont des choses que l'on compte et que I'on ne voit point ; ce qui se voit, c'est l'avantage de gouverner et de commander aux autres. L'or, l'argent, les femmes, les concubines, une nombreuse suite, les meubles, les festins, les divertissements, tous les biens, les honneurs et la gloire, ce sont les avantages que nous procure l'état de mandarin. Voilà la félicité après laquelle nous aspirons et dont nous jouissons dans notre grand et sublime Empire, et non pas la ${ }_{p .370}$ vôtre qui est aussi inutile qu'invisible et impossible à acquérir ${ }^{1}$.

Par conséquent la morale chinoise que vont révéler les Jésuites n'est pas une morale dogmatique dont les applications aux cas particuliers sont déduites de principes abstraits, mais une morale pratique dont les différents préceptes ne sont que les lois qui permettent de maintenir dans un état d'équilibre parfait la société chinoise. Et ce n'est pas non plus une morale idéaliste qui cherche la réalisation d'une vertu abrupte, difficilement accessible, c'est au contraire une morale un peu terre à terre dont le but est la recherche du bonheur plus encore que de la vertu : en somme un eudémonisme, mais limité et corrigé par la raison, et un eudémonisme qui ne sépare pas le bonheur individuel du bonheur social.

\footnotetext{
${ }^{1}$ Gemelli Careri, Voyage autour du Monde, t. IV De la Chine, p. 249.
} 


\title{
La Chine et la formation de l'esprit philosophique en France
}

\begin{abstract}
.
\end{abstract}
Les premiers missionnaires qui nous ont parlé de la Chine bien que l'admiration soit la note dominante de leurs écrits - ne se sont pas laissé aveugler, et ils ne se sont pas fait faute de signaler les friponneries du menu peuple chinois. Malgré cela, ils admirent la morale et la politique chinoises, surtout la morale parce qu'elle admet ce principe qui est un des préceptes essentiels de la morale chrétienne : « Ne fais pas à autrui ce que tu ne voudrais pas qu'on te fit à toi-même », ce qui permettait d'espérer que les Chinois ne témoigneraient pas de répugnance à l'égard du christianisme ; et ils ont admiré la politique chinoise un peu de confiance, à cause des résultats qu'elle produisait : quel qu'en fût le principe, ou comme on disait alors le ressort, ce principe ne pouvait être que bien choisi, puisque son excellence pouvait se mesurer à ses effets. D'ailleurs les premiers auteurs de relations sur la Chine ne s'accordent pas toujours pour déterminer ce principe essentiel de la politique chinoise qui produit le bonheur des peuples; pour le P. Trigault et pour Baudier (qui d'ailleurs s'inspire si souvent de Trigault) il faut attribuer à la « vertu » ou à la « franchise » des mandarins, qui ne craignent pas d'avertir, voire de réprimander l'empereur, même au péril de leur vie, le mérite de cette félicité du peuple chinois. Pour le voyageur Fernand Mendez Pinto, la prospérité de la Chine tient à l'exacte observation de la justice. Chacun propose son hypothèse pour l'interprétation du fait, mais sur le fait lui-même tout le monde est d'accord : le p.371 peuple chinois 


\section{La Chine et la formation de l'esprit philosophique en France}

est un peuple heureux et prospère, ce qui tient à son excellente morale et à son excellente politique.

Mais quelle est au juste cette morale, quelle est exactement cette politique?

Il nous est assez difficile de nous en rendre compte d'après les premières relations. Quelquefois cependant des missionnaires qui ont longtemps vécu en Chine semblent avoir vu quelques lueurs. « La morale humaine, dit le P. Semedo, se divise.. en trois parties... qui sont l'Éthique, l'CEconomique et la Politique. L'Éthique règle les coutumes, les mœurs et les actions des hommes considérées en elles-mêmes dans le rapport qu'elles ont à leurs personnes; I'CFconomique les considère comme utiles et profitables à la famille; la Politique les pousse plus haut et les rapporte au gouvernement de la République, aux biens des peuples et à la conservation de l'Estat. La direction particulière de la personne est subordonnée à la conduite de la famille, et celle-cy au Gouvernement du Royaume ; par exemple comment est-ce qu'un Père de famille pourra-t-il sagement gouverner une ville ou une province, s'il ne sçait pas régler ses Domestiques, et, $s^{\prime} i l$ ne peut pas se conduire soy mesme, comment pourra-t-il conduire l'Estat de sa maison ? De sorte que le premier fondement de la morale est appuyé sur les bonnes mœurs des particuliers, d'où elle s'élève ensuite au belle (sic) ordre des familles et monte enfin jusqu'à I'heureux gouvernement des Royaumes bien policés »1.

\footnotetext{
1 Semedo, op. cit., p. 72.
} 


\section{La Chine et la formation de l'esprit philosophique en France}

Mais ce sont des notes éparses, jetées comme en passant au milieu d'autres observations, assez intéressantes pour éveiller l'attention d'un lecteur curieux, mais trop peu précises pour satisfaire entièrement sa curiosité. Le livre qui allait exposer les principes de la morale et de la politique chinoises est la traduction des trois livres de Confucius faite par les PP. Intorcetta, Herdtricht, Rougemont et Couplet, qui parut en 1687, « jussu Ludovici Magni ». Le public attendait ce livre avec non moins d'impatience que la chronologie chinoise, depuis que le départ des Jésuites missionnaires pour la Chine, annoncé d'une manière retentissante et célébré avec éclat, avait laissé espérer toute une manne de documents nouveaux sur cette Chine si ancienne, si digne d'attention à tous égards et cependant encore à peu près inconnue. Mais la traduction des PP. Jésuites est en latin et c'est un gros in-folio, livre d'ailleurs destiné aux futurs missionnaires plutôt qu'au public. Ce qui devait révéler au public la morale et la politique chinoises, c'est plus que le livre même des PP. Jésuites, les traductions, ou plus exactement les adaptations qui en furent faites.

L'abbé Simon Foucher, chanoine de Dijon, adversaire de Descartes et de Malebranche, s'empare, dès la publication des PP. Jésuites, de la morale de Confucius et, dans une Lettre sur la morale de Confucius Philosophe de la Chine, il extrait et traduit quelques maximes du philosophe chinois qui lui semblent conformes aux principes qu'il défend contre les Cartésiens, à savoir ceux de l'Académie : «La plupart de ceux qui entendent parler de la Philosophie, écrit-il dans une courte conclusion à ces maximes traduites de Confucius, s'imaginent d'abord des 


\section{La Chine et la formation de l'esprit philosophique en France}

raisonnements sur la Physique et des Observations curieuses sur les Phénomènes de la Nature; au lieu que ce n'est pas cela que I'on doit entendre par ce mot, mais c'est l'étude et la recherche des premières Véritez qui servent de principes à toutes nos connoissances et nous conduisent dans nos jugemens. Or, on ne doute pas qu'il ne soit de la dernière importance de s'appliquer à reconnoitre ces véritez et à éviter les erreurs dans lesquelles nous pouvons tomber en jugeant des biens et des maux, et en même temps des premiers devoirs des hommes, puisque c'est en cela que consiste véritablement la Sagesse $\gg 1$.

Ce qu'il trouve dans Confucius, ce n'est pas une métaphysique - et cela n'est pas pour lui déplaire, bien au contraire - mais l'ensemble des règles qui doivent mener à la sagesse, règles pour l'homme privé, ce qui est la morale, et règles pour l'homme public ou le souverain, ce qui est la politique. Or la grande règle du philosophe chinois est qu'il faut travailler à acquérir le souverain bien qui consiste dans une « parfaite conformité à la droite raison » 2 , et que, pour y parvenir, il faut d'abord débarrasser l'âme humaine « du trouble

1 Il a écrit ailleurs ceci, qui non seulement précise ce qu'il entend par philosophie, mais aussi explique pourquoi il a cru bon de traduire Confucius : « Chercher la vérité en toutes choses, éviter l'erreur dans ses jugemens, suivre la droite raison et observer en quoy consistent les devoirs de I'homme : travailler à la connoissance de soy-mesme, esclaircir son entendement et tascher de se mettre dans la meilleure disposition où I'on puisse estre pour acquérir les biens de l'esprit et du corps c'est proprement et véritablement philosopher : et voilà sur quoy les grands Philosophes ont appuyé la notion qu'ils avoient de la Philosophie. » (Dissertations sur la recherche de la vérité contenant l'Histoire et les Principes de la Philosophie des Académiciens; avec plusieurs réflexions sur les sentiments de $M$. Descartes, p. 216).

2 Lettre sur la morale de Confucius, p. 4. 


\section{La Chine et la formation de l'esprit philosophique en France}

que lui apportent ou les passions ou les préjugés »1. Morale intellectualiste, qui consiste à éclairer le plus possible l'entendement (car lorsque l'entendement sera élevé à sa perfection, la volonté ne manquera pas de se porter aussi à la sienne) 2, morale dont le principe est de rechercher la vérité, ce qui pour Simon Foucher est toute la philosophie ${ }^{3}$.

Simon Foucher trouve donc avec satisfaction une certaine conformité entre les idées du philosophe chinois et les siennes. S'il rapporte cette formule de Confucius : « Rejettez tout ce qui est incertain et douteux quand il s'agit de science $\gg 4$, il n'hésite pas à mettre en marge Première loy des Académiciens. Confucius, comme Socrate, a renoncé aux nuages métaphysiques pour ne chercher qu'une sagesse humaine et, ce faisant, il semble avoir trouvé lui aussi, comme grand principe de la morale des anciens philosophes de l'Occident ce nul nimis, cette vertu du juste milieu : «Il ne faut pas se proposer des vertus extraordinaires ni trop éloignées de la Pratique ne devant point aspirer à l'impossible ; ni demander plus que la condition humaine ne peut accorder »5. Donc morale païenne, plutôt que chrétienne, malgré les précautions que prend l'abbé de rapprocher certaines maximes de Confucius de maximes analogues de Saint-Paul, malgré aussi cette affirmation que cette

\footnotetext{
1 ibid., p. 4.

2 ibid., p. 5.

3 ibid., p. 23.

4 ibid., p. 15.

5 ibid., p. 7.
} 


\section{La Chine et la formation de l'esprit philosophique en France}

morale de Confucius qui a été transmise depuis la plus haute antiquité, provient peut-être de Noé, ou des patriarches d'avant le Déluge, ou du premier homme lui-même, affirmation d'ailleurs corrigée par cette phrase qui ne tend à rien de moins qu'à l'affirmation d'une morale naturelle : «Admirons la Providence divine qui a donné à toutes les nations de la terre des enseignemens et des maîtres pour les conduire $\gg 1$.

L'inspiration du petit livre intitulé La Morale de Confucius et qui a été attribué tantôt à un pasteur protestant J. de la Brune, tantôt au Président Cousin 2, sans que nous puissions décider en faveur de l'un ou de l'autre, semble la même que celle du chanoine Simon Foucher.

Comme l'abbé Foucher, l'auteur de cet abrégé de La Morale de Confucius critique les philosophes païens et les moralistes p.374 chrétiens qui outrent les devoirs presque partout, qui s'abandonnent à la fougue de leur imagination, ou à leur mauvaise humeur, qui s'éloignent presque toujours de ce juste milieu où la vertu doit être placée, qui la rendent, par les faux portraits qu'ils en font, impossible à pratiquer, et qui par conséquent ne rendent pas beaucoup de gens vertueux $\gg 3$.

Les philosophes, ou les moralistes, auxquels notre auteur en veut particulièrement, c'est d'abord Nicole qui a écrit dans ses

\footnotetext{
1 ibid., p. 2.

${ }^{2}$ La France protestante de Haag est à peu près dépourvue de renseignements sur ce J. de la Brune, et elle se déclare incapable de décider si ce pasteur est ou n'est pas l'auteur de cet ouvrage sur La Morale de Confucius.
}

3 op. cit.. Avertissement, p. 2. 


\section{La Chine et la formation de l'esprit philosophique en France}

Essais de Morale ${ }^{1}$ : «Quand les hommes y auroient fait de grands progrès [dans la science des choses] ils ne s'en devroient guère plus estimer, puisque ces connoissances stériles sont si peu capables de leur apporter quelque fruit et quelque contentement solide, qu'on est tout aussi heureux en $y$ renonçant d'abord qu'en les portant par de longs travaux au plus haut point où on les puisse porter $\gg 2$. A quoi notre auteur répond avec indignation, pour défendre les sciences au nom du bonheur, au nom de la vertu, au nom même de la religion : «Quoi ! Les sciences et les belles découvertes ne rendent-elles pas plus heureux plus content et plus honnête homme, lorsqu'on en sçait faire un bon usage ? Ne sçait-on pas même qu'il y a beaucoup de Théologiens qui croient qu'une des choses qui feront la félicité des Saints dans le Ciel sera une grande connoissance d'une infinité de véritez qui nous sont inconnues ou peu connues sur la Terre ? »3. Les autres philosophes qui excitent sa bile, ce sont tous les métaphysiciens dont les traités de morale, et notamment celui de Malebranche ${ }^{4}$ sont « pleins de subtilitez épouvantables » alors que «la simplicité, la clarté, l'évidence devroient régner partout et se faire sentir aux esprits les plus grossiers »5. Au contraire dans la morale de Confucius

\footnotetext{
${ }^{1}$ Essais de Morale, t. I, chap. 7.

2 op. cit., Avertissement, f. 5 ro.

3 op. cit., Avertissement, f. 5 ro.

${ }^{4}$ Il précise dans une note que c'est à Malebranche particulièrement qu'il fait allusion : « Voyez le traité de morale de l'Auteur de la Recherche de la vérité » Avertissement, f. $6 r^{\circ}$.

5 ibid., f. 6 r.o.
} 


\section{La Chine et la formation de l'esprit philosophique en France}

tout est simple parce qu'il n'y a rien d'extrême, tout est solide « parce que la droite raison, cette vérité intérieure, qui est dans l'âme de tous les hommes et que notre Philosophe consultoit sans cesse, sans préjugé, « conduisoit toutes ses paroles. Aussi les règles qu'il donne et les devoirs auxquels il exhorte sont tels qu'il n'y a personne qui ne se sente porté à y donner son approbation $\gg 1$.

p.375 Notre auteur s'accorde donc avec Simon Foucher. Les raisons de son admiration pour la morale de Confucius, c'est que cette morale n'est pas déduite de principes abstraits, mais qu'elle est suggérée par la raison, ce criterium de vérité intérieure : c'est une morale d'homme pratique et non une morale de métaphysicien. Et d'autre part, à cause de l'esprit pratique dont elle procède, cette morale ne propose pas à I'homme des vertus inaccessibles mais des devoirs que tout homme moyen peut connaître et par suite pratiquer, puisque la raison est universelle : «On peut dire que la morale de ce philosophe est infiniment sublime mais qu'elle est en même temps simple, sensible et puisée dans les plus pures sources de la raison naturelle. Assurément jamais la raison destituée des lumières de la révélation divine n'a paru si développée ni avec tant de force $\gg 2$.

Le cartésien Régis, qui fit, un compte rendu du Confucius Sinarum Philosophus dans le Journal des Sçavans, se trouvant dans l'impossibilité d'énumérer toutes les maximes de la morale

\footnotetext{
1 ibid., f. 6 r.o.

${ }^{2}$ La morale de Confucius, philosophe de la Chine. Avertissement, p. 2.
} 


\section{La Chine et la formation de l'esprit philosophique en France}

chinoise qui auraient pu être utiles ou agréables à l'esprit de ses lecteurs, se contente de choisir une seule maxime dans le III Livre de Confucius, mais une maxime longuement développée, et il la traduit. - très élégamment mais très exactement - du latin des PP. Jésuites. Or cette maxime est la définition de la charité, ou de la « pitié parfaite » qui est « une constante disposition d'esprit et conforme à la raison par laquelle un homme abandonnant son utilité ou sa commodité particulière aime généralement tous les hommes, comme s'ils étoient une seule et mesure chose avec lui, et a par conséquent avec eux un mesme et commun sentiment qu'il fait paroitre soit dans la prospérité ou dans l'adversité ». Confucius cite des exemples de la manière dont il entend cet amour du prochain qui ne consiste pas à s'abstenir de faire aux autres le mal que nous ne voudrions pas qu'on nous fit, mais plutôt à leur faire tout le bien que nous désirons pour nous-mêmes : «Or lorsque cette charité aura une fois pris racine dans l'esprit des mortels, alors toute la terre sera comme une seule et mesme famille. Que dis-je ? Tous les hommes seront comme un seul et mesme homme, et tout ce qu'il y a de choses dans le monde à cause de cet ordre admirable et de ce lien mutuel des plus hautes des moyennes et des plus basses semblera estre $d^{\prime}$ 'une seule et mesme nature $\gg 1$.

Et Régis, pour terminer, commentant en quelques mots cette définition de la charité selon le philosophe chinois fait cette remarque, que l'auteur de La Morale de Confucius lui aussi avait faite : « Je ne voi pas qu'au motif près, la charité des Chinois

1 Journal des Sçavans, 5 janvier 1688. Ed. in $4^{\circ} 103-4$. Le texte des PP. Jésuites que traduit Régis se trouve p. 35 du III ${ }^{\mathrm{e}}$ Livre de la morale. 


\section{La Chine et la formation de l'esprit philosophique en France}

soit différente de celle des Chrétiens, tant il est vrai que Dieu a répandu dans l'esprit mesme des Infidèles des lumières qui les conduisent à des vertus qui, quant à l'extérieur de l'action, ne sont en rien différentes des vertus chrétiennes ».

Au motif près, la morale chinoise et la morale chrétienne sont donc semblables : I'une est une morale tout humaine, qui procède uniquement de la raison, tandis que l'autre provient de dogmes religieux et d'une révélation divine, et cependant elles mènent à des vertus identiques. Quant à l'extérieur de l'action, ajoute Régis, mais c'est une restriction imposée par la prudence. Cette restriction mise à part, on peut se demander à quoi sert l'Évangile puisque les Chinois même avant le Christ, sont arrivés aux mêmes conclusions que lui. L'étonnement qu'éprouva Régis à constater cette identité entre la morale chinoise et la morale chrétienne fut une des raisons qui dut l'inciter à choisir particulièrement ce passage dans la traduction latine des PP. Jésuites. Mais ce ne dut pas être la seule. Il y avait en effet dans ce passage l'exposé d'un principe moral ne s'appliquant pas seulement à une catégorie d'individus ou à une caste ou à une nation, mais s'appliquant, à toutes les catégories, à toutes les castes, à toutes les nations, mais un principe moral humain et universel, et capable de créer un lien entre tous les hommes. Bernier, en envoyant ses Etrenes à Madame de la Sablière insinuait que Régis aurait dû encore mieux mettre en valeur ce caractère d'universalité.

«Vous aurez sans doute veu ce bel endroit de la Charité que M. Régis nous en a donné dans le Journal des Sçavans du 5 de 


\section{La Chine et la formation de l'esprit philosophique en France}

janvier ; ce passage est admirable et $M$. Régis a bien raison de dire qu'au motif près, aucun Chrétien n'a jamais mieux parlé de cette véritable Charité qui regarde généralement tous les hommes ; mais je souhaiterois qu'il eust ajouté cet autre petit passage qui est aussi du mesme Philosophe : Je me souviens avec plaisir de ce Soldat du Royaume de Lu, qui avait perdu son bouclier, et qui après l'avoir bien cherché sans le trouver dit

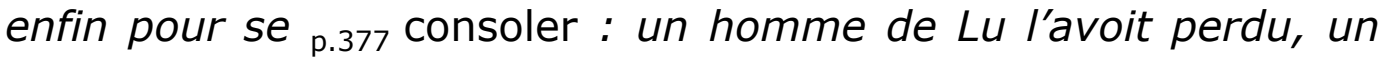
homme de Lu l'aura trouvé. Il auroit encore pu mieux dire : un homme l'aura trouvé »1.

Il n'est pas étonnant que dans ces Etrenes envoyées à Madame de la Sablière pour 1688 et qui ne sont autre chose qu'une causerie à bâtons rompus sur les sujets les plus variés (une classification des diverses races humaines d'après leurs caractères ethniques, une épitaphe pour Chappelle, etc.), l'idée lui soit venue de parler de Confucius à Madame de la Sablière, puisqu'aussi bien il était en train de traduire en français la morale de Confucius, telle qu'il la trouvait dans la traduction latine des PP. Jésuites, travail auquel I'avait poussé Mme de la Sablière, avec l'abbé de la Chambre ${ }^{2}$. Assez mal satisfait de son travail, parce qu'il n'y avait point d'ordre dans la traduction latine et que ce n'étaient que « des pièces décousues », il se demandait s'il y aurait moyen de faire, de cette traduction quelque chose qui pût plaire et il remettait à son retour à Paris le

\footnotetext{
${ }^{1}$ Copie des Etrenes envoyées à Madame de la Sablière, p. 12.

2 ibid., p. 11.
} 


\section{La Chine et la formation de l'esprit philosophique en France}

soin de décider s'il publierait cette traduction, après en avoir discuté avec ses amis.

Cette traduction ne vit jamais le jour : d'ailleurs Bernier mourait quelques mois après (22 septembre 1688) ${ }^{1}$, et il n'aurait pas eu le temps de publier son ouvrage même s'il l'eût voulu. Quant à ses amis, ils ne se chargèrent pas de ce soin ; si bien que cette traduction est restée manuscrite et inconnue jusqu'à ce jour. Seul l'introduction en fut publiée dans le Journal des Sçavans et encor d'une manière tout à fait incomplète ${ }^{2}$.

p.378 Dans les passages qui ont été supprimés par le Journal des Sçavans, Bernier nous indique les raisons qui l'ont poussé à faire ce long et fastidieux travail de traduction, malgré les conseils de nombreuses personnes qui ont essayé de l'en

1 Port, Dictionnaire historique, géographie et biographie de Maine-et-Loire t. II, p. 327.

2 Ce manuscrit, conservé à la Bibiothèque de l'Arsenal ( $n^{\circ} 2331$ ) (il y en a un second, à la même bibliothèque, $\mathrm{n}^{\circ} 2689$, mais certaines fautes décèlent la main d'un copiste négligent) porte cette annotation manuscrite : « Cet ouvrage est probablement de François Bernier médecin et voyageur mort en 1688. En 1687 il parut un ouvrage sous le titre d'Introduction à la lecture de Confucius où I'on trouve un Extrait de la morale des Chinois par Mr. Bernier. C'est peut-être l'ouvrage dont voici le mss. Cela est à vérifier. En attendant j'ay comparé ce volume cy avec un autre petit que j'ay intitulé Morale de Confucius et ce n'est pas la mesme chose. »Par «Introduction à la lecture de Confucius », l'auteur de cette note fait-il allusion à la Copie des Etrenes envoyées à Madame de la Sablière, mais qui ne parut qu'en 1688, ou fait-il allusion à la publication fragmentaire de la préface de Bernier dans le Journal des Sçavans (mai 1688) qui porte ce titre Extrait de diverses pièces envoyées pour étreines par Mr Bernier à Mme de la Sablière, et ce sous-titre : Introduction à la lecture de Confucius ? Voici maintenant le titre exact du manuscrit de Bernier : «Confucius ou la Science des Princes contenant les Principes de la Religion, de la Morale particulière du Gouvernement Politique, des anciens Empereurs et Magistrats de la Chine. Abrégée et mise en françois par Mr Bernier, Docteur en Médecine. » La traduction est précédée d'une introduction, celle-là même qu'on trouve en partie dans le Journal des Sçavans, avec ce titre Avis au Lecteur Pour servir de clef ou d'Introduction à la lecture de Confucius. 


\section{La Chine et la formation de l'esprit philosophique en France}

détourner. Confucius, lui a-t-on dit, ne peut rien nous donner de meilleur que Salomon et I'Ecclésiaste, et, « pour ne parler que des morales naturelles et laisser à part la morale chrétienne qui surpasse infiniment toutes les autres », Epictète, Socrate, Aristote, Plutarque, Sénèque, Cicéron et même Gassendi, que Bernier lui-même a tant prôné, ont fourni tous les principes de morale nécessaires pour la conduite de la vie humaine. «Il est vrai, répond Bernier, que toutes ces morales sont excellentes et bien mieux digérées et ordonnées que celle-ci, mais comme j'ay déjà dit plus haut, il y a toujours bien plaisir de sçavoir ce que des gens du bout du monde pensoient sur cette matière longtemps avant nous, lorsque I'Europe estoit pour ainsi dire encore comme brute et barbare et de voir qu'ils avoient et ont encore des maximes de morale et de Politique que nous n'aurions jamais cru estre fondamentales pour le gouvernement de I'Empire telles que sont I'obéissance filiale, l'exemple du Prince et même la Musique en tant que par la douceur de son harmonie elle adoucit la férocité de l'homme et que par les sages instructions que les vers qu'on chante en musique contiennent elle instruit agréablement les jeunes gens et principalement les jeunes Princes dont l'instruction est d'une merveilleuse conséquence $\gg 1$.

Mais ce n'est pas la seule raison : il y en a une autre plus importante ; en effet cette morale est en même temps la meilleure des politiques, et c'est pourquoi Bernier a donné ce titre à sa traduction de Confucius, La Science des Princes : « Je

\footnotetext{
1 Mst 2331, f. 8 r $^{\circ}$ et $v^{\circ}$.
} 


\section{La Chine et la formation de l'esprit philosophique en France}

ne l'ay principalement entrepris [ce travail] que parce que j'ay remarqué qu'il n'y a point de morale qui instruise mieux les Princes de leur devoir, plus sagement, plus prudemment, plus respectueusement. Elle insinue doucement que la majesté et la gravité estant des qualités indispensablement attachées à la personne des princes, elles doivent néanmoins estre tempérées de beaucoup de douceur et d'humanité. Elle insinue de même que les Princes sont indispensablement ${ }_{\text {p.379 }}$ obligés d'entrer dans le détail des affaires de leurs Estats et d'écouter volontiers soit les plaintes soit les remontrances qu'on leur fait, soit les avis et les conseils qu'on leur propose, s'ils ne veulent pas fermer la porte à la vérité et en même temps ouvrir la barrière à la flatterie qui tost ou tard les doit perdre. Enfin pour comprendre tout en un mot, elle fait que le Prince ne doit point d'autre intérest que celuy de ses sujets, de façon qu'aimant ce qu'ils aiment et hayssant ce qu'ils hayssent, il les aime aussi tendrement qu'un bon père aime ses propres enfants n'y ayant point d'autre moyen de parvenir à la véritable gloire à une solide éternelle renommée $\gg 1$.

Donc la morale de Confucius n'est pas une spéculation philosophique, capable de satisfaire uniquement l'esprit d'un philosophe, c'est une science concrète, ayant un objet pratique, puisqu'elle se confond avec la politique ; et les maximes morales et politiques qu'elle enseigne peuvent être utiles pour l'éducation des jeunes Princes de tous les pays du monde.

1 ibid. , f. 8, $v^{\circ} 9 r^{\circ}$. 


\section{La Chine et la formation de l'esprit philosophique en France}

Or, à cette époque le problème de l'éducation du prince n'était-il pas le plus grand problème politique qui pût se poser, au moment où l'on cherchait des précepteurs pour le Duc de Bourgogne et ses frères ${ }^{1}$ ? « Je me suis même imaginé, comme j'aime tendrement mon Prince et ma Patrie que cecy pourroit peut estre servir à ces grands hommes qu'on va donner pour Précepteurs et pour gouverneurs à nos trois jeunes Princes, et qu'au lieu de cet air fier, impérieux et sourcilleux si ordinaire et si pernicieux aux Princes qui ont le malheur d'y estre eslevez ils pourroient en se servant des principes de cette morale leur inspirer un certain esprit d'amour, de douceur, de bonté, de simplicité, d'humanité et de bénéficence sans toutefois les éloigner de cette majesté et grandeur d'âme qui leur doit estre comme naturelle, ce qui auroit un jour des suites merveilleuses pour le bien général de l'estat et pour la gloire particulière de leurs Disciples p.380 qui se feroient, immanquablement estimer, honorer et pour ainsi dire adorer de tout le monde $\gg 2$.

Ce qui séduit donc particulièrement Bernier dans la doctrine de Confucius, c'est qu'elle n'est pas seulement une morale individuelle, ou une morale sociale réglant les rapports des individus entre eux mais une véritable morale politique, la Science des Princes qui veulent accomplir leur mission et réaliser l'objet pour lequel ils sont faits, à savoir le bonheur de leurs

1 «Un contemporain qui traçait alors dans une sorte de traité de politique sacrée le portrait idéal du parfait gouverneur, écrivait que mettre auprès du prince, pour diriger sa jeunesse, un guide incapable ou impuissant, c'était ouvrir la route au malheur des peuples. » Lacour-Gayet, L'éducation de Louis $X I V, 2^{\mathrm{e}}$ éd., p. 5 . Mais un bon gouverneur pouvait être la cause première du bonheur de ces mêmes peuples.

2 Mst. 2331, f. 9 ro. 


\section{La Chine et la formation de l'esprit philosophique en France}

peuples. Bernier se distingua donc un peu de Simon Foucher ou de Jean de la Brune, qui cherchaient à mettre en valeur, dans la morale de Confucius, son caractère d'universalité et les traits communs qu'elle pouvait avoir avec les morales du paganisme ou la morale chrétienne. Bernier, lui, met l'accent sur la politique, surpris de trouver en Chine une politique rationnelle dont le principe est le même que celui de la morale individuelle et de la morale familiale.

Non seulement les extraits inédits que nous avons cités de sa préface, mais encore ses procédés de traduction marquent cette intention de Bernier. Cependant sa traduction, sans être absolument littérale est en général exacte. Si elle ne s'astreint pas à suivre le texte rigoureusement mot à mot et si parfois même elle est plutôt une adaptation qu'une traduction, surtout dans le III Livre, l'esprit du texte est respecté. Cependant il y a de-ci de-là un mot ajouté ou un développement que le texte latin indiquait seulement et qui se trouve amplifié et poussé jusque dans ses plus minutieuses conséquences par la traduction française. Parfois c'est une formule, mais une formule essentielle, qui est mise en valeur, d'autres fois c'est un simple mot dont la traduction est une interprétation plutôt qu'une traduction. En examinant ses procédés de traduction, nous pouvons saisir quelques-unes des préoccupations politiques de Bernier, découvrir les emprunts qu'il voudrait faire à la politique chinoise pour la politique de la France, avec les atténuations ou les corrections qu'il voudrait y apporter. 


\section{La Chine et la formation de l'esprit philosophique en France}

Comme il l'a dit dans sa préface ${ }^{1}$, les deux grands ressorts de la morale politique de la Chine, c'est d'abord que l'intérêt du prince et l'intérêt des sujets se confondent au point de n'être qu'une seule et même chose, et ensuite que l'exemple du prince est p.381 déterminant pour la conduite des sujets : s'il est vertueux le peuple sera vertueux et heureux ; s'il ne l'est pas, le peuple à son exemple se livrera à tous les désordres. Si le prince donne l'exemple de la vertu « il sera cher à tout le monde et digne de vénération », disait la traduction latine ${ }^{2}$ (corus foetus omnibus ac venerabilis) ; « il pourra, écrit Bernier, s'acquérir l'amour de tout le monde et le renom éternel de père de la patrie $\gg 3$.

L'importance de l'exemple du prince est chose qui mérite d'être mise en valeur et Bernier n'hésite pas à développer, plus que les PP. Jésuites les arguments ou les affirmations qui le prouvent. Voici par exemple ce qu'il ajoute au texte latin et qui écarte purement et simplement une objection qu'on pourrait faire à l'existence de ce principe dans un pays grand comme la Chine : «Quoique les peuples soient de tous costez répandus dans la vaste étendue de l'Empire, néanmoins leurs esprits et leurs yeux sont toujours tendus sur la personne de leur Prince et ils regardent tous la Cour et la maison Royale comme leur

\footnotetext{
1 Voir plus haut, p. 379.

2 Couplet, Confucius Sinarum Philosophus, p. 35.

3 Mst. 2331 , f. $18 v^{\circ}$.
} 


\section{La Chine \\ et la formation de l'esprit philosophique en France}

centre, comme la source de leurs biens, de leurs fortunes et de leur bonheur $\gg 1$.

Bernier revient sans cesse sur la valeur morale et sociale de cet exemple du Prince et il présente cet argument de toute sorte de manières. Si les Jésuites laissent entendre que ce principe universellement admis en théorie n'a pas toujours été suivi dans la pratique, Bernier laisse de côté cette restriction :

1 ibid., f. $11 \mathrm{v}^{\circ}$. 


\section{La Chine et la formation de l'esprit philosophique en France}

\begin{tabular}{|c|c|}
\hline $\begin{array}{l}\text { Omnes per se ipsi expoliverunt } \\
\text { naturam suam rationalis quasi } \\
\text { diceret ; tametsi omnibus } \\
\text { hominibus a coelo immissum ac } \\
\text { inditum sit grande hoc et } \\
\text { sublime naturae rationalis } \\
\text { donum ac lumen, plerique } \\
\text { tamen mortalium inordinatis } \\
\text { appetibus suis ac vitiis illud } \\
\text { obnubilarunt et imminuerunt, } \\
\text { non nulli etiam propemodum } \\
\text { extinxerunt. }\end{array}$ & $\begin{array}{l}\text { Mais pour ne vous écarter pas } \\
\text { de ce que nous avons dit dès le } \\
\text { commencement, comme entre } \\
\text { nos Empereurs et Législateurs } \\
\text { les plus anciens et les plus } \\
\text { célèbres, et ceux qui estant les } \\
\text { plus sages et les plus pénétrans } \\
\text { ont mieux connu leur propre } \\
\text { intérest, sont tous demeurez } \\
\text { d'accord que l'exemple du } \\
\text { Prince est le fondement général } \\
\text { et primitif du bon gouvernement } \\
\text { de l'Estat, ils sont aussi tous } \\
\text { demeurez d'accord qu'il falloit } \\
\text { comme j'ay dit commencer par } \\
\text { eux-mesmes et par cultiver } \\
\text { soigneusement leurs mœurs, la } \\
\text { vertu et la raison, en un mot } \\
\text { qu'il falloit commencer par } \\
\text { cultiver leur nature raisonnable, } \\
\text { ce précieux et sublime présent } \\
\text { que le ciel a fait à tous les } \\
\text { hommes. }\end{array}$ \\
\hline
\end{tabular}

Ici Bernier interprète plus qu'il ne traduit. Sans doute son interprétation n'est pas infidèle, car les PP. Jésuites, dans les pages qui précèdent ont parlé de ce double principe du gouvernement chinois fondé sur l'exemple du prince et sur l'identité d'intérêts entre le peuple et le roi ; mais on voit quelle importance extrême il lui accorde, non seulement en le plaçant sous la garantie des Législateurs « les plus anciens et les plus célèbres, les plus sages et les plus pénétrans » mais en lui 


\section{La Chine et la formation de l'esprit philosophique en France}

subordonnant le principe de la morale qui est de cultiver la raison.

Quelles sont maintenant les qualités du roi parfait, dont Bernier croit trouver des exemples en Chine ? Le grand principe du gouvernement est l'amour, amour semblable à celui d'un père ou d'une mère pour ses enfants, de telle manière que les peuples n'ont pas besoin « d'exposer leurs souhaits et leurs besoins à leur Prince, le Prince qui a une tendresse naturelle pour eux les prévient et les devine et leur fournit de même amoureusement et sans peine tous leurs besoins »1. Cet amour n'est pas une soumission, une lâche complaisance pour les peuples «foibles et imbécilles $\gg 2$ car si le souverain doit aimer ce que le peuple aime et haïr ce que le peuple hait 3 , il dispose tout au moins d'un ressort qui lui permet d'imposer ses préférences au peuple : « Le Prince a en soy la mesure de tout le Royaume ; il peut mesurer p.383 tous les sujets sur sa propre personne, et par son exemple il les portera à aimer et à hayr ce qu'il aimera et hayra lui-même ${ }^{4}$. Ainsi le prince tient en mains les ressorts du gouvernement et il possède le moyen de faire le bonheur de ses peuples : il n'aura aucune peine à réaliser les désirs et les souhaits de ses peuples, puisque c'est lui par son exemple qui leur aura inspiré ces souhaits et ces désirs.

\footnotetext{
1 ibid., f. $15 \mathrm{r}^{\circ}$. Ce passage n'est pas dans la traduction latine.

2 ibid., f. $15 \mathrm{r}^{\circ}$. Ne se trouve pas dans la traduction latine.

3 Confucius Sinarum Philosophus, p. 26.

4 Mst. 2331 , f. $16 r^{\circ}$. Ne se trouve pas dans la traduction latine.
} 


\section{La Chine et la formation de l'esprit philosophique en France}

Bernier ne trouve donc pas en Chine le modèle d'un gouvernement populaire, mais une sorte de despotisme sentimental où l'autorité du souverain, toute puissante, puisque le peuple a toujours les yeux fixés sur lui pour modeler ses actions sur les siennes, s'exerce non par la force mais par la persuasion, par l'exemple et par l'amour. Les qualités d'un bon roi sont donc des qualités sentimentales. Il doit, dit Bernier, se faire aimer de ses peuples et se les attirer « par la douceur, par la clémence et la bénéficence ». (Les Jésuites avaient écrit : pietate ac beneficentia) ${ }^{1}$. Bernier ne croit donc pas à l'excellence du gouvernement chinois parce que le souverain est lié par la loi, ce qui depuis le $X V I^{e}$ siècle semblait à de nombreux théoriciens la pierre de touche du gouvernement parfait, et ce qui semblera au XVIII ${ }^{e}$ siècle, à Voltaire et aux physiocrates par exemple une raison d'admiration pour la Chine.

L'idéal du gouvernement, selon Bernier, est donc le pouvoir absolu que ne limite aucune puissance extérieure à ce pouvoir même ; ce n'est pas la loi, ce ne sont pas les tribunaux (ou comme on le dira un peu plus tard les parlements) qui peuvent l'empêcher de dégénérer en un despotisme n'ayant pour règle que la fantaisie du souverain. Mais cet absolutisme, s'il est bien compris, comme il semble l'être en Chine, comporte dans sa définition même une limite à l'arbitraire du Prince. S'il est bien compris sans doute, mais on en jugera par les résultats. Or, les résultats que I'on peut constater en Chine - richesse des campagnes, exubérance de la population - sont la preuve que

\footnotetext{
1 Mst. 2331, f. 19 r’. Confucius Sinarum Philosophus, p. 35.
} 


\section{La Chine et la formation de l'esprit philosophique en France}

ce principe est juste, même si l'application en est défectueuse en France. Une mauvaise application d'un principe n'implique nullement que ce principe soit faux. L'exemple de la Chine prouve précisément le contraire.

Bernier n'est donc pas du tout un réformateur qui veut modifier en quoi que ce soit les principes sur lesquels repose le gouvernement du roi de France. Ce n'est même pas un légiste, comme ${ }_{\text {p.384 }}$ on en trouvait au XVII ${ }^{e}$ siècle, ou un philosophe, comme on en trouvera au siècle suivant, croyant que le respect de la loi, même par le souverain, est le moyen de sauvegarder la liberté du peuple, malgré l'absolutisme royal ; ce n'est pas non plus un démocrate, car s'il trouve dans sa traduction latine de Confucius que le roi Ven-Vam «dans chaque ville de I'Empire, et ainsi des citez et des Bourgades à proportion il assigna des fonds pour nourrir et entretenir cent pauvres vieillards », il prend sur lui d'ajouter « chacun selon leur naissance et leur condition » 1 . C'est un bon Français de son temps qui sans rien bouleverser de l'ordre traditionnel et de la hiérarchie des conditions voudrait seulement que le gouvernement du roi de France réalisât mieux I'objet pour lequel il était fait. Avec cette traduction de Confucius et avec les légères retouches qu'il y apporte, Bernier nous apparaît donc comme un des premiers critiques de la politique de son temps, mais nous n'osons pas dire un des premiers réformateurs, tels que seront quelques années plus tard,

${ }^{1}$ Confucius Sinarum Philosophus, p. 10. Bernier, Mst. 2331, f. 12. 


\section{La Chine et la formation de l'esprit philosophique en France}

Fénelon, Boisguilbert ou Vauban ; il se classe plutôt à côté de La Bruyère ${ }^{1}$.

Toutes ces traductions ou ces adaptations de la morale de Confucius, sans parler de la traduction même des PP. Jésuites, montrent l'intérêt que les gens instruits de la fin du XVII ${ }^{\mathrm{e}}$ siècle, quelle que fût la diversité des écoles philosophiques qui les avaient formés, ou dont ils se croyaient les défenseurs, portèrent à cette morale ancienne d'Extrême-Orient qui tout à coup leur était révélée, et à cette politique qui depuis la plus haute antiquité, assurait le bonheur et la prospérité d'un peuple immense. Il nous reste à chercher les raisons de cet intérêt et de cette admiration pour la Chine que provoqua la traduction des Jésuites et à nous demander si c'est par leur nouveauté, totale, absolue, que la morale et la politique chinoises plurent au public français, ou si les principes de cette morale et de cette politique ne se trouvaient pas conformes au contraire à toute une série de préoccupations de gens cherchant le moyen, non certes de bouleverser, mais de corriger tout au moins, la morale et la politique traditionnelles de la France.

p.385 Or comme l'a montré lumineusement $M$. Gustave Lanson 2 , pendant cette période qui va de 1680 à 1715 et où se

\footnotetext{
1 Avec cette restriction peut-être que, si La Bruyère n'a parlé des droits du souverain que « pour en fixer la limite morale, et cette limite c'est toujours le bien de l'état. » (Lange, La Bruyère critique des conditions et des institutions sociales, p. 220), Bernier s'occupe moins de marquer des bornes au despotisme du souverain que de montrer à l'exemple de la Chine tout le bien que l'on peut tirer pour l'État et pour le peuple de ce principe de l'absolutisme si on l'entend comme il doit être compris.

2 La transformation des idées morales et la naissance des morales rationnelles de 1680 à 1715. Revue du Mois, janvier 1910. L'Éveil de la conscience sociale et les premières idées de réformes politiques. ibid., avril 1910.
} 


\section{La Chine et la formation de l'esprit philosophique en France}

forme l'esprit philosophique, le Français moyen, I'honnête homme, cherche à se faire une morale qui ne soit pas une morale imposée par le dogmatisme religieux ni une morale déduite de principes métaphysiques, mais une morale de prétentions plus modestes et mieux adaptée à ses besoins : c'est dans sa conscience - ou comme le disent les traductions de Confucius : dans sa raison - qu'il trouve les fondements de cette morale des honnêtes gens. Et en même temps la morale rejoint la politique : «Le développement de la conscience morale va profiter de celui de la conscience civique et se confondre presque, au moins se mêler avec lui »1. Sans doute en Chine c'est la règle politique qui dérive de la règle morale, mais ces deux règles sont indissolublement liées, et c'est peut-être cette union de la politique et de la morale dont la Chine fournissait un exemple, qui fit la fortune de la traduction de Confucius des PP. Jésuites.

Mais le principe de l'union entre la morale et la politique mis à part, en quoi la traduction de Confucius pouvait-elle aider à dégager de nouvelles tendances, soit au point de vue de la politique, soit au point de vue de la morale ? Était-ce par les nouveautés qu'elle apportait ? Était-ce au contraire par la concordance entre les idées chinoises et les idées traditionnelles de la France, l'exemple chinois apportant en somme le miroir non terni des véritables idées françaises ?

Pour en juger nous pouvons consulter un traité de morale d'un de ces Mondains, Des Coutures, dont M. Lanson a fait

\footnotetext{
${ }^{1}$ Revue du Mois, t. IX, p. 28.
} 


\section{La Chine et la formation de l'esprit philosophique en France}

précisément état pour marquer l'évolution des idées entre le $X V I I^{e}$ et le XVIII ${ }^{e}$ siècles. Le livre de Des Coutures parut en 1687, la même année que le Confucius Sinarum Philosophus, et par conséquent il ne peut s'en inspirer. C'est un traité de morale d'un Français honnête homme, qui ne doit rien à une influence étrangère et qui croit même exprimer les idées traditionnelles de la morale, voire de la morale religieuse.

Si Des Coutures prétend que la félicité peut être obtenue par I'observation du double principe du christianisme : Aimez Dieu, et aimez votre prochain, parce que celui qui l'observera sera le maître ${ }_{\text {p.386 }}$ de ses passions ${ }^{1}$, il n'entend nullement par là que maîtriser ses passions soit la même chose que les supprimer. Il s'inscrit en faux contre la morale stoïcienne qui « n'admettoit point de passions dans son Sage $\gg 2$, et il déclare tout net que «si quelques hommes extraordinaires ont dompté les fureurs de leurs mouvemens, ce n'a point été par leur propre force, la nature n'a point été leur guide, non plus que la raison leur secours ; la grâce qui a secondé leurs efforts a fait ce grand ouvrage »3. Pour les hommes ordinaires qui n'ont ni l'orgueil des stoïciens ni la grâce divine le grand principe moral est dans le juste milieu : « Heureux est celuy qui s'est conservé dans le juste milieu qui fait le repos de la vie, et heureux celuy qui a triomphé de la révolte des passions ${ }^{4}$. C'est le principe essentiel

\footnotetext{
1 Des Coutures, Morale universelle, p. 230-231.

${ }^{2}$ Id., ibid., p. 174.

${ }^{3}$ Id., ibid., p. 85-86.

${ }^{4}$ Id., ibid., p. 86.
} 


\section{La Chine et la formation de l'esprit philosophique en France}

de la morale de Confucius, mais c'est aussi un principe de la sagesse occidentale. Pour Des Coutures, le philosophe qui a le mieux compris la sagesse, c'est Épicure qui « a soutenu que pour être heureux, il ne falloit point aller dans les déserts ni fuir la société des hommes, qu'il suffisoit de borner ses désirs $\gg 1$. Ainsi pas de morale de renoncement total, pas de morale strictement limitée à l'individu, mais au contraire une morale sociale, dont le principe est le désir : « Le désir fait prendre à l'âme l'essor par tout I'Univers, ainsi on pourroit sans injustice l'appeler l'âme de l'âme. C'est luy qui est le lien de la société civile, quand par de communs désirs l'on contribue à son agrément ; il fait aller dans le champ de la gloire ; il nous pousse dans la vaste carrière des sciences ; il fait naître l'émulation qui donne du progrès à toutes les actions $\gg 2$. Or la morale sociale de la Chine n'est-elle pas le couronnement de la morale individuelle et de la morale familiale, ou plutôt même la fin vers laquelle elles tendent. Détail curieux, Des Coutures attribue à la musique une valeur morale et sociale parce qu'elle « nous fait comprendre par ses accords la sympathie qui unit tous les êtres différents de la nature »3. La fable d'Amphion qui bâtit les murailles de Thèbes au son de la flûte est une « moralité » qui nous montre que la musique « eut le pouvoir d'adoucir le naturel farouche des hommes et qu'elle leur montra le secret de s'unir en société de la même ${ }_{\text {p.387 }}$ manière que les cordes de la lire

\footnotetext{
1 Id., ibid., p. 208.

${ }^{2}$ Id., ibid., p. 207-8.

${ }^{3}$ Id., ibid., p. 252.
} 


\section{La Chine et la formation de l'esprit philosophique en France}

faisoient par leur union la justesse de leur concert »1. Et de même Bernier signale à Madame de la Sablière le caractère social que les Chinois attribuent à la musique bien qu'il considère ce fait comme une singularité : «Croiriez-vous que la musique et l'harmonie est chez eux considérée comme un des principaux chefs d'où dépendent la douceur, la concorde, I'union, la tranquillité, le repos, les bonnes mœurs, la vertu et par conséquent le bonheur et la tranquillité de l'empire jusque-là que de vouloir changer, altérer ou abollir la musique, ce seroit quasi comme vouloir perdre I'Estat. Cependant ils ont leurs raisons et je me promets que vous ne les trouverez pas impertinentes $\gg 2$.

Au point de vue de la politique nous pouvons observer une concordance semblable entre les idées de ceux qui se sont enthousiasmés pour la Chine et de ceux qui ne l'ont pas connue, ou qui du moins ne semblent pas s'en être préoccupé.

Nous ne pouvons affirmer que La Bruyère ait lu I'Introduction à la lecture de Confucius du Journal des Sçavans de mai 1688, bien qu'il semble avoir lu les publications spéciales du Mercure Galant relatant la visite des ambassadeurs siamois à Paris ${ }^{3}$. Mais peu importe. Le véritable souverain, tel qu'il le comprend, le véritable souverain de la France, s'il se conformait au principe qui fonde son autorité, serait tel que l'empereur de Chine, qui, lui du moins selon Bernier, réalise sa définition :

1 Id., ibid., p. 256.

2 Bernier, Mst. 2331 f. 5 vo.

3 Lange, op. cit., p. 217. 


\section{La Chine et la formation de l'esprit philosophique en France}

« Nommer un roi Père du Peuple est moins faire son éloge que I'appeler par son nom, ou faire sa définition » (Ed. 7).

« Tout prospère dans une monarchie où l'on confond les intérêts de l'État avec ceux du Prince » (Ed. 7) ${ }^{1}$.

Mais le Prince, « s'il est bon Prince », ne doit pas seulement être persuadé de cette identité entre son intérêt particulier et l'intérêt de ses peuples; il y a un autre lien plus fort qui lie le souverain à ses sujets : ce lien c'est la bonté, première qualité d'un roi. Au souverain appartiennent en effet « les obligations $p$. 388 indispensables de bonté, de justice, de soins, de défense, de protection 》2. Bossuet lui aussi, bien que théoricien de l'absolutisme a justifié le principe de l'autorité royale de la même manière que La Bruyère, ainsi que l'a montré Lange : « L'autorité royale est paternelle et son propre caractère est la bonté ${ }^{3}$. « Les princes sont faits pour être aimés » ${ }^{4}$. C'est que pour les partisans du pouvoir absolu (qui, remarquons-le, ne croyaient nullement défendre le despotisme), il n'y avait que deux moyens de concilier le principe de l'absolutisme et la liberté des peuples : ou bien soutenir avec Bossuet et La Bruyère que

1 Du Souverain ou de la République, t. I, p. 384. Boursault écrit aussi dans Esope à la Cour :

Protéger votre peuple autant qu'il vous révère

C'en est être Seigneur le véritable Père

Et Père de son peuple est un titre plus grand

Que ne le fut jamais celui de Conquérant.

(A. I, sc., 3, Ed. 1702 p. 5).

2 Du Souverain et de la République, t. I, p. 385.

3 Politique tirée de l'Ecriture sainte, III, art. 3 (titre de l'article).

4 ibid., art. 3 propr. 3. 


\section{La Chine et la formation de l'esprit philosophique en France}

I'autorité royale est analogue à celle d'un père sur ses enfants, ou d'un pasteur sur son troupeau, parce que cette autorité se corrige d'elle-même par la communauté d'intérêts entre le souverain et ses sujets et par la bonté du premier à l'égard des seconds, ou bien prétendre avec d'Aguesseau et d'autres publicistes du temps de la Fronde ${ }^{1}$ que le roi se trouve lié luimême par la loi qu'il a faite : « Toute substance du gouvernement français est contenue dans ces deux principes : I'un que le gouvernement est purement monarchique, le roi ne devant compte de sa conduite qu'à Dieu seul, I'autre que cette puissance suprême est tempérée uniquement par les lois que nos rois se dictent à eux-mêmes comme à leurs peuples, en sorte qu'il n'y a point de monarques qui puissent dire plus véritablement à l'exemple des empereurs romains : quoique audessus des lois, nous vivons cependant sous les lois, ou pour se servir d'une autre de leurs expressions, il est digne de la majesté du souverain de reconnoître qu'il est lié par les lois » 2 .

Aucune de ces deux théories n'est sans difficultés, car la première qui veut préserver tout d'abord le pouvoir absolu du roi, parce qu'il est de droit divin, fait dépendre le bonheur du peuple du cœur et de l'intelligence du roi, ce qui ramène la politique à un problème d'éducation ; mais la meilleure éducation ne peut faire que le futur roi devienne nécessairement intelligent et bon. Quant à la seconde théorie qui, mettant l'accent sur la liberté des peuples, s'efforce de lier le roi, tout en

\footnotetext{
1 Voir les textes rassemblés par Lacour-Gayet : L'Education de Louis XIV, p. 311-312.

2 d'Aguesseau, Fuvres, éd. Pardessus, t. X, p. 23.
} 


\section{La Chine et la formation de l'esprit philosophique en France}

reconnaissant son pouvoir absolu, elle ouvre la porte aux remontrances, c'est-à-dire au contrôle des juristes. Mais où les juristes passeront, les peuples p.389 risquent de vouloir passer aussi. Difficultés des deux côtés, parce que ces deux théories ont essayé de concilier par peur du despotisme, deux choses contradictoires, l'absolutisme et la liberté ${ }^{1}$. Les philosophes et les économistes au siècle suivant seront plus conséquents ou du moins auront moins peur des mots : ils inventeront le despotisme éclairé ou le despotisme légal. L'exemple chinois d'ailleurs les y aidera 2.

Bernier, nous l'avons vu, voulait proposer aux jeunes princes l'exemple des empereurs chinois, parce que la morale chinoise insinue doucement que le souverain doit avoir de la majesté et de la gravité mais que ces qualités doivent être tempérées de beaucoup de douceur et d'humanité. Or ces qualités ne sontelles pas les mêmes que celles que La Bruyère attribue, non certes au souverain idéal et bon pour tous les peuples, mais au souverain idéal pour les Français ? 3 Sans doute « le caractère des Français demande du sérieux dans le souverain ». «Que de dons du ciel ne faut-il pas pour régner ? » Mais le souverain doit

\footnotetext{
1 Depuis que ceci a été écrit, $M$. Carcassone a montré surabondamment que « c'était... une idée courante dans la première moitié du siècle que la monarchie française devait se distinguer du despotisme. » (Montesquieu et le problème de la constitution française au XVIIIe siècle, Ch. I : Les conceptions de la monarchie française avant Montesquieu, p. 1-61).

2 Pinot, Les Physiocrates et la Chine au XVIII siècle, Revue d'histoire moderne et contemporaine, t. VIII, 1907, p. 200-214.

3 Rappelons que ce passage n'ayant pas été reproduit par le Journal des Sçavans, non plus que dans la Copie des Etrenes envoyées à Madame de la Sablière, La Bruyère n'a pu le connaître.
} 


\section{La Chine et la formation de l'esprit philosophique en France}

avoir «...le cœur ouvert, sincère et dont on croit voir le fond, ainsi très propre à se faire des amis, des créatures et des alliés »1. Et Bossuet dit aussi au Prince : «Ne soyez point orgueilleux : rendez-vous accessible et familier »2. D'ailleurs, dans les propres mémoires de Louis XIV, on trouverait des affirmations analogues qui montrent bien que, tout au moins sur le principe, tout le monde était d'accord :

«Comme nous sommes à nos peuples nos peuples sont à nous » 3 . Et surtout cette formule lapidaire qui n'a rien à envier à celles de Bernier, de Bossuet ou de La Bruyère : « Quand on a l'État en vue, on travaille pour soi. Le bien de I'un fait la gloire de l'autre. Quand le premier est heureux, élevé et puissant, celui qui en est cause en est glorieux, et par conséquent doit plus goûter p.390 que ses sujets, par rapport à lui et à eux tout ce qu'il y a de plus agréable dans la vie $\gg 4$.

Mais Louis XIV, qui acceptait volontiers ces principes, les oubliait parfois dans la pratique, et c'est la raison pour laquelle non seulement des prédicateurs comme Bossuet, mais des laïcs comme Bernier et La Bruyère essayaient de I'y ramener.

\section{$*$}

Si les critiques ou les observations de Bossuet perdent de leur valeur, au point de vue de la critique politique, parce qu'il est

\footnotetext{
${ }^{1}$ Du Souverain et de la République, t. I, p. 388-9.

2 Politique tirée de l'Ecriture sainte. III, art. 3, propr. 3. Cf. Lange, loc. cit.

3 Mémoires pour l'année 1661. Ed. Longnon, p. 91.

4 Réflexions sur le métier de Roi. Ed. Longnon. p. 226.
} 


\section{La Chine et la formation de l'esprit philosophique en France}

prédicateur, si La Bruyère n'est qu'un observateur aigri des mœurs de son temps parce qu'on ne rend pas justice à son mérite personnel, si Bernier se montre optimiste en supposant que l'exemple chinois pourra servir à remédier à certains maux, grâce aux moyens traditionnels, à savoir une bonne éducation du futur roi, des réformateurs vont venir, d'autant plus nombreux que se précipiteront les malheurs de la fin du règne de Louis XIV ; et, non contents de signaler le mal, ils voudront y apporter le remède.

Le premier de ces réformateurs fut Fénelon.

Ce n'est pas que Fénelon ait fait appel à la Chine pour réformer le gouvernement français : il a cherché ailleurs ses modèles, et il les a trouvés en Occident. Mais il a connu l'exemple chinois, et, l'ayant connu, il l'a repoussé.

Il a en effet composé un Dialogue des Morts, où les deux interlocuteurs sont Socrate et Confucius, ces deux philosophes dont on se plut à rapprocher les noms, dès qu'on connut quelque chose de l'ancienne morale chinoise, non seulement, parce qu'ils vécurent tous les deux à la même époque, mais parce qu'ils essayèrent tous les deux de « ramener la philosophie du ciel sur la terre » et d'en faire uniquement l'étude de l'âme humaine. Or dans ce Dialogue, qui ne parut d'ailleurs qu'en $1787^{1}$, Fénelon nous révèle ses idées sur la Chine, sur son antiquité, sur les origines du peuple chinois, sur la morale et la politique de la

\footnotetext{
1 Nous ne connaissons malheureusement pas la date de la composition de ce dialogue, de sorte que nous ne pouvons savoir si elle est antérieure ou postérieure à la date de composition de Télémaque, qui est d'ailleurs ellemême incertaine.
} 


\section{La Chine et la formation de l'esprit philosophique en France}

Chine, et il est curieux de constater qu'il ne partage pas l'admiration de ses contemporains pour ce pays, et encore moins la fureur dithyrambique de ses amis, les Jésuites. Cependant tout au long de la p.391 Querelle des Cérémonies chinoises, il a été tenu au courant des tribulations des Jésuites à Rome, d'abord par l'abbé de Chanlérac, ensuite par le P. Daubenton ; il a même pris parti pour eux en 1702, dans une lettre adressée au P. de la Chaize non certes sur le fait des cultes chinois qu'il ne juge pas, mais sur la légitimité de l'attitude des missionnaires jésuites en Chine ${ }^{1}$. Or malgré ces affinités avec les Jésuites, et malgré les sympathies qu'il a pour eux, il ne partage aucunement leur admiration pour la Chine, pour Confucius et pour sa morale.

Fénelon ne croit pas à l'antiquité fabuleuse de la Chine, pas plus d'ailleurs qu'à celle des Égyptiens, et il résout très facilement le problème des origines chinoises : «Quelques siècles avant le vôtre (dit Socrate à Confucius) des Asiatiques, peut-être des Babyloniens, peuplant l'Asie de proche en proche out poussé une colonie jusqu'à la Chine et y ont fondé un empire ». Mais rétorque Confucius, les observations anciennes de nos astronomes ne prouvent-elles pas notre antiquité ? 2 Nullement, répond Fénelon, les raisons qui persuadent aux astronomes occidentaux que vos observations doivent être véritables peuvent avoir frappé de même vos astronomes et leur avoir fourni une vraisemblance pour autoriser vos vaines fictions

\footnotetext{
1 Correspondance, t. II, p. 466-471.

2 En réalité, pour cet exposé, nous avons suivi l'ordre inverse des arguments du Dialogue.
} 


\section{La Chine et la formation de l'esprit philosophique en France}

sur les antiquités de la Chine ». Il n'est donc pas prouvé que la Chine soit supérieure à l'Occident par son antiquité. Il n'est pas prouvé davantage que l'ancienneté des arts dont elle se vante soit une raison de supériorité, car l'imprimerie « n'est qu'une commodité pour les gens de lettres, la poudre à canon est une invention pernicieuse, quant à la porcelaine ... ». Cela était plus embarrassant, car on admirait beaucoup alors la porcelaine chinoise que l'on pouvait connaître par les belles pièces des collections de Richelieu et de Mazarin ou par les cadeaux rapportés du Siam par le Chevalier de Chaumont, peut-être aussi (cela dépend de la date de la composition de ce dialogue) par les pièces assez nombreuses que commençaient à rapporter les navires de la Compagnie de la Chine. Mais on ignorait le secret de la fabrication de la porcelaine. Le kaolin était inconnu et le mot n'existait pas encore. Ce mystère ne faisait que piquer la curiosité et contribuait à créer l'idée de la supériorité de la Chine sur l'Occident. Fénelon-Socrate qui ne veut laisser à la Chine aucune supériorité p.392 écarte l'objection possible par un argument qui n'est peut-être pas des meilleurs : « Vous avez cela de commun avec les peuples les plus barbares qui ont quelquefois le secret de faire en leur pays par le secours de la nature des choses ce que les nations les plus industrieuses ne sauroient exécuter chez elles ». Mais la morale ? N'est-ce pas le plus grand titre de gloire des Chinois ? Pas du tout répond Socrate, car selon les voyageurs « le peuple de la terre le plus vain, le plus superstitieux, le plus intéressé, le plus injuste, le plus menteur, c'est le Chinois ». Comment donc expliquer que le peuple chinois vive heureux depuis de nombreux siècles si on lui 


\section{La Chine et la formation de l'esprit philosophique en France}

refuse la vertu qu'il considère comme le principe et l'âme même de son gouvernement et de sa vie sociale ? Ici Fénelon fait une distinction entre la morale qui remonte aux principes du bien et du vrai, mais qui est seulement le partage de quelques âmes privilégiées et certaines vertus « d'habitude et d'opinion », dont le peuple peut être capable, «sur l'autorité de ceux qui ont gagné sa confiance ». Ceux qui ont gagné sa confiance, ce sont les sages comme Confucius, ce sont aussi les empereurs qui ont toujours eu en vue le bien du peuple et qui lui ont imposé des règles capables d'assurer la tranquillité publique. Ces vertus « d'habitude et d'opinion » ne sont donc en réalité qu'une discipline sociale ; mais elles ne sont pas le produit d'une morale supérieure à la morale de l'Occident. Personne au XVIII ${ }^{\mathrm{e}}$ siècle n'a compris aussi bien que Fénelon le caractère social de la morale chinoise qui n'est en réalité qu'une sage politique. Mais il repousse cette morale parce qu'elle manque de caractère dogmatique. Et c'était la raison même pour laquelle l'admiraient tant les autres compilateurs de la morale de Confucius !

Mais cette sage politique, capable d'assurer le bonheur des peuples est-elle le privilège de la Chine ? Fénelon ne le pense pas non plus, car il y a eu en Occident des royaumes heureux et prospères à l'exemple de la Chine, bien que se gouvernant par des principes différents : il y a eu la Crète, lorsqu'elle était régie par les lois de Minos - dont le système politique et social présente d'ailleurs certains traits communs avec le système chinois -, mais il y aura surtout Salente qui appliquera quelques-uns des principes de Minos, mais revus et corrigés par Mentor et Fénelon. Or dans cette république idéale de Salente, 


\section{La Chine et la formation de l'esprit philosophique en France}

les points de ressemblance que I'on peut trouver avec l'empire chinois sont précisément les caractères qu'un Bossuet, un La Bruyère ou même un Bernier attribuaient à la monarchie française, si elle eût été parfaite ; quant aux détails ils ne sont ni de la France, ni de la Chine.

p.393 Le roi est le père de ses peuples; le principe qui lie le souverain et les sujets, ce n'est pas de se faire craindre et d'être craint, c'est d'aimer et d'être aimé ${ }^{1}$. A cet égard, Fénelon est d'accord avec Bernier, Bossuet et La Bruyère. Mais il se sépare d'eux par le pouvoir qu'il donne à la loi : ce n'est pas que la loi soit une limitation du pouvoir du souverain, mais elle l'engage lui aussi : «Il peut tout sur les peuples mais les lois peuvent tout sur lui » 2. C'est l'idée même de d'Aguesseau. Sur le principe du pouvoir du souverain, les idées de Fénelon n'ont donc rien qui lui soit absolument personnel.

Mais Fénelon ne se contente pas, soit en philosophe, soit en juriste de chercher la définition du roi parfait. Il veut aussi déterminer dans la pratique ce qui résultera pour le bonheur des peuples de cette perfection du souverain. Mentor qui veut aider Idoménée à réaliser la cité idéale est bien obligé d'entrer dans quelques détails. Or, la pratique, dont il va préciser les règles, lui est suggérée par l'exemple d'États florissants tels que l'Égypte ou la Crète. Si quelques États comme ceux-là sont parvenus à la richesse et s'ils ont fait le bonheur de leurs populations c'est qu'ils ont sacrifié les arts inutiles qui ne développent que le luxe

\footnotetext{
${ }^{1}$ Fénelon, Télémaque, éd. Cahen, t. II, p. 191-3.

${ }^{2}$ Id., ibid., t. I, p. 190-1.
} 


\section{La Chine et la formation de l'esprit philosophique en France}

- disons d'un mot l'industrie - à l'agriculture. Car le développement de l'agriculture amène comme conséquence nécessaire, suivant les idées de l'époque, l'abondance de la population ; et ces deux choses, agriculture florissante et population nombreuse sont la preuve évidente d'un bon gouvernement. C'est ainsi que Mentor et Télémaque, dès qu'ils aperçoivent les côtes en amphithéâtre de l'île de Crète, et qu'ils peuvent distinguer la prospérité de la campagne crétoise peuvent être assurés de l'excellence des lois de Minos : «De tous côtés nous remarquions des villages bien bâtis, des bourgs qui égalaient des villes, et des villes superbes. Nous ne trouvions aucun champ où la main du diligent laboureur ne fût imprimée ; partout la charrue avait laissé de creux sillons ; les ronces, les épines et toutes les plantes qui occupent inutilement la terre sont inconnues en ce pays. Nous considérions avec plaisir les creux vallons où les troupeaux de bœufs mugissaient dans les gras herbages le long des ruisseaux; les moutons paissaient sur le penchant d'une colline; les vastes campagnes couvertes de jaunes épis, riches dons de la féconde Cérès; enfin les montagnes ornées de pampres et de grappes d'un raisin déjà coloré qui ${ }_{\text {p.394 }}$ promettait aux vendangeurs les doux présents de Bacchus pour charmer les soucis des hommes ». Il est permis de trouver quelque fadeur vieillotte dans cette description idyllique. Mais à cette époque ce n'était pas un simple développement littéraire. C'est en effet de la même manière que les missionnaires et les voyageurs qui arrivaient à Canton manifestaient leur enthousiasme pour la Chine : les plaines luxuriantes où pas un pouce de terre n'était laissé en friche, les 


\section{La Chine et la formation de l'esprit philosophique en France}

jardins en terrasse, les montagnes cultivées jusqu'au sommet, les foules innombrables qui circulaient sur les routes, sur les rivières et dans les rues des villes, tout cela provoquait un enthousiasme qui s'exprimait en formules peut-être un peu trop banales, mais un enthousiasme d'autant plus sincère qu'il n'était pas provoqué seulement par le plaisir des yeux, mais aussi par la découverte des causes de cette prospérité.

A part le principe physiocratique du gouvernement, Fénelon n'aurait pu trouver en Chine son rêve de république idéale. Socrate reproche en effet à la Chine d'être restée repliée sur elle-même, dans l'ignorance du reste du monde, ce qui a provoqué dans le peuple chinois un excès d'orgueil, une croyance injustifiée en ses mérites incomparables, et, avec le mépris des étrangers, un manque d'honnêteté dans les relations commerciales. Or ce qui a fait la fortune et la grandeur des Phéniciens, comme Narbal I'explique à Télémaque, ce sont des principes tout contraires à ceux de la Chine : « Recevez bien et facilement tous les étrangers ; faites-leur trouver dans vos ports la sûreté, la commodité, la liberté entière ; ne vous laissez jamais entraîner ni par l'avarice ni par l'orgueil. Le vrai moyen de gagner beaucoup est de ne vouloir jamais trop gagner et de savoir perdre à propos. Faites-vous aimer par tous les étrangers ; souffrez même quelque chose d'eux : craignez d'exciter leur jalousie par votre hauteur. Soyez constants dans les règles du commerce; qu'elles soient simples et faciles; accoutumez vos peuples à les suivre inviolablement ; punissez sévèrement la fraude et même la négligence ou le faste des 


\section{La Chine et la formation de l'esprit philosophique en France}

marchands qui ruinent le commerce en ruinant les hommes qui le font $\gg 1$.

Si Fénelon invoque souvent le bonheur du peuple, il n'est cependant nullement démocrate : c'est au roi seul qu'il appartient p.395 de l'assurer par les moyens qui lui semblent appropriés, sans avoir besoin de consulter le peuple. En outre dans la république idéale qu'il imagine il s'efforce d'établir une hiérarchie rigide entre les différentes conditions. Ceux qui ont une noblesse plus ancienne et plus éclatante ont le premier rang, parce que « la distinction la moins exposée à l'envie est celle qui vient d'une longue suite d'ancêtres ». On compte les quartiers de noblesse et cela suffit pour assurer la hiérarchie et la discipline, tandis qu'on peut toujours discuter du mérite. C'était déjà un argument de Pascal. A cet égard, Fénelon, peut-être parce qu'il est d'Église et qu'il a le sens de la hiérarchie, se distingue de La Bruyère qui, dans sa vanité blessée de bourgeois ombrageux eût voulu faire passer le mérite avant la naissance, et il se sépare aussi de tous les admirateurs de la Chine qui ont cru trouver là, et là seulement, un pays où le mérite permît de parvenir aux plus hautes dignités de l'État, un pays où chacun était classé dans la hiérarchie sociale conformément à son mérite, sans que la faveur du prince ou les avantages de la naissance permissent de s'insinuer frauduleusement à une place où I'on n'était appelé ni par ses vertus ni par son savoir. La chose devait être rare ; ou

\footnotetext{
1 Livre III, t. I, p. 120-121. Cf. aussi Livre X, t. II, p. 90. Mentor fait régner sans le port de Salente une « justice sévère » si bien que «la franchise, la bonne foi, la candeur semblaient du haut de ces superbes tours appeler les marchands des terres les plus éloignées. »
} 


\section{La Chine et la formation de l'esprit philosophique en France}

même inexistante en Europe pour que tous les missionnaires de quelque nationalité qu'ils fussent, eussent célébré en termes dithyrambiques cette merveille de la hiérarchie chinoise qui n'était fondée que sur le mérite.

La Chine n'est donc pas un exemple pour Fénelon, ni quant à la morale, ni quant à la politique. Nous savons par le Dialogue entre Socrate et Confucius qu'il repoussait la morale formaliste de la Chine qui se contente d'une conformité entre les actes et les usages établis sans chercher à rapporter les actes individuels aux principes éternels du vrai et du bien. Mais en ce qui concerne la politique chinoise nous ne connaissons pas son opinion. Malgré les ressemblances entre la Crète (ou Salente) et Pékin, les différences sont trop grandes pour que nous puissions même hasarder l'idée que Fénelon ait pu être influencé par l'admiration de la politique chinoise. Mais ces différences s'expliquent-elles par l'intention, chez Fénelon, de critiquer le gouvernement chinois et de lui en opposer un autre, de même que dans son Dialogue des Morts il fait critiquer par Socrate la morale de Confucius ? Cela même est peu vraisemblable, car cette idée n'aurait pu lui venir - la politique chinoise lui étant en elle-même indifférente - que s'il avait trouvé en France de nombreux admirateurs de cette politique. Or, en 1694, on se souciait peu des principes du gouvernement chinois. p.396 Sans doute le Confucius Sinarum philosophus les avait exposés, mais c'était un livre en latin et ses traducteurs et adaptateurs, Simon Foucher et $\mathrm{J}$. de la Brune s'étaient intéressés à la morale plus qu'à la politique. La traduction de Bernier était restée manuscrite et par conséquent inconnue. Les Nouveaux Mémoires sur l'état 


\section{La Chine et la formation de l'esprit philosophique en France}

présent de la Chine du P. Le Comte ne devaient paraître que deux ans après la composition de Télémaque. Il nous faut donc exclure I'hypothèse, si séduisante qu'elle soit, d'une critique aussi bien que d'une imitation.

Il n'en est pas moins vrai qu'il y a des concordances assez grandes entre le gouvernement de la Chine, tel que le décrivaient les missionnaires et l'idéal de gouvernement que se faisait Fénelon. Cela explique peut-être l'admiration des missionnaires pour la Chine, car son gouvernement semblait satisfaire certaines des exigences que les Français de cette époque jugeaient nécessaires et que le gouvernement de Louis XIV ne réalisait pas. Lorsque les Jésuites vantaient la politique chinoise, ou lorsque Fénelon, par la bouche de Mentor, fixait aux Salentins les règles d'un bon gouvernement, volontairement ou non, ils critiquaient le roi de France, puisque les principes de gouvernement de Salente, de Pékin et de la France étaient les mêmes. Les principes, mais pas I'application. A cet égard les idées politiques de Fénelon, tout comme celles de La Bruyère ne laissent pas de nous intéresser : elles nous montrent sur quels points particuliers portaient les désirs de réformes, et les raisons pour lesquelles certains écrivains postérieurs, comme Vauban, feront des emprunts au gouvernement de la Chine; c'est qu'ils les croyaient nécessaires, non pour corriger ou rectifier le principe du gouvernement français, mais pour l'aider à se réaliser.

Vauban, pour justifier le principe de cet impôt nouveau qu'il propose d'instituer, la dîme royale. c'est-à-dire un impôt sur le 


\section{La Chine et la formation de l'esprit philosophique en France}

revenu dont personne ne serait exempt, en remplacement de la taille, impôt personnel et limité à une catégorie de citoyens, éprouve le besoin, pour justifier sa proposition, de montrer que ce n'est pas une innovation puisque l'Écriture sainte en a parlé, que les empereurs grecs et romains I'ont employé et que « nos Rois de la première et de la seconde Race I'ont fait aussi »1. En outre les effets en sont aisément vérifiables, puisque cette forme d'impôt existe en différentes parties du monde : on prétend que le Roy d'Espagne s'en sert dans l'Amérique et dans les Isles p.397 que le Grand Mogol et le Roy de la Chine s'en servent aussi dans l'étendue de leurs Empires 2.

Quels sont les avantages de cet impôt ? Le premier et le plus grand d'où les autres découleront tout naturellement est de remettre en faveur I'agriculture. En effet la campagne est délaissée, «les terres... sont venues à un très bas prix », à cause de la charge exagérée des tailles personnelles. La dîme royale, qui supprimerait l'arbitraire de la fixation de la taille et qui diminuerait la quotité de l'impôt, puisqu'il retomberait sur la nation tout entière, assurerait la stabilité au paysan et lui permettrait de travailler sans crainte d'être dépouillé du fruit de son travail. Il y aurait donc plus de travail, et partant plus de bien-être pour le paysan qui serait mieux nourri et mieux vêtu. Et par une conséquence que Vauban croit nécessaire, sans démonstration, comme le croient aussi Fénelon et tous les contemporains (sans parler même des philosophes du XVIII

\footnotetext{
1 Vauban, Dixme royale, p. 10.

${ }^{2}$ Id.. ibid., p. 11.
} 


\section{La Chine et la formation de l'esprit philosophique en France}

siècle) la richesse de l'agriculture et le bien-être des paysans augmenteront la population : «Le Royaume, dont le peuple est fort diminué se repeuplera bientôt, attendu qu'il s'y fera beaucoup de mariages, que les enfans y seront mieux nourris par rapport à la faiblesse de leur âge, et les Paysans mieux vêtus $\gg 1$.

Le problème de la population est un de ceux qui ont le plus préoccupé Vauban. C'est qu'il avait pu constater, au cours de ses voyages à travers la France, la dépopulation des villes et des campagnes. Déjà Fénelon avait écrit au roi - ou du moins peutêtre projeté d'écrire : « Vos peuples que vous devriez aimer comme vos enfans et qui ont été jusqu'ici si passionnés pour vous, meurent de faim. La culture des terres est presque abandonnée, les villes et la campagne se dépeuplent... La France entière n'est plus qu'un grand hôpital désolé et sans provision $\gg 2$.

Mais pour aider à la repopulation il aurait fallu connaître deux choses essentielles qui étaient inconnues du temps de Vauban, l'état exact de la population du royaume et les lois de l'accroissement de la population.

Nous l'avons vu, lorsque nous avons parlé de la chronologie chinoise, les chronologistes en arrivaient comme le P. Pétau, à supposer des accroissements énormes de population aux époques primitives, pour faire cadrer la chronologie de la Bible avec la p.398 chronologie des plus anciens peuples. C'était le

${ }^{1}$ Id. . ibid. , p. 129.

2 Lettre au Roi, Correspondance, t. II, p. 337. 


\section{La Chine et la formation de l'esprit philosophique en France}

domaine de la fantaisie pure. Le XVIII siècle, au contraire, cherchera des règles précises qui peuvent mener à une science démographique : pour les besoins de la chronologie Newton, Fréret, Voltaire s'efforceront de déterminer la durée moyenne du règne des rois de Rome et la durée moyenne de la vie humaine. On discutera pour savoir s'il naît plus d'hommes que de femmes. L'abbé de Saint-Pierre, se servant d'un dénombrement de la population de Paris fait sous le ministère de Colbert, et de la comparaison entre les naissances et les morts, arrivera à conclure que la population ne peut doubler qu'en douze cents ans ${ }^{1}$. Voltaire tâchera d'établir des tables de mortalité entre la naissance et l'âge adulte. Mais ce ne sont que des tâtonnements, parce que les statistiques ne portent que sur de petits groupes de population et sont par suite insuffisantes. Quand elles sont plus générales, elles sont fausses 2 .

Vauban semble s'être préoccupé de cette question de l'accroissement de la population puisque dans son Éloge de Vauban, prononcé en 1793, Fr. Joseph Noël nous apprend que Vauban avait composé des mémoires «sur l'histoire en général et la géographie, sur le dénombrement des peuples et I'accroissement des 'hommes avant et après le Déluge... »3 . Le général Haxo signale parmi les papiers du château du Mesnil,

\footnotetext{
1 Utilité des Dénombremens, Ouvrajes de Politique, t. IV, p. 255-7.

2 Sur l'importance que les philosophes ont attachée à cette question de la population au XVIII siècle, voir l'article, Population dans I'Encyclopédie et I'article Population du Dictionnaire Philosophique de Voltaire.

3 Cité par de Rochas d'Aiglun, Vauban. Oisivetés et Correspondance, t. I, 97.
} 


\section{La Chine \\ et la formation de l'esprit philosophique en France}

outre des notes sur le recensement des peuples, une Supputation de la progression des peuples en Amérique ${ }^{1 .}$

Mais avant de pouvoir résoudre le problème de l'accroissement de la population - Vauban I'a bien compris - il faut qu'il y ait des dénombrements exacts de la population actuelle, d'après les différentes classes sociales. Ici l'exemple de la Chine montre à Vauban que son idée n'est pas une utopie, puisque le gouvernement chinois a pu faire une statistique de sa population, qui pourtant est cinq ou six fois plus nombreuse que celle de la France. Les auteurs de relations sur la Chine au XVII siècle, Trigault ${ }^{2}$, Bellefleur ${ }^{3}$, s'étaient déjà émerveillés des résultats de ces dénombrements de la population chinoise qui montait, au chiffre ${ }_{\text {p.399 }}$ de 58.550.081 âmes, sans compter «les femmes, les enfans de la mammelle, les soldats, les Magistrats, les Eunuques, ceux qui estoient issus du sang royal et les Escholiers », ce qui devait porter la population totale de l'empire à cent millions au minimum. Malgré les difficultés que doit présenter l'établissement d'une semblable statistique, les Chinois ont mené leur tâche à bien grâce à un système ingénieux que décrit le P. Le Comte et que Vauban voudrait faire adopter en France tant il le trouve « aisé » et «bien ordonné » 4 . On pourrait même appliquer cette méthode de dénombrement aux bestiaux, mais ce n'est pas absolument nécessaire.

\footnotetext{
1 Id., ibid., p. 98-9.

2 op. cit., p. 11.

3 op. cit., p. 21-22.

4 Vauban, Dixme Royale, p. 185.
} 


\section{La Chine et la formation de l'esprit philosophique en France}

Or voici en quoi consiste cette méthode : « Il me paroit que le meilleur [moyen] qu'on puisse mettre en usage est celuy de diviser tout le peuple par Décuries comme les Chinois ou par Compagnies comme nos Regimens et de créer des Capitaines de Parroisses, pourvus du Roy, qui auront sous eux autant de Lieutenans qu'il y aura de fois cinquante maisons ou environ, lesquels seront pareillement sous-ordonnez au Commandant des Lieux où y en aura ». Ces « Lieutenans » seront tenus de visiter quatre fois par an les cinquante familles dont ils auront la charge, et de tenir registre des mouvements de population qui peuvent se produire à l'intérieur de ces familles, naissances, décès, etc., ne se contentant pas d'une simple déclaration, mais étant tenus de «se faire représenter toutes les Familles, Hommes, Femmes et Enfans ; les voir et s'informer des changemens et nouveautez qui y arrivent ». Vauban voudrait aussi que ces statisticiens aient des pouvoirs plus étendus et qu'ils « soient chargez d'appaiser les querelles qui arriveront dans ces cinquante maisons ou Ménages et les empêcher de se plaider les uns les autres »1. Ce Lieutenant serait donc une sorte d'officier de l'état-civil, doublé d'un juge de paix.

Pour hardies que puissent nous paraître les solutions que Vauban propose pour corriger l'état politique et social de la France, il n'est pas pour cela un utopiste : les maux qu'il voulait guérir n'étaient que trop réels ; le problème de la « peuplade » préoccupait tous les gens de bien et il est très naturel que les descriptions des voyageurs célébrant à l'envi les foules

${ }^{1}$ Id., ibid., p. 215-7. 


\section{La Chine et la formation de l'esprit philosophique en France}

encombrant les rues, les routes et les canaux de la Chine aient provoqué de l'admiration pour le gouvernement chinois, et le désir de l'imiter.

p.400 Mais il est un autre fait qui saisissait d'étonnement les voyageurs en Chine, c'est que dans ces foules grouillantes des villes et des campagnes, il n'y avait ni mendiants ni vagabonds ${ }^{1}$. Or à cette époque, au commencement du XVIII ${ }^{\mathrm{e}}$ siècle, la foule de mendiants et de vagabonds était devenue si grande en Europe non seulement dans les villes mais dans les campagnes que tous les gouvernements étaient obligés de s'en préoccuper. Un protestant français, réfugié en Angleterre, où le danger du paupérisme et de la mendicité était aussi grand qu'en France, crut trouver dans les préceptes de Confucius la solution de ce problème social. Est-il besoin de dire que la solution qu'il proposa différait radicalement des principes qu'adoptèrent les gouvernements de France et d'Angleterre ?

En 1685, un protestant français, originaire de la Bresse, François Leguat, fut obligé par la Révocation de l'Édit de Nantes d'abandonner sa famille, ses biens et sa patrie pour ne pas trahir sa foi. Il se réfugia en Hollande où la vie lui fut assez pénible, si bien qu'en 1690, quoiqu'il fût plus que quinquagénaire, il accepta de partir sur le navire qu'armaient les frères du Quesne pour aller coloniser une île sans possesseur de l'archipel des Mascareignes, dans I'océan Indien. Leguat fut déposé avec sept compagnons gascons ou saintongeais, tous protestants comme lui, dans une île déserte, avec les provisions nécessaires, et ils

\footnotetext{
${ }^{1}$ Le Gentil est peut-être le seul voyageur qui affirme le contraire.
} 


\section{La Chine et la formation de l'esprit philosophique en France}

menèrent pendant deux ans une vie idyllique, loin des turpitudes du monde et loin de toute contrainte sociale. Cette vie eût été parfaite et eût pu durer longtemps, si les compagnons de Leguat avaient été comme lui quinquagénaires, mais c'étaient des hommes jeunes, qui n'avaient pas atteint la trentaine, et dans leur île déserte, s'ils étaient bien gardés contre les « occasions », comme disait le petit abbé de Choisy, ils n'étaient pas cependant à I'abri des tentations. Ils décidèrent donc d'abandonner leur île et de gagner coûte que coûte l'île Maurice. Après de nombreuses péripéties, ils atteignirent cette île ; mais le gouverneur hollandais, pour s'emparer de ce qu'ils possédaient, les fit déporter sur un rocher isolé en plein océan. Au bout de trois ans, le gouverneur se rappela qu'il appartenait au tribunal de Batavia de régler le sort de ces captifs, et ils furent transférés à Batavia, où le tribunal leur donna raison contre le gouverneur. Rapatrié en Europe, Leguat alla s'établir en Angleterre. L'aventure avait duré sept ans.

C'est une aventure, une belle aventure, mais trop romanesque pour être vraie : ce Voyage de François Leguat n'est en effet qu'un Voyage extraordinaire, une robinsonnade avant Robinson ${ }^{1}$. Le véritable auteur de ce roman d'aventures est un protestant français réfugié en Angleterre, Maximilien Misson, qui dans un cadre dont les éléments sont empruntés à des récits de

1 M. G. Lanson dans son cours de 1909 (Revue des Cours et Conférences, 1909-1910) a signalé l'importance de ce Voyage de Leguat pour la formation des idées philosophiques. M. G. Atkonson a montré que ce Voyage n'est qu'une robinsonnade (The extraordinary Voyage, p. 35-65, app. II, p. 113-4). Sur Maximilien Missen, le véritable auteur de ce Voyage de Leguat, cf. le curieux article de G. Ascoli dans la Revue $d u X V I I I^{\mathrm{e}}$ siècle, Les Prophètes français, janvier-avril 1916, p. 8-28. 


\section{La Chine et la formation de l'esprit philosophique en France}

voyage authentiques, a exprimé quelques idées personnelles. Rien ne nous attacherait à ce livre si Misson n'avait décrit les mœurs et exposé les principes moraux et sociaux tout particuliers d'une colonie chinoise - dont l'existence est certifiée par tous les voyageurs - qui habite l'île de Java.

Cette colonie chinoise vit repliée sur elle-même, sans se mêler aux indigènes ni aux Hollandais. Elle a donc gardé intactes sa structure sociale particulière et sa morale originelle. Cette loi sociale et morale par laquelle elle se gouverne et se maintient est contenue dans le Livre d'or ou les Sentences dorées d'un des disciples du Sage Roi des Lettrés, c'est-à-dire de Confucius. Or cette loi proclame les « Droits de l'Homme».

Ces « Droits de I'Homme », ce sont essentiellement les droits à la vie, ce qui ne veut pas dire seulement que dans un état qui se gouverne conformément aux principes de Confucius il ne doit pas y avoir de pauvres et de mendiants - et de fait il n'y en a pas dans cette colonie chinoise de Batavia - mais ce qui veut dire aussi que tout être vivant a droit à une vie aisée et confortable. Or à Batavia il est facile de constater qu'on ne voit non seulement aucun mendiant mais aucune personne qui ne soit raisonnablement à son aise, parce que tous les Chinois de Batavia s'assistent d'une manière charitable et prompte ${ }^{1}$. Si les Chinois sont arrivés à réaliser cette solidarité parfaite entre tous les membres de la société, c'est que l'auteur des Sentences d'orées a fulminé contre ceux qui sont les tyrans et les bourreaux du peuple, le rois, les gouverneurs et les nobles, alors

\footnotetext{
1 Voyage et Aventures de François Leguat, t. II, p. 103.
} 


\section{La Chine et la formation de l'esprit philosophique en France}

qu'ils devraient en être les bienfaiteurs et les protecteurs. Et Misson va «fulminer » aussi contre eux, avec une virulence digne du curé Meslier, du vrai curé Meslier, qui n'est pas tout à fait celui de Voltaire.

Les rois ont été faits pour « s'informer avec grand soin de ${ }_{\text {p.402 }}$ l'état du peuple, afin de pourvoir en toute diligence aux pressants besoins de ceux qui sont dans une pauvreté dangereuse et digne de compassion ». Mais « les roys de la Chine ainsi que les autres Monarques orientaux se sont érigés en Maistres souverains des Peuples de qui ils ont extorqué une sorte d'adoration. Les Gouverneurs ne devraient être que les distributeurs des deniers de l'État, selon les besoins publics et particuliers. Et la loi est celle-ci : Souviens-toi, ô Xantung, que la Loi radicale et fondamentale est que tout le monde vive, et que, s'il se peut, chacun vive heureux. Souviens-toi que le droit de chaque Créature humaine qui a reçu le don de vie de la Haute et adorable Puissance est de jouir de tout de ce que la bonne et sage filature produit d'utile au-dessus et au-dessous de la Lune. Souviens-toi que le Maître seul grand et adorable a fait toutes les bonnes choses pour tous, pour sustenter et pour recréer toute âme vivante ».

Or Xantung, le gouverneur, se réserve les paons et les esturgeons, tandis que le peuple, en est réduit à brouter «les sommitez des ronces ». Ne voudrait-il pas ce gouverneur que le « pauvre peuple » ne se nourrit que de ses excréments ? Les représentants du roi ne sont pas seulement rapaces, ils sont injustes et durs et ainsi ils manquent gravement à leur devoir - 


\section{La Chine et la formation de l'esprit philosophique en France}

à leur définition, comme aurait dit la Bruyère - - . Keu-han réduit à l'extrémité a succombé à la tentation de ne pas mourir de faim ; pour s'en garantir il a pris un pain chez un Boulanger, et pour cela vous l'avez rigoureusement puni. Mais vous avez commis double iniquité, o vous qui portez le beau nom de Pères de la Patrie. Vous n'avez pas secouru le malheureux prêt à succomber, et vous l'avez frappé sans user de miséricorde ». La loi qui établit la propriété individuelle est en effet subordonnée à une autre loi, suivant laquelle « il ne faut pas qu'aucun périsse par la malheureuse Pauvreté ».

Les troisièmes bourreaux du peuple, avec les rois et les gouverneurs, ce sont les nobles. Pour stigmatiser leurs rapines, la fureur du disciple de Confucius et de Misson ne connaît plus de bornes. Ce sont des «voleurs carnassiers et inexorables», des « sangsues opiniâtres et insatiables », de « Hauts et Puissans Larrons », des « scélérats illustres ». Une montagne fertile nourrissait trois cents familles qui y vivaient heureuses. Le noble brigand Xao-ti-cao «trouva le moyen, pour sa gloire, de Réunir à ses anciens domaines dix-huit ou vingt de ces petits héritages. Son fils continua, d'après les mêmes principes, si bien que « la montagne entière est maintenant entre les mains du grand TiHohai qui par sa raison royale ${ }_{\text {p.403 }}$ de bienséance et courant à la Gloire, comme ses Pères, a tout englouti ».

Un doux philosophe qui aime la retraite et la tranquillité d'esprit que procure la philosophie « cultiveroit volontiers quelque agréable verger qu'il auroit lui-même planté » pour y goûter quelques plaisirs idylliques et champêtres ; il entendrait 


\section{La Chine et la formation de l'esprit philosophique en France}

les « innocens fredons de l'harmonieux rossignol », il ferait serpenter de clairs ruisseaux où il pourrait prendre « des bains de santé », sans jamais dépeupler ces ruisseaux « du goujon dont la nature l'auroit pourvu ». Mais ce rêve du philosophe ne peut être accompli parce que « la Terre est toute envahie, tout est pris... Les Grands la possèdent et il n'en reste pas un seul petit coin pour lui. Il faudra même qu'il achète cher celle que son Tombeau doit bientôt occuper $\gg 1$.

Ainsi Misson vitupère, sous le nom du disciple de Confucius, non contre le droit de propriété en soi, car son philosophe serait volontiers propriétaire, d'un simple verger sans doute, mais propriétaire tout de même ; il vitupère surtout contre l'ardeur de posséder lorsqu'elle est servie par la puissance. Les méfaits du droit de propriété ne sont donc que des conséquences indirectes de l'inégalité. Ce n'est donc pas la propriété qui engendre l'inégalité, mais c'est l'inégalité qui rend dangereuse la propriété. En effet les huit compagnons, dans leur île déserte, ont vécu heureux bien que chacun possédât son petit domaine, parce qu'ils étaient tous égaux, chacun d'eux étant la huitième partie d'un roi. Aussi lorsque les hardis compagnons quittent leur île et laissent dans le creux d'un arbre le récit de leurs aventures, ils le

1 Toutes ces citations sont faites d'après les Voyages et Aventures de François Leguat. Ed. Amsterdam, 1708, p. 105-113. 


\section{La Chine et la formation de l'esprit philosophique en France}

datent de cette manière pompeuse : « Fait au palais des huit Rois de Rodrigue, I'an $1693 \gg 1$.

Une vie simple et paisible, telle qu'elle devait être dans les temps primitifs, lorsque régnait l'égalité, voilà l'idéal de Leguat et de Mission. Mais ce temps de vie simple, ce temps d'égalité est révolu, et deux terribles Tyrans, la Terreur et la Coutume, ont rendu les peuples esclaves et idolâtres de leurs Rois. Les Chinois n’ont pas p.404 échappé à ce fléau, mais « les leçons de leur Sage qu'ils ont bien conçues et bien goûtées, les ont portez à se secourir si efficacement les uns les autres qu'on ne trouve chez eux aucun indigent ». Le grand problème des sociétés modernes, qui ne peuvent revenir à l'égalité primitive, c'est donc la charité. Or cette vérité que les Chinois ont aperçue, les Chrétiens ne doivent-ils pas l'accepter de tout leur cœur, puisque Moïse a proclamé « qu'il ne devait y avoir aucun soufreteux en Israël » et que les mêmes principes « sont établis et tant de fois répétez dans I'Évangile ${ }^{2}$.

C'est donc le grand problème du paupérisme et de l'assistance que Misson pose ici et qu'il résout d'une tout autre manière que les divers gouvernements d'Europe à cette époque. Le nombre des mendiants et des vagabonds était considérable,

\footnotetext{
1 Voir à cet égard le texte significatif qu'est la dédicace du monument élevé à la mémoire de l'un des huit compagnons décédé dans l'île (t. I, p. 145). Remarquons au passage, sans en tirer la moindre conclusion, que la reproduction du monument semble attribuer au chiffre 3 une valeur symbolique, cabalistique ou autre ? - que nous ne pouvons déterminer : sur un socle, trois globes supportent une grande croix trêflée; sur le socle trois buissons d'épines, chaque buisson ayant trois crosses, dont chacune porte trois épines.

2 Leguat, op. cit., t. II, p. 204.
} 


\section{La Chine et la formation de l'esprit philosophique en France}

en Angleterre aussi bien qu'en France, et nous avons eu I'occasion de remarquer l'étonnement des voyageurs en Chine de ne voir nulle part, ni dans les campagnes ni dans les villes pourtant si peuplées, tous ces gueux qui infestaient les rues et les grandes routes d'Europe. Pour limiter le nombre de ces miséreux, et en même temps pour les rendre inoffensifs, le gouvernement français avait toujours usé de deux moyens intimement liés, l'assistance et la répression ${ }^{1}$. La mendicité était en effet considérée moins comme un malheur que comme un crime, car « les mendiants embrassent cette vie moins par nécessité que par libertinage et fénéantise », comme le déclare un arrêt du Parlement du Dauphiné du 4 avril $1698^{2}$; de même dans ses Déclarations royales du 23 juillet 1700 et du 6 août 1709, Louis XIV traitait les gueux et les mendiants de gens qui « trouvent tant de douceur à gagner par la mendicité, dans une vie libertine et fainéante, beaucoup plus que par un travail rude et continu »3. En Angleterre, quelques années plus tard (1713) un Act de la reine Anne faisait revivre les sévères lois relatives aux fripons, mendiants en pleine santé, chanteurs ambulants, escamoteurs, bohémiens, prétendus Égyptiens et autres gens de même sorte «véritable fléau pour le royaume » qu'ils parcouraient en tous sens ${ }^{4}$.

\footnotetext{
1 Christian Paultre, De la répression de la mendicité et du vagabondage en France sous l'ancien régime, p. 313.

2 Léon Lallemand, Histoire de la charité, t. IV, p. 153.

3 ibid., p. 153.

${ }^{4}$ Id., ibid., p. 153.
} 


\section{La Chine et la formation de l'esprit philosophique en France}

Tous ces mendiants, tous ces marchands d'orviétan et diseurs de bonne aventure, qui peuvent devenir à I'occasion tire-laine ou p.405 coupe-jarret, Misson a pu les voir en Angleterre, comme il aurait pu les voir en France. C'est donc à un problème social de son temps qu'il s'attaque. Mais il ne partage pas cette idée des gouvernements que la pauvreté est un crime résultant de la paresse et du libertinage. Il croit au contraire qu'elle est la conséquence de l'égoïsme et de l'avarice de tous ceux qui, détenant la puissance publique, sacrifient l'intérêt général à leurs intérêts particuliers. Mais à ce mal quel remède apporter ? Misson ne propose pas un bouleversement de l'État pour faire disparaître le paupérisme : l'esprit de charité répandu universellement peut y suffire. En « fulminant » contre les rois comme le faisait le disciple de Confucius, pour leur rappeler le principe de leur puissance, on doit pouvoir réaliser une société meilleure. Misson est un prédicateur chrétien qui veut appliquer au gouvernement des sociétés le principe moral du christianisme ${ }^{1}$. Comme réformateur il ne se distingue guère de Fénelon ou de La Bruyère. Mais il y a chez lui quelque chose de plus dangereux, c'est le ton, la virulence contre le roi et contre les Grands, sans parler des allusions très nettes à Louis XIV, à son désir de gloire et à son appétit de conquêtes. C'est le livre d'un prédicateur chrétien, mais aussi d'un protestant français qui n'a pas oublié la Révocation de l'Édit de Nantes.

\footnotetext{
1 Levesque de Burigny dans son Histoire de la philosophie payenne, t. II, p. 120-121, cite un passage de Leguat rapportant une opinion des Docteurs chinois au sujet du vol et d'après laquelle il est permis de voler pour ne pas périr de la malheureuse pauvreté. Et il ajoute ce commentaire : « Ce sentiment ne peut point, entre accusé d'erreur ; il est conforme à la doctrine des plus célèbres Théologiens ».
} 


\section{La Chine et la formation de l'esprit philosophique en France}

@

Le livre de Leguat-Misson, bien que la description des mœurs des Chinois de Batavia ne fût qu'un hors-d'œuvre, tendait à renforcer l'idée que les Jésuites voulaient inspirer aux Européens sur l'excellence de la morale chinoise par leurs Lettres édifiantes et curieuses. Exposer par de petits faits, anodins en apparence, mais curieux, l'excellence de cette morale, c'était à leur avis un bon moyen de prouver la croyance des Chinois à l'immortalité de I'âme ; en tout cas la plupart des lecteurs de ces Lettres étaient prêts à se contenter de cette démonstration. Mais encore une fois les Jésuites trouvèrent sur leur chemin un de leurs pires ennemis, I'abbé Eusèbe Renaudot.

On n'a peut-être pas oublié le rôle que joua l'abbé Renaudot dans la Querelle des Cérémonies chinoises. Comme agent du Cardinal de Noailles, il essaya de faire condamner les Jésuites en s'efforçant de démontrer d'une part que les philosophes chinois étaient athées, puisqu'ils n'avaient même pas de terme pour désigner Dieu, suivant les affirmations du Jésuite Martini ; et d'autre part que les cérémonies cultuelles du peuple chinois étaient idolâtriques.

Mais même après la Constitution Ex illa Die de 1715 les Jésuites purent continuer à défendre leurs idées sur les cultes chinois, ou du moins à propager dans le public par leurs Lettres édifiantes et curieuses leur admiration pour les sciences, pour la morale et pour la politique des Chinois, ce qui pouvait créer un préjugé favorable à la Religion. C'est à ruiner ce préjugé que s'emploie Renaudot dans les cinq éclaircissements qui suivent la 


\section{La Chine et la formation de l'esprit philosophique en France}

publication de ses Anciennes Relations des Indes et de la Chine. Mais s'il s'attaque à la morale et à la politique des Chinois, c'est surtout parce qu'il veut s'en prendre à leur religion, du moins telle qu'elle est interprétée par les Jésuites.

A la suite du P. Couplet les écrivains qui s'étaient intéressés à la morale chinoise avaient remarqué que certains principes de cette morale se rapprochaient des principes essentiels de la morale chrétienne, mais en même temps ils avaient constaté que ces règles n'étaient pas déduites d'un principe abstrait ou d'une loi transcendante mais qu'elles étaient seulement le résumé d'une longue expérience qui avait assuré le bonheur de l'empire et maintenu sa durée. Donc une morale toute pratique et heureuse dans ses résultats, mais non imposée par une loi religieuse ; ce qui risquait de laisser entendre qu'il pouvait y avoir une morale exacte, même rigoureuse et féconde, sans I'appui de la religion. C'est à cette idée d'une morale indépendante que s'attaque Renaudot : « Il est difficile de comprendre, dit-il, comment on peut admirer une Morale et une Politique qui n'ont aucuns Principes, mais qui consistent en des Sentences vulgaires et en des exemples tirez de l'histoire et sans aucun examen des actions et des passions humaines, de leurs motifs et de leur fin, puisqu'il est certain que les Chinois n'ont aucune opinion fixe sur l'immortalité de l'âme et que presque tous conviennent que la récompense des bons et la punition des méchants se fait en cette vie, sur eux ou sur leur postérité $\gg 1$. Ainsi les Chinois ne sauraient avoir une véritable morale

\footnotetext{
${ }^{1}$ Renaudot, op. cit., p. 378.
} 


\section{La Chine et la formation de l'esprit philosophique en France}

puisqu'ils n'ont pas de religion qui leur permette de croire à l'immortalité ${ }_{\text {p.407 }}$ de l'âme, et la morale qu'ils ont, qui exclut tout dogmatisme, prouve bien qu'ils n'ont pas de religion spiritualiste. Et puisque les cultes chinois sont idolâtriques, rien ne trouve grâce devant Renaudot, pas même les honneurs funèbres, car ces cérémonies pourraient s'excuser chez ceux « qui croyoient l'âme immortelle, comme la plupart des anciens Payens, mais elles sont inexcusables dans les Chinois qui.... ne croyoient rien de semblable »1. Quant aux cérémonies civiles, elles sont ridicules par leur complication. «Elles sont si peu conformes à la simplicité des premiers siècles que ce caractère seul suffit pour prouver qu'elles ne sont pas aussi anciennes que s'imaginent les Chinois $\gg 2$.

Après la morale, la politique. On dit souvent que si les philosophes régnaient, les peuples seraient heureux. Or, constate Renaudot, les philosophes, plus qu'en aucun autre pays du monde, ont gouverné la Chine. Cela n'a pas empêché les Tartares de conquérir la Chine : « Tous les défauts qui ont été considérés comme la cause de la ruine des plus grands empires d'Orient, le pouvoir despotique, le luxe des Princes enfermés dans un Palais avec des femmes et des Eunuques, la négligence pour les affaires publiques, le mespris de l'art militaire et la mollesse se trouvent dans le gouvernement de la Chine. Les Tartares peu Philosophes se sont rendus maistres de ce grand Empire en fort peu de temps, lorsqu'ils I'ont attaqué, et lorsqu'ils

\footnotetext{
${ }^{1}$ Id., op. cit., p. 370.

${ }^{2}$ Id., op. cit., p. 372.
} 


\section{La Chine et la formation de l'esprit philosophique en France}

ont pris les mœurs chinoises, ils se sont trouvez dans la suite exposez aux mesmes disgrâces que leurs prédécesseurs $\gg 1$.

L'affaire des Cérémonies chinoises n'était ni oubliée ni même terminée, aussi la Chine ne peut trouver grâce devant Renaudot. Sans doute cette querelle s'efface-t-elle devant la querelle plus grave de la Bulle Unigenitus mais elle reparaît de temps en temps lorsque la crise devient particulièrement aigu, entre Jésuites et Jansénistes. Le jeune Silhouette, élève du $P$. Tournemine put s'apercevoir de la vigueur des haines que les théories des Jésuites sur la Chine pouvaient encore susciter en 1729, lorsqu'il reçut de tous côtés des volées de bois vert à la suite de son livre, pourtant bien faible et bien anodin «Idée générale du gouvernement et de la morale des Chinois ». Il ne faisait cependant que reprendre les idées du P. Lecomte censurées il est vrai par la Sorbonne et notamment la troisième proposition - lorsqu'il écrivait : « La p.408 lecture des ouvrages de Confucius est curieuse, elle fait connoître l'Empire de la Chine, mais elle est encore plus utile. On y voit des préceptes de vertu dont un Philosophe chrétien s'applaudiroit. Ces préceptes se trouvent confirmés par des exemples dont les Héros Grecs ou Romains n'ont point approché. Un autre motif encore m'engage d'en faire l'extrait : les livres du Philosophe chinois nous font voir ce que la nature seule est capable de faire lorsqu'on écoute ses conseils »2. Et les Nouvelles Ecclésiastiques, d'accord avec

\footnotetext{
${ }^{1}$ Id., op. cit., p. 378.

2 Silhouette, Idée générale du Gouvernement et de la morale des Chinois, p. 2.
} 


\section{La Chine et la formation de l'esprit philosophique en France}

I'évêque de Montpellier ${ }^{1}$, en rapportant ce passage, doutaient fort que la Sorbonne de 1731, qui n'était plus qu'une ombre de Faculté, parce que tous ses docteurs avaient reçu la Constitution Unigenitus, osât condamner ce que la Sorbonne de 1700 avait si résolument flétri.

Sur la morale et la politique des Chinois, pas plus que sur leur religion, le livre de Silhouette n'apporte rien que I'on n'eût pu lire chez le P. Le Comte ou dans les Lettres édifiantes et curieuses. La morale des Chinois est une morale intellectualiste, « La Raison est un présent céleste, c'est d'elle que nous devons prendre des règles de vertu ; elle est intérieure à l'homme même, et n'en peut être séparée. « C'est la science qui guide le choix et l'examen : elle doit accompagner toutes les autres vertus. «Par conséquent pour devenir sage, il faut se défaire de ses préjugés, ensuite méditer, raisonner sur toutes choses, tâcher de s'en former des idées claires et distinctes, peser tout, examiner tout $\gg 2$. Les enseignements de Descartes avaient donc porté leurs fruits et en 1729 un élève des Jésuites pouvait se prévaloir de la méthode cartésienne : la nécessité d'accepter la morale de Confucius n'avait peut-être pas été étrangère à cette sympathie en somme assez nouvelle pour la méthode cartésienne.

Les préceptes de la morale de Confucius que Silhouette met particulièrement en valeur sont ceux-là mêmes qui avaient

1 Cf. le livre de Silhouette, $2^{\mathrm{e}}$ éd., p. 43, et la IVe Lettre de Monseigneur l'évêque de Montpellier (Colbert de Croissy) à Monseigneur l'évêque de Marseille (Belzunce), p. 2-3.

2 Silhouette, op. cit., p. 28-33. 


\section{La Chine et la formation de l'esprit philosophique en France}

séduit Bernier et Simon Foucher : «Ce principe de la Loi naturelle : Ne fais à autrui que ce que tu veux qui te soit fait est regardé par Confucius comme le fondement de toutes les Loix »1. Et aussi cet autre principe qui avait semblé si admirable

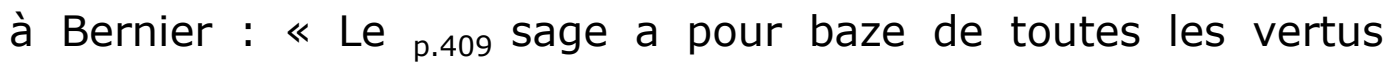
I'humanité »2. Mais Silhouette rapporte aussi cette maxime qui peut être grosse de conséquences : « La vertu veut être pratiquée pour l'amour d'elle-même »3 ${ }^{3}$. Ce qui exclut l'idée de récompense et tend à ruiner l'argument moral en faveur de l'immortalité de l'âme.

Les observations de Silhouette sur la politique des Chinois ne sont pas plus originales. Il remarque lui aussi que suivant Confucius « la vertu est la baze d'un Empire et la source d'où découle tout ce qui peut le rendre florissant $\gg 4$. Les rois euxmêmes doivent pratiquer la vertu parce que les peuples se conforment aux exemples de leur roi. Les rois doivent conserver leur gravité, leur majesté, car de cette manière ils conserveront leur autorité (c'était déjà l'idée de La Bruyère) : «Toutes les fois qu'un foi se montre à son peuple il doit le faire avec majesté. La vertu qui n'est point soutenue par la gravité n'acquiert point d'autorité sur les hommes »5. En Chine l'autorité de l'Empereur est despotique en principe, mais en fait deux choses limitent ce

\footnotetext{
${ }^{1}$ Id., op. cit., p. 33.

2 Id., op. cit., p. 31.

3 Silhouette, op. cit., p. 29.

${ }^{4}$ Id., op. cit., p. 35.

5 Silhouette, op. cit., p. 36.
} 


\section{La Chine et la formation de l'esprit philosophique en France}

despotisme, d'abord le pouvoir de la loi qui engage l'Empereur lui-même (idée chère à Fénelon) et la manière dont on compose I'histoire de son règne. Si l'auteur rapporte des particularités du gouvernement chinois qui peuvent paraître des critiques du gouvernement français ce sont les mêmes faits que I'on se plaisait à citer à la fin du XVII ${ }^{\mathrm{e}}$ siècle, et par conséquent les mêmes critiques, la vénalité des charges et la faveur. En Chine Hégésippe ne trouverait un emploi que si son mérite personnel I'en rendait digne.

Hors la question de religion, rien dans ce livre n'était capable de motiver les critiques qui lui furent faites, mais les Nouvelles Ecclésiastiques ainsi que l'évêque de Montpellier n'étaient pas fâchés de faire encore une fois une diversion contre les Jésuites en les attaquant sur leur point faible, et le Nouvelliste du Parnasse était heureux de pouvoir constater à l'occasion de ce livre que les Chinois étaient athées. Mais sur la morale et sur la politique des Chinois ce livre n'apportait rien de neuf qui justifiât la publication d'un livre séparé en dehors des Lettres édifiantes et curieuses. On n'y trouve rien sur le rôle particulier des grands tribunaux qui devait attirer particulièrement l'attention de Voltaire, et à peu près rien sur les conseils donnés à l'Empereur par les grands mandarins qui semblent avoir séduit Montesquieu en faveur de la Chine ${ }_{p .410}$ dès 1717 , avant qu'il eût constitué son système des trois formes de gouvernement : «Les historiens de la Chine, dit-il, attribuent la longue durée, et, si je l'ose dire, l'immortalité de cet empire, aux droits qu'ont tous ceux qui approchent du Prince, et surtout au principal officier nommé Kotaou de l'avertir de ce qu'il peut y avoir d'irrégulier dans sa 


\section{La Chine et la formation de l'esprit philosophique en France}

conduite. L'empereur Tkeou, qu'on peut justement nommer le Néron de la Chine, fit attacher en un jour à une colonne d'airain enflammée vingt-deux mandarins qui s'étoient succédés les uns aux autres à ce dangereux emploi de Kotaou. Le tyran, fatigué de se voir toujours reprocher de nombreux crimes, céda à des gens qui renaissoient sans cesse. Il fut étonné de la fermeté de ces âmes généreuses et de l'impuissance des supplices, et la cruauté eut enfin des bornes, la vertu n'en eut point $\gg 1$.

Le marquis d'Argens, faisant promener un Chinois en Europe, se sert de ce moyen, déjà bien usé mais fort commode, de critiquer les idées et les mœurs françaises. Or suivant le Chinois, porte-parole du marquis, si la France est inférieure à la Chine c'est qu'elle néglige la morale alors qu'elle s'applique avec succès à la physique et aux sciences expérimentales. Mais si les Français négligent la morale c'est que la morale a été accaparée par les Théologiens : «Les sages philosophes européens n'ont pas eu d'adversaires plus redoutables et d'ennemis plus opiniâtres que les Théologiens. Par qui Descartes a-t-il été injurié, maltraité, persécuté ? Par des Théologiens françois. Qui sont les gens qui ont voulu rendre Locke odieux ? Des Théologiens anglois. Qui sont ceux qui ont écrit avec aigreur contre Mallebranche ? Des Théologiens encore. Le Vulgaire qui suit toujours aveuglément et sans examen toutes les opinions de ceux qu'il regarde comme les dépositaires de la Religion, méprise les plus grands Philosophes sans les connoître, et préfère l'étude vague incertaine et infructueuse d'une

\footnotetext{
1 Montesquieu, Mélanges inédits, p 24-5.
} 


\section{La Chine \\ et la formation de l'esprit philosophique en France}

métaphysique et d'une morale scolastique à celle d'une philosophie presque divine $\gg 1$

Les Chinois peuvent donc s'attacher à la vertu parce que la morale est indépendante de la théologie. Mais cet amour qu'ils ont de la vertu prouve-t-il qu'ils sont nécessairement et par làmême vertueux ? Un Français le fait remarquer au Chinois à I'Opéra.

p.411 « Un Chinois n'est pas plus vertueux qu'un Européen, mais il trouve son avantage dans la pratique de la vertu $\gg 2$. C'est le premier doute que nous trouvions, non certes sur les vertus pratiques des Chinois dont les voyageurs pouvaient douter beaucoup, mais sur la valeur morale de l'attachement des Chinois à l'éthique. La vertu, lorsqu'elle confère les honneurs et les dignités, risque de n'être plus qu'une « vertu plâtrée » qu'un masque qui dissimule, mais sans les supprimer toutes les faiblesses d'une très médiocre et débile humanité.

Mais si la vertu, dont les Chinois se vantent si fort, n'est souvent que le masque d'un intérêt bien compris (ce qui ne saurait évidemment conférer aucune supériorité aux Chinois sur les Européens) les Chinois ont du moins l'avantage incontestable de pratiquer la tolérance. Tandis que I'Europe a été ensanglantée par les guerres de religion et par les cruautés qui ont été exercées - catholiques et protestants peuvent être renvoyés dos à dos - la Chine a été à l'abri de cette calamité, non pas parce qu'elle veut être tolérante mais parce que sa religion n'est pas,

${ }^{1}$ D'Argens, Lettres chinoises, Lettre LI, t. I, p, 163.

2 D'Argens, Lettres chinoises, Lettre XXIV, p. 190-1. 


\section{La Chine et la formation de l'esprit philosophique en France}

comme le christianisme, intolérante. Donc le christianisme, ferment d'intolérance, doit être proscrit de Chine : «Si jamais... on est instruit à la Chine des divisions criminelles et meurtrières des Lettrés français, je ne doute pas que cela ne porte un grand préjudice aux Missionnaires. On craindra les suites de leur Religion et I'on voudra éloigner des gens, qui prêchant sans cesse la tolérance lorsqu'ils sont faibles, ne cherchent qu'à contraindre les consciences dès qu'ils en ont le pouvoir »1. Nous retrouvons ici l'idée de Bayle, ce n'est pas la tolérance qu'il faut instituer, c'est I'intolérance qu'il faut détruire. C'est aussi l'idée que Voltaire avait voulu mettre en lumière dans ses Lettres philosophiques lorsqu'il avait décrit les différentes sectes anglaises, et c'est aussi l'idée de Montesquieu 2.

$*$

La merveilleuse réussite du classicisme français à l'époque de Louis XIV était évidemment peu faite pour inspirer auX contemporains l'idée de la relativité du goût : les œuvres réalisées par le ${ }_{\text {p.412 }}$ génie français leur semblaient au contraire pouvoir servir de modèles à toutes les nations de l'univers. De là à conclure à une supériorité de l'esprit français - conclusion qui n'était pas formulée, mais qui était instinctive - il n'y avait qu'un pas. Et comme toutes les nations de I'Europe se trouvaient alors sous la domination intellectuelle de la France, c'était en réalité la suprématie de l'esprit européen, héritier de l'antiquité gréco-romaine que proclamait le classicisme.

\footnotetext{
${ }^{1}$ Id., ibid., Lettre VIII, t. I. p. 59-62.

2 Montesquieu, Pensées et Fragments inédits, t. II, p. 511.
} 


\section{La Chine et la formation de l'esprit philosophique en France}

D'autre part le développement des sciences, sans doute encore dans l'enfance à la fin du XVIIe siècle, mais qui semblait autoriser d'autant plus d'espoirs qu'on n'en connaissait pas les limites, ne pouvait que renforcer ce préjugé français - ou européen - que le classicisme à lui seul eût été capable de faire prévaloir.

Or c'est à la plus belle époque du Siècle de Louis XIV que I'Europe découvre la Chine. Autre pays, autres mœurs. Autre civilisation aussi mais qui ne le cède en rien, ni en antiquité, ni en splendeur, à la civilisation européenne. Sur certains points peut-être la Chine est inférieure à l'Europe, mais sur certains autres elle la dépasse : en tout cas le parallèle peut être fait. Essayer ce parallèle c'est déjà limiter l'esprit européen, car c'est admettre que sa suprématie n'est pas indiscutable.

Le premier qui ait tenté ce parallèle est Leibniz, qui s'est tant intéressé à la Chine. Au total il s'efforce de maintenir la balance égale entre la Chine et l'Europe. Il considère que la Chine et l'Europe, si elles ont des civilisations différentes n'ont rien qui permette de proclamer la supériorité de l'une ou de l'autre. Elles ont des avantages différents, mais qui somme toute se compensent : nous avons l'art de raisonner, l'art de la guerre, mais les Chinois ont sur nous l'avantage d'une morale supérieure à la nôtre : «Qui olim credidisset esse gentem in orbe terrarum quæ non opinione nostra ad omnem morum elegantiam usque adeo erudita, tamen vincat civilioris vitæ praescriptis et hoc tamen in Sinensibus nunc experimur, ex quo illa gens nobis notior facta est. Itaque si artibus operatricibus pares sumus, si 


\section{La Chine et la formation de l'esprit philosophique en France}

scientiis comtemplativis vicimus, certe pratica philosophia (quod propemodnm fateri pudet) victi sumus, id est Ethicæ et Politicæ, præceptis ad ipsam vitam usumque mortalium accommodatis. Dici enim non potest quam pulchre omnia ad tranquillitatem publicam ordinemque hominum inter se ut quam rninimnm sibi ipsi incommodent, supra aliarum gentium leges apud Sinenses sint ordinata $\gg 1$.

p.413 Si donc les Chinois nous sont inférieurs ou au plus égaux dans les sciences spéculatives, ils nous surpassent dans le domaine des sciences pratiques notamment dans la Morale et la Politique - et c'est un aveu qui sera fait souvent par la suite - ; mais il est une autre supériorité que Leibniz accorde aux Chinois, c'est leur connaissance de la théologie naturelle. Si nous envoyons en Chine des missionnaires pour enseigner aux Chinois la religion révélée, ils pourraient en échange nous envoyer des missionnaires pour nous enseigner la théologie et la philosophie naturelles. Cette préoccupation de la théologie naturelle que conservaient les Chinois est une des raisons de l'admiration de Leibniz pour la Chine, qui tendait à leur conférer sur l'Europe une certaine supériorité ; mais la philosophie naturelle, la morale naturelle, révélées par le P. Couplet, d'après les anciens livres de la Chine avaient été déjà, quelques années auparavant, une cause d'étonnement pour un Bernier ou un Simon Foucher.

Renaudot accabla les Chinois, leur refusant même l'avantage d'une morale qui fût supérieure à celle des Iroquois, mais cette attitude d'esprit était dictée par des vues particulières, et c'était

\footnotetext{
1 Leibniz, Novissima Sinica, p. 3.
} 


\section{La Chine et la formation de l'esprit philosophique en France}

en réalité le religion des Chinois qui déterminait toutes ses opinions défavorables. Le voyageur Le Gentil, qui cependant avait lu Renaudot, mais qui pouvait se tenir à l'écart des querelles religieuses, esquissa à la fin du récit de son voyage en Chine un parallèle entre les Européens et les Chinois, qui ne manque pas d'intelligence et qui ne laisse pas d'être nouveau pour son temps.

Il cherche à dissiper le préjugé français et européen qui fait de sa forme d'esprit particulière la norme de l'esprit de l'univers. «Quoique leur esprit [des Chinois] ne ressemble point à celui des Européens, il ne laisse pas d'être esprit ; il n' y a qu'à décider si l'esprit françois doit être la règle générale de tous les esprits de l'univers. Ce principe posé, on peut justifier les coutumes des Chinois, si différentes qu'elles soient des nôtres. Les cérémonies des Chinois paraissent aux Européens insupportables par leur longueur, mais les Chinois ne les jugent pas telles. La musique chinoise n'est pour une oreille européenne qu'une cacophonie, mais les Chinois, élevez dès leur bas âge à entendre un certain son, y accoutument insensiblement leurs oreilles. Tout ce qui n'a pas la même harmonie leur semble ridicule ». Il en est de même de toutes les coutumes, «c'est le caprice qui leur donne l'être ». Dans ces conditions on ne saurait établir une hiérarchie entre les mœurs des différents peuples et s'il y a diversité, il n'y a ni supériorité ni infériorité. « Les Chinois ont leurs arts et les sciences p.414 conformes à leurs usages, leur génie et au climat sous lequel ils sont nez ». C'est l'idée de la relativité, nettement exprimée avant Montesquieu. Mais Le Gentil exprime en outre, en passant une autre idée qui sera celle des 


\section{La Chine et la formation de l'esprit philosophique en France}

philosophes lorsqu'ils chercheront à marquer la différence entre l'esprit des Français et l'esprit des Chinois : les Français sont instables, mais les Chinois sont constants. Le costume des Chinois est traditionnel et immuable, ce qui peut le rendre ridicule pour un Européen, mais le Chinois répondra : « D’où vient cette inconstance qui vous fait changer de mode chaque année ? » Et ce caractère de permanence ne s'observe pas seulement dans le costume des Chinois, c'est un véritable caractère national : « Les Chinois plus constans mille fois n'innovent rien. Religieux observateurs des coutumes de leurs Pères ils en ont aujourd'hui le génie, la manière de vivre, les mêmes loix, tout se soutient, rien ne se dément »1. Et voilà nettement formulée la différence entre l'esprit chinois et l'esprit français (ou européen), la constance qui s'oppose à l'instabilité.

La publication de l'ouvrage du P. du Halde, cette Somme des connaissances des Européens sur la Chine dans la première partie du XVIII ${ }^{e}$ siècle fut une occasion pour beaucoup d'écrivains et de savants, d'examiner si l'admiration sans réserves des Jésuites pour la Chine était réellement fondée, et si cette nation surpassait les nations européennes par ses sciences, par sa morale et par sa politique. Or certains journaux, comme le Pour et Contre et les Observations sur les Écrits modernes, bien loin de partager l'admiration des Jésuites, ont recueilli des faits, assemblé des arguments pour tâcher de montrer que cette prétendue supériorité des Chinois n'était qu'une fiction.

\footnotetext{
${ }^{1}$ Le Gentil, Nouveau Voyage autour du Monde, t. II, p. 134-48.
} 


\section{La Chine et la formation de l'esprit philosophique en France}

A propos d'une relation de voyage en Perse, réimprimée à Londres, le Pour et Contre observant que les sciences, même I'astrologie pourtant si répandue en Orient, ne sont encore que rudimentaires en Chine, ajoute cette remarque, «....Ce n'est pas ordinairement dans les lieux où les Arts ont été inventez qu'ils arrivent à leur plus grande perfection. Les Nations étrangères ne manquent guères d'y ajouter quelque chose en les recevant et de rendre ainsi presqu'autant qu'elles ont reçu $\gg 1$.

L'année suivante, à propos de l'Essai politique sur le commerce de Melon, c'est à l'idée de la stabilité, de la permanence du gouvernement et des institutions de la Chine que l'auteur s'en prend, p.415 pour montrer que cette immobilité n'est pas une preuve de supériorité, bien au contraire. On nous vante, dit-il, ces Empereurs chinois qui écoutent et qui suivent les conseils de leurs mandarins et ces mandarins qui risquent même leur vie pour faire des critiques à l'empereur, mais cela ne pourrait être un bien que si l'empereur et ses conseillers étaient débarrassés des «préventions populaires qui rejettent avec opiniâtreté tout ce qui est opposé à d'anciens usages, quelque extravagants et quelque pernicieux qu'ils soient ». Cette permanence tant vantée des institutions chinoises n'est donc que le résultat de préjugés enracinés et d'un faux orgueil d'un peuple qui n'a rien voulu apprendre de l'étranger. On vante sans doute la richesse de la Chine où chaque pouce de terrain est cultivé, ce qui permet de nourrir des quantités énormes d'habitants. Il n'en reste pas moins - et les jésuites eux-mêmes doivent l'avouer -

1 T. VI (1735), p. 266-8. 


\section{La Chine et la formation de l'esprit philosophique en France}

qu'il est permis aux parents d'exposer leurs enfants, lorsqu'ils ne peuvent les nourrir, ce qui prouve bien que la quantité des denrées que produit le pays est insuffisante pour sa population. Les Chinois sans doute auraient pu remédier à cet excès de population, et renoncer à cette coutume barbare de l'exposition des enfants s'ils avaient fondé des colonies. Mais le mépris constant qu'ils ont eu pour tout ce qui est étranger, les a empêchés de trouver un remède à la barbarie de certaines de leurs coutumes. Donc la permanence de leurs institutions n'est pas une preuve de supériorité, car elle leur a interdit tout progrès et la paix dont ils jouissent « n'est point le fait de leur politique, c'est un hasard de situation ». Quant à leur morale, bien loin d'être supérieure à celle des Européens, elle lui est bien inférieure, à cause de cette autorité absolue des parents qui leur permet de disposer de la vie de leurs enfants et elle n'est pas susceptible d'amendements ni d'amélioration à cause des préjugés des Chinois ${ }^{1}$.

C'est un véritable réquisitoire, si peu de temps après la publication du livre du P. du Halde et dont certains éléments sont pris à ce livre même. L'idée de la supériorité des Chinois n'était donc pas aussi universellement répandue que les écrits des Jésuites pourraient le faire croire. A cet égard nous avons le témoignage de Fréret, qui était en relations avec $M$. de Mairan, que I'on appelait Le Chinois, à cause de ses lettres adressées aux missionnaires de Chine et qui paraissaient - du moins fragmentairement, - dans les Lettres édifiantes et curieuses.

1 T. IX (1736), p. 123-9. 


\section{La Chine et la formation de l'esprit philosophique en France}

Chez M. de Mairan on discutait ${ }_{\text {p.416 }}$ au sujet de la Chine, soit à I'occasion des Anciennes Relations de l'abbé Renaudot, soit au moment où I'on recevait quelque bonne et longue lettre du $\mathrm{P}$. Parrenin. Et Fréret tient à préciser son opinion définitive sur la Chine et sur les Chinois. «Me permettez-vous... de vous faire ressouvenir de la thèse que je soutenois alors, que les Chinois ne méritent ni notre admiration ni notre mépris par rapport aux sciences et surtout par rapport à l'Astronomie, et qu'ils étoient dans le même cas où les Grecs et les Romains ont été dans leurs plus beaux siècles par rapport aux sciences spéculatives, avec cette différence qu'ils leur étoient infiniment supérieurs par rapport à la police intérieure, aux principes de la morale œconomique et à toutes les choses qui contribuent au bonheur et à la tranquillité publique, les seules choses dont les Chinois fassent cas, comme nous le dit le P. Parrenin. Vous estes je croi convaincu maintenant Monsieur, combien je méritois peu les airs de hauteur et les emportemens avec lequels me traita l'auteur du Sethos $\gg 1$.

On n'était donc pas d'accord sur les mérites des Chinois, même dans le clan philosophique. L'abbé Terrasson était nettement contre eux sans doute parce que l'antiquité de leurs arts et de leurs sciences pouvait gêner un partisan déterminé des modernes, Fréret limitait à la morale et à la politique son admiration, parce que ses études très précises ne lui laissaient rien ignorer des faiblesses de l'astronomie chinoise. Quant à de Mairan, à cause de cette notoriété particulière que lui avaient

\footnotetext{
1 Voir notre Thèse complémentaire Documents inédits, p. 47.
} 


\section{La Chine et la formation de l'esprit philosophique en France}

donnée les Lettres édifiantes et curieuses, il fut obligé de préciser ses idées sur la Chine pour répondre aux critiques de l'abbé Desfontaines.

Le XXIe Recueil des Lettres édifiantes et curieuses avait publié en 1734, les fragments d'une lettre de $M$. de Mairan au P. Parrenin, où de Mairan semblait exprimer une admiration sans réserves pour la Chine. Mais outre que le fragment publié, isolé du reste de la lettre, risquait de ne pas refléter exactement I'esprit de son auteur, l'éditeur des Lettres édifiantes, suivant son habitude que nous connaissons déjà, avait supprimé une phrase essentielle. « Les diverses relations que j'en ai lues autrefois m'ont laissé à son égard [de la Chine] comme flottant entre l'admiration et le doute $\gg 1$. Cette simple phrase supprimée par le P. du Halde ${ }_{\text {p.417 }}$ prouvait donc bien que de Mairan ne pouvait être rangé parmi ceux qui admiraient la Chine les yeux fermés. Mais le public, qui ne connaissait rien à la « cuisine » des Lettres édifiantes ne pouvait s'en rendre compte, si bien que de Mairan fut pris à partie par l'abbé Desfontaines pour « avoir accordé la supériorité aux Chinois sur les Européens en fait de politique et de morale ». Et il se crut obligé de s'en défendre 2 .

Il se défend en refusant aux Chinois toute habileté dans les sciences mathématiques et spéculatives, et « si l'on considère la

1 Lettres de M. de Mairan au R. P. Parrenin missionnaire de la Compagnie de Jésus à Pékin, contenant diverses questions sur la Chine, Paris, 1759. p. 2. La Lettre du P. Parrenin se trouve dans le XXI Recueil des Lettres édifiantes et curieuses (1734).

2 Lettre de M. de Mairan, de I'Académie des sciences, à M. I'abbé D. F., Observations sur les écrits modernes, t. VII, p. 56-64. 


\section{La Chine et la formation de l'esprit philosophique en France}

morale et la politique comme des sciences spéculatives on doit avouer qu'ils n'y ont fait aucun progrès depuis trois mille ans qu'ils les cultivent et qu'ils semblent en faire leur étude essentielle ». Dans les sciences spéculatives, les Chinois sont donc nettement inférieurs aux Européens, mais cette infériorité, sans se justifier, du moins s'explique. Elle tient en effet « à cette tranquillité d'esprit, à cette paresse, si I'on veut, qui fait leur caractère, et qui les éloigne si fort de cette espèce d'inquiétude qu'ils diront peut-être qui fait la nôtre, en un mot à cet amour de la constance et de la Persévérance à tous égards dans leur manière de penser comme dans leur façon de vivre ». Mais si les Chinois ont fait peu de progrès dans les sciences spéculatives, et si on peut leur en faire le reproche, ne peuvent-ils pas se revancher sur la question de fait, sur la supériorité de leur morale et de leur politique, non plus considérées comme des sciences abstraites mais comme des règles pratiques capables de procurer le bonheur à l'individu et à l'état la stabilité « Ils peuvent reprocher à l'Europe, et à ses habitans en général, qu'ils ne sont pas plus avancés dans les qualités qui produisent un gouvernement constant et une vie tranquille, et que bien que depuis Platon et Aristote on ne cesse de parler ici Morale et Politique, il ne paroît pas cependant qu'on y soit plus sage, ni moins étourdi sur les véritables intérêts, qu'on l'étoit il y a deux mille ans ». A quoi nous sert donc cette supériorité dans les sciences spéculatives, étant donné le peu d'utilité que nous en retirons « pour vivre heureux et tranquilles et pour faire un état permanent ?». 


\section{La Chine et la formation de l'esprit philosophique en France}

Cette lettre de $M$. de Mairan est un texte lumineux, qui nous révèle ce que pouvaient penser sur la Chine, après la publication des principales œuvres des Jésuites, des gens d'esprit qui sans doute étaient assez portés à l'admiration mais que malgré tout $\mathrm{p}$. 418 l'admiration n'aveuglait pas. Comme l'abbé Renaudot, de Mairan avouait que les Chinois, peu portés par nature aux sciences spéculatives, n'avaient pas de morale dogmatique et qu'ils ne se souciaient pas de codifier les principes de leur politique, mais il constatait qu'ils ne laissaient pas d'avoir une morale fondée sur la tradition et une politique pratique que I'on pouvait juger par ses effets. Si d'autre part on pouvait reprocher aux Chinois d'être figés dans leurs traditions ancestrales et de se refuser à tout changement - ce que l'on appelle quelquefois le progrès - c'est que ce sentiment de l'immobilité, de la permanence tenait à leur nature d'esprit, tandis que la mobilité, le besoin de changement, le progrès sont un besoin, une nécessité de l'esprit européen. Nulle part ailleurs avant 1740 n'a été aussi bien marquée la différence entre l'esprit chinois et l'esprit européen.

La morale et la politique des Chinois, quelque admiration qu'elles aient provoquées, n'ont pas eu une influence aussi considérable, du moins jusqu'en 1740, que la découverte de la chronologie chinoise et que la controverse au sujet des cultes chinois. A cette époque, la religion est la préoccupation essentielle, la morale et la politique ne sont que des questions subsidiaires, parce qu'il appartient à la religion de fixer et de régler la morale, et que la politique est l'affaire du roi. 


\section{La Chine et la formation de l'esprit philosophique en France}

Cependant la publication du Sinarum Philosophus, en 1687, provoque un assez gros émoi. C'est l'exposé tout simple d'une morale très ancienne, bien antérieure au christianisme, mais dont les principes essentiels ne sont guère différents de la morale chrétienne. Il y a donc une morale naturelle, partant une morale indépendante de la religion qu'un peuple professe puisque les principes de la morale sont les mêmes partout et à toutes les époques; et si les Chinois peuvent être convaincus d'athéisme, comme le veulent les adversaires des Jésuites, non seulement une morale pure peut exister, sans la révélation chrétienne, mais encore la morale est indépendante de toute religion.

En outre cette morale des Chinois que révèlent les missionnaires n'est pas une morale dogmatique ; elle ne se déduit pas de principes abstraits ; elle est toute pratique et se justifie, non par des arguments ou des raisonnements mais par les résultats qu'elle a produits. Pour cette raison quelques adversaires de la Chine, Fénelon, Renaudot, nient qu'il y ait en Chine une morale, mais les Jésuites dans leurs ouvrages, Lettres édifiantes ou Description de la Chine, accumulent les faits qui tendent à montrer dans le peuple chinois non seulement un grand souci de la morale et une ${ }_{\text {p.419 }}$ très haute moralité, mais encore le souci de conserver, de protéger même coutre les influences étrangères, des règles de conduite qui assuraient depuis l'antiquité la stabilité de la société chinoise. Donc une morale qui, pour n'être pas dogmatique, n'était cependant pas inférieure, puisqu'elle avait fait ses preuves. C'était une morale fondée sur l'expérience et adaptée au caractère d'une nation 


\section{La Chine et la formation de l'esprit philosophique en France}

particulière. D'où I'on pouvait conclure au relativisme de la morale. Enfin, surtout à la fin du XVII ${ }^{e}$ siècle, les Français remarquèrent aussi que chez les Chinois la morale et la politique se confondaient : les principes politiques étaient exactement les mêmes que les principes moraux. L'État se comportait comme une famille. L'Empereur exerçait son pouvoir non comme maître, mais comme père. Si les Jésuites français et ceux qui les ont lus ont été tentés de dissimuler ou de passer sous silence les faits qui témoignaient d'un despotisme en Chine, c'est que le principe du gouvernement chinois leur semblait identique au principe du gouvernement français, et que pour eux l'absolutisme de Louis XIV n'était pas un despotisme. Mais une des raisons de leur admiration pour la Chine fut qu'ils crurent trouver dans l'empire chinois une réalisation plus parfaite des principes mêmes du gouvernement français : un absolutisme tempéré par le sentiment. 


\section{La Chine \\ et la formation de l'esprit philosophique en France}

\section{CONCLUSION}

p.421 La Chine, nous l'avons dit, et ce long exposé ne l'a que trop montré, ne s'est pas dévoilée en un seul jour aux Européens. Il fallait d'abord vouloir la découvrir, c'est-à-dire trouver un certain intérêt, matériel ou intellectuel, à cette découverte, et partant il fallait laisser de côté, du moins provisoirement, le préjugé européen. Cette excitation préliminaire, mais nécessaire, ce furent les premières relations sur la Chine qui la fournirent. Sans doute on connaissait déjà I'ouvrage de Marco Polo, dont les éditions furent nombreuses au $X V I^{e}$ siècle et se continuèrent au siècle suivant. Mais les récits à la fois merveilleux et imprécis du Vénitien semblaient tenir du roman d'aventures autant que de la relation de voyage. A tout le moins, l'imagination y trouvait son compte, si le besoin de précisions géographiques n'était pas satisfait.

Les premières relations des Jésuites, les lettres écrites annuellement de la mission au début du XVII siècle, mais surtout le livre du P. Trigault qui condensait en un seul volume de multiples renseignements, et qui avait l'avantage d'être traduit en français, eurent une influence beaucoup plus considérable. Non seulement parce que la position de la Chine se précisait, que son existence ne pouvait plus être mise en doute, mais aussi parce qu'à l'intérêt géographique se superposait un intérêt religieux. La Chine était le pays béni des missionnaires, où ils faisaient une abondante moisson d'âmes. Elle apparaissait 


\section{La Chine et la formation de l'esprit philosophique en France}

donc dès le début, grâce aux Jésuites, comme une terre privilégiée qui allait, peut-être, par la conversion d'une centaine de millions d'habitants, fournir la preuve expérimentale de la vérité du christianisme, en montrant sa force d'expansion, et aussi de la vérité du catholicisme, qui allait peut-être enfin réaliser sa définition, c'est-à-dire devenir vraiment l'Église universelle.

Le nombre relativement important de traductions françaises de relations sur la Chine, écrites tout d'abord en latin ou en espagnol, aussi bien que les adaptations qui en furent faites par des polygraphes montrent suffisamment que dès la première moitié du XVIIe siècle, cet intérêt pour la Chine commençait à s'éveiller.

L'extension du commerce en Extrême-Orient, la création de la Compagnie des Indes, avec la réclame habile que lui fit Colbert, p.422 suscitèrent une vive curiosité dans I'opinion publique, non seulement chez les marchands de Nantes et de Saint-Malo, mais encore chez tous ceux qui s'intéressaient au sort des âmes errantes, plus qu'au poivre ou à la cannelle ; car si les missionnaires en s'insinuant dans les pays infidèles frayaient la voie aux négociants, les compagnies de commerce, comme elles le devaient d'ailleurs d'après les termes du privilège qui leur était accordé, leur rendaient ce service de toutes sortes de manières, en les transportant sur les lieux de leur mission, en les aidant même matériellement au besoin. Ainsi commerçants et missionnaires, bien loin de soutenir des intérêts contraires, ou même seulement différents, avaient partie liée, si bien que tout 


\section{La Chine et la formation de l'esprit philosophique en France}

progrès d'une compagnie de commerce était une conquête pour la mission, et réciproquement ce qui ne pouvait qu'augmenter considérablement en France le nombre de gens désireux de s'intéresser aux pays d'Extrême-Orient.

Joignons à cela l'intérêt que, grâce à Colbert, on porte de plus en plus au développement des sciences. Si Colbert s'est préoccupé du progrès des sciences théoriques, comme il apparaît notamment par la fondation de l'Académie des Sciences et de l'Observatoire astronomique de Paris, il n'a jamais perdu de vue les applications immédiates des sciences. II a voulu avoir de bons mathématiciens et de bons astronomes, mais peut-être surtout pour avoir de bons géographes. Il a eu le souci de posséder des cartes exactes, permettant aux navigateurs de gagner plus sûrement les ports des Indes, sans l'aide des pilotes hollandais, qui n'étaient d'ailleurs pas disposés à mettre leur expérience au service des Français. D'où lui vint - peut-être l'idée d'envoyer en Chine des mathématiciens et des astronomes. Mais où prendre ces savants ? A l'Académie des Sciences ? Il en eût sans doute trouvé pour un rapide voyage. Mais ce n'était pas son affaire. Il lui fallait des savants capables de faire un travail de longue durée, dans des pays lointains, et les savants de ce genre, il ne pouvait les trouver que chez les religieux et les missionnaires, parce que pour eux l'intérêt de la mission se superposait à l'intérêt des sciences.

Pour réaliser un semblable projet, il y avait bien des hostilités à briser, bien des susceptibilités à endormir. Les hostilités devaient venir des Portugais qui défendaient âprement leur droit 


\section{La Chine et la formation de l'esprit philosophique en France}

de patronage en Extrême-Orient ; les susceptibilités étaient celles du Saint-Siège qui, avec I'aide de la Compagnie du SaintSacrement de l'Autel, et de la Société des Missions étrangères qui en était issue, venait de créer des vicariats apostoliques. En vertu de la séparation des deux pouvoirs, le spirituel et le

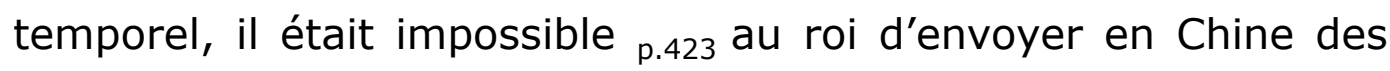
missionnaires, mais il lui était possible d'y envoyer des savants, même missionnaires, s'ils avaient brevet de mathématiciens du roi. C'était sans doute une fiction diplomatique, à laquelle Louis XIV n'aurait peut-être pas consenti, si la question du serment, imposé par les vicaires apostoliques aux missionnaires pour les obliger à reconnaître la suprématie du pouvoir spirituel, n'avait été contraire aux principes gallicans qu'il s'efforçait précisément de défendre contre la papauté. Il ne fallait plus de ces missionnaires, qui, bien que Français, se croyaient déliés de leur serment de fidélité envers le roi.

Une autre cause générale de cette décision fut l'approche de la Révocation de l'Édit de Nantes. Le nombre des conversions, plus forcées sans doute que volontaires, semblait permettre d'entrevoir la prochaine unité religieuse de la France. D'autre part les missionnaires laissaient espérer la conversion du roi de Siam, et par suite, suivant les idées du temps, (Regis ad exemplum...) la conversion de tout le peuple siamois. Nul doute que la même aventure merveilleuse n'arrivât en Chine, si des missionnaires habiles parvenaient à s'emparer de la faveur de l'empereur - et les Jésuites s'étaient déjà glissés à la cour de Pékin depuis le début du siècle. Mais pour réaliser ce grand projet il fallait flatter les passions dominantes des Chinois, et les 


\section{La Chine et la formation de l'esprit philosophique en France}

voyageurs et les Jésuites avaient déjà répandu I'histoire - ou la légende - d'une Chine savante, honorant les sciences, et versée particulièrement dans les mathématiques et dans l'astronomie.

A ces causes premières s'ajoutent des causes secondes qui emportèrent I'adhésion du roi, malgré ses hésitations. Le $P$. Couplet était venu à Paris, il avait été reçu à la cour, et nous savons l'intérêt de curiosité que sa visite provoqua. Mais nous savons aussi, grâce au questionnaire qui lui fut remis, que ce ne fut pas un simple intérêt de curiosité mondaine. Le gouvernement voulait être renseigné sur les sciences des Chinois, sur leur histoire, sur leur chronologie, non moins que sur les possibilités de commerce entre la Chine et l'Europe. Mais le P. Couplet n'était pas français ; le gouvernement eût mieux aimé confier cette mission à des Français, et dès ce moment le départ des Jésuites mathématiciens fut décidé. Il ne restait plus qu'à trouver l'occasion de les faire partir, et ce fut l'ambassade des Siamois qui la fournit.

Les années 1684, (visite du P. Couplet) et 1685, (départ des Jésuites mathématiciens pour la Chine) sont des dates importantes dans I'histoire des relations intellectuelles entre la Chine et la France. p.424 Les Jésuites qui partaient ainsi emportaient bien des espoirs, non seulement l'espoir de l'unité religieuse, mais aussi l'espoir de la découverte intellectuelle d'une ancienne civilisation, désormais soupçonnée, mais encore inconnue.

La Chronologie du P. Couplet, publiée dès 1686, et le Confucius Sinarum Philosophus qui parut I'année suivante 


\section{La Chine \\ et la formation de l'esprit philosophique en France}

semblaient devoir satisfaire toutes les curiosités. Ces deux publications avaient la prétention d'apporter tous les éléments nécessaires pour qu'on se fit une idée précise de la chronologie, de I'histoire, de la religion, de la morale et de la politique des Chinois.

La Chronologie passa presque inaperçue. Elle était prudente sans doute et permettait une conciliation avec les données chronologiques de la Bible, mais personne alors ne doutait que cette conciliation ne fût possible, à part les libertins que l'on réduisait d'ailleurs facilement au silence par la menace du bûcher, comme ce fut le cas de La Peyrère. Le véritable problème chronologique, c'est-à-dire la confrontation des chronologies des peuples profanes avec celle du peuple de Dieu n'était pas encore posé. Les difficultés de la chronologie ne regardaient que les théologiens - ce qui ne veut pas dire que les discussions n'étaient pas vives entre eux - mais les dissensions portaient seulement sur le choix de la version de la Bible que chacun d'eux adoptait pour le calcul des temps. Fallait-il s'en tenir à la Vulgate, ou, comme le croyait le P. Pezron, adopter la Version des Septante ? Tous néanmoins étaient d'accord pour prendre les données chronologiques de la Bible comme norme des différentes chronologies de tons les peuples du monde.

Le Confucius Sinarum Philosophus eut une tout autre destinée. Ce fut une véritable révélation. Non certes au point de vue religieux. La préface du P. Couplet sur la religion et les cultes chinois (passée un peu à la pierre ponce il est vrai par les reviseurs de Paris) n'offrait rien qui pût émouvoir les esprits, 


\section{La Chine et la formation de l'esprit philosophique en France}

même les plus orthodoxes. Mais la morale ! Mais la politique des Chinois! Voilà de quoi enchanter les esprits.

C'était en effet le moment, où, comme l'a marqué M. G. Lanson, de bons esprits qui n'étaient ni philosophes ni moralistes de profession, mais seulement des honnêtes gens, cherchaient dans leur conscience individuelle les règles de leur vie morale. Ils n'avaient pas la prétention de construire des systèmes et ne cherchaient pas à déduire de l'idée du bien les règles pratiques de leur vie journalière. Mais ils voulaient traduire en idées claires et formuler comme des principes universels les suggestions de leur conscience personnelle. La morale de Confucius vint leur apporter p.425 précisément ce qu'ils cherchaient. C'est qu'elle avait de quoi les satisfaire, non seulement à cause de sa méthode mais aussi à cause de ses résultats.

La morale de Confucius, telle qu'elle était exposée dans le livre des PP. Jésuites, ne se présentait pas comme une morale dogmatique ; elle n'était qu'un recueil de préceptes et d'enseignements suggérés au philosophe chinois par l'expérience de sa vie, parfois brillante à la cour des rois, mais aussi parfois dénuée de tout secours, selon les hasards de la fortune. La lecture de ce livre présentait donc l'expérience d'un homme qui avait connu la grandeur et la bassesse et qui révélait tout simplement les conclusions (plutôt encore que les règles morales) auxquelles l'avaient conduit les événements de sa vie.

En outre cette morale de Confucius apparaissait comme tout humaine : elle ne présentait pas comme idéal une vertu farouche, escarpée, inaccessible mais une vertu du juste milieu, 


\section{La Chine et la formation de l'esprit philosophique en France}

une sagesse qui était un équilibre parfait entre les passions et la raison, en somme un idéal que certains sages de l'antiquité classique avaient eux aussi trouvé et réalisé. Au surplus cette morale, qui n'avait besoin pour se soutenir d'aucun dogme religieux, et qui partant était vraiment une morale indépendante, enseignait certains préceptes que l'on trouve sans doute dans la morale chrétienne, mais qui ne peuvent venir d'une révélation particulière, puisque Confucius les avait enseignés de nombreux siècles avant le christianisme. Il y avait donc non seulement une morale indépendante mais une morale naturelle, que les différentes religions avaient accaparée en la présentant comme une conséquence de leurs dogmes, comme si cette morale naturelle n'était pas une émanation, un produit de la conscience de tout homme venant en ce monde et en n'importe quelle partie du monde.

C'était aussi le moment où l'on cherchait les principes rationnels de la politique. Non que I'on eût l'intention de combattre, et encore moins de ruiner I'absolutisme de Louis XIV. Mais malgré le loyalisme des Français de cette époque, on ne pouvait s'empêcher de remarquer qu'il y avait bien des misères dans le royaume de France. Etait-ce le principe même de I'absolutisme qui était mauvais, était-ce seulement l'application de ce principe qui était défectueuse ? La Chine révélée par les PP. Jésuites vint à point fournir l'exemple d'une monarchie, où le souverain tout comme en France était absolu, mais où cet absolutisme produisait des résultats remarquables, comme le constataient tous les voyageurs. Or, le principe sur lequel reposait l'absolutisme des empereurs de Chine ${ }_{p .426}$ était le 


\section{La Chine et la formation de l'esprit philosophique en France}

même qui justifiait le pouvoir absolu des rois de France, à savoir l'autorité du père de famille. L'exemple de la Chine ne pouvait donc que renforcer le loyalisme des Français et les empêcher de discuter le principe même du gouvernement. Mais il y a les résultats ! Comment expliquer la différence entre la richesse inouïe de la Chine et la pauvreté de la France ? C'est que sans doute ce despotisme des empereurs de Chine doit avoir un correctif qui, malgré tout, le limite. On ne s'inquiète pas encore des détails du fonctionnement du gouvernement chinois - ce sera I'œuvre des philosophes après 1740 - et I'on se contente de chercher cette limitation dans la définition même du pouvoir paternel qui ne peut être absolu que pour le bien des enfants : c'était d'ailleurs l'idée de La Bruyère et de Fénelon. La connaissance du gouvernement chinois ne bouleversait donc pas les idées courantes; la Chine fournissait seulement un exemple précis et réel et non pas des fictions comme celles du Télémaque.

La morale et la politique des Chinois sont les grandes révélations des publications du P. Couplet, parce qu'elles correspondaient à des préoccupations particulières à cette époque. Mais peu à peu la question de la religion des Chinois tourmente de plus en plus les esprits : c'est l'approche de la Querelle des Cérémonies chinoises.

L'affaire des Cérémonies chinoises ne fut d'ailleurs qu'une phase, particulièrement aiguë de la perpétuelle hostilité entre les Jésuites et leurs adversaires. Déjà et bien avant qu'on s'occupât de la Chine, les Jésuites avaient adopté au sujet du problème du 


\section{La Chine et la formation de l'esprit philosophique en France}

salut des infidèles, une attitude libérale qui les rapprochait des sceptiques comme La Mothe le Vayer, et qui, par suite, les faisait vilipender par les protestants et les jansénistes. La thèse du péché philosophique, qui n'est somme toute que l'interprétation théologique d'idées longtemps soutenues par la Compagnie sur le salut des Infidèles, et le bruit qu'elle suscita marquent que dans les dernières années du siècle une résistance particulièrement vive - nous ne dirons pas une cabale s'organise contre les Jésuites. Un peu plus tard la Lettre des cinq évêques, qui dénonce le scandale et le danger de cette thèse, faite «pour flatter les Chinois », indique une détermination des adversaires des Jésuites de les attaquer sur leurs doctrines théologiques à l'occasion des idées qu'ils soutiennent sur les cultes chinois. Le livre du P. Le Comte en fournit le prétexte, mais on attendit quatre ans avant de se risquer à l'attaque : c'est que Bossuet était occupé par sa lutte avec Fénelon. Or, en 1700, il était libre et l'Assemblée du Clergé allait se réunir. D'autre part, p.427 pendant ces quatre années le crédit des « triumvirs », l'archevêque de Paris, Bossuet et l'évêque de Chartres, n'avait fait que grandit, grâce à Madame de Maintenon. Les circonstances ne pouvaient pas être plus favorables.

Le bruit immense que I'on fit en France en 1700 au sujet de I'affaire des Cérémonies chinoises et qui se répercuta à travers toute I'Europe, donne une importance considérable, moins encore à la condamnation elle-même qu'aux raisons pour lesquelles les Jésuites furent condamnés. Dans ce débat, en effet, la question des rites et celle des tolérances accordées par les Jésuites, - ce qui n'était qu'affaire de discipline 


\section{La Chine et la formation de l'esprit philosophique en France}

ecclésiastique - disparaissent devant un autre problème, plein de dangers parce qu'il n'était pas seulement théologique mais philosophique, déjà au sens où le XVIIIe siècle entendra ce mot ; les Chinois sont-ils idolâtres, déistes ou athées ? Sans doute la Sorbonne ne prit pas parti dans cette question de la religion des Chinois, mais elle sembla pencher pour l'opinion qu'ils étaient déistes, et comme elle condamna les Jésuites pour avoir prétendu que les Chinois, malgré cette religion, qui s'apparentait au déisme, avaient toujours pratiqué une morale parfaite, elle signifia par son arrêt, claironné de tous côtés, que des théologiens et des religieux avaient dénoué le lien que I'on devait croire indissoluble entre la morale et la religion révélée.

Les suites de la Querelle des Cérémonies chinoises et l'âpreté des adversaires des Jésuites eurent peut-être encore des conséquences plus considérables. Les ennemis des Jésuites s'efforcèrent, en effet, de prouver que les Chinois étaient athées. Or, d'après les théologiens, l'affirmation que l'athéisme pouvait exister tendait à diminuer I'horreur naturelle que tous les hommes devaient avoir de l'athéisme. En outre, les théologiens étaient persuadés, contrairement aux idées de Bayle, que I'athéisme non seulement est incompatible avec la morale mais qu'il rend impossible l'existence d'une société. Prétendre que la Chine, nation solidement charpentée, puisqu'elle durait depuis des millénaires, pratiquait communément l'athéisme, c'était donner raison à Bayle. Aussi Bayle se saisit de l'argument et par son Dictionnaire il répandit dans tous les milieux l'idée de I'athéisme des Chinois. 


\section{La Chine et la formation de l'esprit philosophique en France}

Somme toute, la Querelle des Cérémonies chinoises profite surtout à Bayle : l'exemple de la Chine est le meilleur qui se puisse trouver pour étayer les idées essentielles qu'il a soutenues avant de s'intéresser à la Chine. Il est certain, en effet, que la démonstration de l'athéisme de la Chine achève de ruiner l'argument du consentement universel. Sans doute un peu plus tard Elie Benoist et p.428 Ramsay vont essayer de modifier l'argument, et, abandonnant l'idée du consentement universel dans l'espace à l'époque moderne, ils chercheront à montrer un consentement universel à l'origine des temps. Mais il leur aurait fallu montrer de quelle manière l'athéisme a pu s'introduire et se répandre, démonstration qu'ils n'apportèrent pas.

En outre les Jésuites avaient montré que les Chinois, bien qu'il n'eussent pas eu la révélation, mais en vertu de leur religion qui s'apparentait de très près au déisme, s'étaient constitué une morale qui souvent rappelle la morale chrétienne et peut être comparée avec elle. Ainsi la révélation n'était pas nécessaire pour trouver les lois morales dont s'enorgueillissent les Chrétiens : d'autres religions avaient pu les trouver elles aussi. Mais l'acharnement que mirent les adversaires des Jésuites à prouver l'athéisme des Chinois eut une influence plus grave encore. S'il est vrai que les Chinois sont athées, et si I'on ne conteste pas l'excellence de leur morale - comme on a oublié de le faire, du moins avant Renaudot, mais il vient trop tard on donne raison à Bayle qui avait démontré par des arguments rationnels que l'athéisme était supérieur à l'idolâtrie, c'est-à-dire au théisme au point de vue moral et au point de vue social. Lorsque Bayle eut pris acte de l'athéisme des Chinois, il était 


\section{La Chine et la formation de l'esprit philosophique en France}

prouvé que la morale et la religion étaient des choses étrangères I'une à l'autre. Sans doute, la morale n'y perdait rien, mais la religion perdait ce rôle éminent qu'on lui accordait généralement : elle cessait d'être la clef de voûte de la société.

La Querelle des Cérémonies chinoises étant sinon terminée, du moins apaisée, l'intérêt pour la Chine n'en fut pas supprimé, car la curiosité européenne avait été trop vivement excitée en faveur de ce pays dont la religion avait provoqué de si vives dissensions parmi les théologiens. Mais on se rendait compte que l'on connaissait en somme peu de choses de la Chine, et que I'on manquait de faits précis parce que les études des PP. Jésuites sur l'astronomie et la chronologie chinoises tardaient à paraître. Cependant les libertins redoublaient d'audace : si les uns, comme autrefois La Peyrère à la suite de Bayle, montraient l'impossibilité de l'origine du monde telle que la rapporte la Bible, d'autres comme Tyssot de Patot insinuaient l'idée de l'éternité du monde. On avait pu imposer silence à La Peyrère par la menace du bûcher, mais cet argument décisif avait déjà perdu de sa valeur démonstrative au début du XVIIIe siècle. Le problème de la chronologie et notamment de l'accord des chronologies profanes avec la chronologie biblique devient dans les premières décades du $\mathrm{XVIII}^{\mathrm{e}}$ siècles un des problèmes les

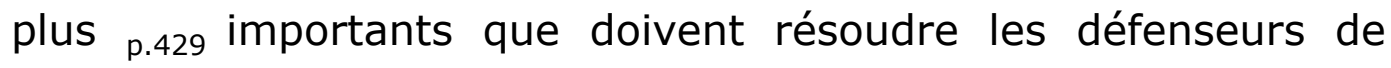
l'orthodoxie religieuse.

Problème d'autant plus essentiel qu'une découverte scientifique, celle du Chevalier de Louville sur les variations de I'obliquité de l'écliptique semblait favoriser les idées des libertins 


\section{La Chine et la formation de l'esprit philosophique en France}

sur l'éternité du monde. S'il est vrai qu'il y eut un temps où, les nuits étant égales aux jours tout le cours de l'année, la terre jouissait d'un printemps perpétuel, les récits des poètes sur l'âge d'or ne sont peut-être pas des fictions mais des réminiscences de traditions très lointaines. Et les récits bibliques sur la beauté du Paradis terrestre, sur l'Eden qui ne connaissait ni les frimas ni l'ardeur du soleil d'été, ne sont que des adaptations de ces mêmes traditions. Or, comme le Chevalier de Louville en confrontant les observations de Pythéas au IVe siècle après J.-C. et les siennes propres sur la valeur de l'angle formé par l'écliptique et l'équateur avait pu déterminer la déclinaison annuelle de cet angle, il avait pu également par un simple calcul fixer à 400.000 ans environ l'époque à laquelle la terre jouissait du printemps perpétuel. Période astronomique sans doute et que I'on établit par un calcul, mais qui, chose curieuse, correspond à peu près à la chronologie dont se vantaient certains peuples orientaux, notamment les Babyloniens, et dont l'existence réelle semblait prouvée par les anciennes traditions des mages d'Égypte recueillies par Hérodote. On voit les dangers de la découverte des variations de l'obliquité de l'écliptique à cause des conséquences extrêmes que dès l'abord on s'efforce d'en tirer contre la Bible. Il n'était donc plus possible d'écarter d'un seul mot, comme le faisait Bossuet, ou même encore l'Histoire Universelle anglaise, toutes ces chronologies orientales en les traitant de fabuleuses à cause de la date reculée de leurs origines qui ne pouvaient s'accorder avec la date de la création du monde, telle que la donne la Bible, il fallait examiner ces chronologies en elles-mêmes et par elles-mêmes, 


\section{La Chine \\ et la formation de l'esprit philosophique en France}

indépendamment de toute préoccupation religieuse : c'est la méthode critique que Fréret s'efforça d'apporter dans l'étude de la chronologie chinoise.

Sa méthode sans doute paraît timide, même aux Jésuites de Pékin, mais elle veut être sûre et ne s'appuyer que sur des faits certains. Elle est aussi éloignée des affirmations audacieuses des libertins que des négations méprisantes d'un Bossuet ou d'un Dom Calmet. Mais malgré ses apparentes timidités, malgré le souci qu'elle témoigne constamment de désarmer par avance toutes les susceptibilités, en montrant que cette chronologie, telle qu'elle est connue d'une manière certaine ne présente encore rien qui soit en p.430 désaccord avec la chronologie biblique, elle pose néanmoins, mais par prétérition, cette importante question : comment un peuple très éloigné des régions que I'on considère comme le berceau de I'humanité, pouvait-il être déjà un peuple nombreux, policé et capable de calculer des éclipses, très peu de temps après le Déluge ? La correspondance de Fréret, mieux encore que ses dissertations de I'Académie des Inscriptions nous montre qu'il avait vu tous ces dangers mais sa méthode était d'établir des faits précis et vérifiés, quelles qu'en fussent les conséquences, et les conséquences, même celles qu'il pouvait souhaiter n'étaient pas capables de faire fléchir sa méthode dans l'établissement des faits.

Avec Voltaire, toutes ces timidités disparaissent, toutes ces précautions qu'un Fréret croyait encore nécessaires sont désormais laissées de côté : dès les premières phrases de son 


\section{La Chine et la formation de l'esprit philosophique en France}

Histoire Universelle, Voltaire en montrant la certitude de la chronologie chinoise qui par son antiquité ne peut s'accorder avec celle de la Bible, laisse percer le bout de l'oreille : la chronologie de la Bible ne peut être la norme des chronologies des peuples profanes, qui de beaucoup la dépassent. Non que Voltaire croie à l'éternité du monde : il lui suffit de ruiner par l'exemple de la Chine I'autorité historique de la Bible. C'est une conclusion à laquelle aucun Jésuite, si féru qu'il fût des antiquités chinoises n'aurait pu souscrire. Il n'en reste pas moins que dans la croisade que Voltaire va mener en faveur de la Chine à partir de 1700, il aura toujours les Jésuites pour alliés : il leur empruntera des faits et des arguments en faveur des Chinois, mais il sera parfois un ami un peu compromettant, lorsqu'il montrera, non sans complaisance indiscrète, que la morale est indépendante de la religion révélée, et qu'une morale parfaite peut se concilier avec le déisme, ce que précisément la Sorbonne avait condamné en 1700 dans les écrits des Jésuites. Cependant il sera résolument l'allié des Jésuites, sans aucune arrièrepensée, pour affirmer avec eux contre Bayle que les philosophes chinois ne sont pas athées, et que la philosophie et l'athéisme ne peuvent se concilier ni en Chine ni en France.

Vu le 12 mars 1931.

Le Doyen de la Faculté des Lettres de I'Université de Paris, 


\section{La Chine \\ et la formation de l'esprit philosophique en France}

H. DELACROIX.

VU ET PERMIS D'IMPRIMER :

Le Recteur de l'Académie de Paris,

L. CHARLETY. 


\section{La Chine \\ et la formation de l'esprit philosophique en France}

\section{BIBLIOGRAPHIE GÉNÉRALE}

1. Bibliographies

2. Ouvrages Généraux

3. Biographies - Mémoires - Correspondances

4. Fuvres des principaux Auteurs

5. Relations de Voyages

6. Missions en général

7. Affaires de Siam

8. La Querelle des Cérémonies Chinoises

9. Chronologie

10.La Religion des Chinois

11.La Morale et la Politique des Chinois

\section{1. - Bibliographies}

BENGESCO (Georges). - Voltaire. Bibliographie de ses œuvres. Paris, 1882-1890, 4 vol.

CHÉREL (Albert). - Fénelon au XVIII e siècle en France. Paris, 1917. (Bibliographie à la fin du volume).

CORDIER (Henri). - Bibliotheca indo-sinica. Dictionnaire bibliographique des ouvrages relatifs à la péninsule indochinoise. Paris, 1912-5, 4 vol.

Bibliotheca sinica. Dictionnaire bibliographique des ouvrages relatifs à l'Empire chinois. $2^{\mathrm{e}}$ éd. Paris, 1904-7, 4 vol.

INGOLD. - Essai de bibliographie oratorienne. Paris, 1880-4.

LALANDE (Jérôme de). - Bibliographie astronomique avec I'histoire de l'astronomie depuis 1781 jusqu'à 1802. Paris, an XI.

MONOD (Albert). - De Pascal à Chateaubriand. Paris, 1916. (Bibliographie à la fin du volume). 


\section{La Chine et la formation de l'esprit philosophique en France}

SOMMERVOGEL (le P. Carlos). - Bibliothèque de la Compagnie de Jésus. Paris, 1890-1909, 10 vol.

\section{2. - Ouvrages Généraux}

ALLIER (Raoul). - La Cabale des Dévots, (1627-1660). Paris, 1902.

ATKINSON (Geoffroy). - The extraordinary Voyage in French Literature before 1700. New-York, 1920.

The extraordinary Voyage in French Literature from 1700 to 1720 . Paris, 1922.

Les Relations de voyages du XVII siècle et l'évolution des idées. Contribution à la formation de l'esprit du XVII siècle. Paris, s. d.

BALDENSPERGER (Fernand). - Où l'Orient et I'Occident s'affrontent. (Revue de Littérature comparée. II ${ }^{\mathrm{e}}$ année, 1922, pp. 5-29).

BARNI (J. R.). - Histoire des idées morales et politiques en France au XVIII e siècle. Paris, 1867, 2 vol.

BARUZI (Jean). - Leibniz et I'organisation religieuse de la terre. Paris, 1907.

BRUCKER (le P. Jos.). - Sur l'exécution des cartes de la Chine par les missionnaires du XVIII ${ }^{e}$ siècle. (IVe Congrès des sciences géographiques, t. I, pp. 378-90). Paris, 1890.

BELEVITCH-STANKEVITCH $\left(\mathrm{M}^{11 \mathrm{e}} \mathrm{H}\right.$. $)$ - Le goût chinois en France au temps de Louis XIV. Paris, 1910.

BRUNETIERE (Ferdinand). - Études critiques. VIIIe Série. Paris, 1907.

BUSSON (Henri). - Les sources et le développement du rationalisme dans la littérature française de la Renaissance (1533-1601). Paris, 1922.

CAHEN (Gaston). - Histoire des relations de la Russie avec la Chine sous Pierre le Grand (1689-1730). Paris, 1911.

CARCASSONNE (F.). - Montesquieu et le problème de la constitution française au XVIII $I^{e}$ siècle. Paris, 1927. 


\section{La Chine et la formation de l'esprit philosophique en France}

CAPÉRAN (Louis). - Le Problème du salut des Infidèles. Paris, 1912.

CHARBONNEL (J. Roger). - La Pensée italienne au XVI siècle et le courant libertin. Paris, 1919.

CHÉREL (Albert). - Fénelon au XVIII e siècle en France. Paris, 1919.

Un aventurier religieux au XVIII $I^{e}$ siècle : André Michel Ramsay. Paris, 1926.

CHINARD (Gilbert). - L'exotisme américain dans la littérature française au XVI e siècle d'après Rabelais, Ronsard, Montaigne, etc... Paris, 1911.

L'Amérique et le rêve exotique dans la littérature française au XVII et au XVIII ${ }^{e}$ siècles. Paris, 1913.

CORDIER (Henri). - La Chine en Europe au XVIII siècle (Institut de France. Académie des Inscriptions). Paris, 1908.

La Chine en France au XVIII siècle. Paris, 1910.

Mélanges d'histoire et de géographie orientales. Paris, 1914-1923, 4 vol.

Notes pour servir à l'histoire des études chinoises en Europe jusqu'à l'époque de Fourmont l'aîné. (Nouveaux mélanges orientaux p. p. les professeurs de l'école spéciale des langues orientales vivantes). Paris, 1886.

Les études chinoises (1891-1894). Leide, 1903, 3 vol.

Histoire de la Chine. Paris, 1920, 4 vol.

DAVILLÉ (Louis). - Leibniz historien. Paris, 1909.

DEDIEU (I'abbé). - Le rôle politique des protestants français (1685-1715). Paris, 1920.

DELVAILLE (Jules). - Essai sur l'histoire de l'idée de progrès jusqu'à la fin du XVIII siècle. Paris, 1910.

DELVOLVÉ (Jean). - Essai sur Pierre Bayle. Religion, critique et philosophie positive. Paris, 1906.

DESCHAMPS (Arsène). - La genèse du scepticisme érudit chez Bayle. Liége, 1878.

DESCHAMPS (Léon). - Histoire de la question coloniale. Paris, 1891. 


\section{La Chine et la formation de l'esprit philosophique en France}

DROUET (Joseph). - L'abbé de Saint-Pierre. L'Homme et I'Euvre. Paris, 1912.

DUCROS (Louis). - Les Encyclopédistes. Paris, 1900.

GAZIER (Augustin). - Histoire générale du mouvement janséniste depuis les origines jusqu'à nos jours. Paris, 1992, 2 vol.

GAZIER (Georges). - Un artiste comtois à la cour de Chine au XVIII ${ }^{e}$ siècle : le frère Attiret (1702-1768). Besançon, 1912.

GRANET (Marcel). - Danses et Légendes de la Chine ancienne. Paris, 1925, 2 vol.

La civilisation chinoise. Paris, 1929.

Histoire de l'Académie des sciences depuis son établissement en 1666 jusqu'en 1699. Paris.

KÆPPELIN (Paul). - La Compagnie des Indes orientales et François Martin. Paris, 1908.

KOU-HOUNG-MING. - L'esprit du peuple chinois. Traduit de I'anglais par J. Rival. Paris, 1927.

LACOUR-GAYET. - L'éducation de Louis XIV. 2e éd. Paris, 1993.

LACHÈVRE (Frédéric). - Le libertinage au XVII siècle. Paris, 1909-1921, 11 vol.

LANGE (Maurice). - La Bruyère critique des conditions et des institutions sociales. Paris, 1909.

LANSON (Gustave). - Les Provinciales et le livre de la théorie morale des Jésuites (Revue d'hist. lit. 1900).

Formation et développement de l'esprit philosophique au $X V I I I^{e}$ siècle (influence de l'Orient et de l'Extrême-Orient). Revue des Cours et Conférences, 18 mars 1909, p. 65 sq.

Le rôle de l'expérience dans la formation de la philosophie du XVIII e siècle : I. - La transformation des idées morales et la naissance des morales rationnelles; II. - L'éveil de la conscience sociale et les premières idées de réformes politiques (Revue du Mois, 1910).

Questions diverses sur l'histoire de l'esprit philosophique en France avant 1750 (Revue d'hist. lit., 1912).

Voltaire. Paris, 1906. 


\section{La Chine et la formation de l'esprit philosophique en France}

LE ROY (Albert). - La France et Rome de 1700 à 1715. Paris, 1892.

LOMBARD (Alfred). - L'Abbé du Bos. Paris, 1913.

La Querelle des Anciens et des Modernes, I'Abbé du Bos. Neuchâtel, 1908.

LOUIS XIV. - Mémoires pour les années 1661 et 1666, suivis des Réflexions sur le métier de Roi, des instructions au Duc d'Anjou et d'un projet de harangue, p. p. Jean Longnon. Paris, 1923.

MAILlA (le P. Moyriac de). - Histoire générale de la Chine ou annales de cet empire, p. p. I'abbé Grosier et Le RouxDeshauterayes. Paris, 1777-1785, 13 vol.

MARTINO (Pierre). - L'Orient dans la littérature française aux $X V I I^{e}$ et XVIII $I^{e}$ siècles. Paris, 1906.

MASPÉRO (Georges). - La Chine. Paris, 1918. Nouv. éd. t. II, Paris, 1925.

MASPÉRO (Henri). - La Chine antique. Paris, 1927.

MAURY (A.). - Histoire de l'ancienne académie des Inscriptions et Belles Lettres. Paris, 1865

Histoire de l'ancienne Académie des sciences. Paris, 1864.

MONOD (Albert). - De Pascal à Chateaubriand. Paris, 1916.

MORNET (Daniel). - Les sciences de la nature en France au XVIII ${ }^{e}$ siècle. Paris, 1911.

PELLISSON (Maurice). - La sécularisation de la morale au XVIII siècle (Révolution française, nov. 1903).

Les opinions sur le bonheur au XVIII siècle (Grande Revue, 1906).

Un philosophe amateur sous la Régence, le marquis de Lassay (Rev. polit. et parl., 10 oct. 1904).

PHÉLYPEAUX (I'abbé). - Relation de l'origine, du progrès et de la condamnation du Quiétisme. Paris, 2 vol.

REICHWEIN (Adolf). - China and Europa intellectual and artistic contact in the eighteenth century. London, 1925.

Recueil des instructions données aux ambassadeurs de France :

Portugal, p. p. le Vte de Caix de Saint-Aymour. Paris, 1886. 


\section{La Chine et la formation de l'esprit philosophique en France}

Rome, p. p. Gabriel Hanotaux, t. I-III. Paris, 1888-1913.

RIGAULT (Hippolyte). - La Querelle des Anciens et des Modernes. Paris, 1856.

ROCQUAIN (Félix). - L'esprit révolutionnaire avant la Révolution française (1715-1798). Paris, 1878.

SÉE (Henri). - Les idées politiques en France au XVIII ${ }^{e}$. Paris, 1920.

SOUÉO GOTO. - Les premiers échanges de civilisation entre I'Extrême-Orient et l'Occident dans les temps modernes (Revue de littérature comparée, 1928, pp. 401 et 601).

TING TCHAO-TS'ING. - Les Descriptions de la Chine par les Français (1650-1750). Paris, 1928.

VILLEY (Pierre). - Les sources et l'évolution des Essais de Montaigne. Paris, 1908, 2 vol.

\section{3. - Biographies - Mémoires - Correspondances}

\section{a). - MANUSCRITS}

BOUHIER (Le Président). - Lettres à Mathieu Marais. B. N. Fr. 25.442.

BOUVET (Le P.). - Lettres à l'abbé Bignon. B. N. Fr. 17.240.

FOUCQUET (Le P.). - Lettres. B. N. Fr. 22.228.

Lettres à l'abbé de Rothelin. Obs. Astr. A B² 4 (149-5-9)

Lettres au P. du Halde. Obs. Astr. A B 4 (149-3).

FRÉRET (Nicolas). - Lettres aux PP. Jésuites missionnaires en Chine. (Brouillons et minutes). Obs. Astr. A B 10 (150).

GAUBIL (le P.). - Lettres à Fréret. Obs. Astr. A B 10 (150). (Cf. le P. Jos. Brucker : Correspondance scientifique d'un missionnaire. Revue du Monde catholique 1883).

HALDE (le P. du). - Lettre à Foucquet, 5 juillet 1734. Obs. Astr. $A^{2} 4$ (149).

Lettre au P. Foureau, 13 octobre 1739. B. N. N. A. F. 6556. JÉSUITES. - (Lettres de différents)... B. N. Fr. 15476. 


\section{La Chine et la formation de l'esprit philosophique en France}

PARRENIN (le P.). - Lettre à M. de Mairan. B. N. Fr. 17240. (Cf. Lettres édifiantes et curieuses, $\mathrm{XXI}{ }^{\mathrm{e}}$ Recueil).

PRÉMARE (le P. de). - Lettre. B. N. Fr. 17239.

Lettres à Fourmont l'aîné. B. N. Fr. 15195.

Lettres à Fourmont sur I'Y-King. B. N. N. A. Fr. 4754.

RÉGIS (le P.). - Lettres à Fréret. Obs. Astr. A B 10 (150-6).

b) IMPRIMÉS

ANDRÉ (le P.). - Vie de Malebranche, p. p. Ingold. Paris, 1886.

ARGENSON (le marquis $\mathrm{d}^{\prime}$ ). - Journal et Mémoires, p. p. Rathery. Paris, 1859-67, 9 vol.

ARNAULD (Antoine) - Correspondance. Euvres complètes, éd. 1755 , t. III.

Vie de Messire Antoine Arnauld, Docteur de la maison de Sorbonne. Fuvres complètes, t. I.

ARTIGNY (I'abbé Gachet d'). - Nouveaux Mémoires d'Histoire, de Critique et de Littérature. 1749-56, 7 vol.

BARBIER. - Journal historique et anecdotique du règne de Louis XV. 1849-56, 4 vol.

BAYLE (Pierre). - Lettres inédites de divers savants, t. I. Correspondance inédite de Bayle, p. p. Gigas. Copenhague, 1890.

BLAMPIGNON. - Étude sur Malebranche et correspondance inédite. Paris, 1869.

BLIARD (le P. P.). - Les Mémoires de Saint-Simon et le P. Le Tellier, confesseur de Louis XIV. Paris, 1891.

BOSSUET. - Correspondance, p. p. Urbain et Lévesque. Paris, 1909-25.

BROSSES (le Président de). - Lettres familières écrites d'Italie en 1739 et en 1740, p. p. Colomb. 4éd. 1885, 2 vol.

BUVAT. - Journal de ce qui s'est passé de plus important pendant la Régence, p. p. Campardon. Paris, 1865.

CHANTELAUZE. - Le Père de la Chaize. Paris, 1859. 


\section{La Chine et la formation de l'esprit philosophique en France}

CLÉMENT (Pierre). - Histoire de Colbert et de son administration. Paris, 1874, 2 vol.

COLBERT. - Lettres, instructions, mémoires, p. p. P. Clément. Paris, 1861-82, 10 vol.

DANGEAU. - Journal de la cour de Louis XIV (1684-1790), p. p. Soulié, Dussieux, etc. Paris, 1854-60, 19 vol.

DENIS (Dom Paul). - Lettres autographes de la collection de Troussures. Paris-Beauvais, 1919, in-4.

DU BOS (Abbé). - Vingt lettres inédites de l'abbé J.-B. du Bos, p. p. Paul Bonnefon. Rev. hist. lit., 1907, pp. 141-62.

FÉNELON. - Correspondance : Fuvres complètes. (Ed. de Versailles, t. XXIII-XXXV).

FLOQUET (A.). - Bossuet, précepteur du Dauphin, fils de Louis XIV et évêque à la Cour (1670-1682). Paris, 1864.

FOUCQUET. - Lettres au Cardinal Gualterio. (Revue de I'Extrême-Orient, t. I, p. 27 sq.).

Lettre à Rome le 12 septembre 1738 (Observations sur les écrits modernes, 1738, t. XV, pp. 137-140).

GEFFROY. - Madame de Maintenon d'après sa correspondance inédite. Paris, 1887.

HUET (Daniel). - Mémoires, traduits par Nisard. Paris, 1853.

HAUSSONVILLE ( $\mathrm{d}^{\prime}$ ) et HANOTAUX. - Souvenirs sur Madame de Maintenon. Paris, 1902-5, 3 vol.

JORDAN. - Histoire de la vie et des ouvrages de M. La Croze, avec des remarques de cet auteur sur divers sujets. Amsterdam, 1741.

LA PEYRĖRE. - Lettre de La Peyrère à Philotime, dans laquelle il expose les raisons qui l'ont obligé à abjurer la secte de Calvin qu'il professait et le livre des Préadamites qu'il avoit mis au jour. Traduit en françois du latin imprimé à Rome par l'auteur mesme. Paris, 1658.

Recueil de lettres écrites à M. le Comte de La Suze pour l'obliger par raison à se faire catholique. Suite des lettres écrites à M. le Comte de La Suze. Paris, 1661-2.

Apologie de La Peyrère. Paris, 1663. 


\section{La Chine et la formation de l'esprit philosophique en France}

LE DIEU (I'abbé). - Mémoires et journal sur la vie et les ouvrages de Bossuet. Paris, 1856-7, 4 vol.

LEGENDRE. - Mémoires, p. p. Roux, 1863.

Éloge historique de M. Leibniz (Mémoires de Trévoux). Juillet 1721, pp. 1350-68.

MAILLA (le P. Moyriac de). - Lettres à Fréret (Mailla : Histoire de la Chine, t. X).

MAINTENON (Madame de). - Correspondance générale, p. p. Lavollée, 4 vol.

MAIRAN (Dortous de). - Lettres de M. de Mairan au R. P. Parrenin contenant diverses questions sur la Chine. Paris, 1759.

MARAIS (Mathieu). - Journal et Mémoires, p. p. de Lescure. Paris, 1863-8.

MONTESQUIEU. - Correspondance, p. p. François Gébelin avec la collaboration d'André Morize. I914, 2 vol.

NICÉRON. - Mémoires pour servir à l'histoire des hommes illustres. 1727-45, 43 vol.

PATIN (Guy). - Lettres de Guy Patin. Ed. Réveillé-Parise, 4 vol.

Lettres. Ed. Triaire, t. T. Paris, 1907.

Quelques lettres inédites de Guy Patin, p. p. A. Chevreau.

QUESNEL (Pasquier). - Correspondance de Pasquier Quesnel, prêtre de l'Oratoire sur les affaires politiques et religieuses de son temps, p. p. avec des notes par $\mathrm{M}^{\mathrm{me}}$ Albert Le Roy. Paris, 1900, 2 vol.

SIMON (Richard). - Lettres choisies de Monsieur Simon, p. p. Bruzen de la Martinière. Amsterdam, 1730, 2 vol.

SAINT-SIMON - Mémoires, p. p. de Boislisle, Lecestre, J. de Boislisle, 1883, sq. 30 vol.

Écrits inédits. Ed. Faugère, t. I-II : Les Confesseurs du Roi. Lettres de ... au Cardinal Gualterio, p. p. de Boislisle.

(Extrait de I'Annuaire Bulletin de la Société de l'Histoire de France, t. XXV, Année 1888, Paris, 1889).

SOURCHES. - Mémoires, p. p. de Cosnac. Paris, 1882-93, 13 vol. 


\section{La Chine et la formation de l'esprit philosophique en France}

TORCY. - Journal de J.-B. Colbert, marquis de Torcy pendant les années 1709, 1710, 1711, p. p. F. Masson. Paris, 1884.

\section{4. - Fuvres des principaux Auteurs}

AGUESSEAU (d'). - Fuvres. Ed. Pardessus, 1818-20, 12 vol. ARNAULD (Antoine). - Fuvres. Ed. 1775-83. Paris, 43 tomes en 36 vol.

BAYLE (Pierre). - Fuvres diverses. Ed. 1727-31, 4 vol. in-fol. 1692.

Projet et fragments d'un dictionnaire critique. Rotterdam, Dictionnaire historique et critique. Rotterdam, 1697.

Dictionnaire historique et critique, $5^{\text {e }}$ éd. Amsterdam, 1734, 5 vol. in-folio.

BOSSUET (J.-B.). - Euvres complètes, p. p. F. Lachat. Paris, 31 vol.

FÉNELON. - Fuvres complètes. Versailles 1820-30, 35 vol.

Les aventures de Télémaque, p. p. Cahen. Paris, 2 vol. FONTENELLE. - Euvres complètes, 1758-66, 12 vol.

Histoire des Oracles, p. p. Maigron. Paris, 1908. FRÉRET (Nicolas). - Fuvres complètes. Londres, 1775, 2 vol.

Fuvres. Londres, 1787.

Fuvres complètes. Edition rédigée par M. de Septchênes. Paris, 1796.

Fuvres complètes. Nouvelle édition, Paris, an VI, 20 vol. in-12.

Guvres complètes... mises dans un nouvel ordre par $\mathrm{M}$. Champollion-Figeac. Paris, 1825, 8 vol.

LA BRUYÈRE. - Les Caractères. Ed. Servois. Paris, 1865-78, 3 vol.

LEIBNIZ. - Novissima sinica. S. I., 1699. 


\section{La Chine et la formation de l'esprit philosophique en France}

Recueil de diverses pièces sur la philosophie, les mathématiques, I'histoire, etc., publiées par Chrétien Kortholt. Hambourg, 1734.

Viri illustris Godefredi Leibnitii epistulæ ad diversos. Lipsiae, 1734-42, 4 vol.

Opuscules et fragments inédits de Leibniz extraits des manuscrits de la Bibliothèque royale de Hanovre, p. p. Louis Couturat. Paris, 1903.

MALEBRANCHE. - Entretien d'un philosophe chrétien et d'un philosophe chinois. Paris, 1708.

Avis touchant l'entretien d'un philosophe chrétien et d'un philosophe chinois. Paris, 1708.

Méditations métaphysiques et Correspondance de Malebranche et Mairan, p. p. Feuillet de Conches. Paris, 1841.

MONTESQUIEU. - Lettres Persanes, p. p. Barkhausen. Paris, 1913, 2 vol.

Fuvres, p. p. Laboulaye. Paris, 1875-9, 7 vol.

Mélanges inédits, p. p. le baron de Montesquieu. Bordeaux, 1892.

Pensées et fragments inédits. Bordeaux, 2 vol.

Voyages de Montesquieu, p. p. le baron Albert de Montesquieu. Bordeaux, 1894-6, 2 vol.

PASCAL (Blaise). - Fuvres, p. p. Léon Brunschwicg et Pierre Boutroux. Paris, 1908-14, 11 vol.

Les Pensées, t. XII-XIV. Paris, 1904.

SAINT-EVREMOND. - Fuvres, p. p. Desmaizeaux. 1706, 5 vol. in-12.

VOLTAIRE. - Fuvres complètes. Ed. Moland. 52 vol. in-8 $8^{\circ}$

Lettres philosophiques. Ed. critique p. p. G. Lanson. Paris.

5. - Relations de Voyages

a) MANUSCRITS 


\section{La Chine et la formation de l'esprit philosophique en France}

Journal du Voyage de la Chine fait dans les années 1701, 1702, 1703. B. N. N. A. F. 2086 (Cf. Madrolle, Les premiers voyages français à la Chine. Paris, 1901).

Du HALDE. - Lettre au P. Foureau. B. N. N. A. F. 6556.

Nouvelle géographie de la Chine et de la Tartane. B. N. Fr. 17242.

\section{b) IMPRIMÉS}

1555. Les trois livres de I'histoire des Indes accomplie de plusieurs choses mémorables autant fidèlement que sommairement composez en latin et depuis naguères faictz en Françoys par Maistre Jehan Macer, licencié en droit. Paris.

MENDOÇA (Gonzalès de). - Histoire du grand Royaume de la Chine situé aux Indes orientales, divisée en deux parties, mise en François avec additions en marge et deux notices par Luc de la Porte Parisien. Paris.

1602. LOMBARD (Nicolas). - Nouveaux advis du grand Royaume de la Chine, escrits par le P. Nicolas Lombard, de la Compagnie de Jésus au T. R. P. Claude Aquaviva, Genéral de la mesme Compagnie, et traduite en françois par le $P$. Jean de Borde. Paris.

1604. LOMBARD (Nicolas). - Nouveaux advis du Royaume de la Chine, du Jappon et de l'Estat du Roy de Mogor successeur du grand Tamburla et d'autres royaumes des Indes à luy subjects, tirez de plusieurs lettres, mémoires et advis anvoyez à Rome et nouvellement traduits de l'Italien en françois. Paris.

1615. TRIGAULT (Nicolas). - De christiana expeditione apud Sinas suscepta ab societate Jesu. Ex P. Mathei Ricci, ejusdem societatis, commentariis Libri $V$. Auctore Nicolao Trigaulio. Augustae Vind. (2 ${ }^{\mathrm{e}}$ éd. Lyon, 1616).

1616. AVITY (d'). - Les Estats empires et principautez du monde. Paris, Fol.

1616. MOCQUET (J.). - Voyages en Afrique, Asie, Indes orientales et occidentales. Paris (Rééd. Rouen 1645, Rouen 1665, Paris, 1717).

1616. TRIGAULT (Nicolas). - Histoire de l'expédition chrétienne au royaume de la Chine entrepris par les PP. de la Compagnie de 


\section{La Chine et la formation de l'esprit philosophique en France}

Jésus, comprise en cinq livres.., tirée des commentaires du $P$. Matthieu Riccius, par le P. Nicolas Trigault, et traduite en françois par le Sr. P. de Riquebourg. Lyon, in-8 (Rééd. Lille, 1617, in-4 ; Paris, 1618).

1697. BELLEFLEUR. Nouvelle Histoire de la Chine avec le progrez que depuis peu de tems les Pères de la Compagnie de Jésus ont fait faire à la, religion chrestienne en ces quartiers-là. Traduite d'espagnol en françois par J. J. Bellefleur percheron. Paris.

BAUDIER (Michel). - Histoire de la Cour du Roy de Chine.

Paris, in- $4^{\circ}$. Nouv. éd. 1638 , à la suite de I'Histoire générale du serrail. Rouen.

BAUDIER (Michel). - Histoire de ce qui s'est passé ès royaumes de la Chine et du Japon... Tirés des lettres escrites ès années 1619, 1620 et $1621 . .$. Traduites de l'italien en françois. Paris, 2 tomes en 1 vol.

1628. PINTO (Fernand Mendez). - Voyages advantureux.

1629. Regni chinensis descriptio ex variis authoribus (Lugduni Respublicae Elzevirorum).

Histoire de ce qui s'est passé au royaume de la Chine en I'année 1624, tirée des Lettres écrites et adressées au $R$. P. Motio Vitelleschi, général de l'ordre des Jésuites, et traduite de l'italien en françois par un Père de la mesme Compagnie. Paris.

1630. FEYNES (de). - Voyage faict par terre depuis Paris jusques à la Chine par le Sr. de Feynes.

1645. SEMEDO (le P.). Histoire universelle du grand royaume de la Chine, traduite en françois par Clovis Coulon. Paris.

1653. RHODES (Le P. Alexandre de). - Divers voyages et missions de la Chine et autres royaumes de l'Orient avec un retour en Europe, par la Perse et l'Arménie. Paris, in-4². Rééd. 1854.

1654. MARTINI (le P. Martin). - De Bello tartarico Historia, in qua quo pacto Tartari hac nostra ætate Sinicum imperium invaserunt, ac fere totum occuparunt narratur... auctore $R$. $P$. Martino Martinio. Antverpiæ in-4. (Rééd. Cologne, 1654, Amsterdam 1655, Rome 1655). 


\section{La Chine et la formation de l'esprit philosophique en France}

Histoire de la guerre des Tartares contre la Chine, contenant les révolutions étranges qui sont arrivées dans ce grand royaume depuis quarante ans. Traduit du latin. Paris, in-8 $8^{\circ}$ (Nouv. éd. Paris 1657).

1657. MARTINI (le P. Martin). - Lettre du R. P. Jacques le Favre de la Compagnie de Jésus au $P$. Procureur de la Province de France et des Missions d'Orient de la même Compagnie, sur son arrivée à la Chine et l'État présent de ce royaume. S. I. (Rééd. Paris, 1662).

1658. MARTINI (le P. Martin). - Sinicæ historiæ decas prima. Amsterdam.

1663. TISSANIER (le P.). - Relation de voyage depuis la France jusqu'au royaume de Tonkin avec ce qui s'est passé de plus mémorable dans cette mission durant les années 1658, 1659 et 1660. Paris.

1663-1679. THÉVENOT (Melchisedech). - Relations de divers voyages curieux qui n'ont point été publiés et qu'on a traduits ou tirés des originaux des voyageurs... Paris, 4 parties en 2 tomes, in-fo contenant notamment :

Briefve relation de la Chine, par le P. Michel Boym.

Flora sinensis, ou Traité des fleurs, des fruits, des plantes et des animaux particuliers de la Chine, par le même.

Route du Voyage des Hollandais à Pékin.

Voyage des ambassadeurs de la compagnie hollandaise.

Description géographique de l'empire de la Chine, par le P. Martin Martini.

Voyage à la Chine des PP. Grueber et d'Orville, fait avant 1665.

Sinarum scientia politico-naturalis sive scientiæ sinicæ liber inter Confucii libros secundus (par le P. Intorcetta).

Synopsis chronologica monarchiæ sinicæ ab anno post diluvium 275 usque ad annum Christi 1666.

1665. NIEUHOFF (Jean). - L'ambassade de la Compagnie orientale des Provinces-Unies vers l'empereur de la Chine ou grand Cam de Tartarie... le tout... mis en françois.... par Jean Le Carpentier. Leyde, in-fo. 


\section{La Chine et la formation de l'esprit philosophique en France}

1666. BOURGES (Jacques de). - Relation du voyage de Monseigneur l'évêque de Béryte... par la Turquie, la Perse, les Indes, etc.... jusqu'au royaume de Siam et autres lieux. Paris, in-8 ${ }^{\circ}$ (aut. éd. 1668,1683 ).

1667. KIRCHERUS (Athanasius). - China illustrata. Amstelodami, in-fo.

1668. PALLU (François). - Relation abrégée des missions et des voyages des évêques françois, envoyés aux royaumes de la Chine, Cochinchine, Tonkin et Siam. Paris, in- $8^{\circ}, 2^{\mathrm{e}}$ éd., 1682.

1670. PALAFOX. - Histoire de la Conquête de la Chine par les Tartares..., traduite en françois par le sieur Collé. Paris, in-8 ${ }^{\circ}$ (Rééd. Amsterdam, 1723).

1670. KIRCHER (Athanase). - La Chine illustrée.... traduite en françois par d'Alquié. Amsterdam, in-fo.

1671. GRESLON. - Histoire de la Chine, sous la domination des Tartares. Paris, in- $8^{\circ}$.

1672. GRESLON. - Suite de l'Histoire de la Chine. Paris, in- $8^{\circ}$.

1673. ROUGEMONT. - Historia Tartaro-sinica nova... Louvain, in $-8^{\circ}$.

1676. NAVARETTE. - Tradados politicos de la monarchia de la China. Madrid (Cf. Histoire générale des Voyages, t. V, 1748, pp. 393-418).

1684. NAVARETTE. - Relation de la Chine. Mercure Galant. Novembre 1684, pp. 131-169.

1684. VERBIEST (le P. Ferdinand). - Lettre... écrite de la cour de Pékin sur un voyage que l'empereur de la Chine a fait dans la Tartarie occidentale. Paris, in $-4^{\circ}$.

1685. VERBIEST. - Voyages de l'empereur de la Chine dans la Tartarie. Paris, in-12.

1685. VOSSIUS (Isaac). - Isaaci Vossii variarum observationum liber. London.

Observations physiques et mathématiques pour servir à la perfection de l'Astronomie et de la Géographie, envoyées de Siam à l'Académie royale des sciences à Paris, par les $P P$. Jésuites françois qui vont à la Chine en qualité de mathématiciens du Roy. Paris, (Cf. Histoire de l'Académie des sciences, t. VII, p. 607, sq.). 


\section{La Chine et la formation de l'esprit philosophique en France}

1688. MAGAILLANS. - Nouvelle relation de la Chine, traduite en françois par Bernon. Paris, in-4 ${ }^{\circ}$

1688. ORLÉANS (le P. Joseph $\mathrm{d}^{\prime}$ ). - Histoire des deux conquérants Tartares qui ont subjugué la Chine. Paris, in- $8^{\circ}$.

1689. CHEVREAU (Urbain). - Histoire du monde. $2^{\mathrm{e}}$ éd., t. $\mathrm{V}$, Livre VIII, Chap. V. Du royaume de la Chine.

1692. AVRIL (le P.). - Voyage en divers États d'Europe et d'Asie, entrepris pour découvrir un nouveau chemin à la Chine... Paris.

1692. MARTINI (le P. Martin). - Histoire de la Chine du P. Martini traduite en françois par Le Peletier. Paris, 2 vol. in-12.

1696. LECOMTE (le P.). - Nouveaux Mémoires sur l'état présent de la Chine. Paris, Jean Anisson, 2 vol. in-12 (Permission du R. P. Provincial du 30 de mars 1696. Lettres patentes du Roy du 22 juin 1696. Achevé d'imprimer pour la première fois le 7 juillet 1696).

1697. LAGERLÖF (Petrus). - De magno Sinarum imperio. Holmiae, in-12.

1697. ROLAND (Ericus). - De magno Sinarum imperio. Holmiae, in-12.

1697. BOUVET (le P. J.). - Portrait historique de l'Empereur de la Chine, présenté au Roi par le R. P. J. Bouvet. Paris, in-12.

L'Estat présent de la Chine en figures. Dédié à Monseigneur le Duc et Madame la Duchesse de Bourgogne. Paris, in $\mathrm{f}^{\circ}$.

1699. BRAND (Adam). - Relation du voyage de M. Evert Isbrand, envoyé de Sa Majesté Czarienne à l'empereur de la Chine en 1692, 93 et 94, par le sieur Adam Brand... Amsterdam, in-8.

1700. GHERARDINI (Giovanni). - Relation du voyage fait à la Chine sur le vaisseau l'Amphitrite en l'année 1698. Paris.

1701-2-3. MADROLLE. - Les premiers voyages français à la Chine. Paris, 1901 , gr. in-8 .

1702-1776. Lettres édifiantes et curieuses écrites des missions étrangères par quelques missionnaires de la Compagnie de Jésus. Paris, 34 vol. in-12. 


\section{La Chine et la formation de l'esprit philosophique en France}

1708. LEGUAT (François). - Voyages et aventures de François Leguat... avec la relation des choses les plus remarquables.... observées... à Batavia, le tout enrichi de cartes et de figures. Londres, 1708, 2 vol. in-12, Amsterdam 1708, 2 vol. in-12.

1718. RENAUDOT (Eusèbe). - Anciennes relations des Indes et de la Chine, de deux voyageurs mahométans, qui y allèrent dans le neuvième siècle, traduites d'arabe en françois, avec cinq dissertations sur la science des Chinois. Paris, in- $8^{\circ}$.

1719. GRAAF (Nicolas de). - Voyages de... aux Indes orientales et en d'autres lieux de I'Asie. Amsterdam, in- $8^{\circ}$.

1726. LANGE. - Journal de la résidence du sieur Lange.... à la cour de la Chine dans les années 1721 et 1719 . Leyde, in-8.

1730-1. LE GENTIL. - Nouveau voyage autour du monde... avec une description de l'Empire de la Chine... Amsterdam, 3 vol. in-12.

1735. Voyages faits principalement en Asie dans les $X I I^{e}, X I I I^{e}$, $X I V$ et $X V^{e}$ siècles par Benjamin de Tudèle, Jean du Plan Carpin, M. Ascelin, Guillaume de Rubruquis, Marc-Paul Venitien, Harton, Jean de Mandeville et Ambroise Contarini... précédez d'une introduction par P. Bergeron. La Haye, 2 vol.

1735. BRUZEN DE LA MARTINIÈRE. - Introduction à I'Histoire de I'Asie, de l'Afrique et de l'Amérique. Amsterdam, 2 vol. in-12, t. I, pp. 68-222.

1735. HALDE (le P. du). Description géographique, historique, chronologie, politique et physique de l'Empire de la Chine et de la Tartarie chinoise. Paris, 4 vol. in-fo.

1737 ANVILLE (d'). - Nouvel Atlas de la Chine de la Tartarie chinoise et du Thibet. La Haye, gr. in-folio.

VI. - Missions en général

a) MANUSCRITS

XXX. - Projet des Jésuites pour envoyer des missionnaires mathématiciens en Chine. B. N. Fr. 17240.

b) IMPRIMÉS 


\section{La Chine et la formation de l'esprit philosophique en France}

BELLESSORT (André). - Saint François-Xavier. 6e éd., Paris, 1918.

BERTRAND (.1.). - Mémoires historiques sur les missions des ordres religieux. $2^{\mathrm{e}}$ éd., Paris, 1862.

BOUVET (le P.). - Lettre au P. Souciet, pp. Cordier. Documents inédits sur I'histoire ecclésiastique de I'Extrême-Orient (Revue de I'Extrême-Orient, t. III, pp. 219-20).

BRUCKER (le P. Jos.). - Le P. Mathieu Ricci fondateur des missions de la Chine (Études, 5-20 juillet, 20 septembre 1910).

CARREZ (le P. Louis). - Le R. P. Louis de Robert (1702-1760). Nancy, 1903.

CORDIER (Henri). - Histoire générale de la Chine, t. I-IV. Paris, 1920.

Documents inédits pour servir à l'histoire ecclésiastique de I'Extrême-Orient (Revue d'Extrême-Orient, t. RIII).

COUPLET (le P. Ph.). - Catalogus Patrum Societatis Jesu qui post obitum S. Francisci Xaverii primo sæculo, sive ab anno 1581 usque ad 1681 in imperio Sinarum Jesus Christi fidem propagarunt... s. 1.1686 , in-4․

Lettre adressée à la Congrégation de la Propagande sur l'état des Missions de la Chine, p. p. La Croze in Bibliotheca Historico-Philologica Bremensis (t. V, p. 618 sq.).

CRÉTINEAU-JOlY (le P.). - Histoire de la Compagnie de Jésus. Paris, 1844-46, 6 vol. in- $8^{\circ}$.

HENRION (le baron). - Histoire générale des missions catholiques. 2 vol., Paris, 1846-7.

JOUVANCY (le P. J. de). - Suite de l'Histoire de la Compagnie de Jésus. Ve Partie, 1710.

LAUNAY (Adrien). - Histoire générale de la Société des Missions étrangères. Paris, 1894, 3 vol. in- $8^{\circ}$.

XXX. - Le Passé et l'avenir des missions. Correspondant. 1847, t. XIX, p. 183 sq.

LUQUET. - Lettre sur la congrégation des missions étrangères. Paris, 1843.

MAILlA (le P. Moyriac de). - Histoire de la Chine. Paris, $1777-83$, t. X. 


\section{La Chine et la formation de l'esprit philosophique en France}

Mémorial du Conseil de 1661, p. p. la Société de l'Histoire de France par Jean de Boislisle. Paris, 1905.

PALLU. - Lettres de Mgr Pallu, p. p. Adrien Launay. Angoulême, s. d., 2 vol. in- $8^{\circ}$.

ROCHEMONTEIX (le P. Camille de). - Joseph Amiot et les derniers survivants de la mission française à Pékin (1750-1795). Paris.

ROHRBACHER. - Histoire de l'Église :

Vol. XXIV. Saint François-Xavier, pp. 115-32. - Le Christianisme en Chine, à la fin du XVI siècle, pp. 72-8.

Vol. XXV. La mission de Chine depuis Mathieu Ricci jusqu'à Adam Schall, pp. 69-75.

Vol. XXVI. Histoire des missions de Chine depuis le $P$. Adam Schall jusqu'à l'année 1730, pp. 609-42.

SERIEY. - Histoire de l'établissement du christianisme dans les Indes orientales. Paris, 2 vol., an XI (1803).

THOMAS (I'abbé A.). - Histoire de la mission de Pékin depuis les origines jusqu'à l'arrivée des Lazaristes. Paris, 1923.

SOULIÉ DE MORAND. - L'épopée des Jésuites en Chine. Paris, 1928.

\section{VII. - Affaires de Siam}

a) OUVRAGES GÉNÉRAUX

LANIER (Lucien). - Étude historique sur les relations de la France et du royaume de Siam. Versailles, 1883.

LAUNAY (Adrien). - Siam et les Missionnaires français. Paris, 1896. - Histoire de la mission de Siam. Documents historiques. Paris, 1920, 2 vol.

b) MANUSCRITS

CHARMOT. - Mémoires. B. N. Fr. 25060.

Documents sur l'affaire du serment. B. N. Fr. 9773. 


\section{La Chine et la formation de l'esprit philosophique en France}

CONSTANCE PHAULEON. - Mémoire de Monsr. Constance ministre du roy de Siam sur l'ambassade que le Roy lui a envoyée pour l'inviter à se faire chrestien. B. N. Fr. 15476.

Mémoire escrit et signé de la main du Sgr. Constance et donné au P. Tachard pour le communiquer au P. de la Chaize et en rendre compte au Roy. A. N.-K. 1334.

Instructions données au P. Tachard. B. N., Fr. 15476.

Lettre aux Cardinaux de la Propagande remise au $P$. Tachard. B. N. Fr. 9773.

FONTANEY (le P. de). - Lettre au P. Verjus du 18 novembre 1685. B. N. Fr. 15476.

TACHARD (le P. Guy). - Lettres. B. N. Fr. 15476.

Mémoire pour establir la Religion et le commerce à Siam. A. N.-K. 1334.

Discours du P. Tachard à N. S. P. le Pape. B. N. Fr. 9773.

Articles convenus entre les Supérieurs et Procureurs des missionnaires françois des Indes orientales de la Compagnie de Jésus et les Supérieurs et Directeurs du Séminaire des missions étrangères de Paris approuvez par I'Archevêque de Paris et authorisez par le Roy. A. N.-M. $203, \mathrm{n}^{\circ} 7$.

\section{c) OUVRAGES IMPRIMÉS}

1668. PALLU (François). - Relation abrégée des missions et des voyages des évêques françois envoyés aux royaumes de la Chine, Cochinchine, Tonkin et Siam. Paris.

1684. PALLU (François). - Lettre de Siam (Mercure Galant, octobre 1684).

Lettre du Roi de Siam au Roi de France. - Lettre du Roi de Siam au Souverain Pontife. - Lettre écrite par le Barcalon ou Ministre du Roy de Siam à Messieurs les Directeurs généraux de la Compagnie du Commerce des Indes orientales. - Lettre du mesme Ministre à M. le Directeur Baron (Mercure Galant, Juin 1684).

1684-5. Récit de la visite des ambassadeurs siamois à Paris (Mercure Galant, décembre 1684, janvier et février 1685). 


\section{La Chine et la formation de l'esprit philosophique en France}

1686. Relation du Voyage de Siam (Mercure Galant, 1686, Supplément, 3 vol.).

CHAUMONT (le Chevalier de). - Relation de l'ambassade. Paris.

Journal de Voyage de Mr. le Chevalier de Chaumont (Mercure Galant, juillet 1686).

TACHARD (le P. Guy). - Voyage de Siam des Pères jésuites envoyez par le Roy aux Indes et à la Chine. Paris.

Lettre adressée à Bayle (Nouvelles de la République des Lettres, avril 1686).

1687. CROISY (Fr. T. abbé de). - Journal du Voyage de Siam fait en 1685 et 1686 par M. L. D. C. Paris (Cf. Journal des Sçavans, février 1688).

Journal ou Suite du Voyage de Siam en forme de Lettres familières (Cf. Bibli. univ. et hist., 1687, t. VI, pp. 274-6).

Mémoires. Ed. Michaud et Poujoulat. Paris.

Fragments de mémoires, p. p. Launay : Histoire de la mission de Siam. Documents historiques.

1687. FORBIN. - Mémoires. Ed. Hachette, 1853.

1688. GERVAISE. - Histoire naturelle et politique du royaume de Siam. Paris (Cf. Journal des Sçavans, mai 1688).

1689. TACHARD (le P. Guy). - Second voyage du P. Tachard et des Jésuites envoyez par le roi au royaume de Siam. Paris.

1690. ORLÉANS (le P. $\mathrm{d}^{\prime}$ ). - Histoire de M. Constance premier ministre du roi de Siam et de la dernière révolution de cet état. Tours et Paris. (Rééd. 169r, 1692

1691. LA LOUBÈRE (de). - Du Royaume de Siam. Paris (Rééd. Amsterdam, 1714, sous le titre Description du royaume de Siam).

1692. LE BLANC (le P. Marcel). - Histoire de la Révolution du royaume de Siam. Lyon.

VIII. - La Querelle des Cérémonies Chinoises 


\title{
La Chine et la formation de l'esprit philosophique en France
}

\author{
a) MANUSCRITS
}

CHARMOT. - Lettres de Rome adressées au Cardinal de Noailles (1698-1700). B. N. Lat. 16981.

Mémoires. B. N. Fr. 25060.

LÉONARD (le P.). - Papiers. A. N. K. 1374-5.

RENAUDOT (Eusèbe). - Journal du voyage à Rome. B. N., N. A. F. 7482.

Lettres au Cardinal de Noailles. B. N. N. A. F. 6212.

\section{b) IMPRIMÉS}

1669-168. CAMBOUT DE PONTCHATEAU (I'abbé S. J. du). - La morale pratique des Jésuites, t. I-II. Amsterdam.

1681. JURIEU. - L'Esprit de Mr. Arnauld. Deventer.

1684-98 (LE TELLIER). - Défense des nouveaux Chrestiens et des missionnaires de la Chine, du Japon et des Indes contre deux livres intitulés « La Morale pratique des Jésuites » et «L'Esprit de Mr. Arnauld». Seconde édition avec une réponse à quelques plaintes contre cette défense. Paris, 2 vol.

1684-98. ARNAULD (Antoine). - Fuvres. Ed. 1775, t. III, pp. 229-30, p. 59, n. a, pp. 488-9, note b, p. 597, p. 771 ; Critique du livre du P. Le Tellier.

1692-3. ARNAULD (Antoine). - La Morale pratique des Jésuites, t. VI-VII. Amsterdam.

1693. MAIGROT. - Ordonnance de M. Maigrot Evêque de Conon. S. I. n. d.

1696. LE GOBIEN (le P.). - Histoire de l'Édit de l'Empereur de la Chine en faveur de la religion chrestienne avec un éclaircissement sur les honneurs que les Chinois rendent à Confucius et aux morts. Paris.

LE COMTE (le P. Louis). - Nouveaux mémoires sur l'état présent de la Chine. Paris, 2 vol. in-12.

Lettre d'un théologien à une personne de qualité sur le nouveau livre des Jésuites contre la Morale pratique.

Lettre d'un théologien où l'on fait voir que ce que les Jésuites ont débité comme des vérités certaines touchant 


\section{La Chine et la formation de l'esprit philosophique en France}

l'auteur du «Theatro jesuitico » sont des faussetés manifestes. S. I. n. d.

1699. LE COMTE (le P. Louis). - Sinarum quæsita proponenda in S. Congregatione S. Officii. S. I. n. d.

Apologie des Dominicains, missionnaires de la Chine, en réponse au livre du P. Le Tellier. Par un Religieux de l'ordre de St-Dominique. Cologne.

1700. Lettre de Messieurs des Missions Étrangères au Pape sur les idolâtries et les superstitions des Chinois. S. I. n. d.

Réponse à la lettre de Messieurs des Missions Étrangères au Pape sur les Cérémonies chinoises. S. I. n. d.

Éclaircissement sur la dénonciation faite à N.S.P. le Pape des nouveaux Mémoires de la Chine, composez par le $P$. Louis Le Comte. S. I.

Réflexions générales sur la lettre qui paroit sous le nom de Messieurs des Missions Étrangères, touchant les Cérémonies chinoises. S. I.

Éclaircissement donné à Monseigneur le Duc du Maine sur les honneurs que les Chinois rendent à Confucius et aux morts. S. I. n. d.

Lettre (I-VI) d'un Docteur de I'ordre de St-Dominique sur les cérémonies de la Chine. Cologne.

LIONNE (abbé de). - Lettre de M. l'abbé de Lionne, évêque nommé de Rosalie... à Monsieur Charmot, directeur du Séminaire des Missions étrangères de Paris. S. I.

Histoire apologétique de la conduite des Jésuites de la Chine, adressée à Messieurs des missions étrangères. S. I.

LE COMICE (le P.). - Lettre à Monseigneur le Duc du Mayne sur les cérémonies de la Chine. S. I.

Historia cultus Sinensium, seu varia scripta de cultibus Sinarum inter Vicarios apostolicos Gallos, aliosque Missionarios et Patres Societatis Jesu controversis. Cologne.

Lettre (I-VII) d'un Docteur sur ce qui se passe dans les assemblées de la faculté de théologie. Cologne. 


\section{La Chine et la formation de l'esprit philosophique en France}

LALLEMANT (le P.). - Journal historique des assemblées tenues en Sorbonne pour condamner les Mémoires de la Chine. S. I.

Journal d'un Docteur de Sorbonne, p. p. A. Gazier (Bulletin philologique et historique jusqu'à 1715). 1916.

Censure de la sacrée faculté de Théologie de Paris portée contre les propositions extraites de livres intitulés « Nouveaux Mémoires sur l'état présent de la Chine », « Histoire de l'édit de l'Empereur de Chine », « Lettre des Cérémonies de la Chine ». S. I. n. d.

Censure de quelques propositions des PP. Le Comte et Le Gobien, jésuites, publiée sous le nom de la faculté de théologie de Paris, réfutée par les écrits des Dominicains et des Franciscains missionnaires de la Chine les plus opposés aux Jésuites. S. I.

Réflexions sur la censure publiée sous le nom de la faculté de théologie de Paris. S. I.

L'enterrement de Confucius réitéré le 19 octobre 1700. S. I. n. d.

1701. MAIGROT. - Lettre de Monsieur Maigrot à Monsieur Charmot du 11 janvier 1699.... Elle montre la fausseté de ce que le Père Lecomte a écrit touchant la religion ancienne des Chinois. S. I.

[RENAUDOT]. - Lettre à Madame de Lionne sur le libelle des Jésuites contre M. l'évêque de Rosalie, son fils. S. I.

Lettre à Messieurs des Missions étrangères sur celle qu'ils ont écrite à Madame de Lionne. S. I.

DU PIN (Ellies). - Défense de la Censure de la Faculté de théologie de Paris. Paris.

1702. Lettres des Pères de la Compagnie de Jésus missionnaires de la Chine à Notre Très Saint Père le Pape Clément XI avec la déclaration authentique de l'Empereur de la Chine touchant les cérémonies chinoises. Liége.

LABBÉ (Marin). - Lettre de M. Marin Labbé... au Pape sur le certificat de l'empereur de la Chine et sur la nécessité de condamner sans délai toutes les superstitions chinoises. Anvers. 


\section{La Chine et la formation de l'esprit philosophique en France}

Bref de Notre Saint Père le Pape à monsieur l'évêque de Conon, vicaire apostolique de Fokin dans la Chine. (Rome, le 20 juin 1702). S. I. n. d.

Décret du Saint Père Clément XI sur les cérémonies de la Chine. S. I. n. d.

1708. L'État présent de l'Église de Chine adressé à Monseigneur l'évêque de... S. I.

1709. Décret de Notre Saint Père le Pape Clément XI dans la grande affaire de la Chine. S. I.

1710. Second décret de N. S. P. le Pape Clément XI sur les affaires de la Chine, du 25 septembre 1710, arec la déclaration que N. S. P. le Pape a faite du véritable sens de ses décrets, le 11 octobre 1710 . S. I. n. d.

1714. MAIGROT. - Examen des faussetez sur les cultes chinois avancées par le $P$. Joseph Jouvenci, Jésuite, dans I'Histoire de la Compagnie de Jésus, traduit d'un écrit latin composé par le $P$. Minorelli de l'ordre de Saint-Dominique, missionnaire à la Chine. S. I.

1733-1741. VILLERS (I'abbé de). - Anecdotes sur l'état de la religion dans la Chine. Paris, 7 vol.

1744. VILLERS (I'abbé de). - Les Jésuites convaincus d'obstination à permettre l'idolâtrie dans la Chine. (Lettres : 10 janvier-8 sept. 1743). S. I.

\section{IX. - Chronologie}

\section{a). - MANUSCRITS}

1703. MAIGROT. - Lettre de l'évêque de Conon, datée de Focheu le 15 octobre 1703, à Mgr. de Lionne sur l'ancienneté de la nation chinoise. B. N. Fr. 14657.

1703. RÉGIS (le P.). - Concordia chronologiæ Annatium Sinensium Imperii cum epochis Historiæ nostræ et prophanæ a creatione mundi asque ad initium æræ christianæ. (Abrégé ap. Vojeu de Brunen : Histoire de la Conquête de la Chine, 1754.

1719. PRÉMARE (le P. de). - Mémoire sur le système des 3 dynasties que l'on prétend avoir gouverné la Chine depuis Yao jusqu'aux Tcin. B. N. N. A. F. 4755. 


\section{La Chine et la formation de l'esprit philosophique en France}

1729. FOUCQUET (le P.). - Explication de la nouvelle table chronologique de l'histoire chinoise. B. N. Fr. 12209.

Tabula chronologica historiæ sinicæ, connexa cum cyclo, qui vulgo Kia-tse dicitur. B. N. Fr. 12209.

Lettres des PP. Gaubil, Parrenin, Régis, de Mailla, de Prémare, Gollet. Obst. Astr. A B ${ }^{1} 10$ (150).

1729 sq. FRÉRET (Nicolas). - Minutes de ses lettres adressées aux PP. Gaubil. Parrenin, Régis, de Mailla, de Prémare, Gollet. Obs. Astr. A B' Io (150).

Recueil de Mémoires de M. Fréret, t. I-IV. Obs. Astr. $11^{2} 2$ (154.157).

Notes et Papiers divers aux Archives du Service hydrographique de la Marine.

\section{b) IMPRIMÉS}

1630. PÉTAU (le P. Denis). - La Pierre de touche chronologique contenant la méthode d'examiner la chronologie et en reconnoistre les défauts, vérifiée par pratique et exemple. Paris.

1642. GROTIUS. - De origine gentium americanarum dissertatio. S. I.

1643. LAET (Joannes de). - Notæ ad dissertationem, Hugonis Grotii De origine gentium americanarum et observationes aliquot ad meliorem indaginem difficillimæ illius quæstionis. Paris.

1643. GROTIUS. De origine gentium americanarum. Dissertatio altera adversus obtrectatorem. Paris.

1641. LAET (Joannes de). - Responsio ad dissertationem secundam Hugonis Grotii de origine gentium americanarum. Amsterdam.

1649. MARSHAM. - Diatriba chronologica. Londres.

1650. ULUG-BEG. - Epochæ celebriores. Ed. Grævius. Londres.

1650-4.USSERIUS (Usher). - Annales Veteris et Novi Testamenti. Londini.

1655. MARTINI (le P. Martin). - Novus Atlas sinensis... S. I.

1655. LA PEYRÈRE. - Præ-Adamitæ sive exercitatio super versibus duodecimo, decimo tertio et decimo quarto capitis 


\section{La Chine et la formation de l'esprit philosophique en France}

quinti Epistulæ D. Pauli ad Romanos. Systema theologicum ex Præ-Adamitarum hypothesi. S. I.

1659. VOSSIUS.Dissertatio de vera ætate mundi. Hagæ Comitis.

1659. HORN (Georges). - Georgii Hornii Dissertatio de vera ætate mundi qua sententia illorum refellitur qui statuunt natale mundi tempus annis minimum 1440 vulgarem æram anticipare. Lyon.

1661. VOSSIUS. - De LXX Interpretibus.

1666. HORN (Georges). - Arca Noæ. Historia Imperiorum et Regnorum a condito orbe ad nostra tempora. Lyon.

1669. RICCIOLI (J.-B.). Chronologiæ reformatæ et ad certas conclusiones redactæ. 3 t. en 1 vol. in-fo.

1672. RICCIOLI (J.-B.). - Synopsis chronologiæ Monarchiæ sinicæ ab anno post Dituvium CCXXV usque ad annum Christi MDCLXVI. Ap. Thévenot Relations de divers voyages curieux. IVe Partie $\mathrm{n}^{\circ} 17$, Paris.

1673. MARSHAM. - Chronicus canon ægypticus, hebraicus, græcus. Lipsiæ.

1685. SIMON (Richard). Histoire critique du Nouveau Testament.

1686. COUPLET (le P. Ph.). - Tabula chronologica trium familiarum imperialium monarchiæ sinicæ a Hoam-Ti primo gentis Imperatore, per 86 successores, et annos 2457 ante Christum, e sinica latine exhibita n R. P. Philippo Couplet. Parisiis ex Bibliotheca regia.

1687. COUPLET et autres Jésuites. - Confucius Sinarum Philosophus. Paris.

ALLIX. - Réflexions sur les cinq livres de Moïse. Londres.

PEZRON (le P.). - L'Antiquité des tems rétablie (Cf. Nouvelles de la République des Lettres, juin 1687. Journal des Sçavans, 15 décembre 1687. Mémoires de Trévoux, juillet 1707).

1689. MARTIANAY (DOM Jean). - Défense du Texte hébreu et de la chronologie de la Vulgate contre le livre de l'Antiquité des tems rétablie. Paris. 


\section{La Chine et la formation de l'esprit philosophique en France}

1690. LE QUIEN. - Défense du texte hébreu et de la version vulgate servant de réponse au Livre intitulé L'Antiquité des tems rétablie. Paris.

1691. PEZRON (le P.). - Défense de l'Antiquité des Tems (Cf. Journal des Sçavans, 21 janvier 1692).

CASSINI. - Réflexions sur la chronologie chinoise, ap. La Loubère : Du Royaume de Siam, t. II, pp. 379-400.

LA LOUBÈRE. - Du Royaume de Siam, t. II : Du Soin des Mœurs chez les Chinois et de l'ancienneté de leur Histoire.

1692. MARTINI (le P.). - Histoire de la Chine, traduction Le Peletier (Cf. Journal des Sçavans, juillet 1692).

MARTIANAY (dom. Jean). - Continuation de la défense du texte hébreu et de la Vulgate par la véritable tradition des Églises chrestiennes, et par toute sorte d'anciens monumens... contre Isaac Vossius protestant et contre les livres du P. Pezron. Paris.

FLEURY (abbé). - Mémoires pour les études des missions orientales. Lettres édifiantes et curieuses. Ed. du Panthéon Littéraire, t. I.

1693. LE MAISTRE DE SACY. - Les Paralipomènes traduits en françois avec une explication tirée des Saincts-Pères et des auteurs ecclésiastiques. Paris.

LE QUIEN. - L'Antiquité des Tems détruite ou Réponse à la Défense de l'Antiquité des Tems. Paris.

1696. MENZELIUS. - Brevis sinensium chronologia, exhibens omnes imperatores chinenses, a prima quam putant mundi originem usque ad nostra tempora. Berolini.

VALLEMONT (P. L. L. de). - Les Eléments de I'histoire. Paris, 2 vol. (Cf. Journal des Sçavans, 19 nov. 1696).

1697. HARDOUIN (le P.). - Chronologia Veteris Testamenti. Paris.

1700. LE PELLETIER (Jean). - Dissertation sur l'arche de Noé et sur l'Hermine et le livre de St-Benoist... Dans l'une on examine plusieurs questions curieuses, dont la décision prouve la matière, la capacité, la figure ou disposition de cette Arche, le nombre des Animaux, et la quantité des provisions qu'on y renferme, la 


\section{La Chine et la formation de l'esprit philosophique en France}

durée et la vérité du Déluge universel. Rouen 1700 (Cf. Nouvelles de la République des Lettres, avril 1702).

1704. JURIEU. - Histoire critique des dogmes et des cultes bons et mauvais qui ont été dans l'Église depuis Adam jusqu'à JésusChrist et où l'on trouve l'origine de toutes les idolâtries de l'ancien paganisme, expliquées par rapport à celles des Juifs. Amsterdam.

1706. DUHAMEL. - Biblia sacra Vulgatae editionis (Cf. Journal des Sçavans, 22 mars 1706).

1711. DU PIN (Ellies). - Dissertations historiques, chronologiques, géographiques et critiques sur la Bible, t. I. Paris (Cf. Mémoires de Trévoux, janv. 1713).

1718. CALMEZ (Dom). - Histoire de l'Ancien et du Nouveau Testament. Paris (Cf. Journal des Sçavans, janvier 1719).

1723. TYSSOT DE PATOT. - Discours dans la vue de concilier les différentes nations au sujet de la chronologie (Journal Littéraire. 1723, p. 153 sq.).

1726. NEWTON. - Abrégé de la chronologie de Newton, à la suite de I'Histoire des Juifs de Prideaux (Cf. Journal des Sçavans, juillet 1726).

Réponse aux observations sur la chronologie de M. Newton de l'abbé Conti. Bibliothèque Française, t. VII (Cf. Journal des Sçavans, février 1727).

1726. SOUCIET (le P. Et.). - Recueil des Dissertations du P. Et. Souciet, t. II.

1728. FOUCQUET (le P.). - Dissertation pour prouver la conformité de la Chronologie des Chinois avec celle des Chrétiens. - Conformité de la Chronologie des Tartares depuis la création du monde jusqu'à présent avec la nôtre (Collection Ch. Schefer. Ap. Cordier : Bibliotheca sinica, t. I. p. 225).

1729. LENGLET-DUFRESNOY. - Méthode pour enseigner I'histoire. Paris, 4 vol.

SOUCIET (le P. Et.). - Observations mathématiques, astronomiques, géographiques, chronologiques et physiques tirées des anciens livres chinois ou faites nouvellement aux Indes et à la Chine par les Pères de la Compagnie de Jésus. Paris, in- $4^{\circ}$. 


\section{La Chine et la formation de l'esprit philosophique en France}

1729. FOUCQUET. - Tabula chronologica historiæ sinicæ connexa cum cyclo qui vulgo Kia-tse dicitur. Romæ (Cf. Journal des Sçavans, février 1730. Mémoires de Trévoux, janvier 1730).

1730. FOUCQUET. - Explication de la nouvelle table chronologique de l'histoire de la Chine. Philosophical Transaction ( $\mathrm{n}^{\circ} 15$ art. $\mathrm{V}$, sept.-oct. 1730), (Cf. Bibliothèque Britannique, janv.-mars 1736, p. 301).

CASSINI. - Réflexions sur la chronologie chinoise. Mémoires de l'Académie des Sciences, t. VIII, pp. 300-11.

LISLE (de). - Traité de Chronologie. in : Abrégé chronologique de l'Histoire universelle du P. Pétau, Trad. Maucroix, t. I. Paris.

CREQUINIERE (de la). - Conformité des coutumes des Indiens orientaux avec celle des Juifs et des autres peuples de l'antiquité.

1732. GAUBIL (le P.). - Observations mathématiques, astronomiques, géographiques, chronologiques et physiques, $\mathrm{t}$. II : Contenant une histoire de l'astronomie chinoise avec des Dissertations par le P. Gaubil. t. III : Contenant un Traité de l'astronomie chinoise. Paris.

1734. CALMET (DOM). - Brevis chronologica seu rationarium temporum ecclesiasticæ ac civilis historiæ a Mondo condito.

FOURMONT (Etienne). - Dissertation sur les annales chinoises où l'on examine leur époque et la croyance qu'elles méritent. Mémoires de l'Académie des Inscriptions. t. XIII, pp. 507-19.

1735. CALMET (Dom). - Histoire universelle, t. I.

FOURMONT (Etienne). - Réflexions critiques sur I'histoire des anciens peuples... jusqu'au temps de Cyrus. Paris, 2 vol.

1736. FRÉRET (Nicolas). - De l'antiquité et de la certitude de la chronologie chinoise (Mémoire lu en novembre 1733). Mémoires de I'Académie des Inscriptions et Belles-Lettres. t. X, 1736.

1737. ARGENS (Boyer $\mathrm{d}^{\prime}$ ). - La philosophie $d u$ bon sens ou réflexions philosophiques sur l'incertitude des connaissances humaines à l'usage des cavaliers et du beau sexe. Londres. 


\section{La Chine et la formation de l'esprit philosophique en France}

1737. VIGNOLES (des). - Chronologie de I'histoire sainte et des histoires étrangères depuis la sortie d'Égypte jusqu'à la Captivité de Babylone. Paris, 2 vol.

1740. BERNARD (J. L.). - Dissertations mêlées sur divers sujets importans et curieux. Amsterdam ( $1^{\text {re }}$ Dissertation qui traite de I'origine du monde).

1741. BERNARD (J. L.). - Lettre de M. G. à Mr. Fréret de I'Académie royale des Inscriptions sur I'histoire ancienne. Paris, in-12 (Cf. Observations sur les écrits modernes, t. XXVII, p. 282. - Journal des Sçavans, déc. 1743).

1743. FRÉRET (Nicolas). - Éclaircissement sur le Mémoire lu au mois de novembre 1733 touchant l'antiquité et la certitude de la chronologie chinoise (Lu à l'Académie des Inscriptions le 20 février 1739). Mémoires de l'Académie des Inscriptions et BellesLettres, t. XV, 1743, et t. XVIII, 1753.

GIBERT. - Chronologie des Babyloniens et des Égyptiens.

Lettre de M. Gibert à m. X sur la chronologie.

1747. COSTARD. - Philosophical Transaction (mars-avril-mai, pp. 476-92).

1751. BERNARD (J. L.). - Le Monde, son origine et son antiquité. Londres.

1753. SHUCKFORD (Samuel). - Histoire du monde sacrée et profane. (Cf. Lettres sur quelques écrits de ce temps, t. VIII, p. 94-5. Journal des Sçavans, fév. 1755).

1754. Examen de I'Apologie de M. de Prades touchant la chronologie de Moyse (Journal de Verdun, avril 1754).

Lettre à M. X sur la Chronologie de la Genèse (Journal des Sçavans, mai 1754).

\section{X. - La Religion des Chinois}

a) MANUSCRITS

COUPLET (le P. Phil.). - Confucius Sinarum Philosophus. B. N. Lat. 6277. 


\section{La Chine et la formation de l'esprit philosophique en France}

FOUCQUET (le P.). - Essai d'introduction préliminaire à l'étude des King. Deux lettres du P. de Prémare et du P. Foucquet (1725-1796). B. N. Fr. 12209.

MALPEINES (Léonard des). - Papiers. B. N. Fr. 12215.

PRÉMARE (le P. de). - Correspondance du P. Joseph-Henri de Prémare et de l'abbé Jean-Paul Bignon avec M. Fourmont l'aîné. B. N. Fr. 15195.

Dissertation sur les lettres et les livres de la Chine tirée d'une lettre au P. Briga, interprète de la bande d'Isis. B. N. N. 9. F. 14753.

Lettre du $P$. de Prémare au $P$. Foucquet, 21 décembre 1721 B. N. Fr. 12209.

Lettres à Etienne Fourmont sur I'Y-King et les livres chinois. B. N. N. A. F. 4754.

Lettre sur le prétendu athéisme des Chinois (avec une lettre à I'abbé Raguet, 25 nov. L731). B. N. N. A. F. 4756.

Notes critiques pour entrer dans l'intelligence des King. B. N. Fonds Chinois, 2720.

\section{b) IMPRIMÉS}

1604. Discours en forme de comparaison entre les vies de Moïse et d'Homère. Cf. Rigault : Histoire de la Querelle des Anciens et des Modernes.

1624. GARASSE (le P.). - La doctrine curieuse des beaux esprits de ce tems ou prétendus tels.... Paris, in- $4^{\circ}$.

Un mémoire inédit de François Garasse, adressé à Mathieu Molé pendant le procès de Théophile, p. p. Frédéric Lachèvre (Rev. Hist. oct-déc. 1911).

1637. LA MOTHE LE VAYER. - Petit discours chrestien de I'Immortalité de l'âme. Paris.

1639. CHERBURY (Herbert de). - De la vérité en tant qu'elle est distincte de la révélation, du vraysemblable, du possible et du faux. $3^{e}$ éd., revue et augmentée par l'auteur. S. I. (Une édition en latin avait paru à Londres en 1633).

1642. LA MOTHE LE VAYER. - De la Vertu des Payens. Paris, in $-4^{\circ}$ 


\section{La Chine et la formation de l'esprit philosophique en France}

ARNAULD (Antoine). - De la nécessité de la foy en JésusChrist pour être sauvé.... p. p. Ellies du Pin, 2 vol. in-12, 1701,

1662. COSTA (Ignatius a). - Sapienta sinica, exponente $P$. Ignatio a Costa, a P. Prospero Intorcetta.... orbi proposita. Kien Cham in urbe Sinarum provinciae Kiam Si, 2 parties en I vol. in $-4^{\circ}$.

1663. CHERBURY (Herbert de). - De religione gentilium errorumque apud eos causis. Amstelodami.

BEURRIER (Paul). Speculum christianæ religionis in triplici, lege, naturali, mosaica et evangelica. Parisis, 2 t. en I vol.

1667. LORD (Henry). Religion des Banians. Trad. franç. par P. Briot (Ce livre avait paru à Londres en 1630).

1672. BEURRIER (Paul). - Perpetuitas fidei ab origine mundi ad hæc usque tempora. Paris, 2 t. en I vol. in- $8^{\circ}$.

1673. CONFUCIUS. - Traduction du II Livre de.. in Thévenot : Recueil de divers voyages curieux qui n'ont point été publiés, $\mathrm{t}$. II.

INTORCETTA (le P.). - La Science des Chinois.

1676. Annales des Provinces-Unies, t. II, p. 772 sq. : Les Coccéiens.

CUDWOERTH. - The True Intellectual System of the Universe. Londres.

1679. HUET (Daniel). - Demonstratio evangelica. Paris, fol. (3० éd. Paris, 1690).

1680. BEURRIER (Paul). - La Perpétuité de la foy et de la religion chrétienne dans les trois états de la loi de Nature, de la loi écrite et de la loi de grâce. Paris, z vol. in-8 $8^{\circ}$

1681-5. THOMASSIN (le P.). - La méthode d'enseigner chrétiennement :

Les Poètes, par rapport aux lettres divines et aux Écritures Saintes. Paris, 1681.

La Philosophie. Paris, 1685.

1685. FÉNELON. - Sermon pour la fête de l'Épiphanie, prêché dans l'Église des Missions étrangères le 6 janvier 1685 en 


\section{La Chine et la formation de l'esprit philosophique en France}

présence des ambassadeurs de Siam : Sur la Vocation des Gentils. (Fuvres complètes, t. XVII).

1687. COUPLET (le P. Ph.). - Confucius Sinarum Philosophus sive scientia sinensis latine exposita, studio et opera Prosperi Intorcetta, etc... Paris, in-fo.

1689. ARNAULD (Antoine). - Nouvelle hérésie dans la morale dénoncée au Pape et aux évêques, aux Princes et aux Magistrats. Cologne.

1690. HUET (Daniel). - Alnetanæ Questiones de concordia rationis et fidei. Cadomi, in $4^{\circ}$.

1690. sq. ARNAULD (Antoine). - Seconde (cinquième). Dénonciation de la Nouvelle hérésie du Péché philosophique par les Jésuites de Dijon défendue avec quelque changement par ceux de Louvain dans leur Écrit contre la première. Dénonciation et soutenue auparavant en quinze de leurs thèses de différentes années depuis 1688 .

1692. LE TELLIER (le P. Michel). - L'erreur du péché philosophique combattue par les Jésuites. Liège.

FÉNELON. - Dialogues des Morts : Confucius et Socrate (Guvres complètes, t. XIX.

1696. LE COMTE (le P. Louis). - Nouveaux Mémoires sur l'état présent de la Chine. Paris, 2 vol. in-12.

1699. DACIER. - Platon. Les Fuvres, avec des remarques sur la vie de ce philosophe et l'exposition des principaux dogmes de sa philosophie. Paris, 2 vol.

1700. HYDE (Thomas). - Historia religionis veterum Persarum. Oxonii.

1700. LE COMTE (le P. Louis). - Éclaircissement sur la dénonciation faite à N. S. P. le Pape des Nouveaux Mémoires de la Chine composez par le P. Louis Le Comte de la Compagnie de Jésus confesseur de Madame la Duchesse de Bourgogne. S. I.

1701. LONGOBARDI (le P.). - Traité sur quelques points de la religion des Chinois. Paris, in-12.

SAINTE-MARIE (le P. Antoine de). - Traité sur quelques points importants de la mission de la Chine. Paris.

COULAU. - Judicium unius e Societate Sorbonica de propositionibus quibusdam circa antiquam Sinarum 


\section{La Chine et la formation de l'esprit philosophique en France}

religionem ad sacram facultatem Parisiensem delatis. Paris, in $-4^{\circ}$.

Appendix ad acta de Sinensium ritibus seu $R$. P. Dominici Sarpetri... tractatus de Deo uno, vivo vero a veteribus Sinis cognito.... Paris, in- $8^{\circ}$.

1702. TOURNEMINE (le P.). - Projet d'un ouvrage sur l'origine des fables (Mémoires de Trévoux, nov. 1702, p. 84 sq. suppl. a nov. p. 1 sq.).

1703-1711. CUDWORTH. - Comptes rendus dans la Bibliothèque choisie de J. Leclerc, t. I, II, III, V, VII, VIII, IX (Cf. notamment t. III : Que les Payens les plus éclairez ont cru qu'il n'y a qu'un Dieu Suprême).

1707. LA CROZE (Vevssières de). - Réflexions historiques et critiques sur le Mahométisme et le socinianisme.

Recherches historiques sur l'Etat ancien et moderne de la Religion chrétienne dans les Indes, Ap. Dissertations historiques sur divers sujets, t. I, p. 257 sq.

Sentimens d'un Docteur de Sorbonne sur un Libelle, dans les Dissertations historiques.... (Cf. Bibliothèque choisie, $t$. XIV, p. 332 sq. et la réponse de La Croze Ibid., t. XV, p. 166 sq.).

Entretiens sur les différentes manières d'expliquer l'Écriture et de prêcher de ceux qu'on appelle les Coccéiens et Voëtiens dans les Provinces-Unies : où l'on voit quel tempérament on doit apporter dans l'explication des Types, des Allégories, des Périodes, des Prophéties et d'autres choses de ce genre avec un portrait des Hébraïzans et de leurs erreurs. Amsterdam, in-12. (Cf. Bibl. choisie, t. XI, 1707).

1708-15. DEYLING (Salomon). - L. Salomonis Deylingi Observationum sacrarum Pars prima (...III). Lipsiæ (Cf. Journal des Sçavans, 1709, p 415).

1708. REICHENBERG. - Advenus Atheos (Cf. Journal des Sçavans, 1708, p. 668).

1711. BALTUS. - Défense des SS. Pères accusés de platonisme. Paris. 


\section{La Chine et la formation de l'esprit philosophique en France}

CONFUCIUS. - Sinensis imperii libri classici sex... e sinico idiomate in latinum traducti a Francisco Noël. Prague,

1711. DES PÉRIERS (Bonaventure). - Cymbalum Mundi (Réimpression de P. Marchand. Autre réimpression de Falconet, 1732).

LA CROZE (Veyssières de). - Entretiens sur divers sujets d'histoire, de littérature, de religion et de critique. Cologne.

1712. BENOIST (Elie). - Mélanges de remarques critiques, historiques, philosophiques, théologiques sur les deux dissertations de M. Toland. Delf.

Sujets de conférences sur la théologie positive où l'on propose les questions dogmatiques et historiques qui concernent la religion tant en général qu'en particulier avec la citation des auteurs qui traitent de cette matière. Rouen, 2 vol. in $-4^{\circ}$ (Cf. t. I, p. 8 sq., t. II, p. 43 sq.)

POUPART (le P. Spiridion). - Lettre du P... Religieux pénitent au $P$. Tournemine sur la première idolâtrie, dans les Mémoires de Trévoux, sept. 1712, p. 1615.

MOURGUES (le P.). - Théologie des Païens.

1711. BERNARD (Jacques). - De l'excellence de la religion. Amsterdam, 2 vol. in-12.

FOPPIUS (J. H.). - Exercitatio de atheismo philosophorum gentilium celebriorum... Bremæ, s. d.

1715. BANIER (I'abbé). - Explication historique des fables (2 éd. complète).

FLOYER (le Chevalier). - Les Oracles des Sibylles traduits sur les meilleurs exemplaires et comparez avec les Prophéties sacrées, particulièrement avec celles de Daniel et de l'Apocalypse, avec des remarques historiques qui montrent qu'une bonne partie des prédications des Sibylles sont accomplies à la lettre, et où l'on répond à toutes les objections que l'on fait ordinairement contre ces oracles.

1716. COUET (Bernard). Lettres d'un théologien à un évêque sur cette question importante : s'il est permis d'approuver les Jésuites pour prêcher et pour confesser. S. I. 2 t. en 1 vol. in-12 (Sur les Cérémonies chinoises, cf. III Lettre, pp. 76-80). 


\section{La Chine et la formation de l'esprit philosophique en France}

LA CROZE (Veyssières de). - Lettre latine sur G. Bruno (XI Partie des Acta Philosophica de Halle).

1716-8. PRIDEAUX. - Histoire des Juifs.

1717. DURAND (David). - La vie et les sentiments d'Ucilio Vanini (Cf. Scramm : De vita et scriptis famosi athei Julii Cæsuris Vanini tractatus singularis (1709) et Arpe : Apologia pro Julio Cæsare Vanino 1712).

1718. LAFITAU (le P. François). - Mémoire présenté à Son Altesse Royale Monseigneur le Duc d'Orléans, concernant la précieuse plante du Ginseng de Tartarie découverte en Canada. Paris, in-12.

RENAUDOT (Eusèbe). - Des Sciences des Chinois, à la suite des Anciennes Relations des Indes et de la Chine.... (Cf. Nouvelles littéraires, 18 février 1719, t. IX, pp. 102-12).

1719. BALTUS. - Jugements des SS. Pères sur la morale et la philosophie païenne. Strasbourg, in $-4^{\circ}$

1720. LA CROZE (Veyssières de). - Lettre à Leibniz sur l'Athéisme des Chinois dans le Recueil de diverses piéces sur la philosophie, les mathématiques, I'histoire de Leibniz. p. p. Kortholt en 1734.

1721. LA CROZE (Veyssières de). - Lettre à Leibniz sur l'ouvrage de Longobardi (Ibid.).

1724. BURIGNY (Lévesque de). - Histoire de la philosophie païenne. 2 vol. in-12.

1724. LA CROZE. - Histoire du Christianisme des Indes. La Haye (Cf. Acta eruditorum, 1725, p. 122 sq., Bibl. germanique, t. VII, p. 131).

LAFITAU (le P. François). - Mœurs des sauvages amériquains, comparées aux mœurs des premiers tems. Paris, 2 vol.

1725. Principes de la nature suivant les opinions des anciens philosophes, vol. in-12.

1727 RAMSAY (André-Michel). - Les Voyages de Cyrus. Avec une Dissertation sur la Mythologie. Paris, in-8 (Rééd. 1730).

1728. BERRUYER (le P.). - Histoire du Peuple de Dieu. Paris, 7 t. en 8 vol. 


\section{La Chine et la formation de l'esprit philosophique en France}

VOLTAIRE. - La Henriade. Ed. 1728.

1730. TINDAL. - Christianity as Old as the Creation : or The Gospel a Republication of the Religion of Nature, t. II. London.

La Religion Chrétienne aussi ancienne que la Création ou Traité dans lequel on montre que l'Évangile est une nouvelle publication de la Religion naturelle, t. I. 1730, in- $4^{\circ}$ (Cf. Bibl. raisonnée des Ouv. des Savans, t. V, pp. 251-82, pp. 5-44 et Chaufepié art Tindal).

JORDAN (Carles-Etienne). - Recueil de littérature, de philosophie et d'histoire. Amsterdam, in-12.

1731. [BOULAINVILLIERS], - Réfutation des erreurs de Spinoza. Bruxelles (Cf. Acta eruditorum, 1732, p. 120 sq.).

Critique de l'édition de 1730 des Voyages de Cyrus de Ramsay dans les Mémoires de Trévoux, mai 1731, p. 755 sq., juin 1731, p. 995 sq.

1733. CROUSAZ (de). - Examen du Pyrrhonisme ancien et moderne. La Haye, in-fo.

1734. BEAUSOBRE (Louis de). - Histoire critique de Manichée et du Manichéisme. Amsterdam, 2 vol. in-4º.

LEIBNIZ. - Recueil de diverses pièces sur la philosophie, les mathématiques, I'histoire, etc., p. p. Kortholt. Hambourg, in-16.

1734-42. LEIBNIZ. - Viri illustris Godefredi Leibnittii epistulæ ad diversos. Lipsiae, 1734-42. 4 t. en 2 vol.

1735. FOURMONT (Etienne). - Réflexions critiques sur les histoires des anciens peuples, Chaldéens, Hébreux, Phéniciens, Égyptiens, Grecs, etc..., jusqu'au temps de Cyrus. Paris, 2 vol. in-4 ${ }^{\circ}$ (Nouvelle éd. augmentée de la vie de l'auteur, Paris, 2 vol, in-4 $\left.{ }^{\circ} 1747\right)$.

Productions d'esprit, contenant tout ce que les Arts et les Sciences ont de rare et de merveilleux. Ouvrage critique et sublime composé par le Docteur Swift, etc. Paris, 2 vol. in-12. (Cf. Observations sur les Écrits modernes, 1736, t. IV, p. 47).

JORDAN. - Histoire d'un voyage littéraire fait en 1733 en France, en Angleterre et en Hollande. La Haye, in-12. 


\section{La Chine et la formation de l'esprit philosophique en France}

LEIBNIZ. - Anciens traités de divers auteurs sur les cérémonies de la Chine, avec des notes de Monsieur de Leibniz dans les Epistulæ ad diversos, p. p. Kortholt, t. II (1735).

Lettre de M. de Leibniz sur la Philosophie chinoise à M. de Remond dans les Epistulæ ad diversos, t. II, p. 413 sq.

1737. BUDDEUS (J. F.). - Theses theologiæ de atheismo et superstitione, variis observationibus illustratæ... Suas quoque observationes et dissertationes contra atheos adjecit Hadrianus Buurt. Trajecti ad Rhenum, in-4 ${ }^{\circ}$

1739. ARGENS (Boyer d'). - Lettres chinoises. La Haye, 1739-40, 5 vol. in-8 ${ }^{\circ}$ (Autres éd. 1751, 1755, 1766).

1740. BUDDEUS (J. F.). - Traité de l'athéisme et de la superstition, traduit par Louis Philon. Amsterdam, in- $8^{\circ}$.

1742-6. - Thesauri epistolici Lacroziani ex Bibliotheca Jordaniana, edidit lo Ludovicus Uhlius, t. I-III. Lipsiæ.

\section{XI. - La Morale et la Politique des Chinois}

a) MANUSCRITS

BERNIER (François). - Confucius ou la Science des Princes, contenant les Principes de la Religion, de la Morale particulière, du Gouvernement Politique des anciens Empereurs et Magistrats de la Chine, abrégée en françois par M. Bernier, Docteur en Médecine. Arsenal. Mst. 2331.

\section{b) IMPRIMÉS}

1673. CONFUCIUS. - La Science des Chinois ou le livre de Cumfu-çu traduit mot pour mot de la langue chinoise par le $P$. Intercetta. Paris, in-fo.

1677-9. VEIRAS (Denis). - L'Histoire des Sévarambes, peuples qui habitent une partie du troisième continent communément appelé la terre australe. Paris.

1685. DESCOUTURES. - La Morale d'Epicure avec des réflexions. Paris. 


\section{La Chine et la formation de l'esprit philosophique en France}

VOSSIUS (Isaac). - Isaaci Vossii Variarum Observationum Liber. London.

1686. FONTENELLE. - Relation de lîle de Bornéo dans les Nouvelles de la République des Lettres. 1686.

1687. COUPLET (le P.) et autres Jésuites. - Confucius Sinarum Philosophus. Paris.

1688. REGIS. - Compte rendu du Confucius Sinarum Philosophus dans le Journal des Sçavans (Janvier 1688).

BERNIER. - Extrait de diverses pièces envoyées pour étrenes par M. Bernier à Mme de la Sablière. Introduction à la lecture de Confucius, dans le Journal des Sçavans (Mai 1688).

Copie des étrenes envoyées à Madame de la Sablière par M. Bernier. A Montpellier le lendemain des Rois. 1688.

1688. FOUCHER (L'Abbé Simon). - Lettre sur la Morale de Confucius, philosophe de la Chine (Cf. Nouvelles de la République des Lettres, mars 1688).

BRUNE (Jean de la) ${ }^{1}$. - La morale de Confucius, philosophe de la Chine. Amsterdam.

1700. GILBERT (Claude). - Histoire de Calejava ou de l'isle des Hommes raisonnables, avec le parallèle de leur morale et du christianisme. S. I.

1703. LESCONVEL (Pierre de). - Idée d'un règne heureux ou relation du voyage du Prince de Montberaud dans l'isle de Naudely (Cf. G. Lanson. R. C. C. 27 mai 1909).

1706. (DUCHÉ). - Recueil d'histoires édifiantes pour servir de lecture à de jeunes personnes de condition. Paris, in-12.

1707. VAUBAN. - projet d'une dixme royale. S. I.

Lettres intimes adressées au marquis de Puysieulx (1699-1705), p. p. Hyrvoix de Landosle. Paris, 1924.

ROCHAS d'AIGLUN. - Vauban, Sa Famille et ses écrits. Ses Oisivetés et sa Correspondance. Analyses et Extraits. Paris, 2 VOL 1910.

1 Cet opuscule est parfois attribué au Président Cousin, non sans raison d'ailleurs, puisque le Président Cousin fut, comme nous l'avons vu, le censeur de la traduction des trois livres de Confucius par les PP. Jésuites en 1687. 


\section{La Chine et la formation de l'esprit philosophique en France}

1708. LEGUAT (François). - Voyages et avantures de François Leguat et de ses compagnons en deux isles désertes des Indes orientales. Londres, 1708. Amsterdam, 1708.

1710. TYSSOT DE PATOT. - Voyages et aventures de Jacques Massé. Bordeaux.

1718. RENAUDOT (Eusèbe). - La Morale et la Politique des Chinois à la suite des Anciennes Relations des Indes et de la Chine.

CHAUSIERGES. - Aventures de Néoptolème, fils d'Achille, propres à former les mœurs d'un jeune prince. Paris.

1723. CHAUSIERGES. - Idée d'un roy parfait, dans laquelle on découvre la véritable grandeur avec les moyens de l'acquérir (Cf. Bibliothèque Françoise, 1723, t. II).

1727. LASSAY (Le marquis de). - Recueil de différentes choses.

1731. SILHOUETTE. - Idée générale du gouvernement et de la morale des Chinois. $2^{\mathrm{e}}$ éd.

1733. SAINT- PIERRE (Abbé de). Ouvrages de politique, t. IV. Utilité des Dénombrements. Rotterdam et Paris.

1737. DESFONTAINES (Abbé). - Compte rendu du XXe Recueil des Lettres édifiantes et curieuses dans les Observations sur les modernes, t. VI, pp. 173-88.

1738. MAIRAN (Dortous de). - Lettre de M. de Mairan de I'Académie des sciences à M. l'abbé D. F. (Observations sur les écrits modernes, t. VII, pp. 56-64).

1749-54. ARGENS (Boyer $\mathrm{d}^{\prime}$ ). - Lettres chinoises. La Haye, 5 vol. 


\section{La Chine \\ et la formation de l'esprit philosophique en France}

\section{N D E X}

ABAILARD, 285.

ABBADIE, 230.

AGUESSEAU (D'), $84 \mathrm{n}, 94,331 \mathrm{n}, 393$.

AIGUILLON (duchesse $D^{\prime}$ ), 27.

ALBANI (cardinal), $98 \mathrm{n}, 109,110 \mathrm{n}$.

ALEXANDRE VI, 27.

ALEXANDRE VII, 94, $117 \mathrm{n}, 138$.

ALEXANDRE VIII, 87.

ALLIX, 215-8.

ANDRÉ (le P. Yves-Marie), 329, $330 \mathrm{n}$.

ANJOU (duc D'), 286.

AMIOT (le P. Joseph-Marie), 19.

ANSON (amiral), $341 \mathrm{n}$.

ARGENS (marquis D'), 204, 363, 410.

ARGENSON (D'), 37.

ARISTOTE, 165, 286, 378.

ARNAUDIN, 102.

ARNAULD (Antoine) , 69, 79, 81, 84, 85, 86, 88, 89, 282, 286, 288-9, 295, 300, 301, 302, 309, 311.

ASCOLI (Georges), $401 \mathrm{n}$.

ATKINSON (G.), $401 \mathrm{n}$.

AUNAY (Daniel HUET, abbé d'), 296.

AYMON, 152, 153.

BAGOT (le P. Jean), 26.

BARON, 31.

BARROS, $241 \mathrm{n}$.

BASNAGE, 152.

BAUDIER (Michel), 194, 283, 370.

BAYLE (Pierre), 62 n, 83, 88, 108, 198, 199, 204 n, 289, 314-27, 327 $n, 332,339,342,343,345,359,362$ n, 363, 364, 365, 411, 427, 428.

BEAUSOBRE (Isaac DE), $173 \mathrm{n}$.

BELLEFLEUR, 194, 285.

BENOIST (Elie), 327-9, 346, 365, 428.

BENOÎT XIV, 132.

BENTLEY, $237 \mathrm{n}$.

BERNARD (Jacques), 322, $323 \mathrm{n}, 325,327$.

BERNIER (François), 10, 376-84, 387, 389, 390, 392, 393, 396, 408, 413.

BERTHIER (le P.), 143.

BERTIN (Ministre d'État), 19.

BEURRIER (le P.), 290-2, 327, 358.

BAYER (Théophile), $242 \mathrm{n}$. 


\section{La Chine et la formation de l'esprit philosophique en France}

BLONDEL (David), 104.

BLOT, 31.

BOCHART, 207.

BOILEAU (abbé), 101, 102.

BOISLILE, 28, $133 \mathrm{n}$.

BOSSUET (abbé), 95, 96.

BOSSUET (Jacques-Bénigne), 94, 95, 96, 99, 105, 106, 116 n, 136,

309-11, 313, 388, 389, 390, 392, 393, 427, 429, 430.

BOUILLON (cardinal DE), 97, 113.

BOUHIER (le Président), 169, 173 n, 337.

BOULAINVILLIERS, 245.

BOURDELOT, 203.

BOURGOGNE (duchesse DE), 108.

BOUVET (le P. Joachim), 15, 23, 24, 25, 142, 148, 149, 150, 251, 252, 256 et $n, 257 \mathrm{n}, 334,336,350,351,352,353,354,356$.

BRISACIER (I'abbé), 67, 68, 86, 90 et n, 92, 93, 96, 97, 99, 100, 105, 113 et $n, 114,302,309,310$.

BROSSES (le Président DE), 132.

BRUNE (Jean DE LA), 373, 380, 396.

BRUNSCHWIG (Léon), $348 \mathrm{n}$.

BUDDEUS, 199.

BUGLIO (le P.), 20.

CALIXTE III, 27.

CALMET (Dom), 228-9, 268, 430.

CAMBOUT DE PONTCHATEAU, 81, 89.

CARDOZO (le P.), 169.

CASSINI, 40, 41 et $n, 182,222$, 238, 245, 268, 271, 277, 286.

CÉBERET, 60, 62, 65.

CHANTÉRAC (I'abbé DE), 391.

CHARLES II, 203.

CHARMOT (I'abbé), 68, 69, 86, 88, 96, 97, 98 n, 99, 108, 109, 126.

CHAUFEPIÉ, 203.

CHAULNES (duc DE), 28, 33.

CHAUMONT (chevalier DE), 15, 45, 50, 51, 54, 55, 56, 59, 61, $62 \mathrm{n}$, 297, 391.

CHÉREL (Albert), $342 \mathrm{n}, 361$.

CHINARD (Gilbert), 357.

CHOISY (abbé DE), 15, 16, 17, 47 n, 49, 52, 55, 56, 81, 64, 242 n, 400.

CHRISTINE DE SUÈDE, 202, 203.

CIBO (cardinal), 47.

CICÉRON, 328, 378.

CLÉMENT IX, 28, 79.

CLÉMENT X, 33.

CLÉMENT XI, 98 n, 119, 131, 132, 153 n.

COISLIN (cardinal DE), 97.

COLBERT, 32,. 33, 34, 39, 40, 41 et n, 44, 48, 49, 333, 398, 422.

COLLINS, $237 \mathrm{n}$. 


\section{La Chine et la formation de l'esprit philosophique en France}

CONDÉ, (prince DE), 199.

CONTANCIN (le P.), 148, 167.

COPERNIC, 191.

COUET (abbé), $118 \mathrm{n}$.

COULAU, 105, 308, 310, 311.

COUPLET (le P. Philippe), 25 n. 26, 44 et n, 45, 88, 151, 152, 153 n, 202, 211-5, 216, 218, 226, 228, 238, 269, 276, 296, 304, 305, $320,324,326,334,344,345,362$ n, 365, 371., 406, 423, 424, 426.

DACIER (Mme), 350.

DANGEAU, $47 \mathrm{n}, 69$.

DANTE, 285.

DAUBENTON (le P.), 391.

DESCARTES, 373.

DES COUTURES, 385-87.

DESFARGES, 60.

DESFONTAINES (abbé), 362.

DESHAYES, 40.

DESLANDES, 50, 60.

DESTOUCHES (Nicolas), $130 \mathrm{n}$.

DIAGORAS, $287 \mathrm{n}$.

DIAZ (le P.), 78.

DODART, 296.

DORSANNE, 117.

DOUCIN (le P.), 134, $137 \mathrm{n}$.

DU BOS (abbé), 108, 115, 135, 322 n.

DUHAMEL, 227-28.

DU PIN (Ellies), 199, 205 n, 288 n, 288, 305 n, 309, 311.

DU QUESNE, 400.

DU RONDEL, 318, 320.

ELIEN, 295.

ENTRECOLLES (le P. D'), 148, 161, 165.

EPICTĖTE, 378.

ÉRASME, 285.

ESPAGNAC (le P. D'), 63.

ESTRÉES (cardinal D'), 86 n, 97, 109, 134.

EUGĖNE (le prince), 337.

FABRONI (cardinal), 113.

FALCONNET, 33 n. 43.

FATINELLI (abbé), 122, 123, 126.

FAUQUE (le P.), $245 \mathrm{n}$.

FÉNELON, 45 n, 95, 96, 101, 390-6, 397, 405, 426, 427.

FERRARI (cardinal), 112.

FEUVRIER (H., docteur de Sorbonne), 102.

FONTAINE (Nicolas), $348 \mathrm{n}$.

FONTANEY (le P. DE), 15, 40, 57, 65.

FONTENAY (chevalier DE), 116.

FONTENELLE, 104, 147, 265, 349, 364. 


\section{La Chine et la formation de l'esprit philosophique en France}

FORBIN, 55.

FOUCHER (Simon), 372-3, 380, 396, 408, 413.

FOUCQUET (le P.), 133 n, 149, 150, 159, 160, 170, 171, 251, 253-8, 263, 269.

FOURMONT (Etienne), 142, 160, 249, 258, 275 n, 354.

FRADELY (le P.), 169.

FRANCEUR (le P.), $128 \mathrm{n}$.

FRANÇOIS-XAVIER, 17, 287.

FRÉRET (Nicolas), 11, 142, 143, 144, 145, 146, 160, 168, 169, 170, 173, 181, 182, 245 n, 249, 252, 258, 261-8, 269, 269-76, 277, 344-6, 351, 354, 359, 362 et $n, 364,398,415,416,429$.

GARASSE (le P.), 286.

GASSENDI, 363, 378.

GAUBIL, (le P. Antoine), 23 n, 24 n, 142, 143, 144, 145, 146, 147, $148,149,167,168,202,221,228,231 \mathrm{n}, 245 \mathrm{n}, 250 \mathrm{n}, 251$, 259-61, 262, 263, 270, 271, 273, 277, 344, 354, 354 n, 362 n.

GEMELLI CARERI, 369.

GERBILLON (le P. J. François), 15, 23.

GOLLET (le P. J. Alexis DE), 170, 257 n, 261, 262.

GOLIUS, 200.

GOVILLE (le P. Pierre DE), 147.

GHIRARDINI, 23.

GODET-DESMARAIS, 94.

GRANET, 362.

GREAVES, 200.

GRENADE, 165.

GRIMALDI (le P.), 24, 113.

GRONOVIUS, 203.

GROS DE BOZE, $213 \mathrm{n}$.

GROTIUS, 248.

GUALTERIO (le cardinal), $133 \mathrm{n}$.

GUIGNES (DE), 143, 144.

HALDE (le P. Du), 12, 99, 135, 138, 141, 143, 145, 147, 148, 151, 159, 160, 161, 268-9, 277 n, 278, 414, 415.

HALLEY, $235 \mathrm{n}$.

HARDOUIN (le P.), 222-3.

HENSIUS, 202, 203.

HÉRACLITE, 306.

HERBERT DE CHERBURY, 292.

HERDTRICHT (le P.), 371.

HERMĖS, 294.

HOMĖRE, 103, 299, 349.

HORN (Georges), 205-9, 217, 219, 223, 275 n, 294.

HÉSIODE, 299.

HUBIN, 44 n. 74.

HUET (Daniel), 293-6, 308, 327, 328.

HURTADO (Thomas), 78, 79, 80, 84.

HYDE (Thomas), 105, 308, 309, 321. 


\section{La Chine et la formation de l'esprit philosophique en France}

INNOCENT IV, 17.

INNOCENT $X, 78$.

INNOCENT XII, 87, 90, 96, 97, 109.

INTORCETTA (le P.), 23, 151, 371.

JACQUES (le P.), 147.

JANSENIUS, 104, $348 \mathrm{n}$.

JANSON (cardinal DE), 97, 109.

JAQUELOT, 322.

JARTOUX, 355.

JOUVANCY (le P. Joseph DE), 124, 125 n, 127, 128, 129, 137.

JULIUS AFRICANUS, 210.

JURIEU, 69, 83, 84, 88, 133.

K/EPPELIN, 31.

KIRCHER (le P. Athanase), 21, 24, 355.

KNUTZEN, 199.

KORTHOLT, 340.

LA BRUYÈRE, 381, 388, 389, 390, 392, 393, 395, 396, 402, 405, 409, 426.

LA CHAIZE (le P. DE) , 24, 44, 45, 46, 47, 56, 57 n, 58, 64, 67, 68, 86, $90 \mathrm{n}, 97,100,103,115,121,163,391$.

LA CHAMBRE (abbé DE), 377.

LACHARME (le P. A. DE), 143.

LA CROZE (Veyssière DE), 334, 337, 363.

LAËT (J. DE), 308.

LA FAYE, $364 \mathrm{n}$.

LAFITAU (le P. J. François), 354-8, 365.

LA FORCE (duc DE), 160.

LA HIRE, $41 \mathrm{n}$.

LAISTRE (le P. DE), $128 \mathrm{n}$.

LALLEMANT (le P.), 134.

LA LOUBÈRE, 59, 60, 62, 63, 65, 221-2, 318, 319, 320.

LAMOTTE-LAMBERT, 28.

LA MOTHE LE VAYER, 103, 285-8, 289, 296, 301, 304, 306, 426.

LANEAU, $45 \mathrm{n}, 52,53,54,55,63$.

LANGE, 169, 388.

LANSON (Gustave), 12, 71, 79, 385, 401 n, 424.

LANTENAY (le P.), 95.

LA PEYRÈRE, 192, 193, 195-200, 204, 205, 206, 207, 214, 216, 236 et $n, 241,246,249,278,287,322 n, 424,4.29$.

LAPLACE, 144.

LA ROCHE (le P. DE), 23.

LA SABLIÈRE (Mme DE), 387.

LA TRÉMOILLE, 127.

LAUNAY (abbé), 37.

LAVAL (François DE), 26, 28.

LE BOSSU (le P. René), 350.

LECLERC (Jean), 152. 


\section{La Chine et la formation de l'esprit philosophique en France}

LE COMTE (le P. Louis), 15, 16, 18 n, 90-2, 96, 98, 100, 104, 108, $120,124,125,134,135,170,178,181,255,301,302,303,304$, 305 et $n, 306,307,309,321,353,365,399,408,427$.

LE DIEU (abbé), 99, 105, $116 \mathrm{n}, 309$.

LEGENDRE (abbé), 102, $137 \mathrm{n}$.

LE GENTIL, $341 \mathrm{n}, 413$.

LE GOBIEN (le P. Charles), 98, 100, 135, 164, 304, 305 n, 321, 324, 325.

LEGUAT (François), 400-5.

LEIBNIZ, 142, 282, 333-40, 351, 354.

LENGLET-DUFRESNOY, 204, 242-4, $245 \mathrm{n}$.

LEMOINE (docteur de Sorbonne), 102.

LÉON X, 34.

LÉONARD (le P.) $, 67,89,93,98,110 \mathrm{n}$.

LE TELLIER (le P. Michel), 67, 83, 34, 86 et $n, 88,108,109 \mathrm{n}, 121$, $122 \mathrm{n}, 124,125,126,127,128,129,133,134,136,137$ et $n$, $138,301,302$.

LE TELLIER (archevêque de Reims), 106, 136.

LEVESQUE DE BURIGNY, 241 n. 104, 342-3, 359, 362 n. 202, 364.

LIGNIËRES (le P. DE), 167.

LIONNE (Artus DE), 38, 52, 53, 55, 63, 64, 67, 138, 142, 224, 329.

L'ISLE, (J. Nicolas DE), 143, 144, 149, 181.

LOCKE, 363.

LONGOBARDI (le P. Nicolas), 19, 77, 78, 139, 310, 312-3, 337 et $n$, 348.

LOUIS XIV, 34, 35, 41, 49, 50, 51, 64, 203, 336, 389, 396, 405, 423.

LOUVILLE (chevalier DE), 235 n, 429.

LOUVOIS, 44.

LUTHER, 104, 286.

MADAME (duchesse d'Orléans), 336.

MAGAILLANS, 20, 220, 221, 369.

MAIGROT, $45 \mathrm{n}, 69,87,116 \mathrm{n}, 117 \mathrm{n}, 118,119,125,128,178,182$, 224-6.

MAILLA (le P. Moyriac DE), 109, 143, 144, 148, 159, 167, 168, 228, $245 \mathrm{n}, 250,251,259,270,271$.

MAINE (duc DU), 46, 211.

MAINTENON (Madame DE), 29, 67 n, 90 et $n, 92,93,96,101,113$ et $\mathrm{n}, 121,137,427$.

MAIRAN (Dortous DE), 25, 142, 143, 144, 161, 168, 173, 174, 181, 275, 276, 331, 415, 416-8.

MALEBRANCHE, 138, 282, 329-33, 340, 373, 374.

MALFERT (le P. Auguste), 246.

MANASSE BEN ISRAËL, 293 n. 35.

MANICHÉE, 353, 354.

MARAIS (Mathieu), 9, 120, 121, 130 n, 173 n, 337.

MARCO POLO, 18, 189, 202 n. 26, 421.

MARTIANAY (le P.), 219. 


\section{La Chine et la formation de l'esprit philosophique en France}

MARTINI (le P. Martin), 78, 82, 168, 178, 180 n, 200-2, 203, 209, $210,211,212,214,215,216,218,220,221,226,228,237 \mathrm{n}$, 238, 242 n, 219, 269, 278, 285, 289-90, 297, 299, 341, 368, 406. MARTINO (Pierre), 9, 159.

MASSIEU, 350.

MAUPERTUIS, 268.

MAZARIN (duchesse DE), 203.

MENDOCE (G. DE), 194, 283.

MERCURE, 294.

MEZZABARBA, 131-2, 173.

MILTON, 316 n. 91.

MINUTOLI, 320.

MISSON (Maximilien), 400-5.

MONACO (le prince DE), 109.

MONTAIGNE, 194.

MONTECORVIN (Jean DE), 18.

MONTESQUIEU, 316 n, 341 n, 362 et n, 409, 411, 414.

MONTIGNO (le P. DE), 87.

MORALEZ, 78.

MUSNIER (le P. François), 94, 302.

NAVARRETE (le P.), 78, 95.

NEWTON, 398.

NICOLAÏ, 126.

NICOLAS V, 27.

NICOLE, 374.

NOBILI (le P. DE), 72, 73.

NOAILLES (Mathieu DE), 90 et n, 93, 94, 98 n, 100 n, 103, 105, 109, $110,111,113,115,121, \mathbf{1 2 2}-\mathbf{9}, 136$.

NOAILLES (duc DE), 153 n. 31, 345.

NORIS (cardinal), 112.

NOYELLES (le P. DE), 46.

ORPHÉE, 103, 104, 291 n, 293.

ORRY (le P.), 147.

PALLU (François), 26, 28, 29, 30, 31, 32, 34, 36, 37, 41, 50.

PANTOYA (le P.), 22.

PARRENIN (le P.) , 23, 24, 25, 26, 142, 145, 147, 148, 160, 161, 162, $165,166,167,173,174,175,177,178,179,180 \mathrm{n}, 228,251,252$ $\mathrm{n}, 259,276,277 \mathrm{n}, 354 \mathrm{n}, 416$.

PASCAL, 10, 79, 347-8, 363, 364, 395.

PATIN (Guy), 33 n, 199, 287 n.

PAUL (Vincent DE), 28.

PEIRESC, 256.

PERNON (le P.), 23.

PERRAULT (Charles), 349.

PÉTAU (le P.), 182, 204, 228, 243, 245, 272, 397.

PEREYRA (le P.), 23.

PERRON (le P.), 218-21, 424.

PHAULKON (Constance), 51-59, 61, 62, 64. 


\section{La Chine et la formation de l'esprit philosophique en France}

PINTO (Fernand Mendez), 285, 370.

PIQUE (I'abbé), 26, 28.

PLAN CARPIN (Jean DE), 17.

PLATON, 104, 248, 286, $291 \mathrm{n}, 361$.

PLOTIN, 343.

PLUTARQUE, 378.

POMEREAU (le P.), 38.

POMPADOUR (Mme DE), 10, 11.

PORPHYRE, 343.

PRÉMARE (le P. DE), 142, 144, 149 et $n, 150,163,170,251,257 \mathrm{n}$, 261, 262, $291 \mathrm{n}, 350,351,352,353,354,358,359,361 \mathrm{n}, 362$.

PRIOU, 100.

PROTAGORAS, $287 \mathrm{n}$.

PROVANA (le P.), 119.

PUCELLE (I'abbé), $126 \mathrm{n}$.

PYTHAGORE, 285, $291 \mathrm{n}, 361,429$.

PYTHÉAS, 429.

QUÉMÉNER (I'abbé), 87, 90.

QUESNAY, 11.

QUESNEL, 67, 109, 122 n. 147, 124, 127, 135, 137, 138.

RADOLOVITZ (cardinal), 112.

RAMSAY, $29 \mathrm{n}, 342 \mathrm{n}, 354, \mathbf{3 5 8}-\mathbf{6 3}, 365,428$.

RÉGIS (le P. J.-Baptiste), 142, 143，144，146，148，168，170，228, 251, 259.

RÉGIS (Pierre-Sylvain), 375-6.

RÉMOND (DE), 337, $338 \mathrm{n}$.

RENAUDOT (Eusèbe), 109, 110-115, 133 n, 136, 138, 160, 178, 182, 199, 226, 228, 233-9, 242, 245, 277 n, 341 n, 341, 342, 363, 405-7, 413, 416.

RHO (le P. Jacques), 19.

RHODES (le P. DE), 26, 27.

RICCI (le P. Mathieu), 18, 21, 22, 24, 73, 75, 77, 78, 284, 312, 339, 369.

RICCIOLI (le P. J.-Baptiste), 209-10, 211, 214.

ROQUES, 31.

ROSLET (le P.), 95, 108, 122-9, 137.

ROTHELIN (I'abbé DE), 253.

ROUGEMONT (le P.), 151, 371.

RUYSBRUECK (Guillaume) [Rubruquis], 17.

SACY (Silvestre DE), 143.

SAINT AUGUSTIN, 287, 348.

SAINT EVREMOND, 9, 203.

SAINT HILAIRE (abbé DE), $90 \mathrm{n}$.

SAINT JUSTIN, 306.

SAINT LOUIS, 17.

SAINT PAUL, 103, 105, 287, 348 n, 370.

SAINT-PIERRE (abbé DE), 398.

SAINT-SIMON, 11, 90 n, 108, 133-8, 159, 166, 180. 


\section{La Chine et la formation de l'esprit philosophique en France}

SAINT THOMAS, 104.

SAINTE-MARIE (A. DE), 17, 78, 139, 310, 312, 337, 340.

SAUMAISE, 202, 203.

SCHALL (le P. Adam), 19, 20, 22, 24.

SCHEUTZER, $235 \mathrm{n}$.

SCHOOUTEN, $241 \mathrm{n}$.

SCHRECK (le P.), 19.

SCALIGER, 244.

SCUDÉRY, 350.

SEIGNELAY, 38 et $n, 50,58,59$.

SEMEDO (le P.), 194, 285, 371, 378.

SFONDRATI (cardinal), 94, 301, 303.

SILHOUETTE, 138, 366, 407-9.

SIRMOND (le P.), 182.

SIXTE IV, 27.

SOCRATE, 285, 286, 306, 374, 378, 390.

SOLON, 335.

SOPHOCLE, 103.

SOUCIET (le P. Etienne), 23 n, 143, 144, 147, 148, 150, 245, 245 n, $250 \mathrm{n}, 258,259,269$.

SPINOZA, 293, 320, 331, 332, $342 \mathrm{n}$.

STUMPFF (le P.), 119.

SIBYLLES, 103, 104, 306.

TACHARD (le P. Guy), 15, 16, 17, 38 et n, 45, 52 n, 55, 54-60, 6166, $68,69,86,242 \mathrm{n}, 297,315 \mathrm{n}, 318$.

TAAUTUS, 294.

TERRAS SON (abbé), 416.

TEUTATÈS, 294, 308.

THEUTH, 294, 295.

THÉVENOT, 210, 211.

THOMASSIN (le P.), 348.

TIBERGE (abbé), 67 n, 68, 90 n, 92, 93, 97, 99, 100, 113 n, 309, 310.

TOLAND, 327 et $n, 359,364$ et $n, 365$.

TOLOMEI (cardinal), 126.

TOMASI, 125.

TORCY (marquis DE), 110, 113, $121 \mathrm{n}$.

TOURNEMINE (le P.), 150, 151, 227, 257 n, 269, 278, 362, 407.

TOURNON (cardinal DE), 116-20, 122 n, 122, 123, 125, 126, 130 n, $137,329,340$.

TOURNON (marquis DE), 115, 122.

TOURREIL, 109.

TRAJAN, 286.

TRIGAỤtT (le P.), 194, 284, 285, 343, 370, 421.

TRISMÉGISTE, $291 \mathrm{n}$.

TURRETINI, 173 n. 79.

TYCHO-BRAHÉ, 222, 238.

TYSANIER (le P.), 38.

TYSSOT DE PATOT, 231-33, 239-41. 


\section{La Chine et la formation de l'esprit philosophique en France}

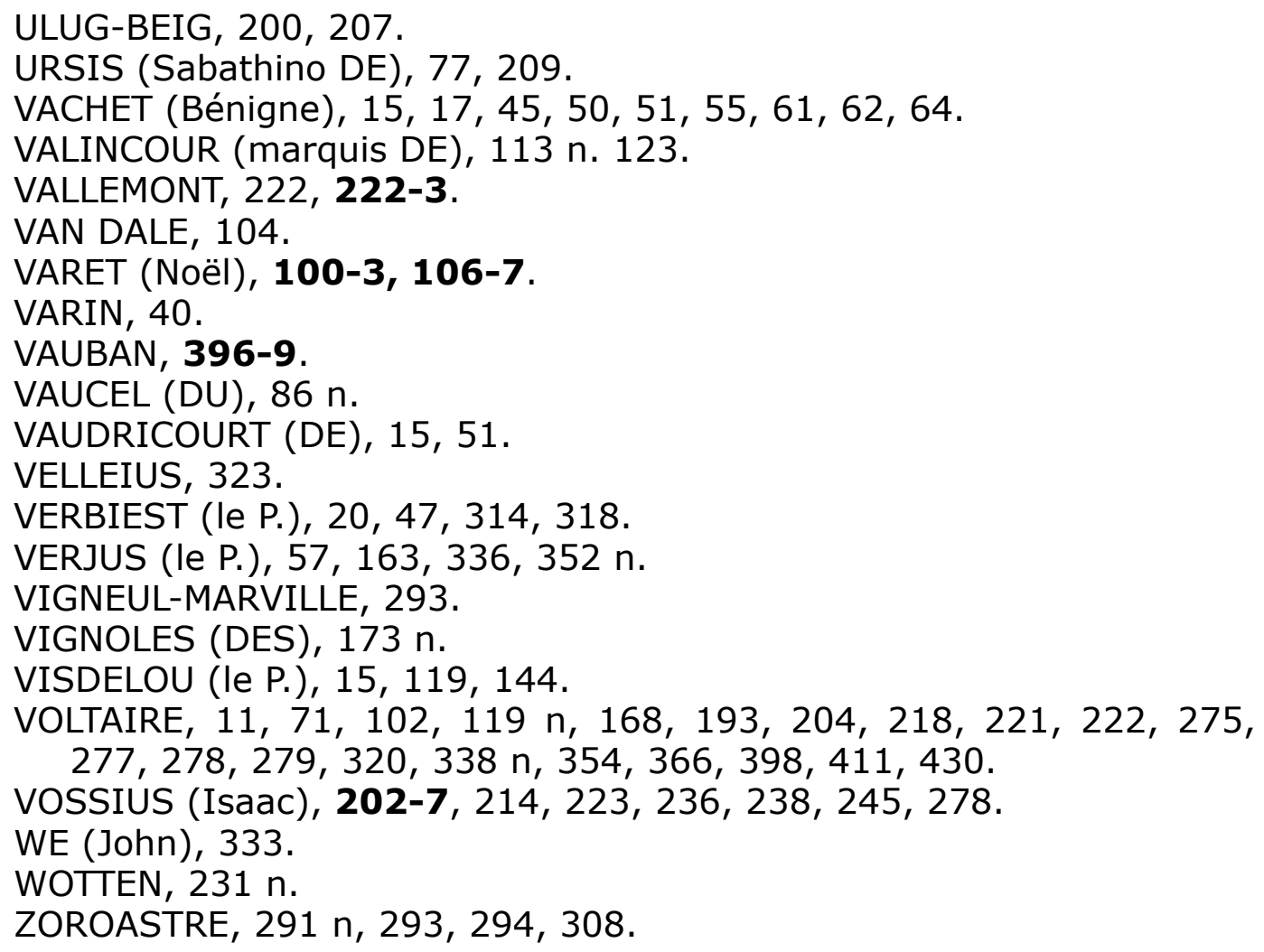

